PNNL-11010

UC-810

Project Technical Information

RECEIVED

MAR 261996

Vitrification of Noble Metals

Containing NCAW Simulant with an

Engineering Scale Melter (ESM):

Campaign Report
W. Grunewald
K. Weiss
G. Roth
M. Elliott
W. Tobie
L.L. Eyler
S. Weisenburger

March 1996

Prepared for the U.S. Department of Energy under Contract DE-AC06-76RLO 1830

Pacific Northwest National Laboratory Operated for the U.S. Department of Energy by Battelle Memorial Institute 


\title{
Vitrification of Noble Metals Containing NCAW Simulant with an Engineering Scale Melter (ESM): Campaign Report
}

\author{
W. Grunewald \\ G. Roth \\ W. Tobie \\ S. Weisenburger \\ K. Weiss \\ M. Elliott \\ L. L. Eyler
}

March 1996

Prepared for

the U.S. Department of Energy

under Contract DE-AC06-76RLO 1830

Pacific Northwest National Laboratory

Richland, Washington 99352 


\title{
DISCLAIMER
}

This report was prepared as an account of work sponsored by an agency of the United States Government. Neither the United States Government nor any agency thereof, nor Battelle Memorial institute, nor any of their employees, makes any warranty, express or implied, or assumes any legal liability or responsibility for the accuracy, completeness, or.usefulness of any information, apparatus, product, or process disclosed, or represents that its use would not infringe privately owned rights. Reference herein to any specific commercial product, process, or service by trade name, trademark, manufacturer, or otherwise does not necessarily constitute or imply its endorsement, recommendation, or favoring by the United States Government or any agency thereof, or Battelle Memorial Institute. The views and opinions of authors expressed herein do not necessarily state or reflect those of the United States Government or any agency thereof.

\author{
PACIFIC NORTHWEST NATIONAL LABORATORY \\ operated by \\ BATTELLE \\ for the \\ UNITED STATES DEPARTMENT OF ENERGY \\ under Contract DE-AC06-76RLO 1830
}

\section{Printed in the United States of America}

Available to DOE and DOE contractors from the Ofiice of Scientific and Technical Information, P.O. Box 62, Oak Ridge, TN 37831; prices available from (615) 576-8401.

Available to the public from the National Technical Information Service, U.S. Department of Commerce, 5285 Port Royal Rd., Springfield, VA 22161 


\title{
VITRIFICATION OF NOBLE METALS CONTAINING NCAW SIMULANT WITH AN ENGINEERING SCALE MELTER (ESM)
}

\author{
Campaign Report \\ Work performed under Contract No. 125818-A-A3 for Pacific Northwest Laboratories \\ Richland, WA, USA
}

W. Grünewald

G. Roth

W. Tobie

S. Weisenburger

K. Weiss

M. Elliott (PNL)

L. Eyler (PNL)

September, 1993

Kernforschungszentrum Karlsruhe (KfK) Institut fïr Nukleare Entsorgungstechnik (INE) 


\section{ACKNOWLEDGEMENTS}

The comprehensive analytical measurements within this project were performed by Dr. D. Hentschel of INE analytical lab and his staff.

Microscopic observations on selected samples were carried out by Dr. W. Bernotat of INE and by Dong-Sang Kim of PNL Richland.

Glass electrical resistivity and viscosity measurements were carried out by $\mathrm{Dr}$. B. Luckscheiter of INE.

Mr. I. Perez and Dr. G. Jensen of PNL provided both technical and programatic support.

Mr. L. Mahoney of PNL provided technical support for the computer modeling.

Fruitful discussions with Prof. Pentinghaus of INE contributed much to the interpretation of the results in respect to glass chemical phenomena.

The authors thank Prof. Kim, director of INE, for supporting this project. 


\section{ABSTRACT}

The Engineering- Scale Melter (ESM) has been designed as a 10th-scale representation of the DWPF-type melter which is currently the reference melter for the vitrification of Hanford double shell tankwaste. The ESM and related equipments have been integrated to the existing mock-up vitrification plant VA-WAK at KfK. From June 22 to July 10, 1992, a shake down test using $2.61 \mathrm{~m}^{3}$ of NCAW simulant without noble metals was performed. From July 11 to August 30, 1992, 14.23 $\mathrm{m}^{3}$ of the same simulant with the nominal concentration of the noble metals ruthenium, rhodium and palladium were vitrified. The main objective of the work was to investigate the behaviour of such a melter type with respect to the discharge of the noble metals with routine glass pouring operations via the glass overflow.

The overall results indicate an accumulation of noble metals in the bottom area of the flatbottomed ESM. In total about $65 \mathrm{wt}-\%$ of the noble metals $\mathrm{Ru}, \mathrm{Pd}$ and $\mathrm{Rh}$ fed to the melter could be drained out during the operation whereas $35 \mathrm{wt}-\%$ accumulated in the melter. These data are based on the results of the analysis of the glass samples taken from glass pouring stream into the canisters. After the melter was drained at the end of the campaign through a bottom drain valve, glass samples were taken from the residual bottom layer. The samples had a significantly increased noble metals content (factor of 20 to 45 to the target loading). They showed also a significant decrease of the specific electric resistance compared to the bulk glass (factor of 10 ).

A decrease of $10-15 \%$ of the electric resistance between the power electrodes could be seen at the end of the run. But the total amount of noble metals accumulated during the run obviously was not yet sufficient enough to disturb the Joule heating of the glass tank severely. 


\section{TABLE OF CONTENTS}

Table of Contents

List of Figures

iii

List of Tables

vii

List of Acronyms viii

\subsection{SUMMARY AND CONCLUSIONS .}

\subsection{INTRODUCTION AND SCOPE OF WORK}

\subsection{SYSTEM DESCRIPTION}

3.1 Vitrification facility

3.2 Material data

3.3 Data acquisition and visualisation system PISA

\subsection{TEST DESCRIPTION}

\section{1 .Feed Preparation}

4.2 Melter operation

4.2.1 Test run U1

4.2.2 Test run U2

\subsection{TEST RESULTS}

5.1 Overall results of the test campaigns $U 1, \mathrm{U} 2$

5.2 Noble metals behavior in the glass melter

\subsubsection{Glass sampling procedure}

5.2.2 Analysis procedure

5.2.3 Results

5.2.4 Interpretation of data

5.2.5 Emptying of melter

5.2.6 Noble metals balance (U2 test run) 
5.3. Microscopic observation of glasses from ESM test run U2

\subsubsection{Glass samples investigated}

5.3.2 Microscopic observations

5.3.3 Investigation of sample material taken from "Cold Cap" covering the glass melt pool (sampling in the region around cold cap)

5.3.4 Investigation of sample material taken from centre of the "Cold Cap"

5.4 Noble metals effects on glass properties

5.4.1 Samples investigated

5.4.2 Results

\subsection{COMPUTER MODELING OF THE ENGINEERING SCALE TEST MELTER}

6.1 Computer modeling results - pre-test predictions

6.1.1 Power and thermocouple stalk data

6.1.2 Further data in preparation

Appendix A Investigation of bubble rich glass product taken from the outer melt surface of the ESM melter during long-term operation

Appendix B PISA data base

Appendix C Listing of all XRF glass analysis data by INE - Analytical Laboratory

Appendix D Computer Modeling 


\section{List of figures}

Fig. 3-1: Basic flowsheet of the test facility. The dotted lines refer to components used for other test programes at INE (HAWC-WAK program)

Fig. 3-2: View from top onto the test facility including the NCAW feed make up tank, the melter feed tank, and the ESM

Fig. 3-3: Front view of the test facility (simplified)

Fig. 3-4: Longitudinal cross section of the ESM

Fig. 3-5: Plan view cross section of the ESM

Fig. 3-6: Transverse cross section of the ESM

Fig. 3-7: View from top onto the ESM

Fig. 3-8: Glass sampling system of the ESM

Fig. 3-9: Glass overflow system of the ESM and heating technique applied

Fig. 3-10: Temperature monitoring points of the ESM

Fig. 3-11: Viscosity versus temperature curves for the glass frit and NCAW glass product

Fig. 3-12: Specific electrical resistance versus temperature of the NCAW glass product

Fig. 3-13: Structure of computerized data acquisition and visualization system PISA

Fig. 3-14: Overview picture of PISA

Fig. 3-15: PISA plot of the data regarding the feed make up tank (FMT)

Fig. 3-16: PISA plot of the data regarding the melter feed tank (MFT)

Fig. 3-17: PISA plot for melter feeding area and glass melting by the ESM

Fig. 3-18: PISA plot for the temperature monitoring points of the ESM

Fig. 3-19: PISA plot concerning power release in the glass tank and glass overflow area of the ESM

Fig. 3-20: PISA plot of data for the off gas area, part 1

Fig. 3-21: PISA plot of data for the off gas area, part 2 .

Fig. 3-22: PISA plot of data for the off gas area, part 3 
Fig. 3-23: PISA plot of NCAW feed simulant storage tank. From this tank the simulant was batchwise pumped into the FMT

Fig. 4-1: NCAW feed preparation procedure

Fig. 4-2: Measured temperatures versus time during feed preparation of NCAW simulant, batch No. 1

Fig. 4-3: Flow rate and vessel pressure versus time during feed preparation of NCAW simulant, batch No. 1

Fig. 4-4: Measured temperatures versus time during feed preparation of NCAW simulant, batch No. 2

Fig. 4-5: Flow rate and vessel pressure versus time during feed preparation of NCAW simulant, batch No. 2

Fig. 4-6: Feeding of formic acid and off gas composition from Feed Make up Tank (FMT) while förmating NCAW feed simulant batch No. 2

Fig. 4-7: Measured temperatures versus time during feed preparation of NCAW simulant, batch No. 3

Fig. 4-8: Flow rate and vessel pressure versus time during feed preparation of NCAW simulant, batch No. 3

Fig. 4-9: Feeding of formic acid and off gas composition from FMT while formating NCAW feed simulant, batch No. 3

Fig. 4-10: Measured temperatures versus time during feed preparation of NCAW simulant, batch No. 4

Fig. 4-11: Flow rate and vessel pressure versus time during feed preparation of NCAW simulant, batch No. 4

Fig. 4-12: Feeding of formic acid and off gas composition from FMT while formating NCAW feed simulant, batch No. 4

Fig. 4-13: Measured temperatures versus time during feed preparation of NCAW simulant, batch No. 5

Fig. 4-14: Flow rate and vessel pressure versus time during feed preparation of NCAW simulant, batch No. 5 
Fig. 4-15: Feeding of formic acid and off gas composition from FMT while formating NCAW feed simulant, batch No. 5

Fig. 4-16: Operational diagram of the first week of the pretest run U1

Fig. 4-17: Operational diagram of the second week of the pretest run U1

Fig. 4-18: Operational diagram for the first week of the ESM noble metals test run U2

Fig. 4-19: Operational diagram for the second week of the ESM noble metals test run U2

Fig. 4-20: Operational diagram for the third week of the ESM noble metals test run U2

Fig. 4-21: Operational diagram for the fourth week of the ESM noble metals test run U2

Fig. 4-22: Operational diagram for the fifth week of the ESM noble metals test run U2

Fig. 4-23: Operational diagram for the sixth week of the ESM noble metals test run U2

Fig. 4-24: Operational diagram for the seventh week of the ESM noble metals test run U2

Fig. 4-25: Operational diagram for the eighth week of the ESM noble metals test run U2

Fig. 4-26: Determination of the feed rate to ESM by monitoring the level in the MFT by ultra-sonic measurements versus operation time

Fig. 4-27: Volumes of NCAW melter feed simulant versus operation time in the Feed Make up Tank and the Melter Feed tank (noble metals test run U2)

Fig. 4-28: Typical vertical temperature profile of the ESM melter during the noble metals test run. Upper curve for maximum glass level before glass pouring. The lower curve typical for minimum glass level after glass pouring

Fig. 5-1 Calibration curves gained from lab samples for XRF measurements of noble metals concentrations in the NCAW glass

Fig. 5-2 XRF measured noble metals concentration diagrams obtained from glass samples while pouring canisters No. 1,2 and 3

Fig. 5-3 XRF measured noble metals concentration diagrams obtained from glass samples while pouring canisters No. $4,5,6$

Fig. 5-4 XRF measured noble metals concentration diagrams obtained from glass samples while pouring canisters No. 7, 8, 9 
Fig. 5-5 XRF measured noble metals concentration diagrams obtained from glass samples while pouring canisters No. $10,11,12$

Fig. 5-6 XRF measured noble metals concentration diagrams obtained from glass samples while pouring canisters No. $13,14,15$

Fig. 5-7 XRF measured noble metals concentration diagrams obtained from glass samples while pouring canisters No. 16,17

Fig. 5-8 Noble metals concentration in glass samples taken during glass pouring into canister Nos. 6 and 15, measured by Griffiths inspectorate, London. The dotted lines give the corresponding XRF values measured at INE's analytical lab.

Fig. 5-9 Corrected noble metals concentration data for glass samples taken while pouring canisters No. $1,2,3$

Fig. 5-10 Corrected noble metals concentration data for glass samples taken while pouring canisters No. $4,5,6$

Fig. 5-1 Corrected noble metals concentration data for glass samples taken while pouring canisters No. $7,8,9$

Fig. 5-12 Corrected noble metals concentration data for glass samples taken while pouring canisters No. $10,11,12$

Fig. 5-13 Corrected noble metals concentration data for glass samples taken while pouring canisters No. $13,14,15$

Fig. 5-14 Corrected noble metals concentration data for glass samples taken while pouring canisters No. 16,17

Fig. 5-15 Content of the noble metals in the canisters and comparision with the target values of each canister

Fig. 5-16 "Feed in" and "discharge" curves of the ESM for the noble metals contained in the NCAW simulant

Fig. 5-17 Electric data of the ESM monitored by the PISA system during the test run

Fig. 5-18 Results of noble metals concentrations in glass samples taken when emptying the melter (glass poured into cans No. 18 and 19, via bottom drain). Noble metals concentrations in the remaining glass layer on ESM bottom

Fig. 5-19 Comparison of the specific electrical resistance versus temperature of the NCAW glass product and sample No. 1 from the melter bottom 
Fig. 5-20 EDS spectra of area \#1 in Photo 3

Fig. 5-21 EDS spectra of area \#2 in Photo 3

Fig. 5-22 EDS spectra of area \#3 in Photo 3

Fig. 5-23 Electrical resistivity of glass samples containing different quantities of noble metals

Fig. 5-24 Viscosity of glass samples containing different concentrations of noble metals

Fig. 6-1 Pre-test predicted power, bulk glass temperature, and average thermocouple stalk temperature compared to preliminary-reported data

Fig. 6-2 Pre-test thermocouple stalk temperature compared to preliminary-reported data

Fig. 6-3 Predicted $\mathrm{RuO}_{2}$ balance at experimental conditions.

Fig. 6-4 Ru balance compared to experimental results.

Fig. 6-5 Ru balance compared to experimental results (10\% biased)

Fig. 6-6 Predicted Pd balance at experimental conditions.

Fig. 6-7 Pd balance compared to experimental results.

Fig. 6-8 Predicted $\mathrm{Rh}$ balance at experimental conditions.

Fig. 6-9 Rh balance compared to experimental results.

Fig. 6-10 Predicted $\mathrm{RuO}_{2}$ sludge layer depth.

Fig. 6-11 Predicted $\mathrm{RuO}_{2}$ balanced for sssumed 3X NM feed rate.

Fig. 6-12 $\mathrm{RuO}_{2}$ retention for sssumed $3 \mathrm{X} \mathrm{NM}$ feed rate.

Fig. 6-13 $\mathrm{RuO}_{2}$ sludge layer depth for assumed 3X NM feed rate.

Fig. 6-14 Total NM retention compared to lumped parameter analysis.

Fig. 6-15 Continuous monitored and temperature controlled average power and temperature.

Fig. 6-16 Comparison of electric resistance.

Fig. 6-17 Comparison of vertical temperature distributions.

Fig. 6-18 Comparison of vertical temperature distributions. 
Fig. 6-19 Comparison of vertical temperature distributions.

Fig. 6-20 Comparison of vertical temperature distributions.

Fig. 6-21 Comparison of vertical temperature distributions. 


\section{List of tables}

Tab. 3-I: Compilation of data of the NCAW simulant:
A: Calculation of melter feed targets
B: .HWVP melter feed composition
C: Feed requirements for frit recycle and formic acid
D: HWVP target glass composition

Tab. 3-II: $\quad$ Types, scanning and storage rates of PISA system

Tab. 4-I: $\quad$ Feed preparation procedure

Tab. 4-II: Compilation of the analysis data obtained for NCAW feed preparation, batch 1 (for pretest run U1)

Tab. 4-III: Compilation of the analysis data obtained for NCAW feed preparation, batch 2 (for noble metals test run $U 2$ )

Tab. 4-IV: Compilation of the analysis data obtained for NCAW feed preparation, batch 3

Tab. 4-V: Compilation of the analysis data obtained for NCAW feed preparation, batch 4

Tab. 4-VI: Compilation of the analysis data obtained for NCAW feed preparation, batch 5 .

Tab. 4-VII: Compilation of data regarding NCAW feed volumes in the FMT and MFT, transfer volumes, densities, sum up numbers and feed rates to melter

Tab. 4-VIII: List of events and distortions experienced during the noble metals test run U2. Time periods of NCAW simulant feeding off are indicated including the reasons for

Tab. 5-I: $\quad$ Table of test results

Tab. 5-II: Content of noble metals in the glass of the different canisters

Tab. 5-III: Noble metals analyzed from the liquid samples of the off gas components

Tab. 6-I: · Summary of two field electric characteristics 
List of Acronyms

$\begin{array}{ll}\text { DOE } & \text { Department of Energy } \\ \text { DWPF } & \text { Defense Waste Processing Facility } \\ \text { ESM } & \text { Engineering Scale Melter } \\ \text { FMT } & \text { Feed Make-up Tank } \\ \text { HWVP } & \text { Hanford Waste Vitrification Plant } \\ \text { ICP } & \text { Inductive Coupled Plasma } \\ \text { ID } & \text { Inner Diameter } \\ \text { INE } & \text { Institut für Nukleare Entsorgungstechnik } \\ \text { KfK } & \text { Kernforschungszentrum Karlsruhe } \\ \text { LEWC } & \text { Low Enriched Waste Concentrate } \\ \text { MFT } & \text { Melter Feed Tank. } \\ \text { MPA } & \text { Melter Performence Activity } \\ \text { NCAW } & \text { Neutralized Current Acidic Waste } \\ \text { PAMELA } & \text { Pilot Anlage Mol zur Herstellung endlagerfähiger Glasprodukte } \\ \text { PHDT } & \text { PNL Hanford Technology Development } \\ \text { PISA } & \text { Produktions - und Maschinendaten - Informations - System für } \\ & \text { Automationsanwendungen } \\ \text { PNL } & \text { Pacific Northwest Laboratories } \\ \text { RFA } & \text { Röntgen - Fluoreszenz - } \text { Analyse (s. XRF) } \\ \text { RHF } & \text { Refractory Heated Feeder } \\ \text { TEMPEST } & \text { Transient Energy, Momentum and Pressure Equations Solutions in Three Dimensions } \\ \text { VA-WAK } & \text { Verglasungs-Anlage - Wiederaufbereitungsanlage Karlsruhe } \\ \text { WST } & \text { Waste Storage Tank } \\ \text { XRF } & \text { X-Ray-Fluorescence } \\ & \end{array}$




\subsection{SUMMARY AND CONCLUSIONS}

In November 1989, a first discussion took place between members of Pacific Northwest Laboratory (PNL), Westinghouse Hanford Company (WHC), the United States Department of Energy (USDOE) Richland Operations and the Institut für Nukleare Entsorgungstechnik of Kernforschungszentrum Karlsruhe (KfK-INE) regarding the question of noble metals behaviour in a liquid fed ceramic melter when vitrifying Neutralized Current Acid Waste (NCAW). A contract was signed in April 1991 between PNL and KfK-INE comprising three tasks for KfK: (i) to design and construct an Engineering-Scale Melter (ESM) together with a suitable feeding system for NCAW melter feed, (ii) to operate the facility with NCAW feed simulant containing the noble metals ruthenium, rhodium and palladium, and.(iii) to evaluate the melter performance particularly in respect to noble metals retention in close cooperation with PNL.

\section{Facility}

The basic design features of the 1/10 scale ESM fit those of the current HWVP reference melter (including flat bottomed melt tank, glass pouring via overflow with underpressure support, two pairs of uncooled Inconel 690 electrodes). Exceptions are the overflow heating technique, the bottom drain, and the geometry of the glass pool, i.e. the ratio of the glass tank height to its diameter. The ratio had to be increased from about 0.5 .of the HWVP full scale melter to 1.25 of the ESM in order to get a glass residence time in the ESM comparable with that of the full scale melter.

The ESM had been designed for a throughput of $20 \mathrm{l} / \mathrm{h}$ NCAW melter feed simulant. The corresponding glass production rate is $10 \mathrm{~kg} / \mathrm{h}$. The actual throughput of the ESM, however, was only $12-15 \mathrm{l} / \mathrm{h}$. Higher feed rates led to overfeeding of the melter. Two SiC melter plenum heating elements, placed horizontally inside Inconel 690 tubes, were maintained at $900^{\circ} \mathrm{C}$ for additional heat supply to the glass pool surface. The residence time of the glass in the melt tank was $80-100$ hours. It exceeded significantly the target value of $58 \mathrm{~h}$. The target value corresponds to the design feed rate of $20 \mathrm{l} / \mathrm{h}$.

The round shaped melter has $0.28 \mathrm{~m}^{2}$ glass pool surface and $550 \mathrm{~kg}$ glass capacity. It is a $1 / 10$ of the current full scale HWVP reference melter. The melt tank is flat bottomed. Two power electrode sets are placed in the upper and lower part of the pool on opposite sides. For glass pouring it posses both an overflow and bottom drain device. The glass overflow serves as the routinely used pouring system. It consists of a thick-walled Inconel 690 pipe with $30^{\circ}$ slope. For pouring, the canister needs airtight coupling with the flange of the overflow housing. The glass flow can be started and sustained by an underpressure of approximately $300 \mathrm{~mm}$ water column, generated in the overflow housing by means of an air jet. 
The construction of the NCAW feeding system and the ESM melter were completed in June 1992. The feeding area consists primarely of a $5 \mathrm{~m}^{3}$ Feed.Make up Tank (FMT) and a $1.6 \mathrm{~m}^{3}$ Melter Feed Tank (MFT) from which the feed is send to the melter by means of a feed pump. For cleaning of the melter off gas the existing equipment could be used. For melter and process control, the data acquisition and visualization system PISA had been modified and applied.

For glass sampling under the described underpressure conditions a specific device had been designed. It allows to take five glass samples from the overflow glass stream during a pouring operation and to store them in the overflow housing until the end of the pouring. The glass was drained in batches of approximately 65 to $75 \mathrm{~kg}$ into stainless steel canisters of $430 \mathrm{~mm}$ in dia and $1350 \mathrm{~mm}$ height. The cans had a glass capacity of maximum $400 \mathrm{~kg}$. Pouring of a batch was carried out every $8-10$ hours with a pouring rate of $50 \mathrm{~kg} / \mathrm{h}$. The bottom drain system of the ESM was used for emptying the melter after run termination.

\section{Test runs}

The test runs were performed with simulated NCAW melter feed which contained $140 \mathrm{~g} / \mathrm{l}$ waste oxides, $17 \mathrm{~g} / \mathrm{l}$ recylcle oxides, and $343 \mathrm{~g} / \mathrm{l}$ of fine powdered glass frit. It was an alkaline suspension with a $\mathrm{pH}$ of approximately 8 to 9 after formating. A volume of $16.8 \mathrm{~m}^{3} \mathrm{NCAW}$ melter feed simulant was processed. Both the NCAW feed simulant and the powdered glass frit were prepared in the United States and shipped to KfK-INE where final preparation took place (including formating with formic acid). NCAW feed processing in the ESM was started on July 2, 1992, with a pretest designated U1. By this test $2.61 \mathrm{~m}^{3}$ of noble metals free NCAW melter feed simulant were vitrified. It served to check the correct function of the melter including the glass pouring systems and the glass sampling device, before the noble metals containing NCAW feed was processed.

In the pretest run $\mathrm{U} 1$ the feeding area proved to be sensitive and critical. Frequent plugging of the feed line between the MFT and the melter was experienced. Moreover, undissolved larger particles in the feed of up to $5-10 \mathrm{~mm}$ in size caused blockages. These particles have been analyzed as $\mathrm{LaF}_{3}$ compound. Other factors contributing to the problem included the flow meter, which was installed in the feed line. It was not applicable because it needed a too low cross section for the measurement effect. In cooperation and discussions with participating staff members of PNL, WHC and US-DOE Richland Operations, the plugging problems could later be substantially reduced in the noble metals test run U2. But the direct feed throughput measurement device had to be eliminated. As alternative method, the measurement of the decrease of the MFT waste simulant level in dependance of the operation time was used to calculate the feed rates by differentiation of the curve. In case of pluggage 
of the feed line to ESM the feeding to the ESM was usually interrupted for 5 to $40 \mathrm{~min}$.

In the main test run, $\mathrm{U} 2$, about $14.23 \mathrm{~m}^{3}$ of NCAW simulant were vitrified. The simulant contained $0.73 \mathrm{~g} / \mathrm{l}$ of the noble metals $(\mathrm{Ru} 0.44 \mathrm{~g} / \mathrm{l}, \mathrm{Rh} .0 .12 \mathrm{~g} / \mathrm{l}$ and $\mathrm{Pd} 0.15 \mathrm{~g} / \mathrm{l})$. The total amount of noble metals processed with the NCAW simulant was $9.94 \mathrm{~kg}$, consisting of $6.16 \mathrm{~kg} \mathrm{Ru}, 1.68 \mathrm{~kg} \mathrm{Rh}$, and $2.10 \mathrm{~kg}$ Pd. The continuous noble metals test run lasted from July 11 until August 30, 1992. Glass pouring operations via the ESM overflow system were carried out 89 times and more than 435 glass samples were taken for analysis. XRF analysis of the glass samples were usually available about two days after sampling. The main operational parameter like melter power, glass temperatures, feed rate, and glass pouring operations were plotted in an operation diagram.

\section{Processing behaviour of NCAW simulant}

The melter feed was difficult to process. The feed in the FMT and MFT tended to become more viscous with time (in terms of days) after the frit was added to the formated waste. This increased the pluggage risk in the feed line between the MFT and ESM. But particularly it also influenced the processing behaviour on the molten glass pool surface. In some cases the slurry was so viscous that it did not self-distribute across the glass pool surface area. The resulting cold cap then became thick (up to $5 \mathrm{~cm}$ ) and rigid with very few vents. The effect of this thick cold cap on noble metals agglomeration is not understood at this time. This effect will be discussed further in future HWVP reports. The feed formed piles 5 to $10 \mathrm{~cm}$ in diameter and up to $30 \mathrm{~cm}$ high until the feed income channel of the feed tube was blocked by the top of the pile. To avoid such conditions the feed in the MFT was diluted when necessary by adding some water (less than $5 \%$ ) or nitric acid.

The feed simulant also tended occasionally to cover the pool surface with somewhat foaming material. In those cases the feed rate to melter had to be reduced in order to avoid total coverage of the pool with obviously highly heat insulating material. Foamy material from the glass pool surface was sampled and analyzed (see Appendix A of this report). This glassy material represents a concentrated suspension of glass product melt, frit melt, calcine and salt melts with a high viscosity.

\section{Noble metals discharge}

The analyzed content of the noble metals in the glass samples, taken during glass pouring operations with overflow system, show for all three elements lower concentrations than the target values. For ruthenium and rhodium, the concentrations in canister $10-17$ reached about $75 \%$ of the targets, and for $\mathrm{Pd} 60 \%$. For each glass canister the noble metals content has been determined by 
integration of the concentration profiles of the measured glass samples. The "fed in" curve and the "discharge" curve (noble metals fed to the ESM with the melter feed and discharged from ESM with the glass) are not parallel. This is indicative that a nearly constant increasing amount of noble metals remained in the melter with time. In the glass pool no air bubbling or other means for intensifying the glass melt convection were used. A portion of $2.13 \mathrm{~kg} \cdot \mathrm{Ru}, 0.54 \mathrm{~kg} \mathrm{Rh}$, and $0.80 \mathrm{~kg} \mathrm{Pd}$ may have settled towards the melter bottom according to the "fed in" and "discharge" data.

At the end of the run the melter was emptied via the bottom drain. A layer of approximately $1-3 \mathrm{~cm}$ variable thickness with very high noble metals concentrations (4-6 wt\%) remained in the melter. Samples from.this layer exhibited one order of magnitude lower el. resistivity than the bulk of the glass. This effect can also be seen from the electric resistance between the power- electrodes when comparing the same current settings at the beginning and at the end of the noble metals run. Between the upper electrodes a decrease of about $9 \%$ and between the lower electrodes of about $13 \%$ can be calculated. This effect was not enough to disturb the Joule heating severely but operation problems with longer times can be predicted from those findings.

\section{Conclusions}

The noble metals discharge efficiency via the glass overflow of a melter type like the ESM indicate a risk for long-term melter operation and, hence, melter lifetime due to the influence of accumulation of noble metals on the melter floor. However, based on KfK's experience in the past decade with processing of LEWC waste in PAMELA, with 5M nitric acid Wackersdorf HLLW simulate, and with HLLW simulate of WAK waste, the noble metals segregation and accumulation effect in the case of NCAW waste glass seems to be not so strong. This can partly be due to the lower concentration of the noble metals in the NCAW glass and also due to formation of smaller noble metals particles observed in the NCAW glass. Anyway, the tendency to disturb the Joule heating can be seen and must be taken into account for a final melter design.

Because the NCAW represents only a smaller portion of the total amount of $\mathrm{HLW}$ to be vitrified by the HWVP a new melter design for NCAW for achieving an optimal noble metals compatible melting system may be not the right solution. However the current HWVP reference melter for NCAW is recommended to get some modifications. Those modifications should include the inner melt tank geometry and specific operational procedures. The tank geometry should be modified to concentrate, the noble metals accumulations in an area where they could be either removed periodically, f.e. via bottom drain, or remobilized by introducing sparging air. Also the distance of the lower power electrodes from this area should be increased. Moreover the modifications are dependant on the specific operation procedures, f.e. use of a bottom drain additionally to the overflow system. 


\subsection{INTRODUCTION AND SCOPE OF WORK}

The Hanford Waste Vitrification Plant (HWVP) is scheduled to vitrify several types of High Level Waste with a total volume of around $30000 \mathrm{~m}^{3}$ until the fiscal year 2013. The first waste to be vitrified will be the Neutralized Current Acid Waste (NCAW) of totally about $7000 \mathrm{~m}^{3}$. Following pretreatment and feed preparation, the NCAW melter feed will contain approximately $0.73 \mathrm{~g} / \mathrm{l}$ noble metals ( $\mathrm{Ru}, \mathrm{Rh}, \mathrm{Pd})$. This corresponds to more than 1-3 tons of noble metals in total.

Noble metals present in the melter feed have been shown in testing conducted by KfK-INE and at the radioactive processing facility PAMELA in Mol, Belgium to result in the premature failure of melters that have flat glass tank floors. The noble metals are mainly insoluble in the glass and therefore will form particulates, that could settle to the floor of the melter. The Hanford reference melter was not designed to assure the suspension of insoluble particles. If a sufficient quantity of noble metals accumulates in the melter, the joule heating effect of the electric current will be impossible to achieve and the melter will have to be replaced. Therefore the melter performance assessment (MPA) activity is responsible for determining the effects on the HWVP reference melter. As a part of this work, an Engineering-Scale melter (ESM) has been designed and constructed by the Institut fur Nukleare Entsorgungstechnik (INE) at the Kernforschungszentrum Karlsruhe (KfK) in Karlsruhe, Germany. Operation took place from July 2 to August 30, 1992. Data from this test will be used directly and via computational modeling to estimate the life of the reference melter. This test program has been performed under contract to, and in cooperation with, the Pacific Northwest Laboratory (PNL). The PNL-HWVP Technology Development (PHTD) Project has been managing this work. The main objectives of the work were as follows:

- Construction of an ESM including necessary feeding equipments for installation into one of KfKINE's test facilities (VA-WAK)

The melter size was defined to be $1 / 10$ th of the reference plant melter concerning the glass pool surface. The mean residence time of the glass, assuming an average feeding rate of $20 \mathrm{l} / \mathrm{h}$, was calculated to be the same as in the reference melter (58h). The melter was equipped with plenum heaters to boost the melting rate. In order to supply the melter with simulated feed, a separate feed preparation and feeding system had to be built. For melter off-gas treatment, the part of the existing VA-WAK equipment could be used.

- Conduction of a 1-week shake down test processing using about $3 \mathrm{~m}^{3}$ of NCAW melter feed simulant without noble metals. 
- Conduction of a noble metal test using flowsheet quantities of $\mathrm{Ru}, \mathrm{Pd}$, and $\mathrm{Rh}$ and a total amount of NCAW melter feed simulant of about $14 \mathrm{~m}^{3}$.

- Determination of the noble metals behavior in the melter using a mass balance based on glass, feed and off-gas samples. Additional information about possible segregation and accumulation of noble metals sediments onto the melter floor is given by analyzing elctric power and restistance data during the run. Further the morphology of the noble metals found in the glass samples should be characterized.

- Providing all the operation data necessary to support the TEMPEST computer modelling for the HWVP.

The test report describes the technical system including especially the ESM and the feed preparation equipment. The performance of the plant operation is outlined and the overall data are given. The main interest is focused on the noble metals behavior. The analytical results are discussed and conclusions are drawn concerning the feasibility of the ESM and the reference melter concept.

\subsection{SYSTEM DESCRIPTION}

\subsection{Vitrification facility}

The existing nonradioactive vitrification test facility designated VA-WAK has been used to integrate the feed preparation system and the ESM for processing NCAW simulant. The basic flowsheet of the integrated equipments is given in Figure 3-1. The part of the plant used for the VAWAK only is drawn in dotted lines.

The NCAW simulant is pumped from the large waste storage tank outside this building into the feed make up tank (FMT). The waste storage tank has an agitator with two impellers to ensure that the waste remains thoroughly mixed. The maximum capacity of the FMT is $4.5 \mathrm{~m}^{3}$. The diameter of the tank is $1.8 \mathrm{~m}$, the overall height is $2.5 \mathrm{~m}$, and the nominal fill level is $1.75 \mathrm{~m}$. It is equipped with a steam heating/water cooling jacket. For homogenization, a $3 \mathrm{~kW}$ stirrer is inserted in the central axis from the top. The stirrer blade is a turbine (without radial plates). It is controlled by a variable speed controller with a range of 54-280 rpm. Additionally, the content of the vessel can be pumped by diaphragm pumps in a circuit. These pumps are also used to transfer the ready prepared feed simulant 


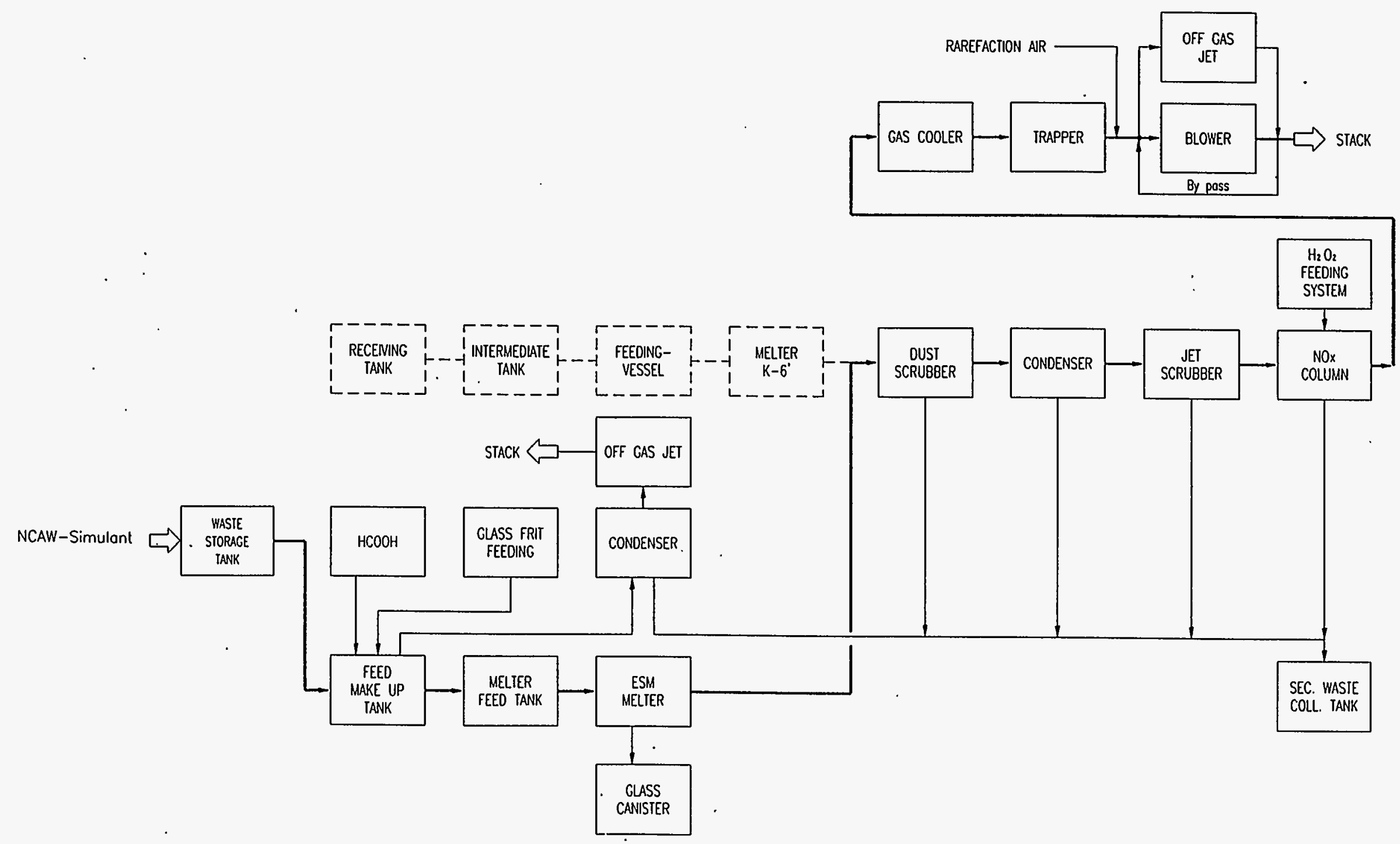

Figure 3-1: Basic flowsheet of the test facility. The dotted lines refer to components used for other test programmes at INE (HAWC-WAK program) 
to the melter feed tank (MFT). During formating the formic acid is also dosed by diaphragm pumps through a submerged tube introduced from the top of the vessel.

The arising off-gas during formating and concentrating is exhausted by a vacuum jet passing a tube bundle condenser. The off-gas composition ( $\mathrm{H} 2, \mathrm{NOx}, \mathrm{CO} 2, \mathrm{~N} 2 \mathrm{O}, \mathrm{N} 2)$ can be analyzed on-line by a gas chromatagraph (Chrompack GmbH/Frankfurt, Gasanalyzer CP2001D) and infrared analyzers (Bodenseewerk Perkin-Elmar GmbH Übèrlingen, Multicomponent Process-Photometer MCS 100). The condensate is transferred together with other secondary waste streams to a collection tank. It is not recycled back to the tank. The instrumentation of the FMT consists of temperature, pressure, level and density measurements. At the beginning of the runs dip tube measurement was used for level and density detection. Due to the high viscosity of the slurry, it could only temporarely be operated after cleaning. Thus an additional ultra-sonic level measurement device was integrated in the FMT as well as in the MFT after the 3rd batch. The glass frit was manually added batchwise through a vertical tube on top of the tank. For adjusting the feed composition, water has been added. Both the MFT and FMT had viewports for visual observations.

The melter feed tank can be operated between a maximum content of $1.4 \mathrm{~m}^{3}$ and a minimum of $0.4 \mathrm{~m}^{3}$. It has a diameter of $1.2 \mathrm{~m}$ and a height of $1.8 \mathrm{~m}$. The maximum level is $1.2 \mathrm{~m}$. The feed is continously transferred by diaphragm pumps to the melter. The Moyno progressive cavity pumps, originally installed for this purpose, had to be replaced due to frequent failures. The MFT is also equipped with a $1.5 \mathrm{~kW}$ stirrer as well as with level and density measurements. The stirrer has a variable speed controller with a range of $54-280 \mathrm{rpm}$. The MFT is connected by a $8 \mathrm{~mm} \mathrm{ID}$ sloped feeding line to the water cooled melter feed tube. In the Fig. 3-2 and 3-3 the facility plan including the integrated ESM melter and the feed preparation equipments are shown.

The structure of the ESM is shown in Figures 3-4 to 3-8. The melter has been designed to have a $1 / 10$ th-scale glass surface area and the average residence time of the glass equal to the HWVP reference melter. As a result the ratio depth to diameter of the glass tank is significantly higher for the ESM melter as for the reference melter. The major design data of the ESM are given below as follows:

$\begin{array}{llll}\text { Glass pool surface area } & : & 0.28 \mathrm{~m}^{2} \\ \text { Pool depth } & : & 0.78 \mathrm{~m} \text { (approx.) } \\ \text { Design feed rate } & : & 20 \mathrm{J/h} \\ \text { Design glass rate } & : & 10 \mathrm{~kg} / \mathrm{h} \\ \text { Glass inventory } & : & 585 \mathrm{~kg} \text { (approx.) } \\ \text { Glass residence time } & : & 58 \mathrm{~h} \text { (approx.) } \\ \text { Melter weight (empty) } & : & 7 \mathrm{t} \text { (metric). } \\ \text { Operating temperature } & : & 1150^{\circ} \mathrm{C}\end{array}$




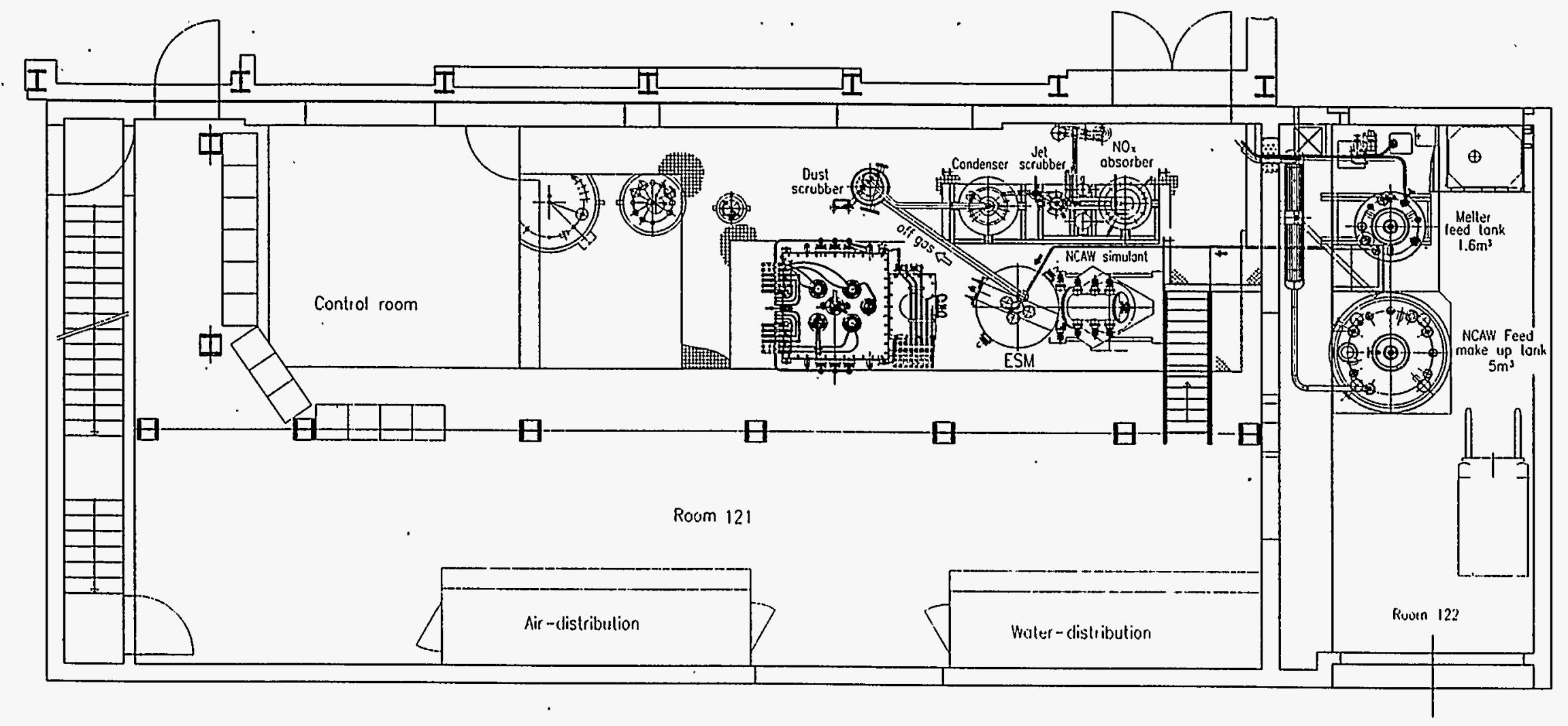

Figure 3-2: View from top onto the facility including the feed make up tank, the melter feed tank and the Engineering Scale Melter (ESM) 


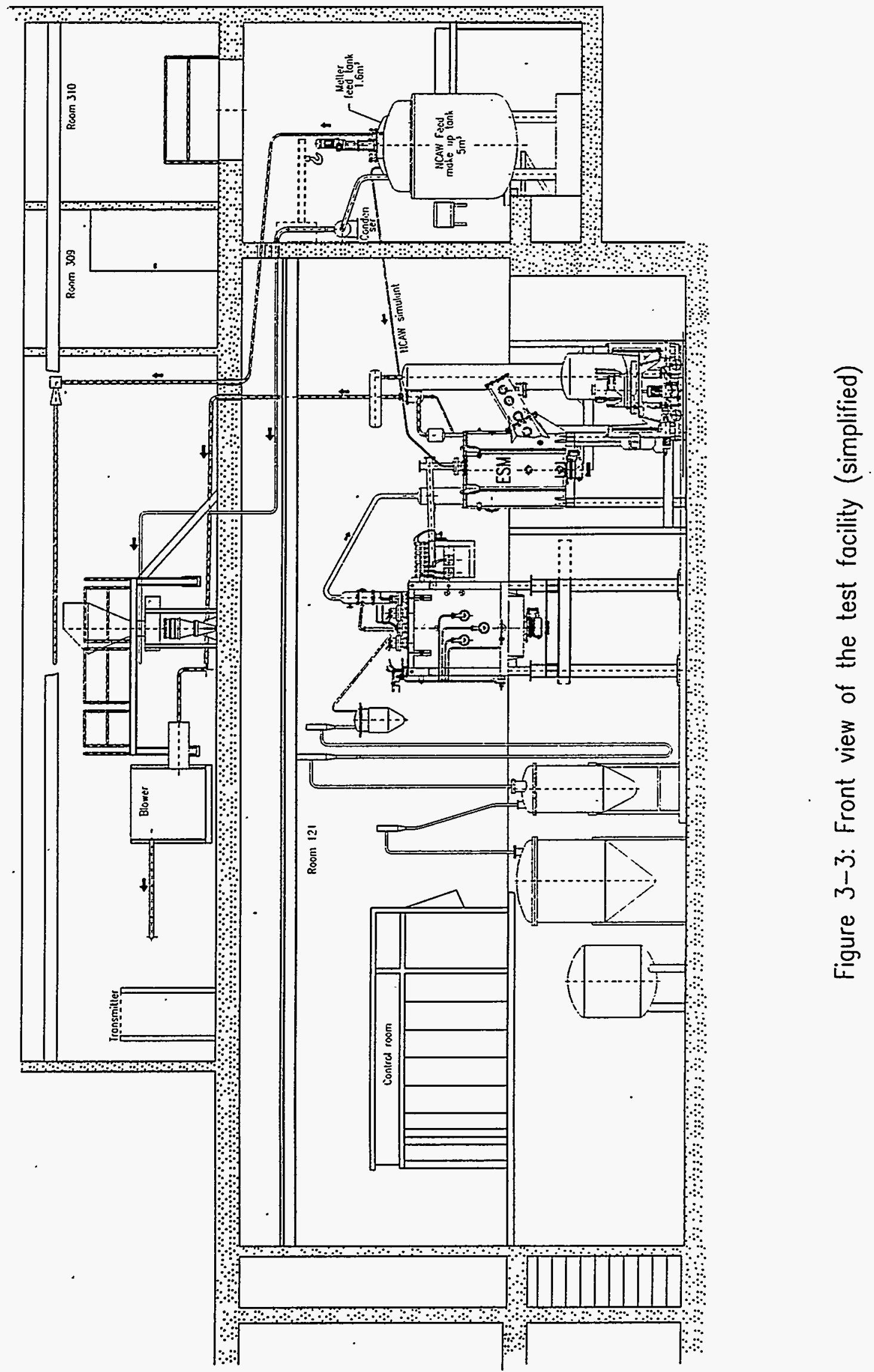




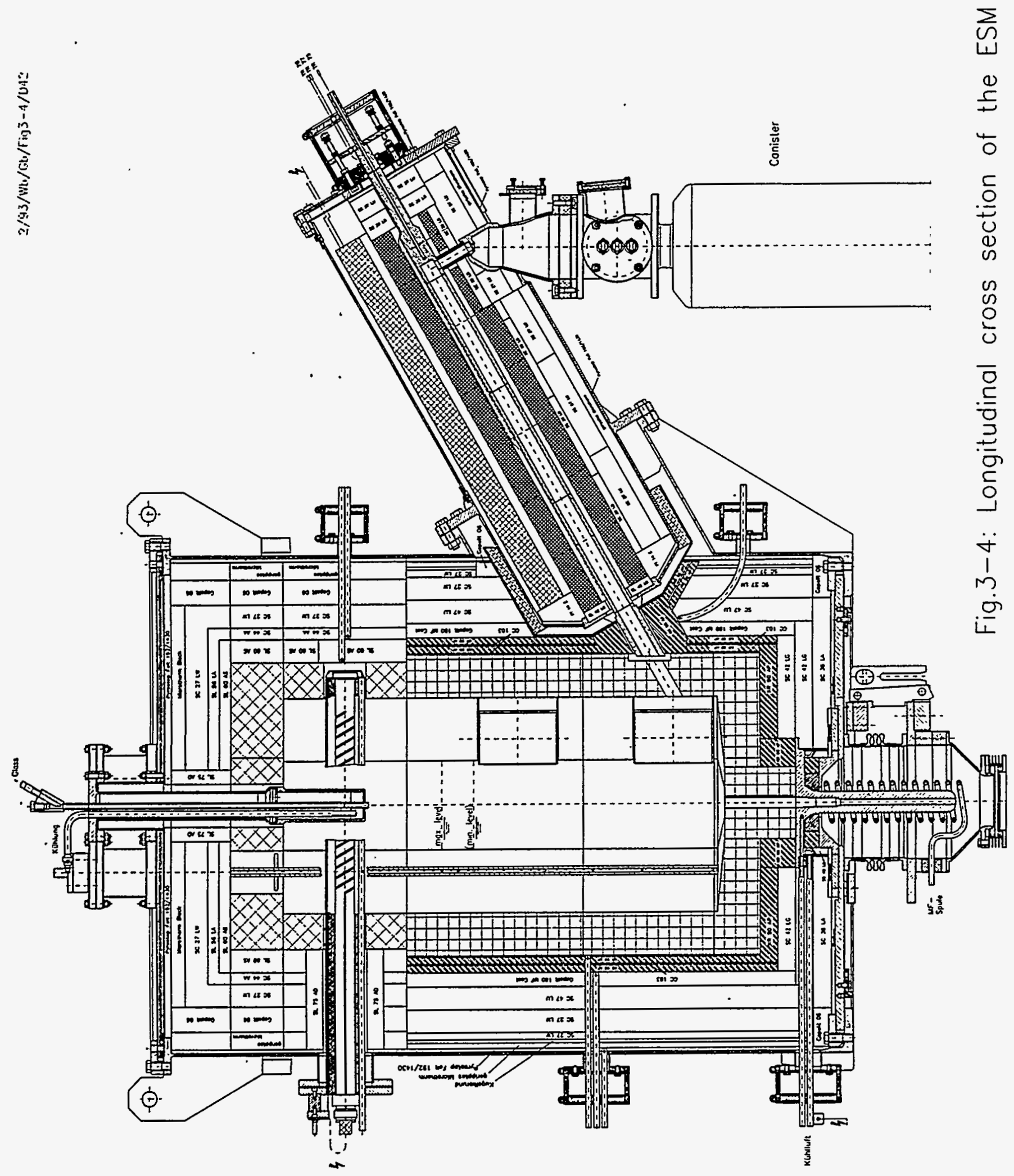




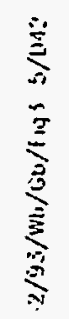

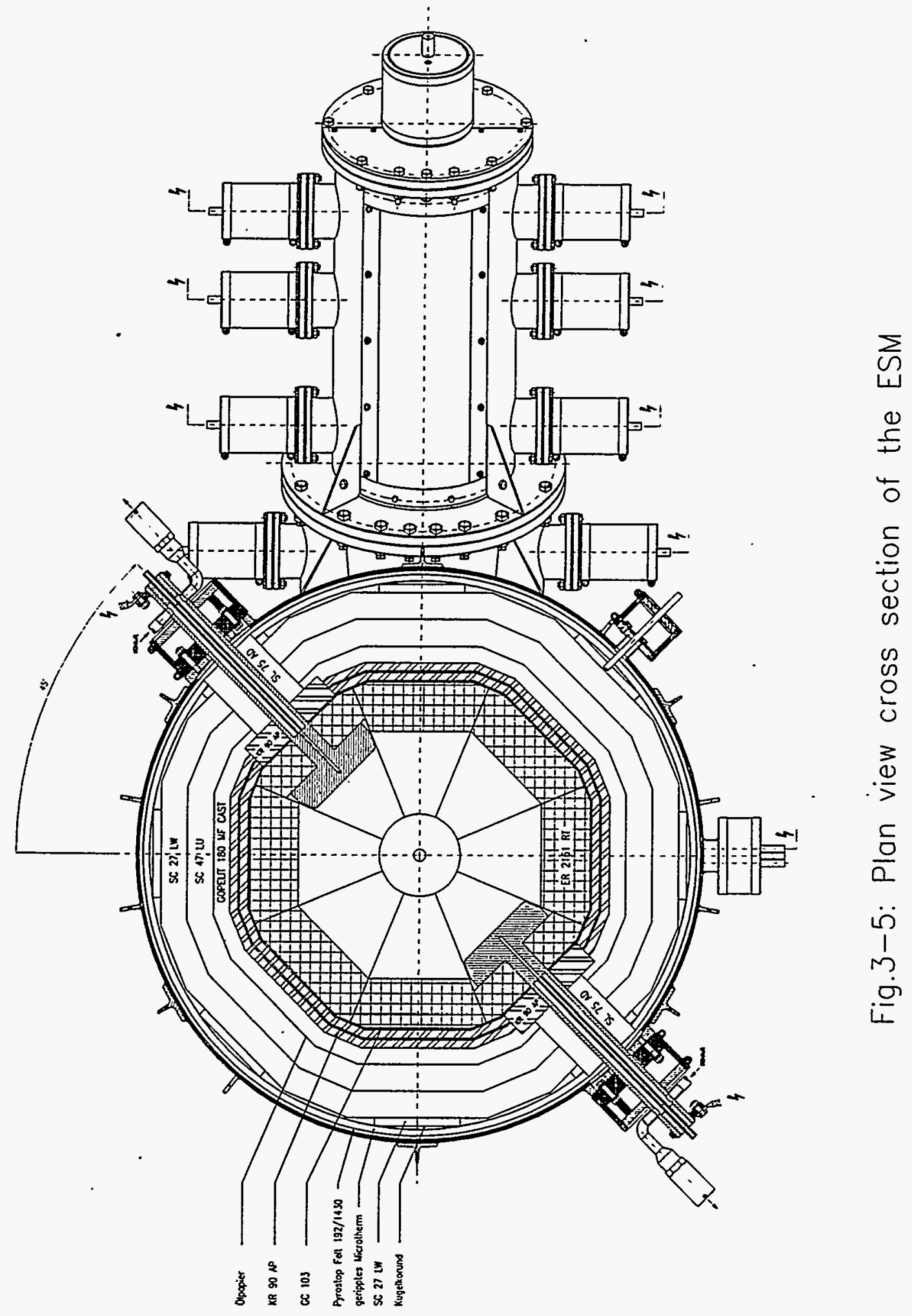




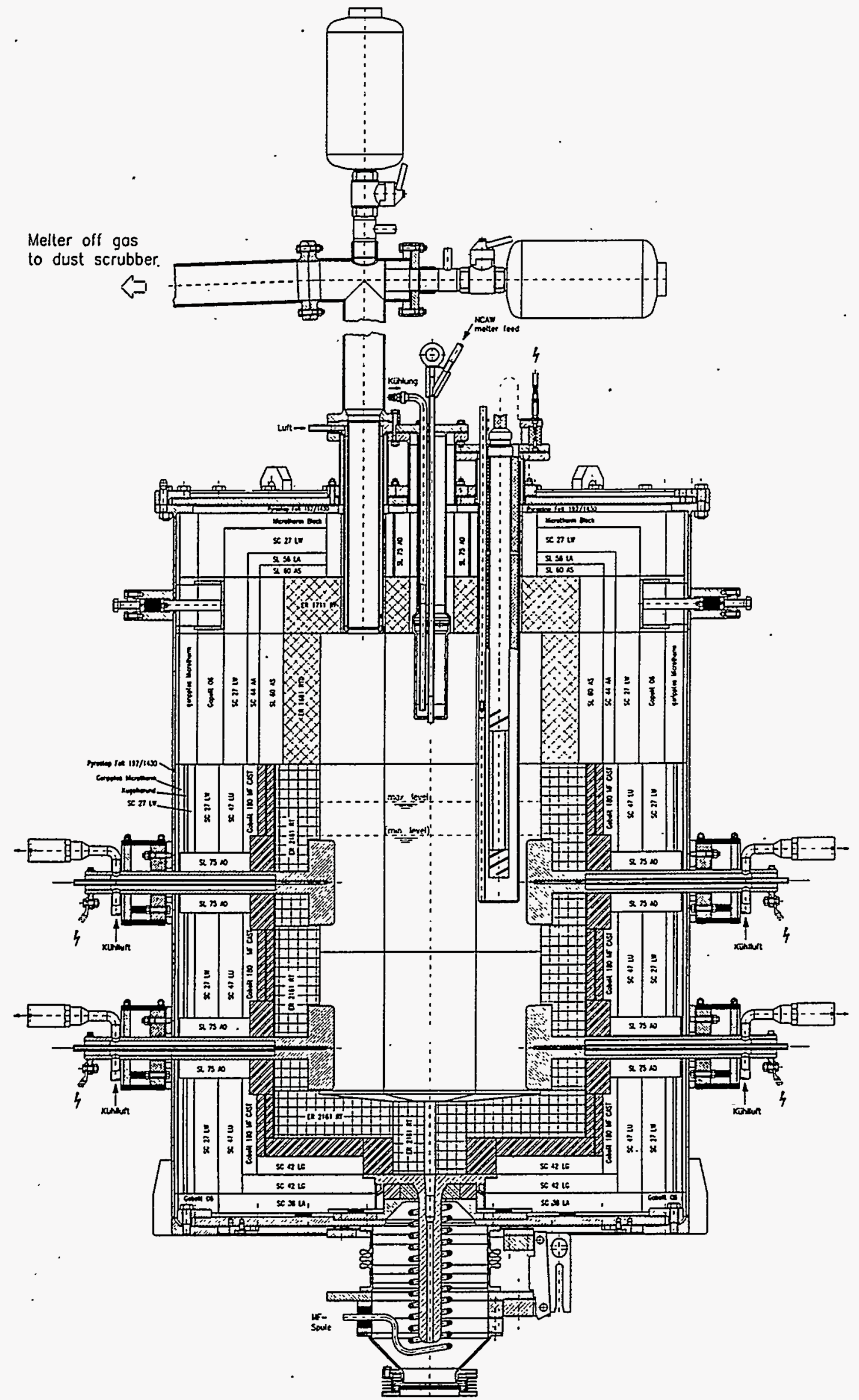

Fig.3-6: Transverse cross section of the ESM 
空

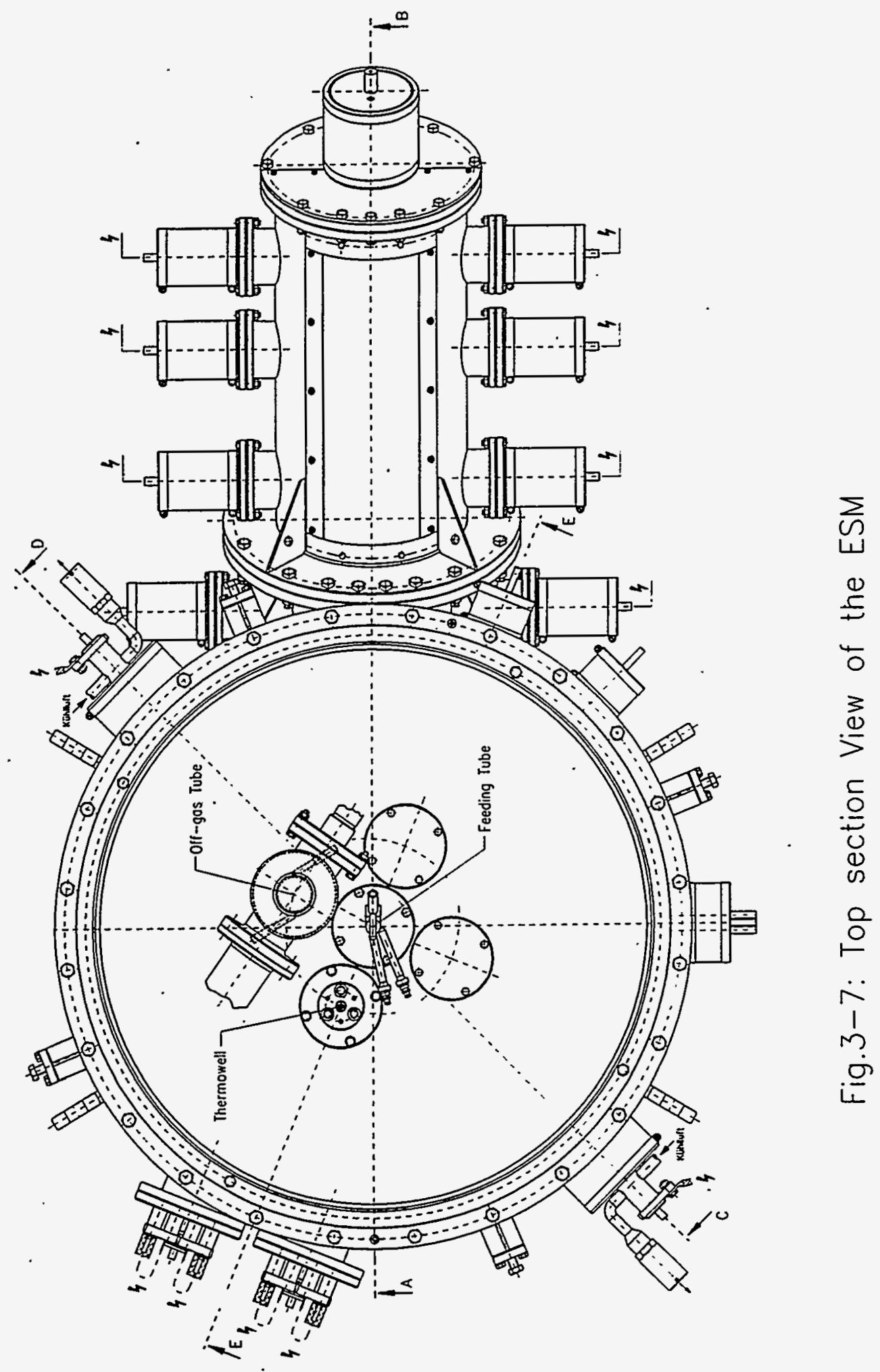




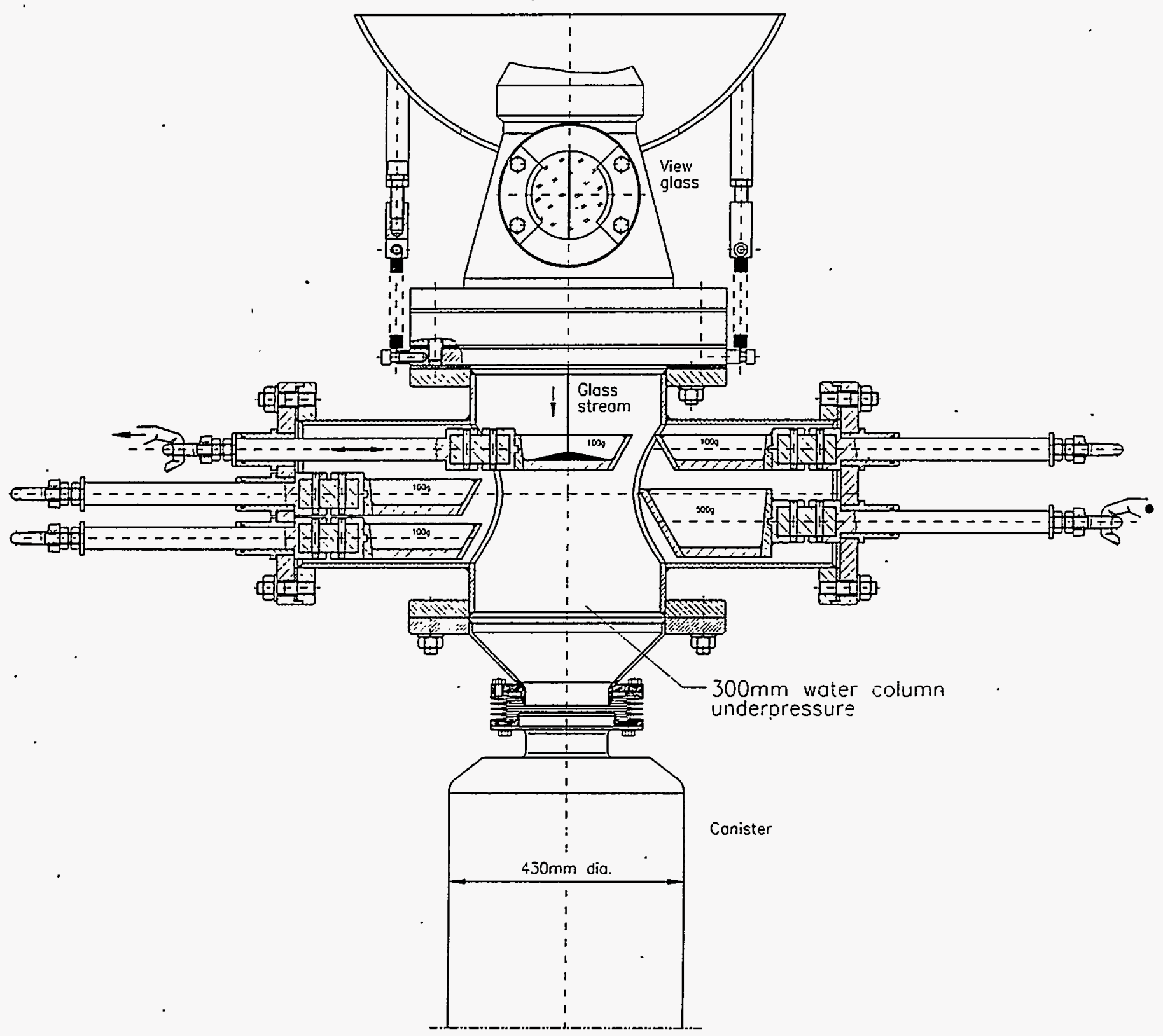

Fig.3-8: Glass sampling system 
The bulk glass is heated by alternating current between two pairs of uncooled Inconel 690 electrodes $26.8 \mathrm{~cm}$ wide by $22.5 \mathrm{~cm}$ high. The temperature of each electrode is monitored by a type $S$ thermocouple that was $30 \mathrm{~mm}$ from the electrode face. The lower set of electrodes is $9 \mathrm{~mm}$ off of the melter floor. The power to the electrodes is supplied by two $60 \mathrm{kVA}$ single phase transformers (in phase).

The current to the main electrodes is controlled by a single phase Thyrovar (AEG) with phase cutting method. The desired current is kept stable by the internal controller in the Thyrovar unit. The Thyrovar supplies the subsequently added single phase transformer and the secondary winding is connected to the electrodes. For the melter plenum heaters the same method is used.

For glass pouring a vacuum supported overflow system is used. The inclination of the overflow channel consisting of an Inconel 690 tube (70 mm outer dia., $40 \mathrm{~mm}$ inner dia., $1100 \mathrm{~mm}$ long) is $30^{\circ}$. Heating of the glass-carrying Inconel 690 pipe is performed by the RHF (Refractory Heated Feeder) system shown in Figure 3-9. Four pairs of electrode plates made of Inconel 690 are placed on opposite sides of 4 ceramic refractory blocks with the channel hole in the center. An alternating current $(50 \mathrm{~Hz})$ between the electrodes heats up the ceramic refractory (isostatically pressed CR100 type, $95 \% \mathrm{Cr} 2 \mathrm{O} 3$ ). This refractory is higher in $\mathrm{Cr} 2 \mathrm{O} 3$ and thus, more conductive than the melter tank refractory so that it can be resistively heated. By temperature radiation, the Inconel 690 pipe and thus the glass is maintained at temperatures of about $1100{ }^{\circ} \mathrm{C}$. The canister is coupled gas tight to the lower flange of the overflow housing. For glass sampling under the described underpressure conditions a specific device had been designed. It allows to take five glass samples from the overflow glass stream during a pouring operation and to store them in the overflow housing until the end of the pouring (see Figure 3-8). The glass was drained in batches of approximately 65 to $75 \mathrm{~kg}$ into stainless steel canisters of $430 \mathrm{~mm}$ inner dia. and $1350 \mathrm{~mm}$ height. The cans had a glass capacity of maximum $400 \mathrm{~kg}$. Pouring of a batch was carried out every $8-10$ hours with a pouring rate of $50 \mathrm{~kg} / \mathrm{h}$. By the use of a vacuum air jet the glass flow can be started and its flow rate controlled. Load cells are installed on the canister car to measure the canister weight. For emptying the melter a bottom drain can be used. The metallic part of the drain channel (Inconel 690) is then induction heated. The glass tank of the melter is constructed with fused cast ceramic material (type ER 2161) surrounded by ceramic insulation. The melter structure is encased in a gastight stainless steel containment box. The melter is equipped with 32 type $\mathrm{S}$ and $\mathrm{J}$ thermocouples. The major portion of the temperature monitoring points are shown in Figures 3-10. The glass and plenum temperatures were monitored by 8 type $\mathrm{S}$ thermocouples in a $2.5 \mathrm{~mm}$ diameter Inconel 690 thermowell placed half way between the melter center and the tank walls. The arrangement of these thermocouples allows very well to identify the melt level (see figures 4.16 to 4.25 ). Additionally, on an experimental base, a test probe was 


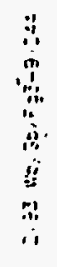

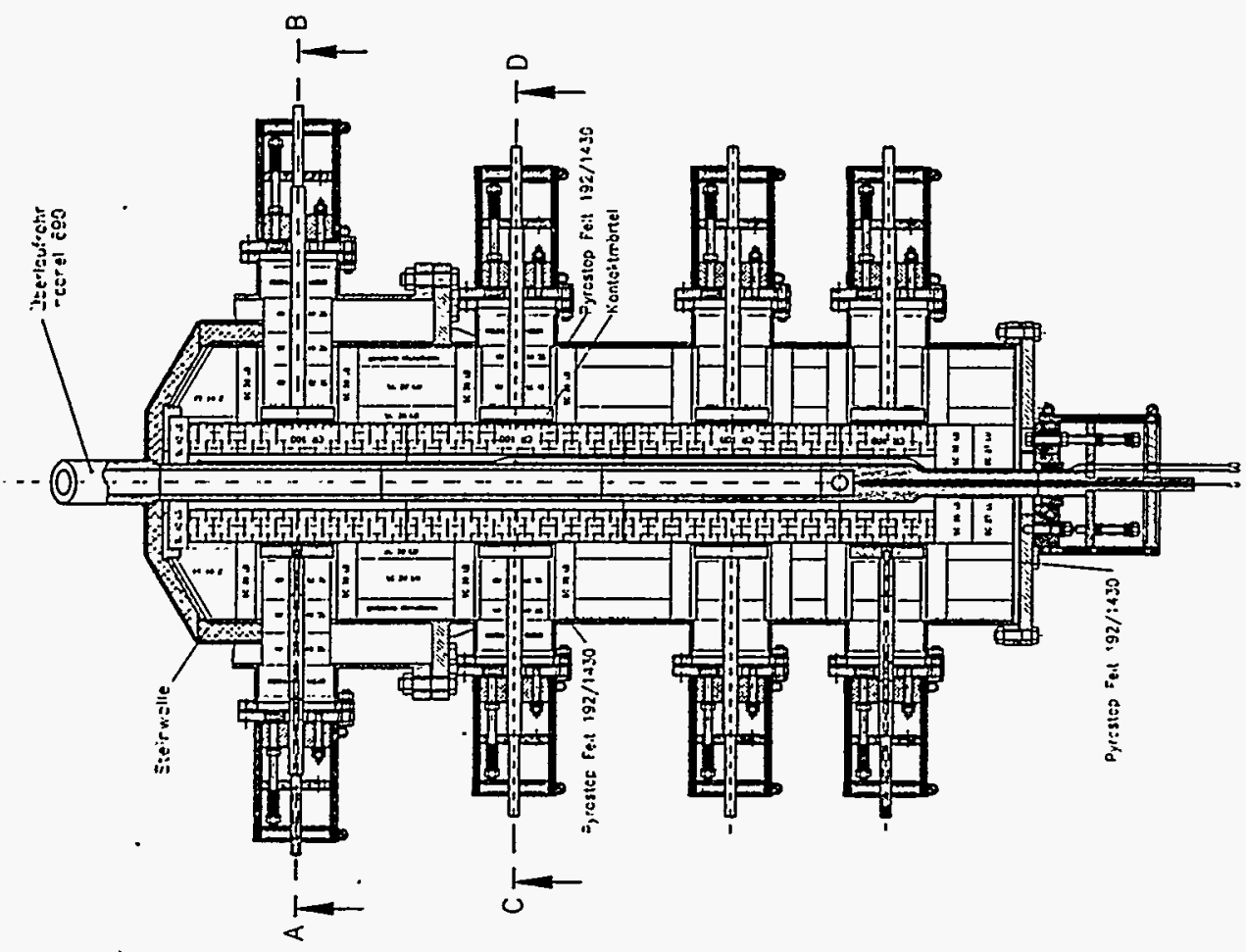

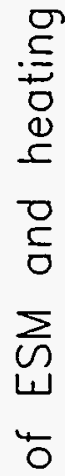
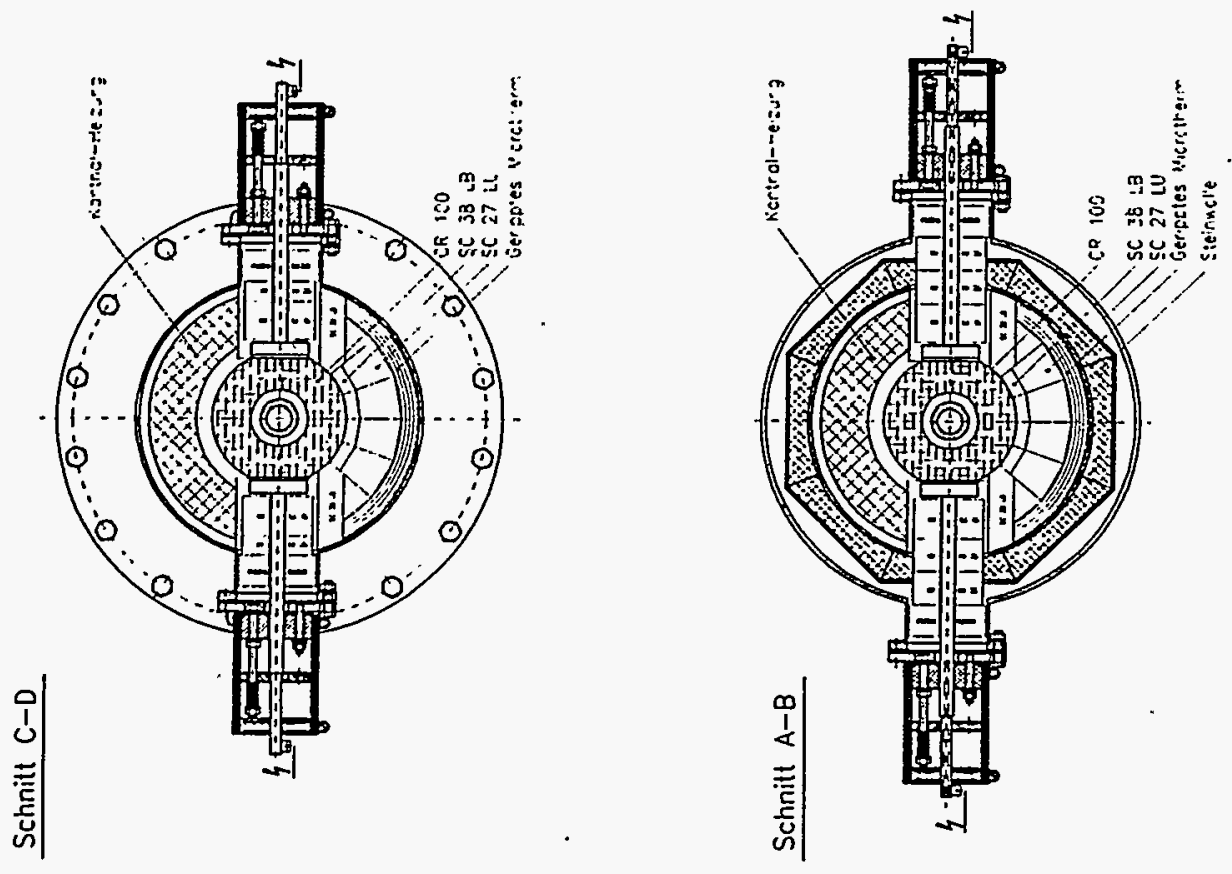

$\frac{\varepsilon}{0}$

के 이

$\frac{-\frac{1}{0}}{0} \frac{0}{0}$

닌

ว $\frac{1}{\partial}$

\begin{tabular}{ll}
$\omega$ & $\frac{1}{E}$ \\
N & 0 \\
\hline & 0
\end{tabular}

$\ddot{\sigma}$

M

i 

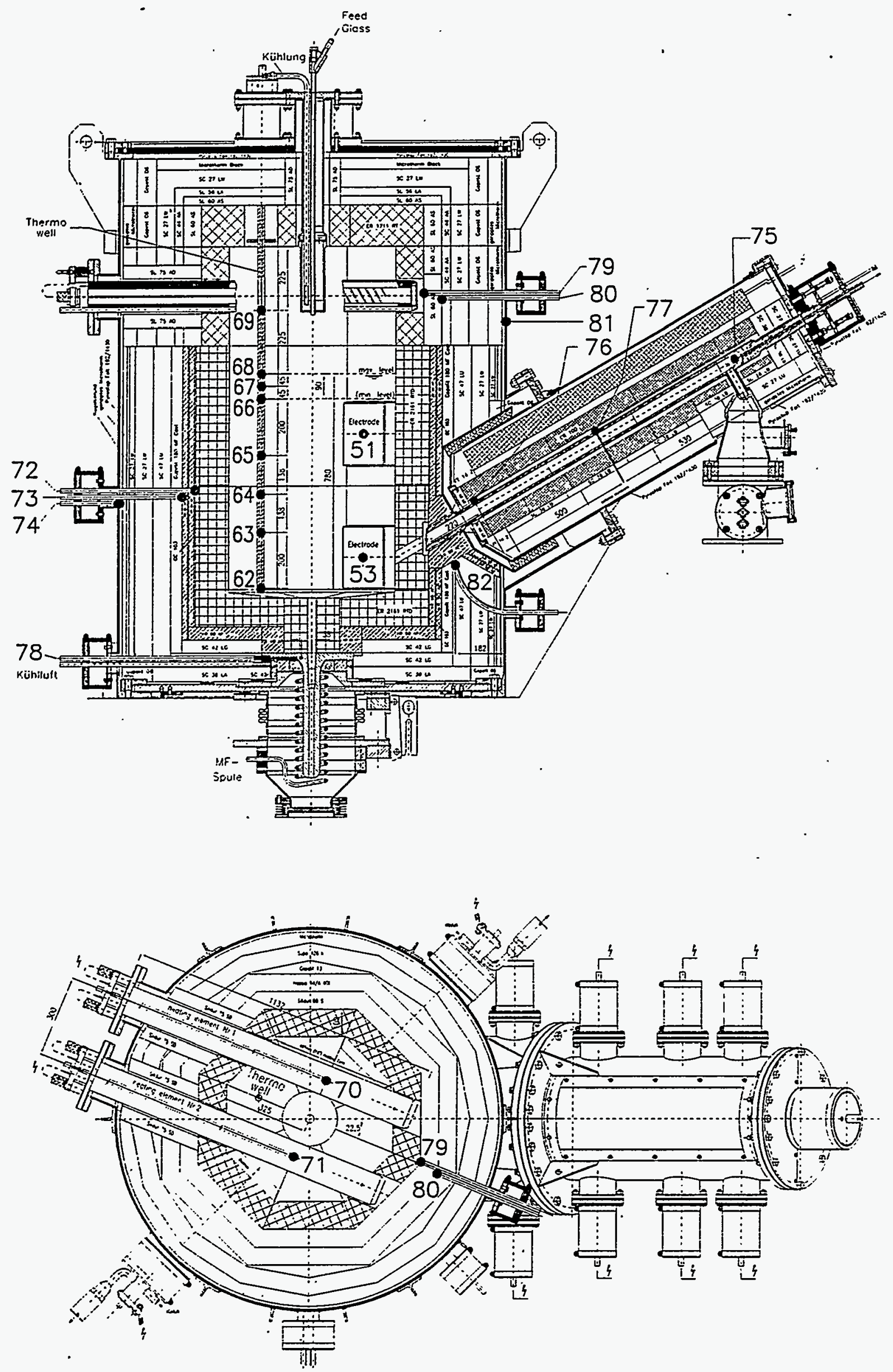

Fig. 3-10: Temperature monitoring points of the ESM 
installed from the melter top to measure the voltage to the main electrodes. When the molten glass reached the level of the test probe the voltage increased from 1 to $20 \mathrm{VAC}$.

The melter off-gas is first directed vertically through the roof of the melter, and then horizontally to the dust removal wet scrubber. The vertical part of the off-gas connection is equipped with a filmcooler to quench the off gas to avoid particle sticking. Additionally supersonic air blasters have been integrated to clean from time to time ( $8 \mathrm{~h})$ the vertical and horizontal part of the off gas line. The washing column of the first of a series of scrubbers consists of three valve and two sieve plates. The scrub solution is circulated by an airlift countercurrently to the gas stream. The main task of this component is to retain larger dust particles. Condensable gases are separated in the following tube bundle condenser with an integrated collection tank. The condenser is operated using chilled water $\left(7^{\circ} \mathrm{C}\right.$ entrance temperature) to increase its efficiency. Fine dust particles are separated in a jet scrubber. The washing liquid is pumped through a nozzle at 3 bar pressure $\left(3.5 \mathrm{~m}^{3} / \mathrm{h}\right)$ to produce a spray cone. The off gas is sucked by the jet.effect of the nozzle through the cone, and fine particles will stick to the small droplets. By a cyclone effect, the droplets are separated from the gas.

A valve plate column is added to absorb the NOx portion of the process gas. The gas passes the column countercurrently to the wash water, which is pumped in a circuit with a rate of $2 \mathrm{~m}^{3} / \mathrm{h}$. Into this circuit Hydrogenperoxide $\left(\mathrm{H}_{2} \mathrm{O}_{2}\right.$ ) is added (about $5 \mathrm{l} / \mathrm{h}$ ) to support the oxidation of NO present in the gas stream. The washing water is cooled with chilled water to improve the efficiency of the absorption reaction. The off-gas finally passes a gas cooler and a trapper. A blower at the end of the line maintains an underpressure in the whole system up to the ESM plenum. The underpressure in the melter is controlled by the blower by-pass and/or the addition of rarefaction air.

\subsection{MATERIAL DATA}

The NCAW waste simulant has been delivered to KfK-INE as a premixed waste solution. The waste simulant was prepared by Optima Chemical in the United States. To adjust this mixture to the target oxide yield of $125 \mathrm{~g} / 1$ the following shim chemicals had to be added: $\mathrm{Al}(\mathrm{OH})_{3}, \mathrm{Ca}(\mathrm{OH})_{2}$, $\mathrm{MoO}_{3}, \mathrm{NaNO}_{2}, \mathrm{NaNO}_{3}$ and $\mathrm{ZrO}_{2}$. The noble metals had already been added by the supplier. The target composition is given in Table 3-I, A-D. The table shows also the compositions of the recycle chemicals to be added during melter feed batch preparation. Also the glass frit composition is shown. This frit was prepared by American Porcelain and Enamel Company. Finally the target values of the resulting melter feed oxides are listed. Based on these numbers $1 \mathrm{l}$ of melter feed yields to $0.5 \mathrm{~kg}$ of glass product. The viscosity of the glass frit as well as of the glass product is shown in Figure 3-11. Fig. 3-12 gives the electrical resistance of the glass product. 
Tabla 3 - 1

Compilation of data of the NCAW simulant

A: Calculation of melter feed targets

Target Food

Whosing= 0.28

Whese 0.28

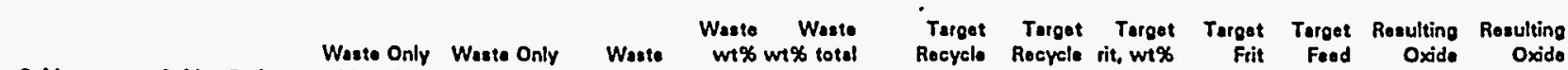

Element

$\begin{array}{lrl}\text { Ad } & 107.88 & A_{0} 20 \\ \text { AN } & 26.98 & \text { A1203 }\end{array}$

mw Oxido Cations mollh at 125

$\begin{array}{rr}231.74 & 2 \\ 101.98 & 2 \\ 69.62 & 2 \\ 153.33 & 1 \\ 56.08 & 1 \\ 128.41 & 1 \\ 172.12 & 1 \\ 151.99 & 2 \\ 281.81 & 2 \\ 79.65 & 1 \\ 159.69 & 2 \\ 104.69 & 1 \\ 84.2 & 2 \\ 325.8 & 2 \\ 29.88 & 2 \\ 40.305 & 1 \\ 86.94 & 1 \\ 143.94 & 1 \\ 61.98 & 2 \\ 285.82 & 2 \\ 336.48 & 2 \\ 74.7 & 1 \\ 141.96 & 2 \\ 239.2 & 1 \\ 122.4 & 1 \\ 328.82 & 2 \\ 218.94 & 2 \\ 253.82 & 2 \\ 133.07 & 1 \\ 291.6 & 2 \\ 110.96 & 1 \\ 60.09 & 1 \\ 348.8 & 2 \\ 134.89 & 1 \\ 103.62 & 1 \\ 441.9 & 2 \\ 169.6 & 1 \\ 79.9 & 1 \\ 225.91 & 2 \\ 81.38 & 1 \\ 123.22 & 1 \\ & \end{array}$

$\begin{array}{rrrrr}1.32 E-3 & 1.69 E-1 & 0.17 & 0.12 & 0.03 E \\ 2.27 E-1 & 6.86 E+0 & 12.96 & 9.33 & 2.01\end{array}$

$\begin{array}{rrrrr}2.27 E-1 & 0.86 E+0 & 12.96 & 9.33 & 2.01 \\ 2.10 E-4 & 2.64 E-3 & 0.01 & 0.01 & 0.00\end{array}$

$\begin{array}{lllll}2.10 E-4 & 2.64 E-3 & 0.01 & 0.01 & 0.00 \\ 1.46 E-3 & 2.26 E-1 & 0.25 & 0.18 & 0.05\end{array}$

$\begin{array}{rlr}10.81 & B 203 & 69.62 \\ 137.33 & B .0 & 153.33\end{array}$

$40.08 \quad \mathrm{C}, \mathrm{O}$

$140.12 \quad \mathrm{C} . \mathrm{O} 2$

$62 \mathrm{Cr} 203$

$\begin{aligned} 132.91 & \text { Cs } 20 \\ 63.55 & \text { CuO }\end{aligned}$

$\begin{array}{ll}63.65 & \text { CuO } \\ 65.85 & \mathrm{~F}=203\end{array}$

$72.69 \quad \mathrm{GeO2}$

$138.91 \quad$ L.203

$6.94 \quad$ Li2O

24.31 MoO

$96.94 \mathrm{MoO}$

$22.99 \quad \mathrm{Nn} 2 \mathrm{O}$

$92.91 \quad \mathrm{Nb} 20$

68.7 NiO

$30.97 \quad$ P205

207.2 PLO2

140.81 Pr203

85.47 Rb203

102.91 Rh203

101.07 RuO2

121.76

78.96

150.4 Sm203

110.09

87.62 S.O

127.8 T.02

47.9 TiO2

$88.8 \quad \mathrm{Y} 203$

$\begin{array}{ll}66.38 & .2 \mathrm{nO} \\ 91.22 & 2102\end{array}$

rotal

$\begin{array}{rr}1.80 E-2 & 8.08 E-1 \\ 3.00 E-2 & 3.78 E+0\end{array}$

$\begin{array}{rrrrr}3.00 E-2 & 3.78 E+0 & 4.31 & 3.11 & 0.87 \\ 4.77 E-3 & 7.49 E-1 & 0.92 & 0.66 & 0.19 \\ 4.39 E-3 & 2.56 E-1 & 0.37 & 0.27 & 0.08\end{array}$

$\begin{array}{lllll}4.33 E-3 & 2.66 E-1 & 0.37 & 0.27 & 0.08 \\ 5.43 E-3 & 8.08 E-1 & 0.86 & 0.62 & 0.17\end{array}$

$\begin{array}{llllll}3.93 E-3 & 2.80 E-1 & 0.36 & 0.25 & 0.07\end{array}$

$\begin{array}{rrrrr}\text { A.61E-1 } & 2.82 E+1 & 40.33 & 29.04 & 8.13 \\ 1.86 E-6 & 1.61 E-4 & .0 .00 & 0.00 & 0.00\end{array}$

$\begin{array}{lllll}1.86 E-6 & 1.61 E-4 & .0 .00 & 0.00 & 0.00 \\ 6.32 E-3 & 2.33 E-1 & 0.28 & 0.20 & 0.06\end{array}$

$\begin{array}{lllll}5.12 E-3 & 7.97 E-9 & 0.93 & 0.87 & 0.19\end{array}$

$\begin{array}{lllll}0.05 E-6 & 4.70 E-5 & 0.00 & 0.00 & 0.00\end{array}$

$1.16 E-2 \quad 3.13 E-1$

3.16E-2 1.94E+0

$\begin{array}{rrrrr}4.96 E-3 & 6.32 E-1 & 0.80 & 0.67 & 0.16 \\ 8.82 E-1 & 2.27 E+1 & 30.01 & 22.04 & 0.17\end{array}$

$\begin{array}{lll}0.52 & 0.37 & 0.10 \\ 3.07 & 2.21 & 0.62\end{array}$

$\begin{array}{llll}1.24 E+0 & 0.02 & 0.01 & 0.00\end{array}$

$\begin{array}{lllll}2.04 E-2 & 4.26 E+0 & 4.97 & 3.68 & 1.00 \\ 3.93 E-2 & 2.68 E+0 & 3.29 & 2.37 & 0.08\end{array}$

$\begin{array}{rrrrr}1.56 E-2 & \text { E.41E-1 } & \mathbf{3 . 2 9} & \mathbf{2 . 3 7} & 0.06 \\ 3.24 & 0.89 & 0.25\end{array}$

$\begin{array}{lllll}3.74 E-3 & 8.68 E-1 & 1.00 & 0.72 & 0.20\end{array}$

$\begin{array}{lllll}1.24 E-3 & 1.48 E-1 & 0.17 & 0.12 & 0.03\end{array}$

$\begin{array}{lllll}1.18 E-3 & 1.86 E-1 & 0.22 & 0.16 & 0.04 \\ 6.70 E-4 & 8.41 E-2 & 0.08 & 0.06 & 0.02\end{array}$

$\begin{array}{lllll}1.04 E-3 & 1.20 E-1 & 0.16 & 0.11 & 0.03\end{array}$

$\begin{array}{lllll}3.85 E-3 & 4.36 E-1 & 0.57 & 0.41 & 0.12\end{array}$

$\begin{array}{lllll}6.11 E-5 & 6.97 E-3 & 0.01 & 0.01 & 0.00\end{array}$

$\begin{array}{lllll}1.82 E-4 & 1.61 E-2 & 0.02 & 0.02 & 0.00\end{array}$

8.66E-2 2.69E+0

6.64E-4 9.33E-2

9.99E.6 $\quad 1.33 \mathrm{E} \cdot 2$

$1.46 E-3 \quad 1.43 E-1$

$\begin{array}{lll}6.70 & 4.16 & 1.10 \\ 0.11 & 0.08 & 0.02\end{array}$

$\begin{array}{llll}0.17 & 0.12 & 0.03 \\ 0.35 E-1 & 0.03\end{array}$

$\begin{array}{lllll}1.94 E-4 & 1.13 E-1 & 0.14 & 0.10 & 0.03\end{array}$

$\begin{array}{llll}5.58 E-1 & 0.93 & 0.87 & 0.03\end{array}$

$\begin{array}{lllll}9.04 E-4 & 9.00 E-2 & 0.11 & 0.00 & 0.02\end{array}$

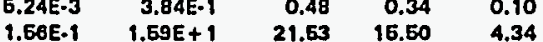

$2.04 E+0$

$\begin{array}{lll}138.88 & 100.00 \quad 28.00\end{array}$

$0.14 \quad 0.370$

$\begin{array}{lllll}14.03 & 21.78 & 7.23 & 2.73 & 13.60\end{array}$

$\begin{array}{lll}0.22 & 0.05 & 0.26 \\ 0.84 & 0.24 & 1.18\end{array}$

$\begin{array}{llll}4.28 & 0.97 & 0.18\end{array}$

$\begin{array}{lll}0.81 & 0.17 & 0.86 \\ 0.28 & 0.07 & 0.63\end{array}$

$\begin{array}{llrrr}0.04 & 0.140 & 0.28 & 0.07 & 0.35 \\ & & 28.35 & 8.11 & 40.53\end{array}$

$\begin{array}{llllll}0.01 & 0.043 & 0.00 & 0.00 & 0.00 \\ & & 0.23 & 0.08 & 0.28\end{array}$

$\begin{array}{llllll}0.03 & 0.095 & 0.34 & 0.11 & 0.67\end{array}$

$\begin{array}{rrr}0.63 & 0.16 & 0.80 \\ 0.09 & 0.67 & 37.80\end{array}$

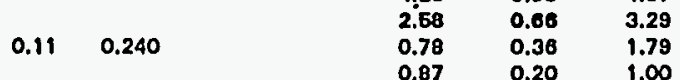

$\begin{array}{lll}0.15 & 0.03400 & 0.17\end{array}$

$\begin{array}{lll}0.19 & 0.04 & 0.22\end{array}$

$\begin{array}{rr}0.02 & 0.08 \\ 0.0296 & 0.16\end{array}$

$\begin{array}{lll}0.44 & 0.1148 & 0.67\end{array}$

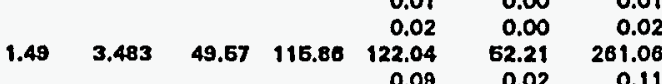

$\begin{array}{lll}0.09 & 0.02 & 0.11\end{array}$

$\begin{array}{lll}0.01 & 0.00 & 0.02 \\ 0.14 & 0.03 & 0.17\end{array}$

$\begin{array}{lllll}4.00 E-03 & 0.012 & 0.11 & 0.03 & 0.14 \\ & & 0.57 & 0.19 & 0.05\end{array}$

$\begin{array}{lll}0.07 & 0.19 & 0.96\end{array}$

$\begin{array}{lll}0.38 & 0.10 & 0.48\end{array}$

3.404

$257.60 \quad 99.78 \quad 498.90$ 


\begin{tabular}{|c|c|c|c|}
\hline Oxide & $\begin{array}{l}\text { Melter Feed Oxide } \\
\text { Concentration } \\
(w t \%)\end{array}$ & $\begin{array}{l}\text { Feed } \\
\text { Compound }\end{array}$ & $\begin{array}{l}\text { Compount } \\
\text { Concentration } \\
\text { (g/L feed) } \\
\end{array}$ \\
\hline $\mathrm{Ag} 20$ & 0.03 & $\mathrm{AgNO} 3$ & 0.25 \\
\hline $\mathrm{A} 1203$ & 2.57 & Al(OH)3 & 19.85 \\
\hline $\mathrm{B} 203$ & $2 E-03$ & H3BO3 & 0.01 \\
\hline $\mathrm{BaO}$ & 0.05 & $\mathrm{Ba}(\mathrm{OH}) 2+8 \mathrm{H} 2 \mathrm{O}$ & 0.52 \\
\hline $\mathrm{CaO}$ & 0.23 & $\mathrm{Ca}(\mathrm{OH}) 2$ & 1.49 \\
\hline $\mathrm{CdO}$ & 0.87 & $\mathrm{Cd}(\mathrm{OH}) 2$ & 4.94 \\
\hline $\mathrm{CeO} 2$ & 0.18 & $\mathrm{Ce}(\mathrm{OH}) 3$ & 1.02 \\
\hline $\mathrm{Cr} 2 \mathrm{O} 3$ & 0.07 & $\mathrm{Cr}(\mathrm{NO} 3) 3+9 \mathrm{H} 2 \mathrm{O}$ & 1.97 \\
\hline Cs2O & 0.17 & CsNO3 & 1.19 \\
\hline CuO & 0.07 & $\mathrm{Cu}\left(\mathrm{SO}_{4}\right)+5 \mathrm{H} 2 \mathrm{O}$ & 1.10 \\
\hline $\mathrm{Fe} 2 \mathrm{O3}$ & 8.06 & $\mathrm{Fe}(\mathrm{OH}) 3$ & 54.23 \\
\hline $\mathrm{GeO} 2$ & $4 \mathrm{E}-05$ & $\mathrm{GeO2}$ & $2 E-4$ \\
\hline $\mathrm{K} 20$ & 0.06 & $\mathrm{KOH}$ & 0.34 \\
\hline \multirow[t]{2}{*}{ La2O3 } & 0.19 & LaF3 & 0.23 \\
\hline & & $\mathrm{La}(\mathrm{OH}) 3$ & 0.86 \\
\hline $\mathrm{MgO}$ & 0.10 & $\mathrm{Mg}(\mathrm{NO}) 2+6 \mathrm{H} 2 \mathrm{O}$ & 3.32 \\
\hline $\mathrm{MnO} 2$ & 0.61 & $\mathrm{MnO2}$ & 3.07 \\
\hline $\mathrm{MoO3}$ & 0.16 & $\mathrm{MoO3}$ & 0.80 \\
\hline $\mathrm{Na} 2 \mathrm{O}$ & 6.10 & $\mathrm{NaCl}$ & 0.70 \\
\hline $\mathrm{Cl}$ & 0.08 & $\mathrm{Na} 2 \mathrm{CO} 3$ & 14.91 \\
\hline \multirow[t]{4}{*}{ F- } & 0.03 & $\mathrm{Na} 2 \mathrm{C} 2 \mathrm{O} 4$ & 1.05 \\
\hline & & $\mathrm{Nal}$ & 0.03 \\
\hline & & NaNO2 & 33.76 \\
\hline & & NaNO3 & 4.01 \\
\hline \multirow[t]{2}{*}{ SO3 } & 0.19 & $\mathrm{Na} 2 \mathrm{SO}_{4}$ & 1.04 \\
\hline & & $\mathrm{NaOH}$ & 3.34 \\
\hline $\mathrm{Nb2O3}$ & 0.03 & $\mathrm{Nb} 205$ & 0.02 \\
\hline \multirow[t]{2}{*}{$\mathrm{Nd} 2 \mathrm{O3}$} & 0.99 & NdF3 & 0.25 \\
\hline & & $\mathrm{Nd}(\mathrm{OH}) 3$ & 5.56 \\
\hline NiO & 0.66 & $\mathrm{Ni}(\mathrm{OH}) 2$ & 4.09 \\
\hline P2O5 & 0.25 & $\mathrm{Na} 3 \mathrm{PO} 4$ & 2.88 \\
\hline PdO & 0.03 & $\mathrm{Pd}(\mathrm{NO} 3) 2$ & 0.32 \\
\hline $\mathrm{PbO} 2$ & 0.20 & $\mathrm{~Pb}\left(\mathrm{NO}_{3}\right) 2$ & 1.39 \\
\hline Pr203 & 0.04 & $\operatorname{Pr}(\mathrm{OH}) 3$ & 0.26 \\
\hline $\mathrm{Rb} 203$ & 0.02 & RbNO3 & 0.11 \\
\hline Rh203 & 0.03 & $\mathrm{Rh}(\mathrm{NO}) 2+2 \mathrm{H} 2 \mathrm{O}$ & 0.30 \\
\hline Ru203 & 0.11 & Ru(NO)(NO3)3 & 1.34 \\
\hline $\mathrm{Sb} 203$ & $2 E-3$ & $\mathrm{Sb} 203$ & 0.01 \\
\hline $\mathrm{SeO} 2$ & $5 E-3$ & $\mathrm{SeO} 2$ & 0.02 \\
\hline $\mathrm{SiO} 2$ & 1.14 & $\mathrm{SiO} 2$ & 5.77 \\
\hline $\mathrm{Sm} 203$ & 0.02 & $\mathrm{Sm}(\mathrm{NO}) 3+6 \mathrm{H} 2 \mathrm{O}$ & 0.28 \\
\hline Sno & $3 E-3$ & Sn(NO3) 2 & 0.03 \\
\hline SrO & 0.03 & $\mathrm{Sr}(\mathrm{NO}) / 2$ & 0.35 \\
\hline Ta205 & $1 E-3$ & Ta205 & $5 E-3$ \\
\hline $\mathrm{TeO} 2$ & 0.03 & $\mathrm{TeO} 2$ & 0.14 \\
\hline $\mathrm{TiO} 2$ & 0.19 & $\mathrm{TiO2}$ & 0.93 \\
\hline Y2O3 & 0.02 & $\mathrm{Y}(\mathrm{OH}) 3$ & 0.14 \\
\hline $\mathrm{ZnO}$ & 0.10 & $\mathrm{Zn}(\mathrm{OH}) 2$ & 0.58 \\
\hline $\mathrm{ZrO2}$ & 4.31 & $\mathrm{Zr}(\mathrm{OH}) 4$ & 28.00 \\
\hline Total: & $28 \%$ & Total: & $204.8 \mathrm{~g} / \mathrm{L}$ \\
\hline
\end{tabular}


Table 3-1: Compilation of data of the NCAW simulant

$C$ : Feed requirements for frit, recycle and formic acid

0

FRIT Composition

Wt. \%

(343 g-frit/L-melter feed)

$\mathrm{SiO} 2$

72.26

B2O3

20.45

$\mathrm{Li} 20$

7.29

Total

100.00

88 wt $\%$ Formic Acid Additions g/L Melter Feed

HWVP Feed

30.68

Recycle Feed

3.26

Frit Addition

3.53

Recycle Composition

g/L Melter Feed (3)

(17 g-equiv.oxides/L-melter feed)

Zeolite (IE-96) (1)

2.80

Diatomaceous Earth

5.60

$\mathrm{KMnO} 4$

0.31

HNO3

0.65

$\mathrm{NaOH}$

(2)

$\mathrm{CdO}$

0.56

$\mathrm{Na2} 2204$

2.11

$\mathrm{Na} 3 \mathrm{PO} 4$

1.29

$\mathrm{NaCl}$

0.02

$\mathrm{NaNO} 3$

14.48

(1) Particle size < 120 mesh

(2) As required to achieve target $\mathrm{pH}$

(3) Concentration in final feed. Recycle can either be added as dry chemicals or as conc. slurry

TAB3IC.XLS 
Table 3-I: Compilation of data of the NCAW simulant

D: HWVP Target glass composition

\begin{tabular}{|c|c|c|c|}
\hline Oxide & $\begin{array}{l}\text { Plant Feed } \\
\text { Oxide Conc. } \\
\text { (Wt \%) } \\
\end{array}$ & $\begin{array}{l}\text { Recycle Feed } \\
\text { Oxide Conc. } \\
\text { (Wt \%) }\end{array}$ & $\begin{array}{l}\text { Frit } \\
\text { Oxide Conc. } \\
(\mathrm{Wt} \%) \\
\end{array}$ \\
\hline $\mathrm{Ag} 20$ & 0.03 & & \\
\hline $\mathrm{Al} 203$ & 2.57 & 0.14 & \\
\hline $\mathrm{B} 203$ & $2 \mathrm{E}-3$ & & 14.03 \\
\hline $\mathrm{BaO}$ & 0.05 & & \\
\hline $\mathrm{CaO}$ & 0.23 & 0.01 & \\
\hline $\mathrm{CdO}$ & 0.87 & 0.11 & \\
\hline $\mathrm{CeO} 2$ & 0.18 & & \\
\hline $\mathrm{Cl}$ & 0.08 & & \\
\hline $\mathrm{Cr} 203$ & 0.07 & & \\
\hline Cs2O & 0.17 & & \\
\hline CuO & 0.07 & & \\
\hline $\mathbf{F}$ & 0.03 & & \\
\hline $\mathrm{Fe} 203$ & 8.06 & 0.04 & \\
\hline $\mathrm{GeO} 2$ & $4 E-5$ & & \\
\hline$K 20$ & 0.06 & 0.01 & \\
\hline La2O3 & 0.19 & & \\
\hline $\mathrm{LiO} 2$ & & & 5.00 \\
\hline $\mathrm{MgO}$ & 0.10 & 0.01 & \\
\hline $\mathrm{MnO2}$ & 0.61 & 0.03 & \\
\hline $\mathrm{MoO3}$ & 0.16 & & \\
\hline $\mathrm{Na} 2 \mathrm{O}$ & 6.10 & 1.45 & \\
\hline Nb203 & $3 E-3$ & & \\
\hline $\mathrm{Nd} 2 \mathrm{O} 3$ & 0.99 & & \\
\hline $\mathrm{NiO}$ & 0.66 & & \\
\hline P2O5 & 0.25 & 0.11 & \\
\hline PdO & 0.03 & & \\
\hline $\mathrm{PbO} 2$ & 0.20 & & \\
\hline Pr203 & 0.04 & & \\
\hline $\mathrm{Rb} 203$ & 0.02 & & \\
\hline Rh203 & 0.03 & & \\
\hline $\begin{array}{l}\text { Ru203 } \\
\text { Sb203 }\end{array}$ & $\begin{array}{l}0.11 \\
2 \mathrm{E}-3\end{array}$ & & \\
\hline $\mathrm{SeO} 2$ & $5 E-3$ & & \\
\hline $\mathrm{SiO} 2$ & 1.14 & 1.49 & 49.57 \\
\hline Sm203 & 0.02 & & \\
\hline Sno & 3E-3 & & \\
\hline SO3 & 0.19 & & \\
\hline SrO & 0.03 & & \\
\hline Ta205 & $1 E-3$ & & \\
\hline $\mathrm{TeO} 2$ & 0.03 & & \\
\hline $\mathrm{TiO} 2$ & 0.19 & $4 E-3$ & \\
\hline Y203 & 0.02 & & \\
\hline Zno & 0.10 & & \\
\hline $\mathrm{ZrO2}$ & 4.31 & & \\
\hline Total: & $28 \%$ & $3.40 \%$ & $68.60 \%$ \\
\hline
\end{tabular}

TAB3ID.XLS 


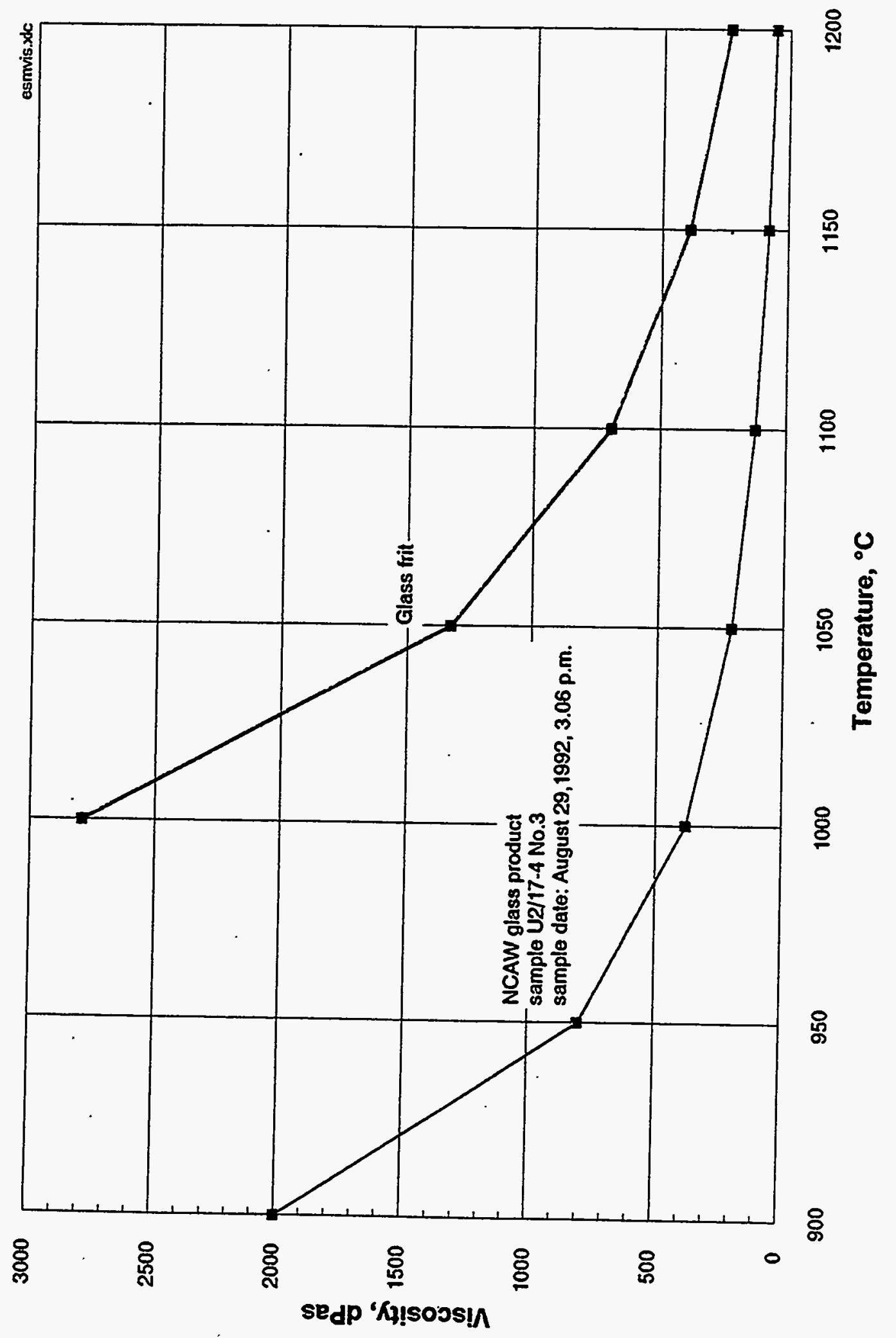

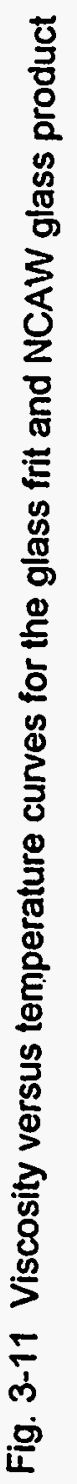




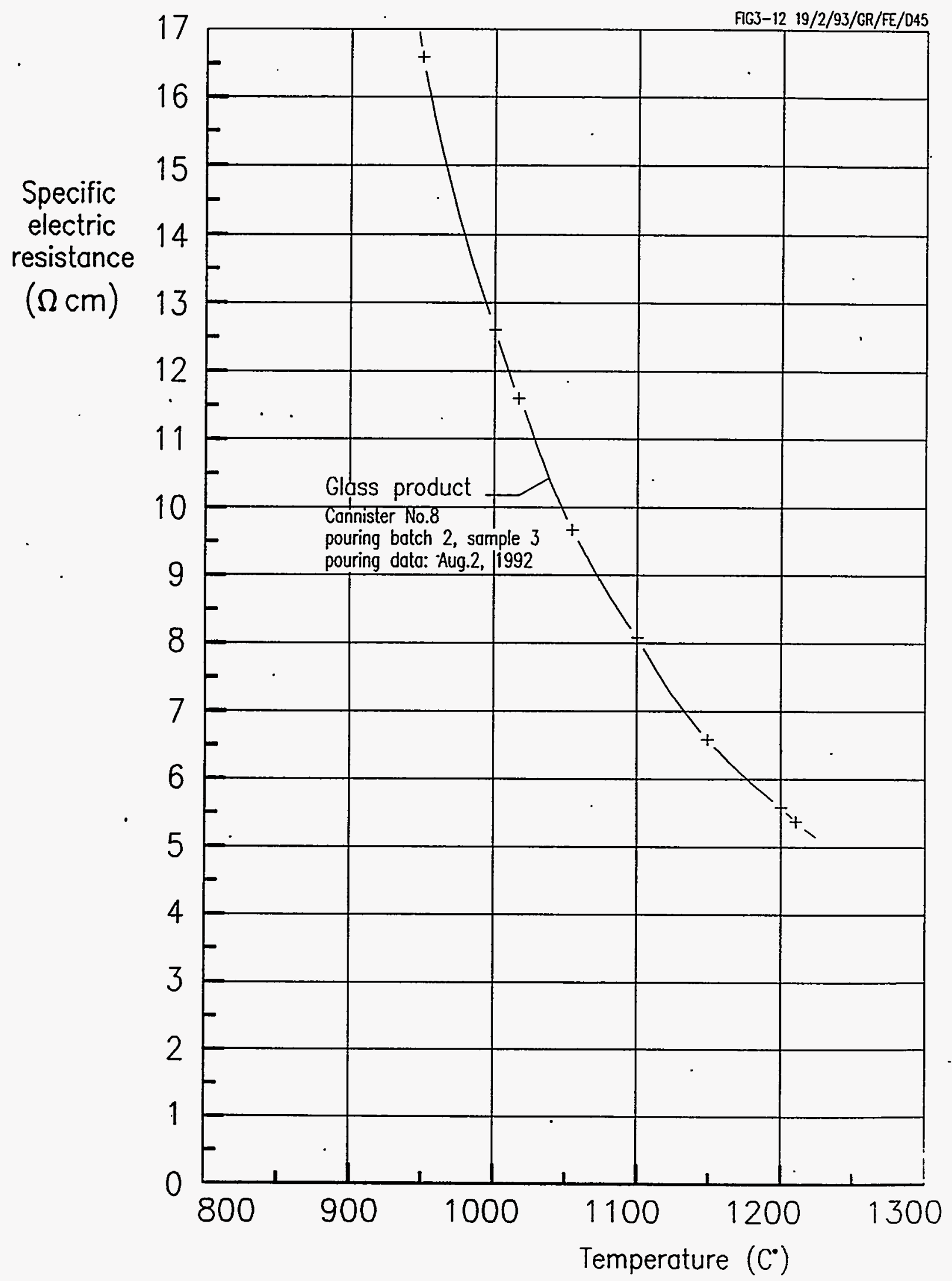

Fig. 3-12 Specific electrical resistance versus temperature of the NCAW glass prodact 


\subsection{DATA ACQUISITION AND VISUALISATION SYSTEM PISA}

The main process data of the vitrification plant were collected by the computer system PISA additionally and independently from line printers on the control panels. The structure of the PISAsystem is given in figure 3-13. It consists of two data loggers (logger 1 for digital, logger 2 for analog signals), two personal computers in master-slave-operation, two monitors, and three printers. The master computer was used for process graphic, bar charts, line charts, tables, actual and history data in diagrams and mass storage for the whole analog data. The digital process data ( status of stop valves, pumps etc.) were not stored. The slave computer had no mass storage and was used to observe the actual process in graphics and tables. The performance of the PISA graphics, tables, line charts and bar charts is shown as typical examples in the figures 3-14 to 3-23. The incoming electrical analog signals were divided into groups concerning their types, scanning and storage rates (given in table 3-II).

Exceptions concerning the scanning rate and the storage rate to the table above were necessary. for the feed make up tank used for the feed preparation. The temperatures, the off-gass flow rate, the underpressure in the vessel and the hydrogen analyses were scanned and stored each 60 seconds. The list of the database contains all the digital and analog process signals, including channel No., denomination, unit, range, storage interval and its limits. The stored process data are available as ASCII-files which can be used for further calculations by other software programmes (a channel listing is be given in appendix B).

Table 3-II: Types, scanning and storage rates of PISA system

Type of measurement
Scanning rate

( $\mathrm{sec}$ )
Storage rates

( $\mathrm{sec}$ )

$\begin{array}{lrr}\text { Levels } & 20 & 60 \\ \text { Densities } & 20 & 60 \\ \text { Flow rates } & 300 & 300 \\ \text { Pressures } & 300 & 300 \\ \text { Temperatures } & 300 & 300 \\ \text { El. powers } & 60 & 300 \\ \text { Currents } & 60 & 300 \\ \text { Voltages } & 60 & 300 \\ \text { Qualities (weights, conc.) } & 600 & 600\end{array}$

60

.60

300

300

300

300

300

300 


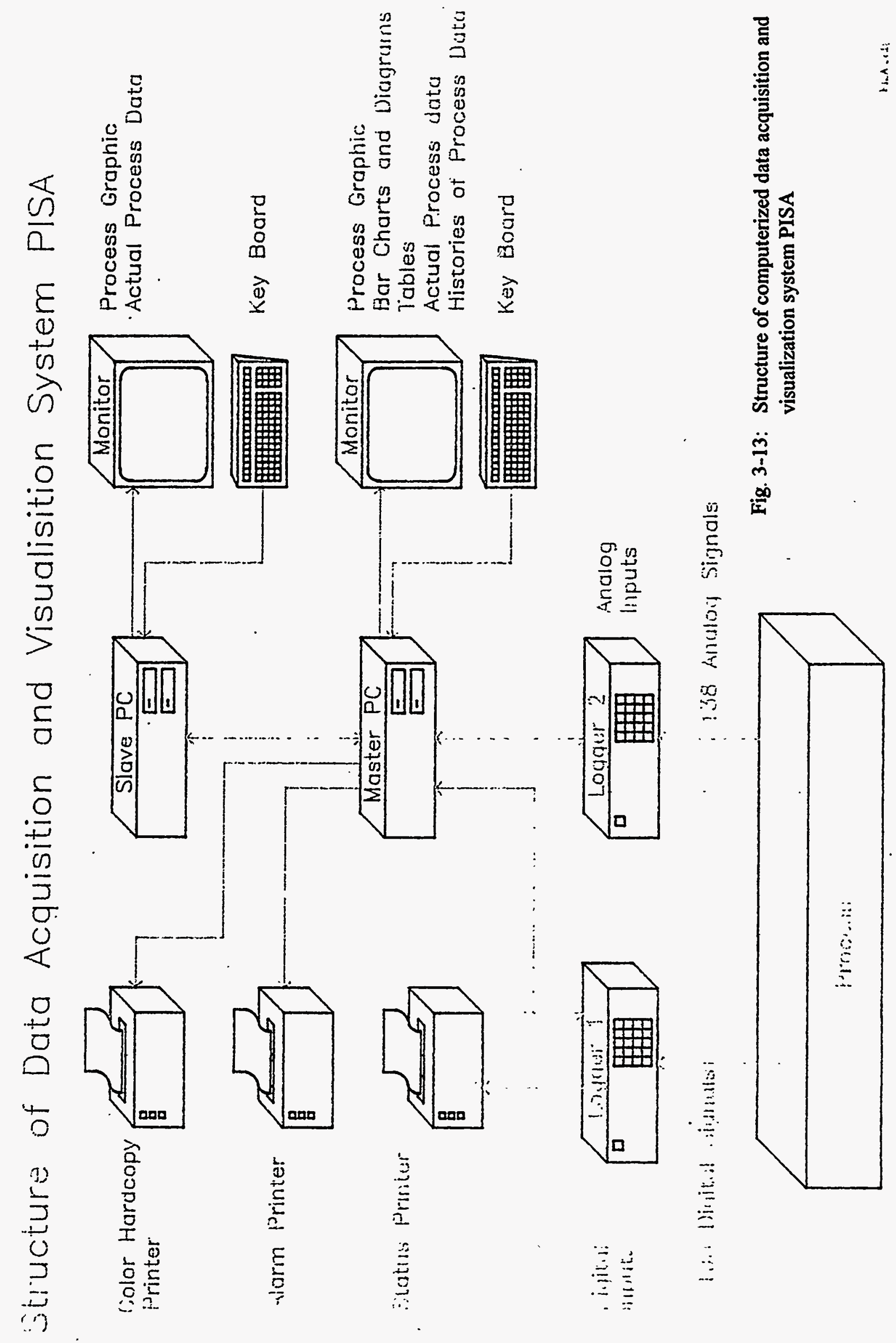



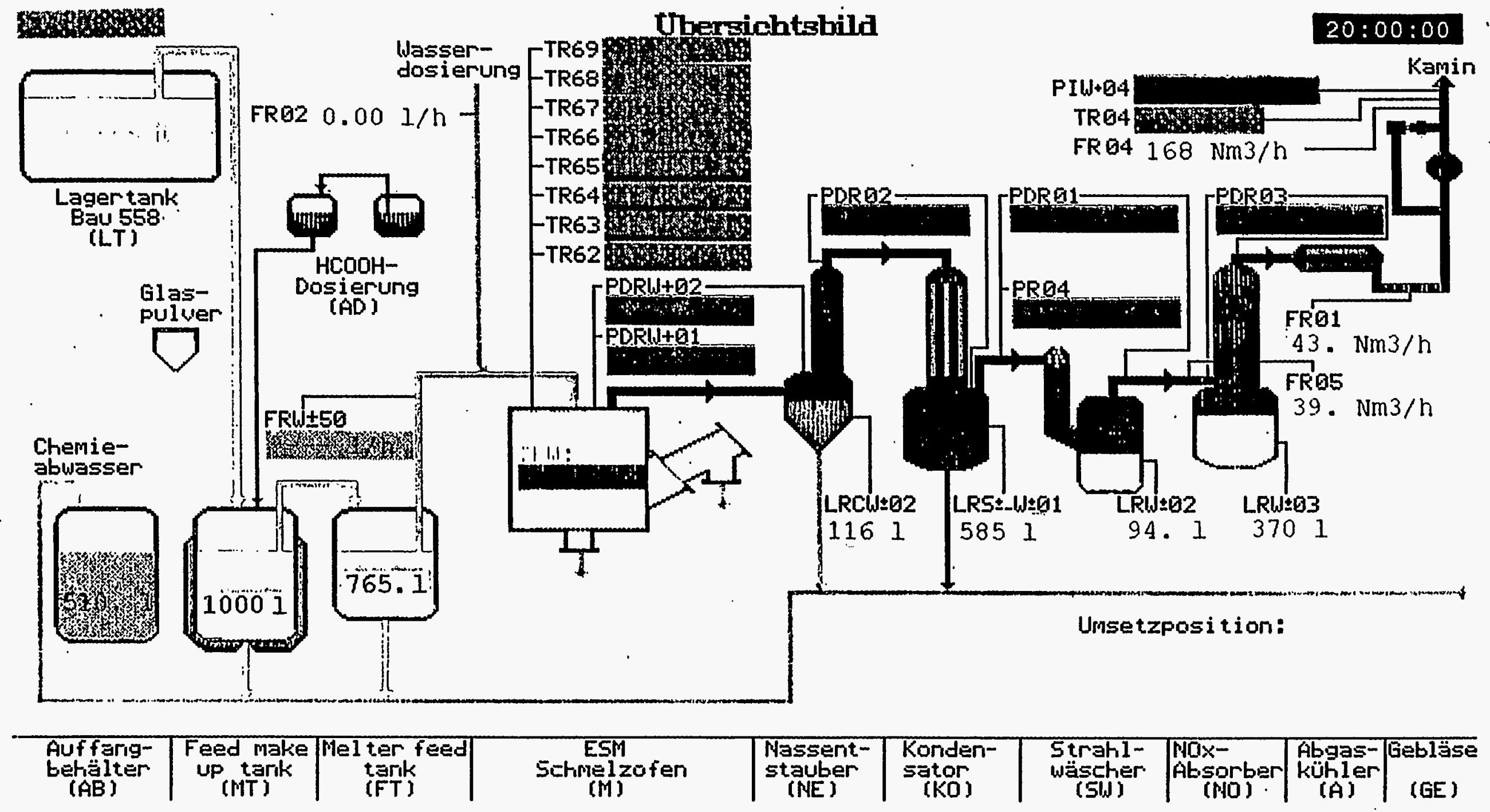

Fig. 3-14: Overview picture of PISA 


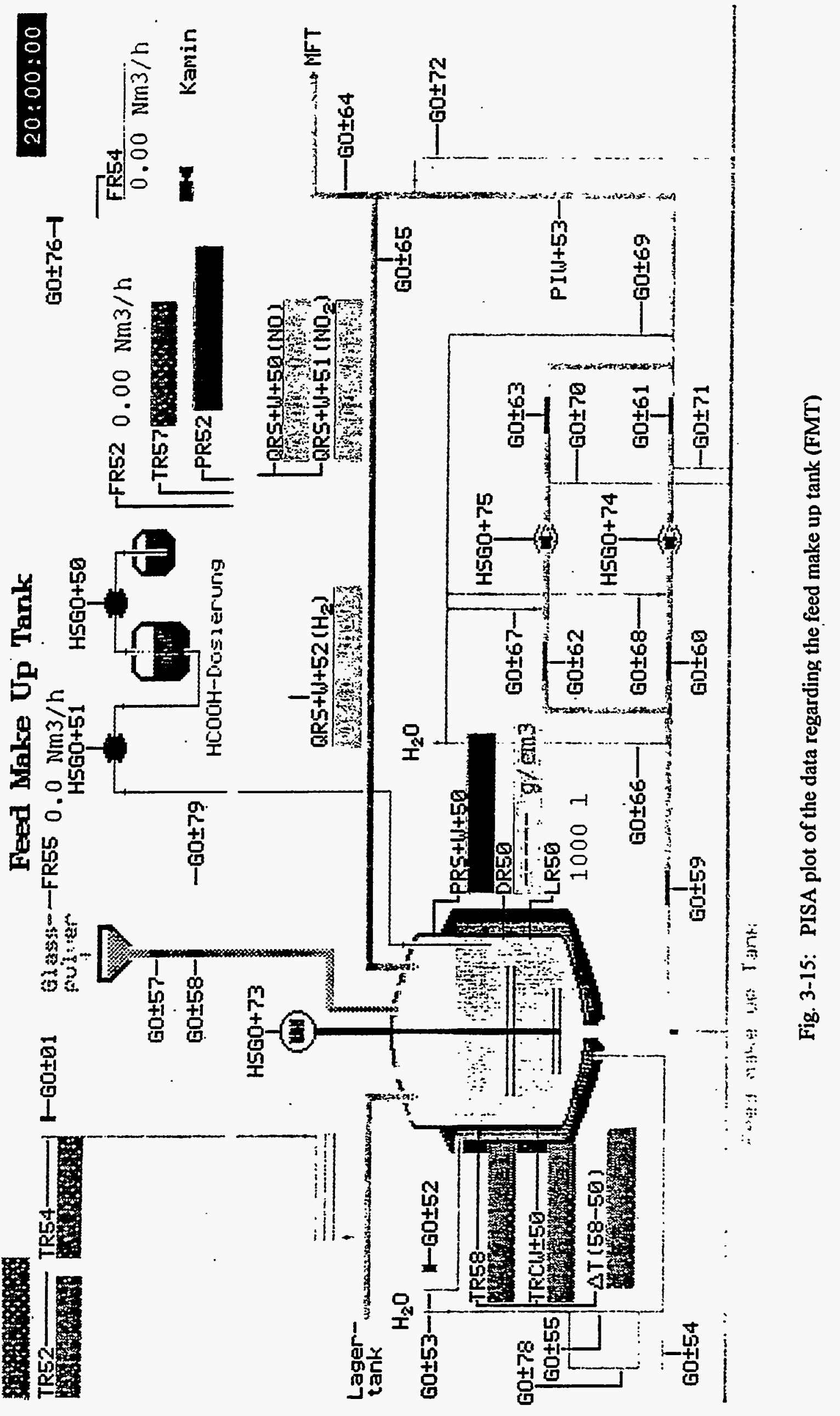




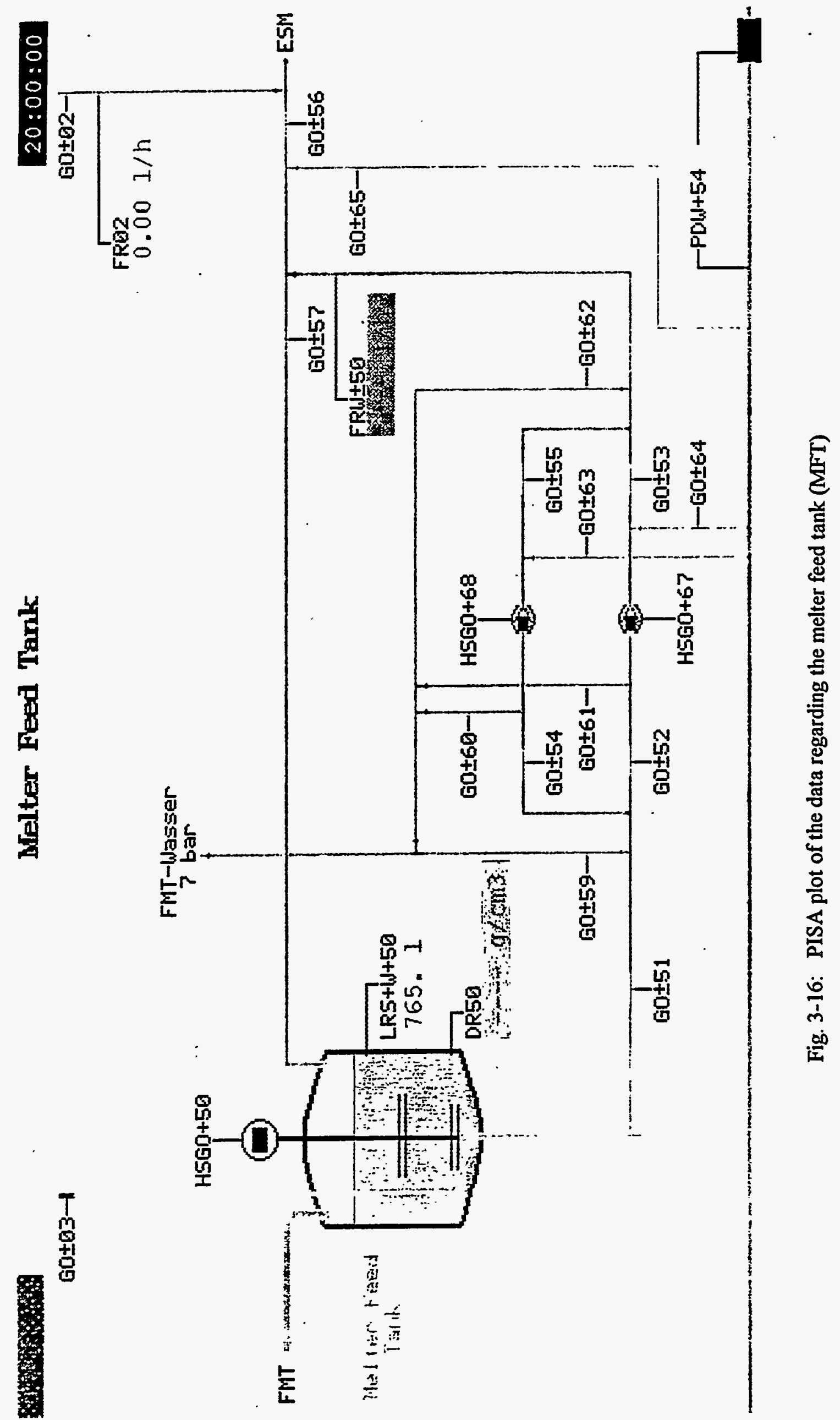




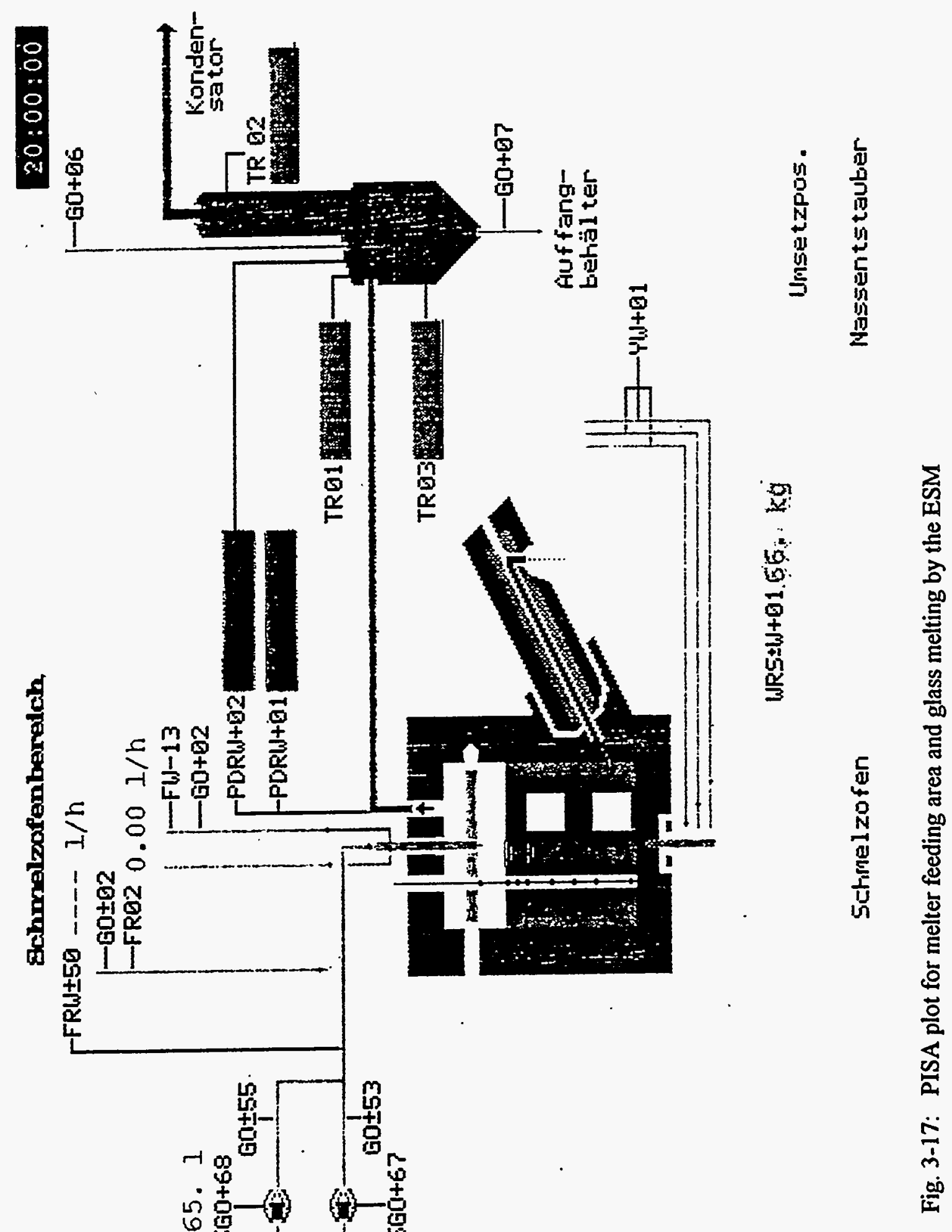

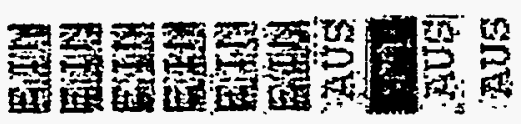

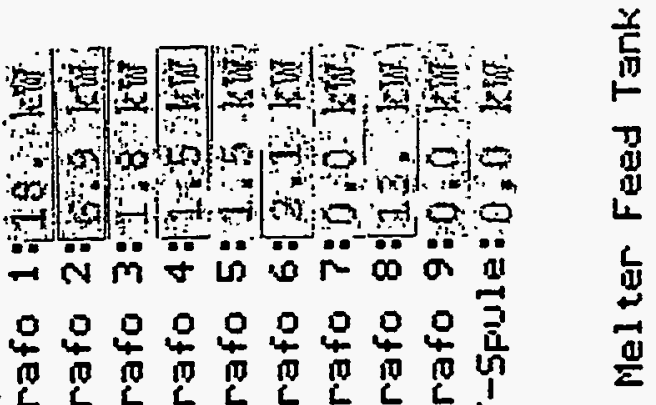




\section{H)}

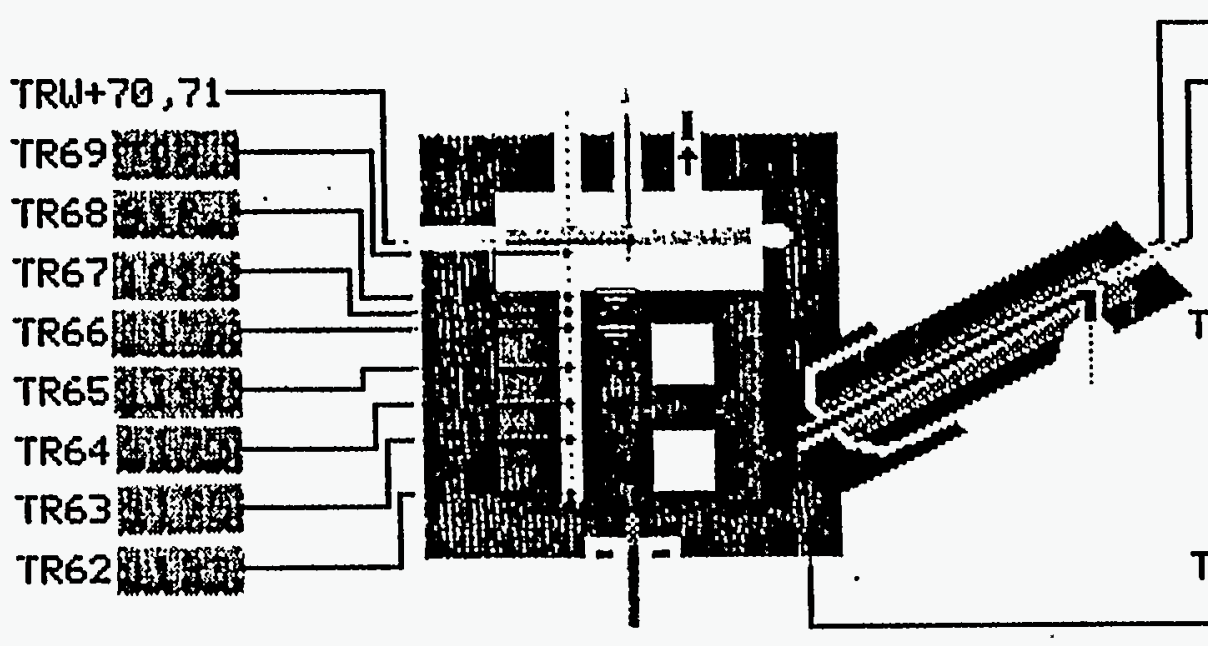

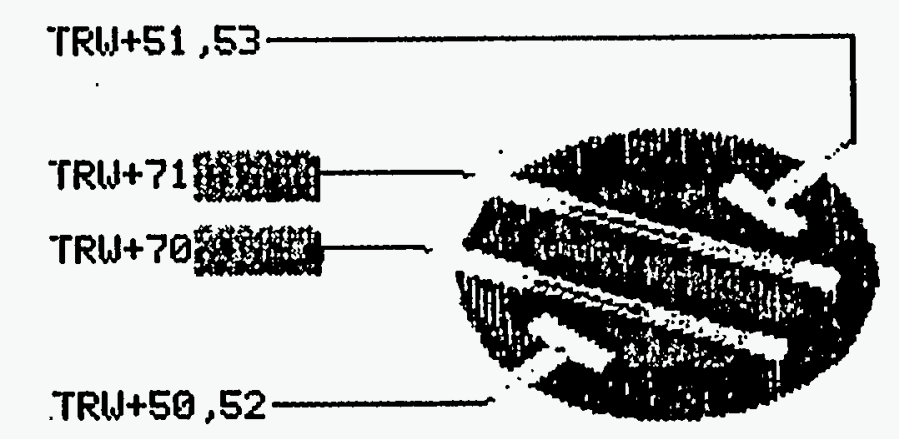

Snhmelzofen-Temperaturen

$20: 00: 00$ 


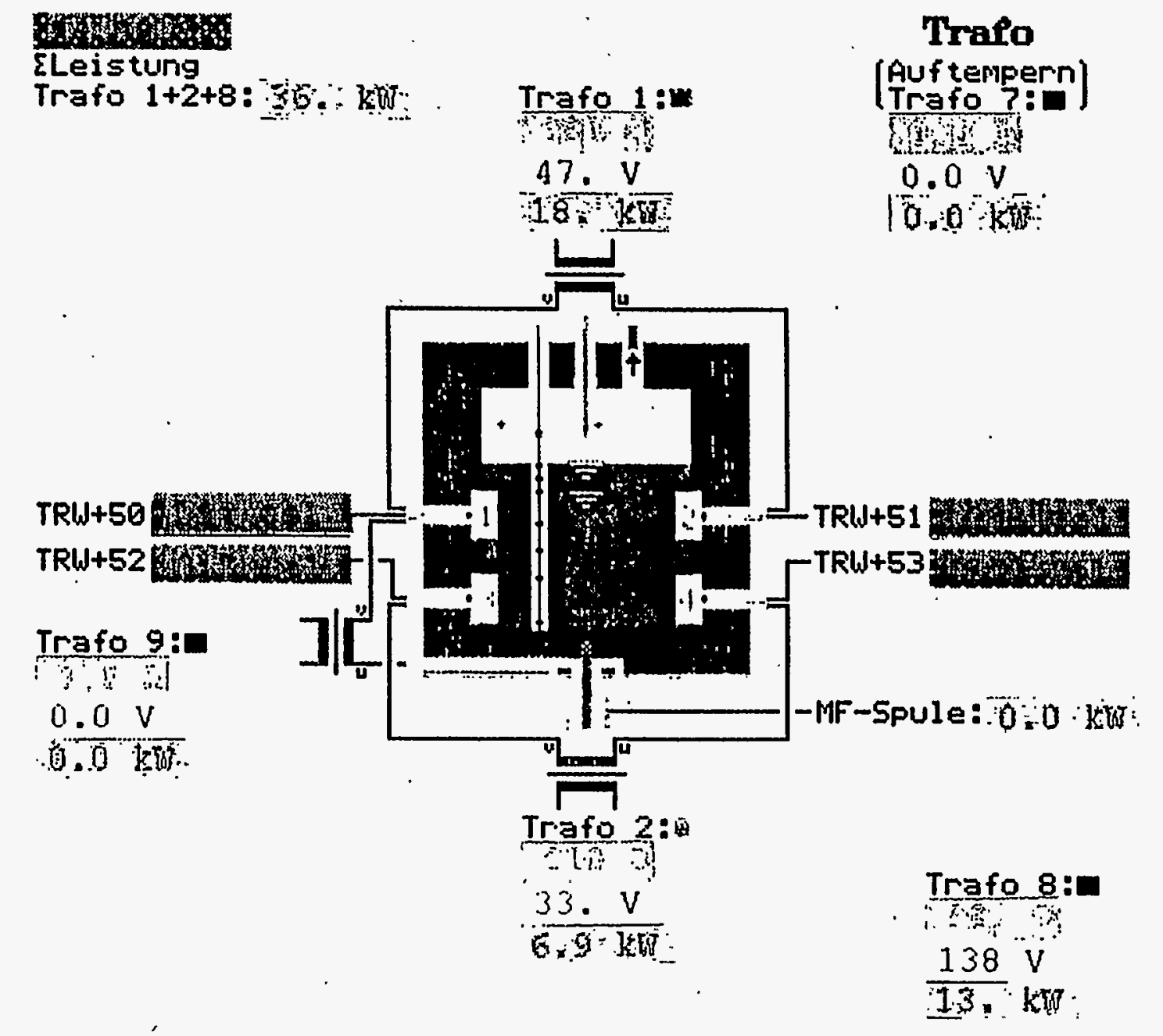

Trafo

A f tempern

Wis

$0.0 \mathrm{~V}$

0.00

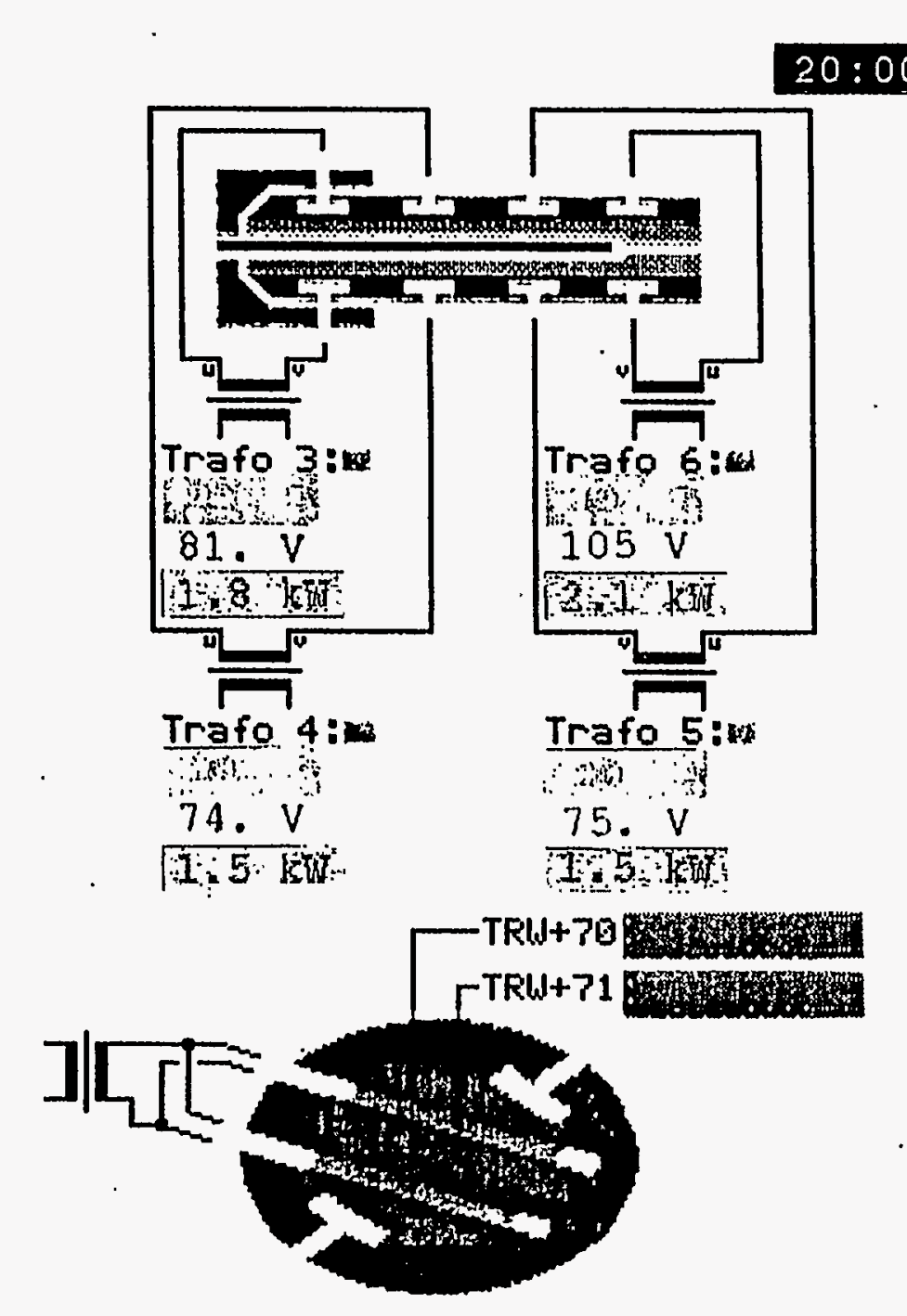

Fig. 3-19: PISA plot concerning power release in the glass tank and glass overflow area of the ESM 


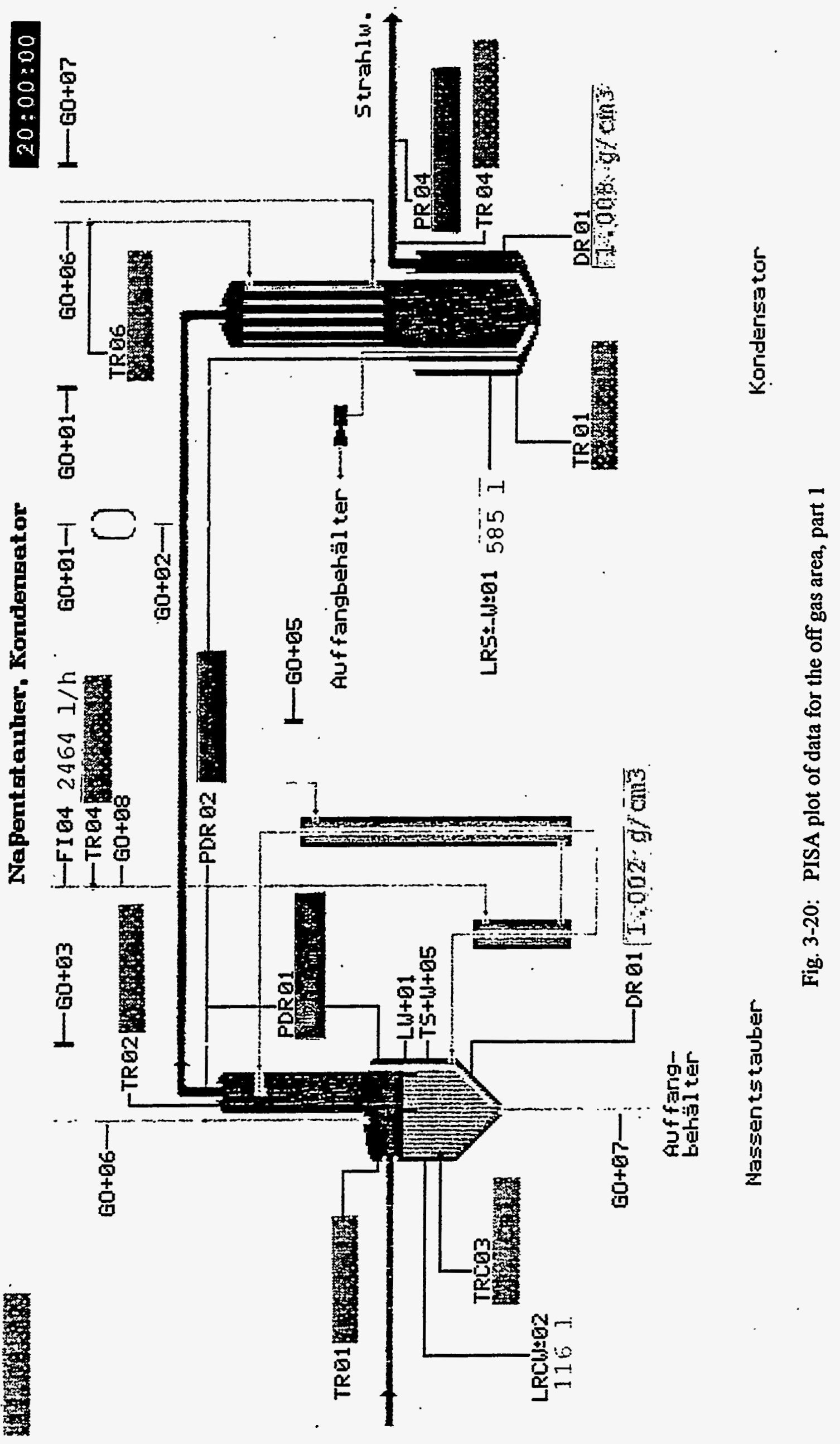




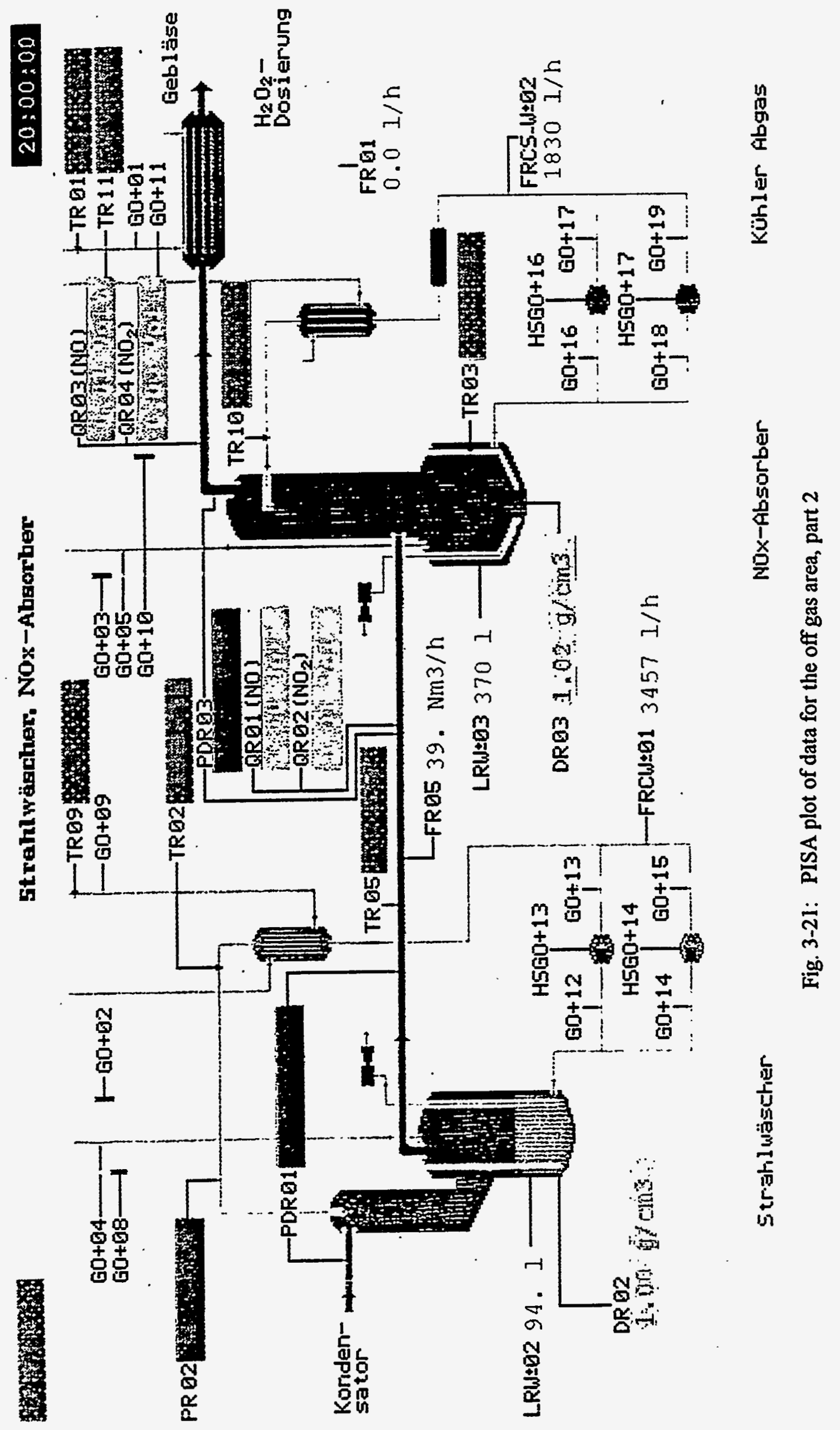




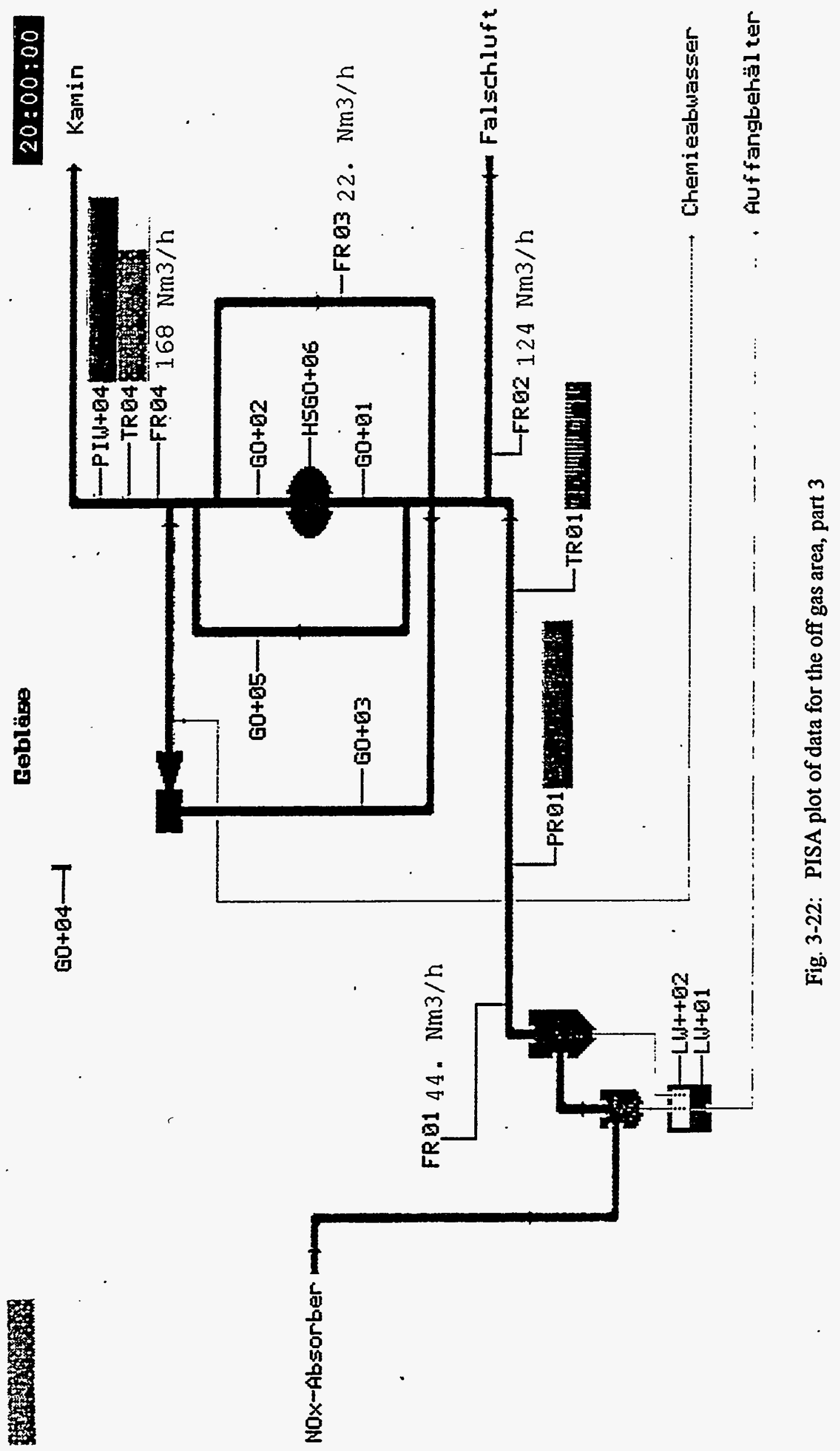




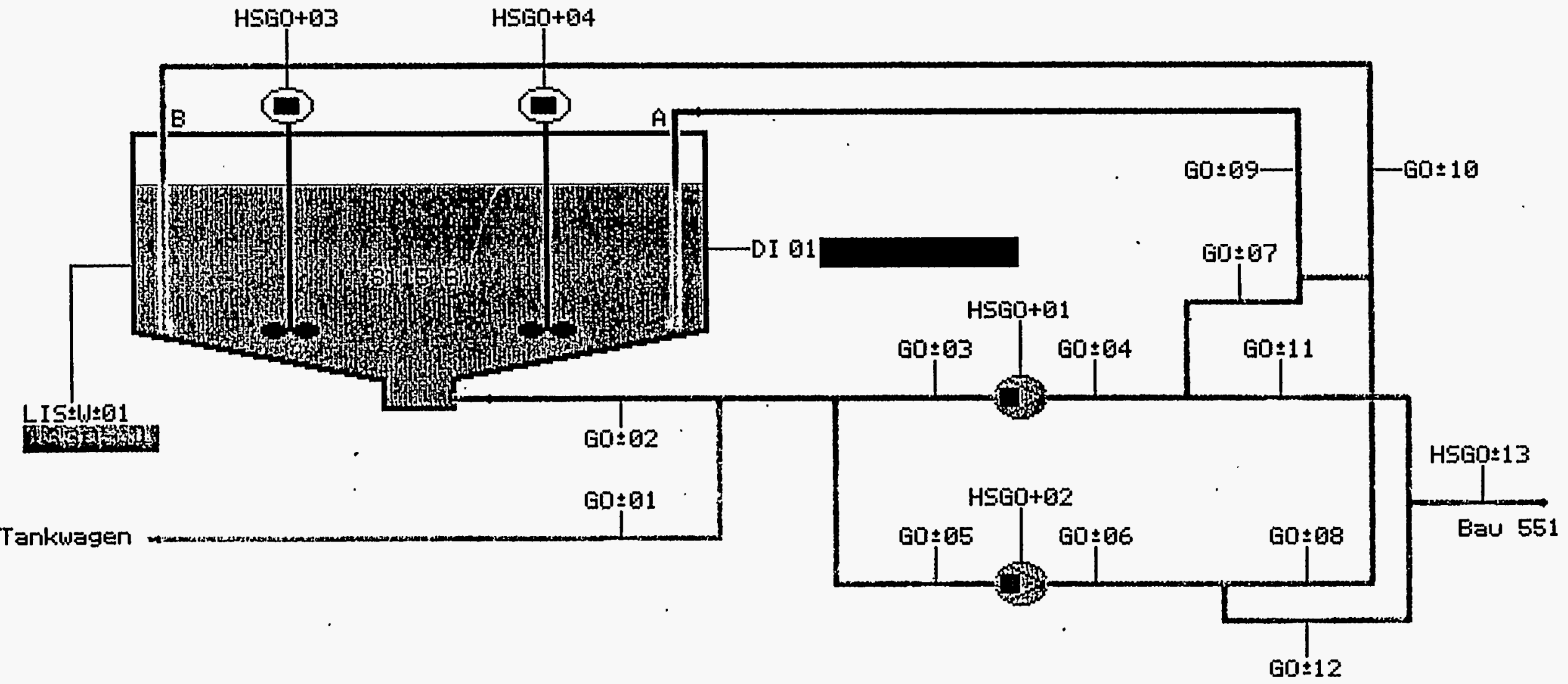

Fig. 3-23: PISA plot of NCAW feed simulant storage tank. From this tank the simulant was batchwise pumped into the FMT 


\subsection{TEST DESCRIPTION}

\subsection{Feed preparation}

The melter feed had been prepared in 5 batches (B1-B5). Batch 1 should not contain noble metals. Due to a mistake during the first filling of the FMT 2 barrels with noble metal containing simulant were added. Thus, the noble metal concentration was about $1 / 6$ of the target for noble metal containing feed. This explains the low concentrations of noble metals analyzed (see table 4-II). The feed preparation procedure is shown in Figure 4-1 and the corresponding data are given in the Table 4-I. The premixed waste simulant was stored in a large waste storage tank (WST, see figure 3-23). Before transfer from WST to the Feed Make up Tank (FMT), an initial liquid sample was taken from WST and analyzed. After the end of this transfer, a sample from the FMT was taken and analyzed, too. Based on this data the shim chemicals have been added. The simulate then was heated up to $95^{\circ} \mathrm{C}$ and a third sample taken. After sampling the formic acid addition was started with an average feeding rate into the FMT of 60 to $70 \mathrm{l} / \mathrm{h}$. $(52-61 \mathrm{l} / \mathrm{h} / \mathrm{l})$. The subsequent digestion was performed at $99^{\circ} \mathrm{C}$ for 4 hours and a final sample taken. For preparation of the first 2 batches, forced cooling was used after digestion. The other batches cooled naturely to $40^{\circ} \mathrm{C}$ before the recycling chemicals were added. At this stage the glass frit powder was mixed to the formated waste simulant. To assure a good mixture the rotation speed of the stirrer of the FMT was increased for some time (230 rpm). After this mixing procedure-another sample has been taken. Its analysis data served as the basis for the final adjustment of the batch with water to the target value of $500 \mathrm{~g} / \mathrm{l}$ oxides. Before the first of the several transfers from the FMT to the smaller Melter Feed Tank (MFT) took place a sample was taken for final control.

The analysis data of the liquid samples taken during the batch preparation are compiled in the tables 4-II to 4-VI. There are some differences between the targets and some of the analyzed elements by ICP. For the noble metals especially this may be due to the reason of the detection limit of the ICP. On the other hand showed the XRF-results of the glass samples that the oxide loading was quite near the target. The figures 4-2 to 4-15 illustrate for each batch in dependance of time the temperatures in the FMT including the off-gas temperature, the gas flow rates, the pressure, and the volume concentrations of the off-gas species NO, $\mathrm{NO}_{2}, \mathrm{~N}_{2} \mathrm{O}$ and $\mathrm{H}_{2}$. Due to safety reasons, the off-gas composition was intended to be analyzed on-line. But the $\mathrm{H}_{2}$ analyzer did not work correctly during batch 2 and 3. During their preparations gas samples were taken every 30 minutes and separately send to a gas chromatograph. The $\mathrm{H}_{2}$ concentrations were all the time about a factor of 10 below the safety limit. Two sets of temperature profiles are shown for the FMT, one for the upper thermocouple and one for the lower thermocouple. There is an offset in the curves for the smaller batches because the upper thermocouple was near the top surface of the liquid. 


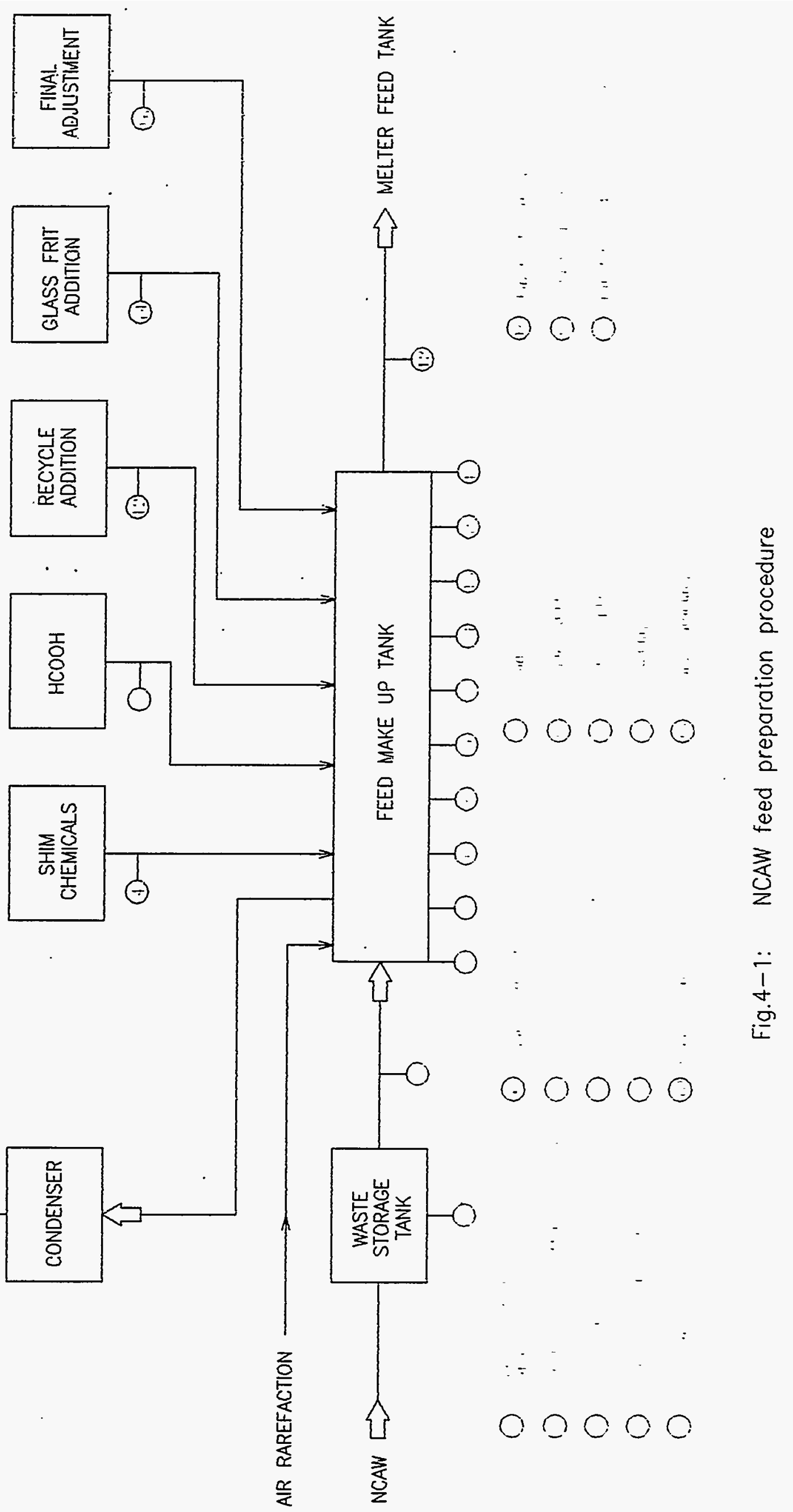


Table 4-I

Feed Preparation Procedure

Campaign
Batch
Start
Stop

1. Lagertank Sampling

2. Transfer to FMT, Vol. (L)

3. FMT Sampling

4. Shim Chemicals, Add. (kg)

$$
\begin{aligned}
& \mathrm{Al}(\mathrm{OH}) 3 \\
& \mathrm{Ca}(\mathrm{OH}) 2 \\
& \mathrm{MoO} 3 \\
& \mathrm{NaNO} 2 \\
& \mathrm{NaNO} 3 \\
& \mathrm{ZrO} 2
\end{aligned}
$$

5. Heat up to $\left({ }^{\circ} \mathrm{C}\right)$

6. FMT Sampling

7. Formic Acid Add. , $85 \%$ (L) Feed rate (L/h)

8. Heat up to $\left({ }^{\circ} \mathrm{C}\right)$

9. Digestion [h]

10. FMT Sampling

11. Cooling down to $\left({ }^{\circ} \mathrm{C}\right)$

12. Recycling Chemicals (kg)

CdO

Diatomacesous Earth

$\mathrm{KMnO} 4$

$\mathrm{NaCl}$

$\mathrm{Na}_{2} \mathrm{C}_{2} \mathrm{O}_{4}$

$\mathrm{NaNO} 3$

$\mathrm{NaPO} 4$

$\mathrm{Na} 3 \mathrm{PO} 4 \times 12 \mathrm{H} 2 \mathrm{O}$

Zeolite

HNO3 65\% (kg)

$\mathrm{HCOOH} 85 \%$ (L)

13. FMT Sampling

14. Frit Additon (kg)

15. FMT Sampling

16. Final Adjustment $\mathrm{H} 2 \mathrm{O}(\mathrm{L})$

17. FMT Sampling

18. Transfer to MFT, Vol. (L)

$\begin{array}{ccc}\text { U1 } & \mathrm{U} 2 & \mathrm{U} 2 \\ \mathrm{~B} 1 & \left.\mathrm{~B} 2^{*}\right) & \mathrm{B} 3 \\ \mathbf{2 8 . 0 6 . 1 9 9 2} & 07.07 .1992 & 19.07 .1992 \\ 01.07 .1992 & 11.07 .1992 & 22.07 .1992\end{array}$

$\begin{array}{cc}U 2 & U 2 \\ B 4 & B 5 \\ 30.07 .1992 & 12.08 .1992 \\ 03.08 .1992 & 16.08 .1992\end{array}$

$\begin{array}{rrrrr}- & - & L 102 & - & - \\ 2400 & 3570 & 3500 & 3750 & 3840 \\ L 1 & L 37 & L 119 & - & L 274\end{array}$

$\begin{array}{rrrrr}14,100 & 15,720 & 12,900 & 17,900 & 18,355 \\ 1,362 & 2,840 & 3,080 & 3,200 & 3,302 \\ 0.51 & 0.55 & 0.541 & 0.86 & 0.883 \\ 89,040 & 27,980 & 125,000 & 129,000 & 132,096 \\ 22,800 & 30,440 & 28,900 & 30,000 & 30,605 \\ - & 4,420 & 0.84 & 2,800 & - \\ 95 & 92 & 95 & 95 & 95 \\ L 2 & L 40 & L 120 & L 186 & L 275 \\ 111 & 147 & 159^{-} & 163 & 167 \\ 63 & 62 & 71 & 61 & 62 \\ 99 & 99 & 99 & 99 & 99 \\ 4(7) & 4 & 4 & 4 & 4 \\ \text { L3A } & L 49 & L 122 & L 187 & L 273 \\ \text { L3B } & & & L 194 & L 276 \\ 40 & 40 & 40 & 40 & 40 \\ \text { forced } & \text { forced } & \text { natural } & \text { natural } & \text { natural }\end{array}$

1,478

2,030

1,700

17,300

0.955

0.062

6,500

44,600

5,570

7,640

52,420

3,406

4,670

$7,392 \quad 10,140$

$2,640 \quad 3,620$

21.7

L4A

L4B

906

L5A

L5B

457

L50

9,200

8,600

3,080

18.4

2,200

21,700

1,200

0.078

8,200

$-56,200$

7,440

10,900

3,800

23,0

1241.7

L51

1056

1331

$\begin{array}{rr}457 & 170 \\ 2610 & 2622\end{array}$
130
L134
3080

1365

L277

2,229

21,460

1,234

0.08

8,398

57,630

11,900

11,440

4,740

24.2

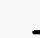

403

$\llcorner 283$

3980 
Tablo 4-1l

Compilation of the analysis data obtained for the NCAW feed preparation, Batch 1 (for pretest run U1)

\begin{tabular}{|c|c|c|c|c|c|c|c|c|c|}
\hline & & & & $\cdot$ & & & & & \\
\hline \multicolumn{2}{|c|}{ NCAW Feed Preparation } & & & & & & & & Batch1.XI.S \\
\hline \multicolumn{10}{|c|}{ U1/Batch 1} \\
\hline \multicolumn{10}{|l|}{ Analysis } \\
\hline & T & & & & & & & & \\
\hline & & & & & & & $\therefore$ & & \\
\hline \multirow[t]{6}{*}{ Sample No. } & & L1 & 2 & L3A & L38 & LAA & L48 & L5A & $\mathrm{LI7}$ \\
\hline & & 28.06 .1992 & 29.06 .1992 & 30.06 .1992 & 30.06 .1992 & 30.06 .1992 & 30.06 .1992 & 01.07 .1992 & 04.07 .1992 \\
\hline & & $17.30 \mathrm{~h}$ & $21.10 \mathrm{n}$ & $15.00 \mathrm{~h}$ & $15.00 \mathrm{~h}$ & $19.45 \mathrm{~h}$ & $19.45 \mathrm{~h}$ & $07.30 \mathrm{~h}$ & $09.00 \mathrm{~h}$ \\
\hline & Melter Feed & FMT before & FMT atter & FMT anter & FMT aner & FMT after & FMT anes & FMT anter & FMT \\
\hline & Target & shimming & shimming & digestion - & digestion & recycle add. & recycle add. & fritaddition & final sample \\
\hline & $a \underline{L}$ & $a l$ & $a \Omega$ & on & gl & gl & ol & $g h$ & $g /$ \\
\hline & & & & & & & & & \\
\hline & & & & & & & & & \\
\hline \multicolumn{10}{|l|}{ Element } \\
\hline & & & & & & & & & \\
\hline$\overline{A q}$ & 0.16 & 0.14 & 0.15 & 0.17 & 0.17 & 0.19 & 0.19 & 0.16 & 0.17 \\
\hline A) & 7.23 & 5.12 & 6.16 & 7.37 & 7.38 & 8.04 & 7.99 & 7.51 & 8.33 \\
\hline B & 21.79 & 0.01 & 0.02 & 0.01 & 0.01 & 0.01 & 0.01 & 19.09 & 21.37 \\
\hline $\mathrm{Ba}$ & 0.22 & 0.23 & 0.20 & 0.23 & 0.23 & 0.25 & 0.25 & 0.23 & 0.26 \\
\hline $\mathrm{Ca}$ & 0.84 & 0.58 & 0.82 & 0.93 & 0.92 & 1.02 & 1.01 & 0.96 & 1.01 \\
\hline Cd & 4.26 & 3.46 & 3.52 & 3.70 & 3.68 & 4.60 & 4.52 & 3.91 & 4.20 \\
\hline Ce & 0.75 & 0.60 & 0.60 & 0.62 & 0.63 & 0.66 & 0.66 & 0.57 & 0.57 \\
\hline $\mathrm{C}$ & 0.26 & 0.23 & 0.25 & 0.24 & 0.24 & 0.27 & 0.28 & 0.22 & 0.22 \\
\hline Cs & 0.81 & 9 & 7 & 9 & 7 & 7 & 7 & 7 & 7 \\
\hline $\mathrm{Cu}$ & 0.28 & 0.32 & 0.29 & 0.33 & 0.34 & 0.36 & 0.36 & 0.30 & 0.34 \\
\hline Fe & 28.35 & 29.59 & 27.60 & 30.14 & 29.49 & 32.62 & 32.48 & 27.67 & 29.95 \\
\hline Ge & 0.00 & 7 & 2 & 7 & 7 & 7 & 7 & 7 & ? \\
\hline $\mathrm{K}$ & 0.23 & 0.00 & 0.00 & 0.00 & 0.00 & 0.00 & 0.00 & 0.00 & 7 \\
\hline La & 0.84 & 0.51 & 0.47 & 0.52 & 0.52 & 0.56 & 0.57 & 0.48 & 0.52 \\
\hline L & 11.61 & 7 & 9 & 9 & 7 & 9 & 7 & 9 & 7 \\
\hline $\mathrm{Mg}$ & 0.34 & 0.48 & 0.48 & 0.53 & 0.53 & 0.58 & 0.58 & 0.52 & 0.55 \\
\hline $\mathrm{Mn}$ & 2.03 & 2.10 & 1.96 & 2.10 & 2.12 & 243 & 2.39 & 2.04 & 2.22 \\
\hline Mo & 0.53 & \begin{tabular}{ll|}
0.37 \\
\end{tabular} & 1.60 & 1.75 & 1.72 & 1.87 & 1.87 & 1.59 & 1.73 \\
\hline $\mathrm{Na}$ & 28.09 & 9.17 & 20.66 & 25.06 & 26.00 & 32.27 & 33.99 & 30.73 & 33.47 \\
\hline $\mathrm{Nb}:$ & 0.01 & y & 2 & 9 & 2 & 7 & 7 & 7 & 7 \\
\hline Nd & 4.26 & 4.18 & 3.75 & 4.34 & 4.38 & 4.65 & $4 . \tilde{62}$ & 4.00 & 4.35 \\
\hline $\mathrm{NI}$ & 258 & 2.66 & 2.56 & 2.83 & 2.79 & 3.04 & 2.99 & 2.55 & 2.73 \\
\hline $\mathbf{P}$ & 0.78 & 7 & 3 & 7 & 9 & 7 & 9 & 7 & 9 \\
\hline $\mathrm{Pb}$ & 0.87 & 0.75 & 0.73 & 0.80 & 0.79 & 0.87 & 0.86 & 0.75 & 0.80 \\
\hline$P d^{-9}$ & 0.00 & 0.09 & 0.13 & 0.08 & $0 . \infty$ & 0.10 & 0.12 & 0.04 & 0.02 \\
\hline$P f$ & 0.19 & 0.19 & 0.20 & 0.20 & 0.20 & 0.22 & 0.21 & 0.18 & 0.18 \\
\hline$R b$ & 0.06 & ? & 7) & 9 & 7 & 9 & 7 & ) & 9 \\
\hline $\mathrm{Rh}^{\text {ने }}$ & 0.00 & 0.02 & 0.05 & 0.03 & 0.03 & 0.03 & 0.04 & 0.02 & 0.09 \\
\hline$R u^{\infty}$ & 0.00 & 0.95 & 0.11 & 0.10 & 0.10 & 0.11 & 0.11 & 0.08 & 0.08 \\
\hline Sb & 0.01 & of & 7 & 7 & 9) & ) & 7 & ) & $?$ \\
\hline Se & 0.02 & 2 & 2 & $\frac{7}{2}$ & 7 & 7 & 7 & 7 & 3 \\
\hline Si & 122.04 & 3 & 2 & $y$ & 3 & 7 & 2 & 7) & 7 \\
\hline Sm & 0.09 & 0.13 & 0.13 & 0.14 & 0.14 & 0.15 & 0.15 & 0.13 & 0.13 \\
\hline Sn & 0.01 & of & 7) & 7 & 5 & 7 & 7 & 2 & 7 \\
\hline sr & 0.14 & 0.18 & 0.17 & 0.18 & 0.18 & 0.20 & 0.20 & 0.18 & 0.19 \\
\hline $\mathrm{Ta}$ & 0.00 & 7 & 2 & 2 & 9 & 7 & 7 & 2 & 7 \\
\hline Te & 0.11 & 2 & 2 & 2 & ) & 7 & 7 & 9 & 7 \\
\hline$\pi$ & 0.57 & 9 & .) & 7 & 7 & 9 & 7 & 9 & 2 \\
\hline $\bar{Y}$ & 0.09 & 0.07 & 0.07 & 0.07 & 0.07 & 0.08 & 0.08 & 0.07 & 0.07 \\
\hline $\mathbf{z n}$ & 0.38 & 0.31 & 0.33 & 0.37 & 0.35 & 0.36 & 0.35 & 0.36 & 0.39 \\
\hline \multirow[t]{2}{*}{ zr } & 15.94 & 15.23 & 14.28 & 16.00 & 16.06 & 17.17 & 17.26 & 14.85 & 15.40 \\
\hline & & & & & & & & & \\
\hline Total & 256.80 & 77.66 & 87.47 & 98.84 & 99.16 & 11271 & 114.14 & 119.19 & 129.26 \\
\hline & & & & & & & & & \\
\hline Fluoride & 0.12 & - & 0.02 & - & - & $=$ & $=$ & - & - \\
\hline Chloride any & 0.38 & $=$ & 0.09 & $=$ & - & - & $=$ & - & - \\
\hline Nitrite & 20.00 & - & 19.80 & $=$ & - & - & $=$ & - & - \\
\hline Sulphate & 0.98 & - & 0.91 & - & - & - & - & - & - \\
\hline Phosphate & 0.10 & $\therefore$ & 0.00 & - & - & - & - & - & - \\
\hline Nitrate & 7.20 & $\therefore$ & 5.00 & - & - & - & - & $=$ & - \\
\hline & & & & & & & • & & \\
\hline $\mathrm{pH}$ & & - & $=$ & 6.50 & - & 6.80 & - & 7.70 & 8.40 \\
\hline Density o/mL & & 1.10 & 1.11 & 1.13 & 1.13 & 1.15 & 1.15 & 1.34 & 1.34 \\
\hline OLoad. ol & & 130.70 & 132.70 & 140.66 & 138.66 & 178.58 & 180.89 & 506.10 & 508.78 \\
\hline Volume L & & 2400.00 & - & 2480.00 & 2480.00 & - & - & 2610.00 & 2960.00 \\
\hline & & $\cdot$. & & & & & & & \\
\hline & & I No analysis & Jata available & & & & & & \\
\hline & - & & & & & & & & \\
\hline & & Due to a mi & stake during fee & d preparation & 16 of the simul & ant contained $n$ & oble metals & & \\
\hline & & & & & & & & & \\
\hline & & Fonta meas & ured by PNL & & & & & & \\
\hline
\end{tabular}


Table 4-ill.

Compilation of the analysis data obtained for NCAW feed preparation, Batch 2 (for noble metal test run U2)

\begin{tabular}{|c|c|c|c|c|c|c|c|}
\hline NCAW Feed P & eparatlon & & & & & & Batch $2 \times 1 S$ \\
\hline \multicolumn{8}{|c|}{ U2/Batch $2 * 1$} \\
\hline \multirow[t]{3}{*}{ Analysis } & & & & & & $\cdot$ & \\
\hline & & & & & & & \\
\hline & & & & & & & \\
\hline \multirow[t]{6}{*}{ Sample No. } & & L37 & $L 40$ & $\mathrm{~L} 49$ & L50 & $\cdot \mathrm{L51}$ & $\mathrm{L} 82$ \\
\hline & & 07.07 .1992 & 08.07 .1992 & $\infty .07 .1992$ & 09.07 .1992 & 10.07 .1992 & 13.07 .1992 \\
\hline & & $10.30 \mathrm{~h}$ & $12.00 \mathrm{~h}$ & $07: 33 \mathrm{~h}$ & $11.00 \mathrm{n}$ & $08.46 \mathrm{~h}$ & $09.00 \mathrm{~h}$ \\
\hline & Mefter Feed & FMT before & FMT after & FMT anter & FMT aner & FMT after & FMT \\
\hline & Tarpet & shimming & shimming & digestion & recycle add. & fit-addition & final sample \\
\hline & 는 & al & $a \Omega$ & on & $a h$ & ol & Q \\
\hline & & & & & & & \\
\hline \multirow{2}{*}{ Eement } & . & & & & & & \\
\hline & & & & & & & \\
\hline$\overline{A Q}$ & 0.16 & 0.17 & 0.17 & 0.24 & 0.25 & 0.17 & 0.15 \\
\hline $\mathrm{Al}$ & 7.23 & 5.09 & 6.13 & 8.72 & 9.48 & 7.30 & 6.29 \\
\hline $\mathbf{B}$ & 21.79 & 0.96 & 0.53 & 0.74 & 0.79 & 71.70 & 17.08 \\
\hline $\mathbf{B a}$ & 0.22 & 0.21 & 0.20 & 0.29 & 0.31 & 0.23 & 0.2 \\
\hline $\mathrm{Ca}$ & 0.84 & 0.39 & 0.78 & 1.11 & 1.19 & 0.93 & 0.82 \\
\hline $\mathrm{Cd}$ & 4.26 & 3.71 & 3.60 & 5.22 & 6.25 & 4.38 & 3.85 \\
\hline Ce & 0.75 & 0.60 & 0.61 & 0.86 & 0.89 & 0.5 & 0.58 \\
\hline $\mathrm{Cr}_{\mathrm{r}}$ & 0.26 & 0.23 & 0.24 & 0.36 & 0.37 & 0.25 & 0.22 \\
\hline $\mathrm{C}_{8}$ & 0.81 & - & 7 & 7 & 7 & 7 & 7 \\
\hline $\mathrm{Cu}$ & 0.28 & 0.0 & 0.29 & 0.41 & 0.43 & 0.30 & 0.25 \\
\hline Fe & 28.35 & 26.62 & 25.52 & 36.89 & 37.99 & 26.38 & 22.6 \\
\hline Ge & 0.00 & 9 & 7 & 7 & 9 & 9 & 7 \\
\hline$k$ & 0.23 & 0.00 & 0.00 & 0.00 & 0.00 & 0.00 & 7 \\
\hline La & 0.84 & 0.57 & 0.56 & 0.79 & 0.80 & 0.58 & 0.53 \\
\hline $\bar{U}$ & 91.61 & ) & 7 & 7 & 7 & 7 & 9 \\
\hline $\mathrm{MO}$ & 0.34 & 0.46 & 0.44 & 0.61 & 0.67 & 0.52 & 0.47 \\
\hline $\mathrm{Mn}$ & 2.03 & 1.90 & 1.85 & 2.66 & 2.90 & 1.97 & 1.71 \\
\hline Mo & 0.53 & 0.41 & 0.48 & 0.70 & 0.73 & 0.51 & 0.46 \\
\hline $\mathrm{Na}$ & 28.09 & - 10.57 & 14.04 & 19.70 & 23.48 & 18.96 & 18.84 \\
\hline $\mathrm{Nb}$ & 0.01 & 7 & 7 & 7 & 7 & of & 9 \\
\hline Nd & 4.26 & 4.24 & 4.06 & 5.98 & 6.18 & 4.23 & 3.7 \\
\hline $\mathrm{Ni}$ & 2.58 & 2.45 & 237 & 3.42 & 3.48 & 2.47 & 2.16 \\
\hline$P$ & 0.78 & 7 & 7 & 7 & 9 & 9 & 9 \\
\hline $\mathrm{Pb}$ & 0.87 & 0.80 & 0.79 & 1.15 & 9.16 & 0.85 & 0.75 \\
\hline $\mathrm{Pd}$ & 0.17 & 0.07 & 0.08 & 0.10 & 0.10 & 0.07 & 0.06 \\
\hline Pr & 0.19 & 0.20 & 0.20 & 0.28 & 0.29 & 0.21 & 0.2 \\
\hline $\mathbf{R b}$ & 0.06 & 7 & 7) & ) & 7 & 9 & 7 \\
\hline $\mathrm{Rh}$ & 0.12 & 0.05 & 0.06 & 0.08 & 0.07 & 0.05 & 0.05 \\
\hline$R u$ & 0.44 & 0.39 & 0.40 & 0.56 & 0.54 & 0.40 & 0.35 \\
\hline Sb & 0.01 & न & ) & 9 & 7) & of & 7 \\
\hline So & 0.02 & 7) & 7 & 7) & ग) & 9 & 5 \\
\hline Si & 122.04 & न) & 7 & 9 & 7) & 7 & 7 \\
\hline Sm & 0.09 & 0.14 & 0.13 & 0.19 & 0.20 & 0.14 & 0.13 \\
\hline Sn & 0.01 & 2 & 7 & 9 & 7 & 4 & $\frac{0.0}{7}$ \\
\hline $\mathrm{Sr}$ & 0.14 & 0.17 & 0.16 & 0.24 & 0.24 & 0.17 & 0.15 \\
\hline Ta & 0.00 & 3 & 9 & 7 & 7 & 7 & 7 \\
\hline$T \theta$ & 0.11 & 94 & 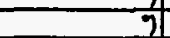 & 7 & गी & नी & $\frac{1}{9}$ \\
\hline$\pi$ & 0.57 & 4 & 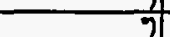 & $\frac{4}{9}$ & $\frac{4}{9}$ & 9 & $\frac{1}{9}$ \\
\hline$Y$ & 0.09 & 0.07 & 0.07 & 0.10 & 0.10 & 0.07 & 0.07 \\
\hline $\mathrm{Zn}$ & 0.38 & 0.39 & 0.39 & 0.57 & 0.60 & 0.48 & 0.42 \\
\hline $2 r$ & 15.94 & 14.18 & 13.96 & 20.23 & 20.61 & 14.29 & 12.63 \\
\hline & & & & & & & \\
\hline Total & 257.52 & 75.34 & 78.21 & 112.20 & 120.10 & 158.24 & 94.72 \\
\hline & & & & & & & \\
\hline Fluorde & 0.12 & - & 0.05 & $=$ & - & - & + \\
\hline Chloride & 0.38 & - & 0.00 & - & - & - & - \\
\hline Nitrite & 4.60 & - & 5.83 & $=$ & 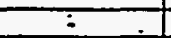 & - & - \\
\hline Sulphate & 0.98 & - & 1.27 & - & - & - & - \\
\hline Phosphate $\cdots$ & 0.10 & - & 0.00 & - & - & - & - \\
\hline Nitrate & 7.20 & - & 9.55 & $=$ & - & - & - \\
\hline & & & & & & & \\
\hline $\mathrm{pH}$ & & 12.40 & 11.60 & 6.20 & 6.30 & 7.60 & 7.6 \\
\hline Density $/ / m L$ & & 1.06 & 1.06 & 1.13 & 1.17 & 1.32 & 1.28 \\
\hline OLoad. o & & 127.00 & - & $=$ & 205.00 & 521.00 & 451.00 \\
\hline Volume $L$ & & & & & & 3420.00 & 3622.00 \\
\hline & & & & & & & \\
\hline & & 7 No analysis data & valable & & & & \\
\hline & & & & & & & \\
\hline & & O Low nitrite batch & & & & & \\
\hline & & & & & & & \\
\hline & & Data measured & Y PNL & & & & \\
\hline
\end{tabular}


Table 4-IV

Compilation of the analysis data obtained for NCAW feed preparation, Batch 3

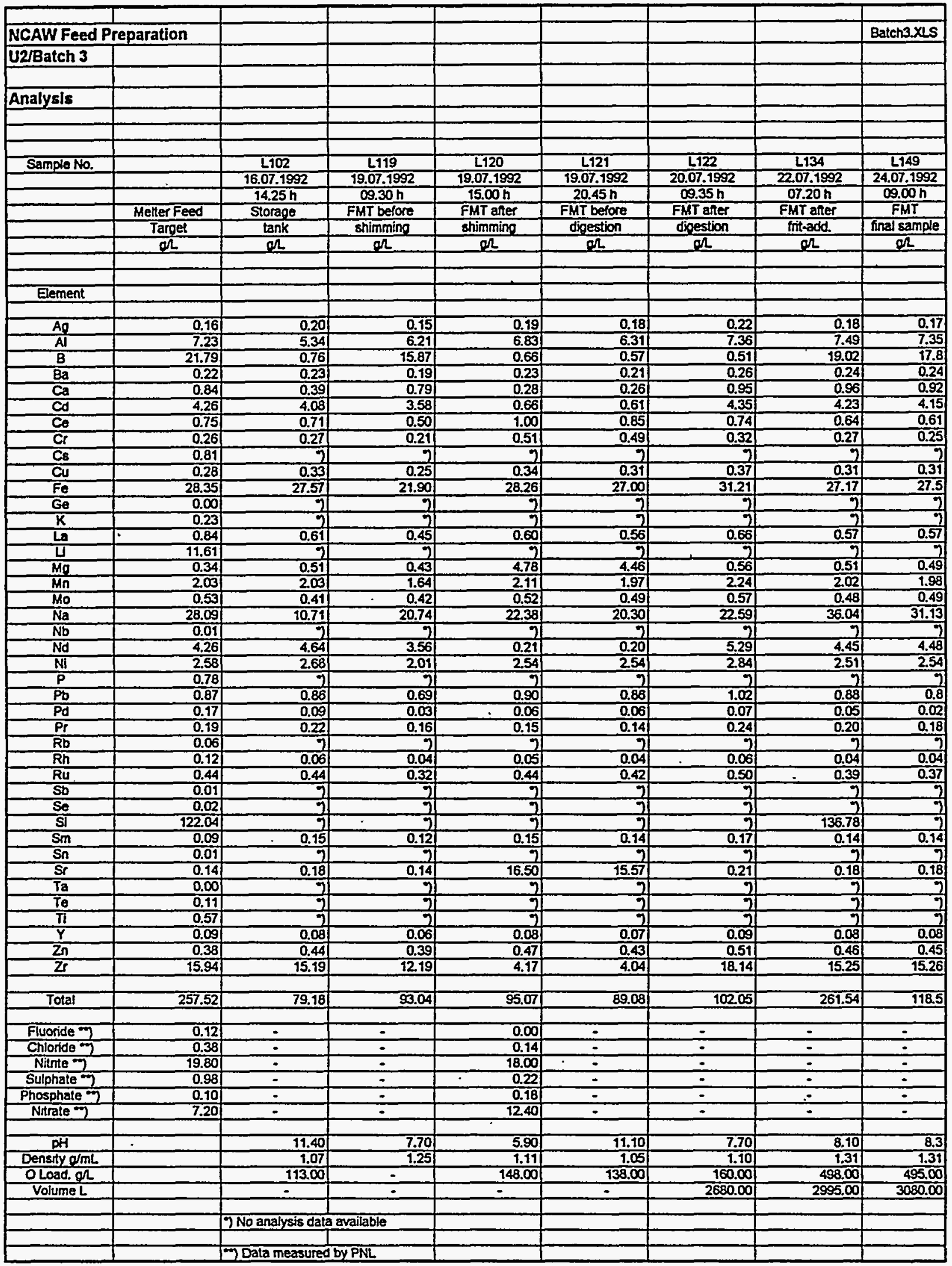


Table 4-V

Compilation of the analysis data for NCAW feed preparation, Batch 4

\begin{tabular}{|c|c|c|c|c|c|c|}
\hline \multicolumn{2}{|c|}{ NCAW Feed Preparatlon } & & & & Batch4.X15 & \\
\hline \multicolumn{7}{|l|}{ U2/Batch 4} \\
\hline \multirow{2}{*}{\multicolumn{7}{|c|}{ Analysls }} \\
\hline & & & & & & \\
\hline & & & & & & \\
\hline \multirow[t]{8}{*}{ Sample No. } & & L186 & L187 & L194 & 206 & $\mathbf{2 1 3}$ \\
\hline & & 30.07 .1992 & 31.07 .1992 & 31.07 .1992 & 02.08 .1992 & 03.08 .1992 \\
\hline & & $19.30 \mathrm{~h}$ & $07.15 \mathrm{~h}$ & $09.00 \mathrm{~h}$ & $\infty 900 \mathrm{~h}$ & $13.00 \mathrm{~h}$ \\
\hline & Mether Feed & FMT anter & FMI after & FMT after & FMT aner & FMT \\
\hline & Target & shimming & digestion & dlgestion & fint-add. & final sample \\
\hline & gh & $g \Omega$ & gl & or & o & ol \\
\hline & & & & $\therefore$ & & \\
\hline & & $\dot{-}$ & & & & \\
\hline \multicolumn{7}{|l|}{ Element } \\
\hline & & & & & & 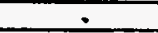 \\
\hline Ag & 0.16 & 0.18 & 0.22 & 0.22 & 0.19 & 0.14 \\
\hline $\mathrm{Al}$ & 7.23 & 6.27 & 8.00 & 8.19 & 8.16 & 6.27 \\
\hline $\mathbf{B}$ & 21.79 & 0.17 & 0.22 & 0.32 & 24.50 & 19.27 \\
\hline $\mathbf{B a}$ & 0.22 & 0.21 & 0.27 & 0.28 & 0.26 & 0.2 \\
\hline $\mathbf{C a}$ & 0.84 & 0.88 & 1.09 & 1.12 & 1.08 & 0.82 \\
\hline $\mathrm{Cd}$ & 4.26 & 3.74 & 4.67 & 4.88 & 4.80 & 3.52 \\
\hline $\mathrm{Ce}$ & 0.75 & 0.62 & 0.78 & 0.82 & 0.68 & 0.51 \\
\hline $\mathrm{Cr}$ & 0.26 & 0.25 & 0.32 & 0.34 & 0.28 & 0.21 \\
\hline Cs & 0.81 & 7 & 9 & 7 & का & 7 \\
\hline $\mathrm{Cu}$ & 0.28 & 0.31 & 0.38 & 0.40 & 0.33 & 0.26 \\
\hline $\mathrm{Fe}$ & 28.35 & 26.24 & 33.16 & 33.83 & 29.42 & 22.33 \\
\hline $\mathrm{Ge}$ & 0.00 & ) & ) & 7 & 7 & 7 \\
\hline$K$ & 0.23 & की & ) & ) & 9 & 7 \\
\hline La & 0.84 & 0.59 & 0.74 & 0.76 & 0.64 & 0.48 \\
\hline L & 11.61 & ᄀ) & 9 & 7 & 7 & 7 \\
\hline $\mathrm{Mg}$ & 0.34 & 0.45 & 0.57 & 0.61 & 0.55 & 0.43 \\
\hline $\mathrm{Mn}$ & 2.03 & 1.90 & 2.38 & 2.43 & 2.21 & 1.77 \\
\hline Mo & 0.53 & 0.49 & 0.65 & 0.66 & 0.56 & 0.43 \\
\hline $\mathrm{Na}$ & 28.09 & 14.92 & 14.35 & 11.30 & 23.64 & 18.71 \\
\hline $\mathrm{Nb}$ & 0.01 & 9 & 7 & 7 & 7) & 7 \\
\hline Nd & 4.26 & 4.11 & 5.16 & 5.31 & 4.52 & 3.44 \\
\hline $\mathrm{Ni}$ & 2.58 & 2.52 & 3.15 & 3.22 & 275 & 2.07 \\
\hline$P$ & 0.78 & 7) & .7 & ) & 7 & 7 \\
\hline $\mathrm{Pb}$ & 0.87 & 0.80 & 1.03 & 1.07 & 0.93 & 0.72 \\
\hline Pd & 0.17 & 0.12 & 0.16 & 0.19 & 0.11 & 0.07 \\
\hline $\mathrm{Pr}$ & 0.19 & 0.19 & 0.24 & 0.28 & 0.21 & 0.16 \\
\hline Rb & 0.06 & of & ) & 7 & ) & 7 \\
\hline Rh & 0.12 & 0.13 & 0.15 & 0.18 & 0.13 & 0.09 \\
\hline Ru & 0.44 & 0.41 & 0.49 & 0.54 & 0.41 & 0.32 \\
\hline Sb & 0.01 & 7 & 9 & ) & 7 & 7 \\
\hline Se & 0.02 & 9 & 2 & 2 & ग) & 7 \\
\hline. $\mathrm{Si}$ & 122.04 & j) & 7) & 7 & गी & 7 \\
\hline $\mathrm{Sm}$ & 0.09 & 0.14 & 0.17 & 0.18 & 0.15 & 0.11 \\
\hline Sn & .0 .01 & 7 & 7 & of & 2 & 7 \\
\hline$S r$ & 0.14 & \begin{tabular}{l|l|}
0.16 \\
\end{tabular} & 0.20 & 0.20 & 0.18 & 0.01 \\
\hline Ta & 0.00 & 7 & 7 & 7 & 9 & 9 \\
\hline $\mathrm{Te}$ & 0.11 & 7 & 7) & की & 24 & 7 \\
\hline II & 0.57 & ग) & ग) & ग) & र्र & $\frac{1}{7}$ \\
\hline$Y$ & 0.09 & 0.07 & 0.09 & 0.10 & 0.08 & 0.06 \\
\hline $\mathrm{Zn}$ & 0.38 & 0.40 & 0.55 & 0.55 & 0.54 & 0.39 \\
\hline $\mathbf{Z}$ & 15.94 & 13.85 & 17.45 & 17.76 & 15.60 & 11.84 \\
\hline & & & & & & \\
\hline Total & 257.52 & 80.13 & 96.64 & 95.74 & 122.91 & 94.63 \\
\hline & & & & & & \\
\hline Fluoride ) & 0.12 & 0.04 & - & - & - & - \\
\hline Chloride "-n & 0.38 & 0.08 & $=$ & - & - & - \\
\hline Natrite & 19.80 & 22.20 & - & $\therefore$ & - & - \\
\hline Sulphate & 0.98 & 1.20 & - & $\div$ & - & - \\
\hline Phosphate & 0.10 & 0.21 & - & - & - & - \\
\hline Nitrate & 7.20 & 5.34 & - & - & - & - \\
\hline & $\therefore$ & & & & & \\
\hline $\mathrm{pH}$ & & 11.50 & 7.80 & 7.60 & 8.60 & 8.5 \\
\hline Densty $\mathrm{g} / \mathrm{mL}$ & & 1.06 & 1.13 & 1.13 & 1.44 & 1.28 \\
\hline Oload. oll & & 135.00 & 174.00 & 177.00 & 612.00 & 457.00 \\
\hline Volume L & & $\div$ & 2630.00 & - & 3050.00 & 3880.00 \\
\hline & & & & & & \\
\hline & & 7 No analysis data & vallable & & & \\
\hline & & & & & & \\
\hline & & Data measured & PNL & & & \\
\hline
\end{tabular}


Table 4-VI

Compilation of the analysis data obtained for NCAW feed preparation, Batch 5

\begin{tabular}{|c|c|c|c|c|c|c|}
\hline \multicolumn{2}{|c|}{ NCAW Feed Preparation } & & & & & Bateh $5 . \times 1 S$ \\
\hline \multicolumn{7}{|l|}{ U2/Batch 5} \\
\hline \multicolumn{7}{|l|}{ Analysis } \\
\hline & & & & & & \\
\hline & & & & & & \\
\hline \multirow{7}{*}{ Sample No. } & & 1274 & L275 & 1273 & $\llcorner 277$ & 1283 \\
\hline & & 12.08 .1992 & 12.08 .1992 & 13.08 .1992 & 13.08 .1992 & 14.08 .1992 \\
\hline & & $18.00 \mathrm{~h}$. & $21.00 \mathrm{~h}$ & $09.00 \mathrm{n}$ & $13.00 \mathrm{n}$ & $\infty .00 \mathrm{~h}$ \\
\hline & Metter Feed & FMT before & FMT anter & FMT aner & FMT anter & FMT \\
\hline & Target & shimming & shimming & dipestion & frit-add. & final sample \\
\hline & ol & ol & ol & $g l$ & ol & ol \\
\hline & & & & 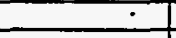 & & \\
\hline & & & & & & \\
\hline \multicolumn{7}{|l|}{ Eement } \\
\hline & & & & & & \\
\hline $\mathrm{Ag}$ & 0.16 & 0.15 & 0.14 & 0.20 & 0.15 & 0.14 \\
\hline A & 7.23 & 3.80 & 4.89 & 6.71 & 5.78 & 5.20 \\
\hline 8 & 21.79 & 0.29 & 0.24 & 0.45 & 17.11 & 15.63 \\
\hline $\mathrm{Ba}$ & 0.22 & 0.17 & 0.17 & 0.23 & 0.18 & 0.17 \\
\hline $\mathbf{C a}$ & 0.84 & 0.34 & 0.69 & 0.92 & 0.73 & 0.72 \\
\hline $\mathrm{Cd}$ & 4.26 & 3.22 & 3.14 & 4.19 & 3.32 & 3.28 \\
\hline $\mathrm{Ce}$ & 0.75 & 0.58 & 0.57 & 0.73 & 0.56 & 0.59 \\
\hline $\mathrm{Cr}$ & 0.26 & 0.21 & 0.21 & 0.28 & 0.20 & 0.19 \\
\hline Cs & 0.81 & 9 & 7 & 7 & 2 & 7 \\
\hline $\mathrm{Cu}$ & 0.28 & 0.25 & 0.24 & 0.33 & 0.23 & 0.22 \\
\hline $\mathrm{Fe}$ & 28.35 & 21.80 & 21.13 & 29.00 & 19.83 & 18.98 \\
\hline Ge & 0.00 & 7 & I & का & ) & 9 \\
\hline $\mathrm{K}$ & 0.23 & 7 & 7 & 7) & ) & 9 \\
\hline $\mathrm{La}$ & 0.84 & 0.49 & 0.48 & 0.64 & 0.44 & 0.45 \\
\hline U & 11.61 & 7) & 7 & I) & 7 & 7 \\
\hline $\mathrm{Mg}$ & 0.34 & 0.42 & 0.42 & 0.53 & 0.43 & 0.45 \\
\hline $\mathrm{Mn}$ & 2.03 & 0.13 & 1.54 & 205 & 1.55 & 1.48 \\
\hline Mo & 0.53 & 0.31 & 0.41 & 0.56 & 0.39 & 0.39 \\
\hline $\mathrm{Na}$ & 28.09 & 5.81 & 14.34 & 18.07 & 19.08 & 16.44 \\
\hline $\mathrm{Nb}$ & 0.01 & 7 & y & ) & ? & 7 \\
\hline Nd & 4.26 & 3.28 & 3.20 & 4.37 & 3.11 & 2.91 \\
\hline $\mathrm{Ni}$ & 2.58 & 2.09 & 2.06 & 275 & 1.87 & 1.83 \\
\hline$P$ & 0.78 & 9 & 9 & ) & 3 & 7 \\
\hline $\mathrm{Pb}$ & 0.87 & 0.71 & 0.71 & 0.93 & 0.69 & 0.68 \\
\hline Pd & 0.17 & 0.17 & 0.16 & 0.19 & 0.13 & 0.21 \\
\hline $\mathrm{PT}$ & 0.19 & 0.21 & 0.20 & 0.25 & 0.19 & 0.22 \\
\hline$R b$ & 0.06 & 7 & 7 & 7 & 2 & 7 \\
\hline Rh & 0.12 & 0.13 & 0.13 & 0.16 & 0.12 & 0.15 \\
\hline Ru & 0.44 & 0.40 & 0.39 & 0.48 & 0.33 & 0.40 \\
\hline Sb & 0.01 & 9 & 7) & ) & ) & 7 \\
\hline $\mathrm{Se}$ & 0.02 & 2 & 2 & ) & 7) & 7 \\
\hline Si & 122.04 & 2 & 9 & 2) & 9 & 7 \\
\hline $\mathrm{Sm}$ & 0.09 & 0.12 & 0.12 & 0.16 & 0.12 & 0.12 \\
\hline Sn & 0.01 & 7 & 7 & 7 & 7 & 7 \\
\hline$S_{r}$ & 0.14 & 0.13 & 0.12 & 0.17 & 0.12 & 0.11 \\
\hline Ta & 0.00 & 2 & 9 & 7 & ) & 7 \\
\hline To & 0.11 & 7 & 7 & 7 & ग) & 7 \\
\hline$\pi$ & 0.57 & 2 & 3 & 3 & ? & 7 \\
\hline$Y$ & 0.09 & 0.06 & 0.06 & 0.08 & 0.06 & 0.05 \\
\hline $\mathbf{Z n}$ & 0.38 & 0.35 & 0.34 & 0.46 & 0.36 & 0.36 \\
\hline $\bar{Z}$ & 15.94 & 11.09 & 11.05 & 15.12 & 10.77 & 9.98 \\
\hline Total & 257.52 & 56.71 & 67.15 & 90.01 & 87.85 & 81.35 \\
\hline & & & & & & \\
\hline Fluotide "9 & 0.12 & - & 0.04 & - & - & - \\
\hline Chloride of & 0.38 & - & 0.09 & - & - & - \\
\hline Nitnite & 19.80 & $=$ & 22.30 & - & - & - \\
\hline Sulphate ${ }^{\infty}$ & 0.98 & - & 1.25 & - & - & - \\
\hline Phosphate 7 & 0.10 & - & 0.00 & - & - & - \\
\hline Nitrate - & 7.20 & $=$ & 5.35 & - & - & - \\
\hline & & & & & & \\
\hline $\mathrm{pH}$ & & 1200 & 11.40 & 9.40 & 8.50 & 8.90 \\
\hline Density o/mL & & 1.06 & 1.06 & 1.14 & 1.29 & 1.31 \\
\hline OLoad. ol & & 121.00 & 136.00 & 175.00 & 468.00 & 482.00 \\
\hline Volume L & & 3840.00 & $=$ & $=$ & - & 3980.00 \\
\hline & & & & & & \\
\hline & & & & & & \\
\hline & & JNo analysis data & railable & & & \\
\hline$\dot{-}$ & & & & & & \\
\hline 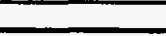 & & 7 Data measured & PNL & & & \\
\hline
\end{tabular}




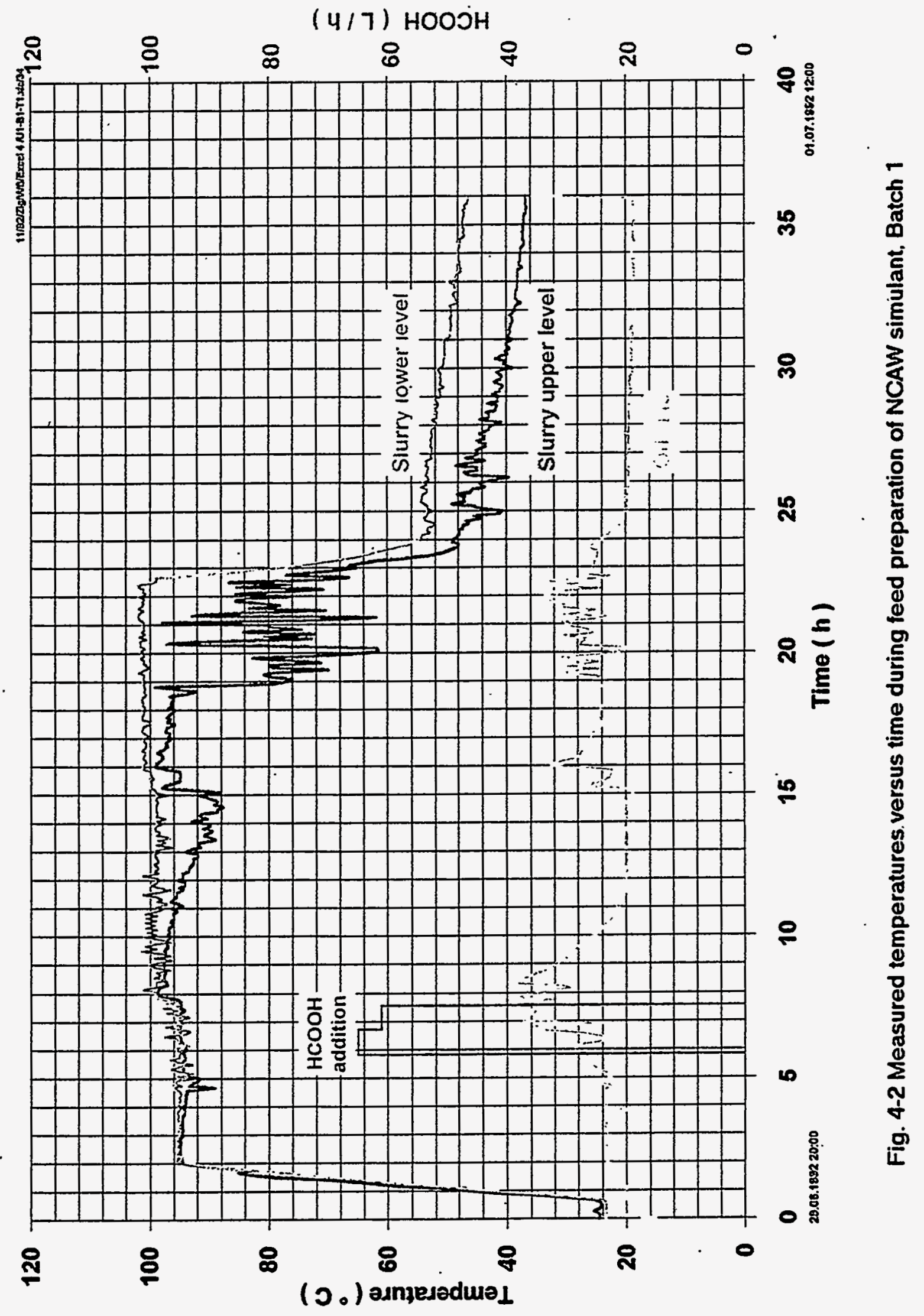




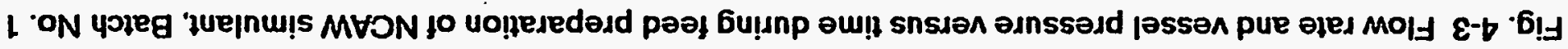

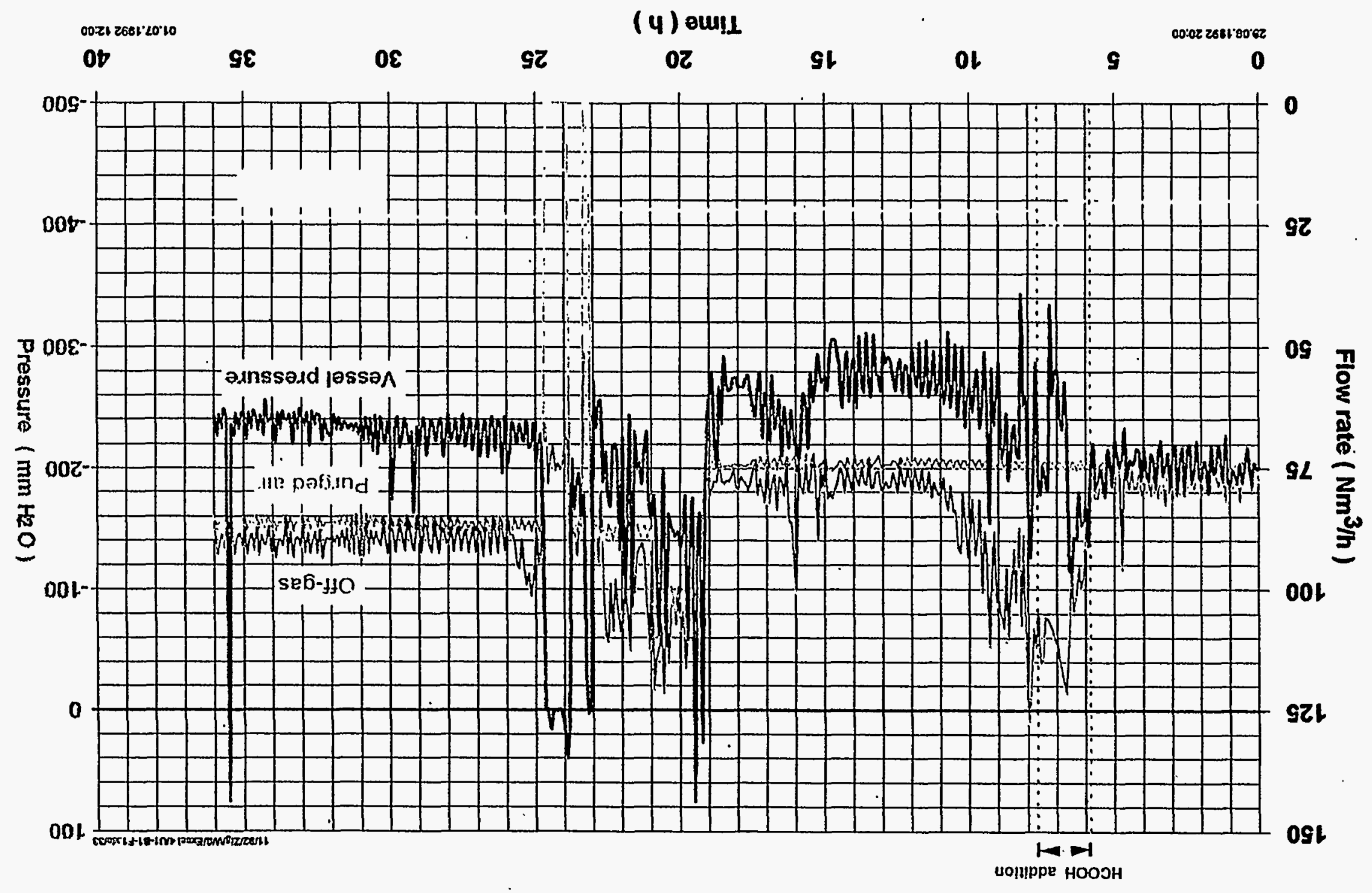




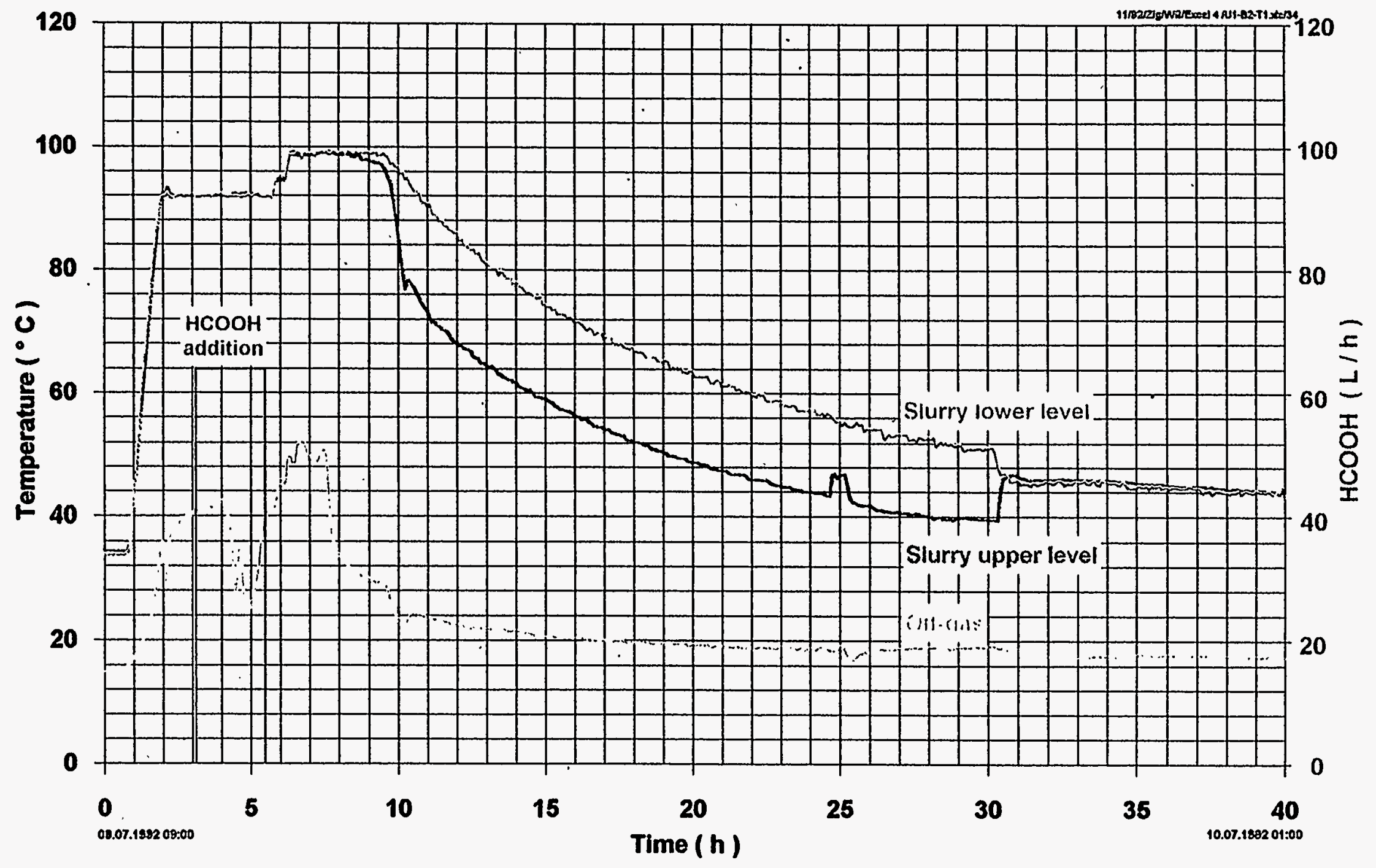

Fig. 4-4 Measured temperatures during feed preparation of NCAW simulant, Batch No. 2 


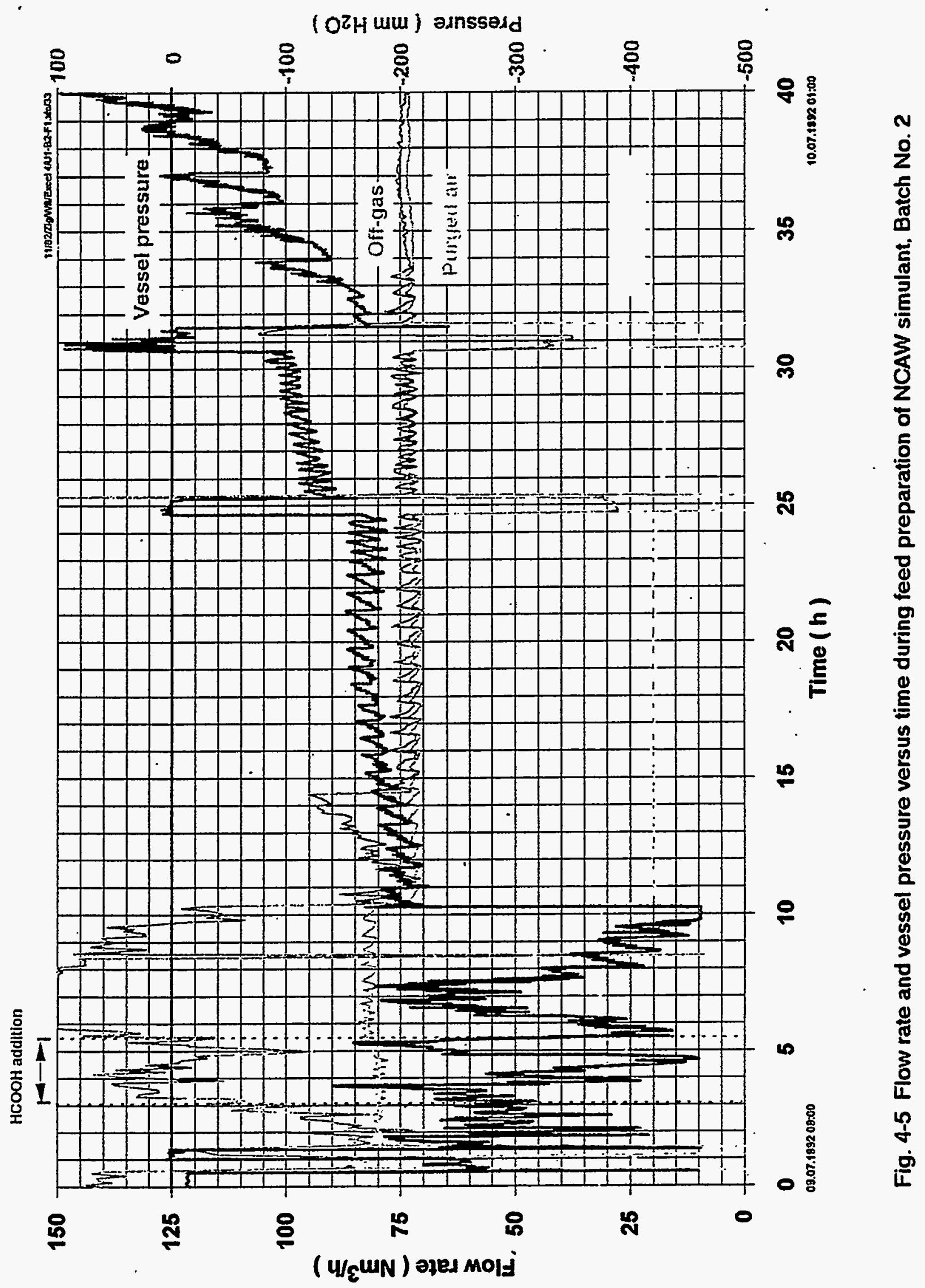




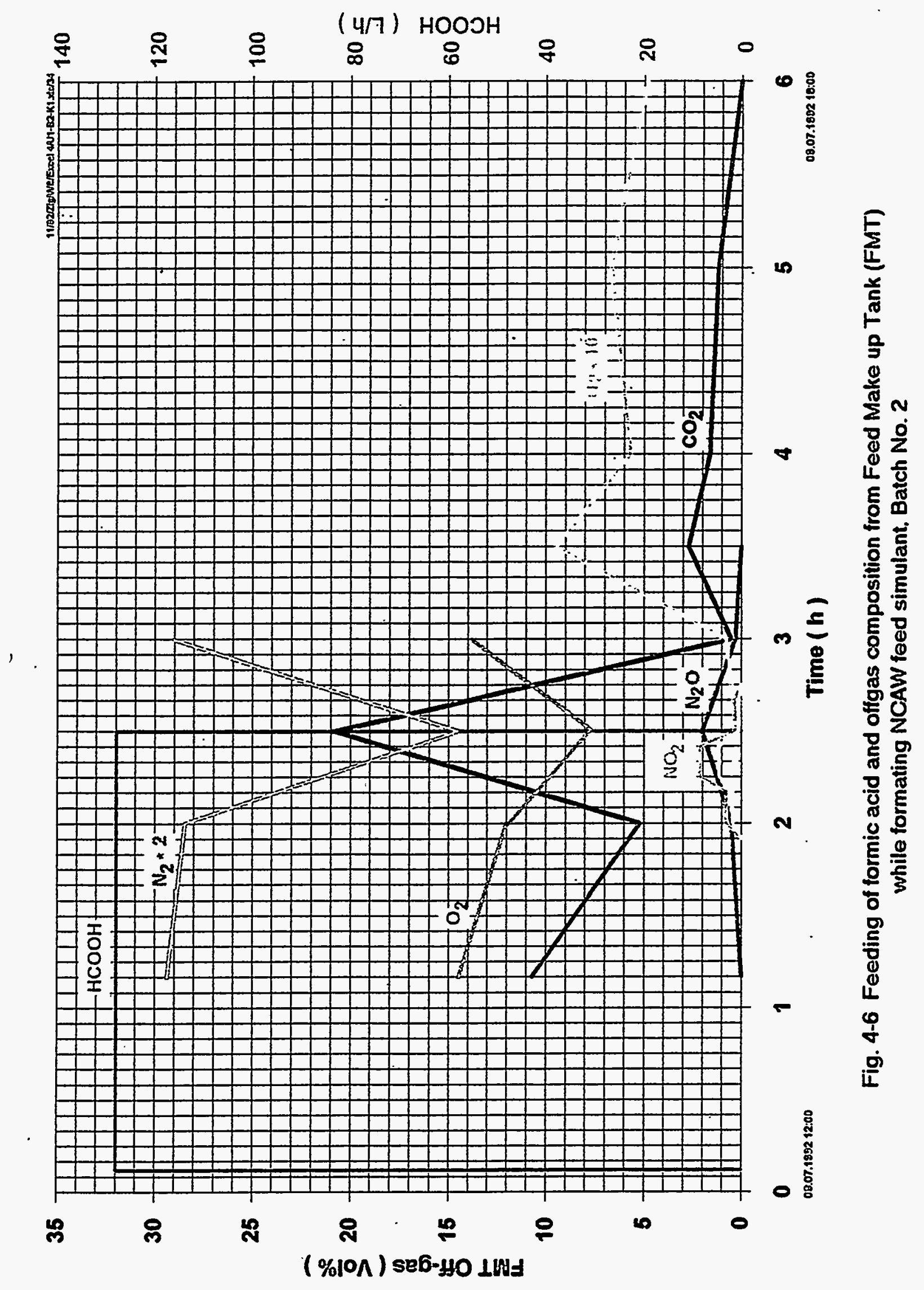




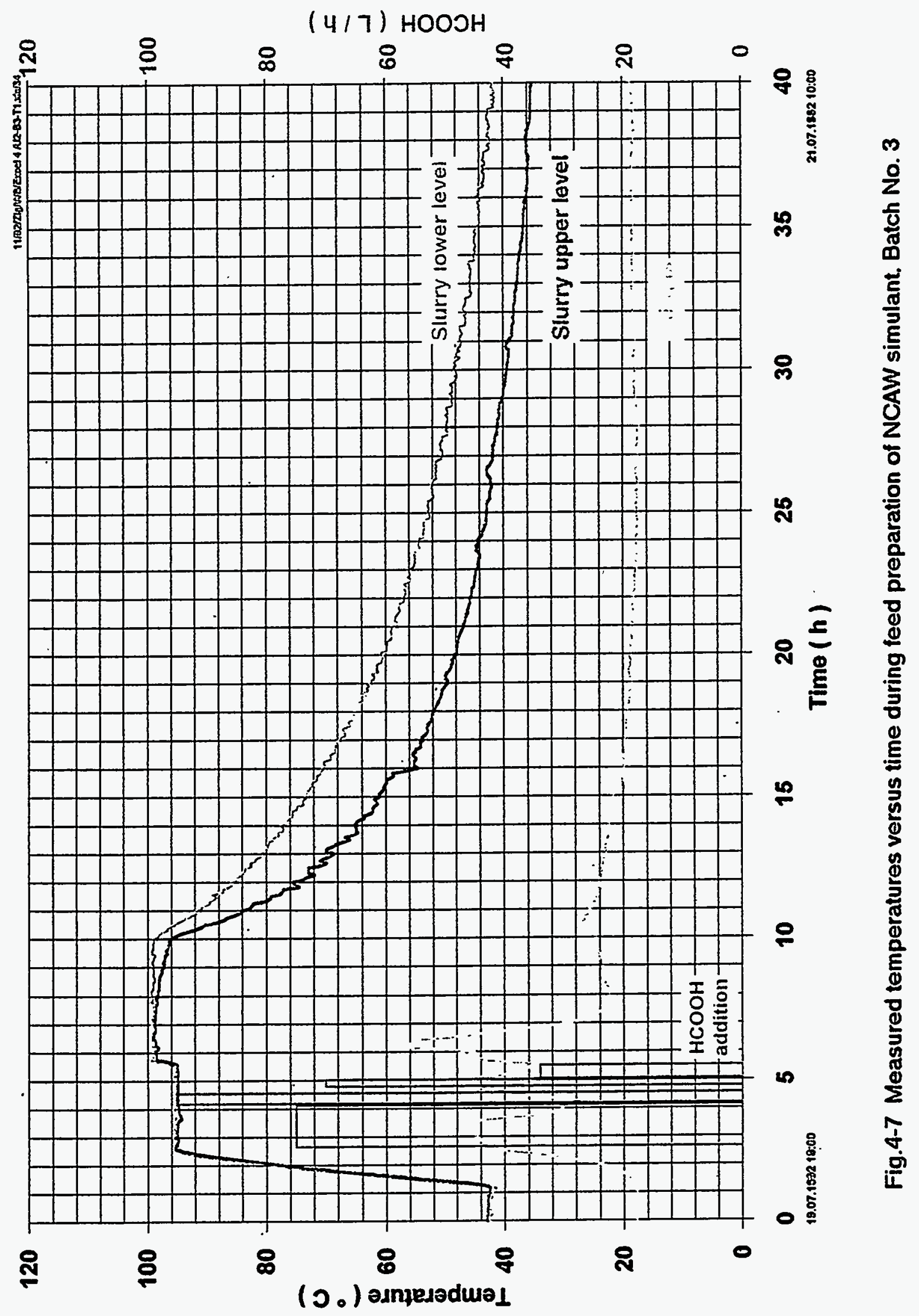




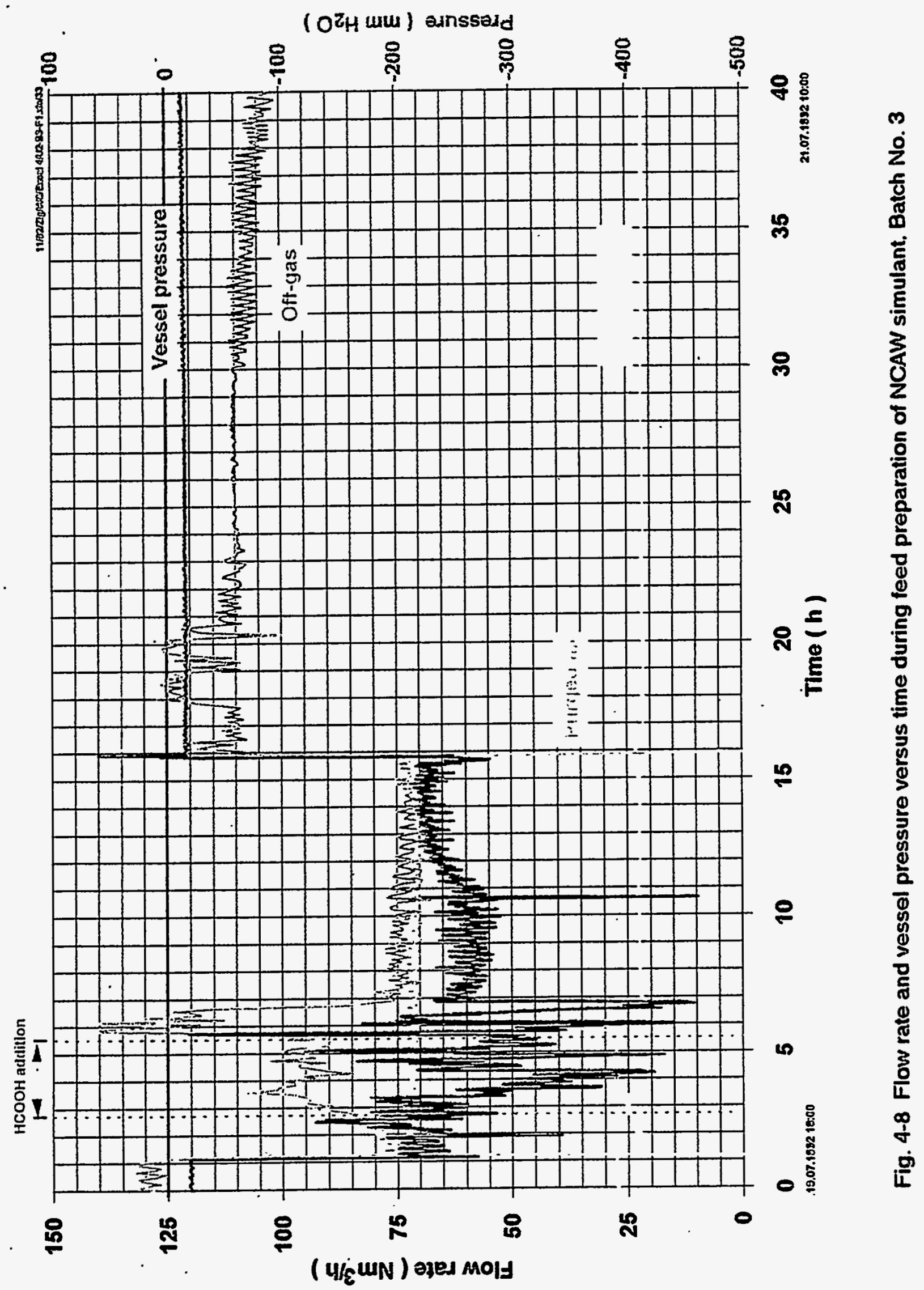




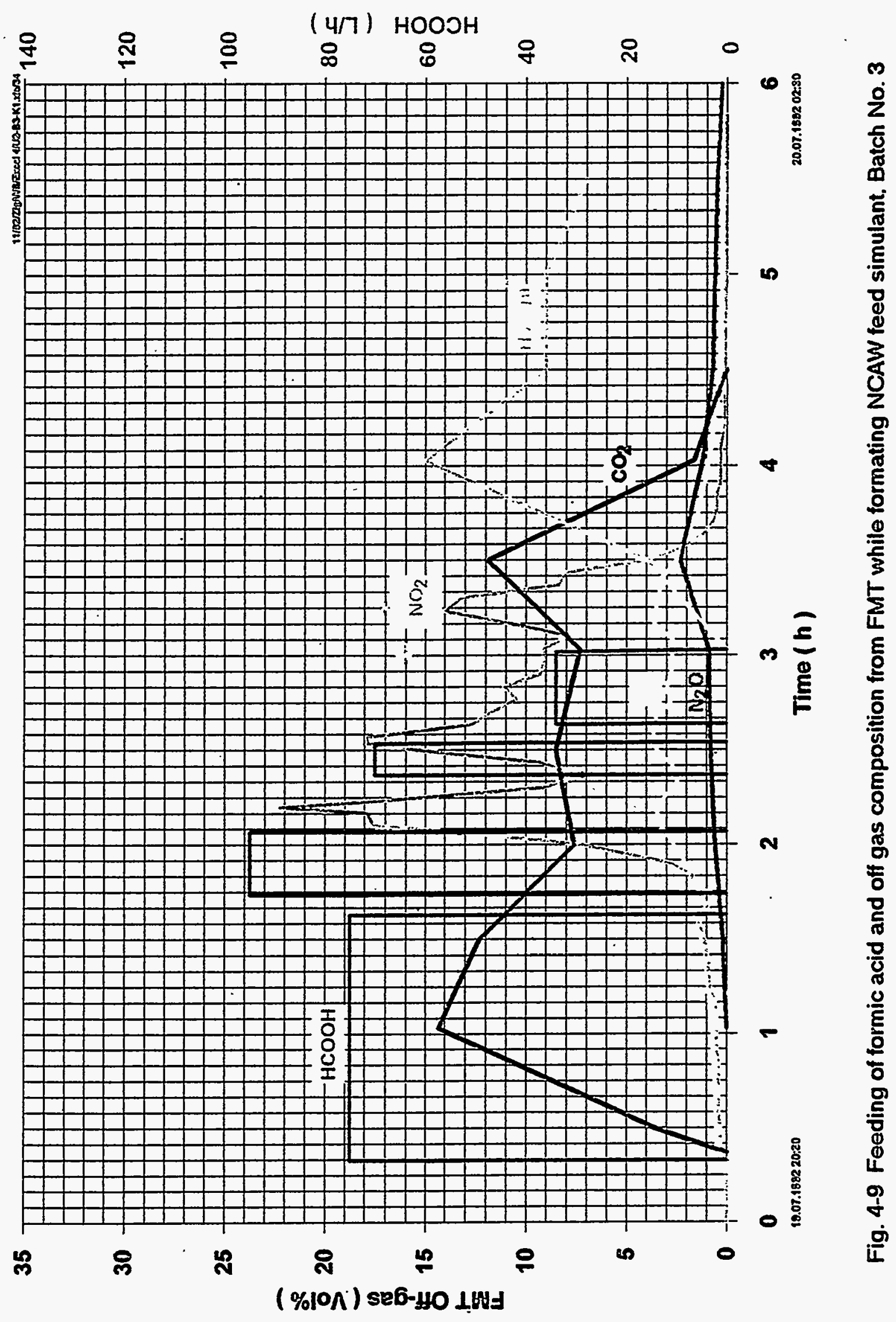




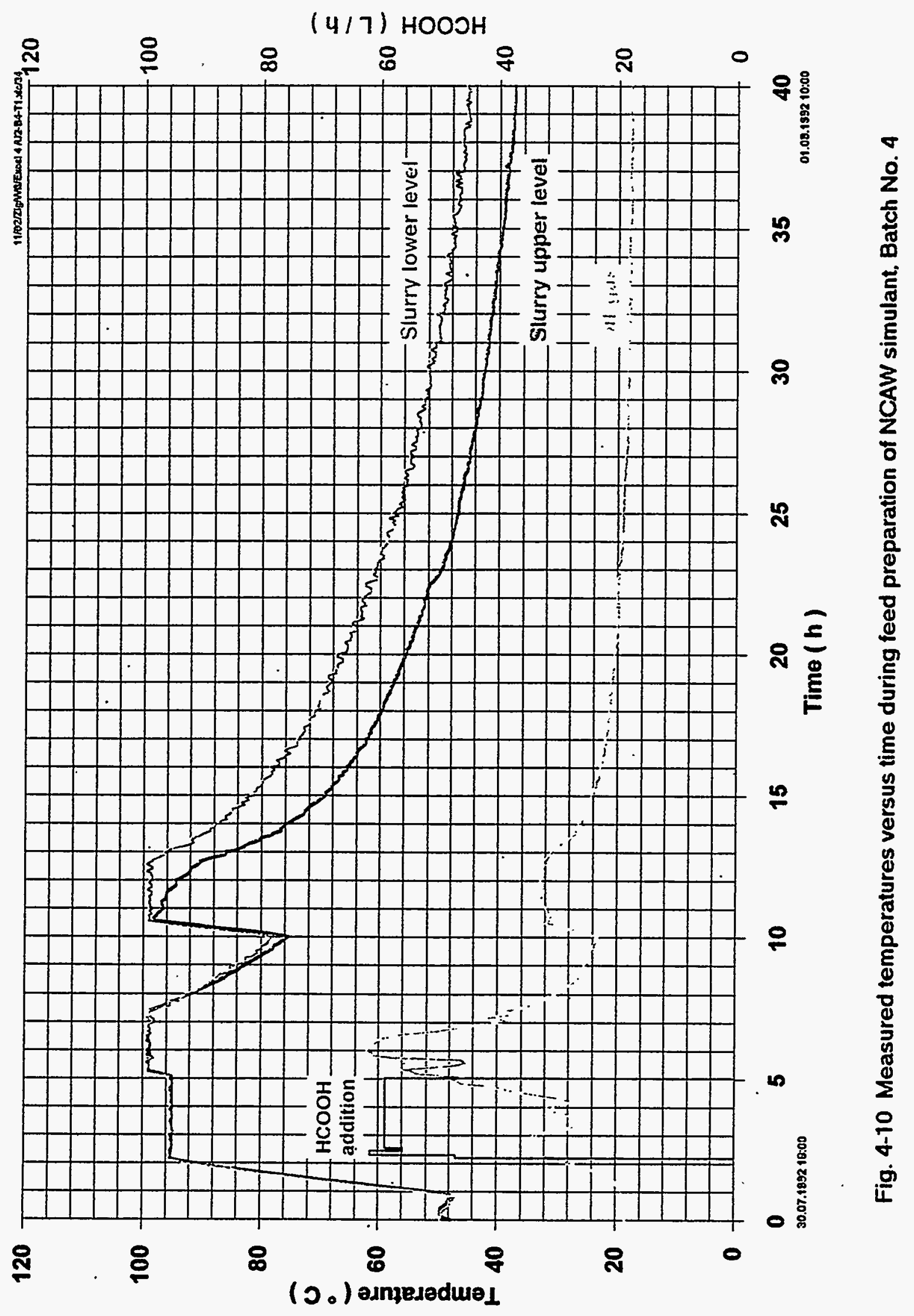




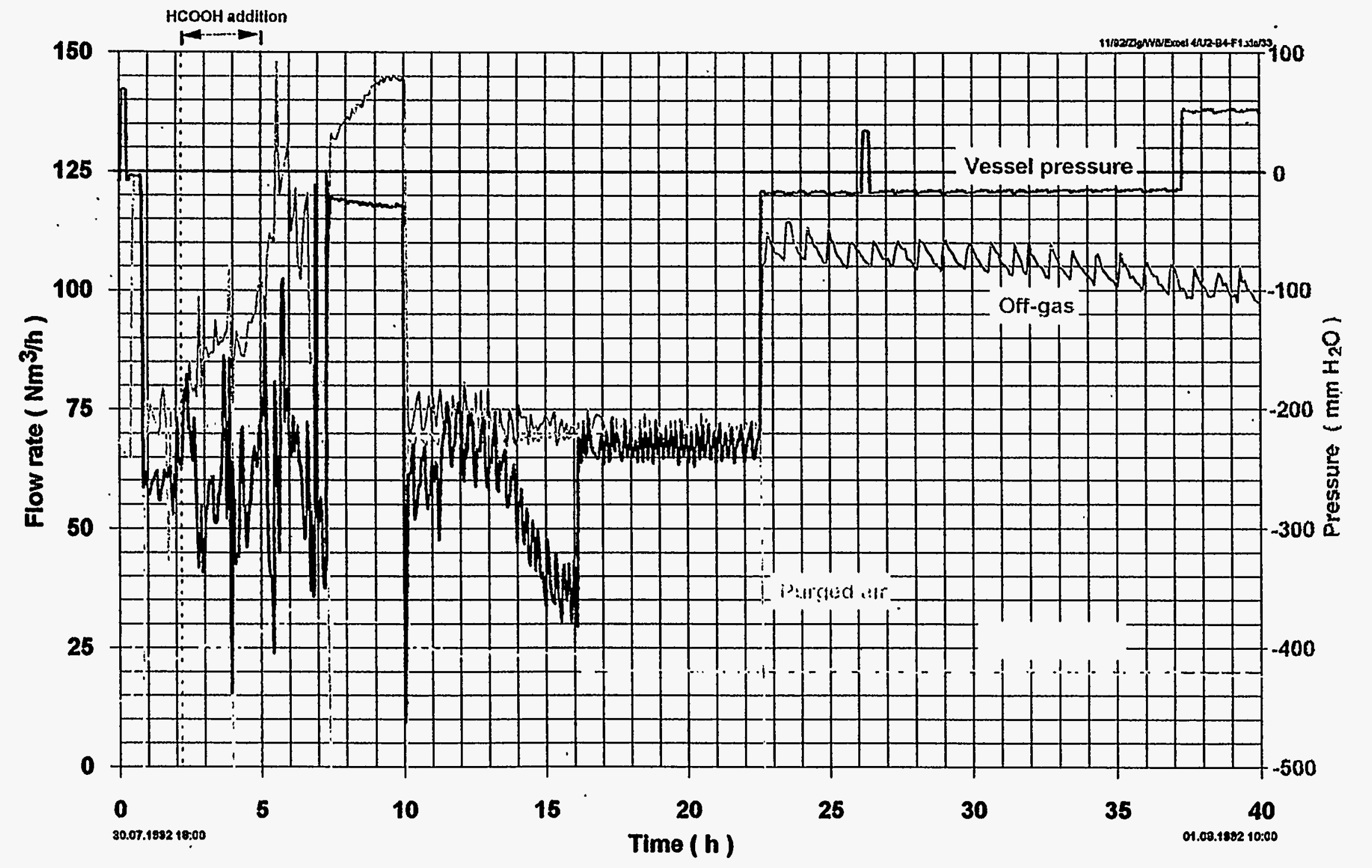

Fig. 4-11 Flow rate and vessel pressure versus time during feed preparation of NCAW simulant, Batch No. 4 


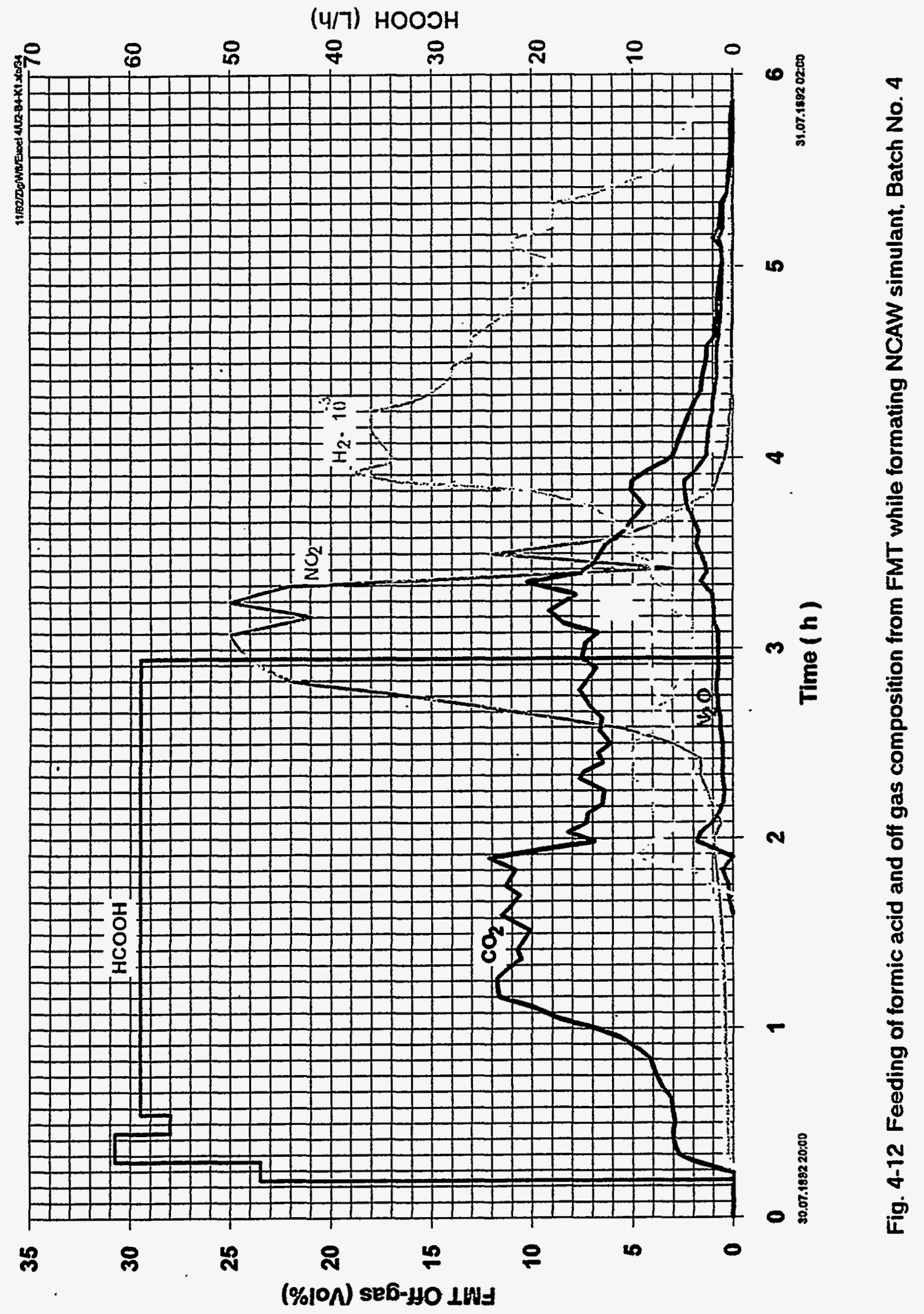




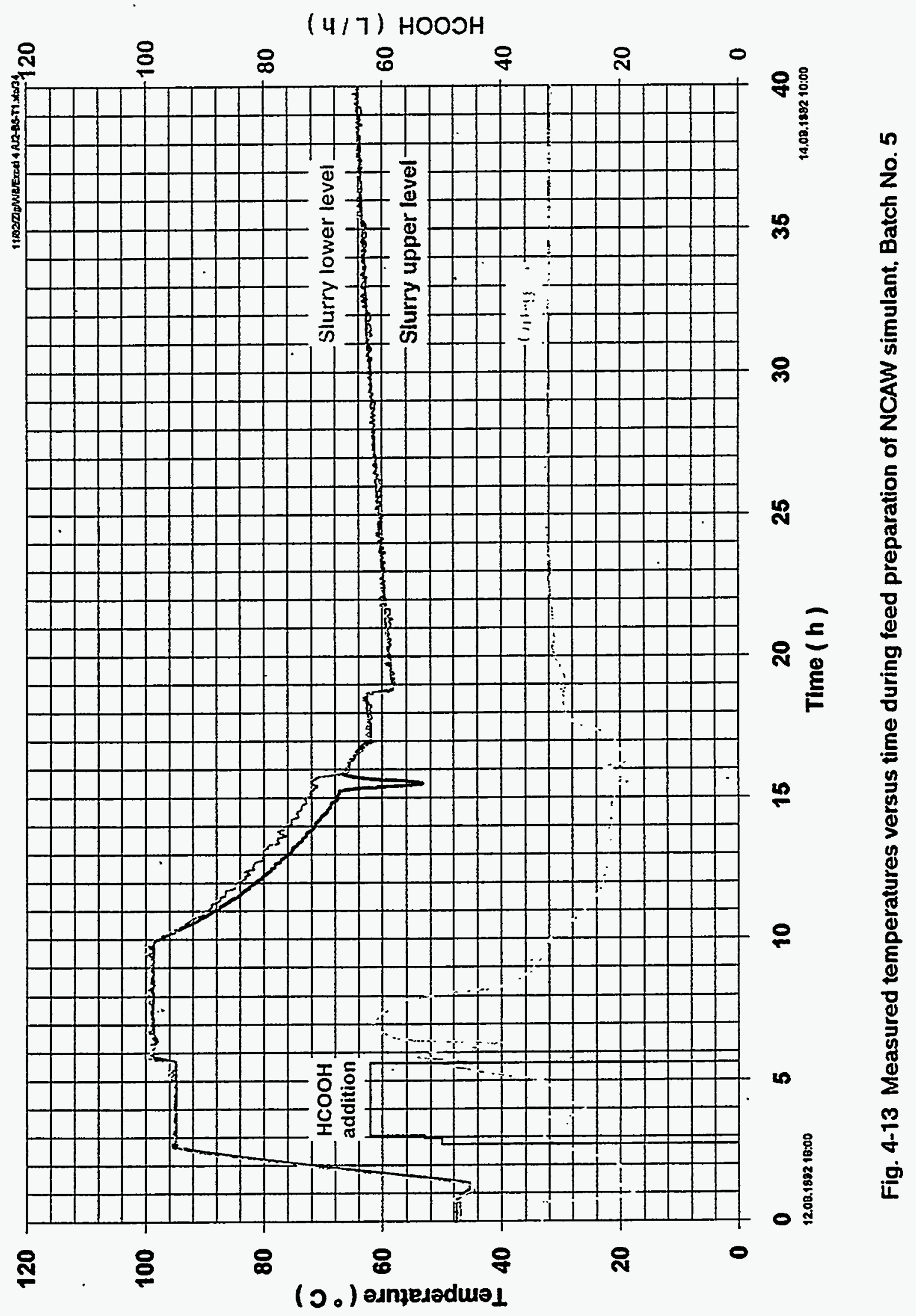




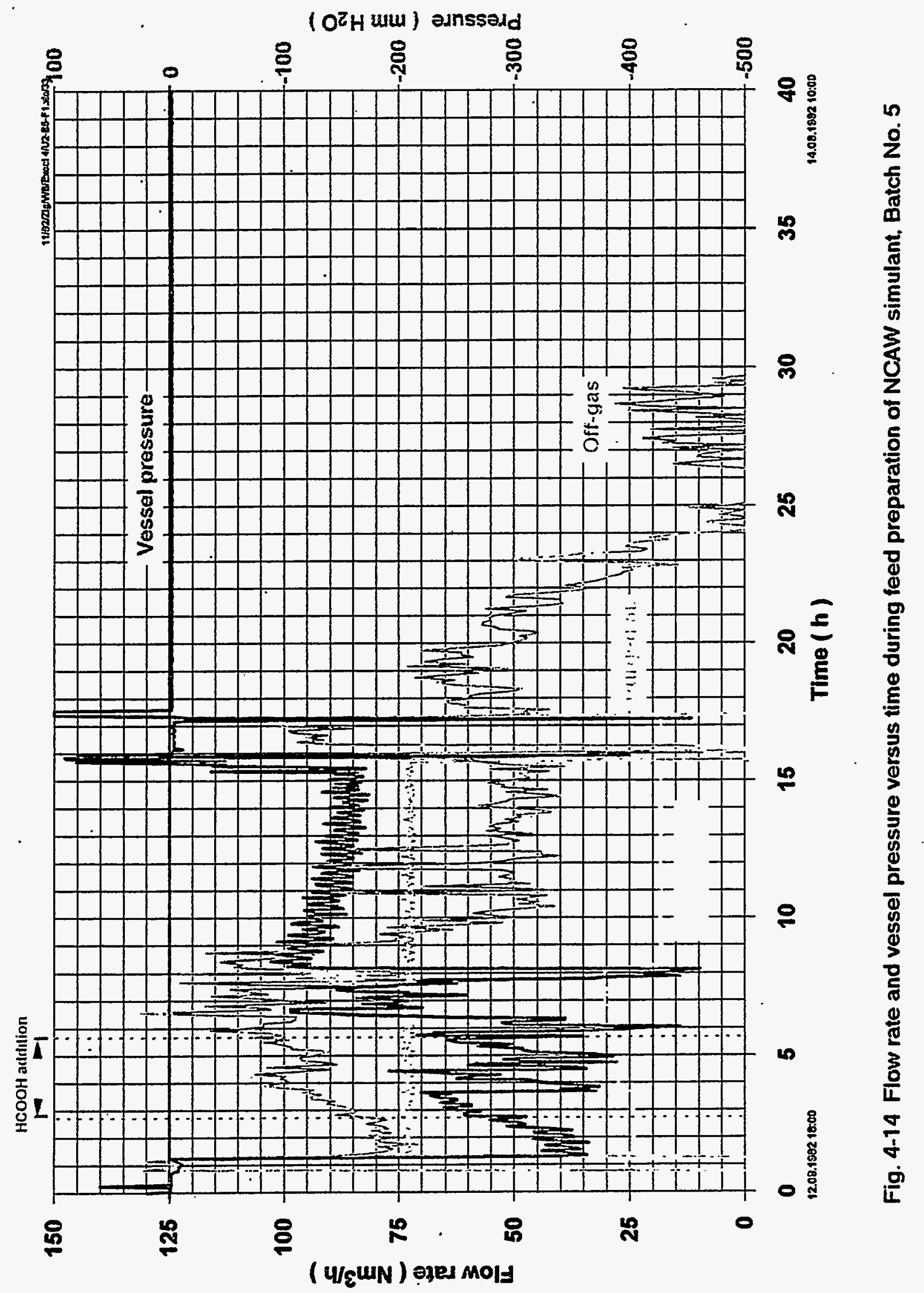




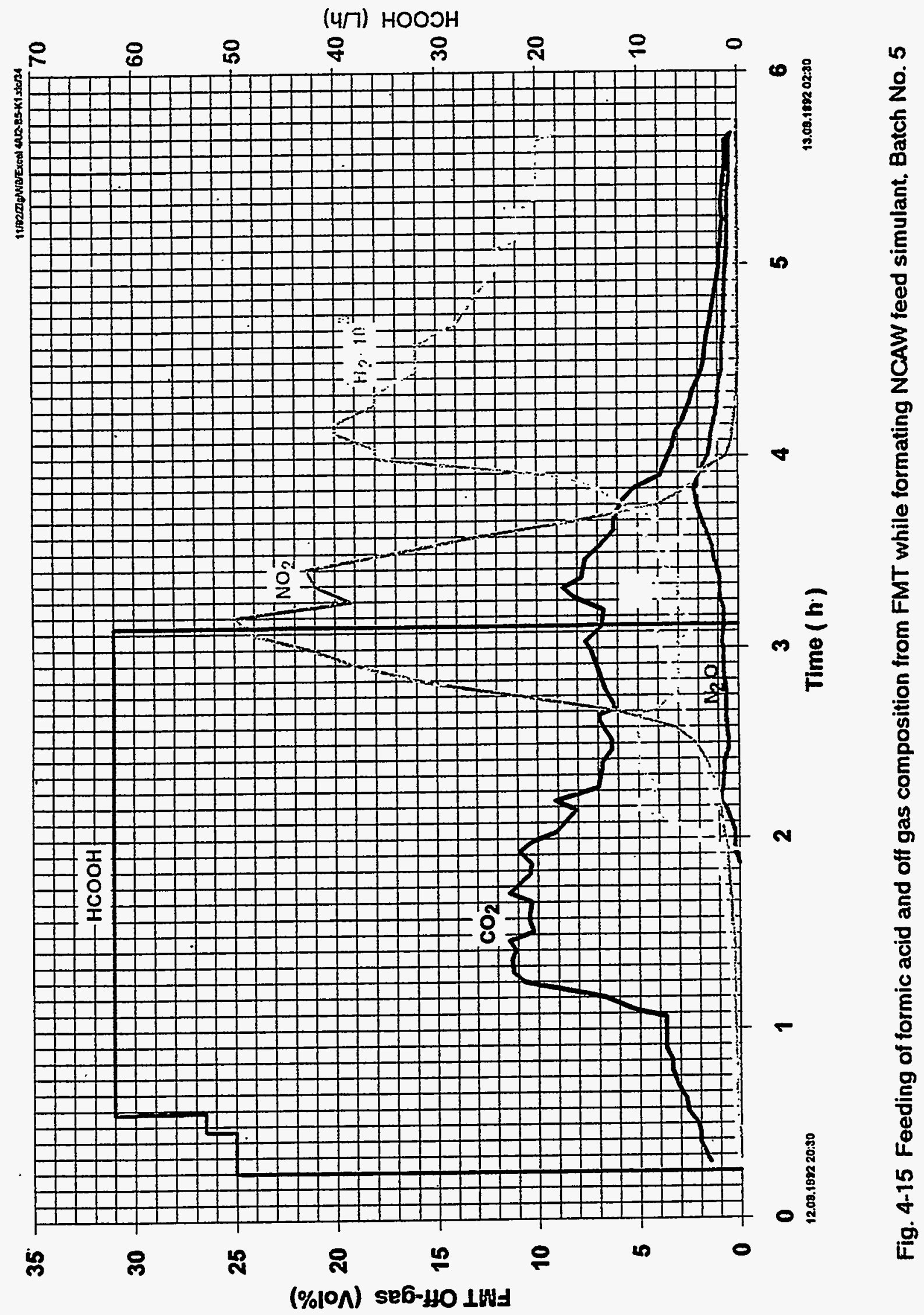




\subsection{Melter operation}

Two vitrification runs have been performed with the ESM-melter. The first one designated U1 served as a shake down test for the new facility and components, respectively. For this purpose $2.61 \mathrm{~m}^{3}$ of non noble metal containing NCAW-simulant have been prepared and continously vitrified. Based on the operation experiences gained the subsequent noble metal test, designated $U 2$, could be started. The operation work in both campaigns had been strongly supported by personel of PNL. Additionally, DOE-Richland Operations, Westinghouse Hanford Company, and SRS delegates took part for some time in the operation. Due to the lower feeding rate of $12-15 \mathrm{l} / \mathrm{h}$ compared to the design value of $20 \mathrm{~J} / \mathrm{h}$, the overall operation time exceeded the scheduled 30 days significantly. The main tasks, however, could be well finished.

Table 4-I gives the overall data for both runs. After termination of the run U2 the melter was drained out via the bottom drain in order to determine a possible accumulation of noble metal enriched glass in the bottom area of the melter tank. The melt tank then was refilled with non noble metal containing glass (black frit) to the top level of the lower electrode pair and set to idling conditions.

\subsubsection{Test run U1}

This test run has been mainly performed to obtain the main operation parameters of the melter. This includes the power input to the electrodes, to the booster heaters in the melter plenum, and to the RHF-heaters in the overflow section. Also, the optimum underpressure level for glass pouring via the overflow system had to be determined and the melter feed preparation, the feed transfer and the feeding system tested. The plant was continuously operated in the test phase U1 from July 2,1992 , to July 11 around the clock.

The overview data for the U1 run indicating the melter function are shown in an operational diagram (Figs. 4-16 and 4-17). The upper part of the figure shows the individual and total power supply to the melt, and also the power released by the plenum heaters, all versus the operation time. In the second part of the figure the feed rate to the melter is plotted. The red color indicates NCAW simulant feeding and the blue one water feeding, when f.e. in a time period the feed line was plugged. The feed rate could not be measured directly due to the difficult flow properties of the slurry. Instead, it had been calculated in the U1 run by the level change in the MFT every four hours. The data were compared with a condensate balance made every 8 hours. For the level detection in the MFT and 

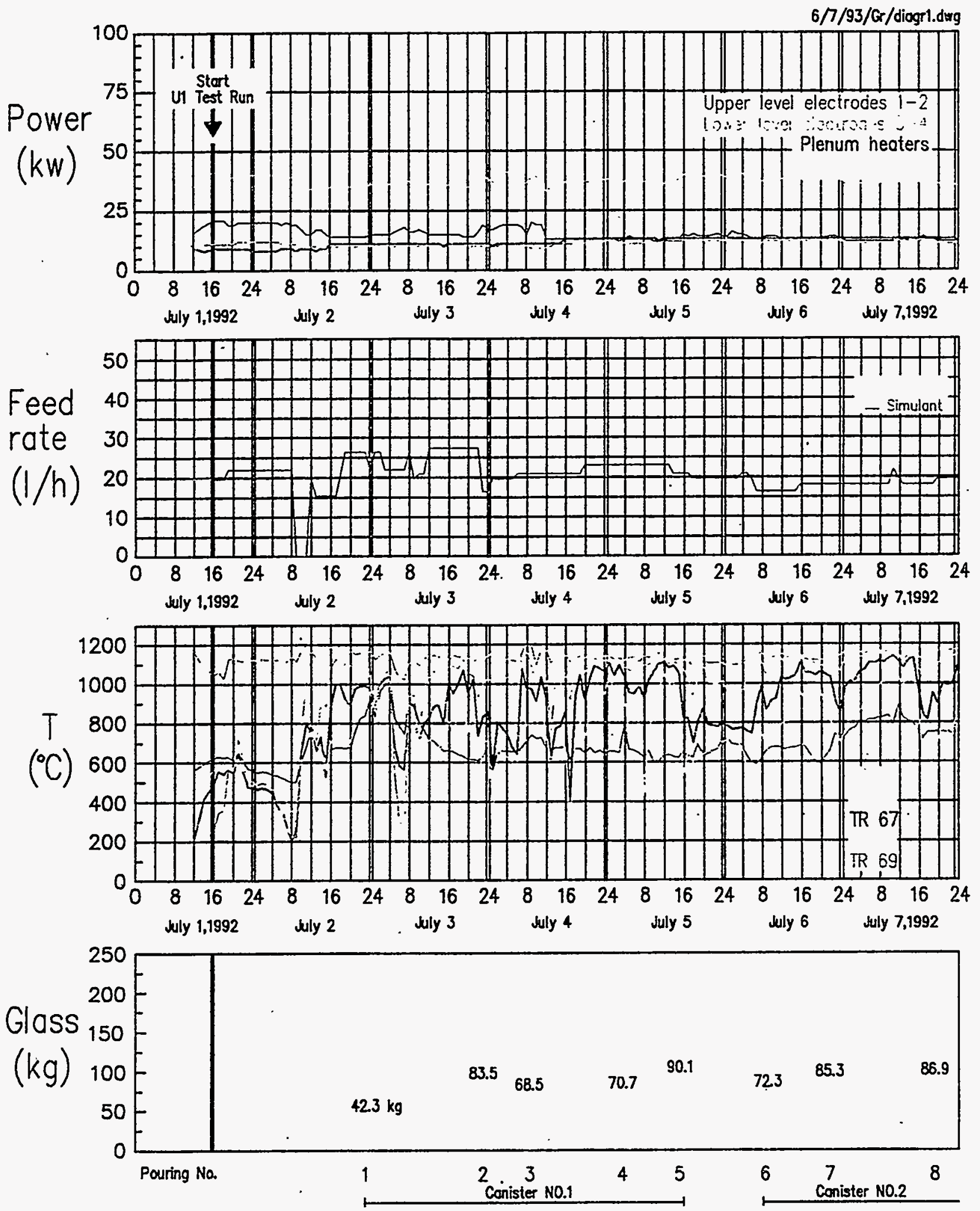

Fig. 4-16: Operational diagram for the first week of the ESM compaign U1 

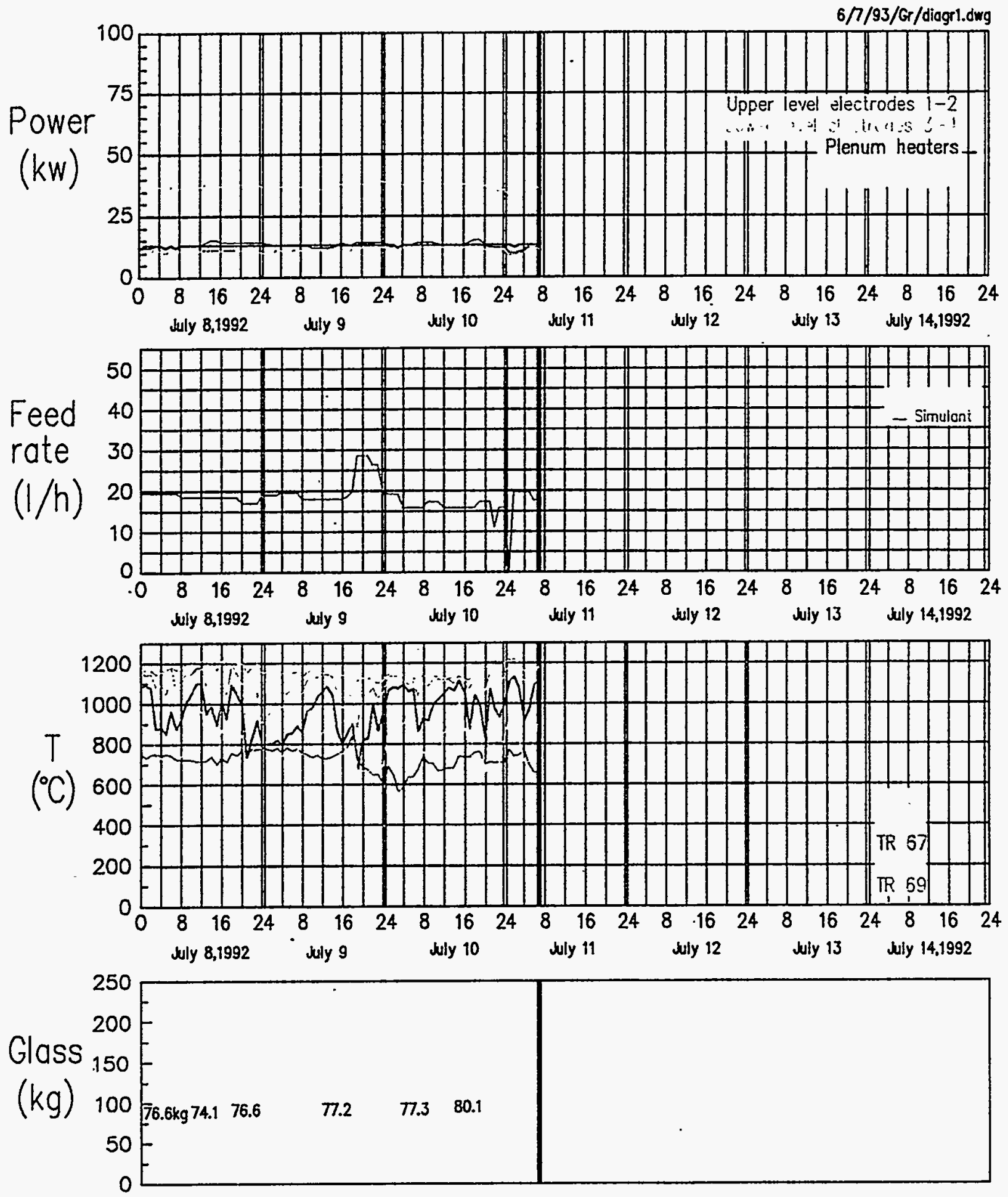

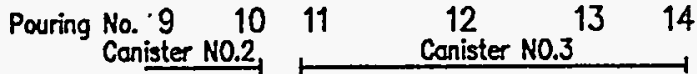

Fig. 4-17: Operational diagram for the second week of the ESM campaign U1 
FMT, dip tube-measurements were used during the run $\mathrm{U} 1$ and also at the beginning of the run $\mathrm{U} 2$. This caused additional problems due to the slurry properties. Later during the run U2 the dip tubemeasurement devices were replaced by a better working ultra-sonic system (Manuf. Co. VEGA Grieshaber GmbH\&Co, 7622 Schiltach/Schwarzwald, Model: Vegason 72-2). The precision of the feeding rate indicated in the figures 4-16 and 4-17 is in a range of 10-20\%.

In the third part of the figures, five melter temperatures reflecting the main melter operation conditions are shown. They were measured by different thermocouples placed in one thermowell. The thermowell was inserted through the melter roof up to the bottom of the tank. The exact location of the thermocouples has been shown already in Fig. 3-10. This selection of the temperatures gives the central glass temperature (TR.65), the melter plenum temperature (TR.69) and temperatures at the minimum, middle and maximum melt level. With this arrangement of temperature monitoring points each glass level change, for example due to glass pouring, can be observed indirectly by the typical change of these temperatures (see later Fig. 4-28). In the fourth subdiagram of the figs. 4-16 and 417 the glass filling batches are listed. The glass weight indicated includes the glass samples taken during the filling.

For start up of the run U1 the plenum heaters had been set to about $950^{\circ} \mathrm{C}$ consuming $10 \mathrm{~kW}$. The glass pool temperature was kept between $1150-1200^{\circ} \mathrm{C}$. The power release of the upper electrode pair was typically $10-12 \mathrm{~kW}$, and of the lower electrodes 8-10 kW. A water feed rate of 20 to $25 \mathrm{l} / \mathrm{h}$ was used before start up of the U1 run with NCAW melter feed. The off gas line was adjusted to an underpressure in the ESM plenum of about $10 \mathrm{~mm}$ water column. Due to the evaporation of the water, the power input had to be increased to keep the bulk glass temperature between $1150-1200$ ${ }^{\circ} \mathrm{C}$. The water feeding finally was switched to $15 \mathrm{l} / \mathrm{h}$ NCAW melter feed simulant as can be seen in Fig. 4-16.

During this pretest the feeding rate for non noble metal slurry could be kept at around $16 \mathrm{l} / \mathrm{h}$ maximum. But the target of $20 \mathrm{~V} / \mathrm{h}$ could not reached. Apart from this, the only real problems were caused in the feeding area due to failures of pumps and plugging of the feed line between the MFT and the ESM. As a consequence, a strainer was fixed between FMT and MFT and the Moyno cavity pumps supplied for use from US were replaced by Alldos diaphragma pumps (model: KM 2541.9901). Because of the relatively low throughput level of the ESM these pumps worked at their minimum range $(20 \mathrm{l} / \mathrm{h})$. Their total range is $20-100 \mathrm{l} / \mathrm{h}$. Small changes necessary for feeding rate adjustments were difficult to handle.

During the U1 run three canisters have been filled by 14 pouring operations. Each batch filling had a target of $75 \mathrm{~kg}$. The operation mode for the overflow system was developed as follows: 
- Indication of the melt level by comparison of the mass balance for the ESM and a level measurement from the melter top

- Connecting the canister airtight to the overflow housing flange

- Operating the vacuum air jet at an underpressure of about $300 \mathrm{~mm}$ water column (to initiate and maintain a desired glass flow rate of about $50-70 \mathrm{~kg} / \mathrm{h}$ )

- Controlling the canister filling weight by subtracting the vacuum effect on the loadcells of the canister car

- Glass sampling according to the schedule (five samples per pour)

The operation mode described above was improved during the first glass pourings in order to control the pouring rate and the actual amount of glass in the canister as accurate as possible. The total amount of glass for each batch was precisely indicated after disconnecting the canister from the overflow housing flange.

The offgas-system worked very satisfying. To prevent a plugging of the off gas tube which connected the ESM exit with the dust scrubber two millisecond supersonic air blasters have been operated every 8 hours. At the end of the run the tube was very clean and no layer of particulates could be seen. Every day liquid samples have been taken from the scrub solutions of the off-gas cleaning components. On July 11 , the run $U 1$ was completed having vitrified $2.61 \mathrm{~m}^{3}$ of the noble metals free NCAW simulant. The melter then was kept under processing conditions for several hours by feeding water to the melter.

\subsubsection{Test run U2}

The noble metal run U2 started on July 11, 1992, a few hours after the pretest U1 was finished. The overview data are given in the operation diagram shown in the figures 4-18 to 4-25. The "total power" indicated in the figures is the sum of the two electrode sets and the plenum heaters. The feeding curve of this run shows in its early stage still a number of feed stops. Two major reasons caused the interruptions:

- In order to reach the target feeding rate of $20 \mathrm{l} / \mathrm{h}$ the melter was operated at its maximum glass production capacity. As a consequence the glass pool surface tended to become flooded very quickly and easily. This appeared to be the result of a thick, rigid cold cap as discussed in the summary. The cause of this cold cap is not clear. 

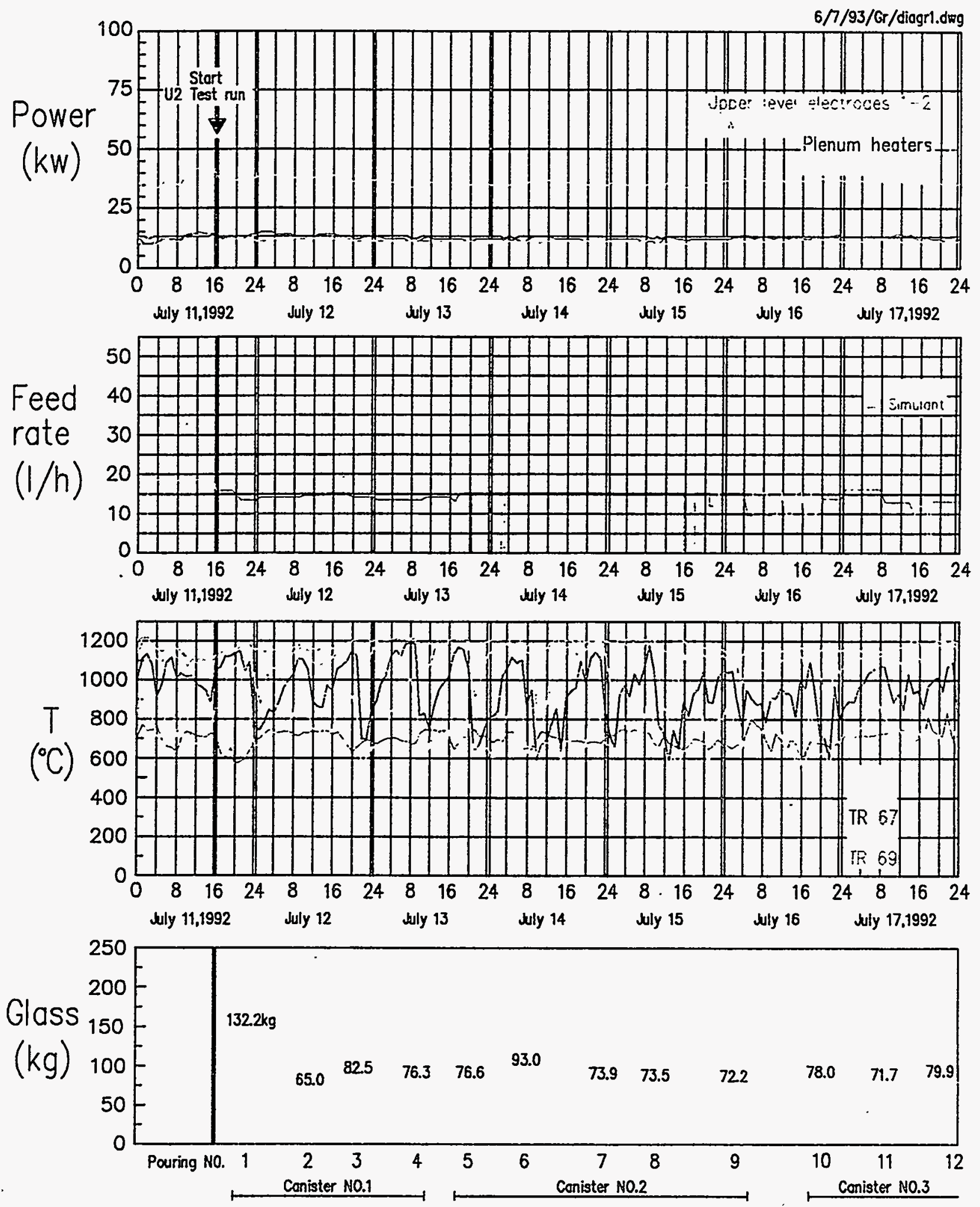

Fig. 4-18: Operational diagram for the first week of the ESM test run U2 

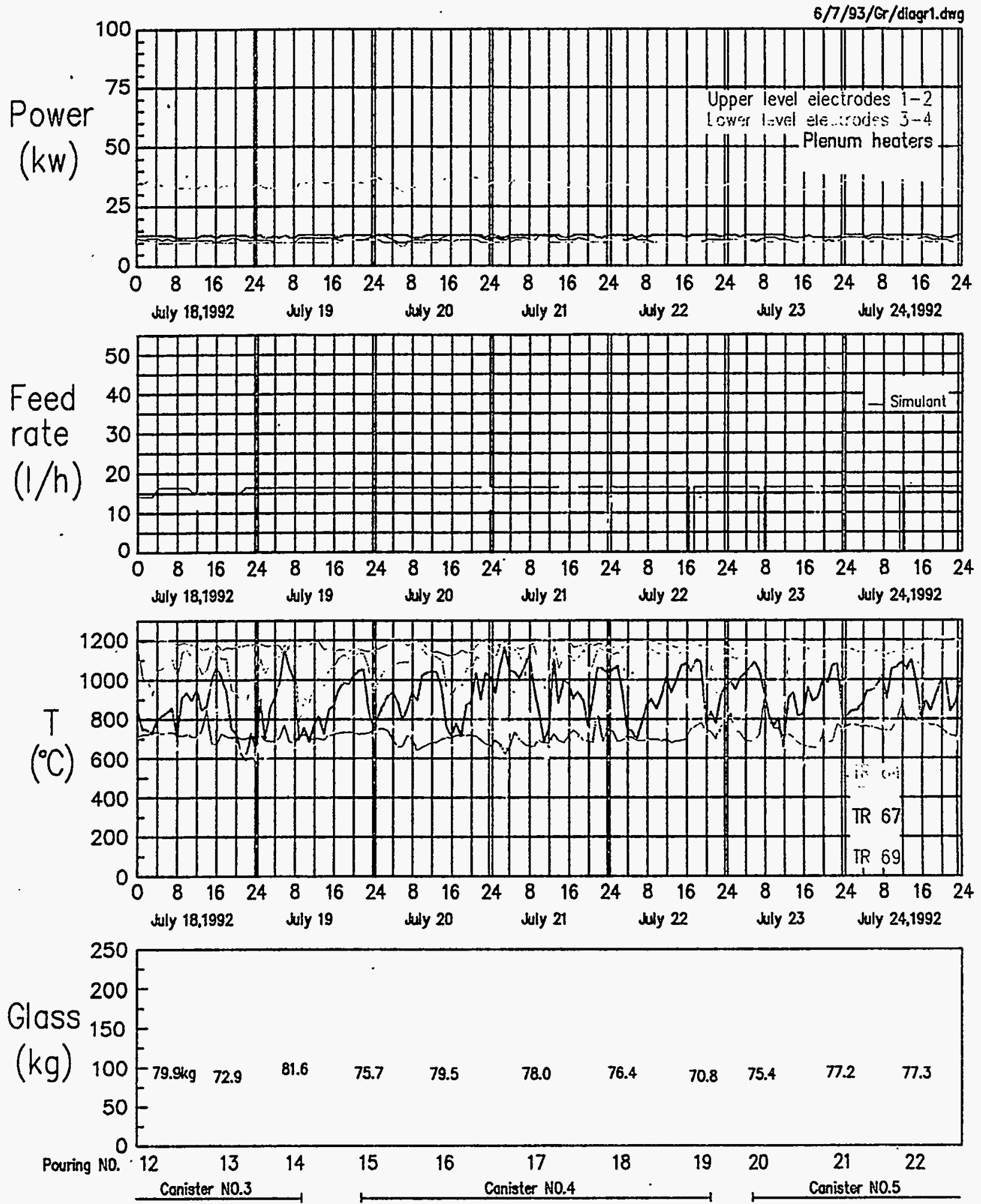

Fig. 4-19: Operational diagram for the second week of the ESM test run U2 

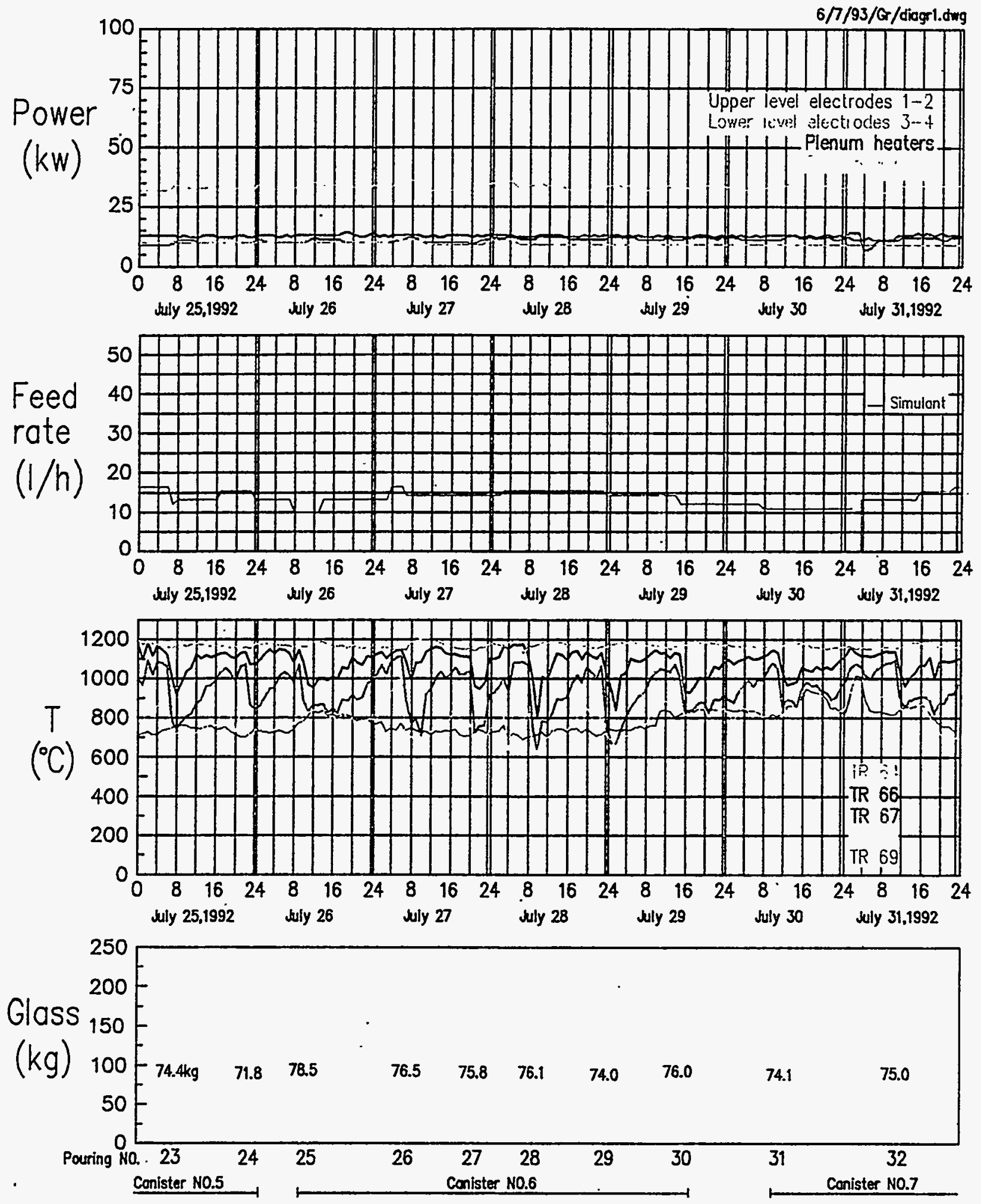

Fig. 4-20: Operational diagram for the third week of the ESM test run U2 

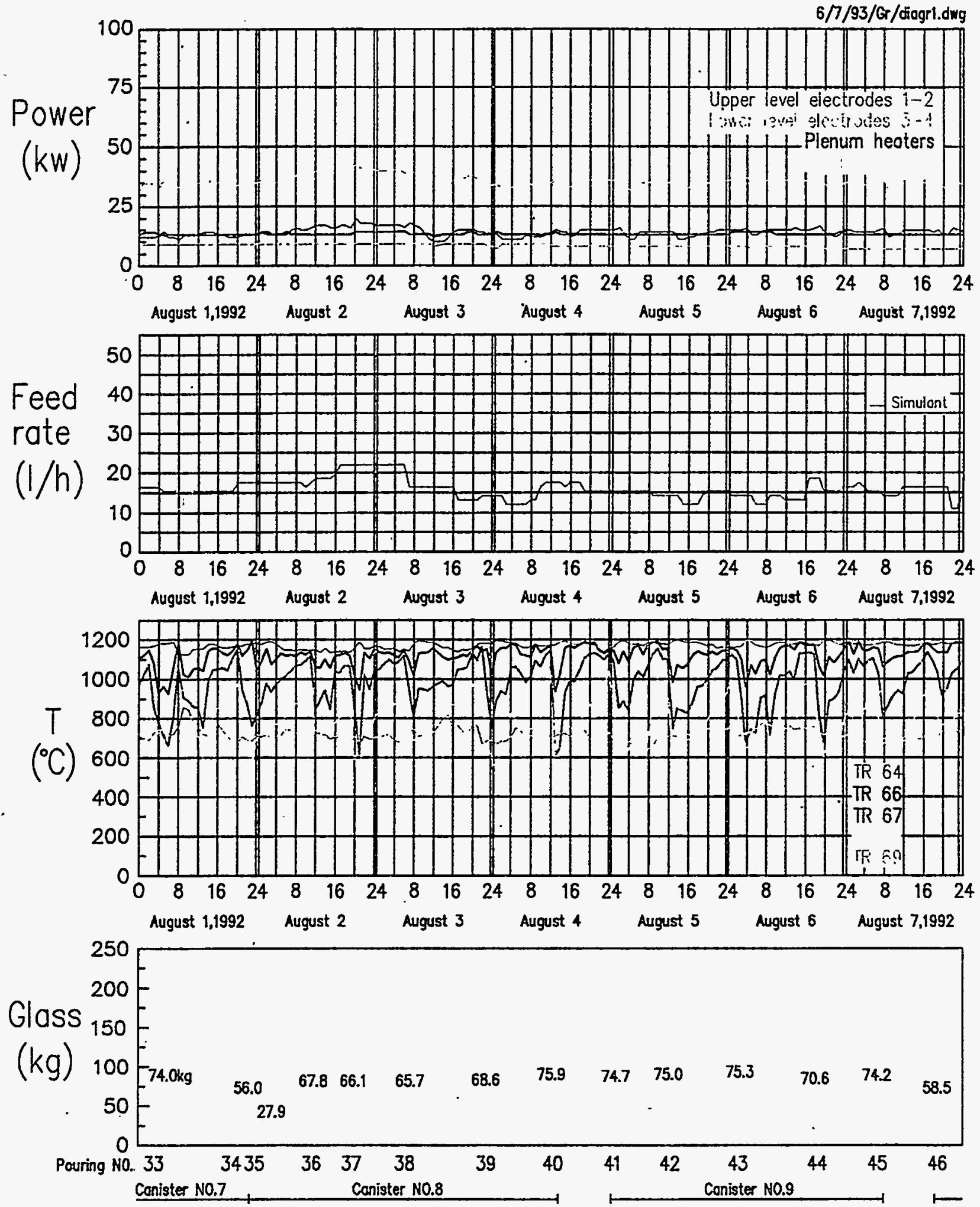

Fig. 4-21: Operational diagram for the fourth week of the ESM test run U2 

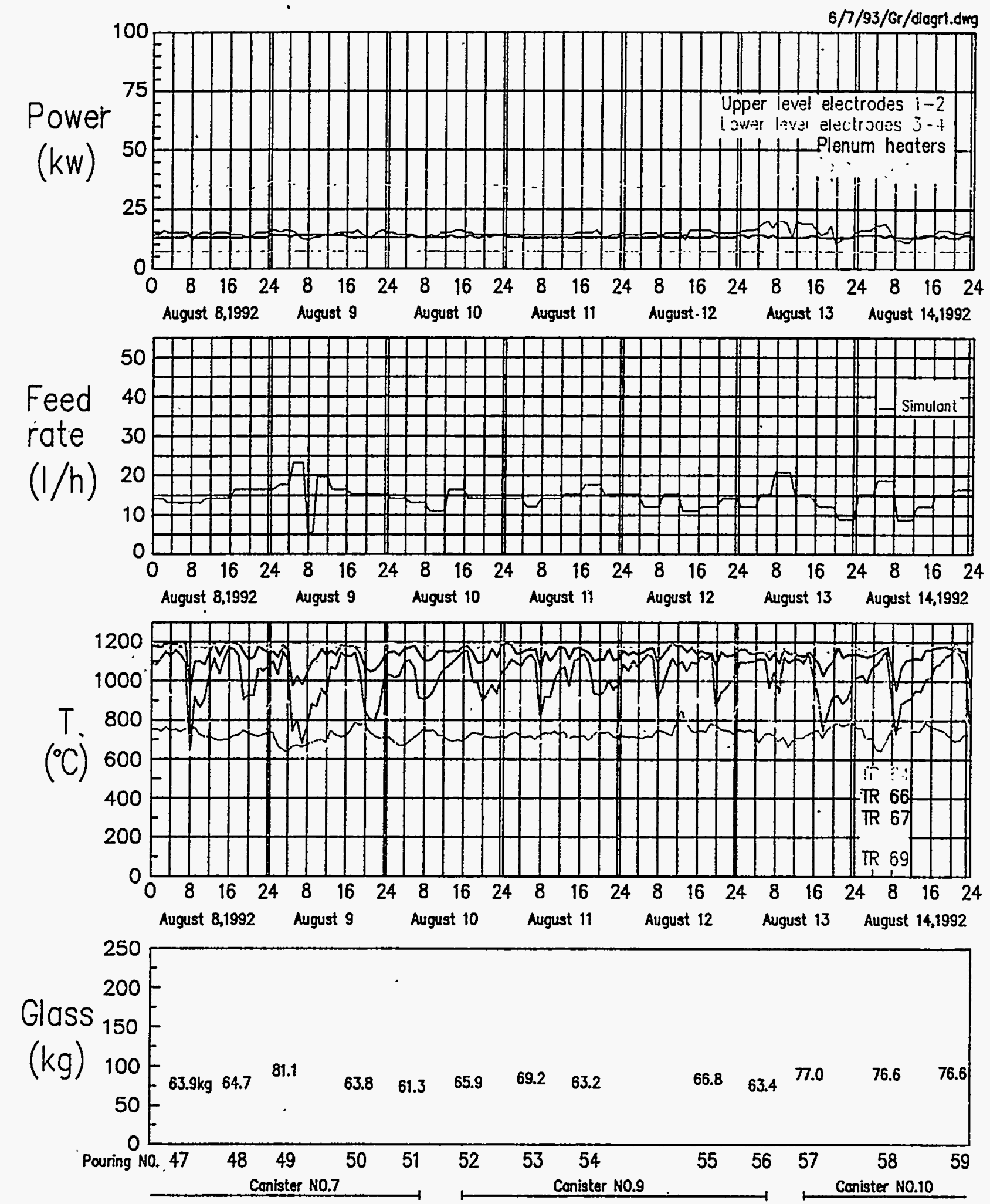

Fig. 4-22: Operational diagram for the fith week of the ESM test run U2 


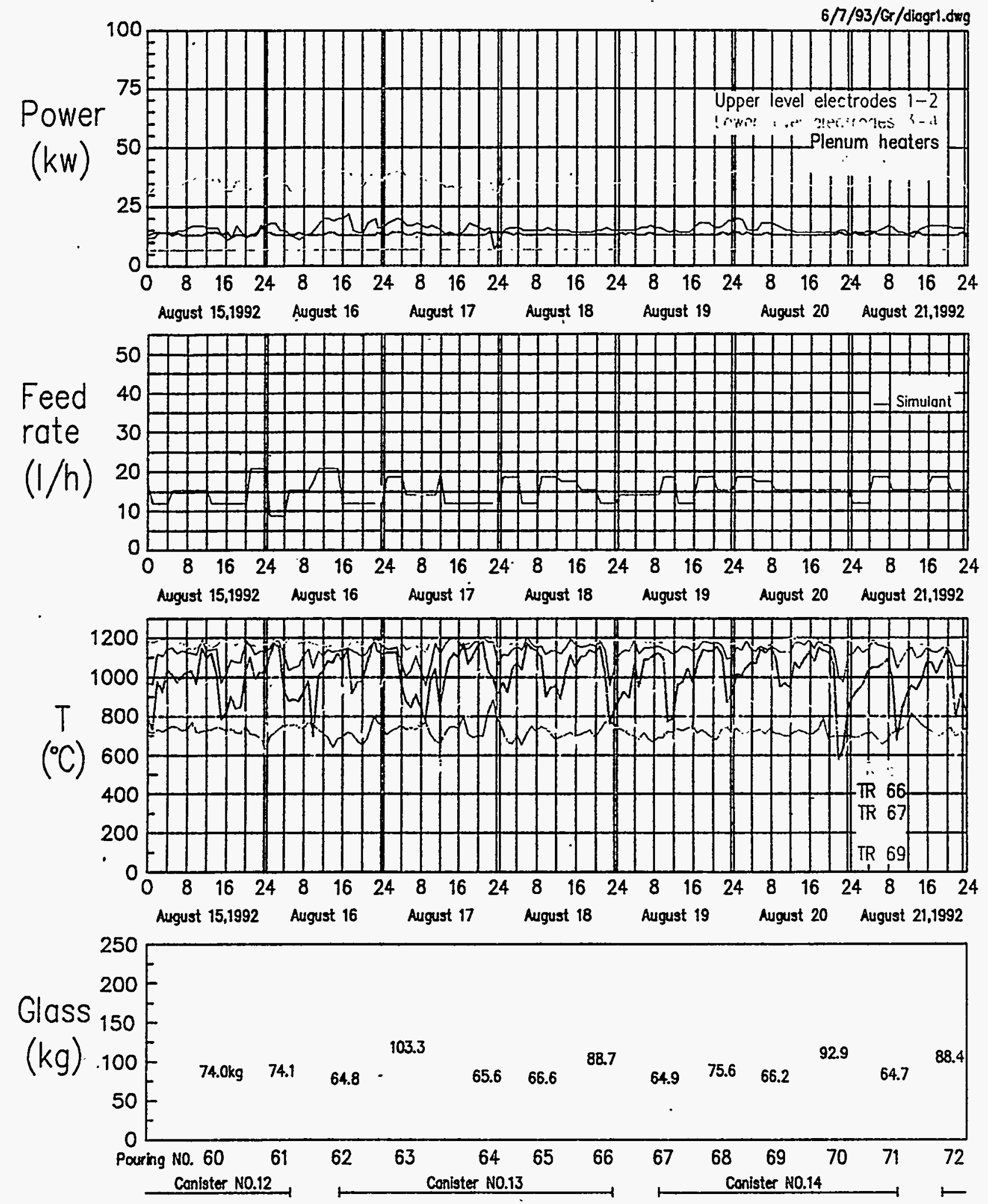

Fig. 4-23: Operational diagram for the sixth week of the ESM test run U2 

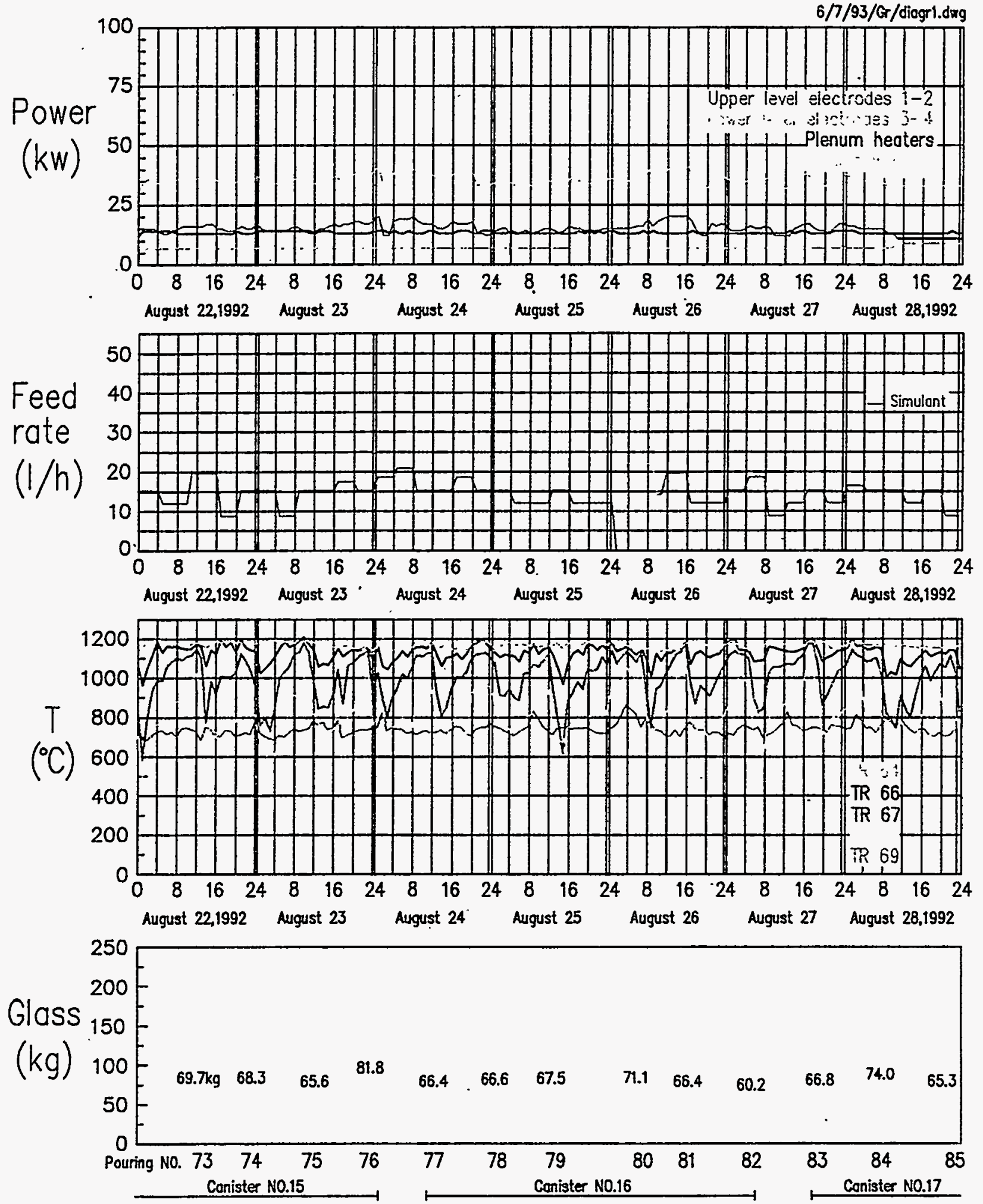

Fig. 4-24: Operational diagram for the seventh week of the ESM test run U2 

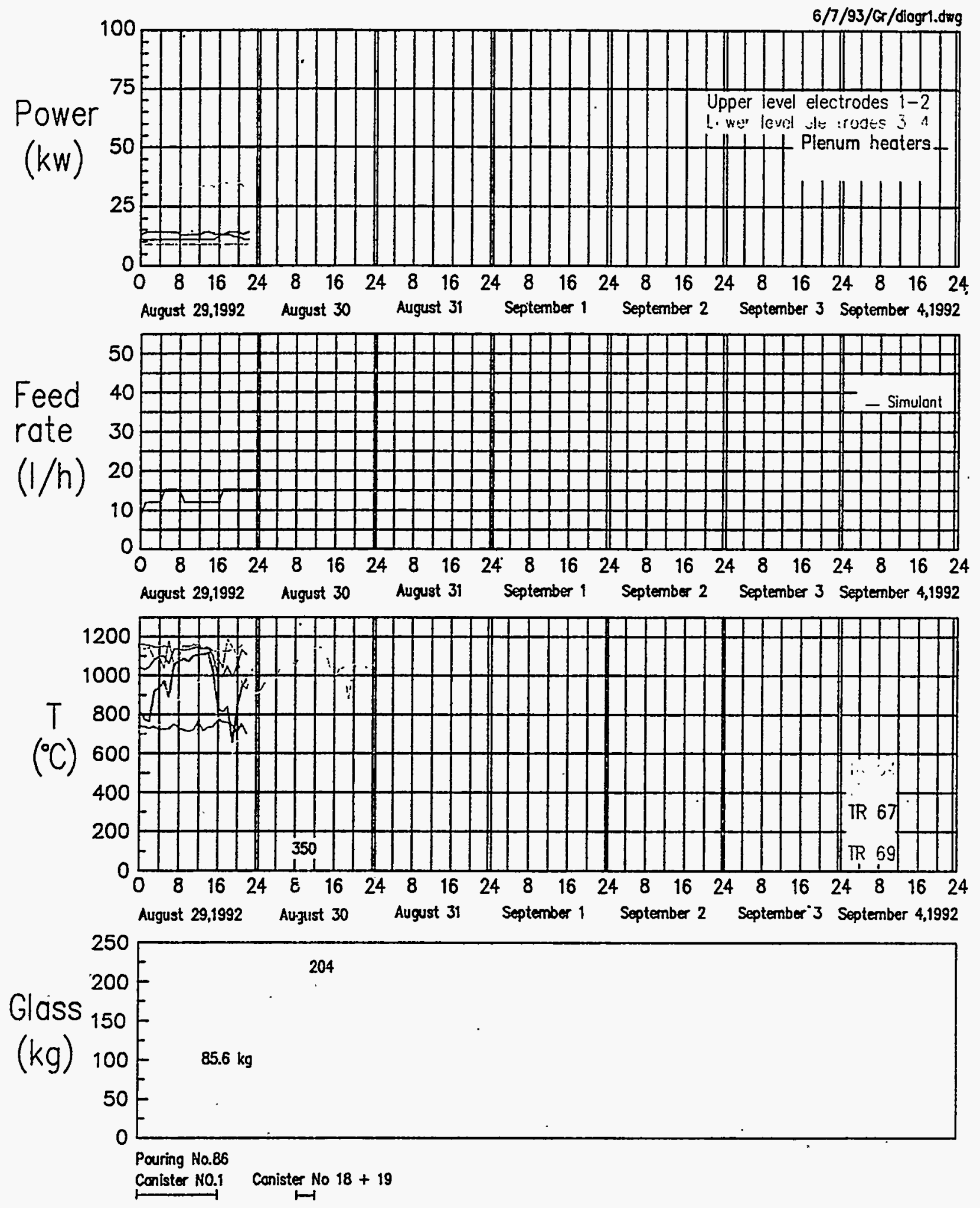

Fig. 4-25:- Operational diagram for the eigth week of the ESM compaign U2 
- Problems with the feeding system, mainly caused by undissolved particles in the NCAW melter feed, plugged the pumps and the feed line. One of these blockages was analyzed and found to be lanthanum flouride particles.

The feed stops are listed in Tab. 4-VIII. Although a strainer was used in the transfer line between the FMT and MFT to retain larger particles, and the flow properties of the slurry were controlled either by adjusting its $\mathrm{pH}$ values with nitric acid, or adding water the number of the feed stops could be reduced but not entirely avoided.

The total power input to the melter was about $35 \mathrm{~kW}$ in the average including the plenum heaters. The power distribution between the upper and the lower pairs of electrodes in the early stage of the run, was 12.5 to $11 \mathrm{~kW}$. It was then gradually changed up to $550 \mathrm{~h}$ of operation time to a ratio of 15 to $7.5 \mathrm{~kW}$, in order to increase the feeding capacity to the target. Additionally the melt level was increased to the maximum, and for minimizing the glass level change, the number of batch fillings per canister was set from 5 each $(75 \mathrm{~kg})$ to 6 each $(60 \mathrm{~kg})$. Despite all these efforts the actual maximum feed rate was about $16 \mathrm{l} / \mathrm{h}$. The target of $20 \mathrm{l} / \mathrm{h}$ could not be achieved. It is difficult to determine the reason for the poor processing rates of this feed. One of the most visable differences between this feed and previous HWVP feeds is the higher viscosity and yield stress of the current formulation. The slurry does not spread easily over the cold cap. The resulting cold caps are thick and rigid with few active vents. It is beyond the scope of this activity to determine the reason for this higher viscosity, but the reason appears to be either the frit or the recycle chemicals. The slurry is easily pumped before formating. After the addition of the recycle chemicals and frit, the $\mathrm{pH}$ of the slurry rises and the viscosity steadily increases. After formating, the $\mathrm{pH}$ of the slurry was usually about $6-8$. Within 72 hours, the $\mathrm{pH}$ usually rose above 9 and the slurry became more difficult to pump. Nitric acid was added to Batches 2, 3 and 5 to bring the $\mathrm{pH}$ value back down to 7 . This helped the viscosity temporarily, but the $\mathrm{pH}$ had risen again within 6 days. Later in the run, Batches 3,4 and 5 , water was used to dilute the slurry to make it easier to pump. The batches were diluted down to $475 \mathrm{~g} \mathrm{TO} / \mathrm{L}$. This reduced the number of feed line blockages and made the slurry more spreadable over the cold cap.

After about $550 \mathrm{~h}$ of $\mathrm{U} 2$ test operation, the dip tube-measurement in the MFT could be replaced by an ultra sonic system. So the feeding rate could be determined more accurately as shown in Fig. 4-26. The overall feeding data versus the run time are given in Tab. 4-VII. These numbers have been calculated by the level changes measured in the FMT and MFT according to Fig. 4-27. In total 14.23 $\mathrm{m}^{3} \mathrm{NCAW}$ melter feed simulant was fed to the melter with feed rates between around 12 to $15 \mathrm{l} / \mathrm{h}$. 


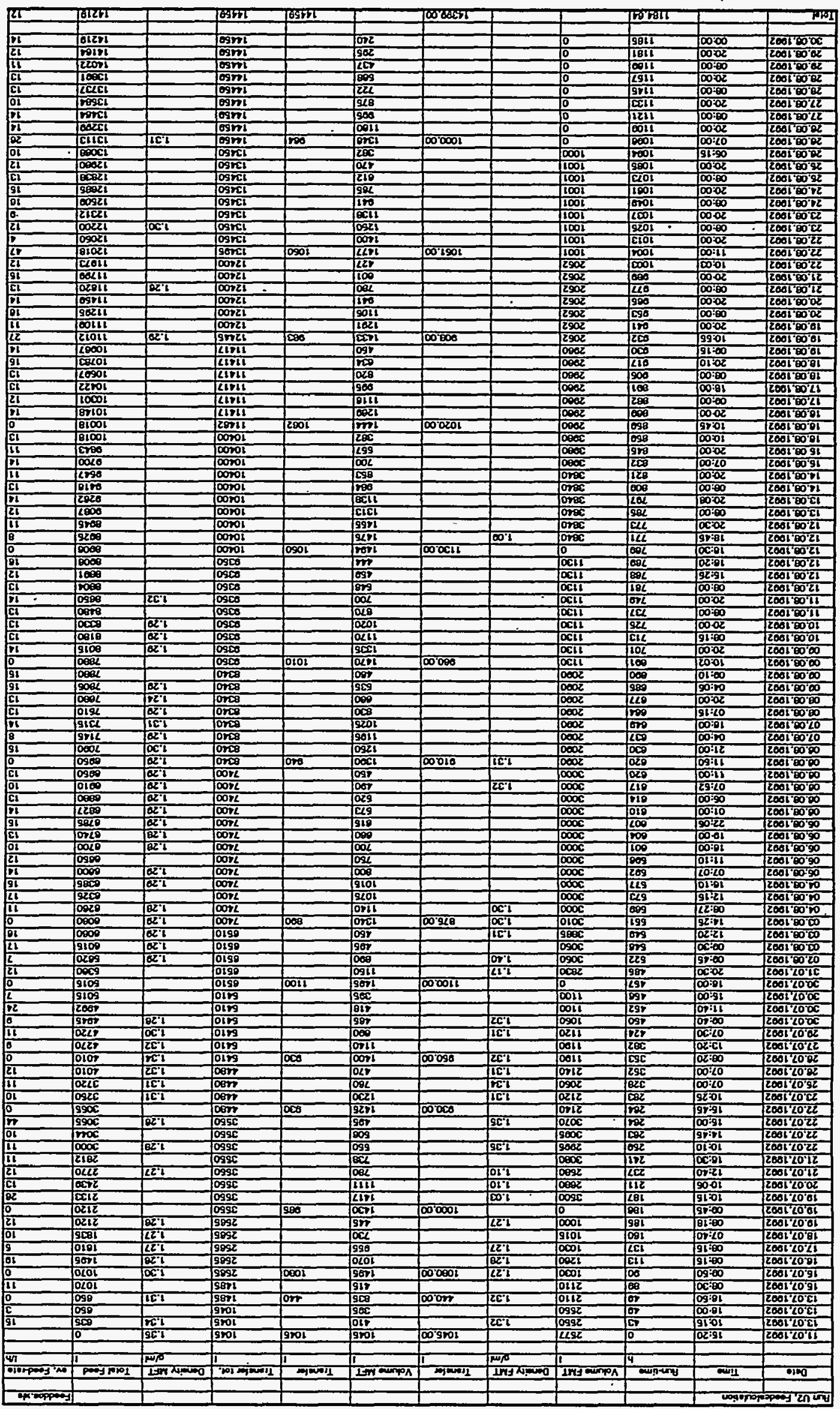

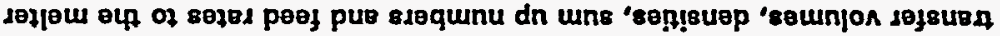

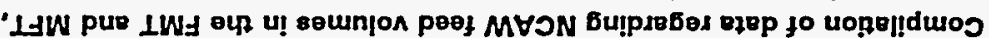


Table 4-VIII

List of events and distortions experienced during the noble metal test run U2. Time periods of NCAW simulant feeding off are indicated including reasons for

\begin{tabular}{|c|c|c|c|}
\hline Foodrenpen & Time Off & Time On & Problem \\
\hline & & $\cdot$ & \\
\hline \multirow[t]{4}{*}{13.07 .1992} & & $15: 00$ & Addition of $61.8 \mathrm{~kg} \mathrm{HNO} 3(65-\%)$ to FMT \\
\hline & $17: 10$ & $17: 43$ & ALLDOS Pump KM263 foed rate tost \\
\hline & $17: 50$ & $18: 35$ & Feed line plugged, solids H2O T-junetion \\
\hline & $19: 50$ & $20: 20$ & Pool surface totally flooded \\
\hline \multirow[t]{2}{*}{14.07 .1992} & $02: 55$ & $03: 30$ & Pool surface totally flooded \\
\hline & $10: 24$ & $10: 50$ & Flow melter installation \\
\hline \multirow[t]{2}{*}{15.07 .1992} & $16: 35$ & $17: 00$ & Pool surface totally flooded \\
\hline & $20: 15$ & $22: 25$ & Feed line plugged \\
\hline \multirow[t]{7}{*}{16.07 .1992} & $.04: 28$ & $05: 13$ & Pool surface totaliy flooded \\
\hline & $05: 30$ & $06: 25$ & Feed nozzle plugged \\
\hline & $07: 08$ & $07: 43$ & ALLOOS Pump KM263 feed rate test, foed line plugged \\
\hline & $09: 35$ & $11: 05$ & Pool surface totally flooded \\
\hline & $12: 30$ & $14: 20$ & Pool surface totally flooded \\
\hline & $16: 30$ & $17: 35$ & Pool surface totally flooded \\
\hline & 18:00 & $19: 30$ & ALLDOS Pump KM263 foed rate test \\
\hline 17.07 .1992 & $14: 40$ & $18: 14$ & Pool surfaco totally flooded \\
\hline \multirow[t]{2}{*}{18.07 .1992} & $11: 40$ & $12: 50$ & Pool surfaco totally flooded \\
\hline & $16: 00$ & $17: 00$ & Pool surface totally flooded \\
\hline \multirow[t]{3}{*}{20.07 .1992} & $05: 35$ & $07: 30$ & Feed line plugoed \\
\hline & $07: 40$ & $07: 50$ & Fead nozzlo plugoed \\
\hline & $22: 46$ & $00: 30$ & Pool surface totally flooded \\
\hline \multirow[t]{3}{*}{21.07 .1992} & $02: 40$ & 05:00 & Pool surface totally flooded \\
\hline & $14: 25$ & $17: 00$ & Pool surface totally flooded \\
\hline & $23: 00$ & $00: 02$ & Pool surface totally flooded \\
\hline \multirow[t]{5}{*}{22.07 .1992} & $00: 45$ & $01: 05$ & Pump ball valvo plugged \\
\hline & & $14: 45$ & 100 I wator addition to FMT \\
\hline & $15: 20$ & $16: 22$ & Feed nazzlo plugged \\
\hline & $17: 45$ & $18: 25$ & Feed line plugged, solids H2O T-junction \\
\hline & $22: 33$ & $23: 15$ & Foed line plugoed, solids $\mathrm{H} 2 \mathrm{O}$ T-junction \\
\hline \multirow[t]{3}{*}{23.07 .1992} & $06: 40$ & $08: 20$ & Feed line plugoed, solids H2O T-junction \\
\hline & $18: 40$ & $19: 04$ & Pool surface totally flooded \\
\hline & $21: 42$ & $22: 45$ & Pool surfaco totaly flooded \\
\hline \multirow[t]{3}{*}{24.07 .1992} & $09: 45$ & $11: 05$ & Switched to ALLDOS pump KM251 \\
\hline & $11: 20$ & $11: 45$ & Pump plugoed \\
\hline & $11: 58$ & $12: 05$ & Pump plugged \\
\hline \multirow[t]{3}{*}{26.07 .1992} & & $02: 00$ & 1201 wator addition to FMT \\
\hline & $15: 00$ & $15: 10$ & Feed line plugoed \\
\hline & $22: 05$ & $22: 15$ & Pump plugged \\
\hline \multirow[t]{2}{*}{27.07 .1992} & & $00: 20$ & 501 watar addition to FMT \\
\hline & & $22: 15$ & 50 I water addition to FMT \\
\hline \multirow[t]{4}{*}{29.07 .1992} & $10: 18$ & $11: 25$ & ALLOOS PUmp KM263 foed rate test \\
\hline & $16: 30$ & 17:05 & Sampling line plugged \\
\hline & $18: 50$ & $19: 00$ & Feed line plugged \\
\hline & $19: 55$ & $20: 20$ & Foed nozzle plugged \\
\hline \multirow[t]{5}{*}{30.07 .1992} & & $11: 40$ & Addition of $18.4 \mathrm{~kg} \mathrm{HNO3}$ to FMT \\
\hline & & $11: 40$ & 50 I water addition to FMT \\
\hline & & $20: 20$ & 100 I wator addition to MFT \\
\hline & $21: 55$ & $22: 25$ & Failure of direct power supply \\
\hline & $23: 19$ & & Failure of direct power supply \\
\hline 31.07 .1992 & & $10: 50$ & 100 I water addition to MFT \\
\hline 01.08 .1992 & $00: 55$ & & Failure of direct power supply \\
\hline & $01: 20$ & $04: 20$ & Failure of direct power supply \\
\hline & $07: 50$ & $09: 25$ & Feed line plugged \\
\hline & $15: 15$ & $15: 50$ & Foed line plugged \\
\hline $02.08,1992$ & $03: 46$ & $03: 58$ & Foed line plugged \\
\hline 03.08 .1992 & $12: 55$ & $14: 14$ & Pool surfaco totally flooded \\
\hline & $14: 57$ & $15: 17$ & Foed line plugged \\
\hline & $19: 37$ & $20: 57$ & Foed line plupged, solids H2O T-junction \\
\hline 04.08 .1992 & $04: 35$ & $04: 55$ & Feed nozzle plugged \\
\hline & $23: 20$ & $23: 30$ & Feed nozzle plugged \\
\hline 05.08 .1992 & $08: 58$ & $09: 35$ & Pool surface totally flooded \\
\hline 06.08 .1992 & 12:10 & $12: 20$ & Feed line plugged \\
\hline & & $21: 30$ & 50 I water addition to MFT \\
\hline 09.08 .1992 & & $09: 55$ & 50 I water addition to MFT \\
\hline
\end{tabular}


Table 4-VIII

continued

\begin{tabular}{|c|c|c|c|}
\hline & $10: 06$ & $10: 16$ & Feod nozzlo plugged \\
\hline & $12: 20$ & $12: 40$ & Food nozzle plugged \\
\hline 12.08 .1992 & $12: 01$ & $13: 10$ & Foed nozzle plugged \\
\hline 13.08 .1992 & $18: 34$ & $18: 55$ & Foed nozzle plugged \\
\hline 14.08 .1992 & $14: 15$ & $14: 30$ & Foed nozzlo plugged \\
\hline \multirow[t]{2}{*}{15.08 .1992} & $06: 50$ & $08: 30$ & Feed line plugged, installation pressure gauge \\
\hline & $19: 15$ & $19: 45$ & Food nozzio plugged \\
\hline \multirow{2}{*}{16.08 .1992} & $08: 26$ & $08: 55$ & Food nozzle plugged \\
\hline & $22: 22$ & $23: 35$ & Foed line plugged \\
\hline \multirow[t]{3}{*}{17.08 .1992} & & $16: 30$ & 501 wator addition to MFT \\
\hline & $16: 25$ & $16: 45$ & Foed nozzle plugged \\
\hline & $22: 38$ & $23: 15$ & Pool surfaco totally floodod \\
\hline \multirow[t]{3}{*}{18.08 .1992} & $05: 10$ & $05: 35$ & Pool surface totally flooded \\
\hline & $06: 45$ & $07: 06$ & Foed line pluggod \\
\hline & $21: 48$ & $22: 10$ & Foed nozzlo plugged \\
\hline \multirow[t]{3}{*}{19.08 .1992} & $05: 05$ & $05: 25$ & Foed nozzle plugged \\
\hline & & $10: 55$ & 501 water addition to MFT \\
\hline & $15: 19$ & $15: 38$ & Food nozzlo plugged \\
\hline 20.08 .1992 & $18: 40$ & 19:15 & Foed line plugged, solids H2O T-junction \\
\hline \multirow[t]{3}{*}{21.08 .1992} & $03: 58$ & $04: 13$ & Feed nozzlo plugged \\
\hline & $12: 10$ & $12: 50$ & Food line plugood. solids H2O T-junction \\
\hline & $23: 09$ & $23: 43$ & Feod nozzle pl.. feod line pl., solids H2O T-junction \\
\hline \multirow[t]{2}{*}{22.08 .1992} & & $11: 05$ & 501 water addition to MFT \\
\hline & $23: 23$ & $23: 44$ & Feed nozzlo plugged \\
\hline 23.08 .1992 & & $12: 02$ & 50 / water addition to MFT \\
\hline \multirow[t]{3}{*}{24.08 .1992} & $00: 20$ & $00: 33$ & Foad nozzlo plugged \\
\hline & $01: 05$ & $01: 42$ & Foed nozzlo plugged \\
\hline & $22: 55$ & $23: 13$ & Foed nozzlo plugged \\
\hline 25.08 .1992 & $08: 10$ & $09: 05$ & Foed nozzle plugged \\
\hline \multirow[t]{4}{*}{26.08 .1992} & $02: 20$ & $03: 52$ & Foed line plugged, solid pluo of the $\mathrm{H} 2 \mathrm{O}$ T-junction \\
\hline & & $06: 05$ & 50 / wator addition to MFT \\
\hline & & $07: 00$ & 50 I wator addition to MFT \\
\hline & $07: 55$ & $09: 00$ & Foed line plugoed \\
\hline 27.08 .1992 & $12: 25$ & $12: 40$ & Feed nozzle plugged \\
\hline \multirow[t]{3}{*}{28.08 .1992} & & $08: 15$ & Addition of $12.08 \mathrm{~kg} \mathrm{HNO} 3$ to MFT \\
\hline & $02: 25$ & $02: 50$ & Foed line plugged \\
\hline & $11: 45$ & $11: 55$ & Foed nozzlo plugged \\
\hline
\end{tabular}




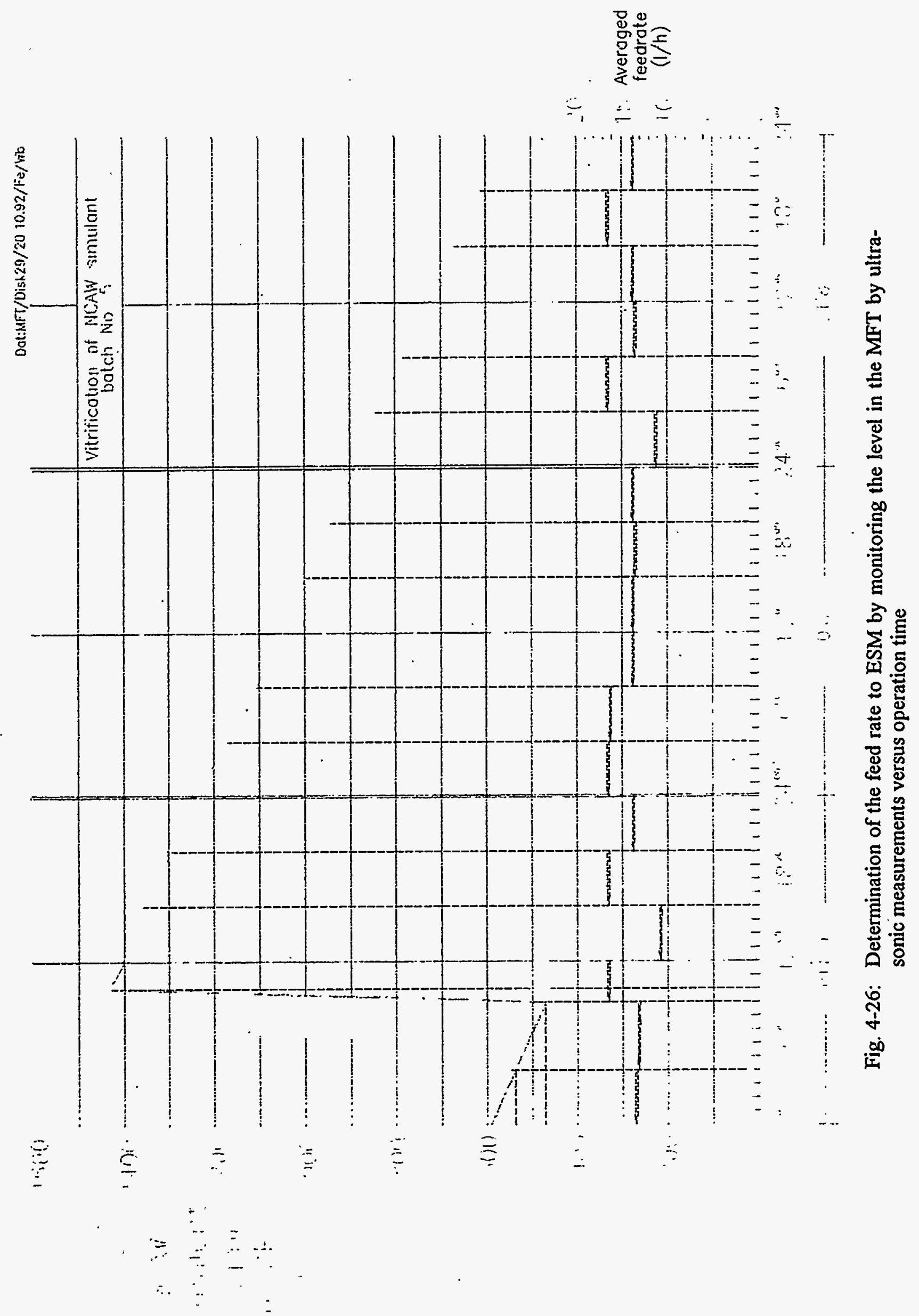



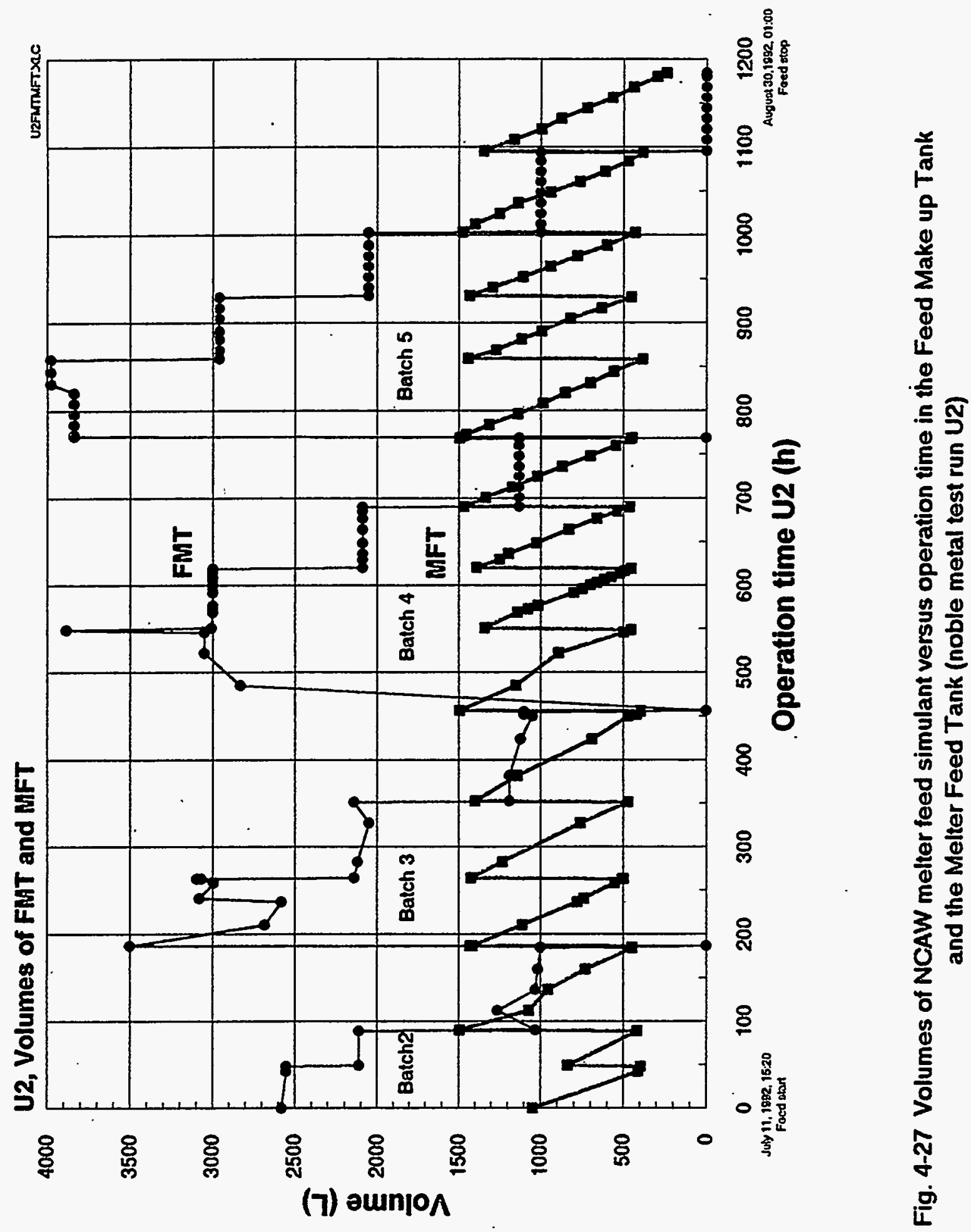
The central glass temperature was mainly kept between 1150 and $1200^{\circ} \mathrm{C}$. Fig. $4-28$ gives details about the vertical temperature distribution measured by the thermowell near the end of the run. The glass product of 6.4 metric tons produced in the run U2 was filled via the overflow system into 17 canisters by 86 pouring operations. According to the sampling schedule, more than 435 glass samples have been taken. At the end of the run the melter was set to the same processing conditions as at the beginning, especially regarding the current input data for the electrodes. Comparison of the electric data show a difference between the beginning of the noble metals test run U2 and the end. Fig. 5-17 shows the electrical resistance data calculated as V/A for the upper and the lower pairs of power electrodes versus the operation time. Additionally the current settings of the electrodes, their temperatures and the central pool temperature are plotted. Between a run time of 120 to $200 \mathrm{~h}$ at the beginning and 1140 to $1180 \mathrm{~h}$ at the end, the electrical current was the same, the temperatures even are slightly lower, but the resistance between the lower as well as the upper electrodes is lower. It has been reduced from 0.167 to $0.146 \mathrm{~V} / \mathrm{A}(87 \%)$ between the lower and 0.151 to $0.138 \mathrm{~V} / \mathrm{A}(91 \%)$ between the upper electrodes. This reduction of the electric resistance from 9 to $13 \%$ indicates a highly conductive layer reflecting an accumulation of noble metals in the bottom area. The change of the resistance after about $550 \mathrm{~h}$ operation time is due to the change of the power distribution as described above, i.e. the electric current between the upper pair of electrodes was substantially increased (from $260 \mathrm{Amp}$ into the range up to 350-400 Amp).

\section{TEST RESULTS}

\subsection{Overall test results}

The overall test results can be summarized as follows:

- $14.23 \mathrm{~m}^{3}$ of noble metal containing NCAW feed simulant have been vitrified continuously in the ESM-melter

- The electrical data of the power electrodes did not show indications for an electrically more conductive noble metal layer on the melter bottom

- Due to lower NCAW simulant feeding rates of 12-15 $\mathrm{l} / \mathrm{h}$ compared to the target of $20 \mathrm{l} / \mathrm{h}$, the average residence time of the glass and thus of the bulk of noble metals in the melter was increased from 58 hours (target) to 80 to 100 hours

- the ESM functioned satisfactorely without serious problems including glass pouring and glass sampling

- XRF measured noble metals concentrations in the glass samples had to be corrected

The overall data are given in table 5-I. 


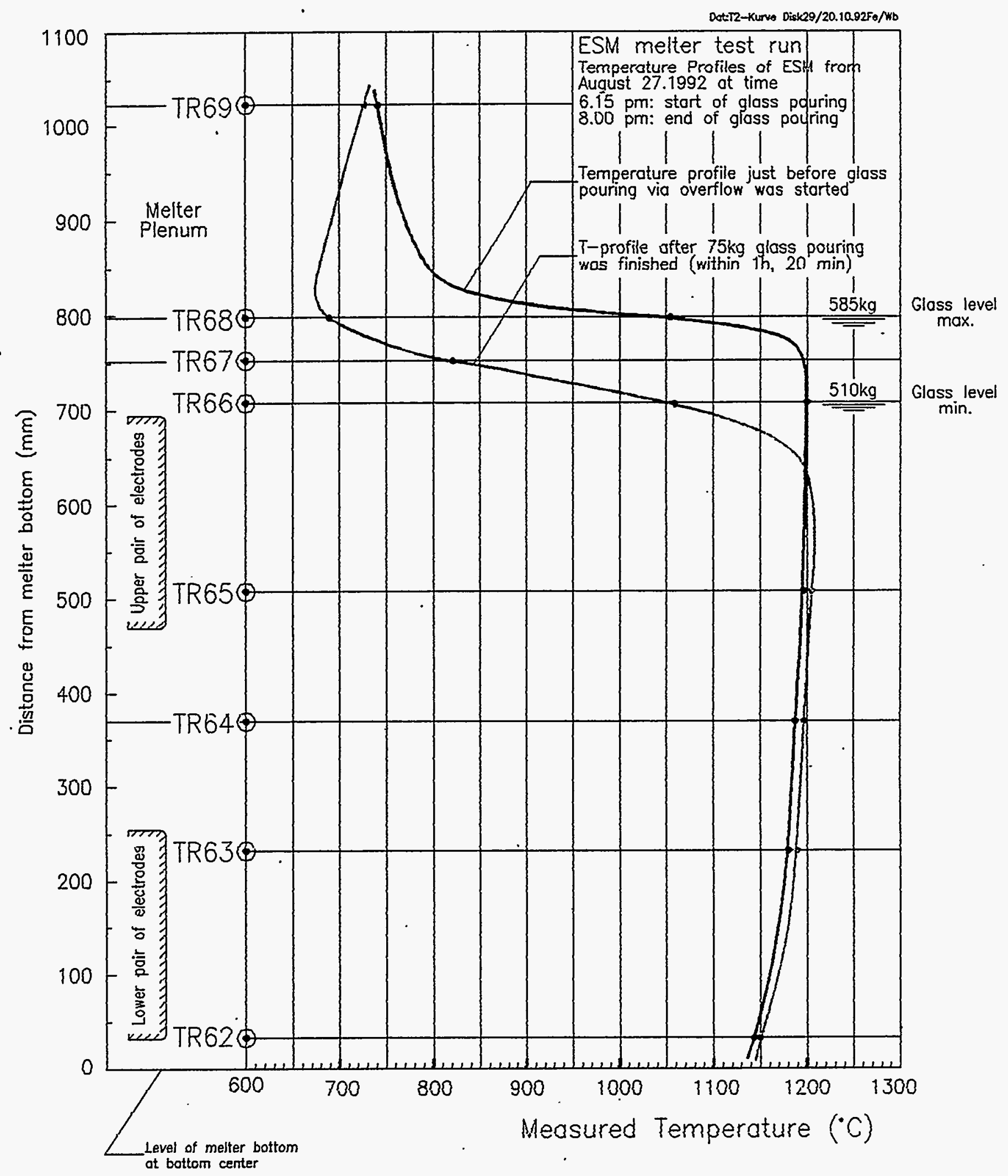

Fig. 4-28: Typical vertical temperature profile of the ESM melter during the noble metals test run. Upper curve for maximum glass level before glass pouring. The lower curve typical for minimum glass level after glass pouring 
Table 5-1: Table of test results

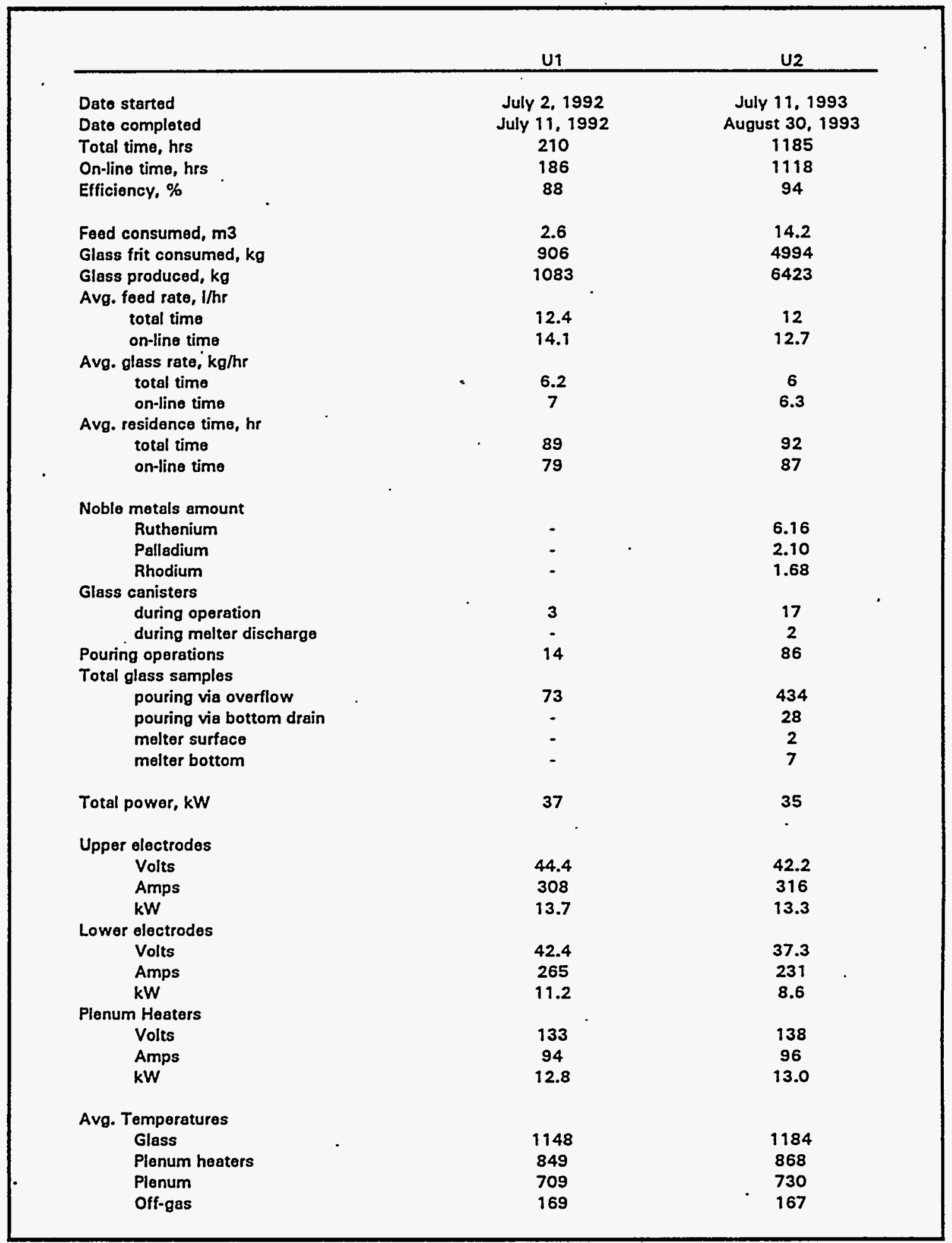

TAB5.XLS 


\subsection{Noble metals behaviour in the glass melter}

According to the noble metals concentrations in the melter feed which were $0.44 \mathrm{~g} / \mathrm{Ru}, 0.12 \mathrm{~g} / \mathrm{l}$ $\mathrm{Rh}$ and $0.15 \mathrm{~g} / \mathrm{Pd}$, the corresponding target values in the glass product were $0.115 \mathrm{wt} \% \mathrm{RuO}_{2}$, $0.030 \mathrm{wt} \% \mathrm{Rh}_{2} \mathrm{O}_{3}$, and $0.035 \mathrm{wt} \% \mathrm{PdO}$. The actual contents in the glass have been determined by analyses of samples taken from the overflow glass pouring stream.

\subsubsection{Glass sampling procedure}

Because the glass tank volume of the melter is 2201 which corresponds to about $550 \mathrm{~kg}$ glass, and pouring of the glass were carried out into canisters with $370 \mathrm{~kg}$ glass capacity, the canisters were filled in batches of usually about $70 \mathrm{~kg}$. Glass pourings were performed by the overflow system on which the canisters were airtight connected. Then an airjet generated and maintained an underpresse of $300 \mathrm{~mm}$ water colomn in the overflow/canister space for start and sustain the glass flow. The glass flow rate into the canister was about $50 \mathrm{~kg} / \mathrm{h}$. During glass pouring a special glass sampling device had to be used because the space within the overflow/canister had to be maintained at underpressure. It allowed to pick-up the sample from the outflowing glass stream. It allowed also to park them in a distinct position inside the evacuated overflow space. After termination of the pouring and disconnecting the canister from the overflow, the samples could be taken out.

Five glass samples were taken during a pouring operation. The quantity of each glass sample, in the form of a big cigar, was usually $120 \mathrm{~g}$. In same cases $400 \mathrm{~g}$ were taken to get enough material for other meausrements like viscosity and el. resistivity. From filling of a canister by 5 or 6 pourings, 25 to 30 glass samples were available for analysis. In total, more than 435 glass samples had been taken and analysed. For the analysis, about $20 \%$ of the sample mass was used. The rest of each sample was stored in a sample bank. All the sample data are given in appendix $\mathrm{C}$.

\subsubsection{Analysis procedure}

During the test run the glass analyses had been performed by the XRF method only. The glass samples were broken, milled to a fine grained powder and imbedded into wax for forming tabletts of $15 \mathrm{~mm}$ in dia and $3 \mathrm{~mm}$ thickness. After run termination, more sophisticated noble metals analysis were made in specialized institutions (see Section 5.2.3). The XRF-equipment was calibrated by specially prepared samples from the lab. They had known contents of $\mathrm{Ru}, \mathrm{Rh}$, and $\mathrm{Pd}$. The calibration 


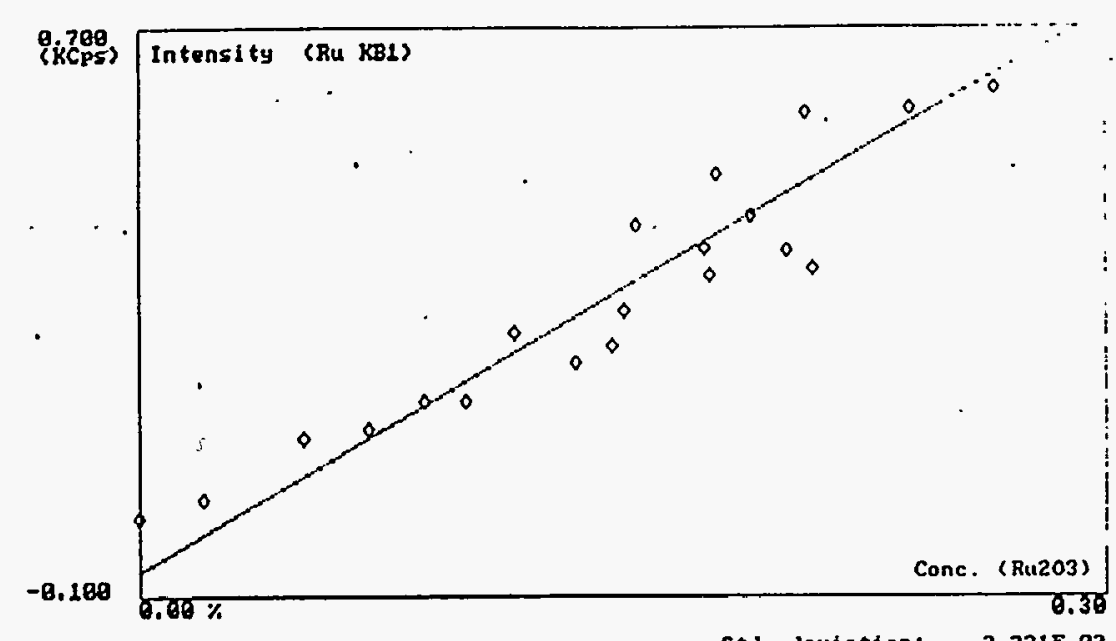

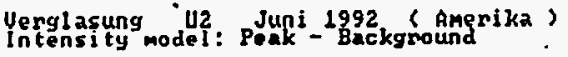

Std, deviation: $2.331 \mathrm{E}-82$ Ahsorption/Enhancenent correction(s) Hone seleoted Cornections: Intensity
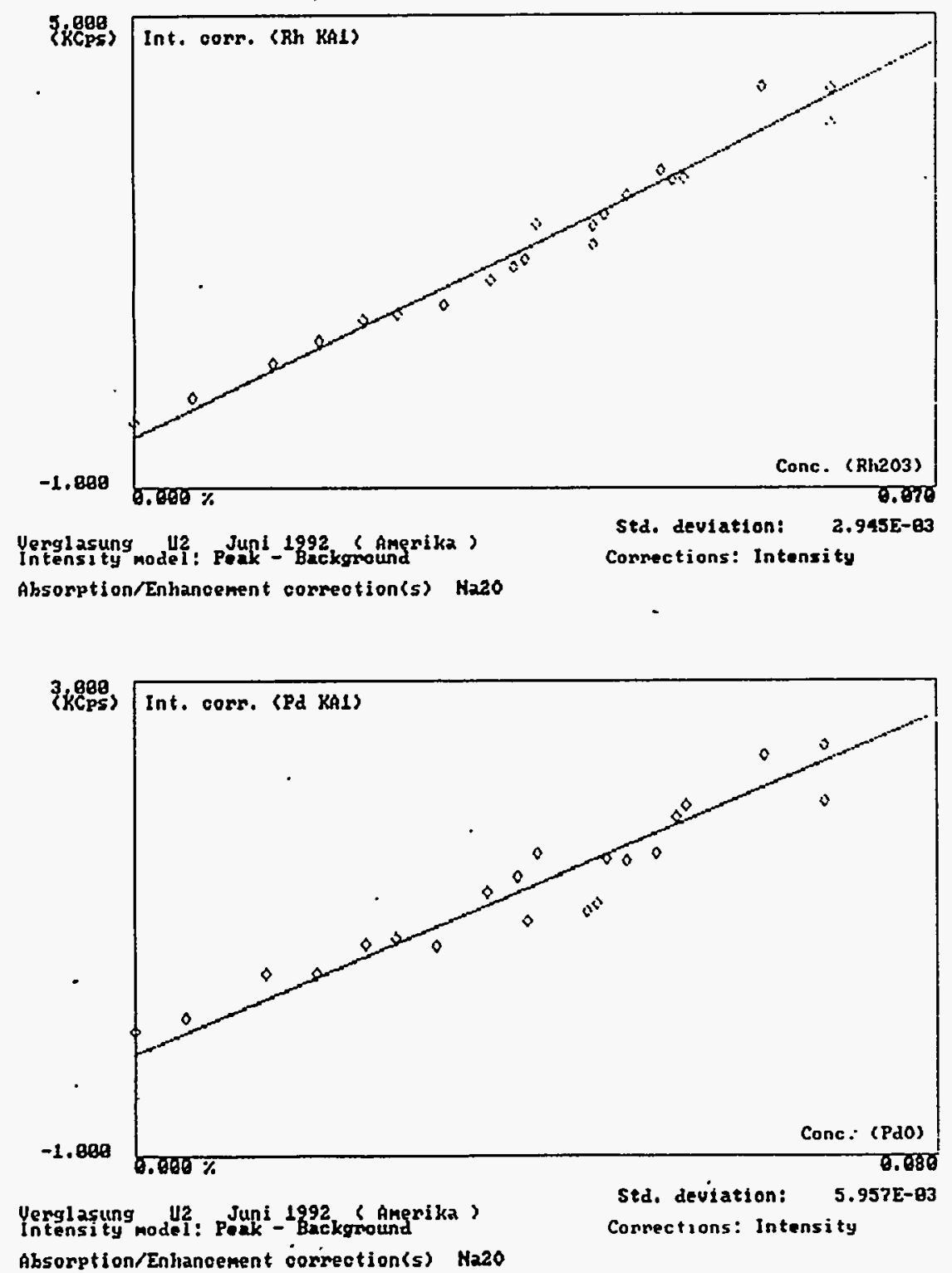

Fig. 5-1 Calibration curves gained from lab samples for XRF measurements of noble metals concentrations in the NCAW glass 

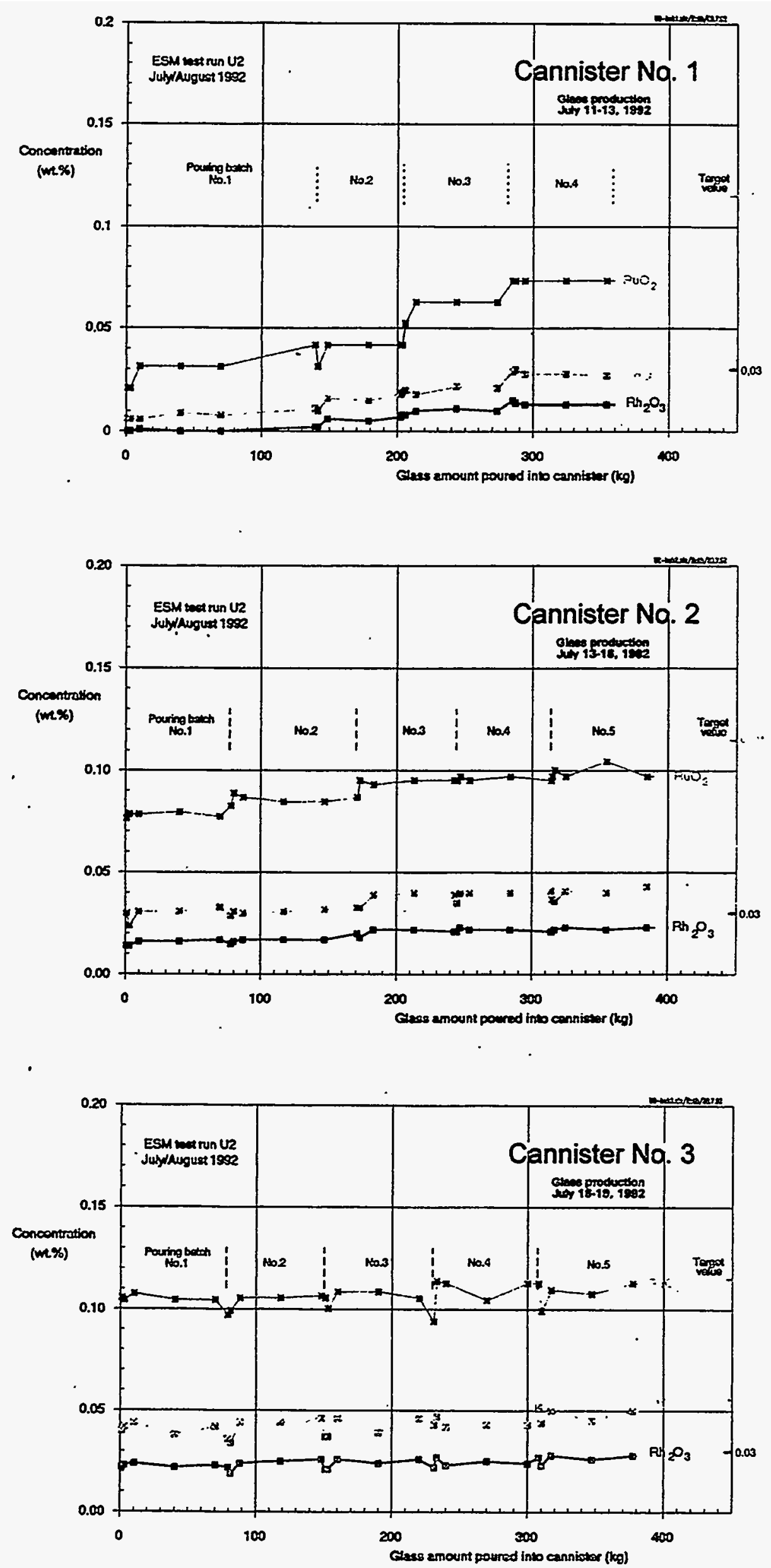

Fig. 5-2: XRF meosured noble metols concentrations obtained from glass somples token during gloss pouring into can No. 1, 2 and 3 

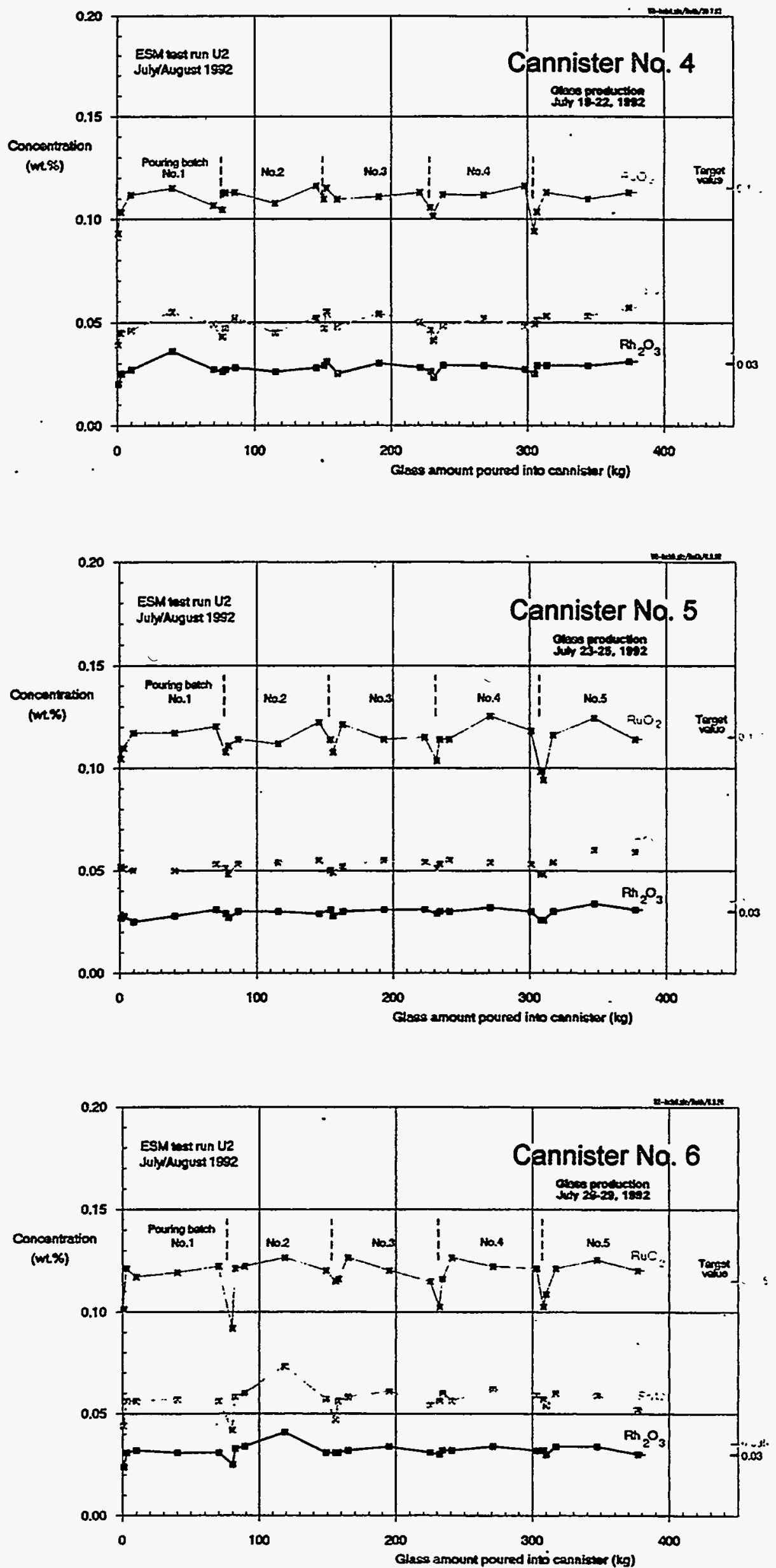

Fig. 5-3: XRF measured noble metols concentrations obtoined from gloss samples token during glass pouring into can No. 4, 5 and 6 

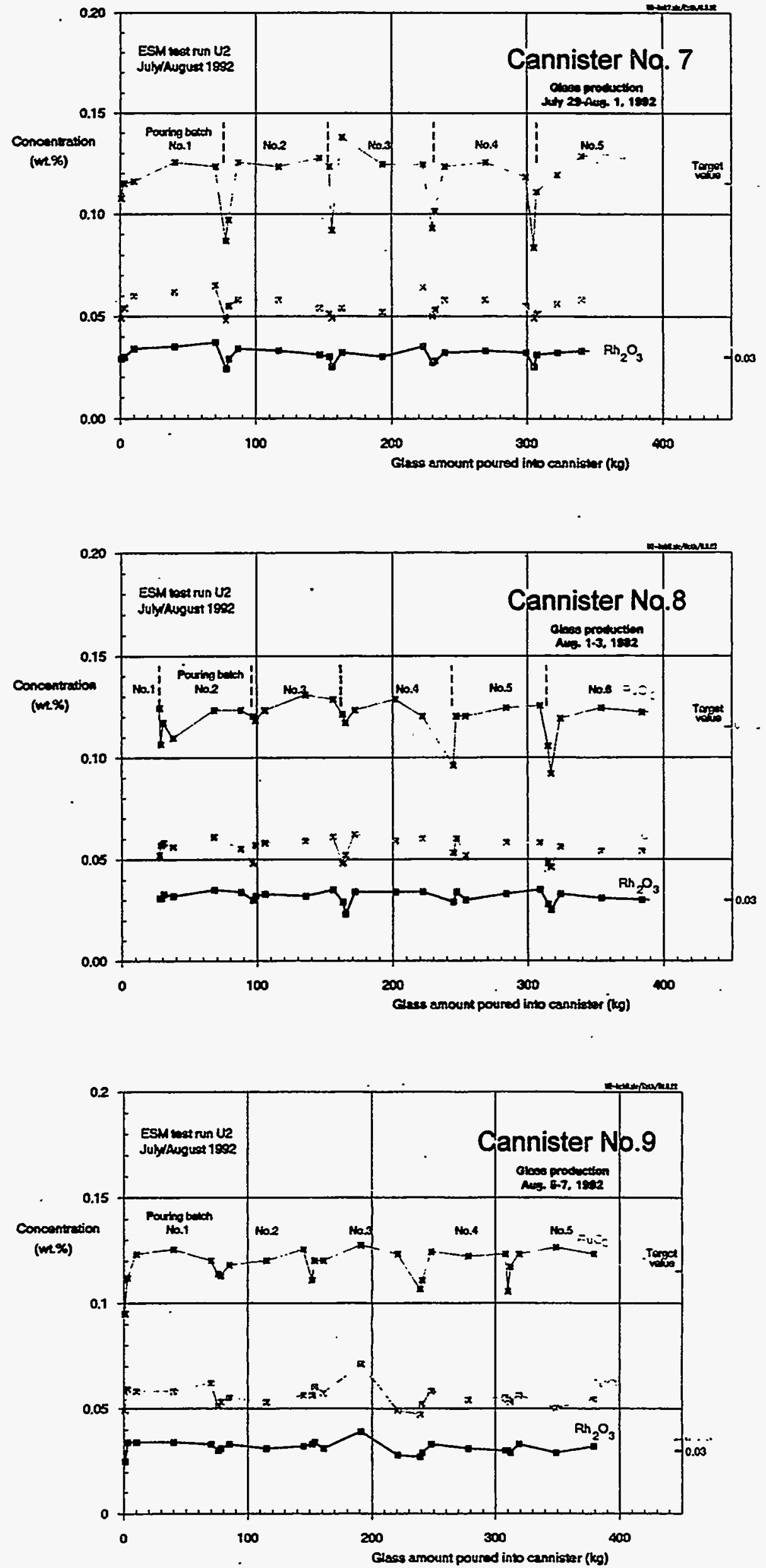

Fig. 5-4: XRF meosured noble metals concentrations obtoined from gloss somples taken during glass pouring into can No. 7, 8 and 9 

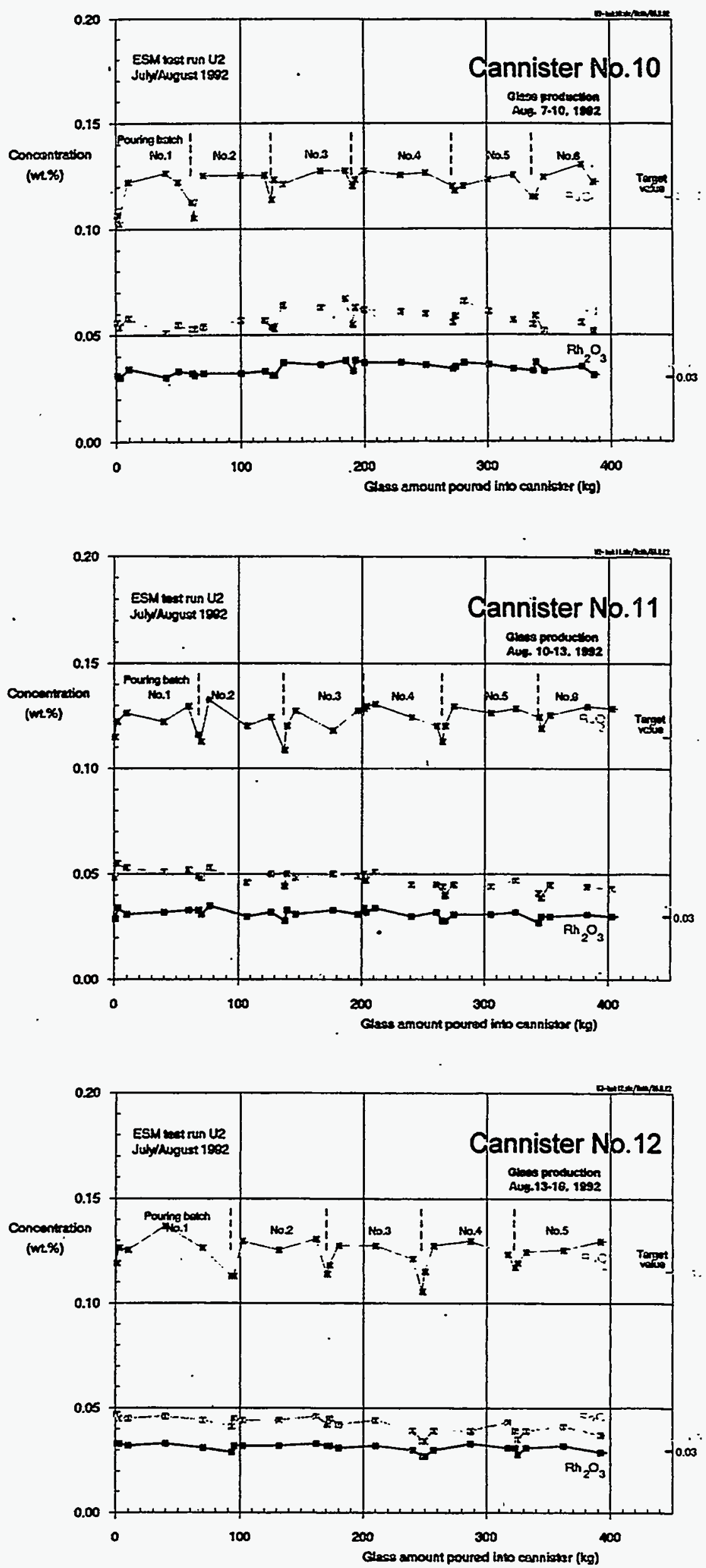

Fig. 5-5: XRF measured noble metals concentrations obtoined from gloss somples token during gloss pouring into can No. 10, 11 and 12 


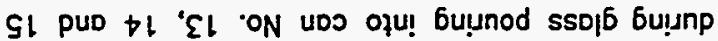

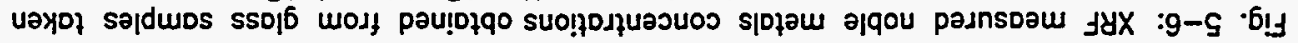
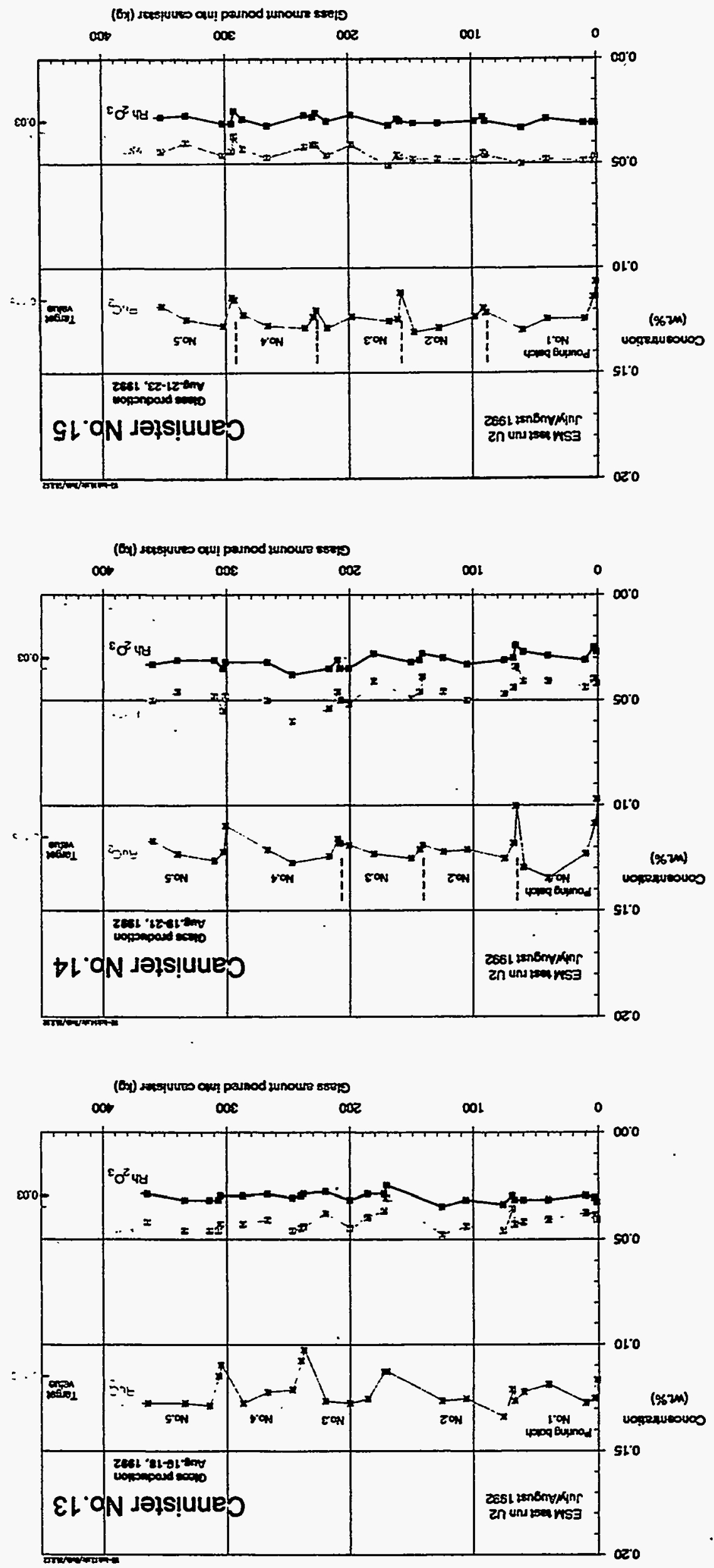

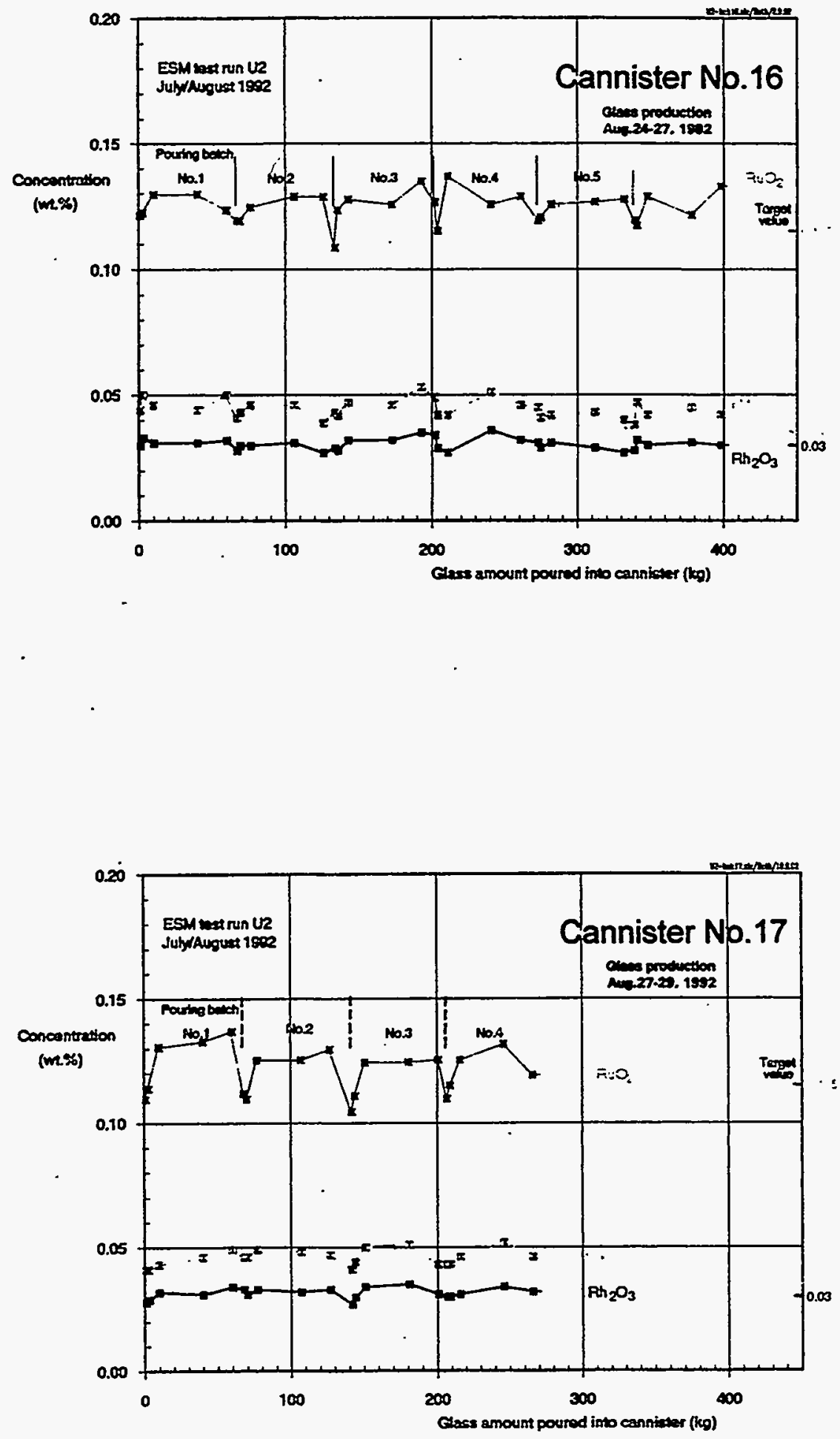

Fig. 5-7: XRF measured noble metals concentrations obtained from glass somples token during glass pouring into can No. 16, and 17 
Tab. 5-II

Content of noble metals in the glass of the different canisters

\begin{tabular}{|c|c|c|c|c|c|c|c|c|c|c|c|c|c|c|c|c|}
\hline Edolbali. $\times\left.\right|_{13}$ & & & & Thoopotical & & Cennistor & & Total Ru fod 9 & Ru & \begin{tabular}{|l|} 
Total Ru \\
\end{tabular} & Total Rh fod $\%$ & Rh & Total Rh & Total Pd fod $\bullet$ & $P d$ & \begin{tabular}{|l|} 
Toulpd Pd \\
doined
\end{tabular} \\
\hline Dete & Time & Run timo & \begin{tabular}{|l|} 
Total Food \\
\end{tabular} & $\frac{\text { Glane }}{\text { Production }}$ & Onintor-No. & woight & Totel olen & Targot & deninod & \begin{tabular}{|l} 
drained \\
\end{tabular} & Terpot & drained & diained & & drained & \begin{tabular}{|l|} 
diained \\
\end{tabular} \\
\hline ( & 烈 & $h$ & $\mathrm{~L}$ & $\frac{\text { Production }}{\mathrm{kg}}$ & Coninorono. & $\begin{array}{c}\text { (1na. Bumples) } \\
\mathrm{kg}\end{array}$ & 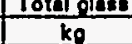 & $\frac{0.44 \mathrm{~kg} /}{\mathrm{kg}}$ & ko & kg & $\frac{0.12 \mathrm{~g} \Omega}{\mathrm{kg}}$ & $k 0$ & $k_{0}$ & $\frac{0.15 \mathrm{~g} \Omega}{\mathrm{kg}}$ & $\mathrm{kg}$ & $\mathrm{kg}$ \\
\hline & & & & $10.4989 \mathrm{~kg} \Omega$ & & & & & corf. dente & corf. date & & corr. date & oorr. data & & cotr. data & Dolf. data \\
\hline 11.07 .1992 & $15: 20$ & 0 & 0 & & & 0.00 & 0.00 & 0,000 & 0.000 & 0,000 & 000 & & & 0000 & & 00000 \\
\hline 13.07 .1992 & $08: 48$ & 41 & 602 & 300 & U21 & 363.02 & 363.02 & 0.265 & 0.034 & 0.034 & 0.072 & 0.004 & 0.004 & 0.090 & 0.001 & $\frac{0.000}{0.001}$ \\
\hline 16.07 .1992 & $01: 40$ & 108 & 1367 & 682 & U22 & 389.08 & 752.08 & 0.601 & 0.149 & 0.183 & 0.184 & 0.033 & 0.037 & 0.205 & 0.033 & 0.034 \\
\hline 19.07 .1992 & $07: 48$ & 184 & 2095 & 1045 & 023 & 384.15 & 1138.23 & 0.922 & 0.196 & 0.379 & 0.251 & 0.048 & 0.085 & 0.314 & 0.057 & 0.091 \\
\hline 22.07 .1992 & $18: 47$ & 207 & 3077 & 1535 & $\mathbf{U 2 4}$ & 380.35 & 1516.58 & 1.354 & 0.208 & 0.585 & 0.369 & 0.000 & 0.145 & 0.462 & 0.080 & 0.171 \\
\hline 25.07 .1992 & $22: 23$ & 343 & 3879 & 1935 & $\underline{425}$ & 378.31 & 1894.89 & 1.707 & 0.221 & 0.806 & 0.465 & 0.084 & 0.209 & 0.582 & 0.090 & 0.281 \\
\hline 28.07 .1992 & $23: 15$ & 416 & 4828 & 2308 & U28 & 382.19 & 2277.08 & 2.035 & 0.234 & 1.040 & 0.555 & 0.073 & 0.282 & 0.694 & 0.108 & 0.367 \\
\hline 01.08 .1992 & 20:05 & 509 & 6517 & 2752 & $\mathbf{0 2 7}$ & 359.78 & 2038.84 & 2.427 & 0.221 & 1.281 & 0.662 & 0.087 & 0.349 & 0.828 & 0.094 & 0.461 \\
\hline 04.08 .1992 & $11: 54$ & 673 & 0312 & 3149 & U28 & 389.71 & 3028.55 & 2.777 & 0.243 & 1.504 & 0.757 & 0.073 & 0.422 & 0.947 & 0.102 & 0.583 \\
\hline 07.08 .1992 & $08: 17$ & $\frac{639}{710}$ & 7148 & 3568 & 029 & 383.79 & 3410.34 & 3.145 & 0.231 & 1.735 & 0.858 & 0.068 & 0.490 & 1.072 & 097 & 0.680 \\
\hline 10.08 .1992 & $05: 25$ & 710 & 8137 & 4060 & U210 & 398.93 & 3807.27 & 3.580 & 0.251 & 1.988 & 0.976 & 0.081 & 0.571 & 1.221 & 0.108 & 0.788 \\
\hline 13.08 .1992 & \begin{tabular}{|l|l|}
$05: 29$ \\
$02: 92$
\end{tabular} & 782 & 9050 & 4515 & U211 & 397.40 & 4204.07 & 3.982 & 0.258 & 2.244 & 1.086 & 0.072 & 0.643 & 1.358 & 0.073 & 0.841 \\
\hline 18.08 .1992 & $03: 13$ & 852 & 9933 & 4956 & U212 & 398.43 & 4801.10 & 4.371 & 0.281 & 2.505 & 1.192 & 0.072 & 0.715 & 1.490 & 55 & 0.895 \\
\hline$\frac{18.08 .1892}{210}$ & 21:03 & 918 & & 5381 & U213 & 393.86 & 4994.96 & 4.746 & 0.248 & 2.753 & 1.294 & & 0.783 & 1.618 & & 0.949 \\
\hline$\frac{21.08 .1992}{2301}$ & \begin{tabular}{|l|l|}
$08: 20$ \\
30,72
\end{tabular} & 977 & 11019 & 6797 & $\mathrm{U} 2$ & 384.42 & 5359.38 & 5.112 & 0.230 & 2.983 & 1.394 & 0.086 & 0.849 & 1.743 & 0.087 & 1.016 \\
\hline 23.08 .1992 & $22: 37$ & 1039 & 12380 & & $\frac{\mathrm{U} 2}{12}$ & 373.78 & 5733.16 & 5.447 & 0.241 & 3.224 & 1.486 & 282 & 0.911 & 1.857 & 63 & 1.079 \\
\hline$\frac{27.08 .1992}{2091009}$ & $\begin{array}{l}04: 40 \\
\end{array}$ & 1117 & 13411 & 8891 & ut & 398.18 & 6131.34 & 5.801 & 0.263 & 3.487 & 1.6 & 0.070 & 0.981 & 2.012 & 0.084 & 1.143 \\
\hline$\frac{29.08 .1992}{30.08 .1992}$ & \begin{tabular}{|l|l|l|l|l|}
$14: 50$ \\
$08: 50$
\end{tabular} & $\frac{1175}{1193}$ & $\frac{1+050}{14225}$ & $\frac{7052}{7097}$ & $\frac{\mathrm{U} 2}{12}$ & 291.75 & 6423.09 & 8.202 & 0.189 & $\frac{3.670}{3.931}$ & $\frac{1.6}{1.7}$ & 0.055 & 1.030 & $\frac{2.114}{2131}$ & 0.052 & $\frac{1.195}{1.972}$ \\
\hline $30: 08.1992$ & $10: 54$ & 1196 & $\frac{14225}{14225}$ & $\frac{7097}{7097}$ & $\frac{U 218}{U 218}$ & $\frac{350.00}{200404}$ & $\frac{6773.09}{6977.13}$ & 8.259 & 0.255 & $\frac{3.931}{4027}$ & $\frac{1.707}{1707}$ & 0.078 & $\frac{1.112}{1.30}$ & 2.134 & 0.078 & 1.273 \\
\hline & & & & & & & & & & & & & & & & \\
\hline Total & & & & & & 6977.13 & & & 4.027 & & & 1.138 & & & 1.297 & \\
\hline & & & & & & & & & & & iffied Instand of & $0 \mathrm{~m}^{3}$ & & & & \\
\hline & & & & & & & & & & & & & & & & \\
\hline The total ordere & noblon & otales amou & nte ser: & & & & & & & & & & & & & \\
\hline Fu & $0.18 \times 0$ & & & & & & & & & & & & & & & \\
\hline Ah & $.68 \times 0$ & & & & & & & & & & & & & & & \\
\hline $\overrightarrow{P d}$ & $2.10 \mathrm{~kg}$ & & & & & & & & & & & & & & & \\
\hline
\end{tabular}


curves are shown in Fig. 5.1. Additionally to the noble metals the concentrations of $\mathrm{Al}_{2} \mathrm{O}_{3}, \mathrm{CdO}$, $\mathrm{Cs}_{2} \mathrm{O}, \mathrm{Fe}_{2} \mathrm{O}_{3}, \mathrm{Na}_{2} \mathrm{O}, \mathrm{Nd}_{2} \mathrm{O}_{3}, \mathrm{NiO}, \mathrm{SiO} 2, \mathrm{TeO}_{2}, \mathrm{ZrO}_{2}$, and $\mathrm{MoO}_{2}$, had simultaneously been determined, too.

\subsubsection{Results}

The noble metals run was started with $550 \mathrm{~kg}$ noble metals free NCAW glass melt which was produced in the pretest run U1 of the ESM melter. Therefore, in the first stage of the test run U2 the noble metals concentrations in the samples were low and increased with time. The measured concentrations were plotted for each canister against the quantity of glass discharged. The 7 concentration diagramms are shown in the Figs. 5.2 to 5.7. The values are given in terms of the oxides $\mathrm{RuO}_{2}, \mathrm{Rh}_{2} \mathrm{O}_{3}$, and $\mathrm{PdO}$. The target values are indicated on the right side of the figures for comparison. Examples of the data base used for these figures are compiled in 5-II which refers to canisters No. 6 and 15.

The concentration profiles have several features. After start of the glass flow via overflow, the first glass sample taken immediately shows generally lower concentrations then the others. It may be due to the fact that in the time period when the overflow system was not in pouring operation ( 7 to 9 hours), the noble metals segregated slowly back in the sloped Inconel 690 tube towards the melt tank. Already the second glass sample, taken when $3 \mathrm{~kg}$ of glass were poured, showed higher concentration levels like the rest of the samples No. 3, 4, 5 did. The corresponding volume of the overflow channel is $1.7 \mathrm{l}$. Anyway sample 6 taken from the bottom area near the overflow channel showed only a slightly higher noble metal concentration than sample 7 from the opposite side (Fig. 518).

Another feature of the curves is that the XRF-measured PdO values are obviously all significantly too high. They indicate more Pd coming out of the melter than fed in.

In order to get independent measurements by other methods and to get necessary correction terms, for the XRF values of all three noble metals element, more than 50 glass samples were remeasured. In Figs. 5.8 the results are given. They are compared with the XRF data. The applied sample peparation and analysis method of the specialized institut (Griffith Inspectorate, London) for remeasuring has been as follows:

- Preparation: Where necessary the samples were crushed to a fine powder and dried at $105^{\circ} \mathrm{C}$ for two hours

- Sample treatment: The material was digested and the Palladium, Ruthenium and Rhodium collected by a sulphur matting process with Nickel oxide AT 1100 DEG. C. 
- The resulting melt was treated with acid to separate the nickel from the P.G. M.'S. These were . then taken into solution by another acid treatment

- Measurement: The P.G.M content of the solution was determined instrumentally using an inductive coupled plasma (ICP) source and comparing against synthetic calibration solutions

These measurement data revealed that all of INE's XRF values were systematically higher. However the nature of the concentration profiles were rather the same as can be seen from Fig. 5-8 where the XRF data are plotted as dotted lines for comparison.

Based on these additional measurements made on glass samples of the canister No. 6 and 15 respectively, all XRF data of the figures 5.2 to 5.7 were corrected by using the following procedure:

i Calculation of the difference between INE's original XRF data and the data obtained by the Griffith inspectorate institute.

ii Formation of an averaged deviation for each noble metals curve from the values of both canisters.

iii Correction of all XRF-concentration data by subtraction of the average deviation from the original XRF-concentration value

$\mathrm{RuO}_{2}$ (minus 0.041), $\mathrm{Rh}_{2} \mathrm{O}_{3}$ (minus 0.009), $\mathrm{PdO}$ (minus) 0.026)

The corrected concentration profiles are given in the Figs. 5-9 to 5-14. These data are considered as the realistic ones on which interpretations and evaluations will be based.

\subsubsection{Interpretation of the data}

Already a rough comparison between the actual data and the targets show that the noble metals concentrations in the glass samples are lower than the target values. This is valid for all three elements. Ruthenium and rhodium data are $75 \%$ of the corresponding target values, and palladium $60 \%$. Each diagram of the figs. 5-9 to 5-14 was used to calculate the total quantity of $\mathrm{RuO}_{2}, \mathrm{Rh}_{2} \mathrm{O}_{3}$ and $\mathrm{PdO}$ in the canister by integrating the concentrations over the discharged glass mass. With $\mathrm{c}(\mathrm{m})$ being the mass concentration, there is the mass of the noble metals in the canister :

$$
m_{R u O i}=\int_{0}^{m_{\text {stmex }}} c_{R u O 2}\left(m_{g l a s s}\right) d m_{\text {glass }}
$$



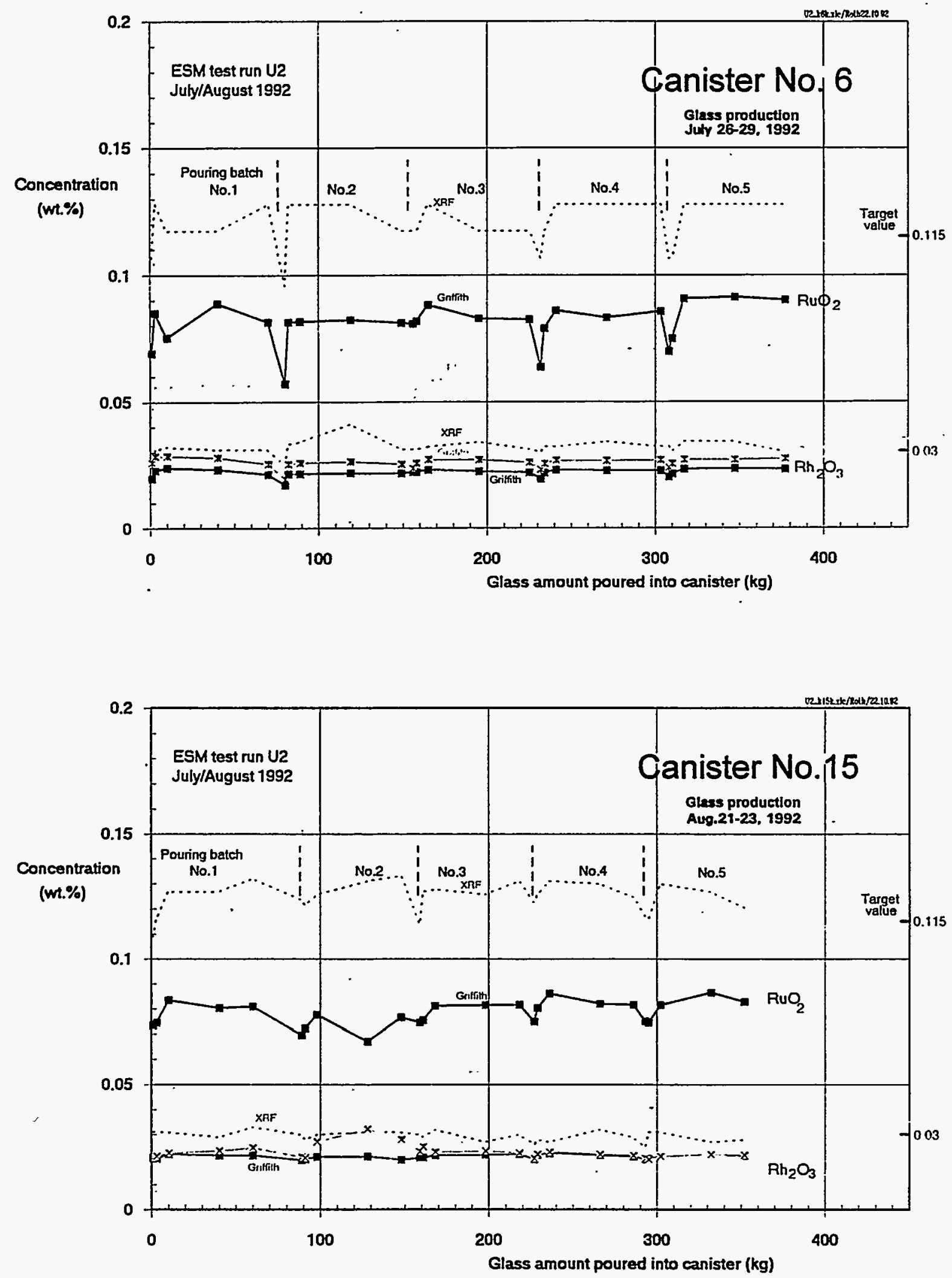

Fig. 5-8 Noble metals concentration in glass samples taken during glass pouring into canister Nos. 6 and 15, measured by Griffiths inspectorate, London. The dotted lines give the corresponding XRF values measured at INE's analytical lab. 

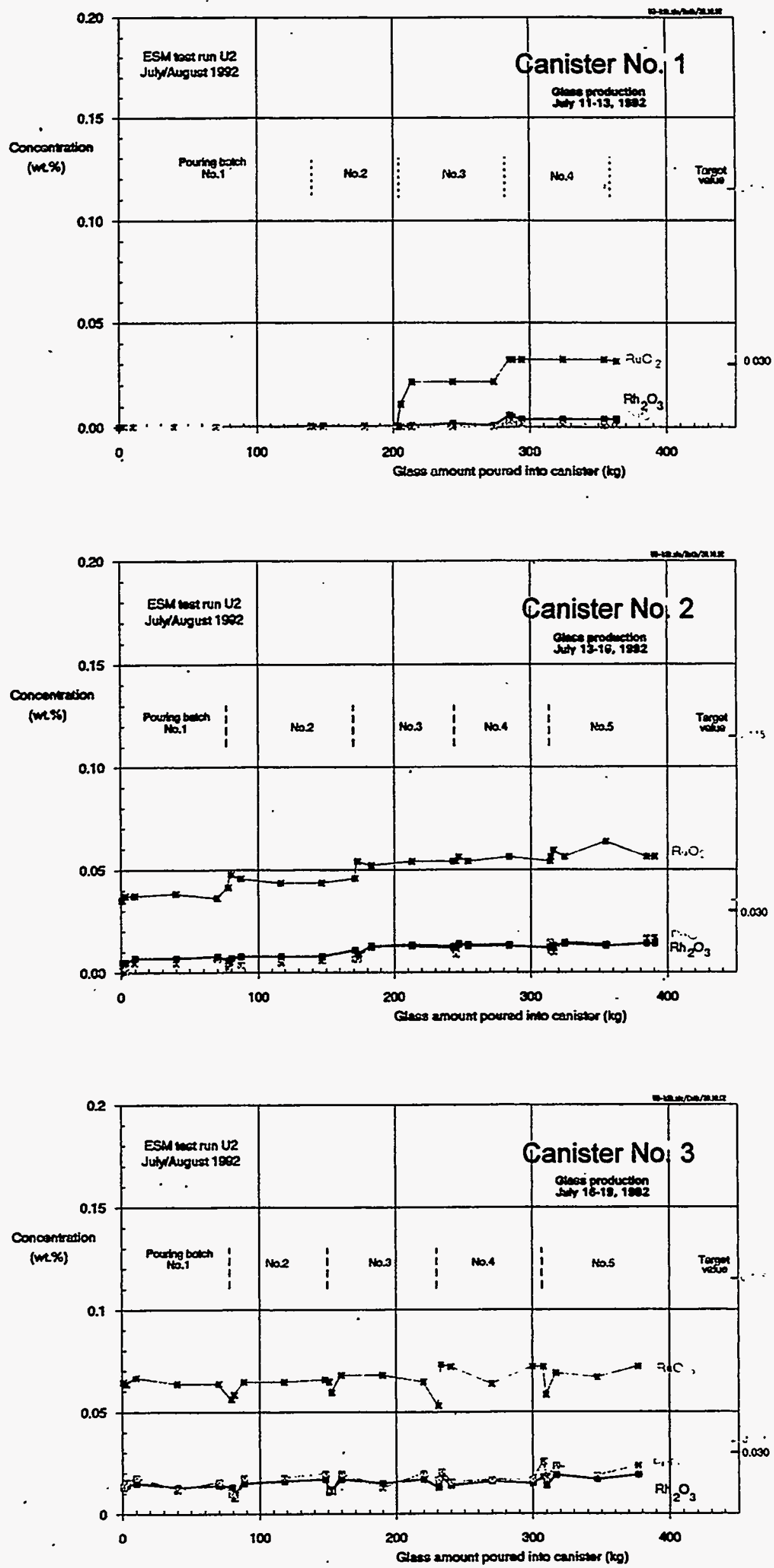

Fig. 5-9: Corrected noble metals concentration dato for gloss somples tokel while pouring can No. 1,2 and 3 

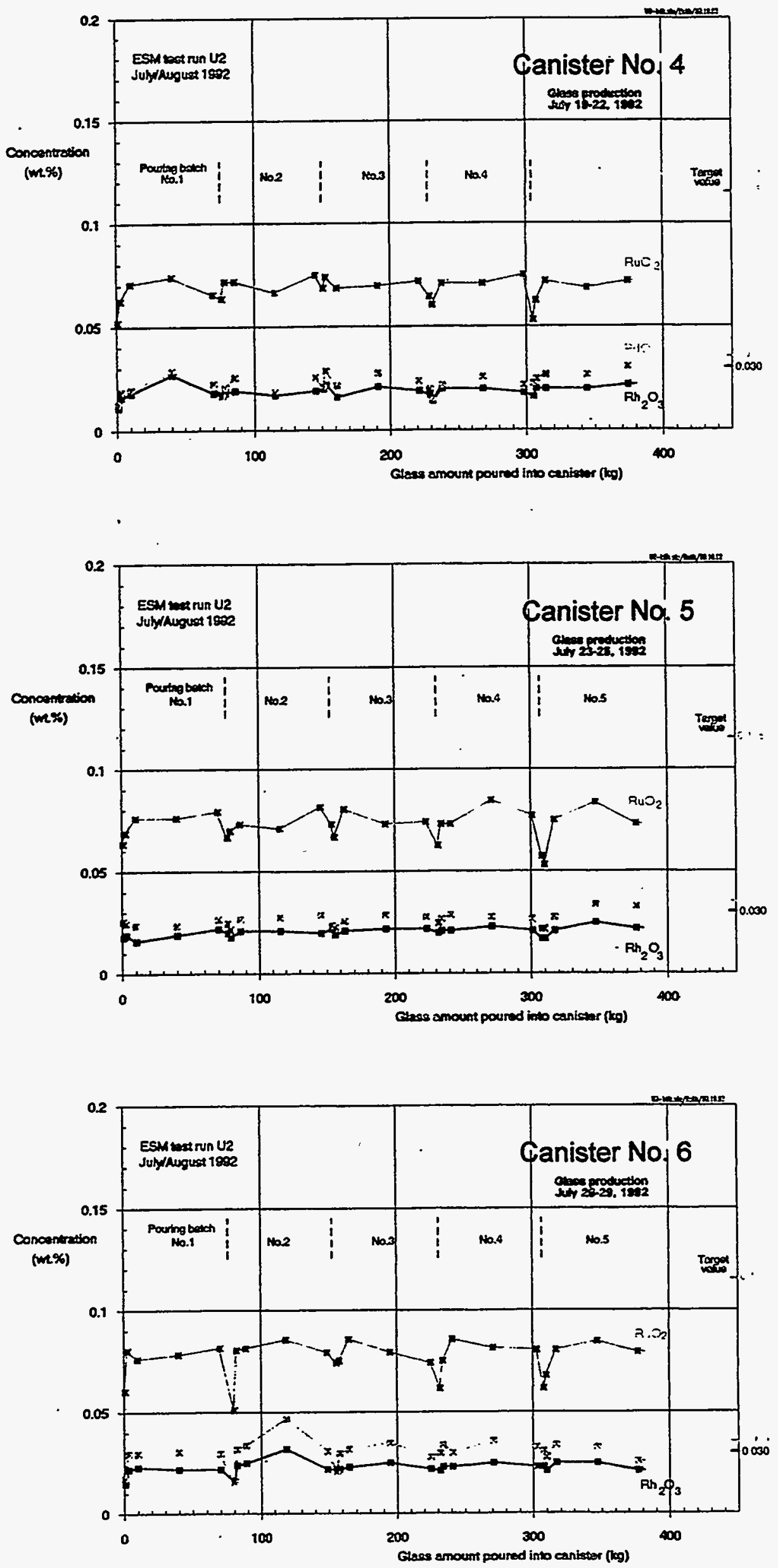

Fig. 5-10: Corrected noble metals concentration data for gloss samples toke while muerinn enn $\mathrm{N} C 4 \quad 5$ and 6 

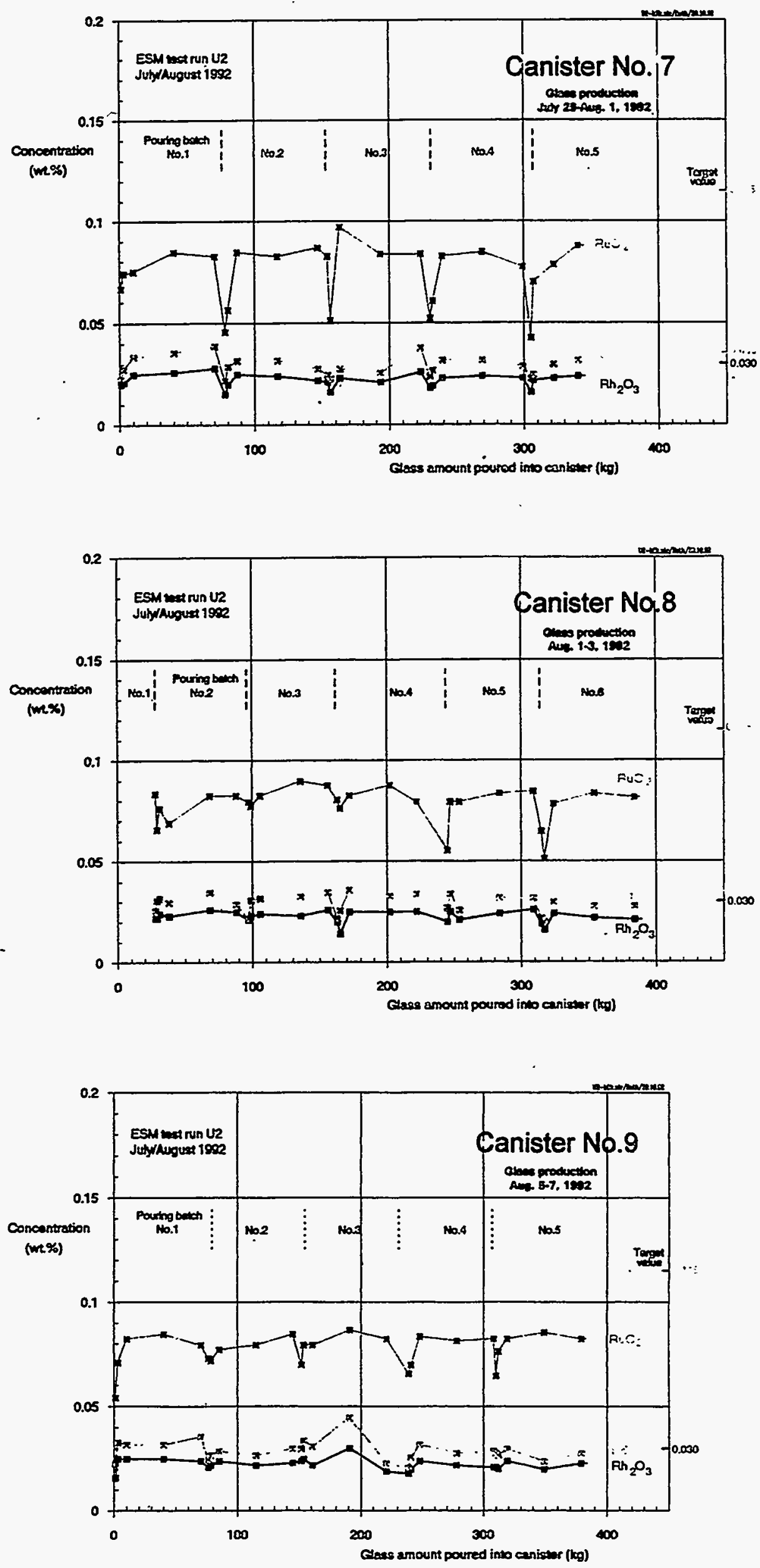

Fig. 5-11: Corrected noble metals concentration doto for gloss samples to whilo mavirima ann $\mathrm{N} n \quad 7$ a nad $a$ 

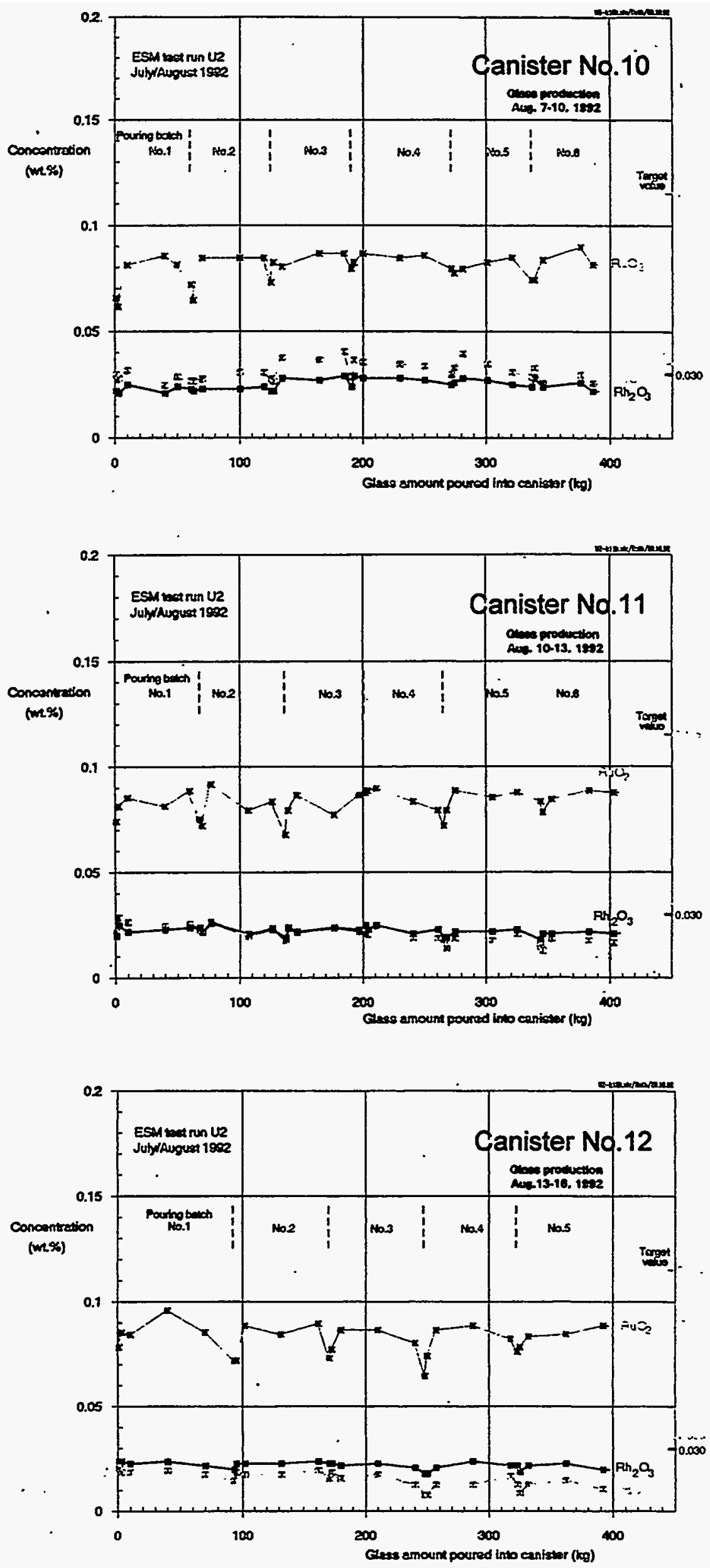

Fig. 5-12: Corrected noble metals concentration dato for glass samples token while pouring can No. 10, 11 and 12 

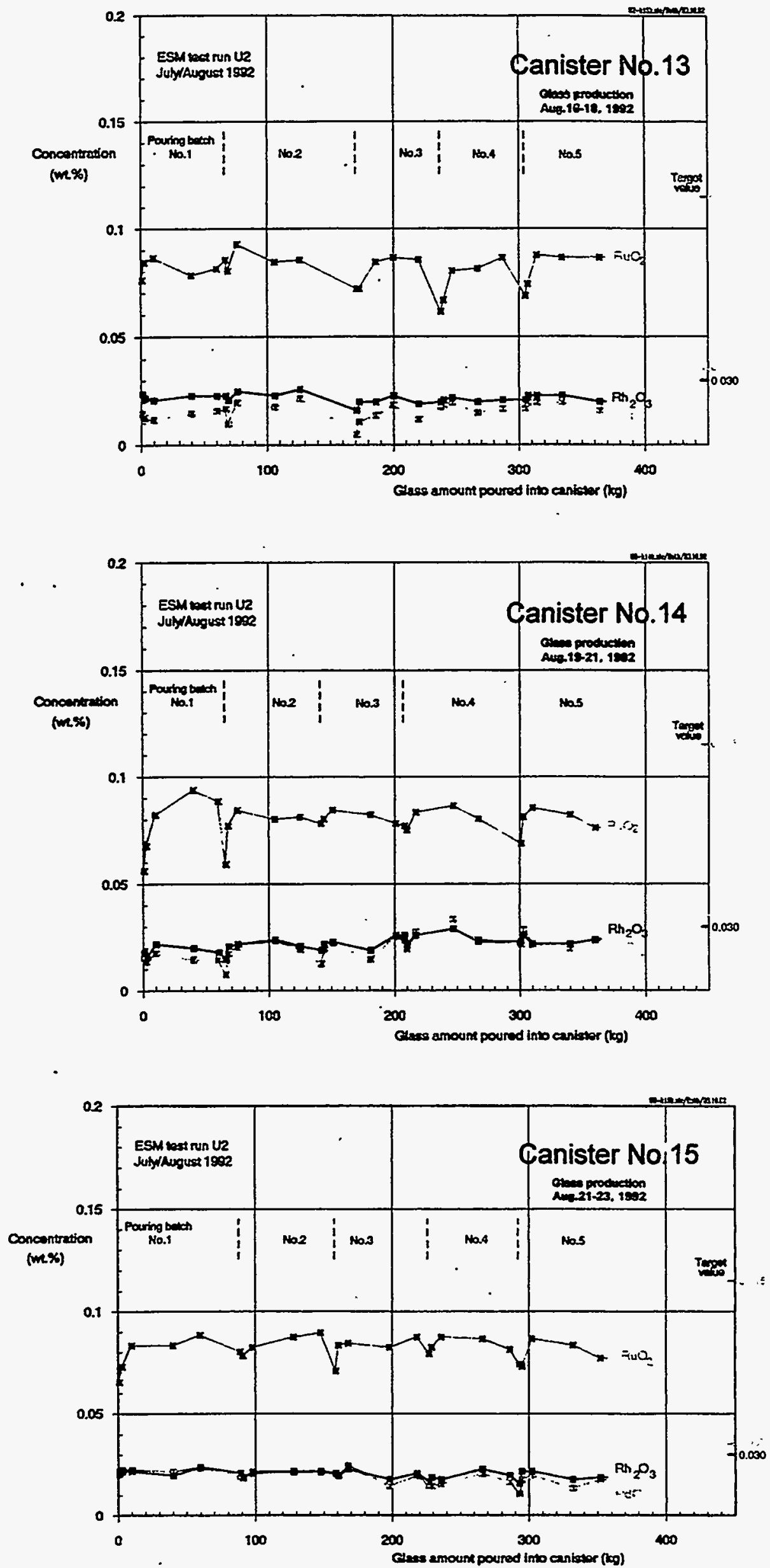

Fig. 5-13: Corrected noble metals concentrotion doto for gloss samples token while pourina can No, 13, 14 and 15 

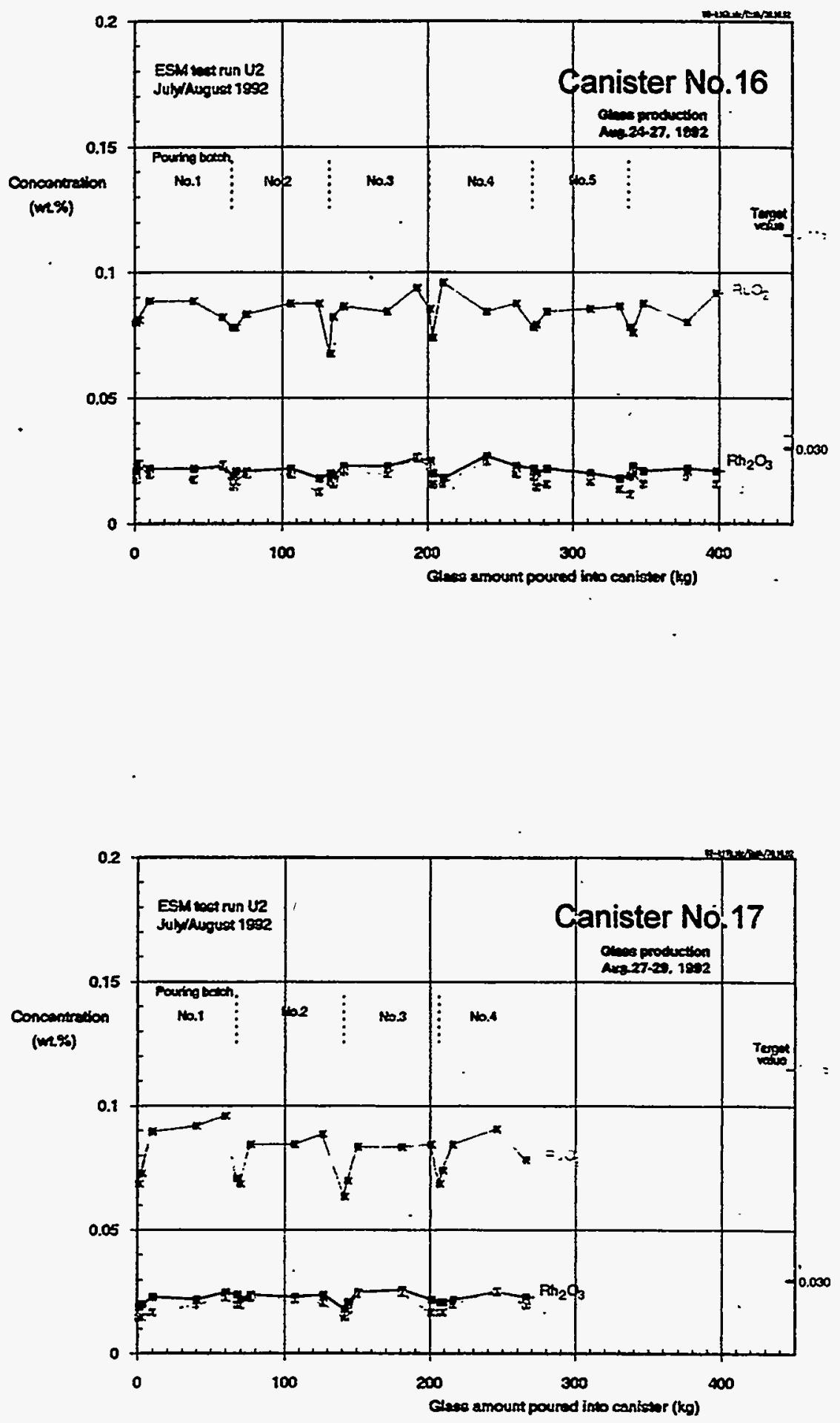

Fig. 5-14: Corrected noble metals concentration data for glass samples token while pouring can No. 16 , and 17 


$$
\begin{gathered}
m_{R h 203}=\int_{0}^{m_{\text {stax }}} c_{R h 203}\left(m_{g l a s s}\right) d m_{\text {glass }} \\
m_{P d O}=\int_{0}^{m_{\text {simax }}} c_{P d O}\left(m_{\text {glase }}\right) d m_{g l a s s}
\end{gathered}
$$

Tab. 5- $I$ and Fig. 5-15 give the results of these calculations. In Fig. 5-15, the target values for the individual canister are indicated, too. Their slight variation is due to the varation of the total glass mass filled into the different canisters. From the figure it can be seen the gap of noble metals in each canister.

This figures are an indication that a portion of the noble metals may have segregated and accumulated on the melter bottom. The mass balances are shown for all three noble metals in Fig. 516. The "fed in" curve of each diagram had been calculated from the melter feed data based on the target feed composition. The "discharge" curve of each diagram is based on the data given in Tab. 5-II. For all three noble metals, the discharge curves are not parallel to the "fed in" curve as it should be.

For ruthenium and rhodium, the "discharge" curves are straight, indicating a constant accumulation rate. The slope of the "discharge" curve for palladium appears to decreasing with time, indicating an increased retention with time. The reason therefore can not be given. They show less slope due to the supposed incomplete removal of the noble metals from the melter with glass pouring. The nominal hold up of noble metals in the glass pool (550 kg glass at average) is $0.480 \mathrm{~kg} \mathrm{Ru}, 0.132$ $\mathrm{kg} \mathrm{Rh}$, and $0.162 \mathrm{~kg} \mathrm{Pd}$.

In Fig. 5-16 the "ideal" discharge curves for complete removal of the noble metals with glass pouring is indicated, too. This curve represents the case when the noble metals would be completely drained out with glass pouring except the portion contained nominally as hold-up in the glass pool. According to the data of Fig. 5.16 the following quantity of noble metals may be accumulated in the melter during the noble metals run:

$$
\begin{aligned}
& 2.13 \mathrm{~kg} \text { of } \operatorname{Ru}(35 \%) \\
& 0.54 \mathrm{~kg} \text { of } \operatorname{Rh}(32 \%) \\
& 0.80 \mathrm{~kg} \text { of } \operatorname{Pd}(38 \%)
\end{aligned}
$$

However, these quantities might have been too low to influence significantly the electric current path through the bulk of the glass. The electric resistance curves are shown in Fig. 5-17. On a first view it does not reveal an influence of accumulated highly conductive noble metals on the Jouleheating of the glass pool. The decrease of the resistance curve after 550 hours operation time is obviously due to the higher current loading of the electrodes, not by noble metals. At the end of the run, a test was made by using the same current load as in the initial period of the run U2. When 

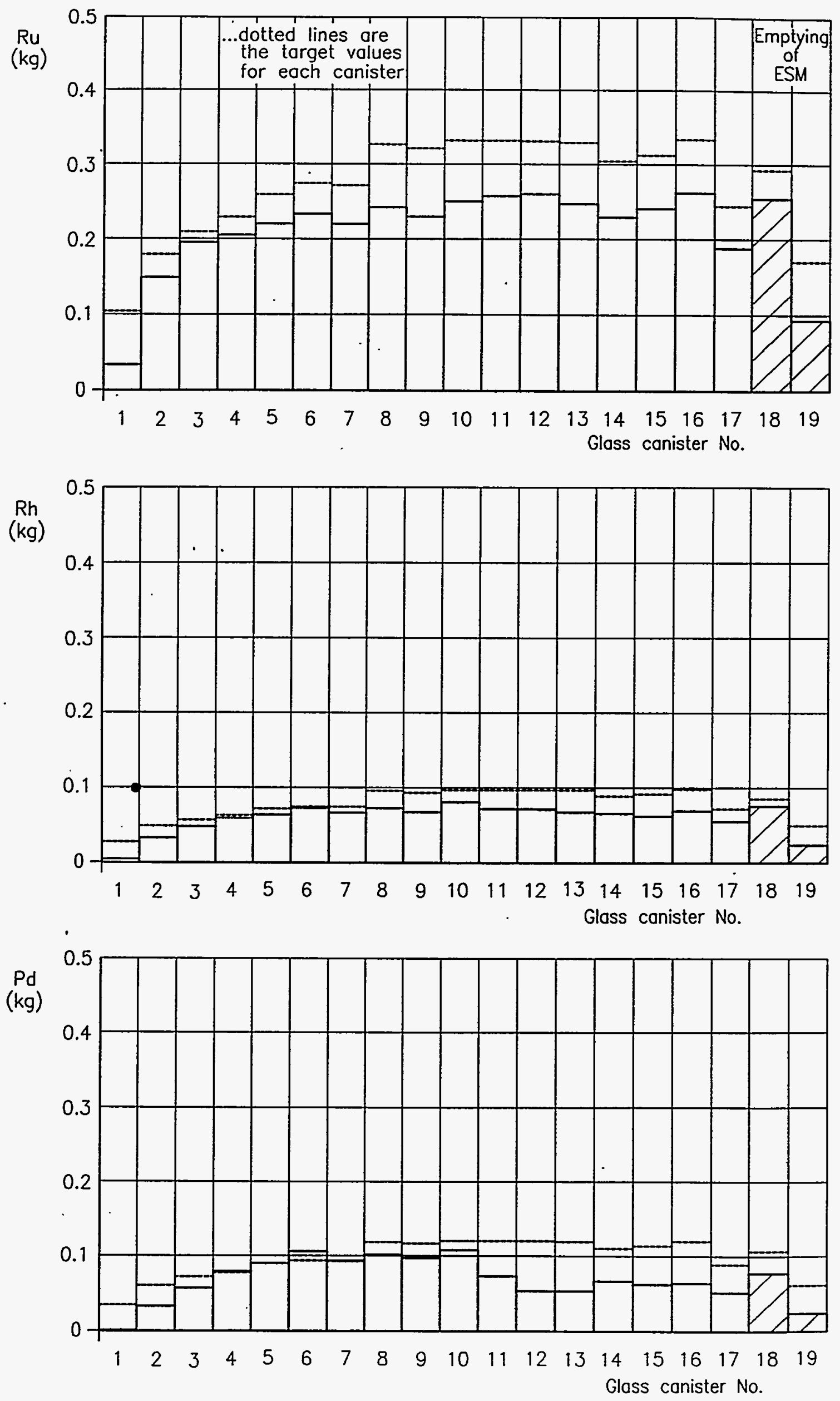

Fig. 5-15: Comparison between the actual quantity of noble metals in the different glass conisters and the torget values 

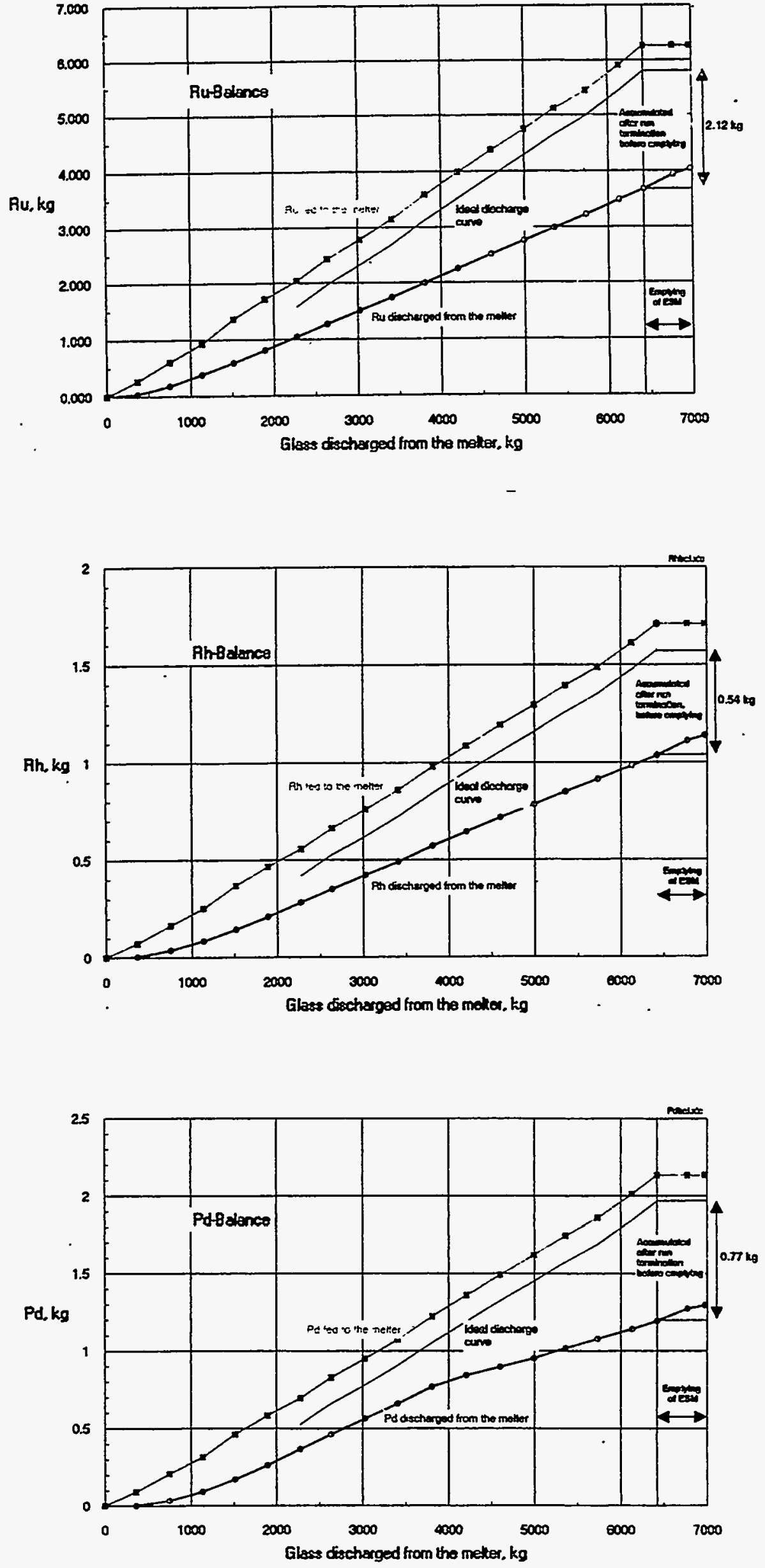

Fig. 5-16 "Feed in" and "discharge" curves of the ESM. for the noble metals contai NCAW simulant 


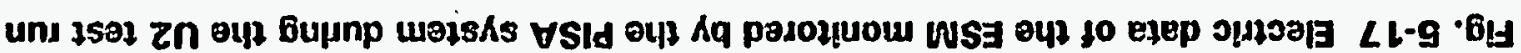
zEal 0 E isnent

4 'uoplexado jo ou!l 1

$00 Z \mathrm{~L}$

$000 l$

008

009

oot

$00 z$

$2631 \cdot \mathrm{HLAnR}$

0

002

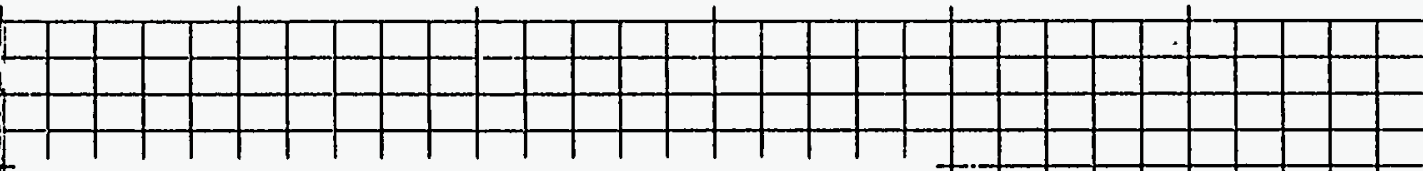

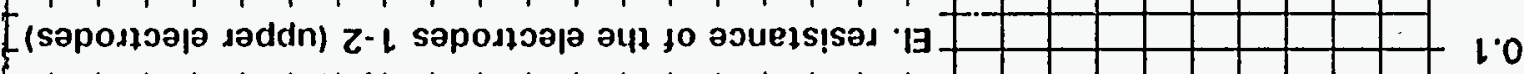

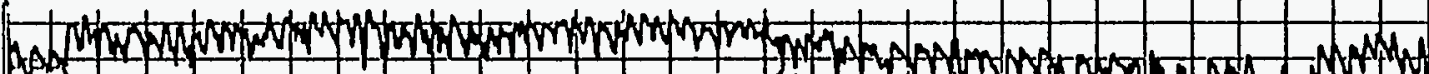

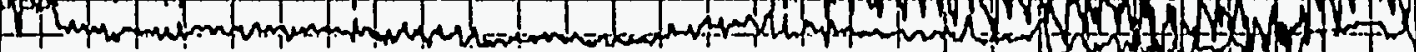

oot

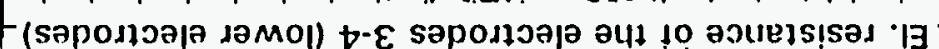

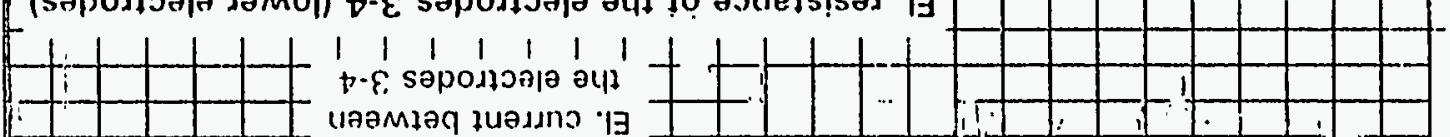

$2: 0$

$\forall 000$ l.

quesมnว 19

$\forall / \Lambda$

009

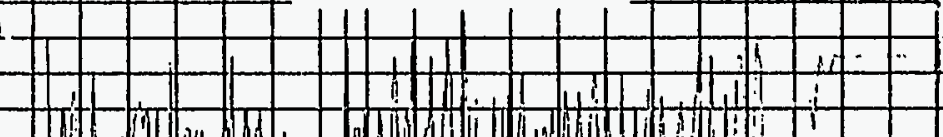

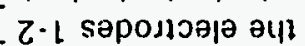

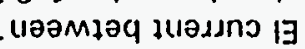
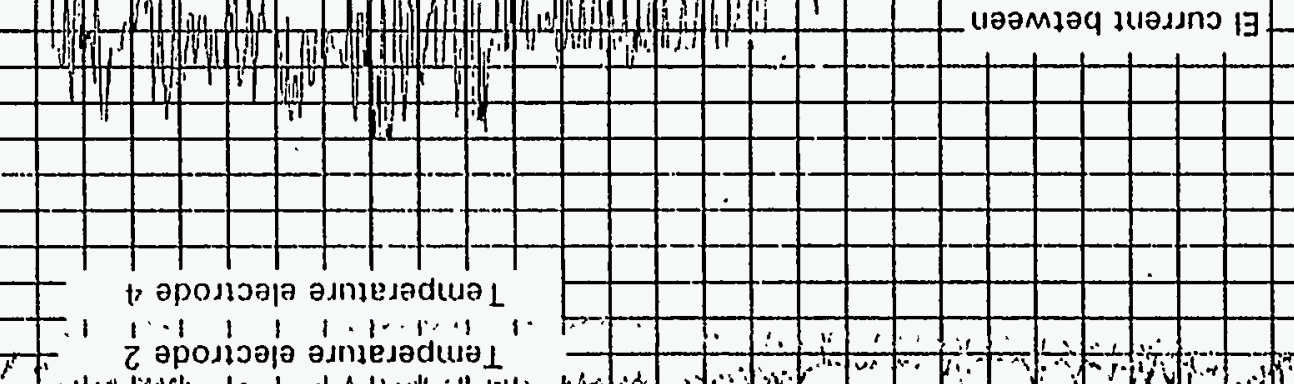

008

- 2 aposioja asmesadual

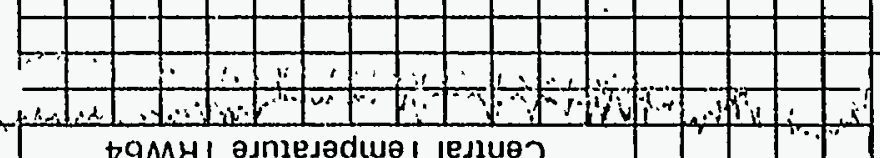

dure 1

A.

0021 
comparing these data a decrease of the resistance between the power electrodes can be calculated up to $13 \%$ for the lower electrodes (see also chapter 5.4 for specific electric resistance data measured on noble metals sludge samples taken from melter bottom after emptying).

Based on the PAMELA experience such a layer of $2-3 \mathrm{~cm}$, homogeniously spread over the melter floor can be enough to influence the electric field. Having processed more than $90 \mathrm{~kg}$ of noble metals in the PAMELA melter, the resistance decrease. between the lower electrodes was more than $65 \%$. But may be due to the convection pattern of the glass melt in the ESM, this layer is not yet contacting the electrodes. Thus a significant influence on the Joule heating is not yet seen.

\subsubsection{Emptying of the melter}

After termination of the U2 run the ESM melter was maintained at $1150^{\circ} \mathrm{C}$ and emptied 3 hours later via the inductively heated bottom drain. The temperature of the bulk glass was kept at $1150^{\circ} \mathrm{C}$ by using the melter plenum heaters and the two power electrode sets (later only the lower electrode pair). During emptying, $450 \mathrm{~kg}$ of glass were drained into canister No. 18 and $43 \mathrm{~kg}$ into No. 19. The draining glass was sampled periodically using a metal crucible and rod. The samples later analyzed for noble metals using XRF. The results of these analyses are shown in Figure 5-18. As shown in this figure, the first glass out of the melter contained a slightly higher noble metals concentration than the bulk glass. This is assumed to be the effect of the sludge layer that was directly above the bottom drain at the start of the draining. The rest of the bulk glass was slightly lower than the target noble metals concentration due to the settling. As canister No. 18 was filled the glass flow was not stopped. Draining was continued into canister 19 without interruption in order to allow the mass of glass to drain out as complete as possible and not to risk lowering of the bulk glass temperatures and thus glass fluidity. The last few drops out of the melter had high concentrations of noble metals (1-4 $w t \%)$. When the glass had stopped draining, there was a $1-3 \mathrm{~cm}$ layer of sludge/glass left on the melter floor. While this layer was still hot, seven samples were taken using a cup attached to a long piece of metal tubing. Again, these samples were analyzed for noble metals. The results of these analyses are shown on the right side of the lower plot in Figure 5-18. A graphic showing a top view of the melter and the sampling positions is superimposed below the lower figure for clarification.

The analytical data show that the layer which remained behind on the melter bottom contained significantly increased concentrations of the noble metals. For Ru the enrichment was up to a factor of 40 higher than the nominal value, for $\mathrm{Rh}$ up to 15 , and for $\mathrm{Pd}$ up to 10 . These higher values correspond to the low specific electric resistance data of such sediments which are more than one order of magnitude below that of the bulk material (Fig. 5-19). 

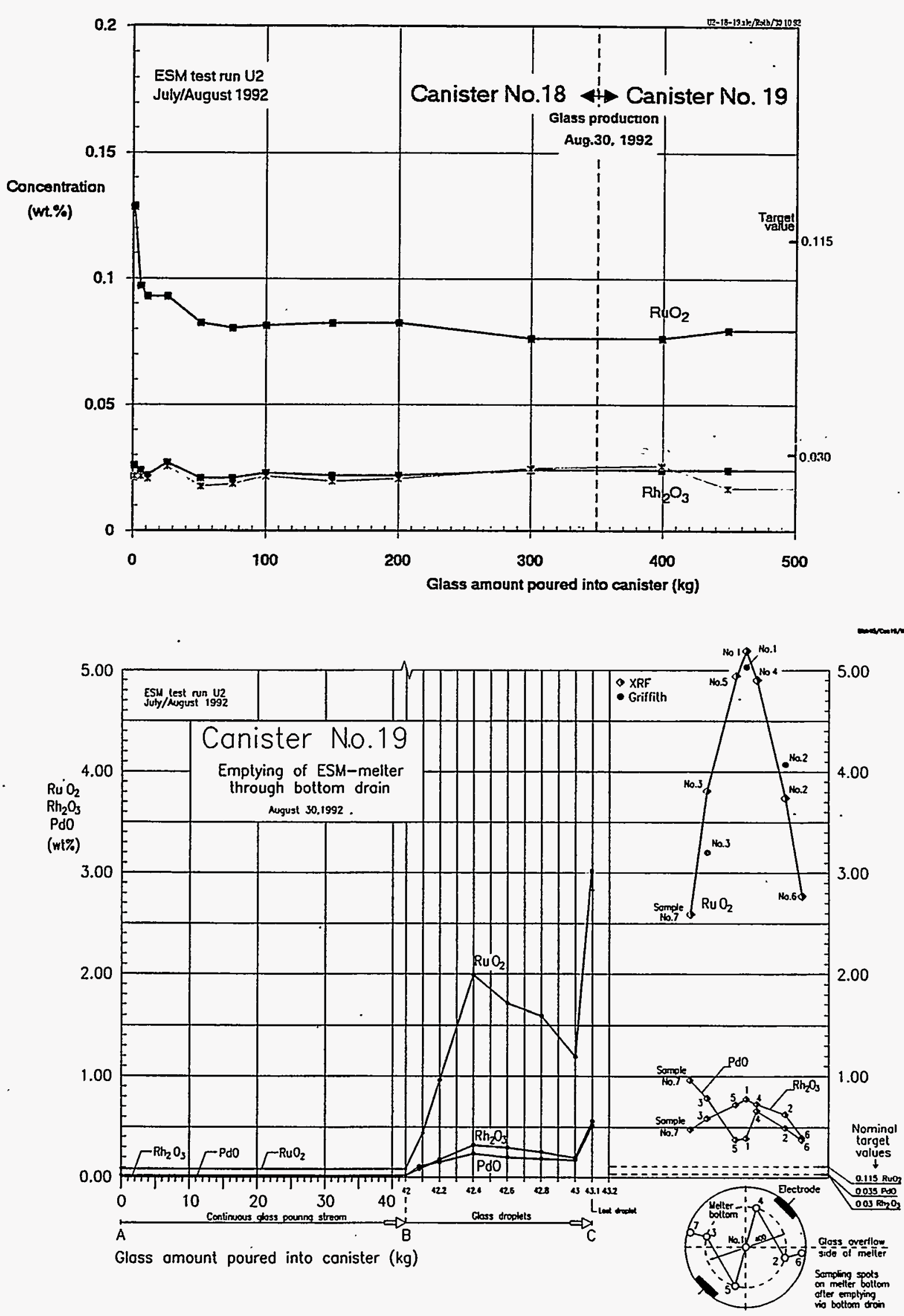

Fig. 5-18 Results of noble metals concentrations in glass samples taken when emptying the melter (glass poured into cans No. 18 and 19, via bottom drain). Noble metals concentrations in the remaining glass layer on ESM bottom 


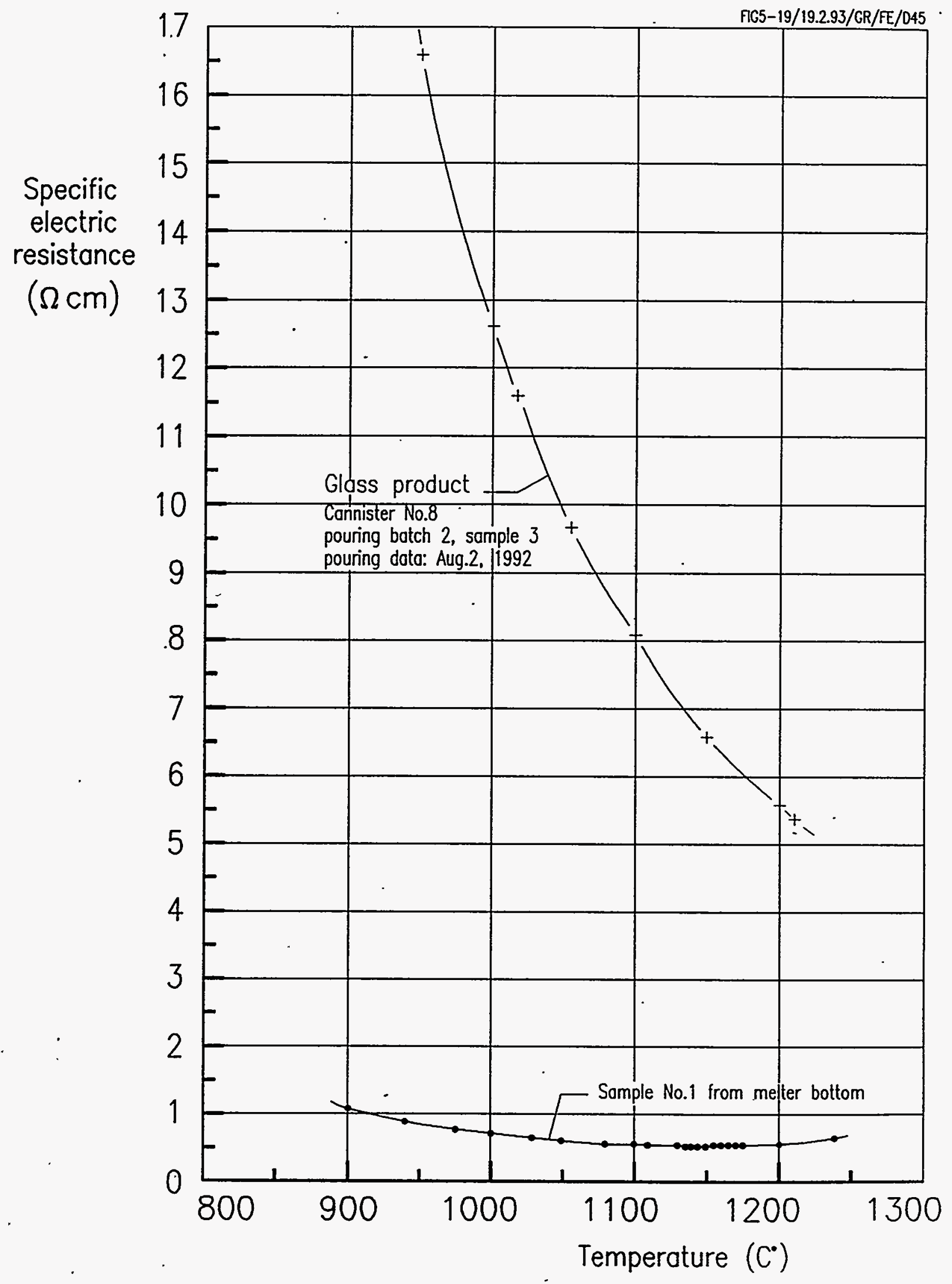

Fig. 5-19 Comparison of the specific electrical resistance versus temperature of the NCAW glass product and sample No. 1 from the melter bottom 


\subsubsection{Noble metals balance (U2 test run)}

To set up the noble metals balance for $\mathrm{Pd}, \mathrm{Ru}$ and $\mathrm{Rh}$ the "fed in" data have been compared with the "discharge" data. This is shown in table 5-III and figure 5-16. The "fed in" data are calculated by the sum of the melter feed volume times the target concentration of each of the noble metals. These data slightly differ from the actual ordered and premixed amounts of noble metals due to the fact that $14.23 . \mathrm{m}^{3}$ of melter feed had been prepared instead of theoretically $14.0 \mathrm{~m}^{3}$. The discharge data are calculated from the corrected noble metals concentration in the glass samples taken from each pouring. The integration of this concentration data over the poured amount of glass delivers the absolute amount of discharged noble metals.

The evaluation of this data shows a gap for the discharge amount and indicates an accumulation in the melter. After total emptying the melter the following balance can be made up:

\begin{tabular}{cccc} 
Element & $\begin{array}{c}\text { Total fed } \\
\text { to the melter } \\
\mathrm{kg}\end{array}$ & $\begin{array}{c}\text {. Total drained } \\
\text { incl. emptying } \\
\mathrm{kg}\end{array}$ & gap \\
\hline $\mathrm{Ru}$ & 6.16 & 4.03 & $\mathrm{~kg}$ \\
$\mathrm{Rh}$ & 1.68 & 1.14 & 2.13 \\
$\mathrm{Pd}$ & 2.10 & 1.30 & 0.54 \\
& & & 0.80
\end{tabular}

In order to close this balance, the amount of the glass remaining in the melter has been estimated by measuring the thickness of the remaining glass layer on the melter floor after emptying. This layer is about 20-30 mm thick, which leads to a total volume of about 8-10 1 of glass. Assuming an average glass density of $2.6 \mathrm{~g} / \mathrm{cm}^{3}$ the residual amount of glass is about $20-26 \mathrm{~kg}$. With an averaged concentration based on the analysis of the bottom samples the following ranges can be given:

\begin{tabular}{cccc} 
Element & $\begin{array}{c}\text { Average concentration } \\
\text { of bottom samples }\end{array}$ & $\begin{array}{c}\text { Total amount in } \\
\text { bottom layer } \\
\mathrm{kg}\end{array}$ & wt \% 1 ) \\
\hline $\mathrm{Ru}$ & 0.030 & $0.6 \div 0.8$ & 11 \\
$\mathrm{Rh}$ & 0.005 & $0.1 \div 0.1$ & 6 \\
$\mathrm{Pd}$ & 0.005 & $0.1 \div 0.1$ & 5
\end{tabular}

1) Referred to input 
Additionally the amount of noble metals entrained with the off gas has been calculated from the liquid samples of the seyeral washing columns. The data are given below.

Tab. 5-III

Noble metals analyzed from the liquid samples of the off gas components

\begin{tabular}{|c|c|c|c|c|c|c|}
\hline \multirow[t]{2}{*}{ Components } & $\mathrm{Ru}$ & $\mathrm{Ru}$ & Pd & $\mathrm{Pd}$ & $\mathrm{Rh}$ & $\mathrm{Rh}$ \\
\hline & $\mathrm{g}$ & wt $\left.\%{ }^{*}\right)$ & g & wt $\left.\% *^{*}\right)$ & $\mathrm{g}$ & wt $\left.\%{ }^{*}\right)$ \\
\hline Dust scrubber & 23.6 & 0.38 & 0.8 & 0.04 & 0.9 & 0.05 \\
\hline Condenser & 8.3 & 0.13 & 0.1 & $<0.01$ & 0.2 & 0.01 \\
\hline Jet scrubber & 5.8 & 0.09 & 0.1 & $<0.01$ & 0.1 & $<0.01$ \\
\hline NOx-column & 2.5 & 0.04 & 0.1 & $<0.01$ & 0.1 & $<0.01$ \\
\hline Total & 40.2 & 0.54 & 1.0 & $<0.07$ & 1.3 & $<0.08$ \\
\hline
\end{tabular}

Even taken into account this very small amount of noble metals the overall balance cannot be closed completely. This may be mainly due to the uncertainties of the data for the above calculation of the remaining glass after draining and may be due to inhomogenity of the glass samples at all. Summarizing the balance from both calculations a significant amount especially of $\mathrm{Ru}$ is in form of $\mathrm{RuO}_{2}$ remained on the melter floor.

When extrapolating these findings to long operation times serious accumulations may easily be imagined. In this case a heavy effect on the melter operation can be expected. As can be seen from the electrical resistance (see Fig. 5-17), the bottom sediments formed in the U2 test run already began to distort the electrical field between the low electrodes. 


\subsection{Microscopic observation of glasses from ESM test run U2}

\subsubsection{Glass samples investigated}

The seven glass samples investigated were taken from glass pouring stream by a special sampling device. Their designation code is as follows:

$$
\begin{aligned}
& \text { U2/2-1, U2/3-1, U2/4-1 } \\
& \text { Pouring batch No. } \\
& \text { Can No. } \\
& \text { Test run } \\
& \text { U2/17-3 probe \#1, U2/17-3 probe \#2 } \\
& \text { U2/17-3 probe \#3, U2/17-4 }
\end{aligned}
$$

taken from the overflow stream when filling canister No. 2, No. 3, No. 4, and No. 17, respectively

\subsubsection{Microscopic observations}

The attached Photo 1 shows the U2/17-3, probe \#3 sample, with one of large clusters, transmitted light optical micrograph. Photo 2 shows the same area as Photo 1, reflected light optical micrograph. Photo 3 is also taken from U2/17-3, probe \#3 sample, with one of large clusters, SEM micrograph. In Figs. 5-20 to 5-22, EDS spectra of areas \#1 to \#3 in Photo 3 are given.

All seven samples had two different particles. The darker particles in optical micrograph (\#2 in Photo 2) had typical shape of noble metal oxide, usually $\mathrm{RuO}_{2}$. They were different from $\mathrm{RuO}_{2}$ particles observed in RSM-glasses in two ways: (1) average particle size was 2 - 3 times larger (2) contained a significant amount of $R$ h (\#2 in Photo 3 and Fig. 5-21). The brighter particles (\#3 in Photo 2) seemed to be metals, not oxides, based on their spherical shape and brightness, and consisted of Rh and Pd (\#2 in Photo 3 and Fig. 5-22). A ratio of noble metals to oxides seemed less than 0.1 in all samples.

Rough estimation by optical microscopic observation of the seven samples indicated that in the samples the volume \% of total noble metals (both oxides and metals) increased in the following order:

$$
\begin{array}{ll}
\underset{\text { Sample } 2-1}{(\sim 0.02 \text { Vol } \%)} & (-0.035 \mathrm{Vol} \%) \\
(\sim 0.05 \mathrm{Vol} \%)
\end{array}
$$


$\varepsilon \delta-5 \tau-\varepsilon \quad x$ cog/ qHaped $\varepsilon-4 / \tau n$ f6t
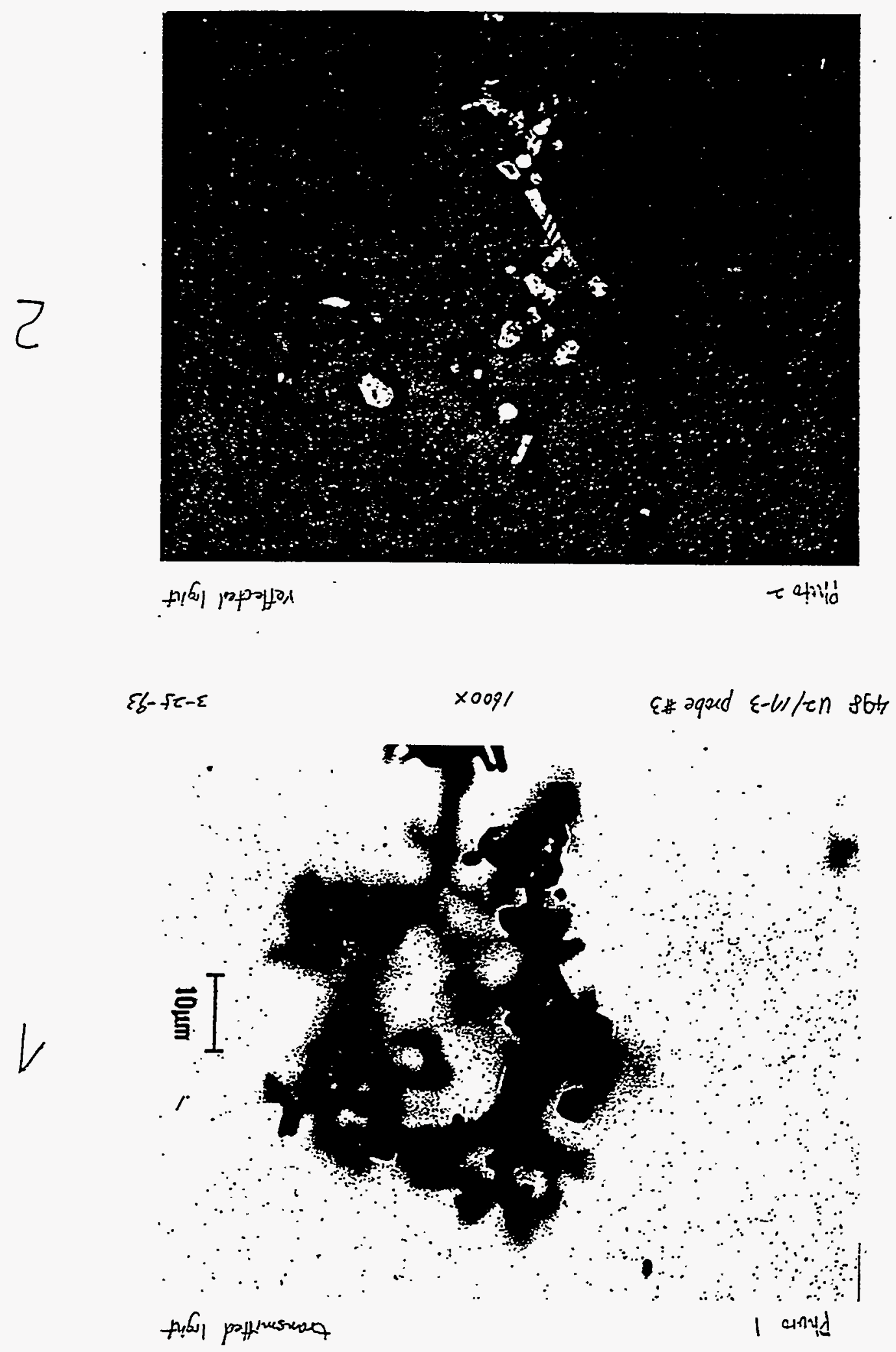

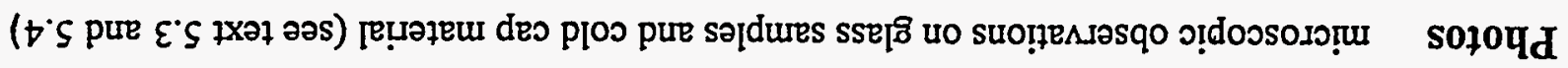


Photos microscopic observations on glass samples and cold cap material (see text 5.3 and 5.4

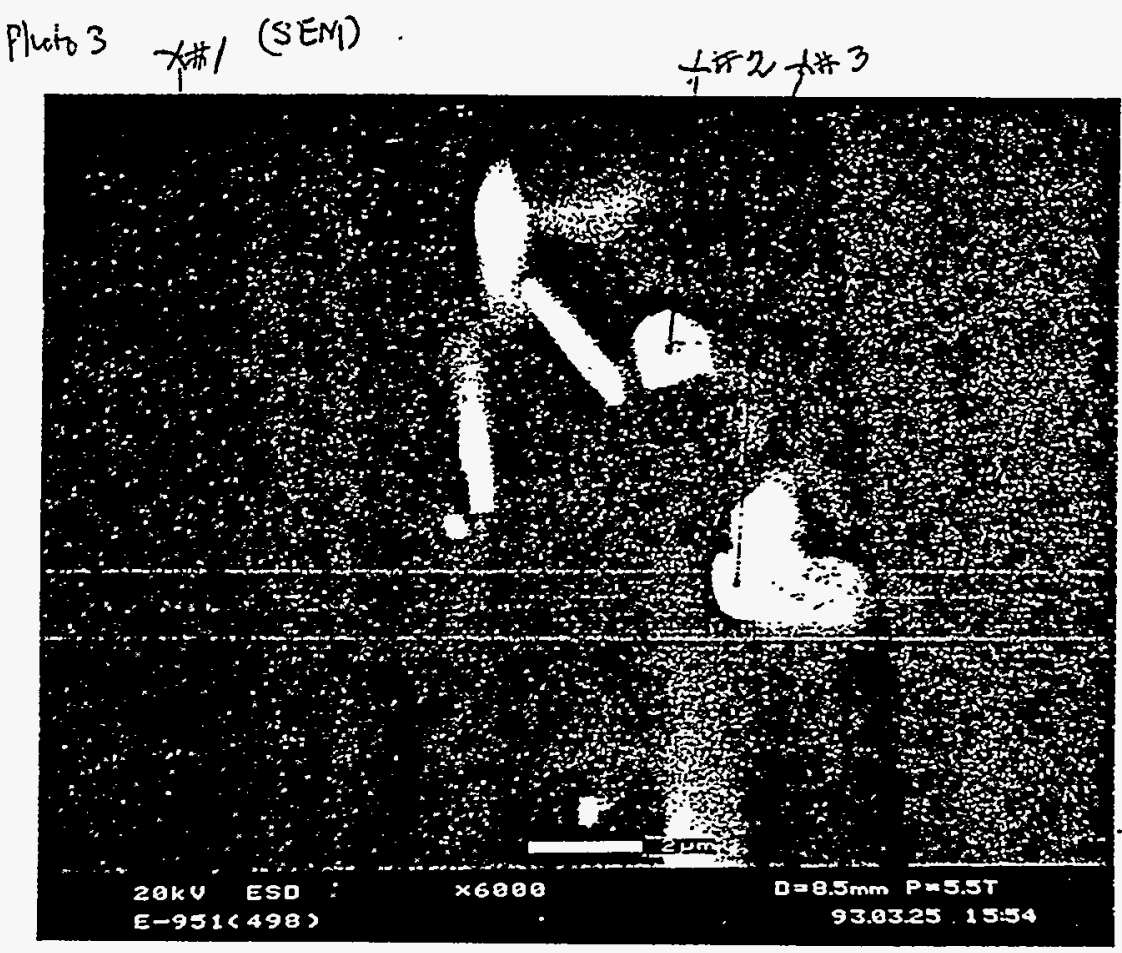

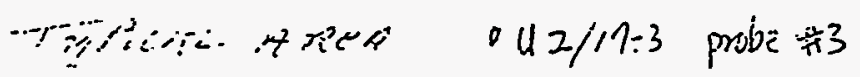




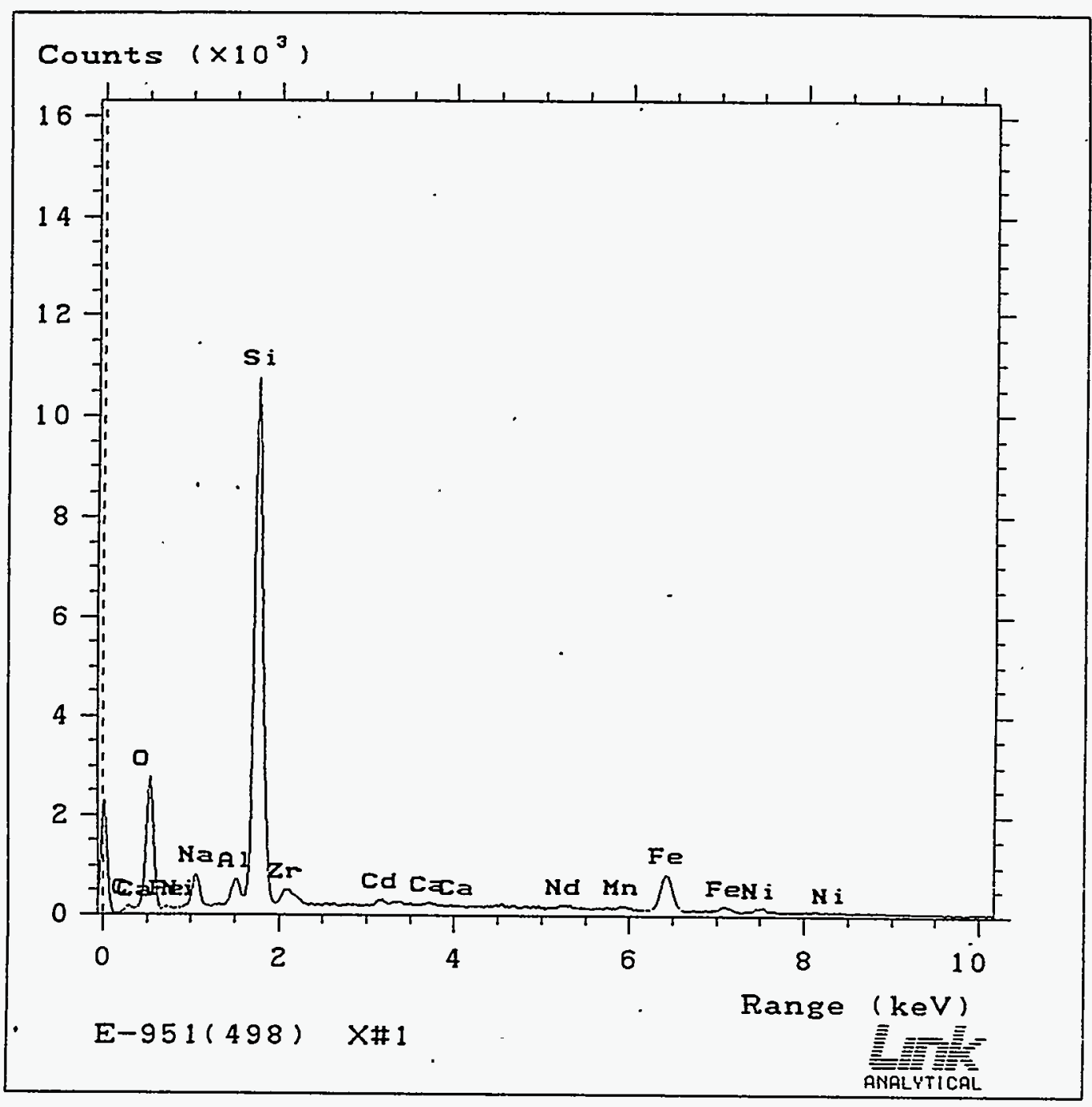

Fig. 5-20: EDS spectra of area \#1 in Photo 3 


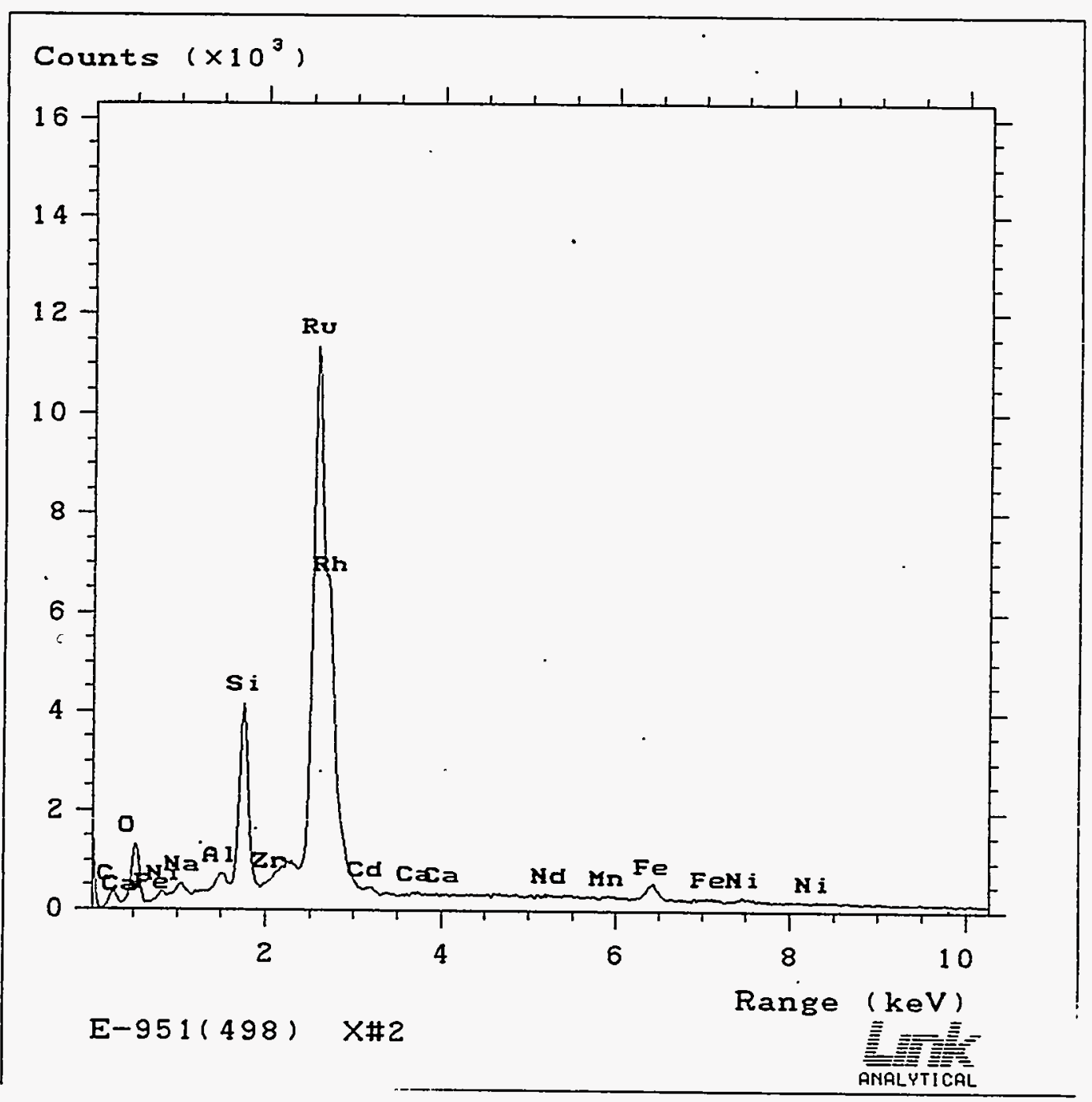

Fig. 5-21: EDS spectra of area \#2 in Photo 3 


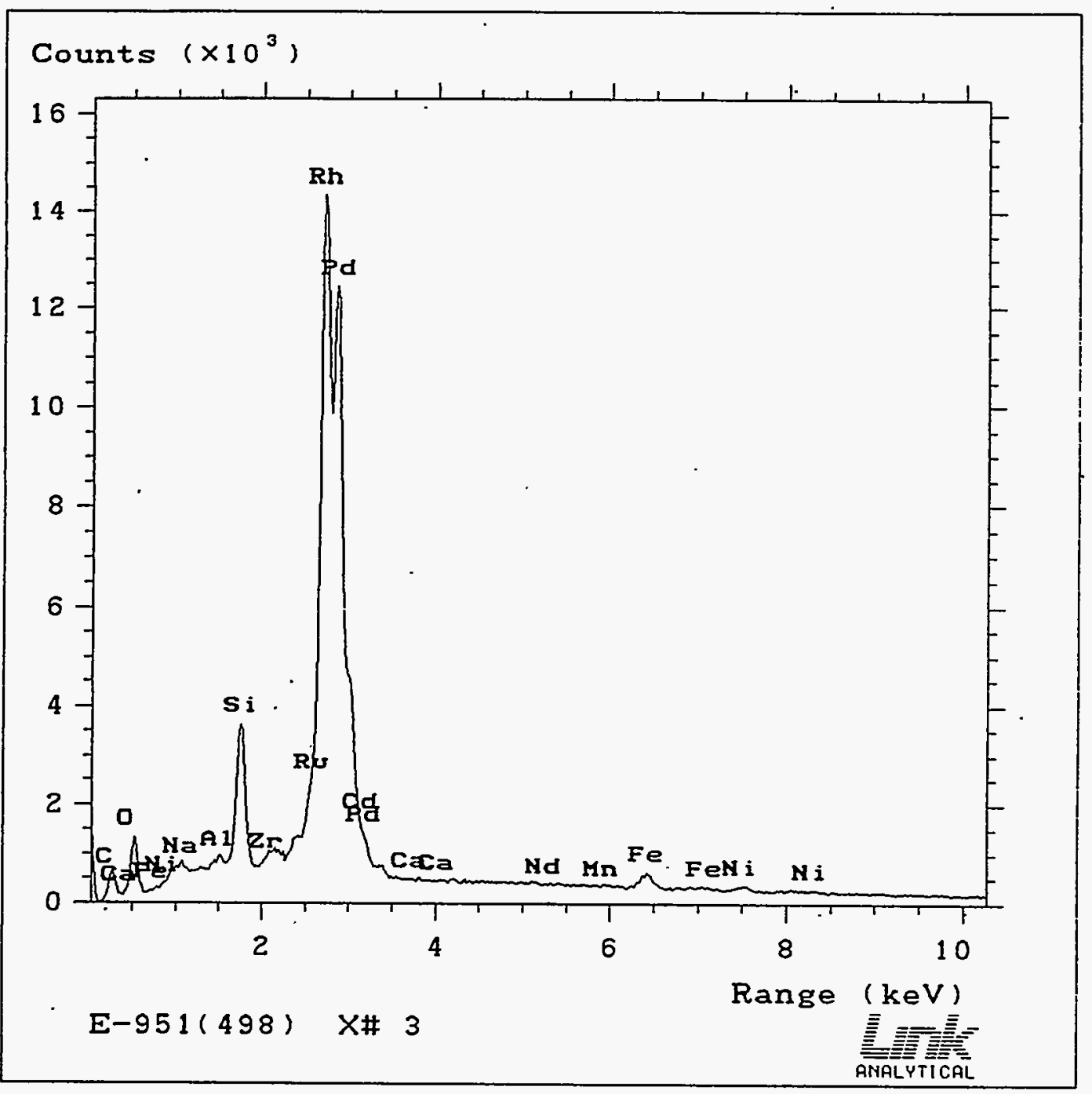

Fig. 5-22: EDS spectra of area \#3 in Photo 3 
The numbers of vol.\% were estimated using an Image Analysis System. The typical size of large clusters of noble metals appeared to have the same order (except for one case, U2/4-1 < U2/17-3\#1).

Transmitted light optical micrographs of the seven glass samples are shown in Photos 4 through 10. Typical areas can be seen with large clusters. These are not necessarily the exact representative areas in each sample nor the areas with the largest clusters.

\subsubsection{Investigation of sample material taken from "Cold Cap"covering the glass melt pool} (sampling in the region around cold cap)

The samples were taken by a special sampling device introduced through a sampling nozzle in the melter roof. The sampling device was a simple cavity of $3 \mathrm{~cm} \mathrm{x} 4 \mathrm{~cm} \mathrm{x} 3 \mathrm{~cm}$ made of Inconel 690 and welded on an long Inconel 690 rod.

Low magnification view of a sample taken from the region around the "Cold Cap" shows Photo 11, transmitted light optical micrograph. Dark (black) area appeared to be agglomeration of undissolved solid particles and/or intermediate crystalline phases. Bright area is glass phase with small amount of noble metals and unreacted solid particles. Bubbles were observed in both areas (from $\sim 5 \mu \mathrm{m}$ up to $\sim 1 \mathrm{~mm}$ in diameter). The further photos show:

- Photo 12, area \#1 in Photo 11, transmitted optical micrograph

Clusters of noble metals are seen within a streak of glass phase between dark areas. Very small bubbles were also observed.

- Photo 13, area \#2 in Photo 11, transmitted light optical micrograph

- Photo 14, same area as Photo 13, reflected light optical micrograph

- Photo 15, rectangular area in Photo 13, transmitted light optical micrograph

- Photo 16 , same area as Photo 15 , reflected light optical micrograph

Dark areas in transmitted light micrographs (Photos 13.and 15) were represented by very small white particles in reflected light micrographs (Photos 14 and 16). Most of all particles in high-magnification transmitted light micrograph of Photo 15 look like crystalline phase (crystallized during melting or undissolved) other than spinel type based on their transparency. Spinels and noble metals were the 
Photos microscopic observations on glass samples and cold cap material (see text 5.3 and 5.4

$$
\text { Piito } 4 \text { transwitted light }
$$

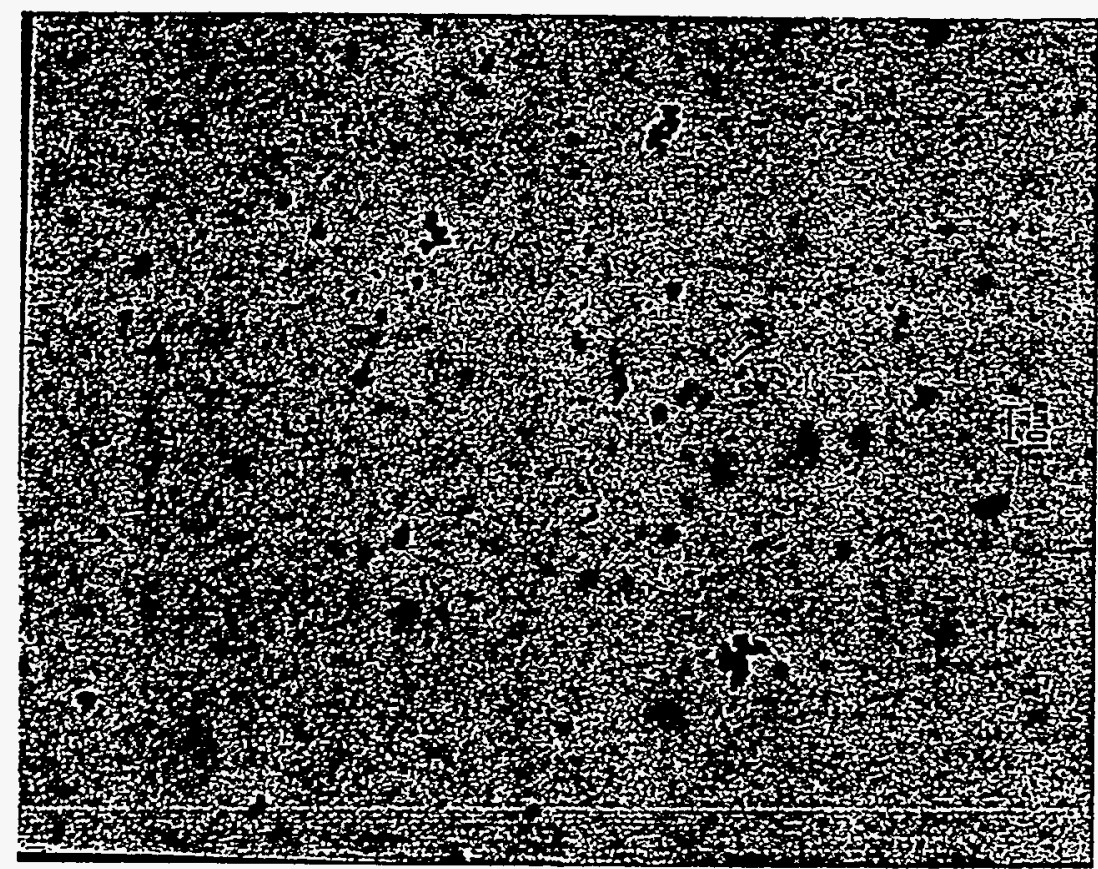

$$
112 / 2-2 \quad 500 x \quad 4-5-93
$$

Plivite 5

$$
\text { transmittatholit }
$$

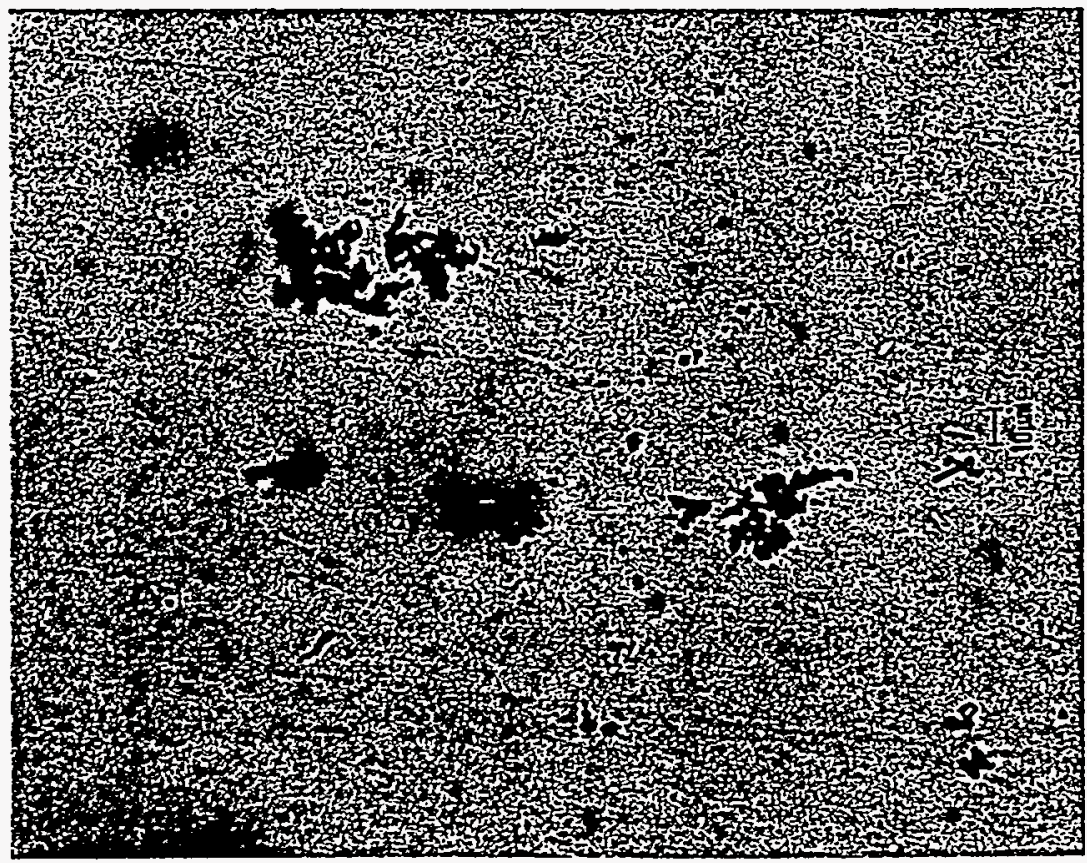

$i i=/ 3-1$

$\operatorname{sen} x$

$4-5-93$ 
Photos microscopic observations on glass samples and cold cap material (see text 5.3 and 5.4 proto 6-... transmetted light

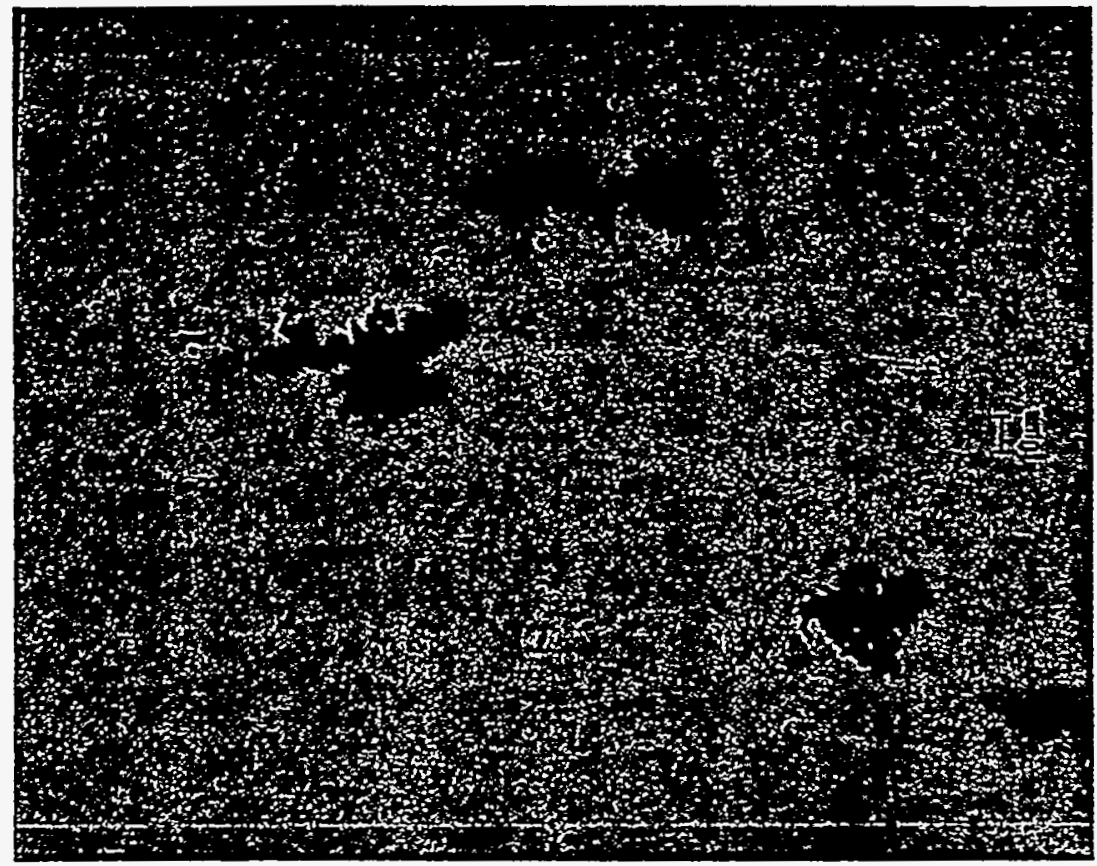

$$
12 / 41+500 x \quad 4-5-93
$$

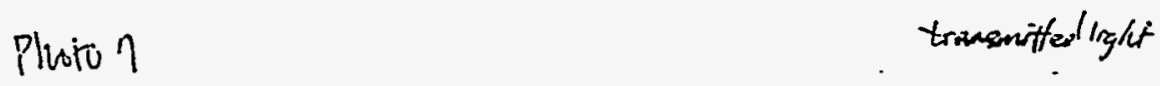

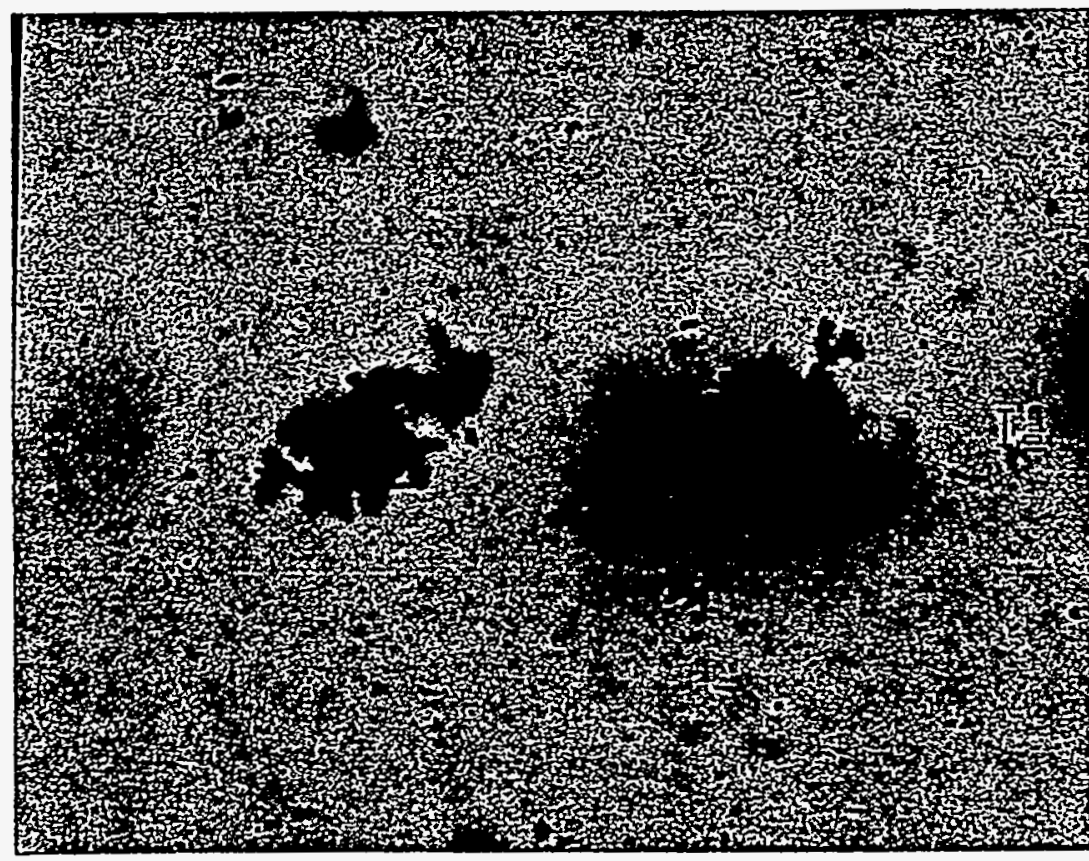


Photos microscopic observations on glass samples and cold cap material (see text 5.3 and 5.4

Ploto:

transwrtted light

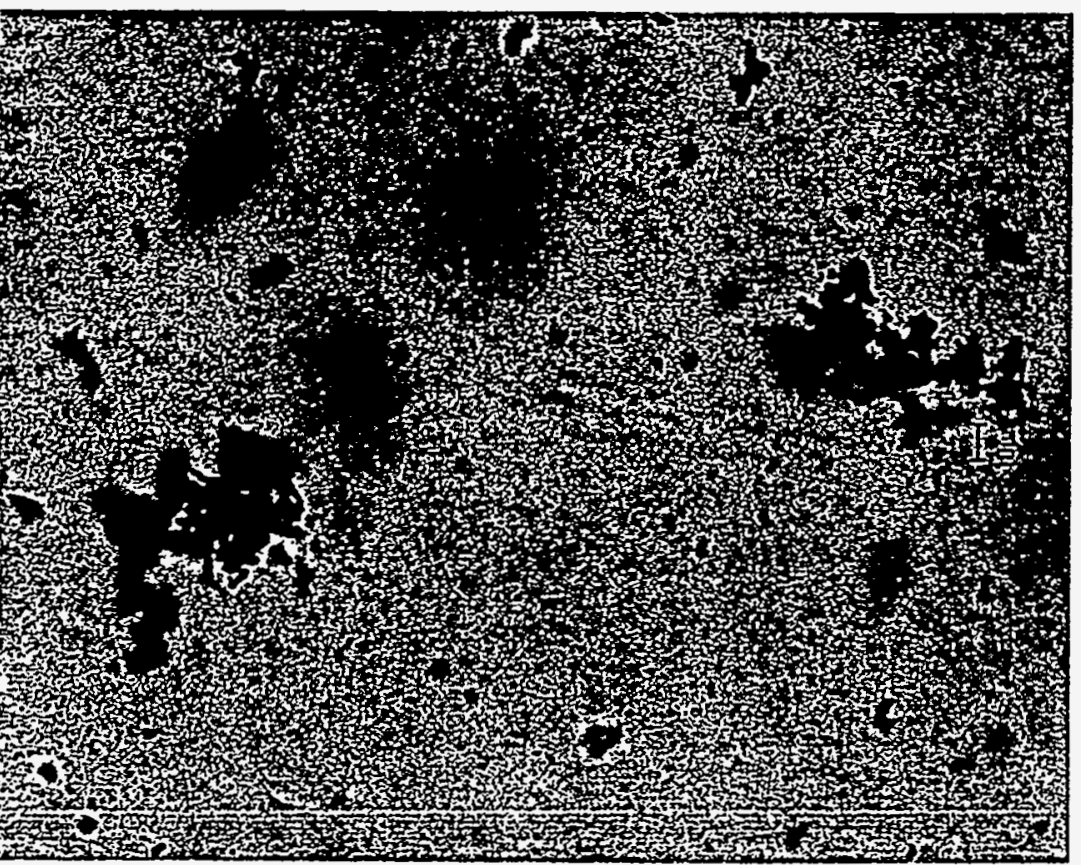

$\tan 42 / 11-3$ probe $\# 2$

$500 x$

$4-5-93$

Phes ?

transmitted loglet

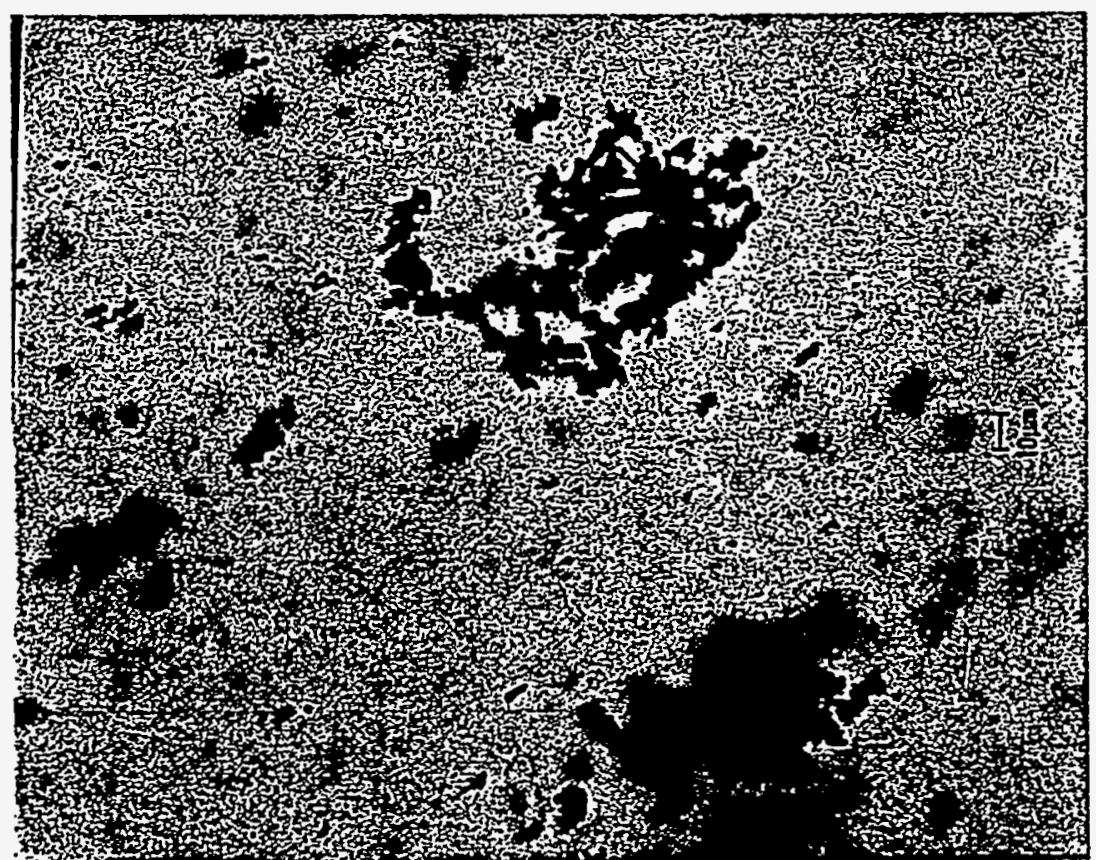

$49 j \quad u=1 / 11-3$ piobe \&3

$500 x$

$4-5-53$ 
Photos microscopic observations on glass samples and cold cap material (see text 5.3 and 5.4)

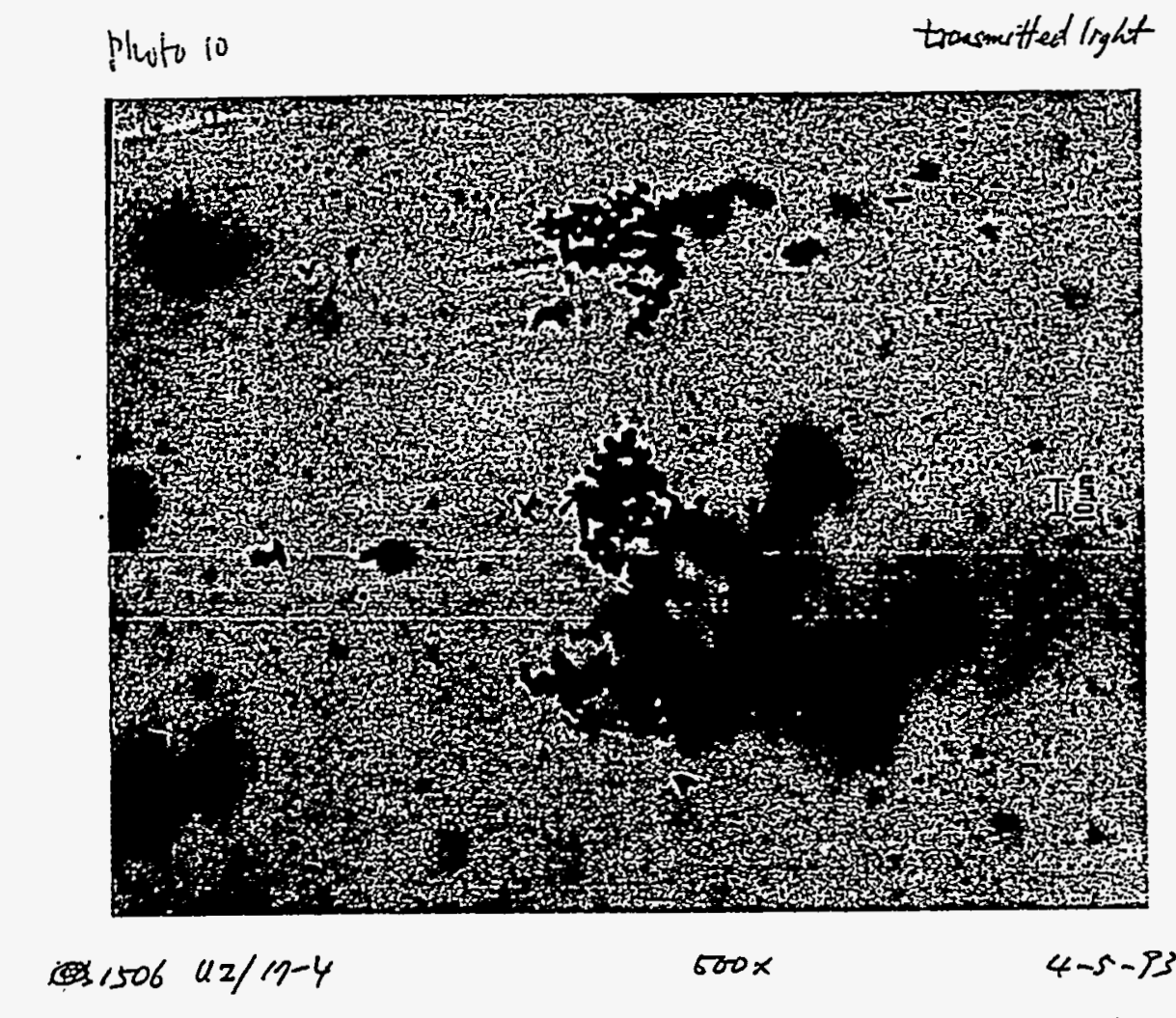


Photos microscopic observations on glass samples and cold cap material (see text 5.3 and 5.4)

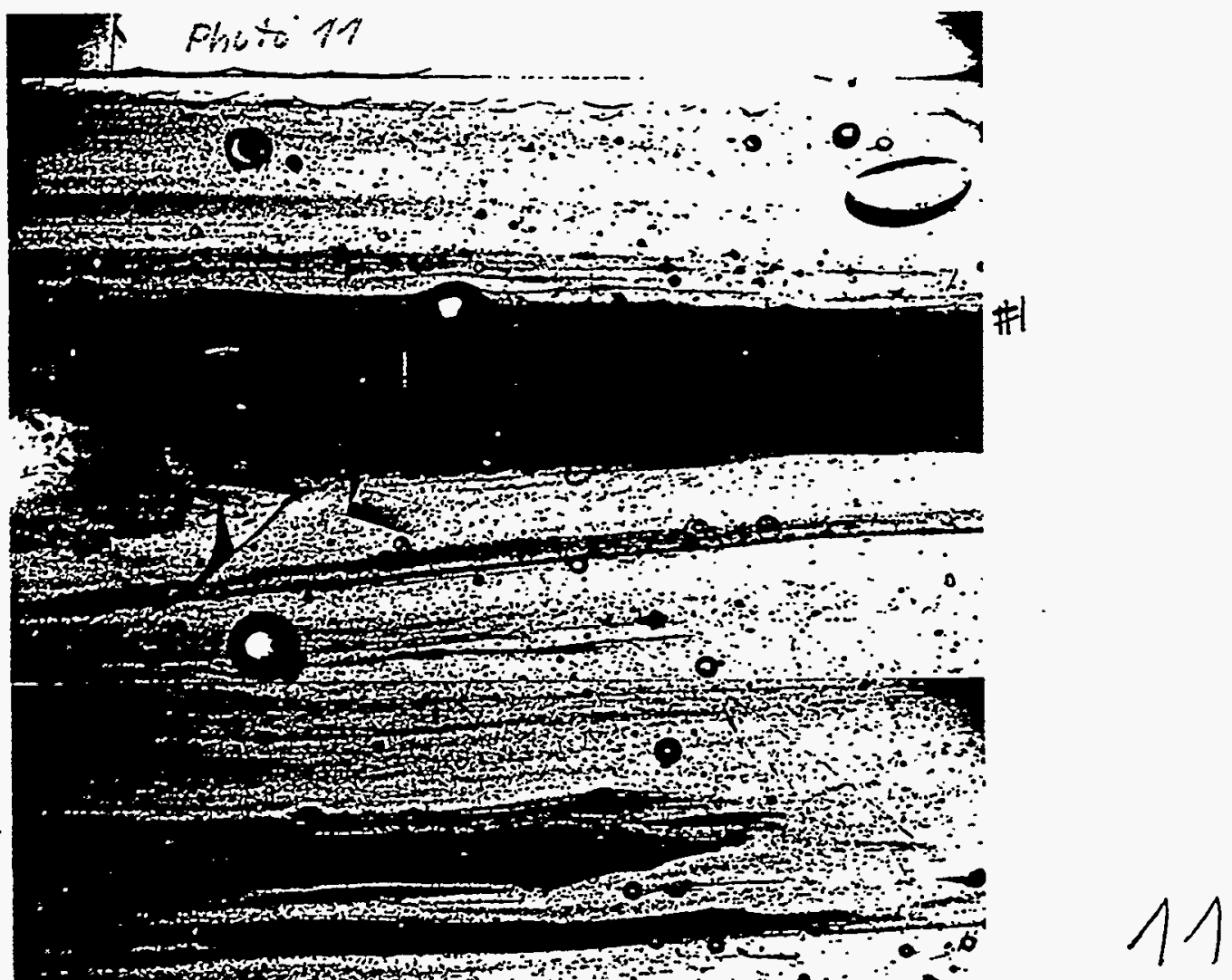

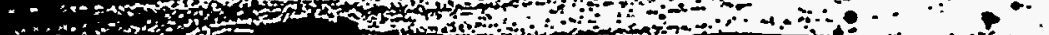

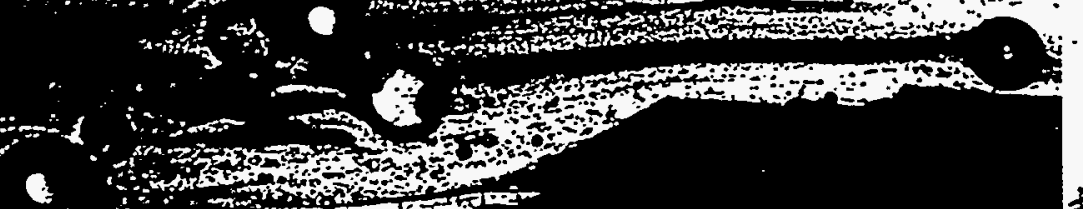

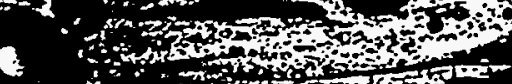

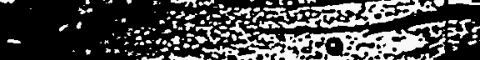

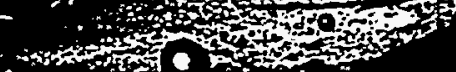

\section{3}


Photos microscopic observations on glass samples and cold cap material (see text 5.3 and 5.4

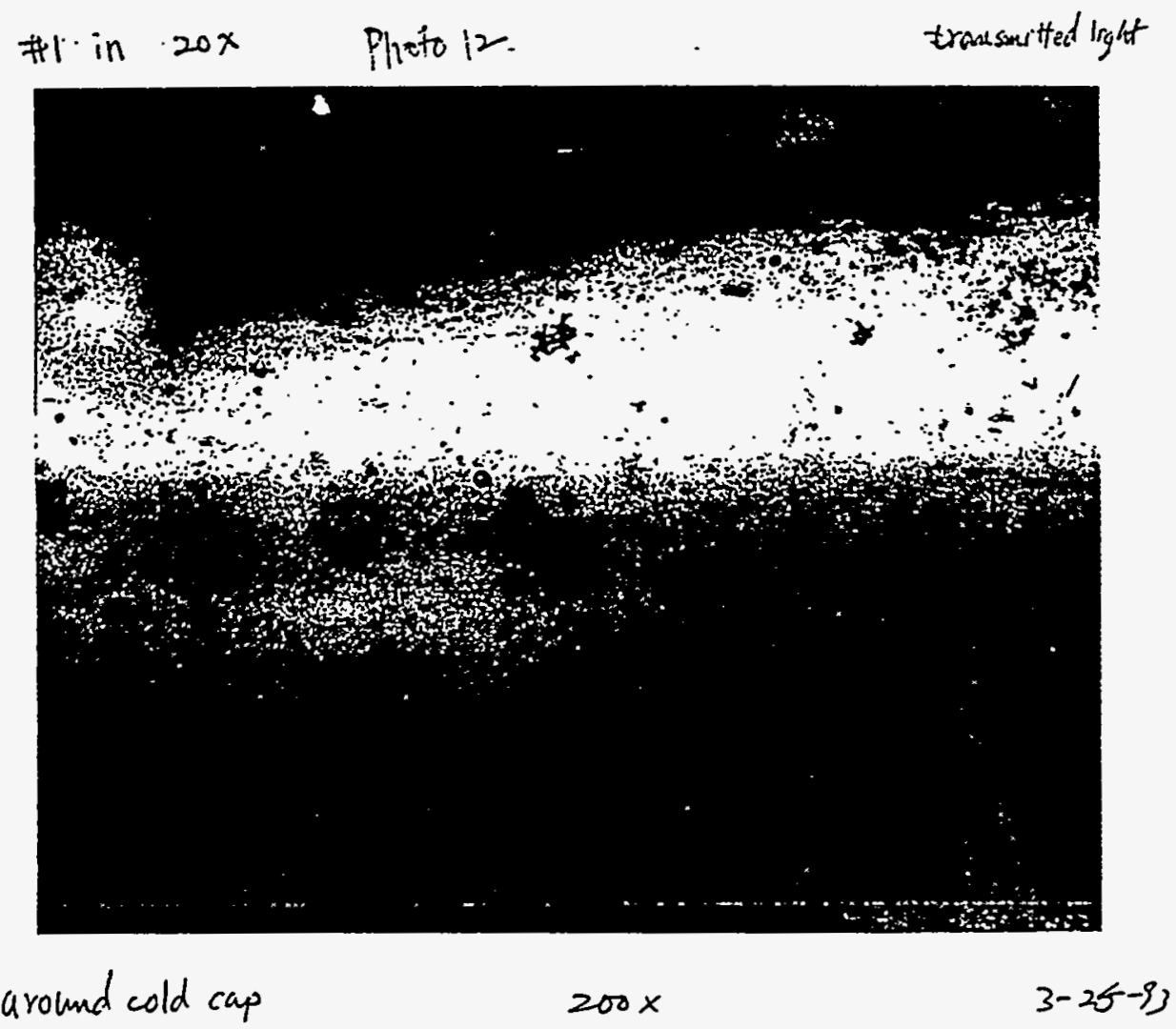

\#2 in $20 x$ Fioto 13 transmitted light

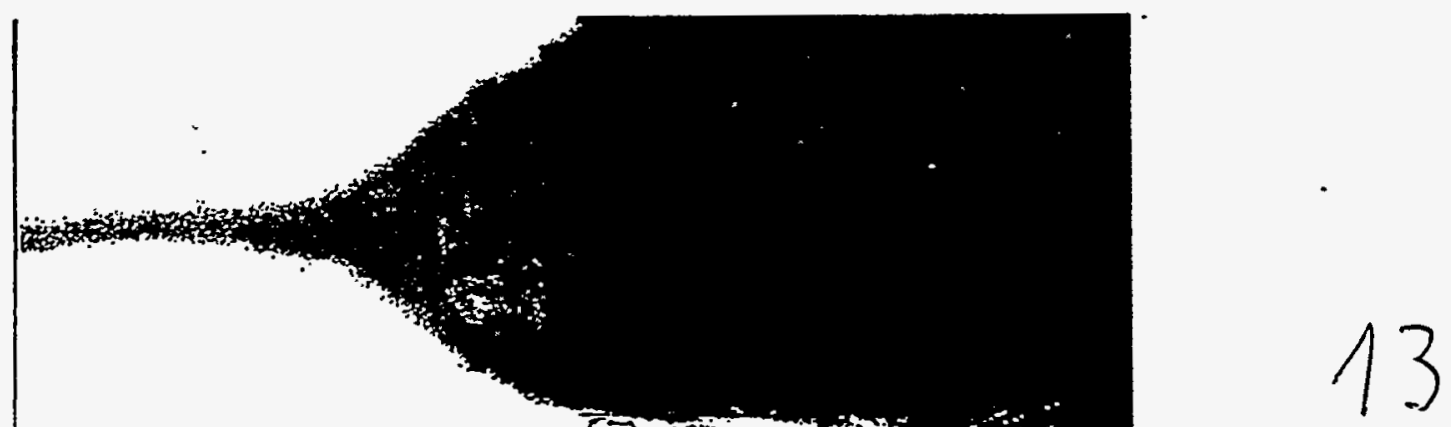

around cold cap

$200 x$

$3-25-93$ 
Photos microscopic observations on glass samples and cold cap material (see text 5.3 and 5.4)

\#2 in $20 x$ Ploto $14 \quad$ reflected loglt

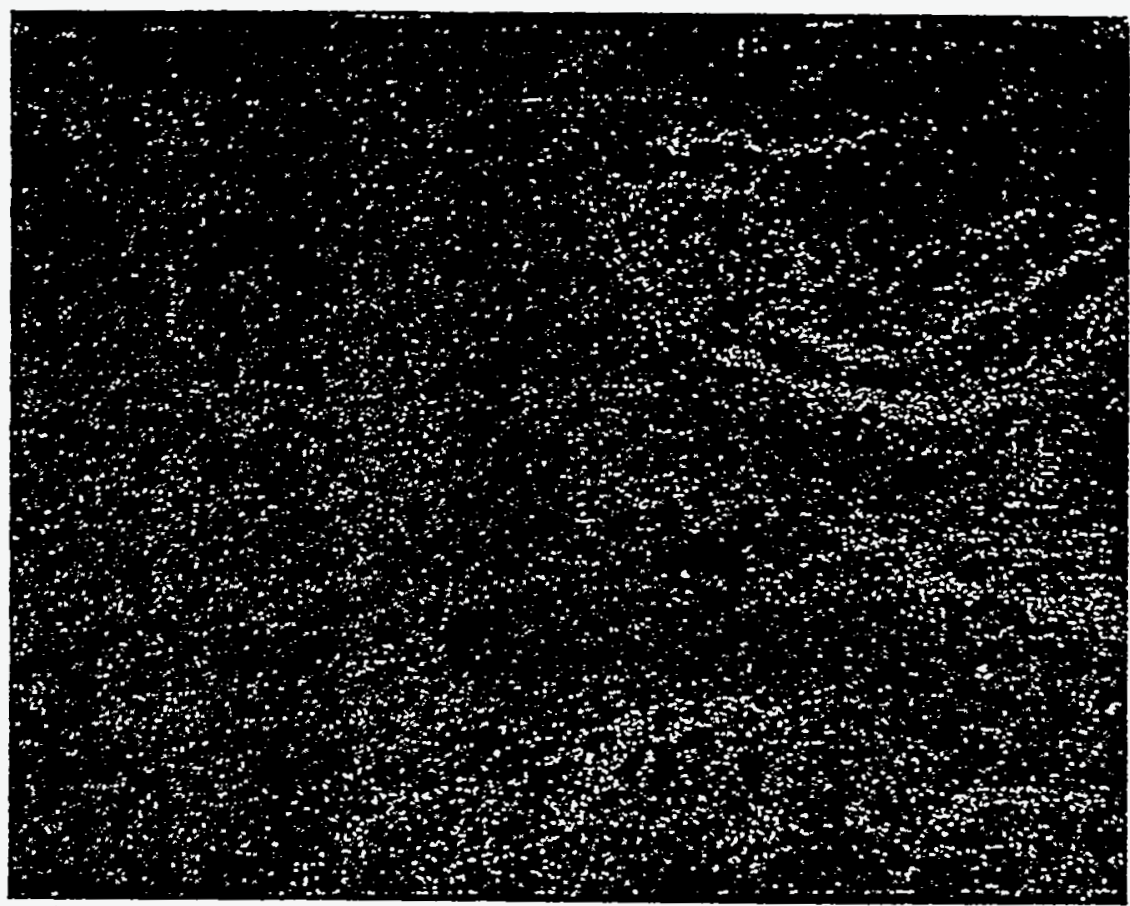

aroind cold cap

$200 x$

$3-25-93$
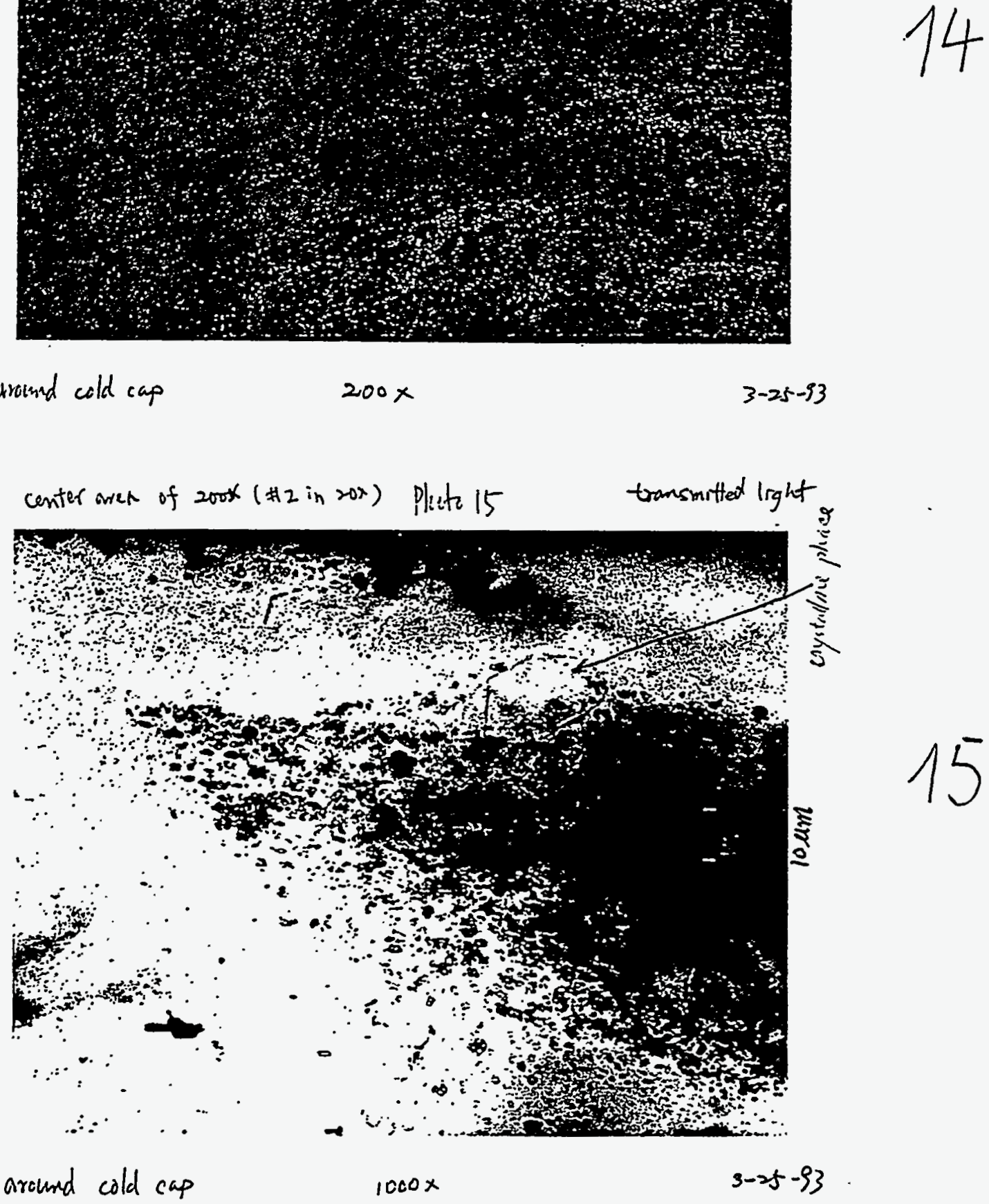
Photos microscopic observations on glass samples and cold cap material (see text 5.3 and 5.4)

$$
\text { center areb if } 200 x \text { (in } 2 \text { in 20r) Plecte it reflected ligit }
$$

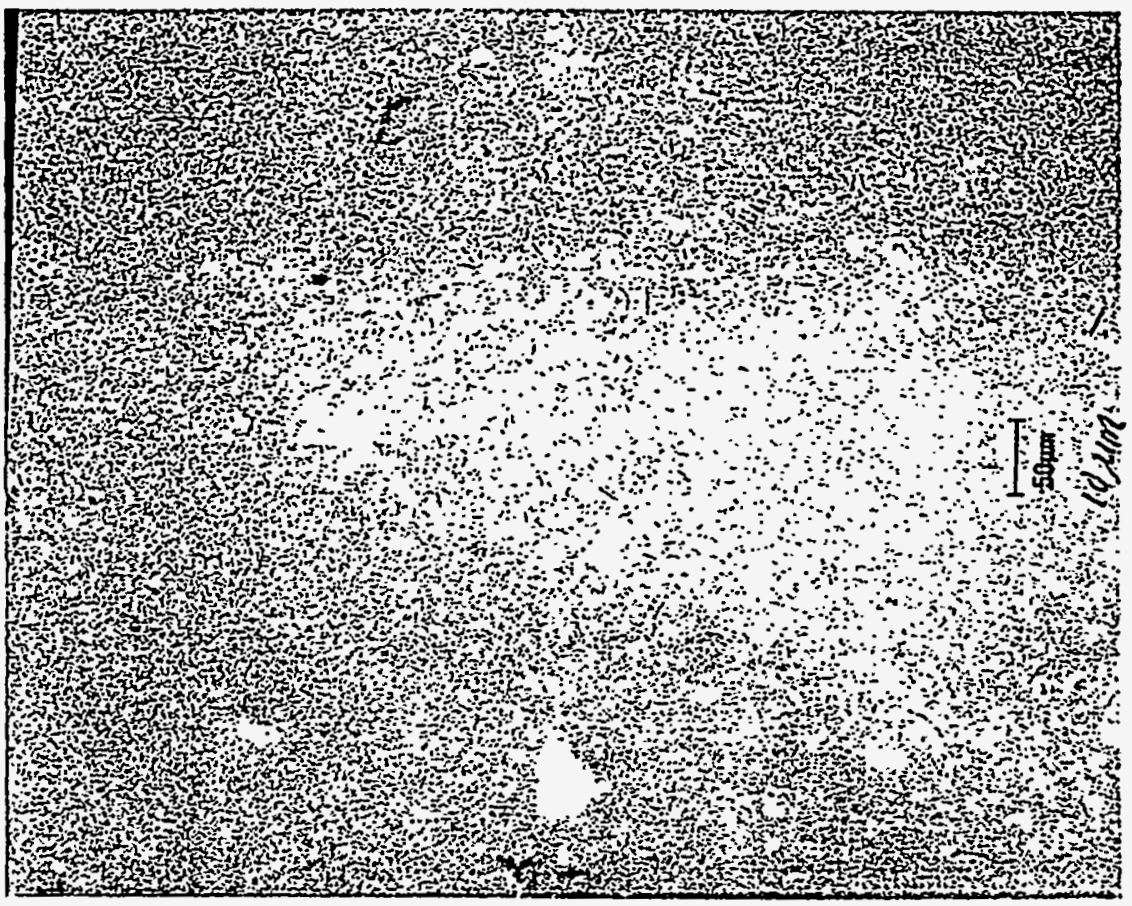

à;curad cold cap

$1000 x$

$3-25-93$
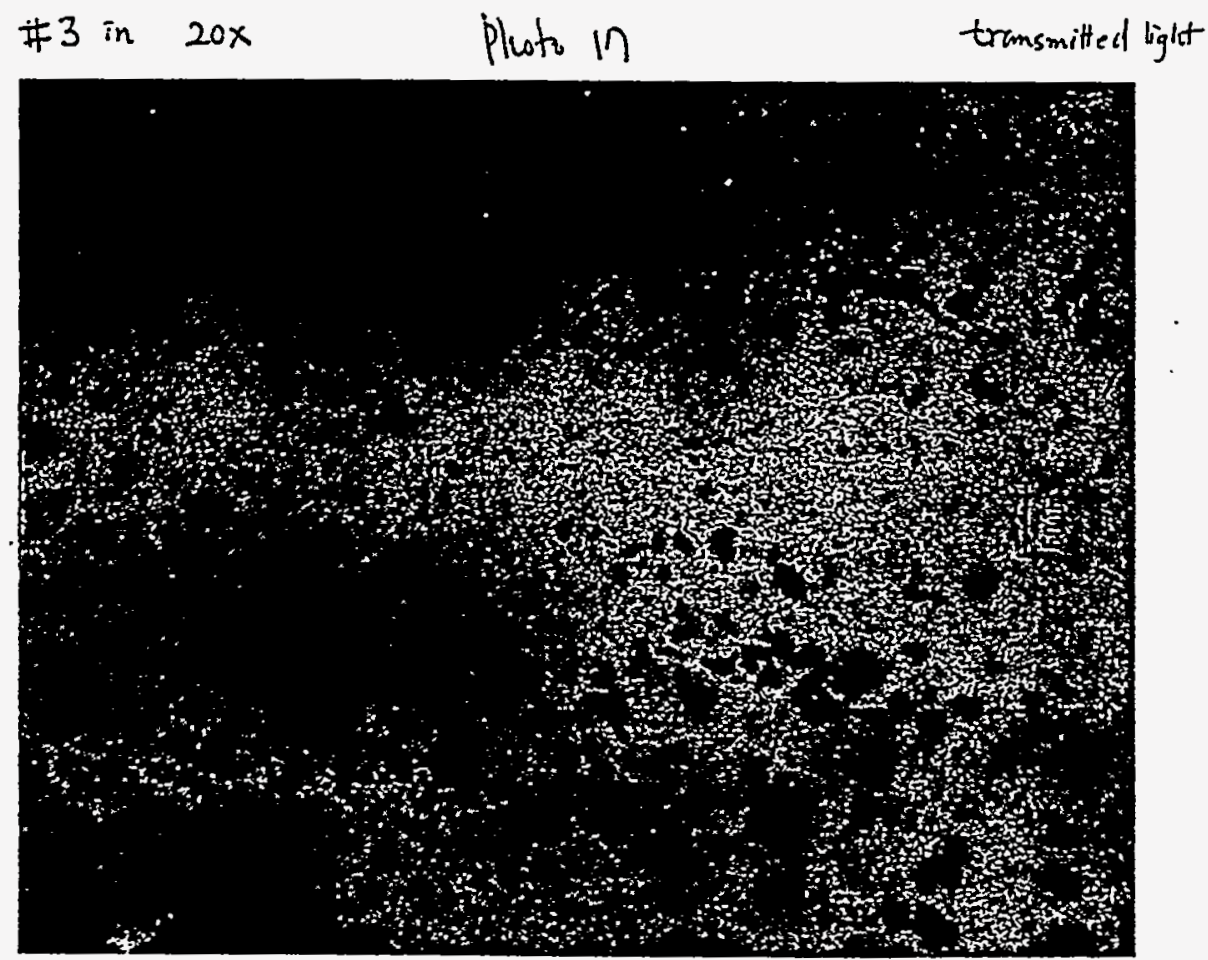

around cold cap

$200 x$

$3-25-93$ 
only opaque phases observed in CVS glasses (noble metals are black, spinels are dark brown or black). An example of large crystalline phase is shown in Photo 15, which may be an intermediate phase (crystallized during melting, $\sim 15 \mu \mathrm{m}$ ).

Photo 17 represents the area \#3 in Photo 11, transmitted light optical micrograph. Streaks of noble metal clusters are seen within the glass area.

\subsubsection{Investigation of sample material taken from centre of the "Cold Cap"}

Photo 18 shows a low magnification view of "Cold Cap Centre" sample material, transmitted light optical micrograph. Strong flow patterns, which at least partly might have been formed during sample collection from the melter, were visible. Most bubbles were distorted or elongated along the flow direction. The dark and bright areas were similar to those in "Region Around Cold Cap" sample, except that "Cold Cap Centre" sample had less dark areas. The cold cap was generally highly viscous and sampling of material required special techniques and procedures to get representative material.

Photo 19 gives the area \#1 in Photo 18, transmitted light optical micrograph. Photo 20 represents the ractangular area in Photo 19, transmitted light optical micrograph. Streaks of undissolved particles (dark area in Photo 19) and clusters of noble metals (Photo 20) were visible whithin the glass area. Photo 21 was taken from the area $\# 2$ in Photo 18 , transmitted light optical micrograph.

\subsection{Noble metals effects on glass properties}

The influence of noble metals on viscosity and electrical conductivity of the waste glass were investigated because these properties are important in respect to glass melting

\subsubsection{Samples investigated}

The glass samples investigated were

- Glass frit used in the ESM test run U2

- Samples taken from pouring stream of the overflow system and from pouring stream of the bottom drain during emptying of the melter.

The sample code is as follows: f.e. U2/8-2, \#3 means: sample taken during the noble metal test run U2 while filling the $8^{\text {th }}$ canister ( $375 \mathrm{~kg}$ glass capacity) with the $2^{\text {nd }}$ of five pouring batches (75 kg each). During filling of one batch, five samples were taken. Here the code indicates sample \#3: 
Photos microscopic observations on glass samples and cold cap material (see text 5.3 and 5.4)

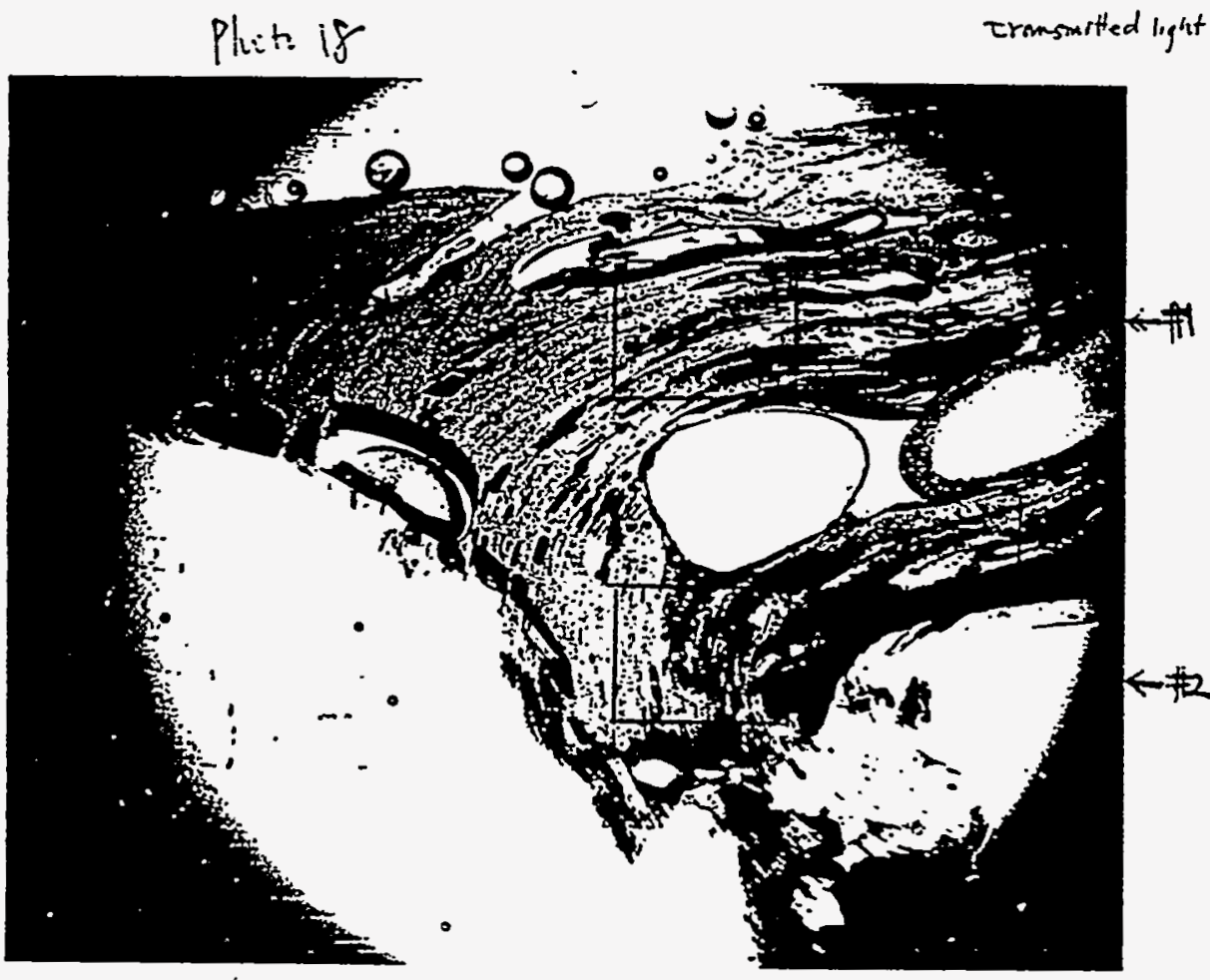

cold cop Zentrum (1).

$15 \times$

$3-26-93$
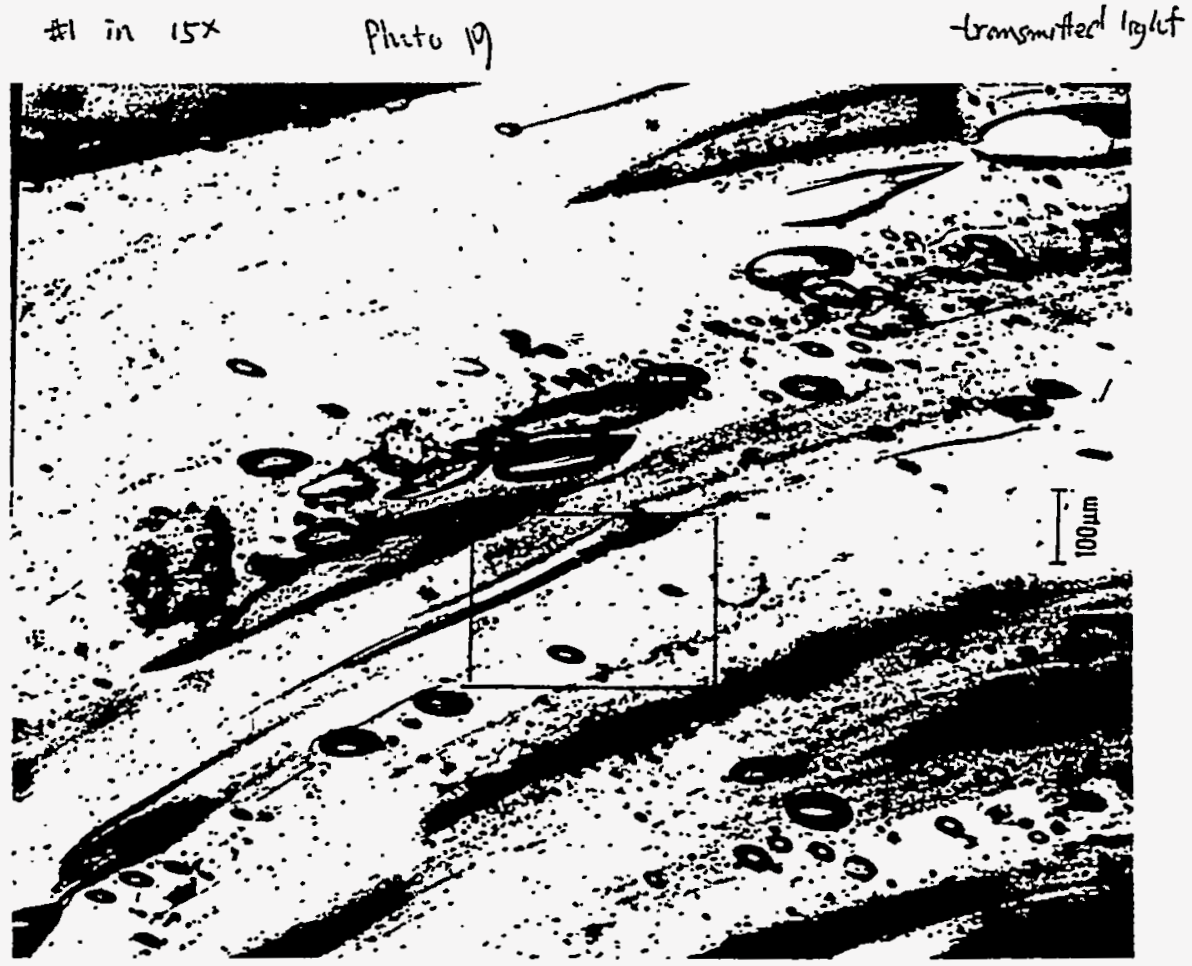

Cold cap zertum(D)

$100 x$

$3-26-93$ 
Photos microscopic observations on glass samples and cold cap material (see text 5.3 and 5.4)

$$
\text { cinter ame of } 100 \times(* 1 \text { in 15x) Photo } 20 \text { trensmittad 1 igit }
$$

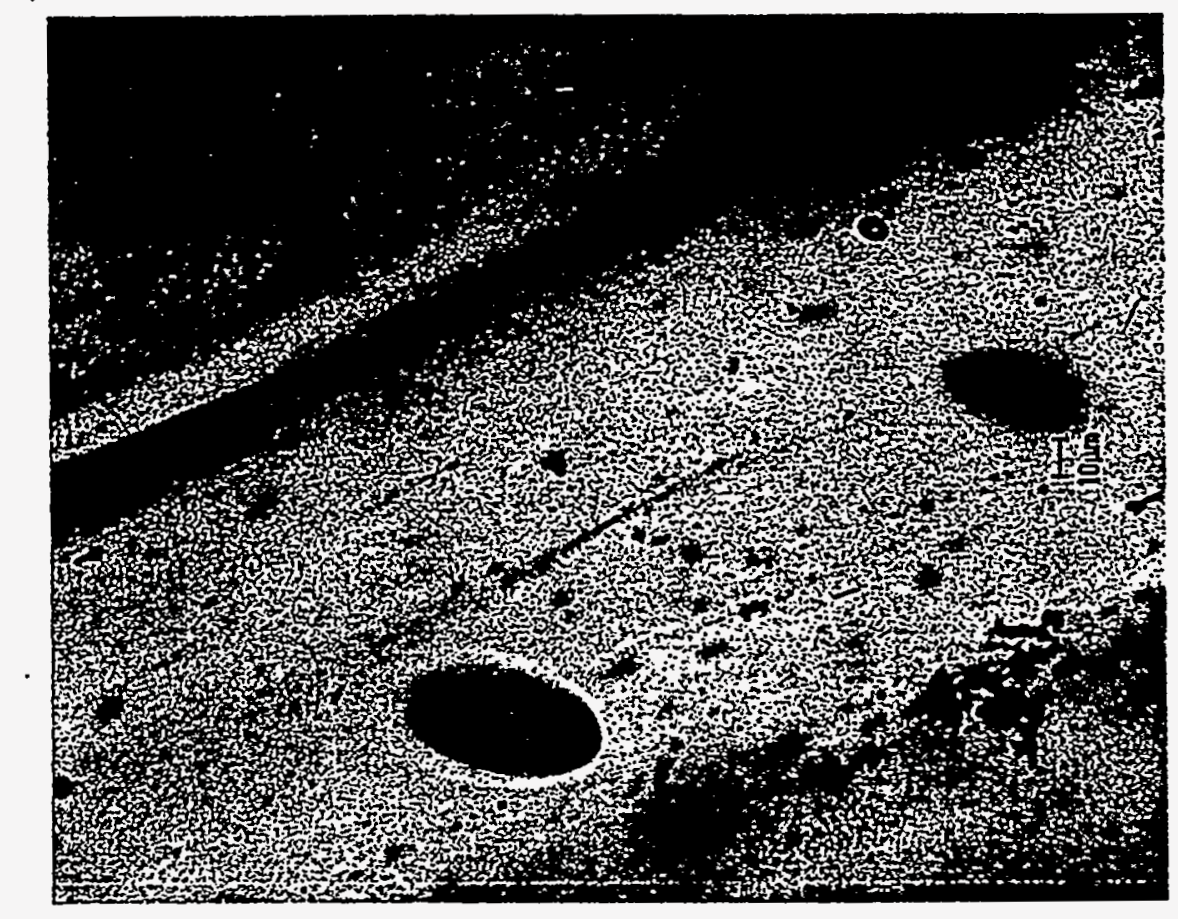

Coldcap zantrum (D)

$500 x$

$3-26-93$

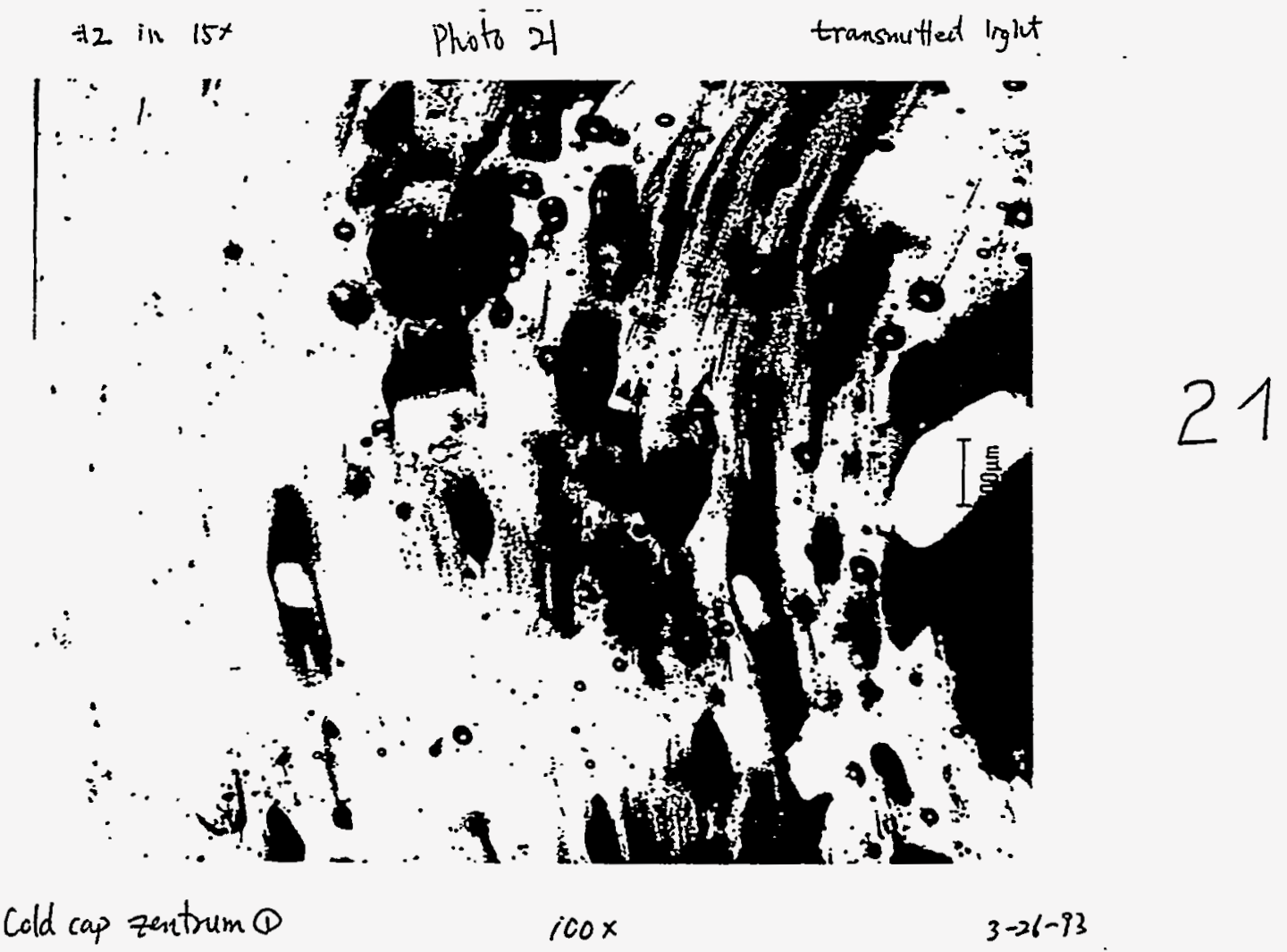


The following samples were used for measurements

\begin{tabular}{|c|c|c|}
\hline For viscosity & For specific el. resistivity & \\
\hline Glass frit & Glass frit & \\
\hline $\mathrm{U} 1 / 2-2, \# 3$ & $\mathrm{U} 1 / 2-2, \# 3$ & \\
\hline $\mathrm{U} 2 / 1-1, \# 3$ & - & \\
\hline - & U2/1-1, \#3 & \\
\hline $\mathrm{U} 2 / 8-2, \# 3$ & U2/8-2, \#3 & \\
\hline - & $\mathrm{U} 2 / 17-4, \# 5$ & \\
\hline $\mathrm{U} 2 / 17-4, \# 3$ & - & \\
\hline$-\quad$. & $\mathrm{U} 2 / 18, \# 1$ & Samples taken \\
\hline Uं2/18, \#5 & $\mathrm{U} 2 / 18, \# 5$ & while emptying \\
\hline - & $\mathrm{U} 2 / 18, \# 12$ & the melter via \\
\hline - & $\begin{array}{l}\text { From melter bottom, No.5 } \\
\text { (after emptying) }\end{array}$ & bottom drain \\
\hline
\end{tabular}

\subsubsection{Results}

The results are plotted versus temperature in Fig. 5-23 for viscosity and in Fig. 5-24 for specific el. resistivity. The most significant influence of noble metals on glass melt properties were found by the lowering of the specific electrical resistivity with increasing contents of noble metals. According to the data in Fig. 5-24 a sample from the remaining glass layer at the melter bottom showed el. resistivity decrease by a factor of $5\left(1200^{\circ} \mathrm{C}\right)$ to $20\left(900^{\circ} \mathrm{C}\right)$, compared to the normal values of the glass product containing the target concentration of noble metals.

Unfortunately the collected quantity of sample material from the remaining layer of glass on the melter bottom is not sufficient to make viscosity measurement, too. However, attempts are under way to get results despite this facts. The highest viscosity has the NCAW glass frit used for the U2 run, see Fig. 5-23. Noticeable higher viscosity of the waste glass, compared to the target, can be seen for sample U2/18, \#5 which has the highest noble metals concentration of all samples measured $(0.268 \mathrm{wt} \%$ totally, see table integrated in Fig. 5-24). The noble metals concentration data given in this table of Fig. 5-24 were obtained by RFA and have not been corrected according to chapter 5.2.3. 


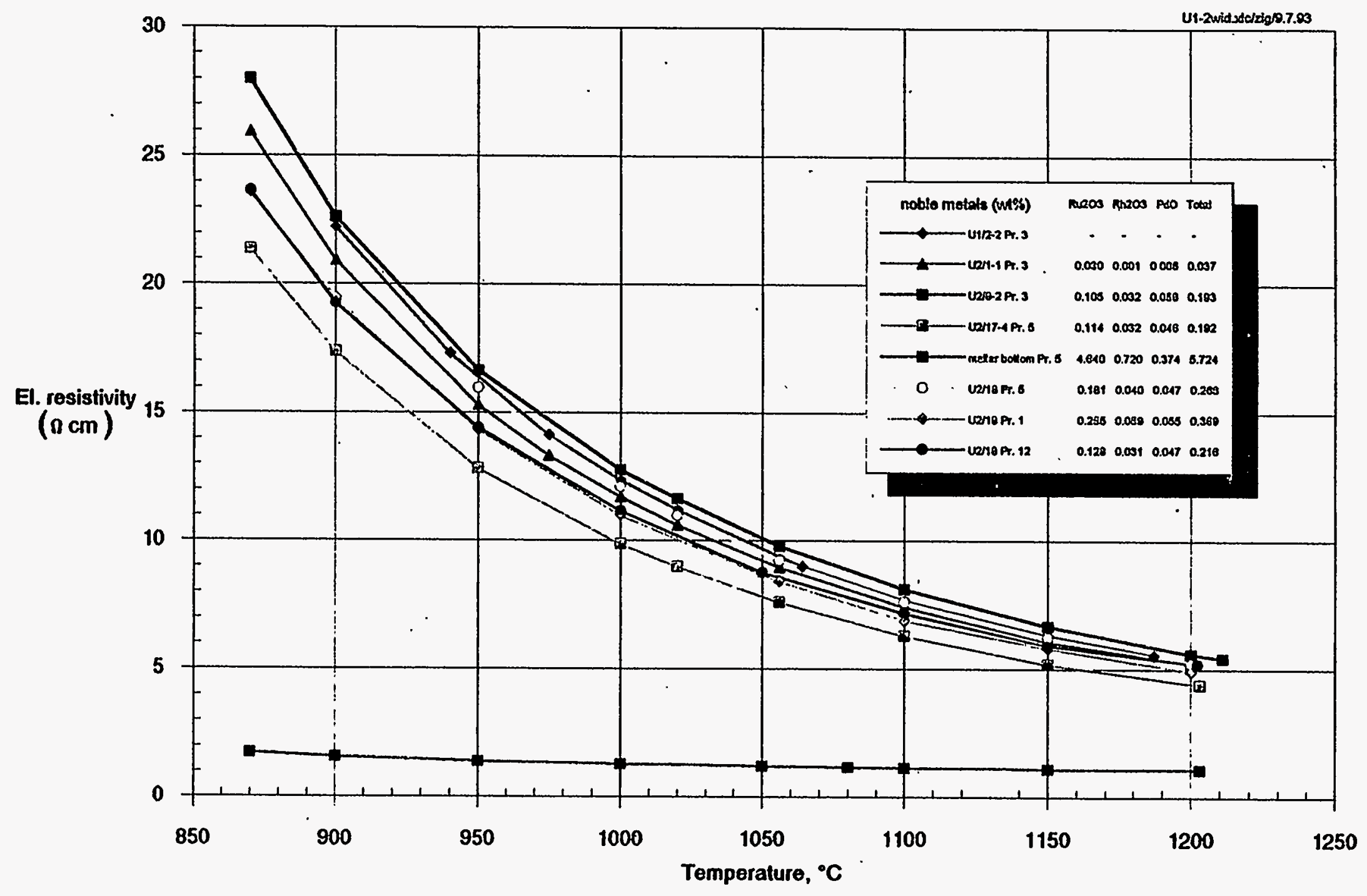

Fig. 5-23: Electrical resistivity of glass samples containing different quantities of noble metals 


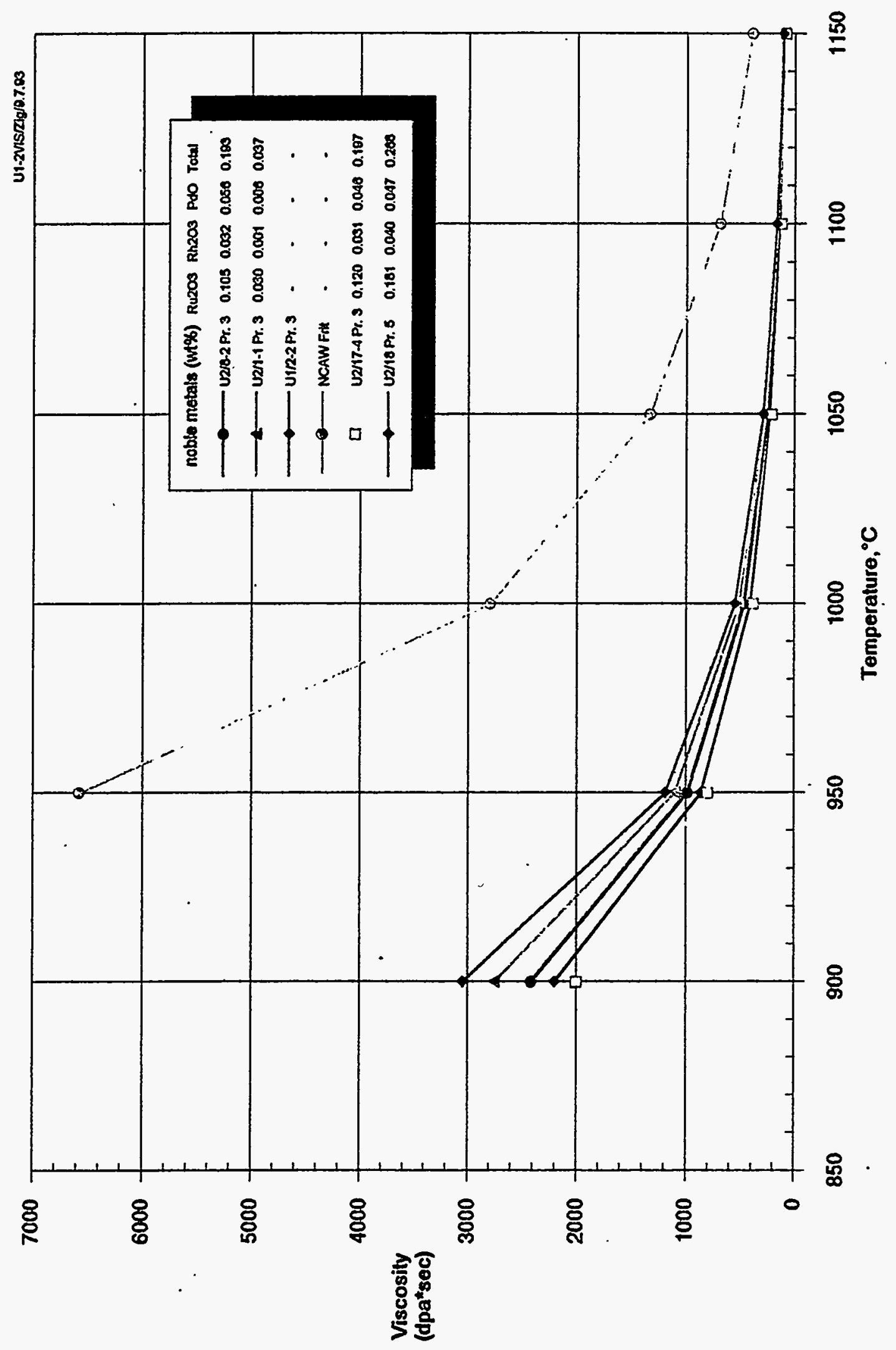

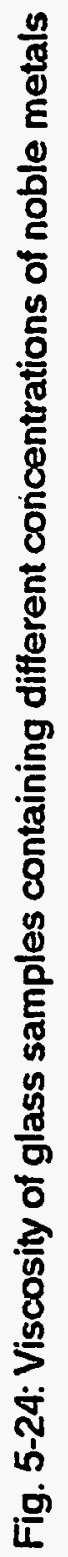




\subsection{COMPUTER MODELING OF THE ENGINEERING-SCALE MELTER}

The objective of this activity within the Melter Performance Assessment (MPA) activity of the Pacific Northwest Laboratory (PNL) Hanford Waste Vitrification Plant (HWVP) Technology Development (PHTD) program is to predict development of a sludge layer containing a high concentration of noble metals and determine the effect of the sludge layer on melter operation. The work scope includes evaluating predictions with experimental data being obtained in the RSM and ESM testing. These predictions, when completed and compared to experimental data, are to be combined with other data and predictions to form the basis for assessing noble metals effects on the operation of the HWVP reference melter design.

The TEMPEST computational fluid dynamics computer program is used in this work. A computer model of the ESM was setup, debugged, and tested. The plan for computer modeling included using this model to perform pre-test predictions. The pre-test predictions were designed to develop computational approaches and to test submodels. Submodels are those which couple concentration dependent properties and noble metals particle characteristics to the computation of melter operation parameters and predictions of development of an enhanced conductivity, noble metals rich, sludge layer. In pre-test computations, target values of the experiment test plan were used to define input.

Subsequent to performance of the ESM experiment, as described in previous sections of this report, post-test computer modeling was done. The post-test computations used data from the experiment in two ways. Measured property data and glass sample analysis to determine particle characteristics were used as input to post-test analysis and as a basis for improving computer submodels. Predictions with the improved submodels are then compared to measured experimental data of melter operation.

1) Work conducted at U.S. Department of Energy's Pacific Northwest Laboratory, operated by Battelle Memorial Institute under contract DE-AC06-76LO 1830

2) Trent, D.S., and L.L. Eyler. 1992. TEMPEST: A Three-Dimensional Time-Dependent Computer Program for Computational Fluid Dynamics, Version T, Volume 1: Theory Manual, Volume 2: Input Instructions. Battelle Memorial Institute, Columbus, Ohio. (In preparation.) 


\subsection{COMPUTER MODELING RESULTS - PRE-TEST PREDICTIONS}

\subsubsection{Power and Thermocouple Stalk Data}

Computer modeling pre-test results are presented in Section 6.1 Post-test simulation results are contained in Section 6.2. Additional details of the modeling including a description of TEMPEST, ESM computer model, analysis approach, boundary conditions, submodels, and property functions are presented in Appendix D.

The computer model described in Appendix D was used to compute the coupled flow, thermal, and electric field characteristics in the ESM. The computational approach used the temperature controller with a target bulk melt temperature of $1150^{\circ} \mathrm{C}$. Bulk temperature integration was conducted over approximately the central 60 percent of the melt pool. This volume was chosen so as not to bias the integration with colder glass temperatures under the cold cap and near walls. Figure 6-1 presents the computed result for time dependent total power, integrated bulk melt temperature, and average thermocouple temperature. The average thermocouple temperature is the linear sum of four locations in the computational domain approximating the four measurement locations on the thermocouple stalk (see Figure 3-10).

Included in Figure 6-1 are experimental data for steady state power and thermocouple temperatures in the glass melt. The computed power is the total joule heating in the glass melt as a result of both electrode pairs operating. The time dependent approach of the computed result towards steady state has reached a value of $22.9 \mathrm{~kW}$ over the time shown. The preliminary power data is shown as $22 \mathrm{~kW}$ which is the sum of the power in the upper electrode pair $(280 \mathrm{~A}, 43 \mathrm{~V}, 12 \mathrm{~kW})$ and the lower electrode pair (250 A, $40 \mathrm{~V}, 10 \mathrm{~kW}$ ). Agreement of these pre-test computed results and the preliminary-reported power data is quite good.

Also included in Figure 6-1 is the time dependent variation of the integrated bulk glass temperature (Tbulk) and the average of the four temperatures (TCouple) in the discrete computational domain corresponding to the four thermal thermocouple locations in the thermocouple stalk. Preliminary data for four thermocouples submerged in the glass melt representing steady state values are included in the figure. They are included as if they occurred at a time near the end of the computed time. The temperature range of the four data points (two of the hotter points are coincident) is shown by the

3) M-L. Elliot, September 29, 1992. Foreign Travel Trip Report. Data reports as obtained July 15, 1992, 13:00. 


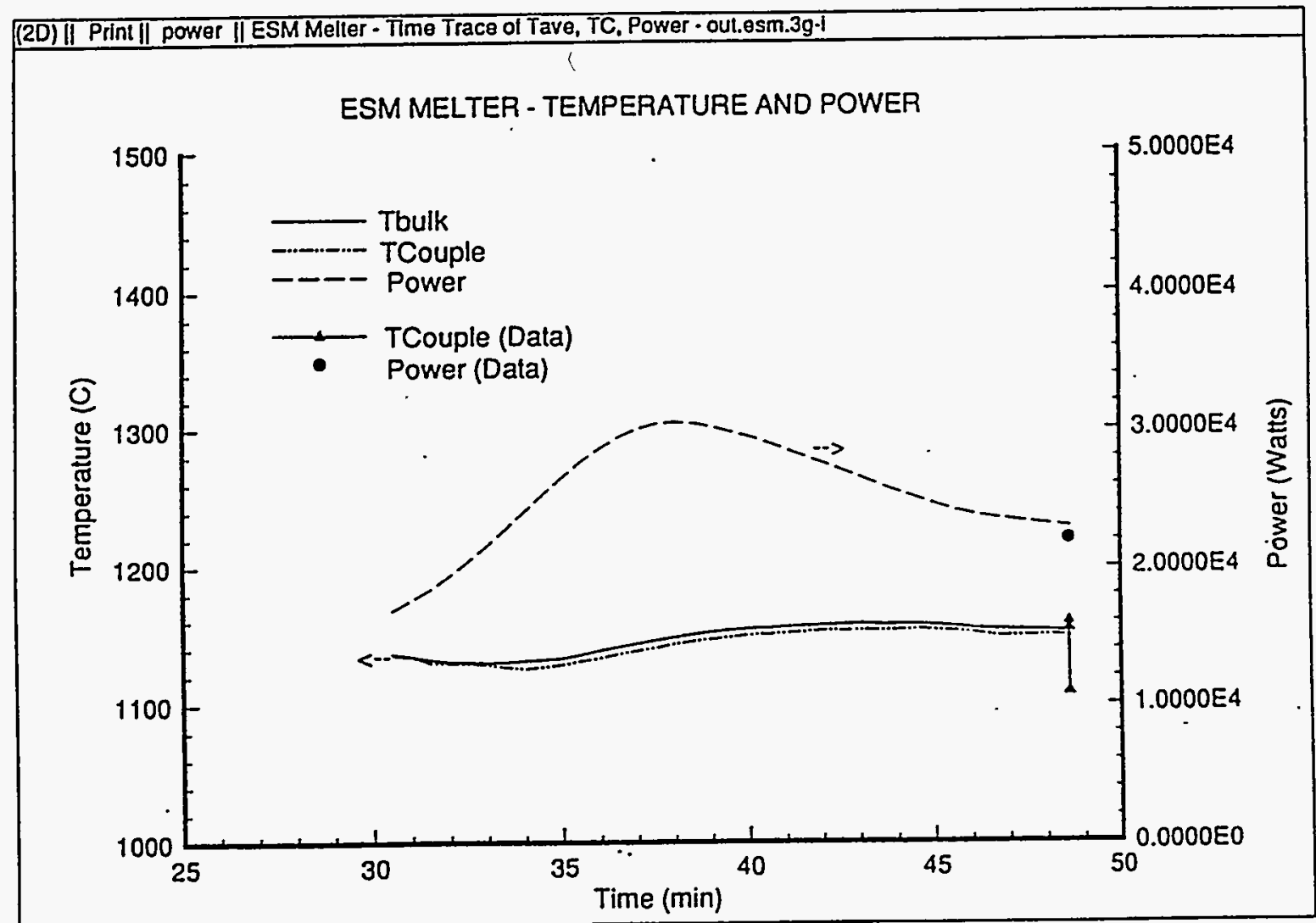

Fig. 6-1: Pre-test predicted power, bulk glass temperature, and average thermocouple stalk temperature compared to preliminary-reported data 
spread in the solid triangles. Agreement at the hotter of the three points is quite good in comparison to the predicted average thermocouple temperature. It should be noted that later reported data (see Figure 4-28) are typically $40-50^{\circ} \mathrm{C}$ higher than these preliminary reported data.

The preliminary-reported experimental data at the four thermocouple locations in the glass melt (TR13 to TR16) are compared in Figure 6-2 to the vertical temperature distribution computed by TEMPEST at a location approximately equivalent to the location of the thermocouple stalk. The TEMPEST data are represented by the solid line and the data are represented by the solid circles. The comparison is made over a vertical distance relative to the bottom center of the melter floor.

\subsection{COMPUTER MODELING RESULTS - POST-TEST PREDICTIONS}

\subsubsection{Noble Metals Material Balance and Retention}

Using the computer model, analysis methodology, and computer submodels described in Appendix D, and data available in the body of the experimental portion of this report, TEMPEST was used to compute noble metals material balance and retention. Analysis was done using continuum species transport to represent each of the three primary components, $\mathrm{RuO}_{2}, \mathrm{Pd}$, and $\mathrm{Rh}$, as settling particulate fields. Analysis was also conducted assuming that the total amount of noble metals could be lumped into a single representative particle field. Results of these analyses are presented in this section. The first is referred to as the three species model and the latter is referred to as the total noble metals model.

The results are for an assumed average $10 \mathrm{hr}$ cycle consisting of nine hours of feeding the melter and one hour of pouring. In the calculation, the glass pour rate during the one hour of pouring is 45.37 $\mathrm{kg}$-glass $/ \mathrm{hr}$. This value corresponds to an average pour rate of $4.5 \mathrm{~kg}$-glass $/ \mathrm{hr}$-online which is somewhat less than the value of $6.3 \mathrm{~kg}$-glass $/ \mathrm{hr}$ given in Table 5-I. However, the value of $6.3 \mathrm{~kg}$ glass $/ \mathrm{hr}$-online given in Table 5-1 is inconsistent with the total glass poured $(6423 \mathrm{~kg})$ and the total online time (1118 hr) which would be $6423 / 1118=5.7 \mathrm{~kg}$-glass $/ \mathrm{hr}$-online. The value of $4.5 \mathrm{~kg}$ glass/hr-online was obtained (see Appendix D) as a representative average of the number of pour and feed intervals presented in Figures 4-18 to 4-23. Furthermore, in Section 5.2.1, the average glass pouring rate in reported to be about $50 \mathrm{~kg} / \mathrm{hr}$. 


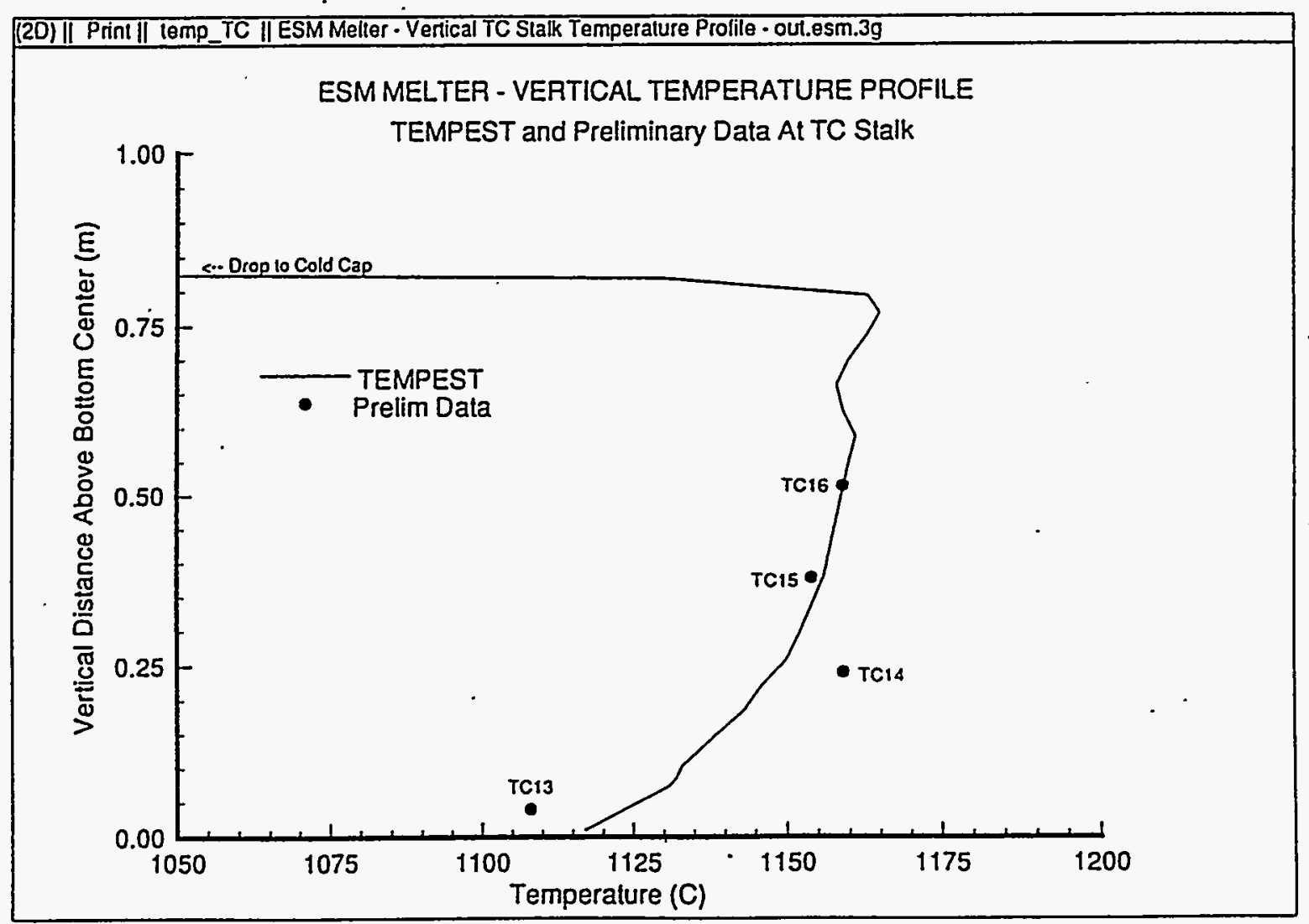

Fig. 6-2: Pre-test thermocouple stalk temperature compared to preliminary-reported data 
The noble metals source terms used in these calculations were determined as presented Appendix $D$. For the three species model analysis, the average source term for $\mathrm{RuO}_{2}$ was $5.2157 \cdot 10^{-3} \mathrm{~kg}$ $\mathrm{RuO}_{2} / \mathrm{hr}$, for $\mathrm{Pd}$ it was $1.374 \cdot 10^{-3} \mathrm{~kg}-\mathrm{Pd} / \mathrm{hr}$, and for $\mathrm{Rh}$ it was $1.100 \cdot 10^{-3} \mathrm{~kg}-\mathrm{Rh} / \mathrm{hr}$. For the single representative total noble metals case, the average source term was $1.78 \cdot 10^{-2} \mathrm{~kg}-\mathrm{NM} / \mathrm{hr}$. In the three species model, each component was assigned a settling velocity and intrinsic density. The density of each species couples the stabilizing density effects as a sludge layer builds up. The settling velocity is also specified for each species field according to the discussion in Appendix D. The settling velocity leads to the predicted floor layer through the floor deposition model also discussed in Appendix D.

The time-dependent variation of the predicted $\mathrm{RuO}_{2}$ balance is presented in Figure 6-3. In the figure, the mass in $\mathrm{kg}-\mathrm{RuO}_{2}$ is plotted as a function of time. Curves are included for the total amount of material fed to the melter, the total amount of material in the melter at a given time, the total amount of material predicted to be on the floor, and the total amount of material contained within the glass in the melter. The total amount of material in the melter is the sum of the material on the floor and the material in the glass. The total amount of material fed to the melter is a linear function which is just mass-source-rate times time, in the absence of operational interruptions. The total amount of material that is in the glass increases and reaches an equilibrium value. For the results presented in Figure 6-3, the amount of material in the glass reaches an asymptotic value of $0.426 \mathrm{~kg}$ during the feed portion of the cycle and drops to $0.397 \mathrm{~kg}$ after a pour cycle. Considering that there is $0.2372 \mathrm{~m}^{3}$ of glass in the computer model, at an average density of $2170 \mathrm{~kg}$-glass $/ \mathrm{m}^{3}$ used in the computer modeling, equilibrium mass fraction of $\mathrm{RuO}_{2}$ varies between 0.083 and $0.077 \mathrm{wt} \%$. This is comparable to the experimental value of about 0.08 to $0.09 \mathrm{wt} \%$ observed in Figures 5-12 to 5-15.

The amount of material that is on the floor after an initial period of adjustment at the start of operation, shows a linear rate of increase. This is consistent with the deposition rate model in these calculations. The jaggedness in the curves for total in the melter and in the glass is not a function of a numerical instability. Rather, the upswing of each jag represents the nine hours of feeding and the down swing of each represents the one hour of pouring.

Figure 6-4 presents the same $\mathrm{RuO}_{2}$ material balance, but plotted as a function of $\mathrm{kg}$ of glass discharged (poured) from the melter. Included in this figure are experimental data from Table 5-II, which are also presented in Figure 5-16. Note that the mass of $\mathrm{Ru}$ is plotted, not $\mathrm{RuO}_{2}$, to be consistent with experimental data. The conversion from $\mathrm{kg}-\mathrm{RuO}_{2}$ to $\mathrm{kg}-\mathrm{Ru}$ is: $(101.07 \mathrm{~kg}-\mathrm{Ru} / 133.07$ $\mathrm{kg}-\mathrm{RuO}_{2}$ ). In the figure, the solid symbols are the experimental data. The lines are TEMPEST predictions. The predictions were only made to a time where $3800 \mathrm{~kg}$-glass were poured. 


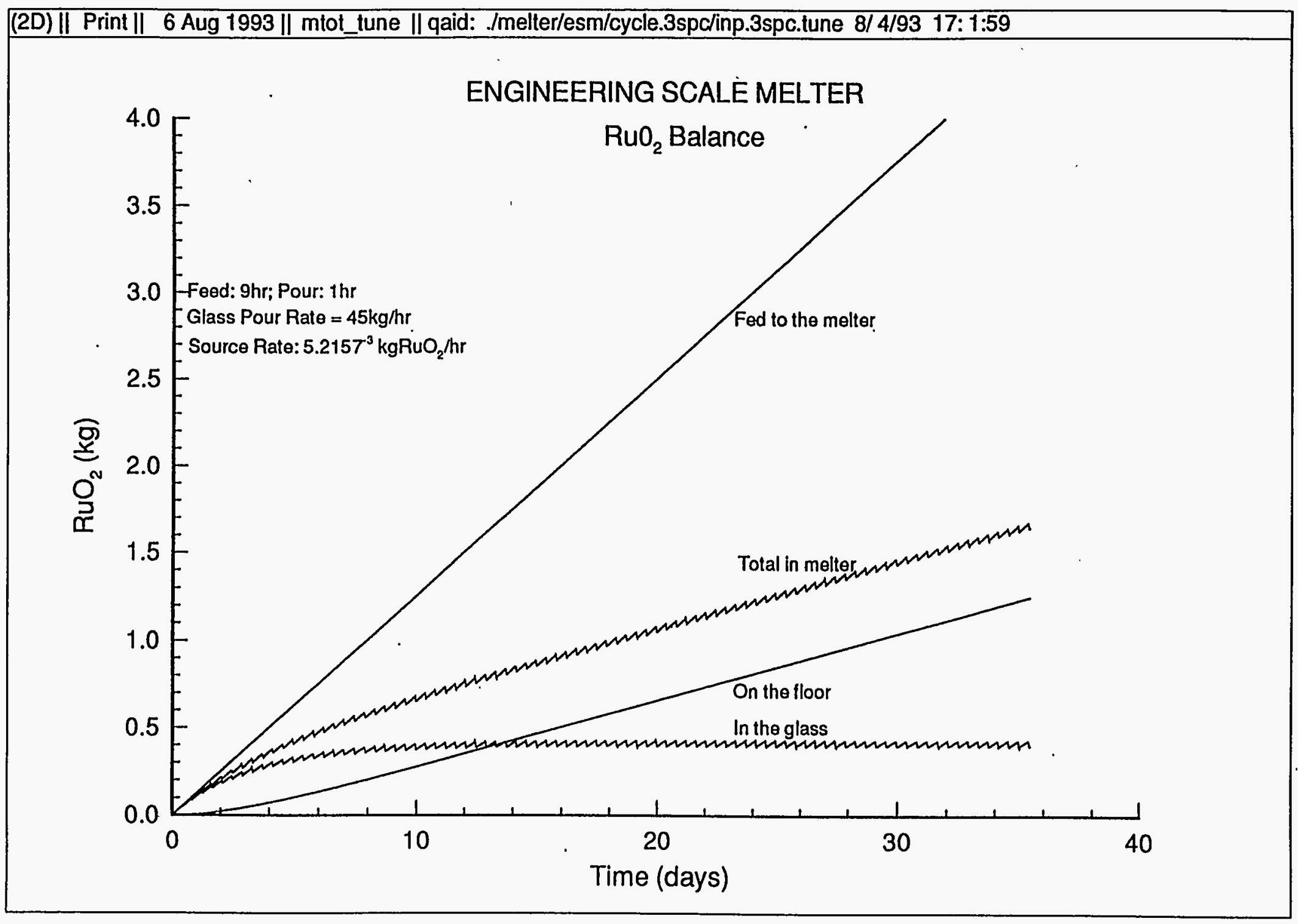

Fig. 6-3. Predicted $\mathrm{RuO}_{2}$ balance at experimental conditions. 


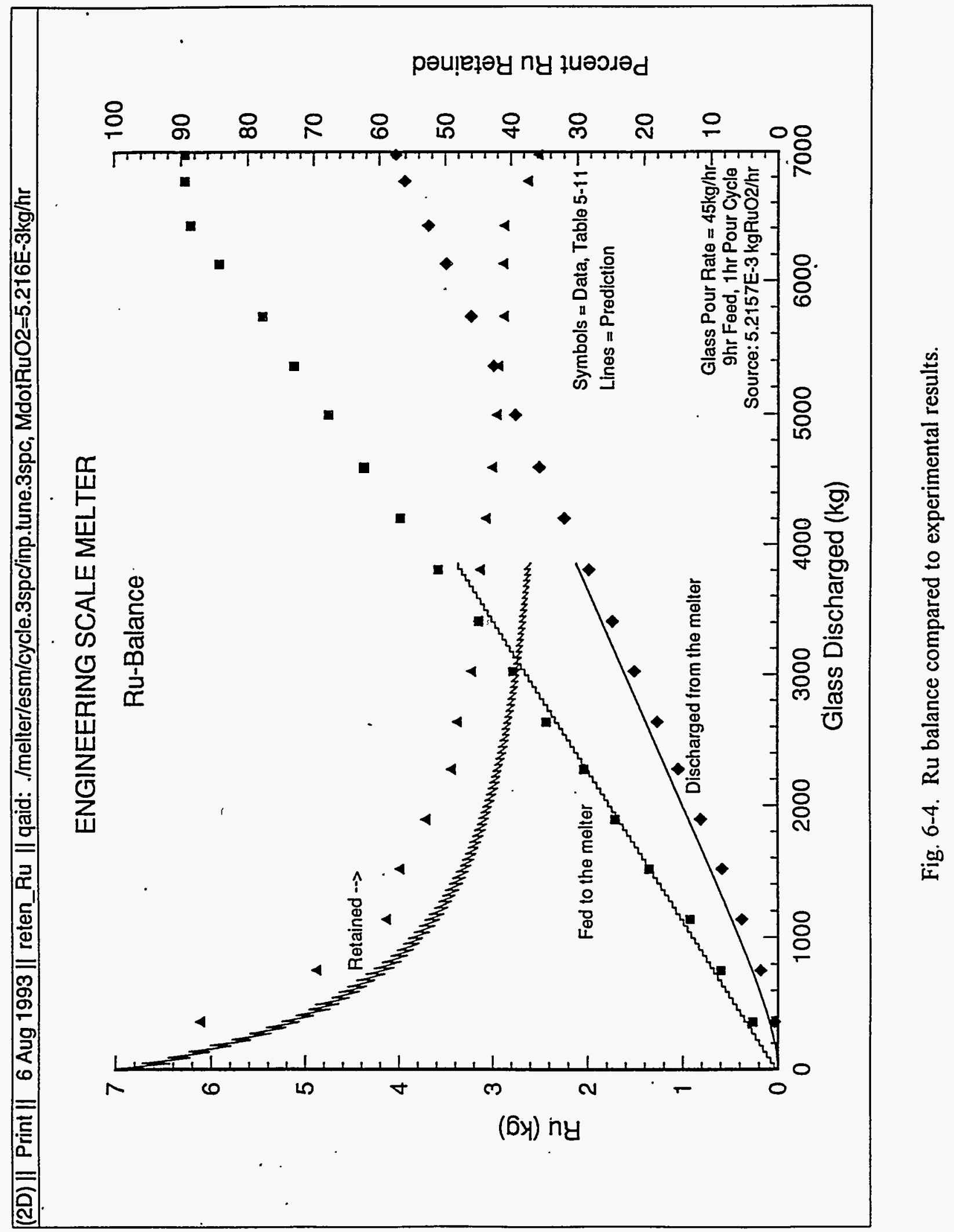


Up to this time, agreement between data and predictions is very good. Close examination of the experimental feed rate indicates that it was not constant, as was assumed in the calculations. The predictions tend to indicate that the amount of $\mathrm{Ru}$ discharged from the melter is slightly over predicted, which correspondingly results in an under prediction of the retention.

Note that the calculation of retention in the TEMPEST prediction is an integrated sum, computed by post processing data in the pour spout. The experimentally determined retention, as shown in Figure 6-4, was computed simply as the ratio of $\mathrm{kg}-\mathrm{Ru}$ discharged from the melter to the $\mathrm{kg}-\mathrm{Ru}$ fed to the melter. This ratio appears to asymptotically approaching a value of $40 \%$ (prior to discontinuing operation at about $6400 \mathrm{~kg}$-glass poured). The experimentally determined retention obtained by integration is reported in Section 5.2 .4 as $35 \%$ for $\mathrm{Ru}$. This latter value is in very good agreement with the asymptotic value of the computer predictions indicated by the results in Figure 6-4.

Figure 6-5 presents the same predicted $\mathrm{Ru}$ material balance. In this figure, it was arbitrarily assumed that a $10 \%$ bias error exists in the experimental data for material discharged from the melter. This was done simply to examine the sensitivity of differences between data and predictions. Agreement between data and predictions are slightly improved in this figure. Considering that all of the measured wt\% data obtained in the experiment was "shifted" (see Section 5.2.2, it is not inconceivable that such a bias error exists in the data. Alternately, it is not inconceivable that a modification to the parameters used in determining the deposition rate (see Appendix D) could also result in a biased shift in the prediction of the discharged concentration of Ru.

Results for the Pd and $\mathrm{Rh}$ components are presented in Figures 6-6 to 6-9. The general character of the material balance of the $\mathrm{Pd}$ and $\mathrm{Rh}$ components, which were modeled as pure material particles, is quite similar to that of $\mathrm{Ru}$ discussed above.

In Figure 6-6, the asymptotic mass fraction of $P d$ in the poured glass varies between 0.10 and 0.11 $\mathrm{kg}-\mathrm{Pd}$ over the feed/pour cycle. These correspond to mass fractions of 0.019 and $0.021 \mathrm{wt} \%$ for glass density of $2170 \mathrm{~kg} / \mathrm{m}^{3}$. Experimental values of Pd wt\% (see Figures 5-9 to 5-12) are mostly in the 0.02 to $0.03 \mathrm{wt} \%$ range. In Table 5-II, over the corresponding equilibrium run time of 416 to $710 \mathrm{hr}$ (2207 to $3807 \mathrm{~kg}$-glass poured), the average mass of Pd in the discharged glass is $0.101 \mathrm{~kg}$. In Figure 6-7, the asymptotic retention is approaching $34 \%$ compared to the experimentally determined value of $38 \%$ (Section 5.2 .4 ) determined by integration. Thus, the agreement between data and predictions is very good. 


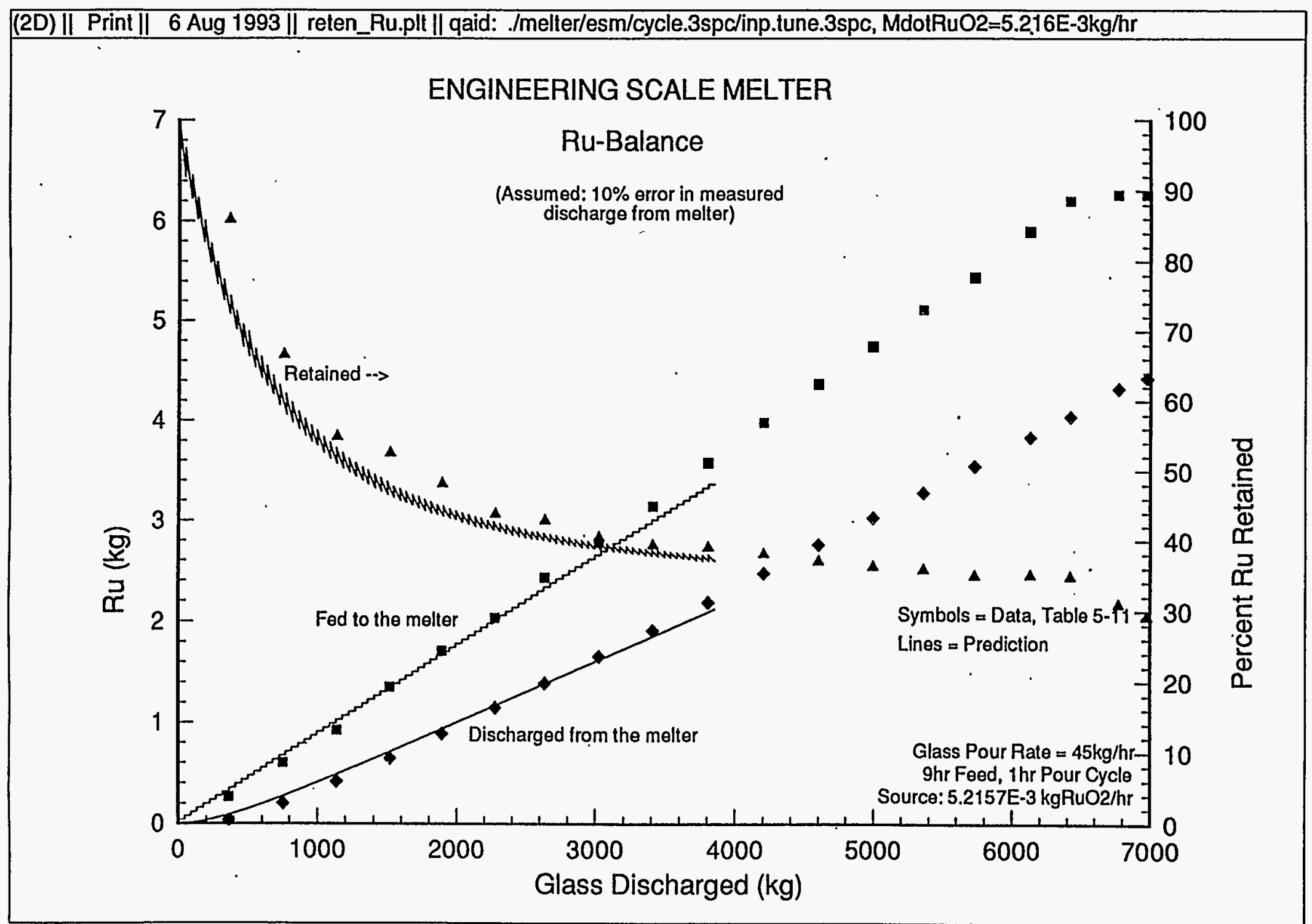

Fig. 6-5. Ru balance compared to experimental results ( $10 \%$ biased) 


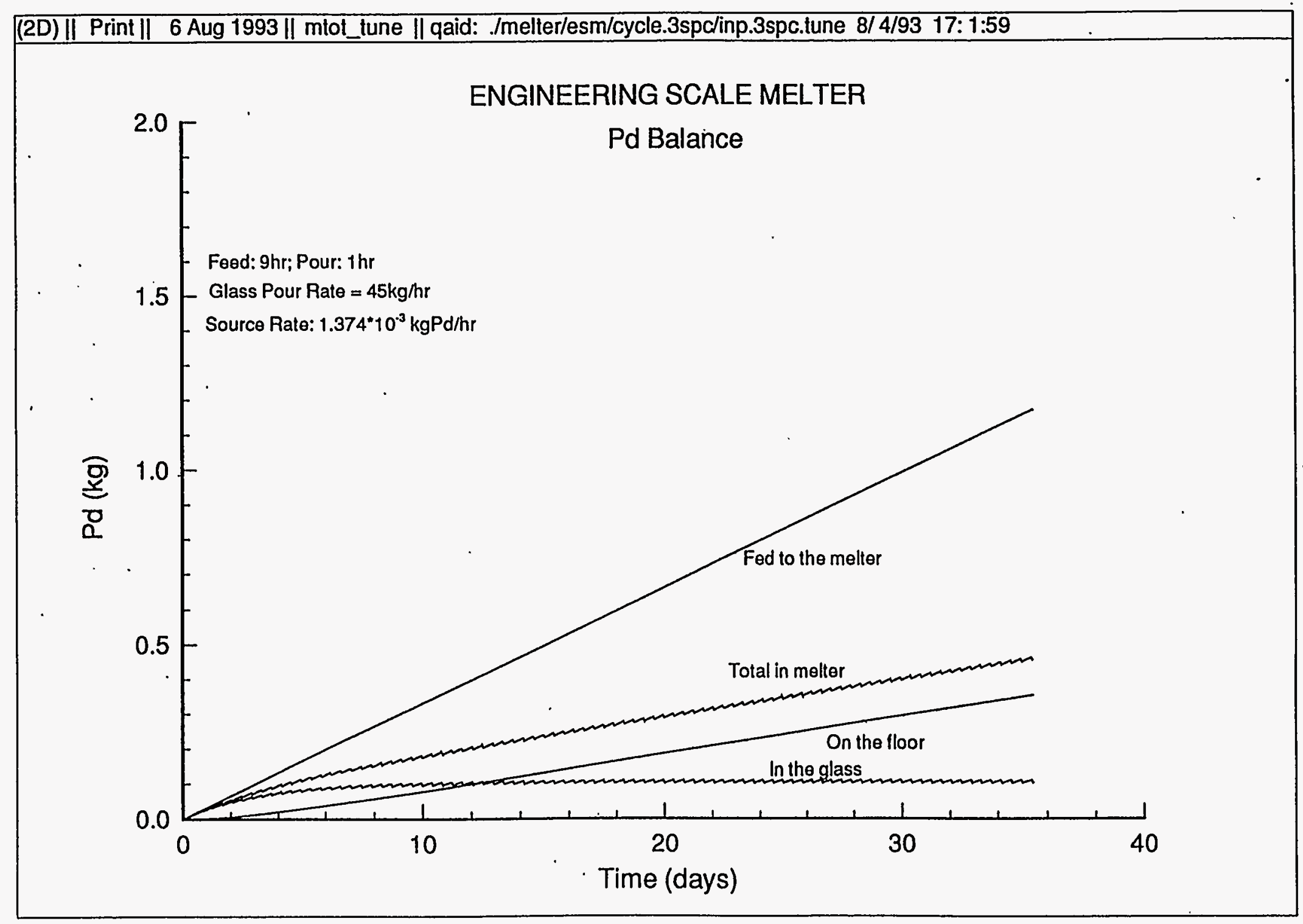

Fig. 6-6. Predicted Pd balance at experimental conditions. 


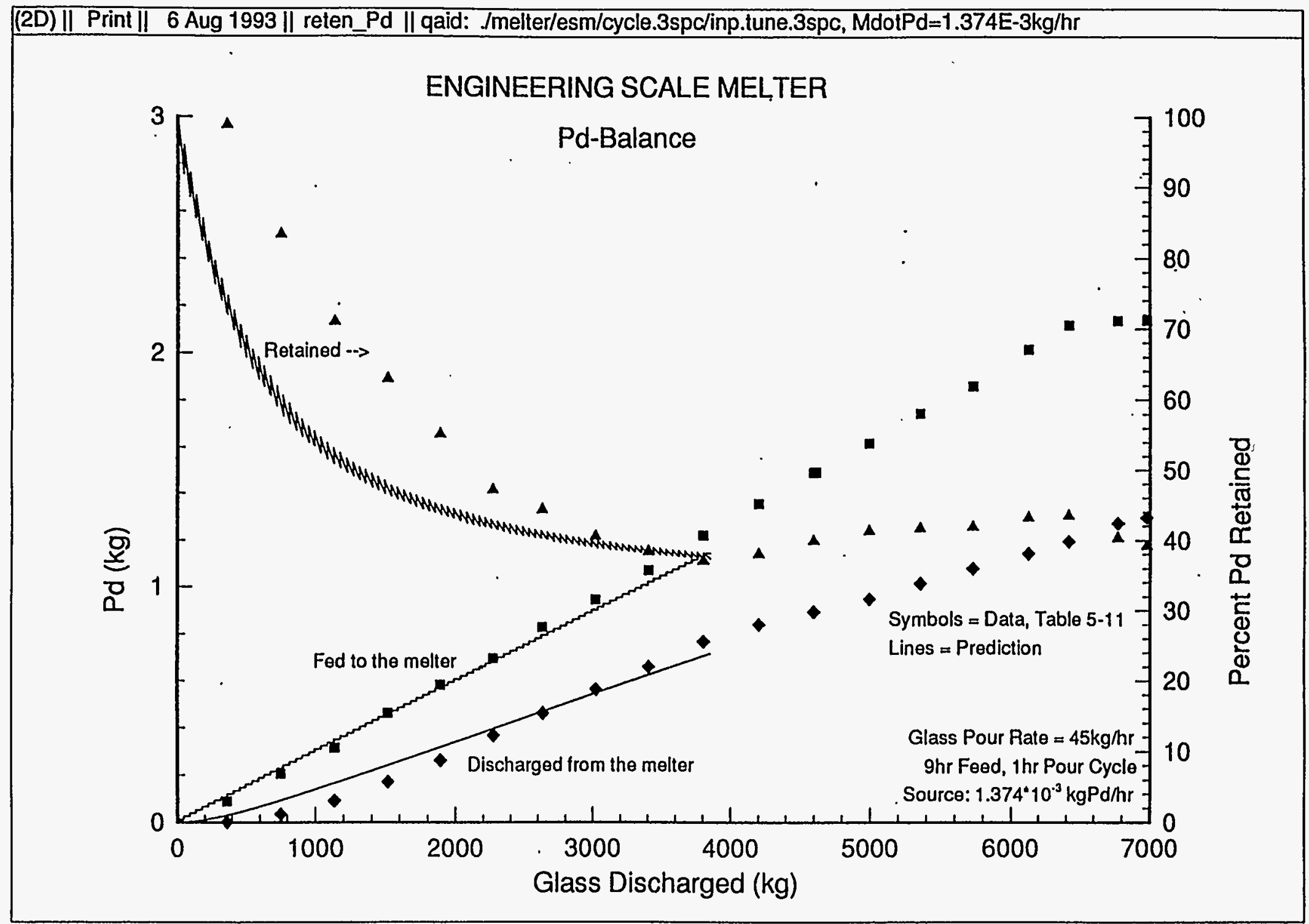

Fig. 6-7. Pd balance compared to experimental results. 


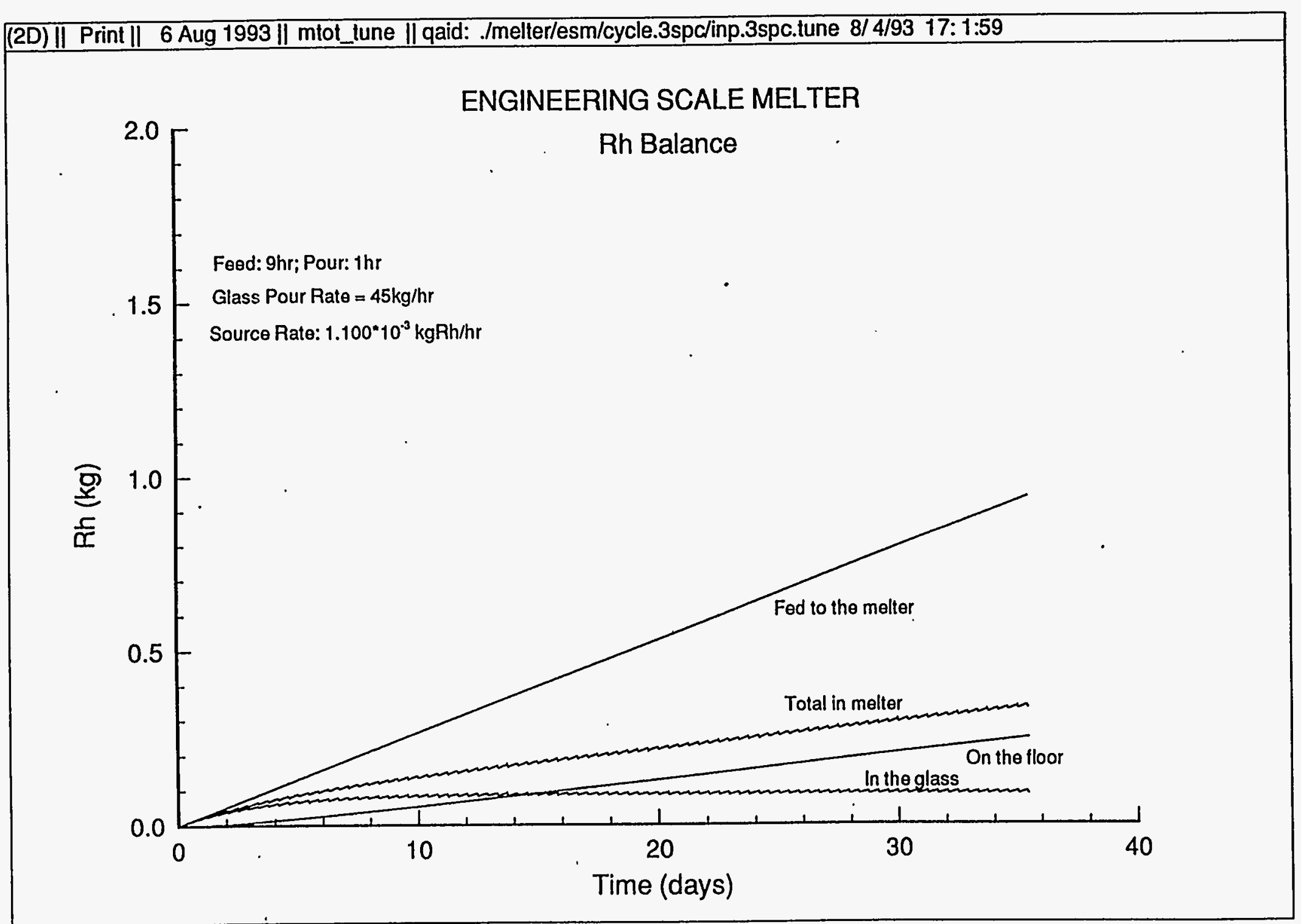

Fig. 6-8. Predicted Rh balance at experimental conditions. 


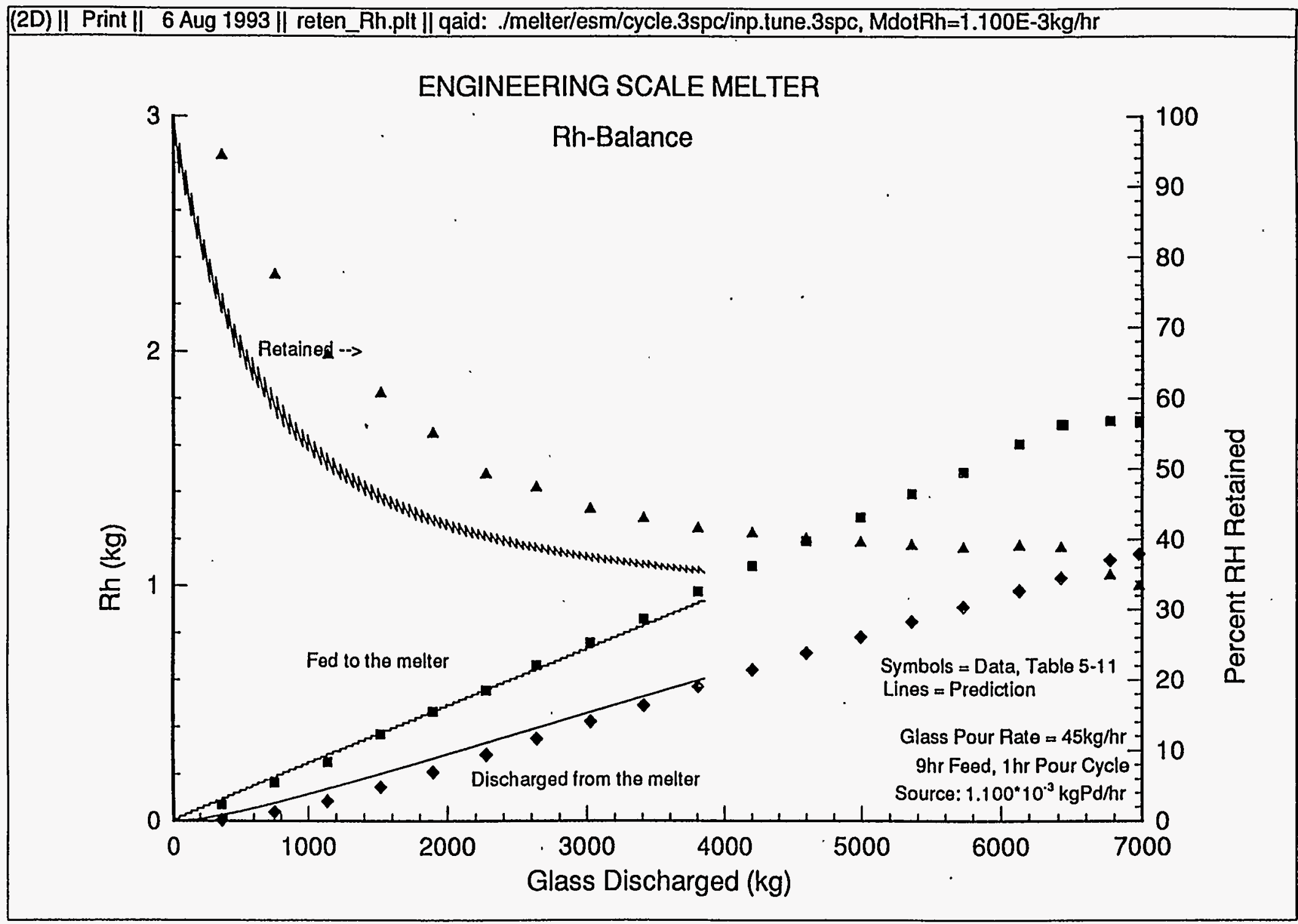

Fig. 6-9. Rh balance compared to experimental results. 
Corresponding results for $\mathrm{Rh}$ in Figure 6-8 show an equilibrium mass of $\mathrm{Rh}$ in the discharged glass between 0.086 and $0.093 \mathrm{~kg}-\mathrm{Rh}$ over the feed/pour cycle. These correspond to mass fractions of 0.017 and $0.018 \mathrm{wt} \%$ in the discharged glass. Experimental values are near $0.025 \mathrm{wt} \%$ over much of the experiment as observed in Figures 5-9 to 5-12. Table 5-II data indicate that the weight of $\mathrm{Rh}$ in the equilibrium range is between 0.06 and $0.08 \mathrm{~kg}-\mathrm{R} 11$ and $0.08 \mathrm{~kg}-\mathrm{Rh}$. In Figure 6-9, the asymp retention is approaching 34\%, a number which is in very good agreement with the experimental value of $32 \%$ (Section 5.2.4). Thus, the predictions of Rh mass are also in good agreement with data.

These results indicate that the modeling assumptions used in this analysis and the analysis approach, as discussed in Appendix D, are quite good and that good agreement with data is obtained for the prediction of retention of noble metals in the ESM.

The time dependent results for the accumulation of mass on the floor of the melter can be used to estimate the thickness of a noble metals enriched sludge layer. Figure 6-10 presents the time dependent $\mathrm{RuO}_{2}$ mass results. Curves for mass of $\mathrm{RuO}_{2}$ in the glass and mass on the floor are presented. The amount of mass on the floor can be converted to an equivalent layer thickness by dividing the mass on the floor by the density of $\mathrm{RuO}_{2}$, area of the floor, and maximum packing factor, or

$$
\begin{array}{ll}
\Delta \mathrm{h}=\mathrm{M}_{\text {floor }} / & \left(\mathrm{\rho RuO} 2 \cdot \mathrm{A}_{\text {floor }} \cdot \mathrm{C}_{\mathrm{V}, \mathrm{max}}\right) \\
\text { where } \Delta \mathrm{h} & =\text { Sludge layer thickness } \\
\mathrm{M}_{\mathrm{floor}} & =\text { Mass of } \mathrm{RuO}_{2} \text { on the floor, } \mathrm{kg}-\mathrm{RuO}_{2} \\
\mathrm{\rho RuO} 2_{\mathrm{R}} & =\text { Density of } \mathrm{RuO}_{2}, 6970 \mathrm{~kg} / \mathrm{m}^{3} \\
\mathrm{~A}_{\text {floor }} & =\text { Floor area, } 0.28 \mathrm{~m}^{2} \\
\mathrm{C}_{\mathrm{V} \cdot \max } & =\text { Maximum packing concentration, } \mathrm{kg}-\mathrm{RuO}_{2} / \mathrm{m}^{3} .
\end{array}
$$

Results for assumed maximum packing concentration of 0.06 and 0.08 are presented in the figure. Extrapolation of these results to the end of the experiment, $1193 / 24=49.7$ days-run-time, indicate a sludge layer between 1 and $1.5 \mathrm{~cm}$. Experimental observations indicate that a sludge layer between 1$3 \mathrm{~cm}$ thick existed after draining of the melter stopped (Section 5.2.5). If a lesser maximum packing concentration were used, the computed thickness would be greater. Samples from the bottom of the melter indicate mass fractions approaching $5 \mathrm{wt} \%$ which corresponds to a volume fraction of about 5 . $2170 \mathrm{~kg}$-glass $/ 6970 \mathrm{~kg}-\mathrm{RuO}_{2}=1.6 \mathrm{vol} \%$. If the $5 \mathrm{wt} \%$ really does represent a maximum packed concentration, then the estimated sludge layer would be nearly $5.6 \mathrm{~cm}$ thick. The 0.06 maximum packed concentration was determined from examination of micrographs as discussed in Appendix $D$. 


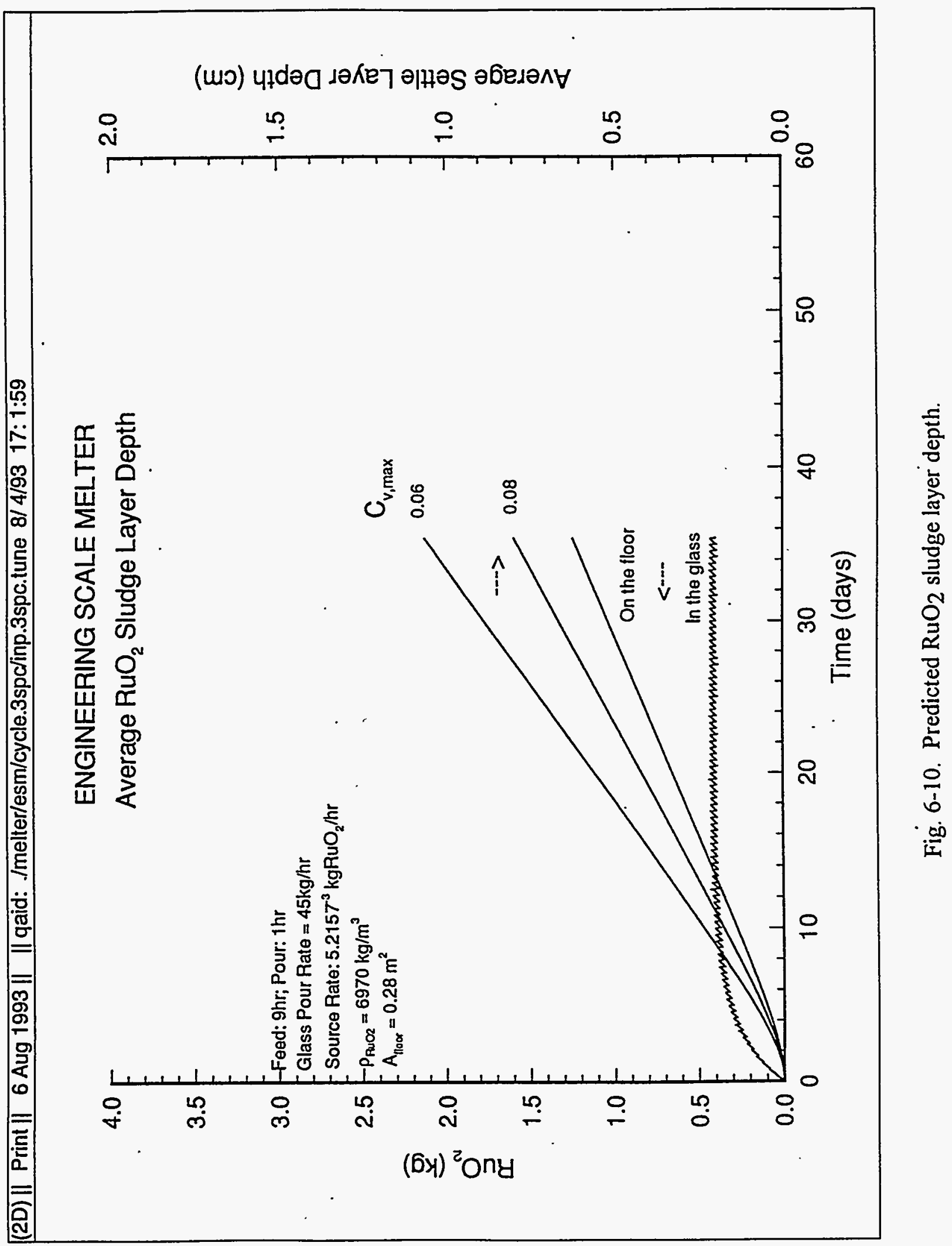


In addition to the individual species calculation for $\mathrm{RuO}_{2}, \mathrm{Pd}$, and $\mathrm{Rh}$, another calculation was conducted assuming a single particle component with characteristics of $\mathrm{RuO}_{2}$. This calculation was conducted as an upper bound calculation. It is an upper bound calculation because $\mathrm{RuO}_{2}$ particles exhibit "hairball" characteristics, with a high degree of porosity. The equivalent included effective volume of these hairballs occupy much larger volume than do the smaller, metallic $\mathrm{Pd}$ and $\mathrm{Rh}$ particles. Thus, they would tend towards a greater sludge layer depth than would small, rounded metal particles. For this calculation, a noble metals (NM) source rate of $0.0178 \mathrm{~kg}-\mathrm{NM} / \mathrm{hr}$ was used. This feed rate is approximately a factor of 3 greater than the actual $\mathrm{RuO}_{2}$ feed rate in the experiment and approximately a factor of 2 greater that the total of $\mathrm{RuO}_{2}, \mathrm{Pd}$, and $\mathrm{Rh}$ fed to the melter. Nevertheless, the results are useful because they indicate that in the range of the concentrations of noble metals under consideration, the retention characteristics are largely independent of the magnitude of the source term. This would be true up to a point in a actual melter where a sludge layer would be come significantly thick as to affect the melt pool flow, thermal, and electric characteristics. These results also provide a second data set from which interpolations of sludge layer thickness can be made.

Results of the single NM component mass balance are presented in Figures 6-11 to 6-13. In Figure 6-11, the mass balance as a function of time is shown. Comparison of this result. with that of the $\mathrm{RuO}_{2}$ results in Figure 6-3 show a very similar characteristic to the overall material balance. Furthermore, the retention for this case, Figure 6-12, is also approaching an asymptotic value of something just less than $40 \%$. Figure 6-13 shows the computed effective sludge layer depth for assumed maximum packing concentration of 6 and 10 vol\%. These depths are approaching the 4-5 $\mathrm{cm}$ thick range.

Figure 6-14 presents a comparison of the TEMPEST predicted results with a lumped parameter method. The lumped parameter method is a mathematical description of a well-mixed volume with associated in flow and out flow. The melt pool is the well mixed volume and the mass balance is a simple ordinary differential equation solution in time. Development of the equations, as used here, is included in Appendix D. The TEMPEST results are very consistent with the lumped parameter results and lie between the two cases of an assumed volume change during pouring and an assumed constant volume melt pool during pouring. This comparison is important for several reasons. It points to the fact that the constant volume melt approximation used in the TEMPEST model is not a serious detractor to the actual situation where the melt surface, and hence melt volume, changes during the pouring and feeding portions of a cycle. 


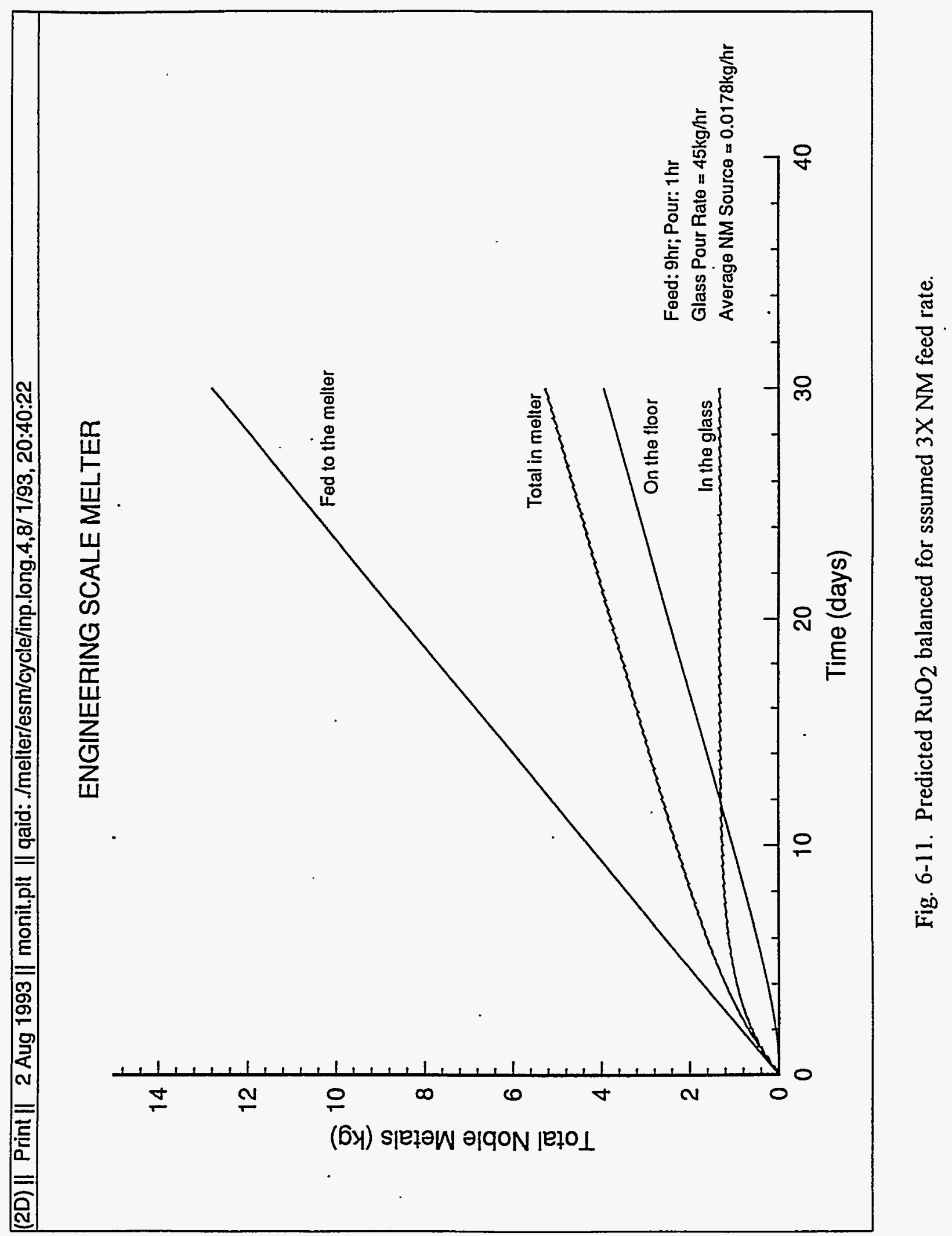




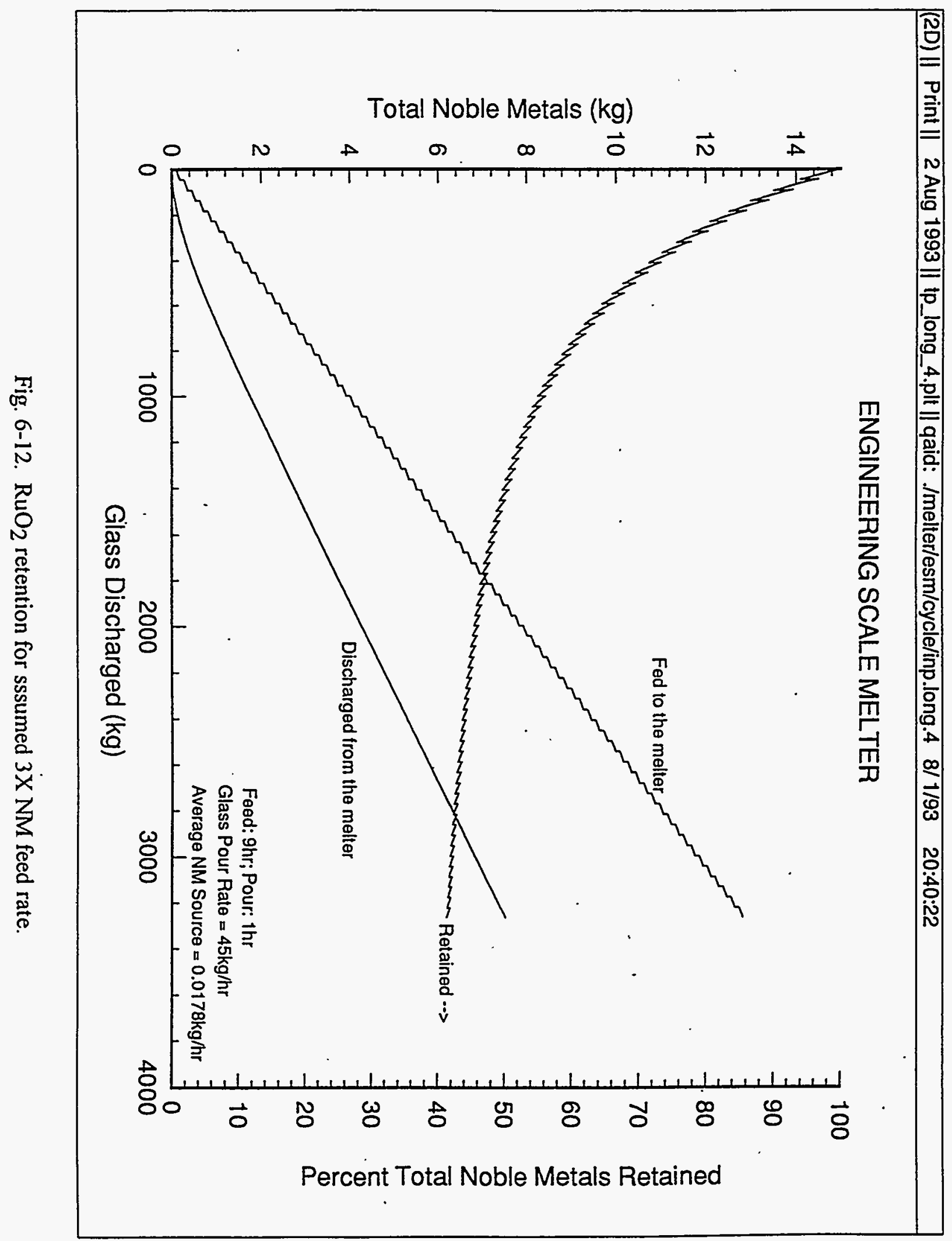




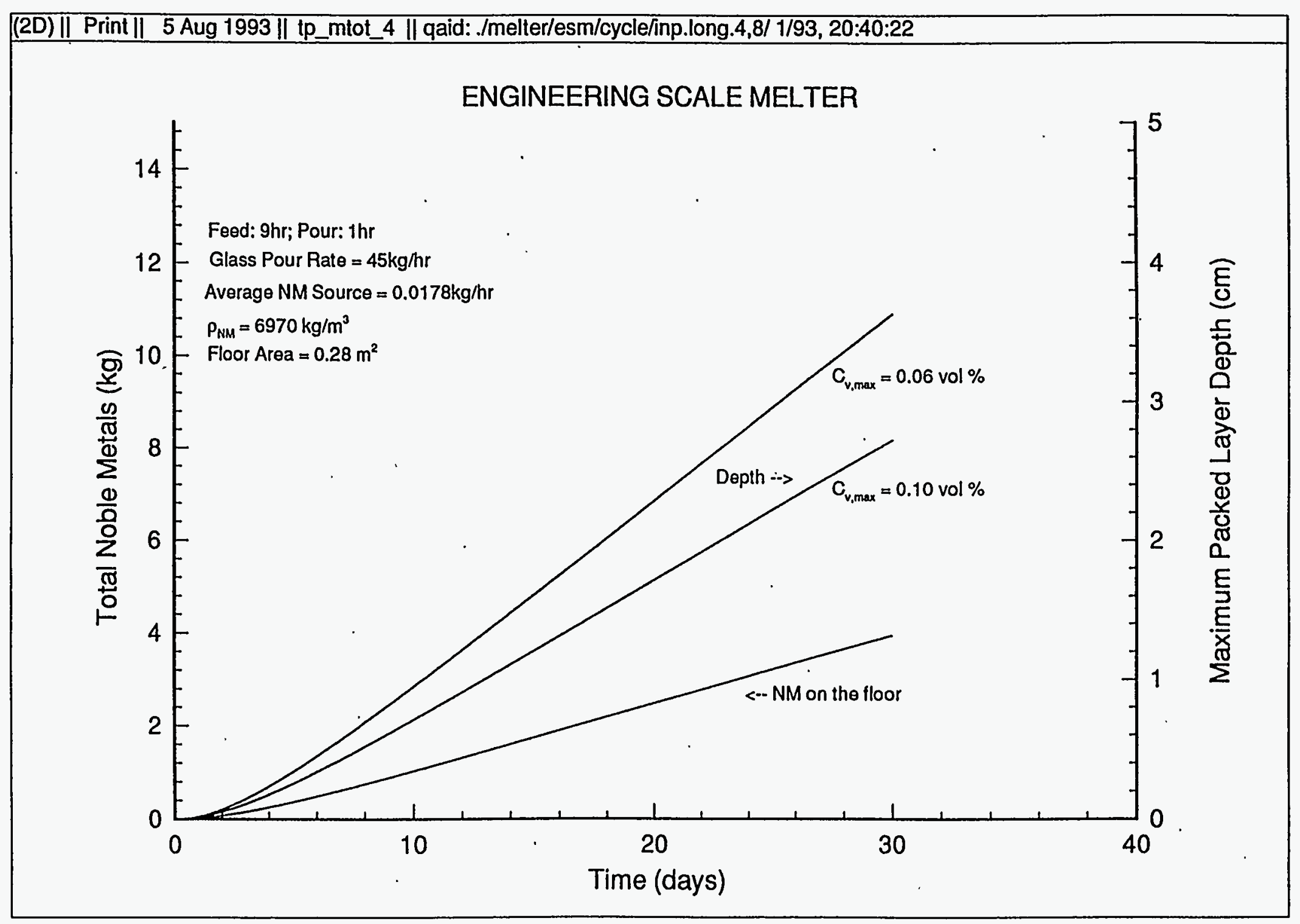

Fig. 6-13. $\mathrm{RuO}_{2}$ sludge layer depth for assumed $3 \mathrm{X} \mathrm{NM}$ feed rate. 


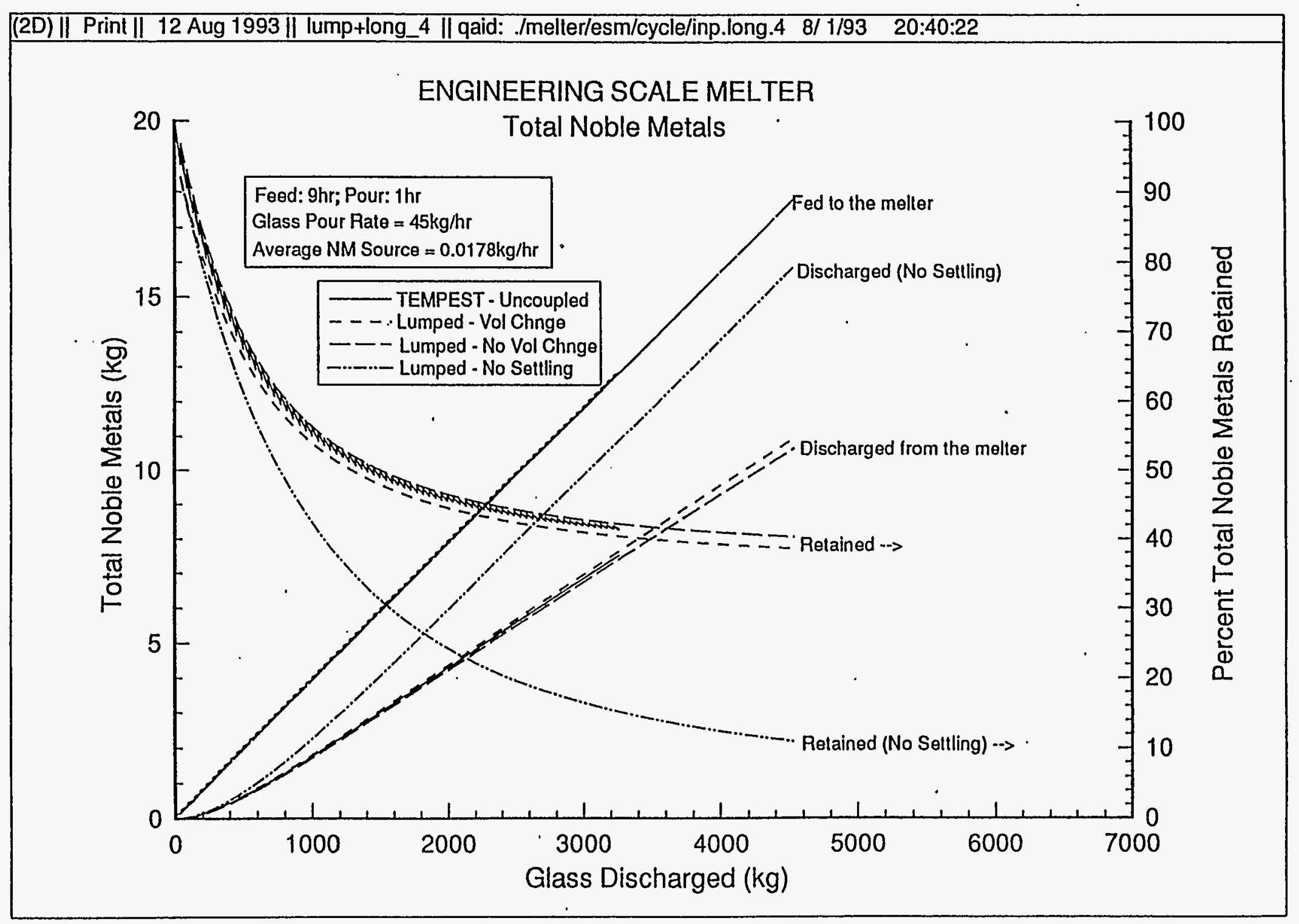

Fig. 6-14. Total NM retention compared to lumped parameter analysis. 
Also included in the figure are results which were computed with the lumped parameter model that . assumed that there was no settling of the material to the floor. In this case, the discharged (no settling) curve represents the ideal situation referred to in relation to data in Figure 5.18. It is useful to note that for the settling cases, the retention is asymptotically approaching a value near $40 \%$, whereas the ideal case of no settling shows an integrated retention (total-in minus total-out)/(total-in) .100 which is asymptotically approaching zero.

Another observation that can be made from the results of Figure 6-14 is that TEMPEST is predicting that the melter is a well mixed volume. In fully coupled calculations conducted without allowing settling of material to a stationary floor layer, less than a $2 \%$ variation existed in the concentration distribution in the melt pool. A by-product of this result is that it supports the use of a lumped parameter method to estimate retention in the melter and to do parametric analysis with the lumped parameter approach. The more computationally intensive TEMPEST approach could then be used to investigate specific aspects of coupled melter operation resulting from a parametric analysis done to define a range of operational limits.

\subsubsection{Power and Electric Operation Parameters}

Operation parameters monitored during ESM test U2 included power to the upper and lower electrode and to the plenum heater. Time history of the power is included in Figures 4-18 to 4-25. In early stages of the U2 test, power distribution to the upper and lower electrode pairs was 12.5 and 11 $\mathrm{kW}$, respectively. The distribution was gradually changed over the first $550 \mathrm{~h}$ of operation to a ratio of 15 to $7.5 \mathrm{kw}$. This ratio was held about constant over the duration of the test. Average voltage, current, and power values are listed in Table 5-I. Resistance of the melter during the test U2, determined by dividing rms-voltage by rms-current, is presented in Figure 5-17. Although not specifically stated, it is assumed that the resistance is rms-equivalent, not open circuit resistance.

Numerous post-test computer simulations were conducted to determine power and electric operation parameters. These were done using various combinations of assumed viscosity, electric conductivity, and sludge layer depth. A synopsis of some of these.results are presented here.

Figure 6-15 presents power, bulk average temperature, and thermocouple stalk temperature for one pouring case. These results are very typical of the several calculations completed. Both the continuous monitored values and the temperature controlled average values are included in the figure. For the latter, the controller integration time was $0.5 \mathrm{~min}$. The total power supplied to the melter typically reached an equilibrium value of 25 to $26 \mathrm{~kW}$. 

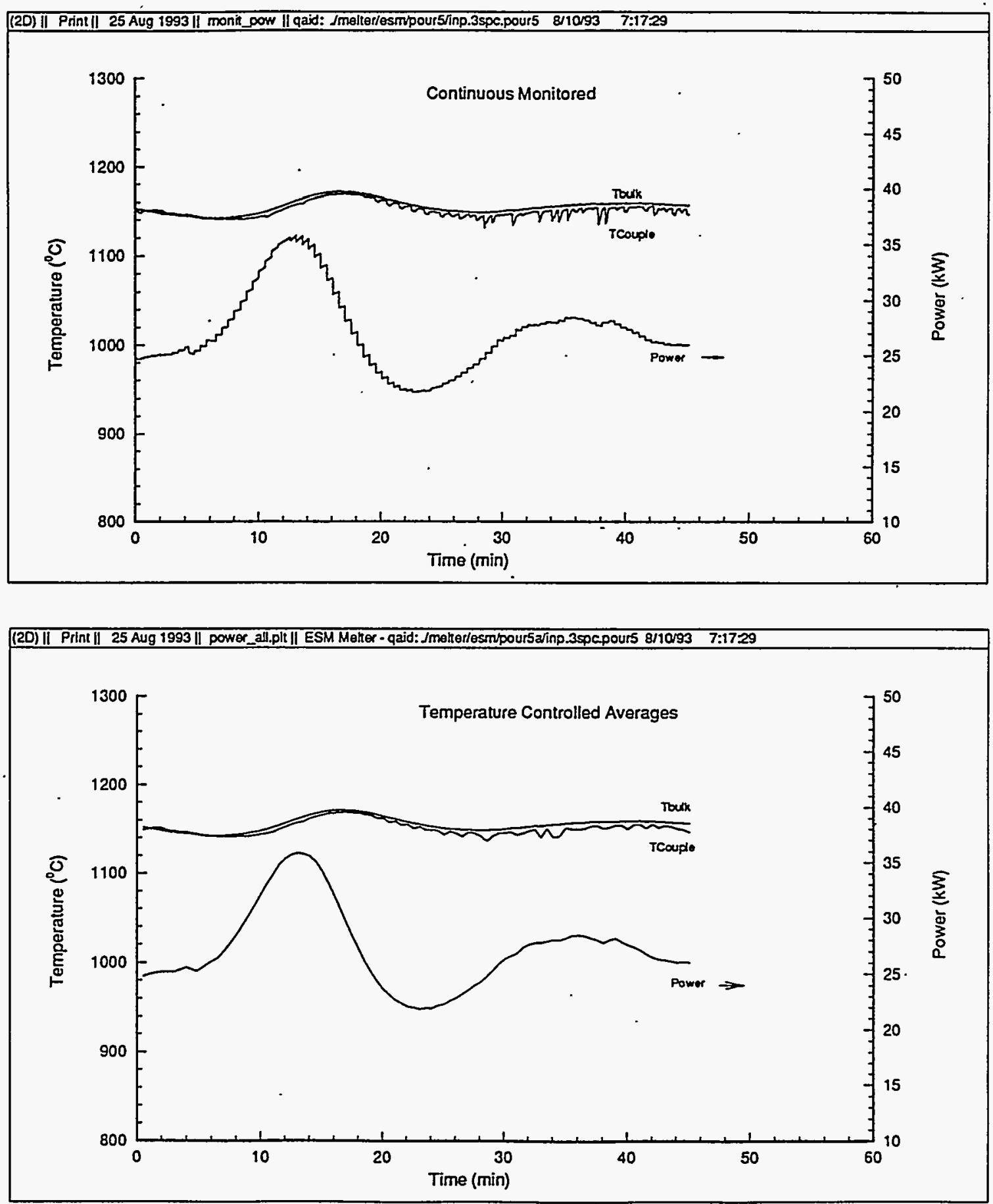

Fig. 6-15. Continuous monitored and temperature controlled average power and temperature. 
The power level required to maintain a controlled temperature is almost exclusively a function of boundary condition. The predicted $25-26 \mathrm{~kW}$ values are comparable to the $\mathrm{U} 2$ test values of $23.5 \mathrm{~kW}$ early in the test, $22.5 \mathrm{kw}$ near the $550 \mathrm{~h}$ point, and the overall average of $22 \mathrm{kw}$ listed in Table 5-I. The over prediction of roughly $10-15 \%$ is considered to be a good agreement.

Comparison of the post-test power result in Figure 6-15 with the pre-test result in Figure 6-1 (which are temperature controlled to a bulk average temperature of $1150^{\circ} \mathrm{C}$ ) indicates a very similar characteristic approach to the thermocouple stalk controlled temperature of $1150^{\circ} \mathrm{C}$. There are some differences in these two results that are worth noting. The pre-test results in Figure 6-1 are for a clean melt (no noble metals) obtained using RSM/Pre viscosity and electric conductivity correlations (see Appendix D). The post-test results are obtained using ESM-correlated data. The post-test results are also obtained using an assumed $1 \mathrm{~cm}$ sludge layer initially on the floor of the melter. The layer was dissipated throughout the melt by the end of the simulation because the concentration dependent viscosity was of insufficient magnitude to completely inhibit convection in the layer. Note that the temperature controlled averages exhibit smoother curves than do the continuous monitored values. The "spiky" characteristics in the continuous monitored values are a consequence of the physical instabilities in the melt and represent predicted falling columns of rather cooler glass passing the monitoring location. These columns tend to move around the melt. An experimental measurement of a thermocouple stalk would probably not sense these characteristics because of the time constant associated with the thermocouple/thermowell dampening due to axial conduction in a thermowell, and any time constant associated with data acquisition systems. In the ESM data acquisition, the scanning and storage rate for temperatures was $300 \mathrm{sec}$ (see Section 3.3). It is not possible from ESM data to confirm the existence of such falling columns of cold glass.

Table 6-I presents a composite of the operational parameters of several investigatory simulations in predicting resistance of the melter. The object of these simulations was to compare predicted resistances to data (Figure 5-17) determined from measured voltage and current. (Note that the time history curves in Figure 5-17 appear to be inversely labeled, relative to average resistance values determinable from average voltage and current in Table 5-I.) For these simulations, the current source was specified in each electrode pair to approximate the early-, mid-, and end-test conditions. Based on the amount of material initialized in the simulations with $1 \mathrm{~cm}$ layer of sludge, approximate experiment times of 0,600 , and $850 \mathrm{~h}$ were simulated . For reference and comparison purposes, U1 and $\mathrm{U} 2$ test average values from Table 5-I are included in Table 6-I. 
Table 6-I: Summary of Two Field Electric Characteristics

\begin{tabular}{|c|c|c|c|c|c|c|c|c|}
\hline \multirow[b]{2}{*}{ Run Number } & \multirow[b]{2}{*}{ flay.0b } & \multirow[b]{2}{*}{ nay.0c } & \multirow[b]{2}{*}{ flay.0a } & \multirow[b]{2}{*}{ nay.2a } & \multirow[b]{2}{*}{ Пay.2. } & \multirow[b]{2}{*}{ flay.0 } & \multicolumn{2}{|c|}{ Experimental Data (Table 5-I) } \\
\hline & & & & & & & U1 Avg. & U2 Avg. \\
\hline \multicolumn{9}{|l|}{ Unper Pair } \\
\hline Voltage $\left(V_{2}\right.$, Volts $)$ & 62.1 & 52.5 & 59.2 & 57.0 & 60.2 & 52.8 & 44.4 & $42: 4$ \\
\hline Resistance $\left(R_{2}, \Omega\right)$ & 0.230 & 0.230 & 0.219 & 0.211 & 0.222 & 0.212 & 0.144 & 0.134 \\
\hline Power $\left(P_{2}\right.$, kw $)$ & 16.76 & 12.01 & 16.00 & 15.40 & 15.21 & 13.17 & 13.7 & 13.3 \\
\hline \multicolumn{9}{|l|}{ Lower Pair } \\
\hline Current $\left(I_{1}\right.$, Amps) & 229.5 & 193.5 & 229.5 & 230.0 & 229.5 & 176.1 & 265 & 231 \\
\hline Voltage $\left(V_{1}\right.$, Volts $)$ & 61.3 & 51.8 & 46.6 & 35.5 & 31.5 & 32.0 & 42.4 & 37.3 \\
\hline Resistance $\left(R_{1}, \Omega\right)$ & 0.267 & 0.267 & 0.202 & 0.154 & 0.137 & 0.182 & 0.160 & 0.161 \\
\hline Power $\left(P_{1}\right.$, kw $)$ & 14.07 & 10.02 & 10.69 & 8.14 & 7.24 & 5.63 & 11.2 & 8.6 \\
\hline Resistance-True $\left(R_{1}^{*}, \Omega\right)$ & 0.217 & 0.217 & 0.165 . & 0.127 & 0.113 & 0.140 & - & - \\
\hline Power Ratio $\left(P_{2} / P_{1}\right)$ & 1.19 & 1.20 & 1.50 & 1.89 & 2.10 & 2.33 & 1.2 & $1.2 / 1.55 / 2.0$ \\
\hline Average Gliss 'Temperature $\left({ }^{\circ} \mathrm{C}\right)$ & 1153.5 & 1153.4 & 1153.4 & .1153 .3 & 1153.4 & 1153.3 & 1148 & 1184 \\
\hline Thermocouple Temperature $\left({ }^{\circ} \mathrm{C}\right)$ & 1149.8 & 1149.7 & 1149.6 & 1149.7 & 1149.6 & 1149.6 & - & - \\
\hline \multicolumn{9}{|l|}{ Average Concentration in Class } \\
\hline $\mathrm{RuO}_{2}\left(\mathrm{~kg} / \mathrm{m}^{3}\right)$ & 0. & 0. & 1.176 & 1.183 & 1.675 & 1.675 & & \\
\hline $\mathrm{Pd}\left(\mathrm{kg} / \mathrm{m}^{3}\right)$ & 0. & 0. & 0.300 & 0.304 & .430 & .426 & & \\
\hline $\operatorname{Rh}\left(\mathrm{kg} / \mathrm{m}^{3}\right)$ & 0. & 0. & 0.253 & 0.256 & .362 & .359 & & \\
\hline \multicolumn{9}{|l|}{ Average Concentration in Sludge } \\
\hline $\mathrm{RuO}_{2}\left(\mathrm{~kg} / \mathrm{m}^{3}\right)$ & 0. & 0. & 283.9 & 283.6 & 402.6 & 402.7 & & \\
\hline $\mathrm{Pd}\left(\mathrm{kg} / \mathrm{m}^{3}\right)$ & 0. & 0. & 80.41 & 80.34 & 113.3 & 113.4 & & \\
\hline $\operatorname{Rh}\left(\mathrm{kg} / \mathrm{m}^{3}\right)$ & 0. & 0. & 55.74 & 55.69 & 78.9 & 79.0 & & \\
\hline Glass Conductivity (I/ $\Omega-m)$ & $\sim 15.5$ & $\sim 15.5$ & $\sim 15.5$ & $\sim 15.6$ & $\sim 15.7$ & $\sim 15.7$ & & \\
\hline Sludge Layer Conductivity $(1 / \Omega-m)$ & $\sim 15.5$ & $\sim 15.5$ & $\sim 770$ & $\sim 770$ & $\sim 1830$ & $\sim 1830$ & & \\
\hline $\begin{array}{l}\text { Approximate Operating Time (hr) } \\
\text { ( } 9 \mathrm{hr} \text { feed, thr pour cycle) }\end{array}$ & $\mathbf{0}$ & 0 & 600. & 600. & 850 & 850 & & \\
\hline
\end{tabular}


Comparing predicted data in column 1 (flay.0b) with data from U1, which represents the clean melter without noble metals, it can be observed that the current is under predicted by about $10 \%$ in both electrode pairs while the power is over predicted by about $10 \%$. This is consistent with the voltage in each pair being over predicted by about $50 \%$. Correspondingly, the rms-resistance is also over predicted by about $50 \%$ relative to the experimental data. The ratio of the rms-resistance of the upper pair to the lower pair is $(0.230 / 0.267)=0.86$. By comparison, the ratio of test $U 1$ values is $(0.144 / 0.160)=0.90$. This is good agreement and consistent with the ratio of upper-to-lower power being 1.19 in the prediction and 1.22 in the $\mathrm{U} 1$ test. Note also that the true-resistance (open circuit value) is less than the rms-resistance determined by dividing the rms-voltage by the rms-current.

The best agreement in the current, voltage, rms-resistance, and power with U2 test data are found in columns 4 and 5 (flay.2a and flay.2), respectively, for the lower electrode pair. These two simulations assumed different floor layers. In the first, a uniformly flat layer which was $1 \mathrm{~cm}$ thick near the walls and $3 \mathrm{~cm}$ thick in the center with an effective electrical conductivity of about $770 \mathrm{~S} / \mathrm{m}$ was used. In the latter, a uniform $1 \mathrm{~cm}$ thick layer existed over the whole floor with an electrical conductivity of about $1830 \mathrm{~S} / \mathrm{m}$. The magnitude of the conductivity in the sludge layer is compared to data in Appendix D. The electrical conductivities are only approximate because while the amount of material is uniform in the layers, the temperature distribution is variable. In these two simulations, the concentration of $\mathrm{RuO}_{2}, \mathrm{~Pb}$, and $\mathrm{Rh}$ are those values predicted by TEMPEST to have settled to the floor over 600 and $850 \mathrm{~h}$ (see Section 6.2.1). For these cases, the current in the lower electrode pair is 230 and 229.5 amps while the $U 2$ average data value is 231 amps. The voltage is 35.5 and 31.5 volts while the $\mathrm{U} 2$ average data value is 37.3 volts. The corresponding rms-resistance is 0.154 and $0.137 \Omega$ compared to the average test value of $0.161 \Omega$.

The rms-resistance and true-resistance from the predictions are compared to data in Figure 6-16. The predicted rms-resistance is determined as the ratio of the predicted rms-voltage and rms-current, $R=$ E/I. This is consistent with the data which was determined as the ratio of the voltage to electric current. The true-resistance shown in the figure is the value of resistance an ohm meter would measure across an electrode pair if the other pair were open-circuited. Note that in all cases, the true-resistance is always less than the rms-resistance in an alternating current system where both electrode pairs are being powered by an in-phase source. With no noble metals in the melt $(t=0)$ the predicted rms-resistance is greater than that of the U2 test, but the ratio of the upper to the lower is about the same, 0.86 compared to 0.90 . The trend in the prediction is that the resistance in the lower pair decreases to values less than the upper pair when the sludge layer is present. The predicted resistance in the upper pair remains largely unaffected by the presence of the sludge layer. 


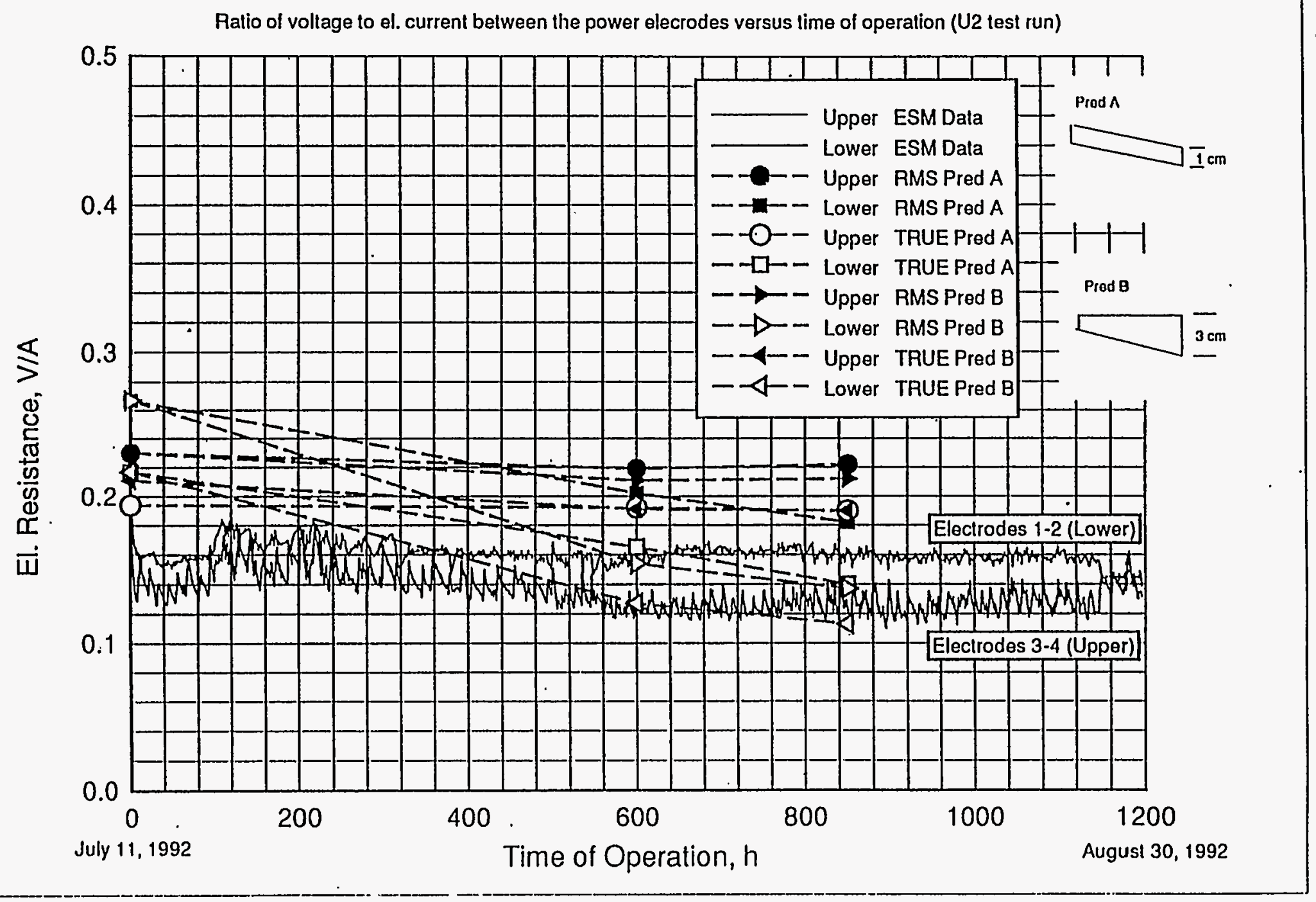

Fig. 6-16. Comparison of electric resistance. 
The decrease in the resistance between the lower electrodes occurs because of the enhanced conductivity sludge layer bridging the electrodes. In the experiment, it is reported that a $2-3 \mathrm{~cm}$ layer of sludge remained on the floor of the melter after draining. Figure 5-18 presents floor samples which exhibit concentrations ranging from about $4-6 \mathrm{wt} \%$ (total) over the melter floor.

The primary difference between the conditions of the predictions and the data is that the electric conductivity in the floor layer is probably too large. A more detailed discussion is given in Appendix $\mathrm{D}$ on how the concentration dependence of the electric conductivity was determined. By 850 hours, $1.84 \mathrm{~kg}$-total of $\mathrm{RuO}_{2}, \mathrm{Pd}$, and $\mathrm{Rh}$ have accumulated on the floor. From Figure 6-10, the estimated sludge layer is between 1 and $1.5 \mathrm{~cm}$ thick. This is consistent with the $1-3 \mathrm{~cm}$ thick sludge layers assumed in Table 6-1. The thickness is based on a maximum packing factor of $6 \mathrm{vol} \%$, which for $\mathrm{RuO}_{2}$, the principal component at a density of $6970 \mathrm{~kg}-\mathrm{RuO}_{2} / \mathrm{m}^{3}$, corresponds to $19.3 \mathrm{wt} \%$. The resistivity data of Figure 5-19 shows the ratio of enhanced conductivity sludge at $1150^{\circ} \mathrm{C}$ to be about 9 times that of glass product. The sludge samples used for the measurements include floor sample No. 1 and a glass sample labeled batch 2, sample 3, pouring glass taken approximately half way through the U2 test. The floor sample is reported (Figure 5-18) as being nearly 6 wt\% (total NM) which corresponds to a volume fraction of about 2 vol\% (considering only the $\mathrm{RuO}_{2}$ component). At 2 vol\% and a maximum packing of 6 vol\%, Eq. (D.30) results in an enhanced conductivity about a factor of 10 greater than the noble metals-free glass. This is consistent with the experimental ratio of 9. Thus the enhanced conductivity correlation used is consistent. It can be concluded that either the maximum packing factor is significantly less than the $6 \mathrm{vol} \%$ determined from analysis of the glass sample micrographs, that the layer is not continuous on the floor or that the noble metals in the sludge layer. are much more dispersed. The latter would suggest that the layer is much thicker than predicted with a correspondingly lower electric conductivity. Resistivity data presented in Figure 523 is of no value in resolving the issue further because it is data of samples which all contain less than $0.4 \mathrm{wt} \%$ (uncorrected), except the one floor sample No. 5 , which contains nearly $6 \mathrm{wt} \%$. Electrical resistivity for Sample No. 5 presented in Figure 5-23 differs by nearly a factor of 1.5 from data for Sample No. 1 in Figure 5-19. The direction of the difference in electrical conductivity is consistent with the correlation used in the analysis. The additional data, however, does not help resolve the issue of maximum packing factor.

\subsubsection{Temperature Profiling}

Experimental temperature profile measurements made in the glass melt are discussed in reference to Figure 4-28 in Section 4.2.2. Figures 4-19 to 4-25 present time history temperature data at five 
locations on the thermocouple stalk. Of these five locations, only one (TR64) is continuously in the melt. The other four are in the cold cap region or the plenum. The one in the melt indicates that the central melt temperature was very nearly $1200^{\circ} \mathrm{C}$ over most of test U2. There are short time durations where the temperature in the central part of the melt would drop as low as $1100^{\circ} \mathrm{C}$. The average operating melt temperature is reported as $1184^{\circ} \mathrm{C}$ (Table 5-I). This is somewhat hotter than the target operation temperature of $1150^{\circ} \mathrm{C}$. Running the melter at the hotter temperature was done in an attempt to increase feed processing and glass production. Control of the ESM melter was by manual adjustment of the electric current to the melter.

All of TEMPEST's post-test simulations were conducted using a temperature controller targeted to a temperature of $1150^{\circ} \mathrm{C}$. It was found that in the ESM computer model, the average melt temperature over the central $2 / 3$ of the melt volume was typically within $\pm 5^{\circ} \mathrm{C}$ of the controlling temperature location. Table 6-1 lists average and controlled temperatures for several cases.

The distribution in temperature from bottom to top varies significantly in the melt, depending upon position and time. Figure 6-17 compares computed temperature profiles with the data from Figure 428. The experiment data were acquired near the end of test $U 2$ and thus the reported $2-3 \mathrm{~cm}$ layer of sludge would have been present at this time. The computations included in Figure 6-17 were for a case in which a $1 \mathrm{~cm}$ layer existed across the floor. Accounting for the difference in average temperature, the agreement between the predicted temperature distribution and the measured data is quite good. Comparison of the predicted curves more in the central region of the melt (Curves 1 and 3 ) with the data at filled condition (upper data curve) indicates a very similar overall shape and slope, except very near the floor of the melter. All of the predicted temperature profiles show a marked affect of the presence of the sludge layer. This is especially pronounce just in front of the electrode faces (Curves 2 and 4, open symbols) where local temperatures reach $1200^{\circ} \mathrm{C}$, some 50 degrees hotter than the average, and nearly 80 degrees hotter than the lower region of the central portion of the melt. (Note that the colder temperatures in Curves 2 and 4, below the lower edge of the lower electrode pair are in the refractory material.) The asymmetry which exists in the upper region of the melt in front of the electrode faces is a consequence of the asymmetric melt flow distribution in this physically unstable condition of cold-over-hot.

Figures 6-18 to 6-21 present a logical progression of temperature profile changes which result as the amount of material in the sludge layer decreases from an assumed $1 \mathrm{~cm}$ thick layer to no layer at all. These results are a characteristic example of the temperature profile variations in a melt which contains a sludge layer in one extreme and no sludge layer in the other. Without the enhanced 


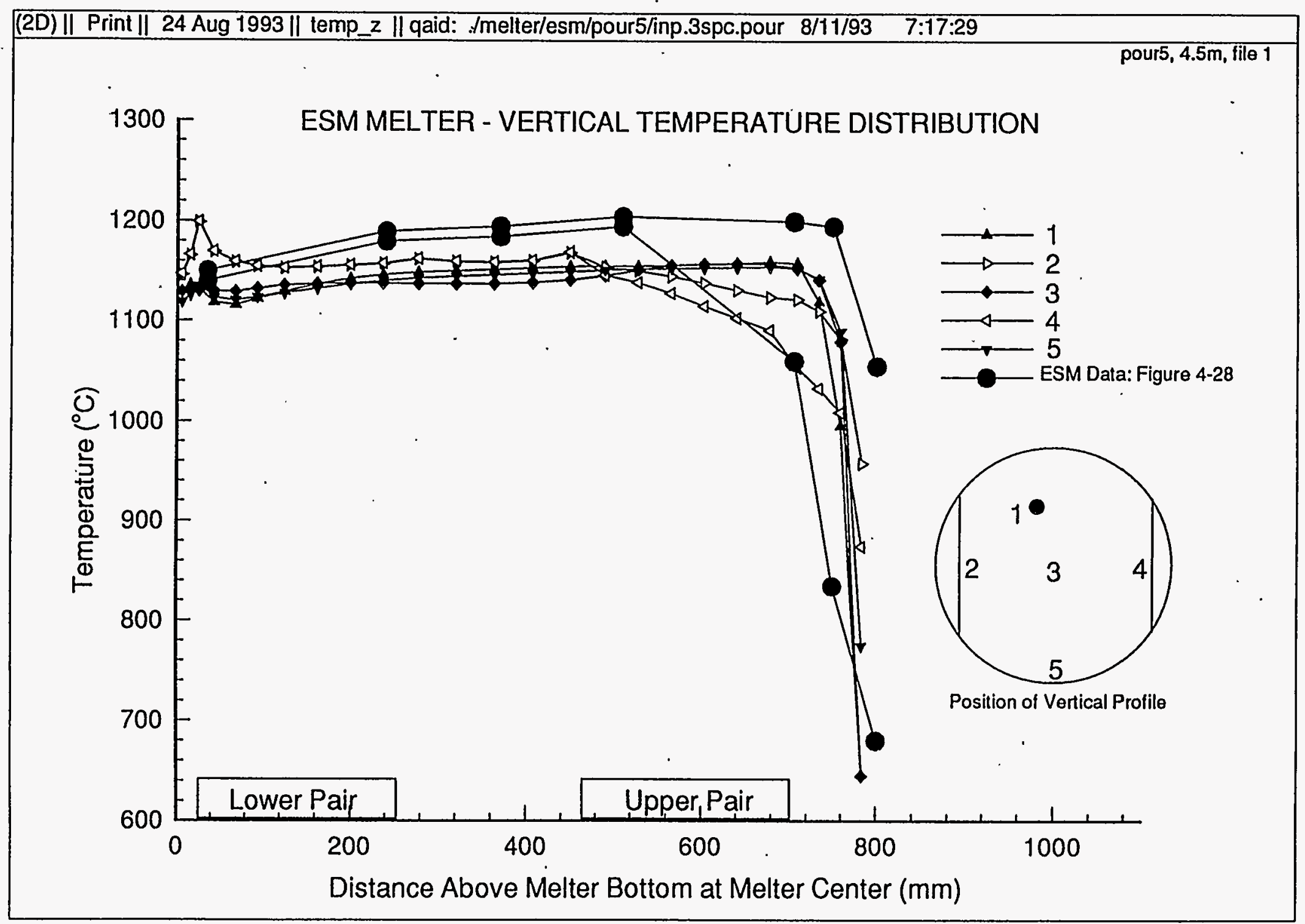

Fig. 6-17. Comparison of vertical temperature distributions. 


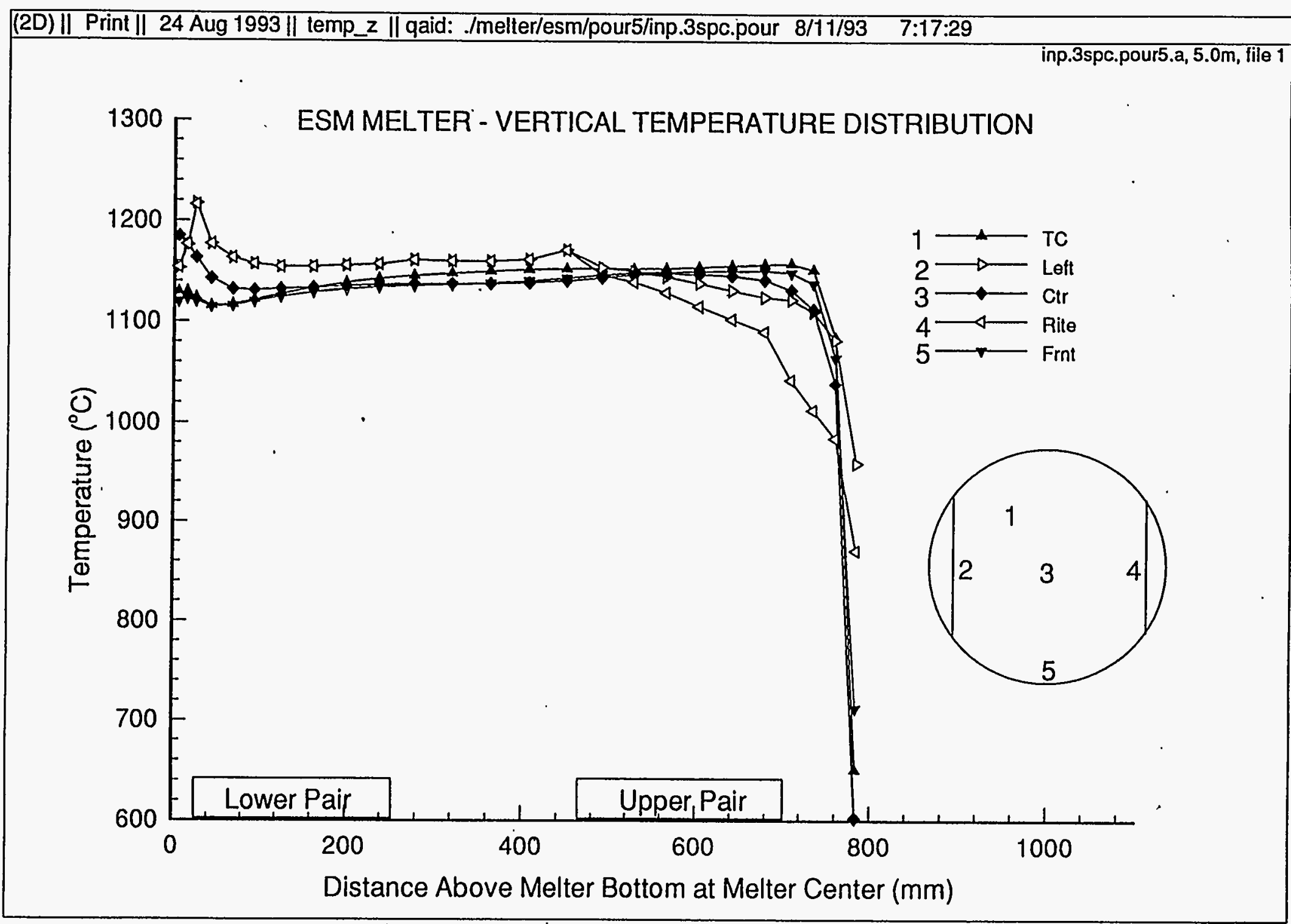

Fig. 6-18. Comparison of vertical temperature distributions. 


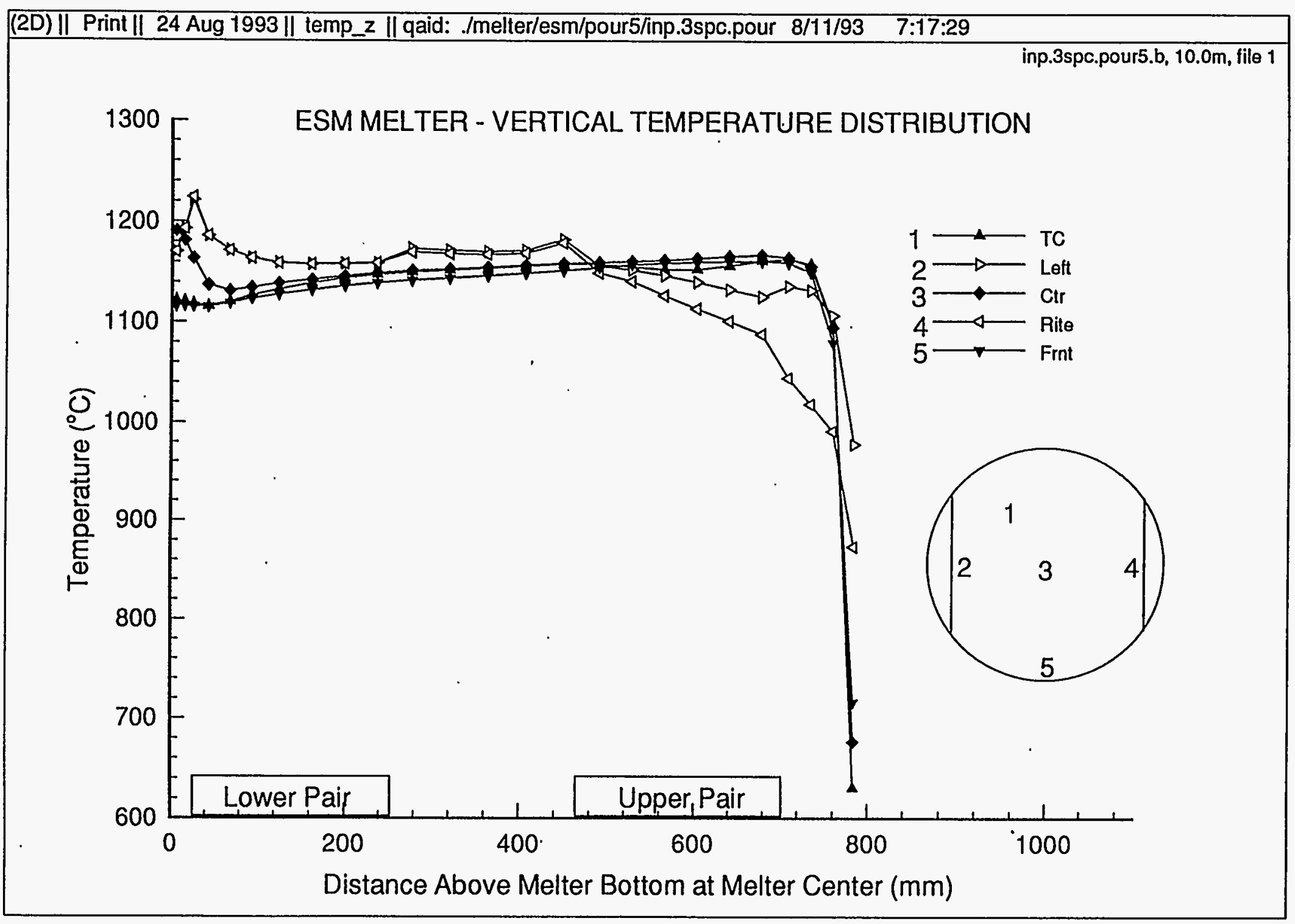

Fig. 6-19. Comparison of vertical temperature distributions. 


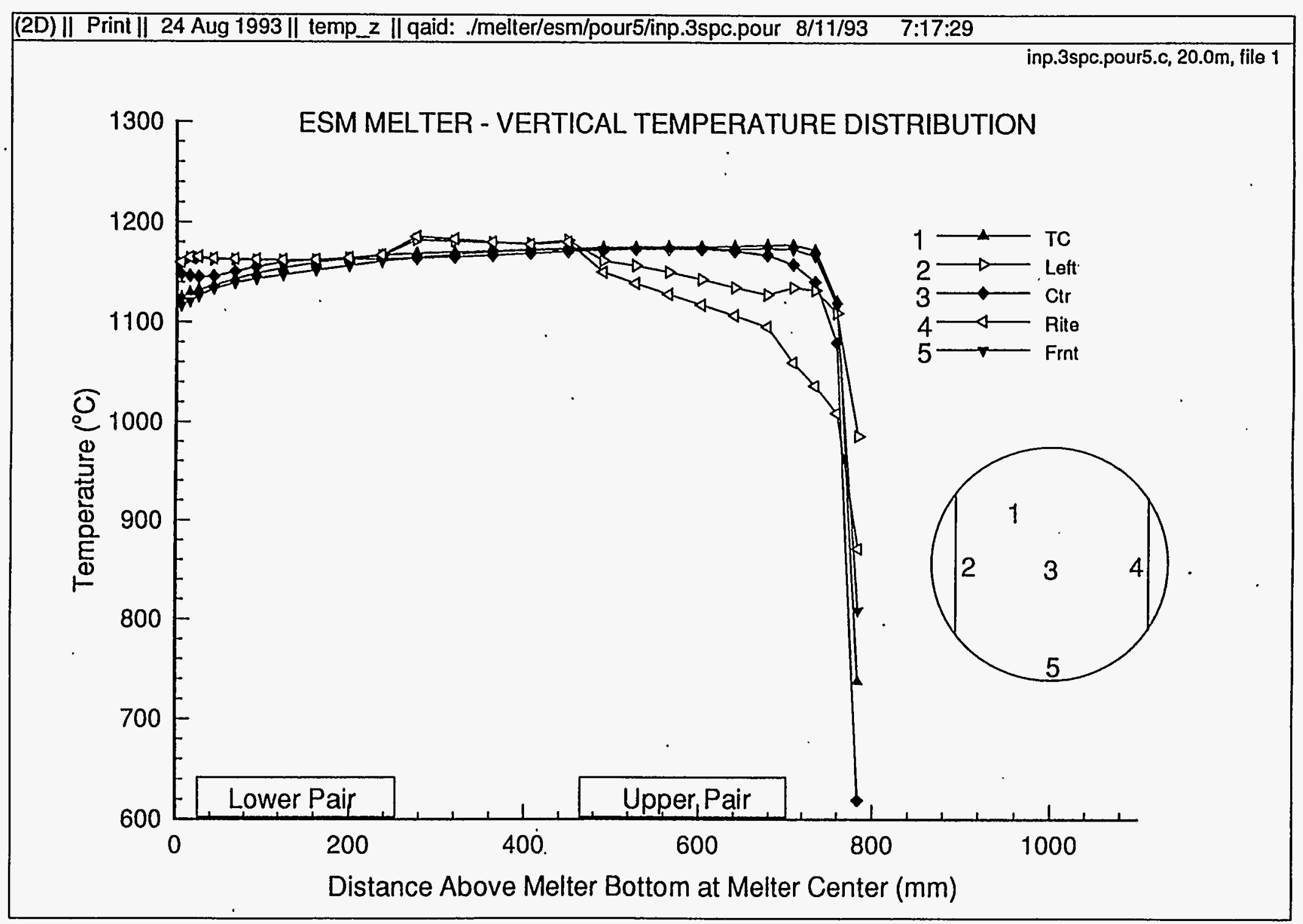

Fig. 6-20. Comparison of vertical temperature distributions. 


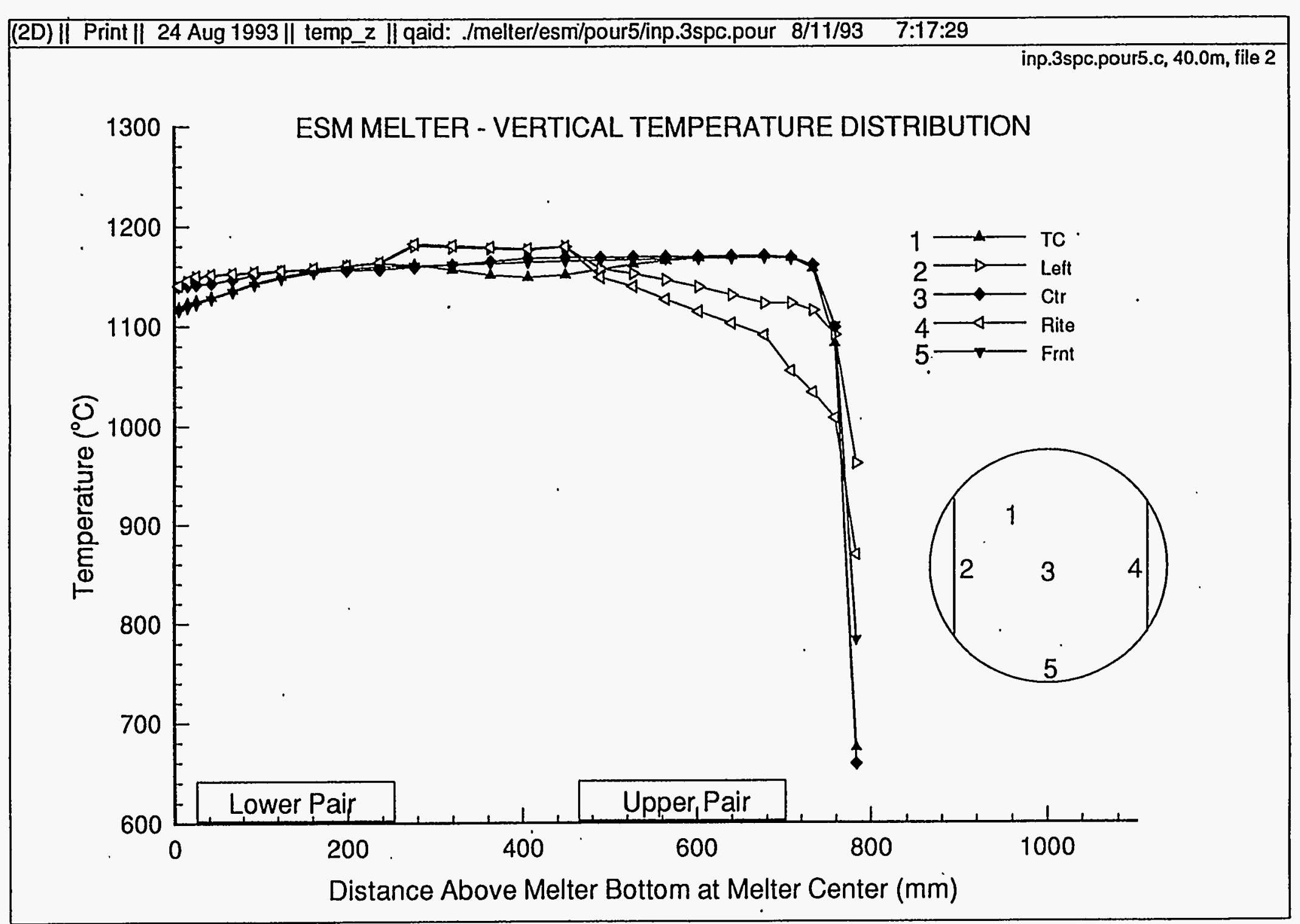

Fig. 6-21. Comparison of vertical temperature distributions. 
electrical heating which occurs in the sludge layer due to the increased electrical current shorting through the layer, the glass in the bottom of the melter does not exhibit locally high temperatures that is seen when the shorting sludge layer is present. This predicted trend is consistent with observations made in the RSM experiments (Cooper, Elliott, et al. 1993) from a limited amount of temperature probing of the melter during operation. No temperature probing was done in the ESM.

\subsection{CONCLUSIONS}

Conclusions drawn from the prediction presented herein include the following:

- Material balances, including retention, for $\mathrm{RuO}_{2}, \mathrm{Pd}$, and $\mathrm{Rh}$ are in excellent agreement with corresponding experimental data. This is key to the objective of this work.

- Concentration distributions throughout the melter are typically less than $\pm 2 \%$ of the average concentration in the melt at any given time (excluding the sludge layer). The melt pool is concluded to be well mixed.

- Sludge layer thickness is between 1 and $1.5 \mathrm{~cm}$ for an assumed maximum packing 6 vol\%.

- Power and current are typically overpredicted by $10-15 \%$. Voltage is underpredicted because of discrepancies in electrical conductivity.

- Comparison of predicted rms-resistance across the electrode pairs with rms-resistance computed in the $\mathrm{U} 2$ test from measured voltage and current are inconclusive.

Predicted resistance across the electrode pairs without noble metals (beginning of test) are greater than those determined in the U2 test. As a sludge layer builds up, predicted resistance across the upper electrode pair remains nearly constant. It is relatively unaffected by the sludge layer. Experimental resistance across the upper electrode pair is also relatively constant. Predicted resistance across the lower electrode pair, however, shows a marked decrease (both the rmsresistance and the true resistance) as the sludge layer builds up. Experimental data indicate the resistance across the lower pair to be relatively constant, even through a $1-3 \mathrm{~cm}$ sludge layer has built up on the melter floor. Thus it can be concluded that either: 
- The maximum packing factor of 6 vol\% used in the electrical conductivity data correlation is too large, or

- The sludge layer thickness during operation was greater than the $1-3 \mathrm{~cm}$ this layer observed, or

- The sludge layer was not continuous across the floor.

The source of the discrepancy in the comparison of the resistance across the lower pair remains to be resolved.

\section{REFERENCES}

Anderson, L. D., T. Dennis, M. L. Elliott, L. L. Eyler., P. H. Hrma. 1992. "Laboratory Testing and Computer Modeling of HWVP Melter Feed", Pacific Northwest Laboratory, Richland, Washington.

Cobb, W. T., and P. R. Hrma. 1990. "Behavior of $\mathrm{RuO}_{2}$ in a Glass Melt", Ceramic Transactions, 23:233-237.

Trent, D. S. and L. L. Eyler. 1992. "TEMPEST A Computer Program for Three-Dimensional TimeDependent Computational Fluid Dynamics". Battelle Memorial Institute.

Westik, J. H., Jr. 1986. "Tẹmperature Control System for Liquid-Fed Ceramic Melters". PNL-6009, Pacific Northwest Laboratory. 
APPENDIX A: Investigation of bubble rich glass product taken from the outer melt surface of the ESM melter during long-term operation 
Investigation of bubble rich glass product taken from the outer melt surface of the ESM melter during long-term operation

\section{INE}

August 1992 


\section{REM/EDS-Analysis}

of sample taken during ESM operation from the outer uncovered region of the foamy glass pool surface

Sample No.: 295 PE 06.08.1992, 20.50 hours

FRIT:

see table 1, page 16

FEED:

Batch No. 4, see table 2, page 17 , as analysed

\section{A. Macroscopic observations}

The sampled material was taken from the outer surface area of the glass pool of the ESM melter during operation (Aug. 6, 8.50 p.m.) It behaves like a rising dough and develops in the liquid state a bubbly texture, see Figs. 1, 2. While sampling from the melt surface of the ESM it had a temperature of approximately $900{ }^{\circ} \mathrm{C}$.

It is not a foaming in the strict sense. However, the material obviously is very viscous and the amount of it may grow in thickness. This material apparently is highly heat insulating and reduces the heat transfer from the hotter melt pool to its surface significantly.

B. Firm qualitative results

1. Appearance and texture

The glassy material is not homogenous and bubbly.

The fracture surfaces are rough. Its colour is dark brown.

2. Inclusions and newly formed crystalline phases

The glassy material is rich in included salty agglomerates (liquid at process temperatures); it is also rich in included calcine and newly formed crystalline phases.

- Newly formed crystalline phases 
$\mathrm{SiO}_{2}$ is frequently. found and the crystal structure type involved presumingly is cristobalite, see Fig. 3 . These crystals may have grown from $\mathrm{SiO}_{2}$-rich part of the unmixed glass frit.

For the basic frit, unmixing occurs at a temperature below about $950^{\circ} \mathrm{C}$, as is shown in Fig. 30, page 19.

Even the delivered glass frit is already unmixed as indicated by its optical anisotropy.

In pores $A g, \cdot$ Cd-iodide crystals grow by a condensation mechanism, when the porous melt is cooled down, see Figs. 6,7 . This is in accordance with the phase diagram $\mathrm{CdJ}_{2}-$ AgJ; $\mathrm{CaJ}_{2}$ boils above $708^{\circ} \mathrm{C}$.

- Calcine

The glass product contains small lumps of calcine, which show individual concentration of the element $\mathrm{Zr}$.

- Salts

A lot of salty agglomerates are present. Their sizes. differ from the $\mu \mathrm{m}$ - to the $\mathrm{mm}$-range. Under the electron beam they become movable and analysis is extremely difficult. Their composition varies drastically from spot to spot. All possible anions are found: sulfate, chloride, iodide, phosphate, nitrate and possibly nitrite. The total amount of salt melt can be estimated from the anion inventory in the feed, table 3, page 18 .

\section{Summary:}

The viscous glassy material from the outer surface which is not covered with cold cap material represents a concentrated suspension of glass product melt, frit melt, 
calcine and salt melts. This explains the high viscosity and therefore the formation of bubbles due to the degassing of the calcine and the thermal decomposition of the salts. This material is a late state of the "cold" cap. The total anion inventory is comparatively low so that the overall vitrification rate is low, too.

A more detailed analysis of the glassy material by EDS is severely handicapped because we cannot measure $\mathrm{Li}$ and $\mathrm{B}$.

It is recommended to determine the viscosity of such a material at a reasonable temperature as a function. of time. That will give us information concerning the homogenization of the suspension. 


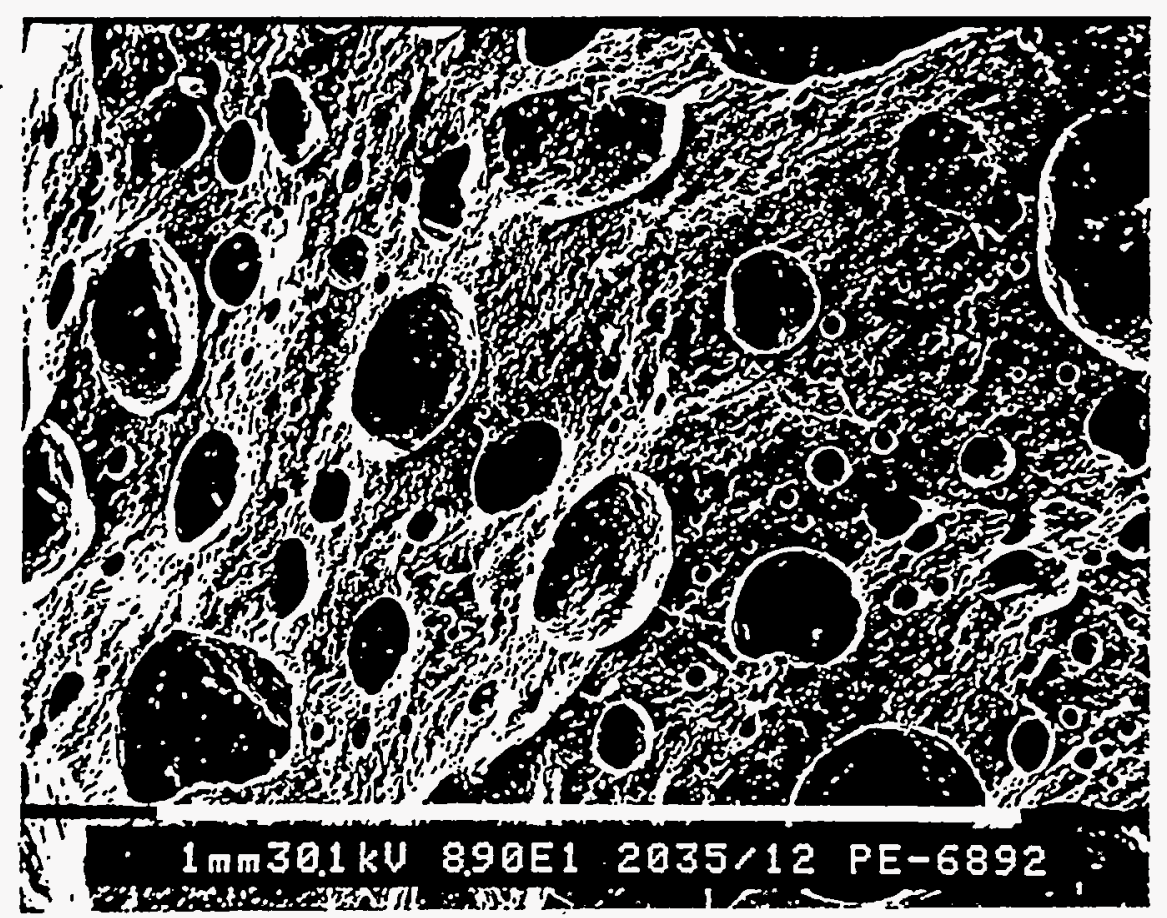

Fig. 1

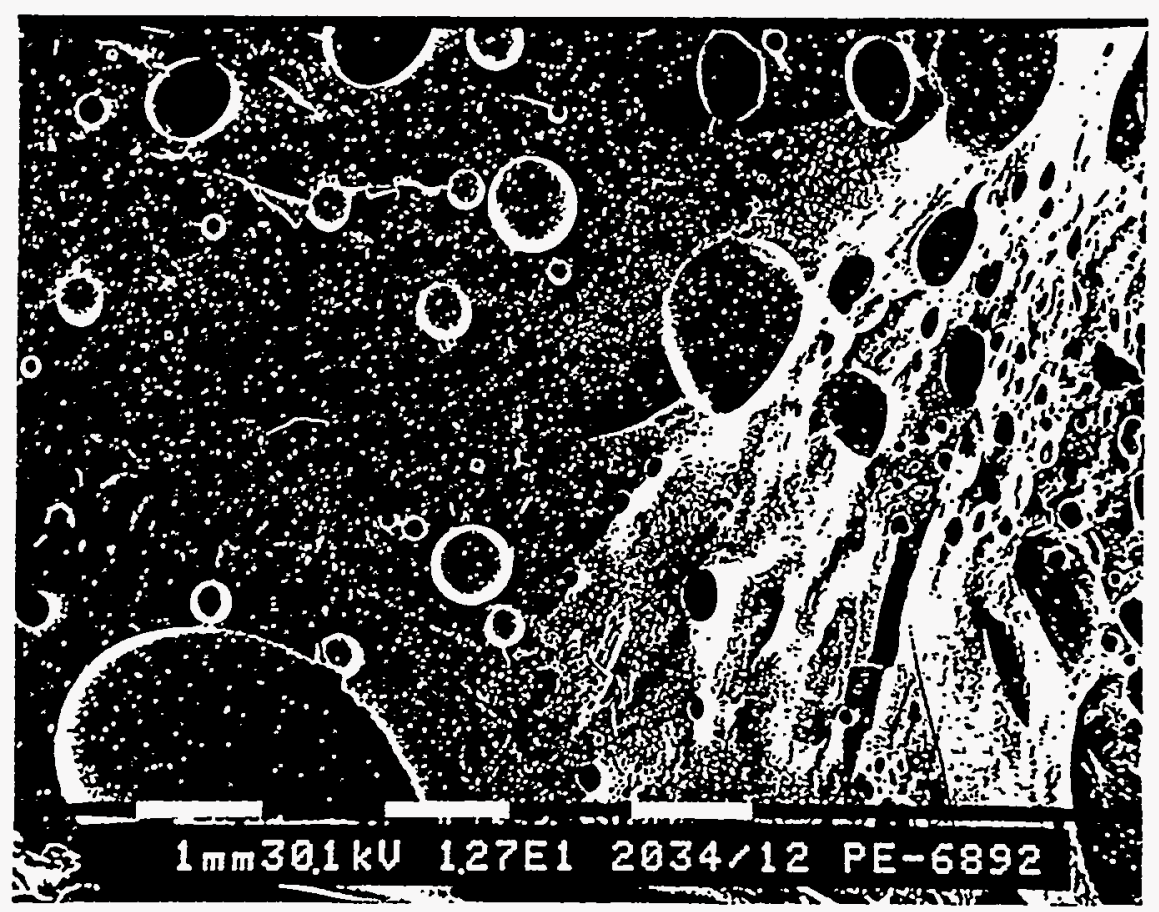

Fig. 2 


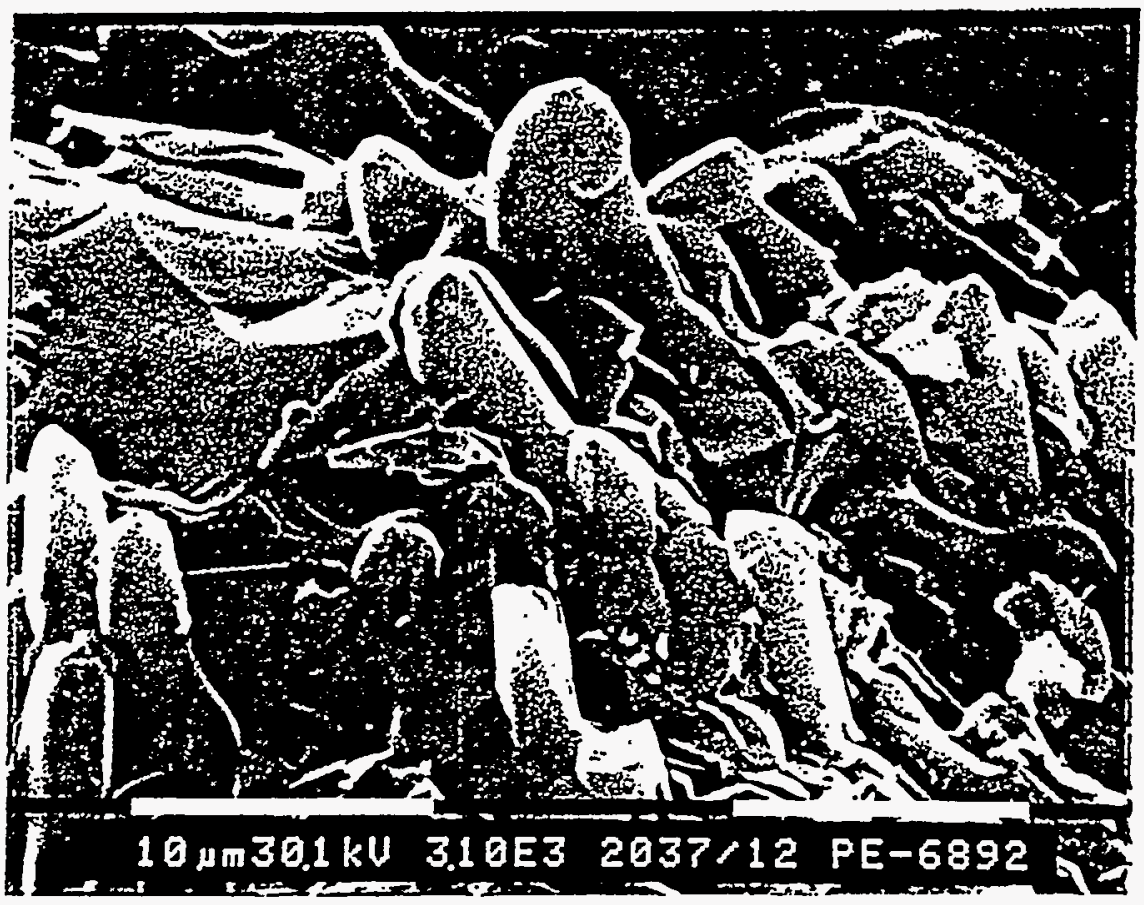

Fig. 3

The glassy matrix of this area contains a larger number of elongated crystals up to $10 \mu \mathrm{m}$ in length having $\mathrm{SiO}_{2}$ composition. Most probably the crystals are cristobalites which grew from the $\mathrm{SiO}_{2}-\mathrm{rich}$ part of the unmixed basic frit. 


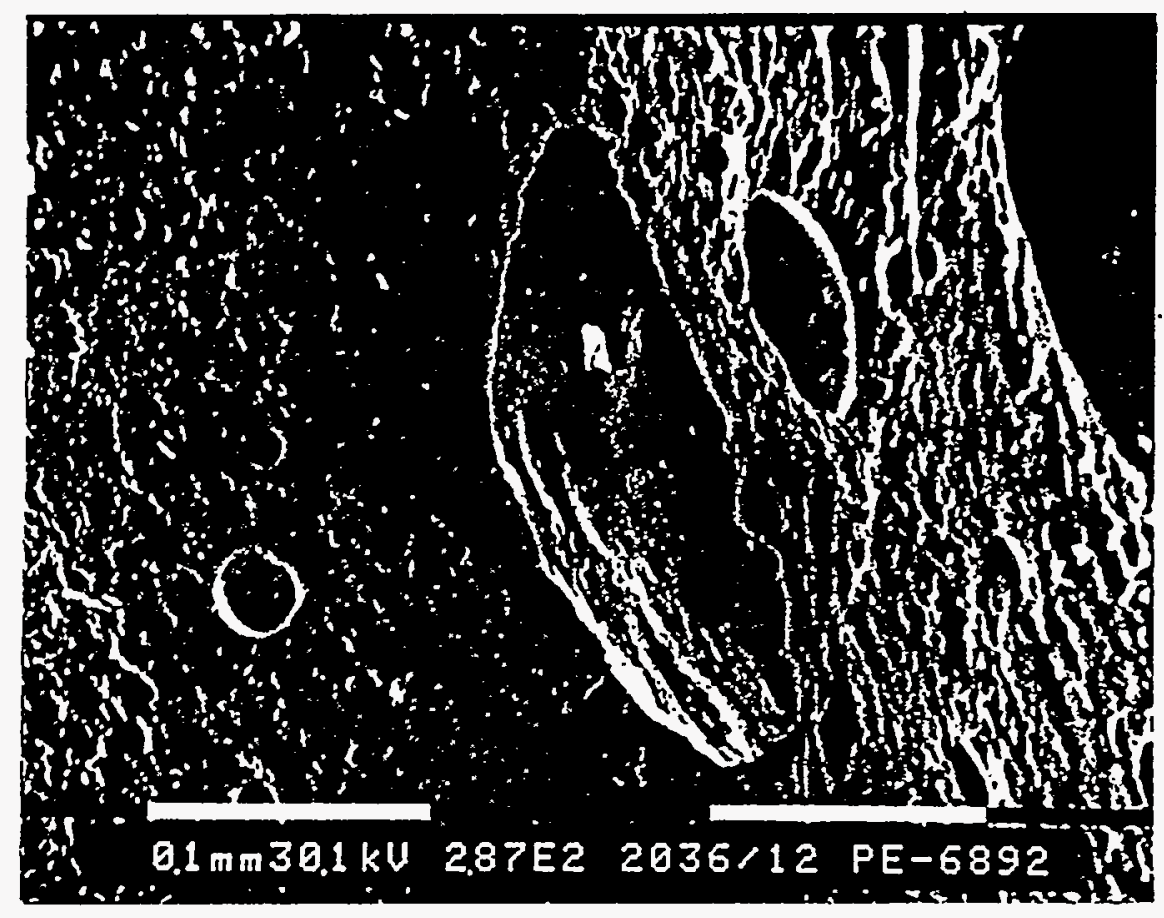

$.287 x$

Fig.4 Rough fracture surface due to many inclusions

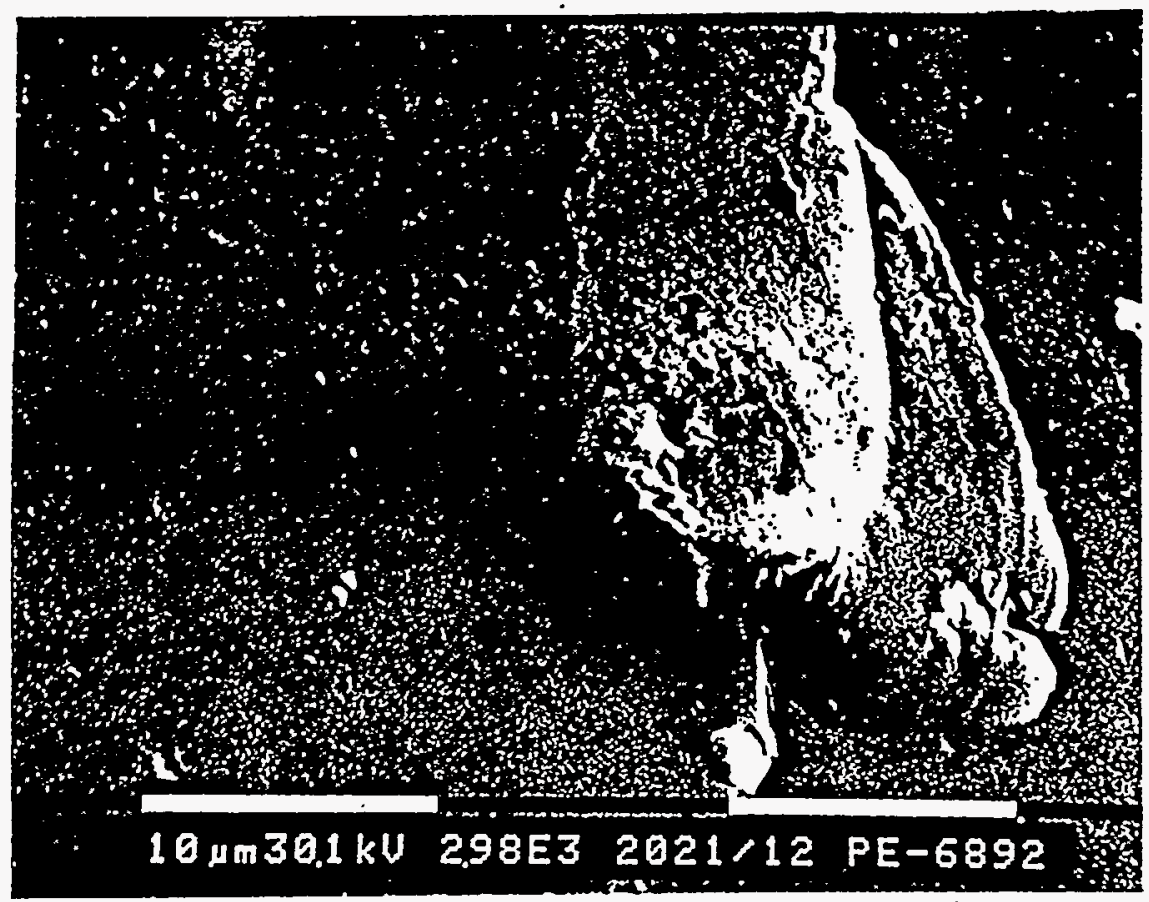

$2980 \times$

Fig.5 Fracture surface under higher magnification 


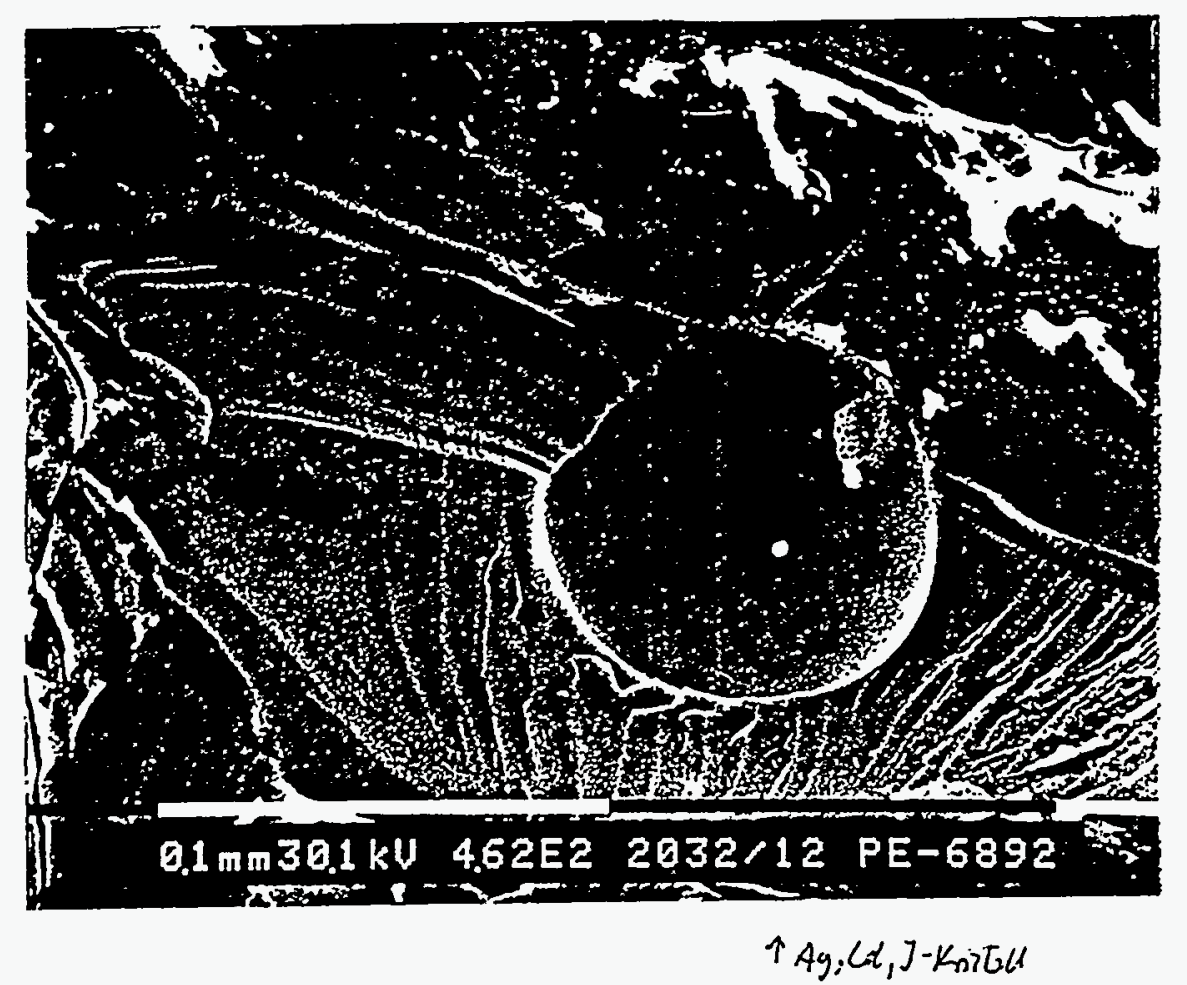

$462 x$

Fig. 6 Tiny crystal of ca, Ag-Iodide on the surface of a pore

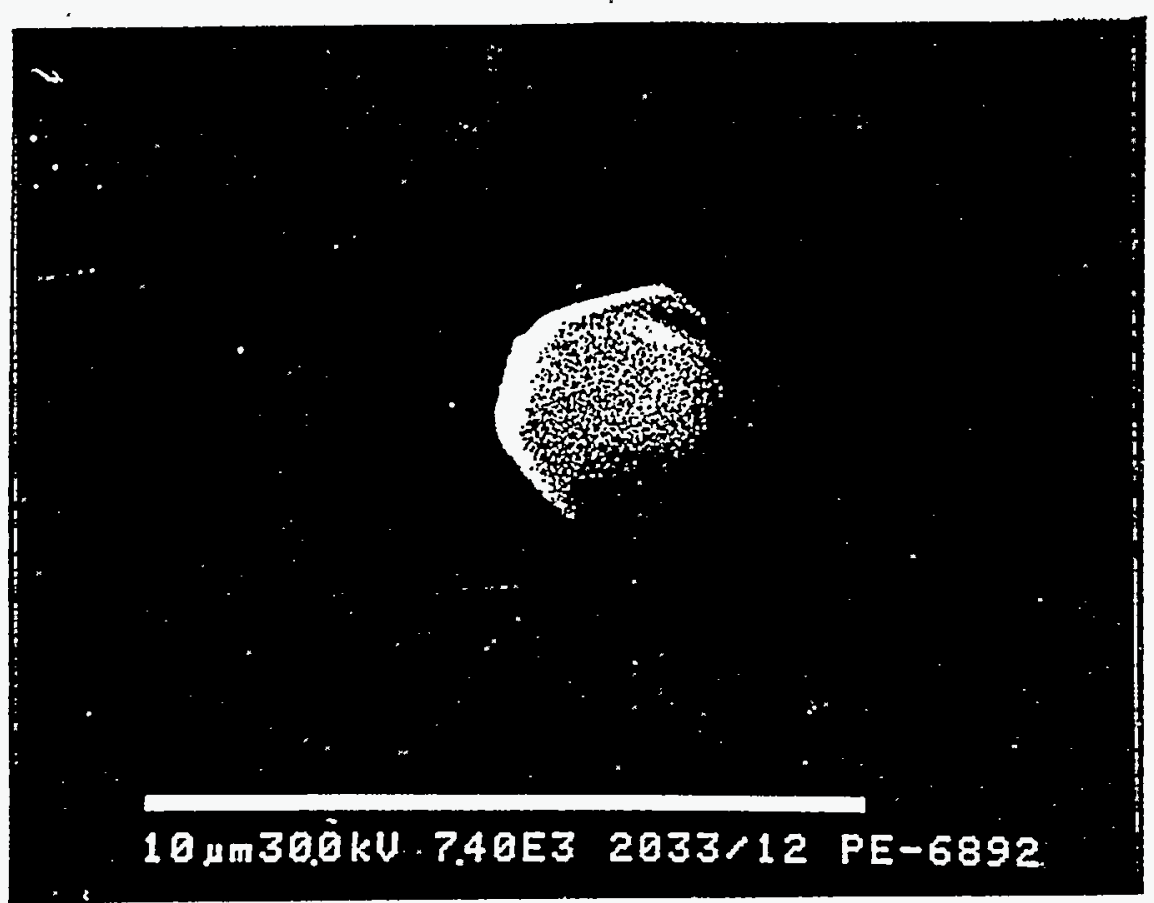

$7400 x$

Fig. 7 The iodide crystal under higher magnification 


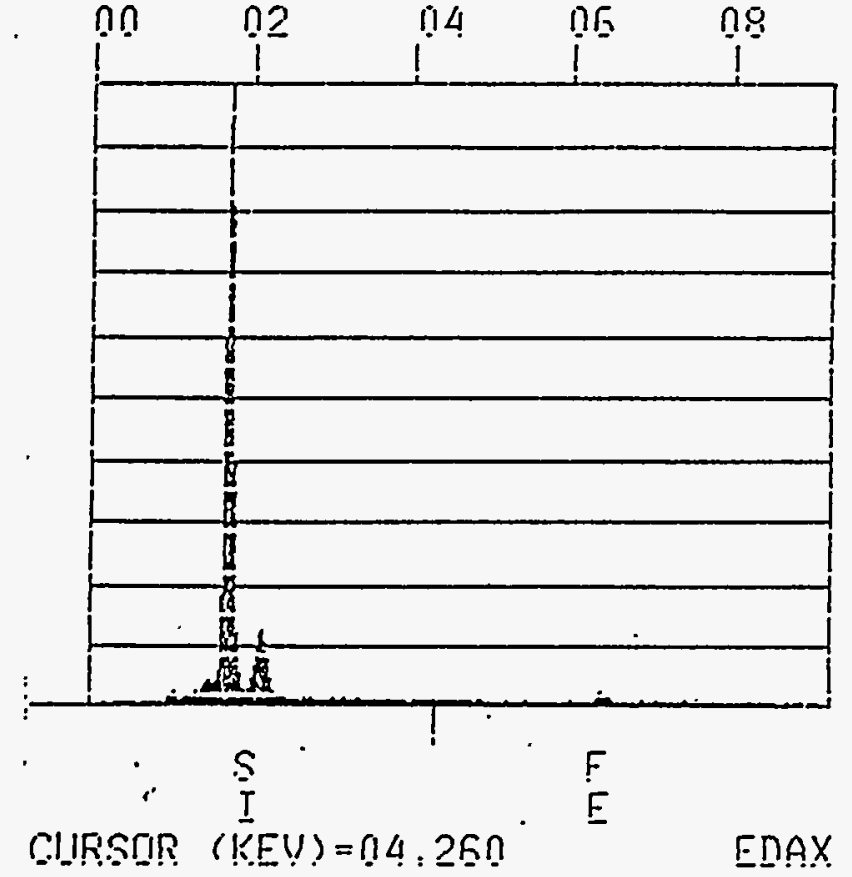

Fig. 16

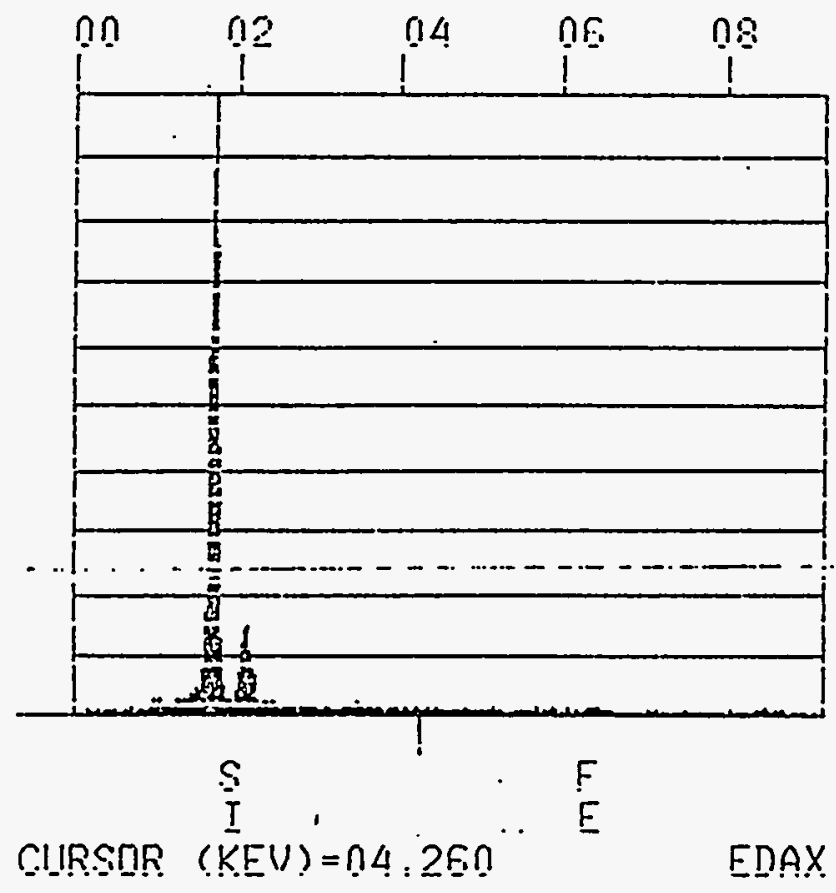

Fig. 17

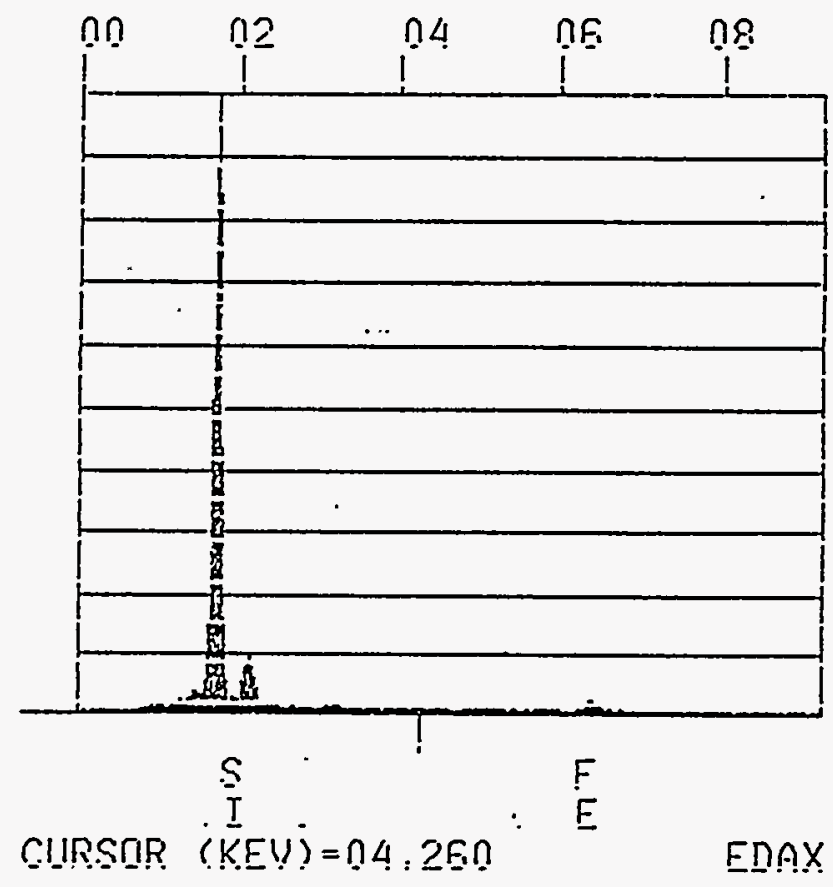

Fig. 18 


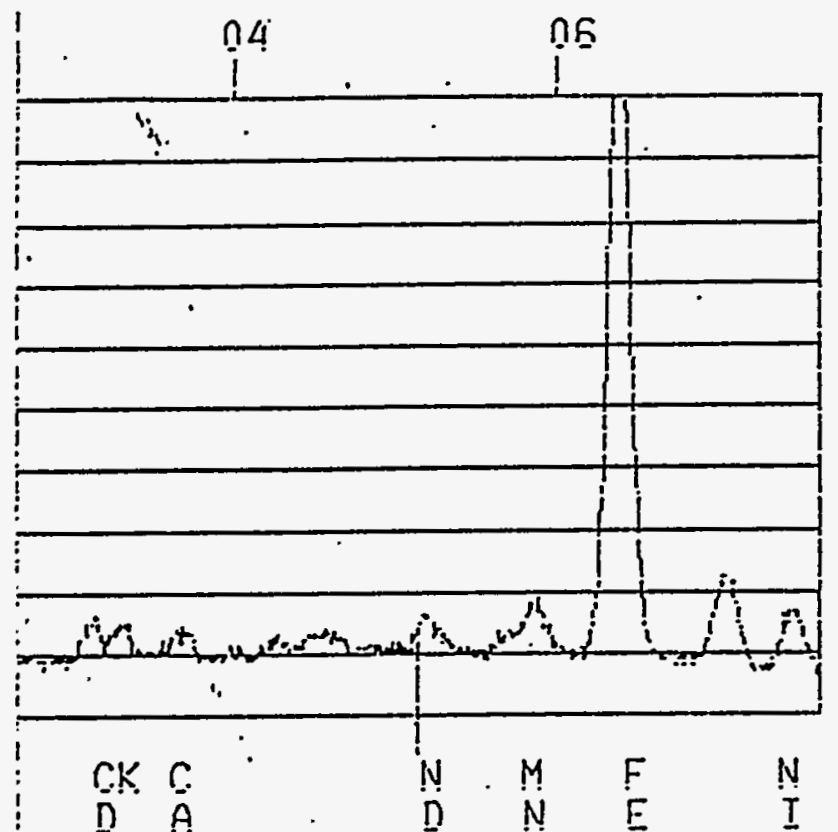

\section{Fig. 19: All feed elements above a concentration}

of 0.05 wt\% can be detected

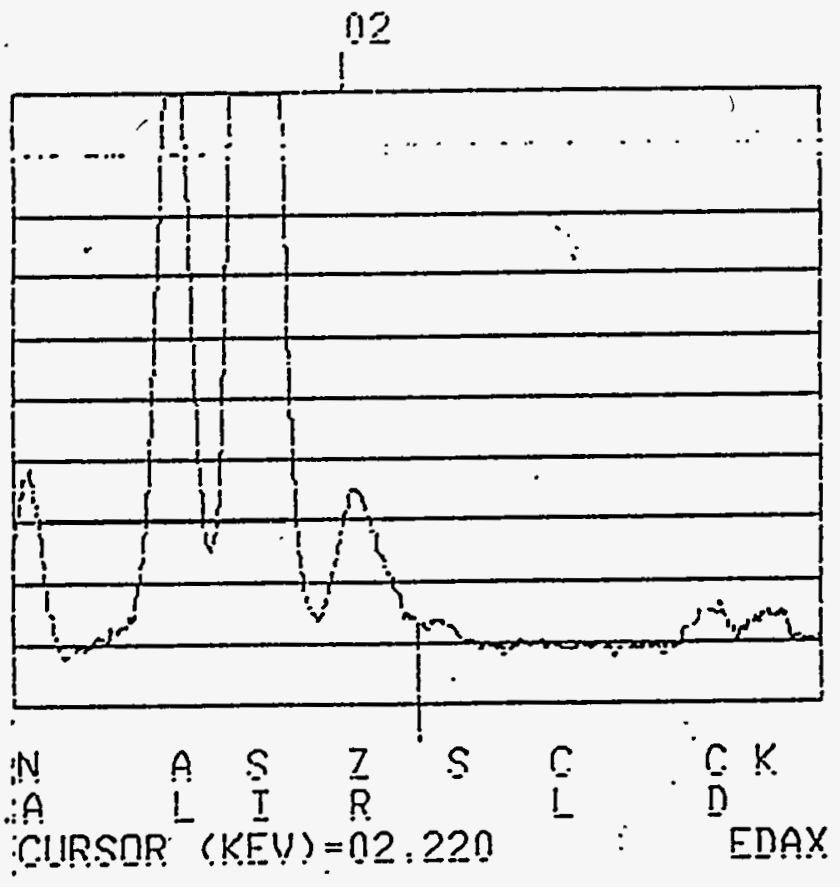

Fig. 20: Area rich in $\mathrm{Zr}$ and calcine 


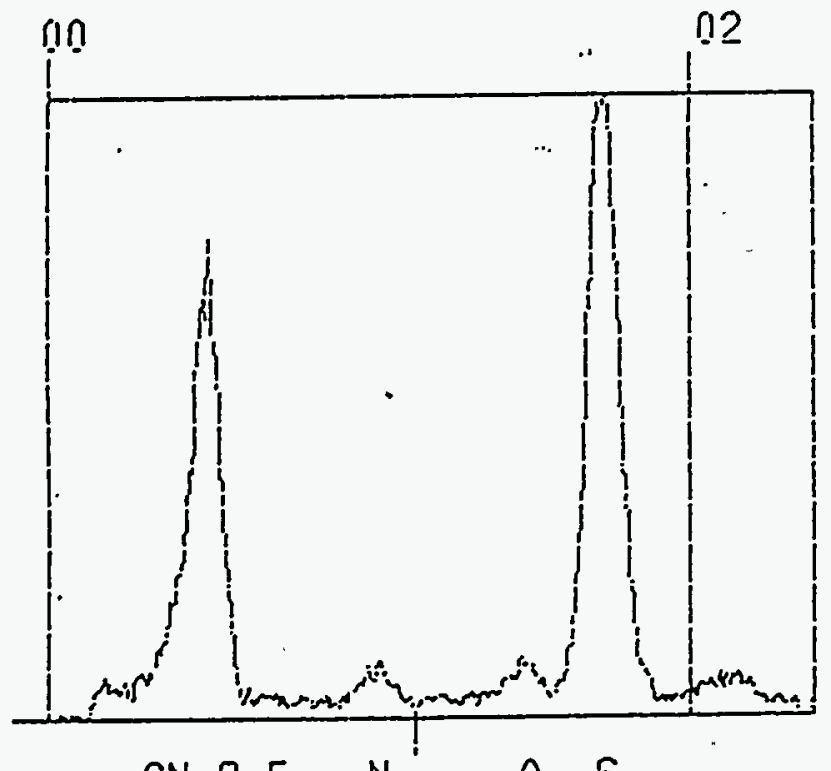

CN $\cap F \quad \stackrel{N}{A} \quad \stackrel{A}{I} \stackrel{I}{I}$

CIIRSOR (KEU) $=0 ! \cdot 140$

EDAX

Fig. 21: Nitrate or Nitrite

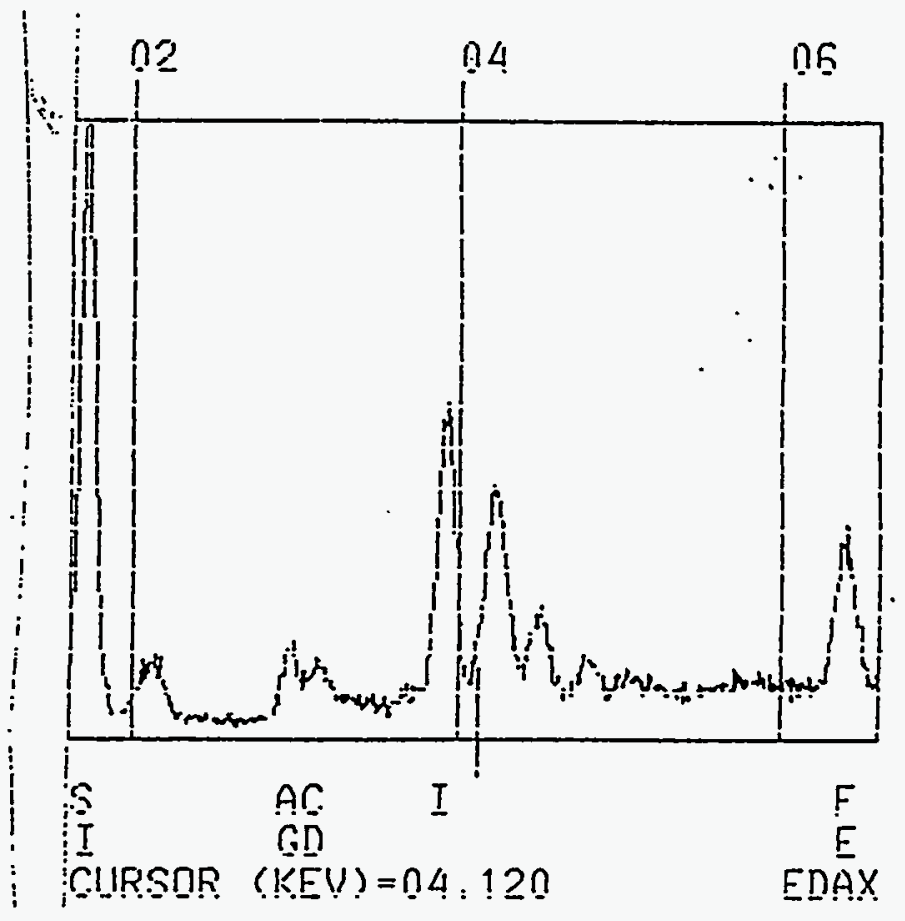

Fig. 22: $\mathrm{Ag}^{+}, \mathrm{Cd}^{2+}, \mathrm{I}^{-}$
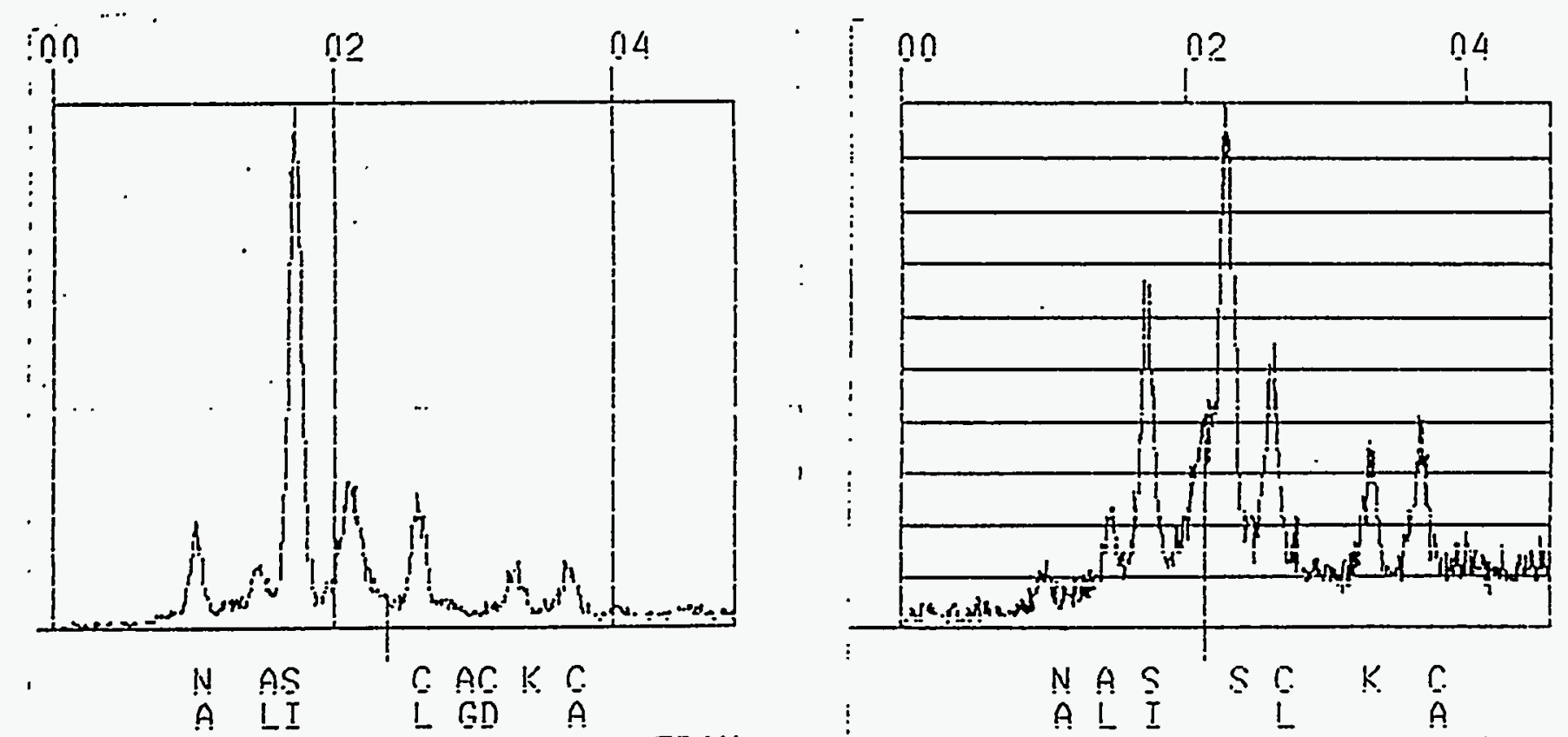

CURSOR $\stackrel{A}{(K E V !)}=\Omega 2,38 \cap$

EDAX

Fig. $23 \mathrm{Cl}^{-}$

Fig. $24: \mathrm{Cl}^{-}, \mathrm{SO}_{4}^{2-}$

Fig. 21-24: Anion inventory of salt inclusions analyzed on a fracture surface 


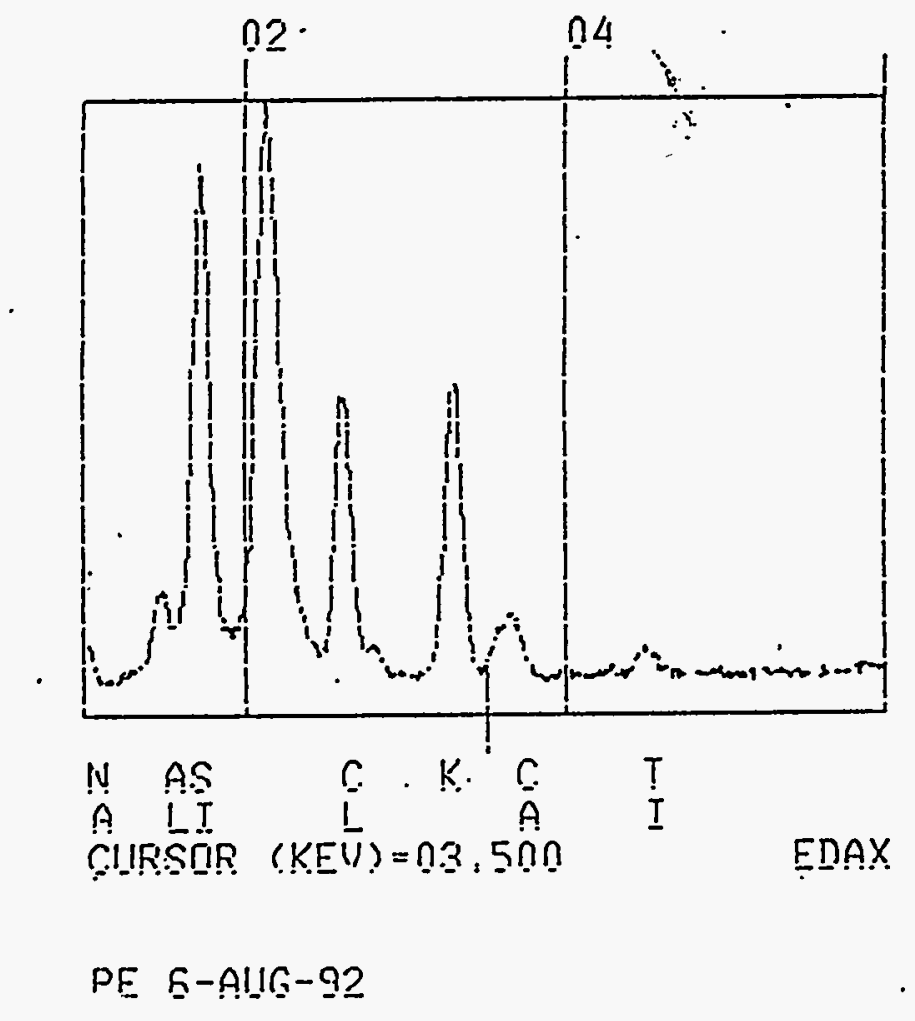

Fig. 25: KCl-rich salt inclusion 


\section{Table 1}

Analysed frit sample Nr. 169

\begin{tabular}{lcc}
\hline & wt\% & target wt\% \\
\hline $\mathrm{SiO}_{2}$ & 72.53 & 72.26 \\
$\mathrm{~B}_{2} \mathrm{O}_{3}$ & 18.93 & 20.45 \\
$\mathrm{Li}_{2} \mathrm{O}$ & 7.17 & 7.29 \\
\hline & 98.63 & 100.00 \\
$\Sigma$ & &
\end{tabular}


$T a b \cdot 3$

on mell surfoce

NCAW feed composition

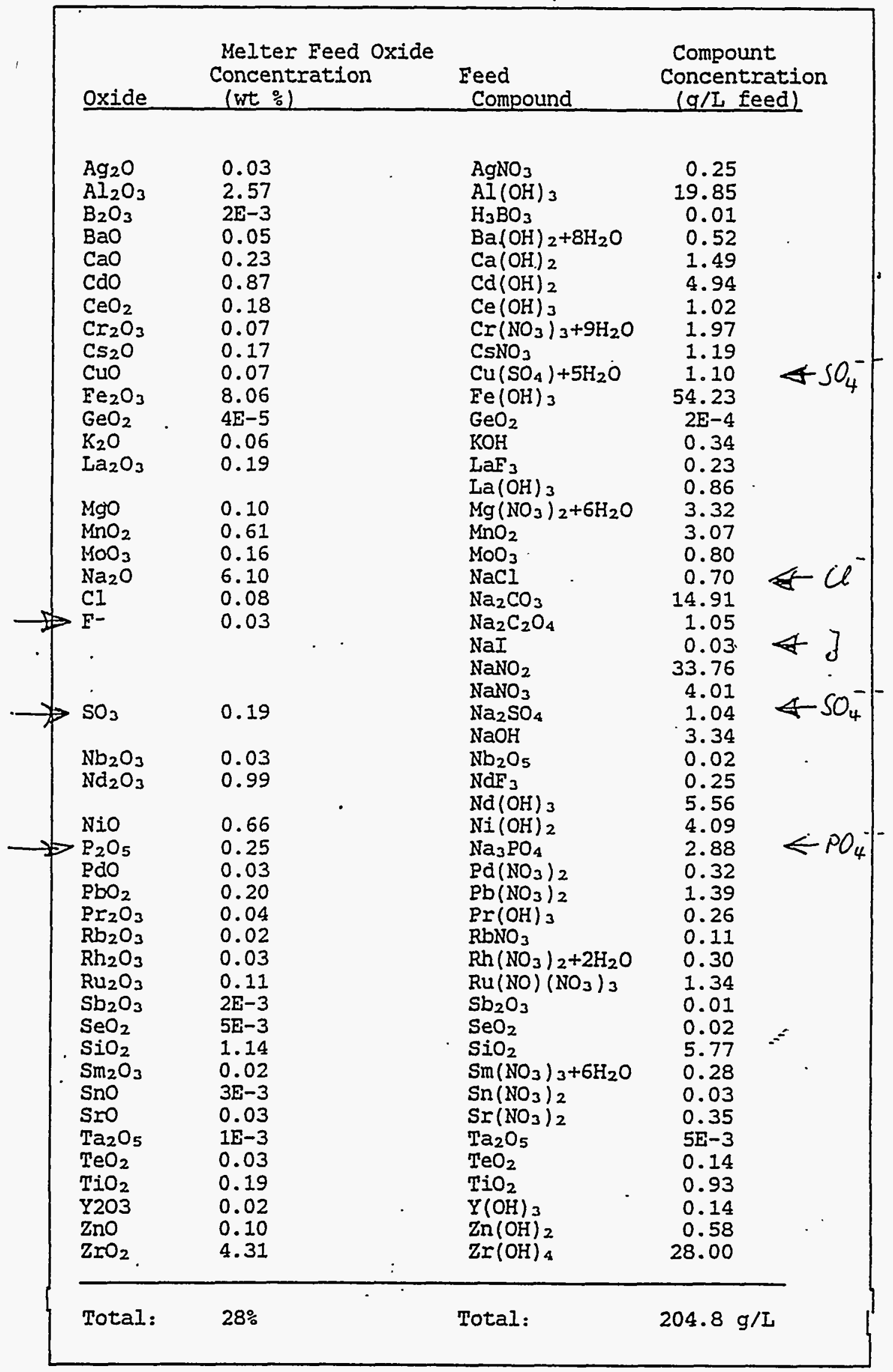




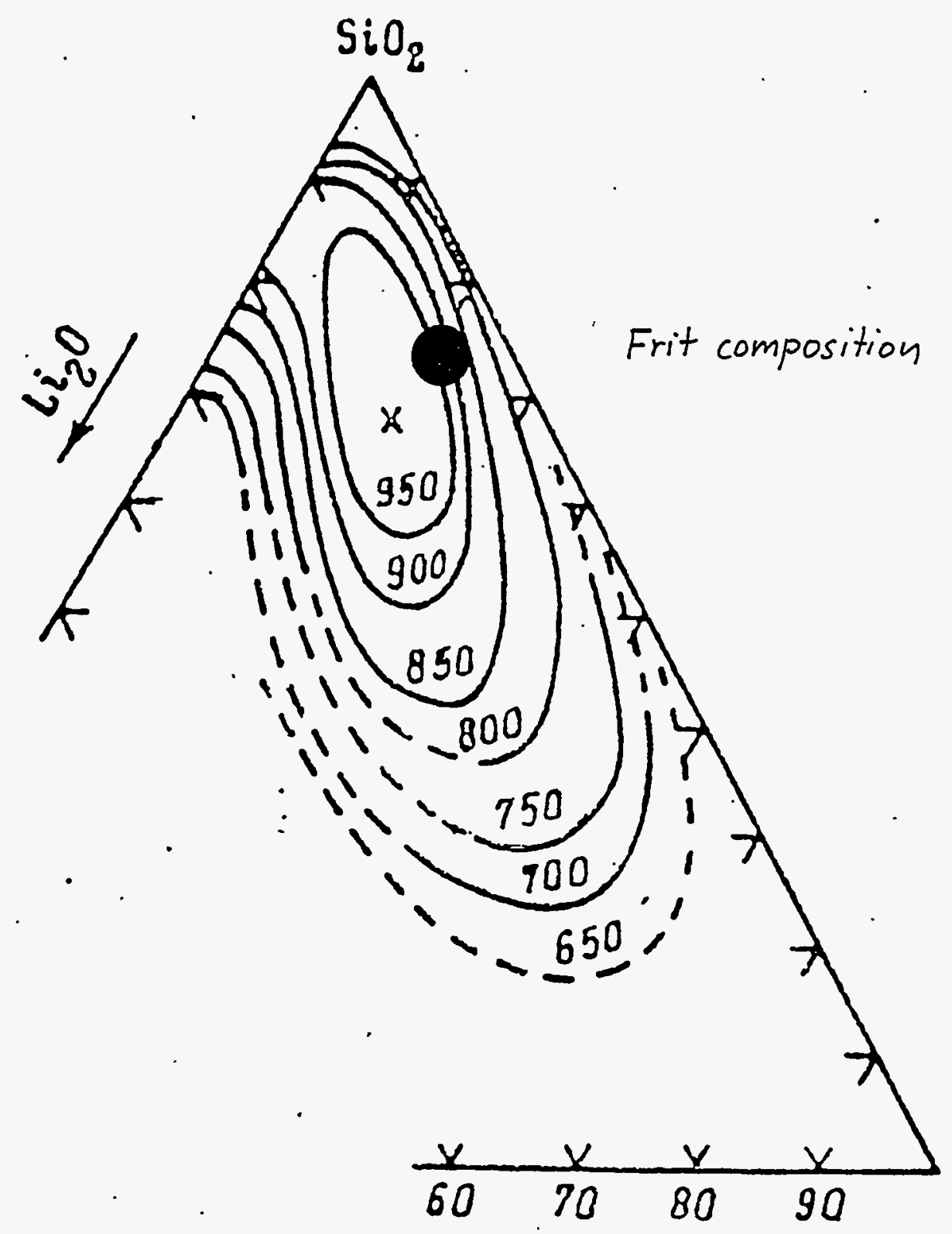

Fig 30: Region of immiscibility in $\mathrm{Li}_{2} \mathrm{O}-\mathrm{B}_{2} \mathrm{O}_{3}-\mathrm{SiO}_{2}$ 


\title{
APPENDIX B: Listing of the data base for the PISA-system
}

\author{
AUSDRUCK DER DATENBASIS
}

KANAL MSR-Nr Signalbeschr.
100\% Intvl Groesse

\begin{tabular}{|c|c|c|}
\hline $1 / 0$ & HSGO01LT & FOERDERPUM \\
\hline $1 / 1$ & G001LT & VENTII TANKWAGENABSCHLUSS \\
\hline $1 / 2$ & HSGO02LT & FOERDERPULPE B \\
\hline $.1 / 3$ & GOO2LT & BODENVENTII IAGERTANK \\
\hline $1 / 4$ & HSGO03LT & RUEHRER A \\
\hline $1 / 5$ & GO03LT & VENTIC, VOR FOERDERPUMPE A \\
\hline $1 / 6$ & HSGO04LT & RUEHRRR B \\
\hline $1 / 7$ & Do4LT. & VENTII NACH FOERDERPUMPE A \\
\hline $1 / 8$ & $05 \mathrm{LT}$ & VENTII VOR FOERDERPUMPE B \\
\hline $1 / 9$ & $06 L T$ & VENTII NACH FOERDERPURPE B \\
\hline $1 / 10$ & $07 L T$ & VENTII RUEHRKREISLAUE \\
\hline $1 / 11$ & $08 L T$ & VENTII RUEHRKREISLAUT \\
\hline $1 / 12$ & LT & VENTIL RUEHRRREISLAUE \\
\hline $1 / 13$ & GOIOLT & VENTII RUUBHRKREISLAUTE \\
\hline $1 / 14$ & G011LT & VENTII TRANSEER PUMPE A \\
\hline $1 / 15$ & G012LT & VENTII TRANSEER PUMPE B \\
\hline $1 / 16$ & HSG013LT & VENTII TRANSEERIEITUNG 551 \\
\hline $1 / 17$ & G014LT & VENTIC CHEMITEBEHAELTER 551 \\
\hline $1 / 18$ & CO15LT & VENTII UEBERNAFAMBEH. 551 \\
\hline $1 / 19$ & G016LT & VENTII ZKISCHENBEH. 551 \\
\hline $1 / 20$ & TSW01LT & FOERDERPUMPE A \\
\hline $1 / 21$ & TSHO2LT & FOERDERPURPE B \\
\hline $1 / 22$ & TSW03LT & RUEHIRER A \\
\hline $1 / 23$ & TSHO4LT & RUEHRER B \\
\hline $1 / 24$ & G052MT & VENTIL DAMPF HEIZMANTEL FMT \\
\hline $1 / 25$ & G053MT & VENTII KUHHLWASSER RL. FMT \\
\hline $1 / 26$ & G054ITT & VENTII CHEMITEABHASSER FMT \\
\hline $1 / 27$ & G055HT & VENTII KUERTWASSER VL \\
\hline $1 / 28$ & GO57MT & VENTII GLASPULVER I \\
\hline $1 / 29$ & G058MT & VENTIL GLASPULVER II \\
\hline $1 / 30$ & GO59MT & VEHTIII AUSGANG FMT \\
\hline /31 & G060MT & VENTIL VOR PUMPE A \\
\hline $1 / 32$ & HSGO01UB & VENTII RUEHRLUET FMT \\
\hline $1 / 33$ & RD1 & \\
\hline $1 / 34$ & HSGO & VENTII AIRJET J50 M \\
\hline $1 / 35$ & $\mathrm{RD2}$ & \\
\hline $1 / 36$ & $\mathrm{RD} 3$ & \\
\hline $1 / 37$ & HSG006ZB & VENTII EIIMCOOLER \\
\hline $1 / 38$ & $\mathrm{RD} 4$ & \\
\hline $1 / 39$ & Goe & VENTII NACH PUMPE A \\
\hline 140 & G06 & VENTII VOR PUMPE B \\
\hline $1 / 41$ & G063MT & VENTII NACH PUNEE B \\
\hline $1 / 42$ & RD5 & \\
\hline $1 / 43$ & HSG002DB & VENTEII WASSERSPUELUNG OEEN \\
\hline $1 / 44$ & HSGO03DB & VENTIL RUEHRLUET MFT \\
\hline $1 / 45$ & G064MT & VENTII TRANSEER MET \\
\hline $1 / 46$ & G065HI & VENTII KREISIAUE MET \\
\hline $1 / 47$ & G066rFT & VENTII HASSERSPUELUNG FHT \\
\hline $1 / 48$ & HSG001S & VENTII SPUEILUETT BIGI A3 \\
\hline $1 / 49$ & HSGO02S & VENTII KUEHIUNG EINLAUEROHR \\
\hline $1 / 50$ & RD6 & \\
\hline $1 / 51$ & FW135 & KUEHIWASSER EINLAUFROHR \\
\hline $1 / 52$ & TRAFO1S & TRAFO NR 1 \\
\hline $1 / 53$ & TRAFO2S & TRAFO NR 2 \\
\hline & & \\
\hline
\end{tabular}


APPENDIX B: Listing of the data base for the PISA-system

KANAL MSR-Nr Signalbeschr. $\quad$ EINH T2-Al T1-Al H1-Al H2-Al $0 \%$

$100 \%$ Intvl Groesse

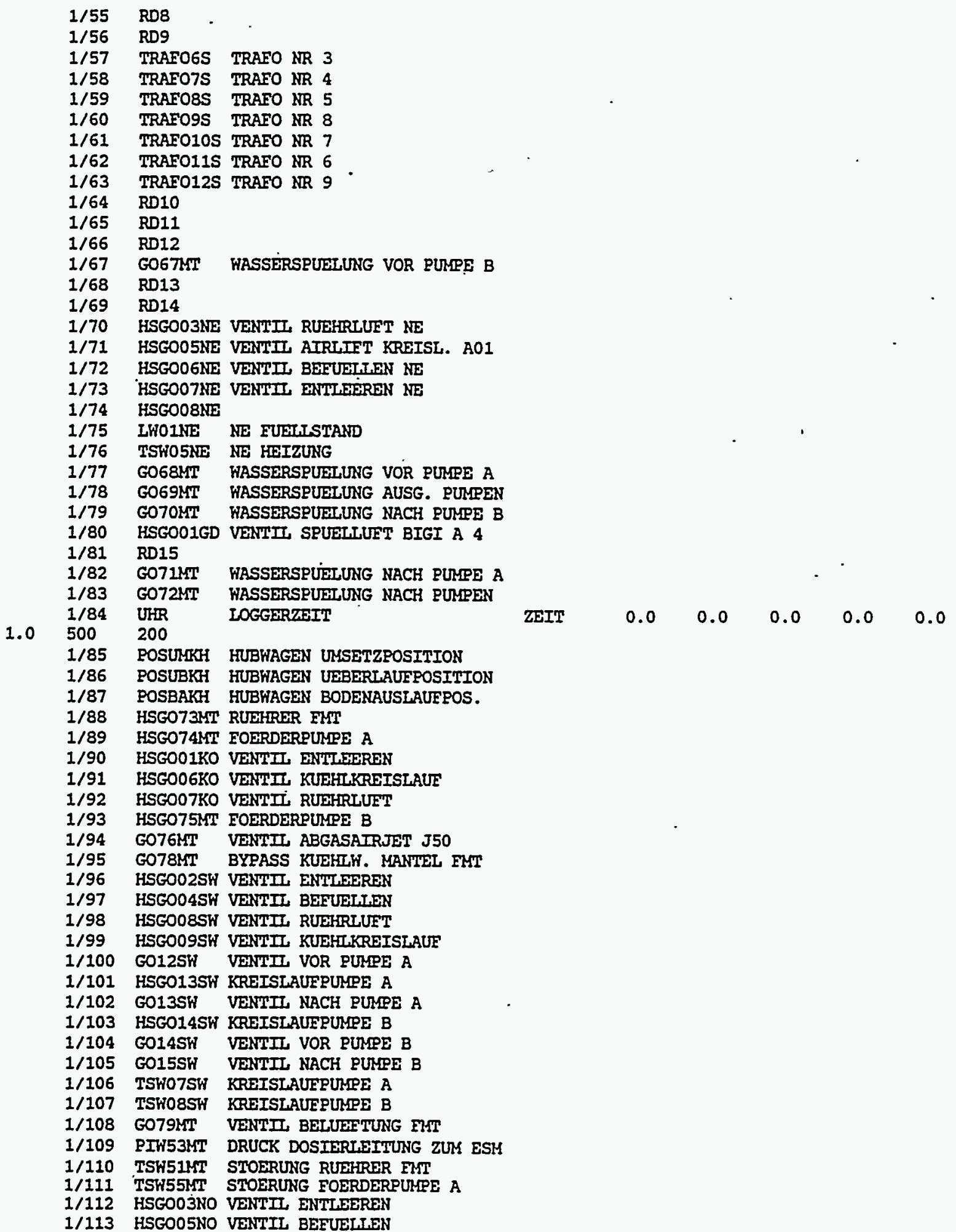

$\begin{array}{llllll}\text { ZEIT } & 0.0 & 0.0 & 0.0 & 0.0 & 0.0\end{array}$


APPENDIX B: Listing of the data base for the PISA-system

KANAL MSR-NI Signalbeschr. EINH T2-Al T1-AI H1-Al H2-Al $0 \%$ 100\% Intvl Groesse

$1 / 114$ HSGO1ONO VENTII RUEHRLUET

$1 / 115$ HSGOIINO VENTIL KUEHLKREISLAUE

1/116 HSG016NO KREISLAUEPUIPE A

$1 / 117$ GO16NO VENTIL VOR PUR.PE A

$1 / 118$ HSGO17NO KREISLAUEPUIPE $B$

$1 / 119$ GO17NO VENTIL NACH PUMPE A

$1 / 120$ GO18NO VENTII VOR PUMPE B

$1 / 121$ GO19NO VENTII NACH PUMPE B

1/122 TSH12NO KREISLAUEPUTPE A

$1 / 123$ TSW13NO KREISLAUEPUMPE B

1/124 TSW56MT STOERUNG FOERDERPUIPE B

1/125 HSGO5OFT RUEHRER MET

$1 / 126$ GO51FT VENTIL AUSGANG MET

$1 / 127$ GO52FT VENTIL VOR PUMPE A

$1 / 128$ HSGOO1A VENTIL KUEHILKREISLAUE

$1 / 129$ LWO2A TROPFENABSCHEIDER

1/130 LWO1A TROPFENABSCHEIDER

$1 / 131$ GO53ET VENTII NACH PUMPE A

$1 / 132$ GO54FT VENTIL VOR FUMPE B

$1 / 133$ GO01GE VENTII VOR GEBLAESE

1/134 GOO2GE VENTII NACH GEBLAESE

1/135 HSGO03GE VENTII ABGASJET ZULEITUNG

1/136 HSGO04GE VENTII ABGASJET TREIBLUET

$1 / 137$ HSGOO5GE VENTIL BYPASS

$1 / 138$ HSGOO6GE GEBLAESE

$1 / 139$ TSW02GE GEBLAESE

$1 / 140$ GO55FT VENTIL NACH PUMPE B

$1 / 141$ GO56ET VENTII TRANSFER ZUM ESM

1/142 GO57ET VENTII TRANSEER KREISIAUT

$1 / 143$ HSGOO1BE VENTIII AIRJET

$1 / 144$ GO59ET WASSERSPUELUNG VOR PURPEN

$1 / 145$ GO60FT WASSERSPUGLUNG VOR PUIPE B

$1 / 146$ HSGO02V KIREISLAUFPUMPE A KUEHLW.

$1 / 147$ GOO2V VENTIL VOR PURPE A KUEHLW.

$1 / 148$ HSGOO3V KREISLAUTPUMPE B KUEHLW.

$1 / 149$ GOO3V VENTII NACH PUMPE B KUEHLW.

$1 / 150$ HSGO04V KREISLAUEPURPE Aे PLATTENWT.

$1 / 151$ GOO4V VENTIL VOR PUMPE B KUEHLW.

1/152 HSGO05V KRIESLAUTPUMPE B PLATTENWT.

$1 / 153$ GO05V VENTII NACH PUMPE B KUEHIL.

$1 / 154$ G007V VENTIL VOR PUNPE A PLATTENFT

$1 / 155$ GOOBV VENTIL NACH PUMPE A PLATTENW

. 1/156 GOOQV VENTII VOR PUMPE B PLATTENW.

$1 / 157$ GOIOV VENTII NACH PUMPE B PLATTENW .

$1 / 158$ ISWOIV LEVEL KUEHLWASSERTANK

$1 / 159$ LSHO4V IEVEL KUEHLWASSERTAKK

$1 / 160$ TSWO5V PURPE A KUEHLWASSER

1/161 TSHO6V PUMPE B KUEHLWASSER

$1 / 162$ TSHO7V PUIPE A PLATTENWT.

1/163 TSWO8V PLRPE B PLATTENWT.

1/164 TCH16V THMPERATUR KUEHLWASSERTANK

$1 / 165$ YWO1V KAELTEBLOCK

$1 / 166$ GO61FT VENTIL WASSERSP. VOR PUMPE A

$1 / 167$ GO62FT VENTI WASSERSP. NACH PUMPEN

$1 / 168$ GO63ET VENTIL KASSERSP. N. PUMPE B

$1 / 169$ GO64FT VENTIL WASSERSP. N. PUMPE A

$1 / 170$ HSGOO1AB VENTIL RUERTLUET

$1 / 171$ HSGOO2AB VENTIL BODEN AUFFANGBEH.

$1 / 172$ HSGOO3AB EOERDERPUIPE A 
APPENDIX B: Listing of the data base for the PISA-system

\begin{tabular}{|c|c|c|c|c|c|c|c|c|}
\hline $00 \%$ & $\begin{array}{l}\text { KANAI } \\
\text { IntVI }\end{array}$ & $\begin{array}{r}\text { MSR-Nr } \\
\text { Groesse }\end{array}$ & Signalbeschr. & EINH & $\mathrm{T} 2-\mathrm{Al}$ & T1-Al & $H 1-A 1$ & $\mathrm{H} 2-\mathrm{Al}$ \\
\hline
\end{tabular}

$1 / 173$ GOO3AB VENTII EINSPEISUNG VON BEH.

1/174 HSGOO4AB FOERDERPUMPE B

$1 / 175$ GOO4AB VENTIL VOR PUMPE $A$

$1 / 176$ GOOSAB VENTII NACH PUMPE A

$1 / 177$ GO06AB VENTII VOR PUMPE $B$

$1 / 178$ GOOTAB VENTIL NACH PUMPE B

1/179 HSGOOBAB VENTII EINLAUE AUEEANGBEH.

1/180 HSGOO9AB VENTII ENTL. CHEMTEABWASSER

1/181 HSGO1OAB VENTII ENTL. IN TRANSPORTBEH

$1 / 182$ GO11AB VENTIL ENTLEEREN SYPHON

1/183 HSGO12AB VENTII SPUELEN SYPHON

1/184 TSWOIAB PUIPE $\bar{A}$

$1 / 185$ TSW02AB PUMPE B

$1 / 186$ GO65FT VENTIL WASSERSP. AUSG. TRANS

1/187 HSGO67FT FOERDERPUMPE A

1/188 HSGO68FT FOERDERPUMPE B

1/189 TSHSOET STOERUNG RUEHRER MFT

1/190 TSW5IFT STOERUNG FOERDERPUMPE A

$1 / 191$ TSW52ET STOERUNG FOERDERPUTME B

1/192 HSGOO1HO VENTII EINLASS H2O2 ZUGABEB.

1/193 HSGOO2HO VENTII AUSLASS H2O2 ZUGABEB.

$1 / 194$ HSGOO3HO H2O2 DOSIFRPUMEE

1/195 LW01HO H2O2 VORRATSBEHAELTER

$1 / 196$ LWO3HO H2O2 ZUGABEBEHAELTER

1/197 TIWO1HO TEHP. H2O2 VORRATSBEHAELTER

$1 / 198$ G005S BIGIIUTT BIGI A53/A54

$1 / 199$ G006S BIGILUET BIGI A3/A4

$1 / 200$ GO07S VENTII SPUELLUET BIGI A53

$1 / 201$ YWO1NF MF-ANLAGE

$1 / 202$ GOOBS VENTII SPUELUET BIGI A54

1/203 PDW54MT DIFE.DRUCK ABHASSERFIITER

1/204 HSGO5OAD FASSPUMPE HCOOH

1/205 HSGO51AD DOSIERPUMPE HCOOH

$1 / 206$ TSW5OAD STOERUNG FASSPUMPE HCOOH

1/207 TSW51AD STOERUNG DOSIIHRPURE HCOOH 
APPENDIX B: Listing of the data base for the PISA-system

KANAL MSR-Nr Signalbeschr. 100\% Intvl Groesse

EINH T2-AI T1-Al H1-AI H2-AL O\%

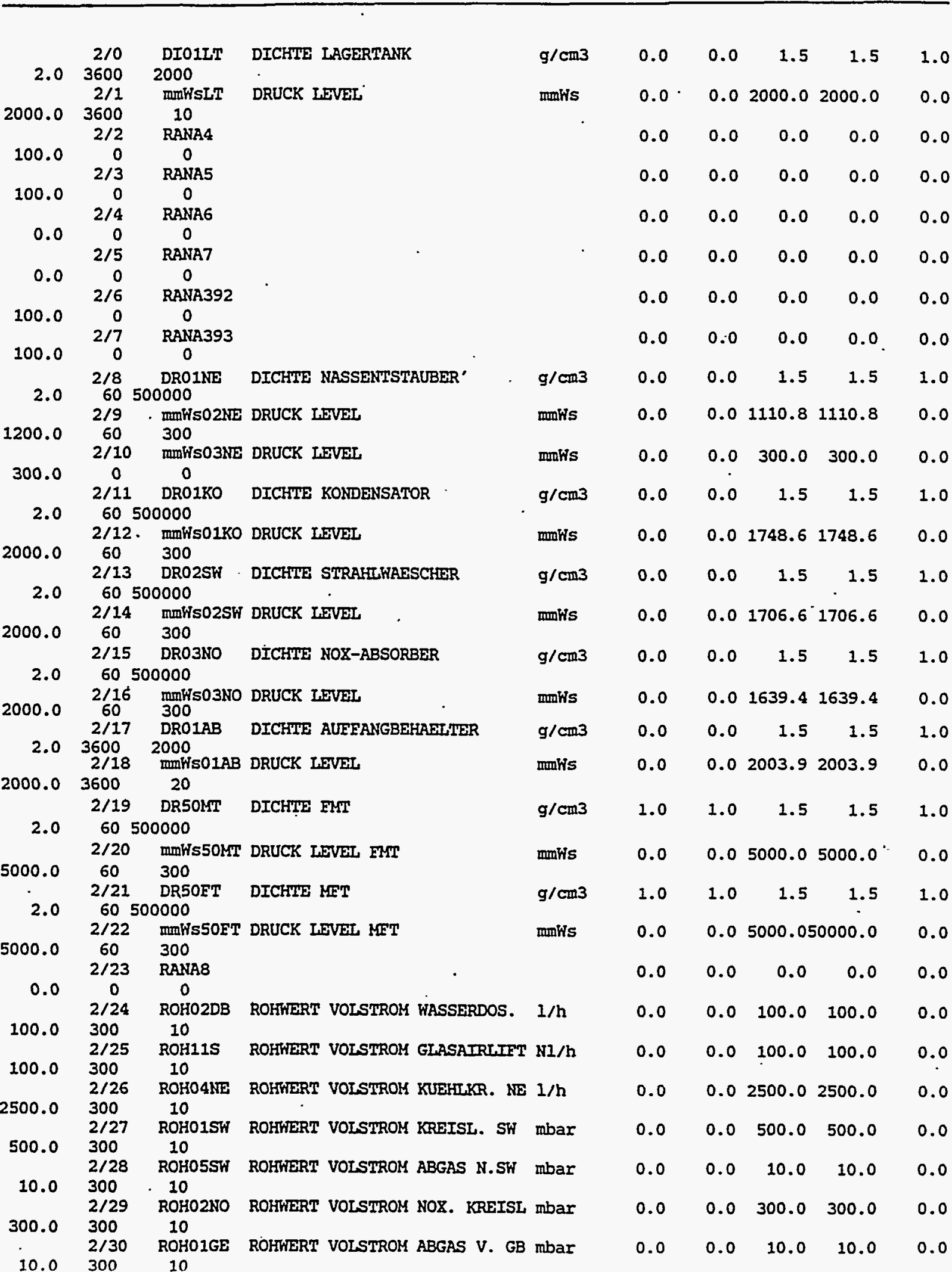




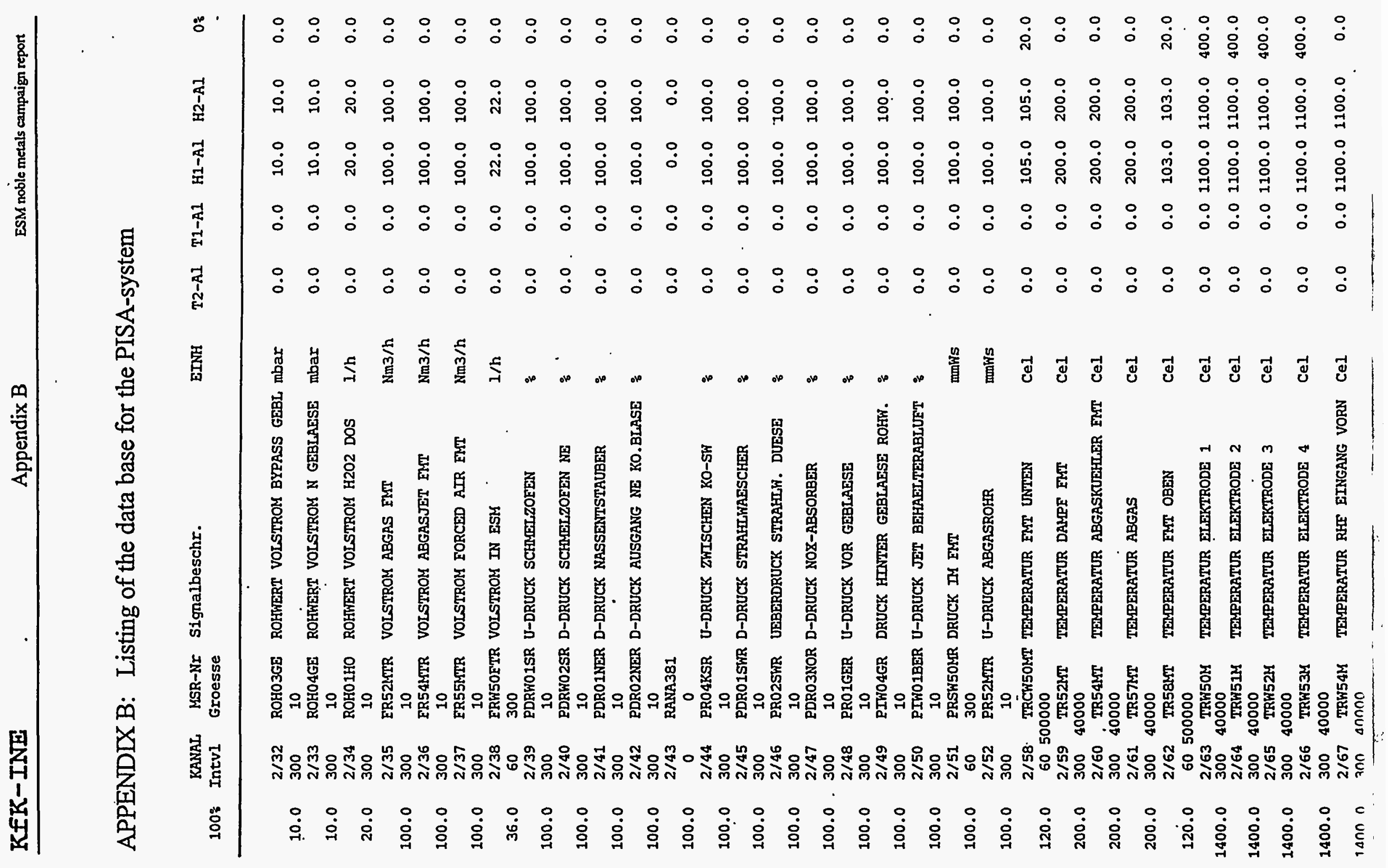


APPENDIX B: Listing of the data base for the PISA-system

KANRL MSR-Nr Signalbeschr.

EINH T2-AI T1-AI H1-AI H2-AI $0 \%$ $100 \%$ Intvl Groesse

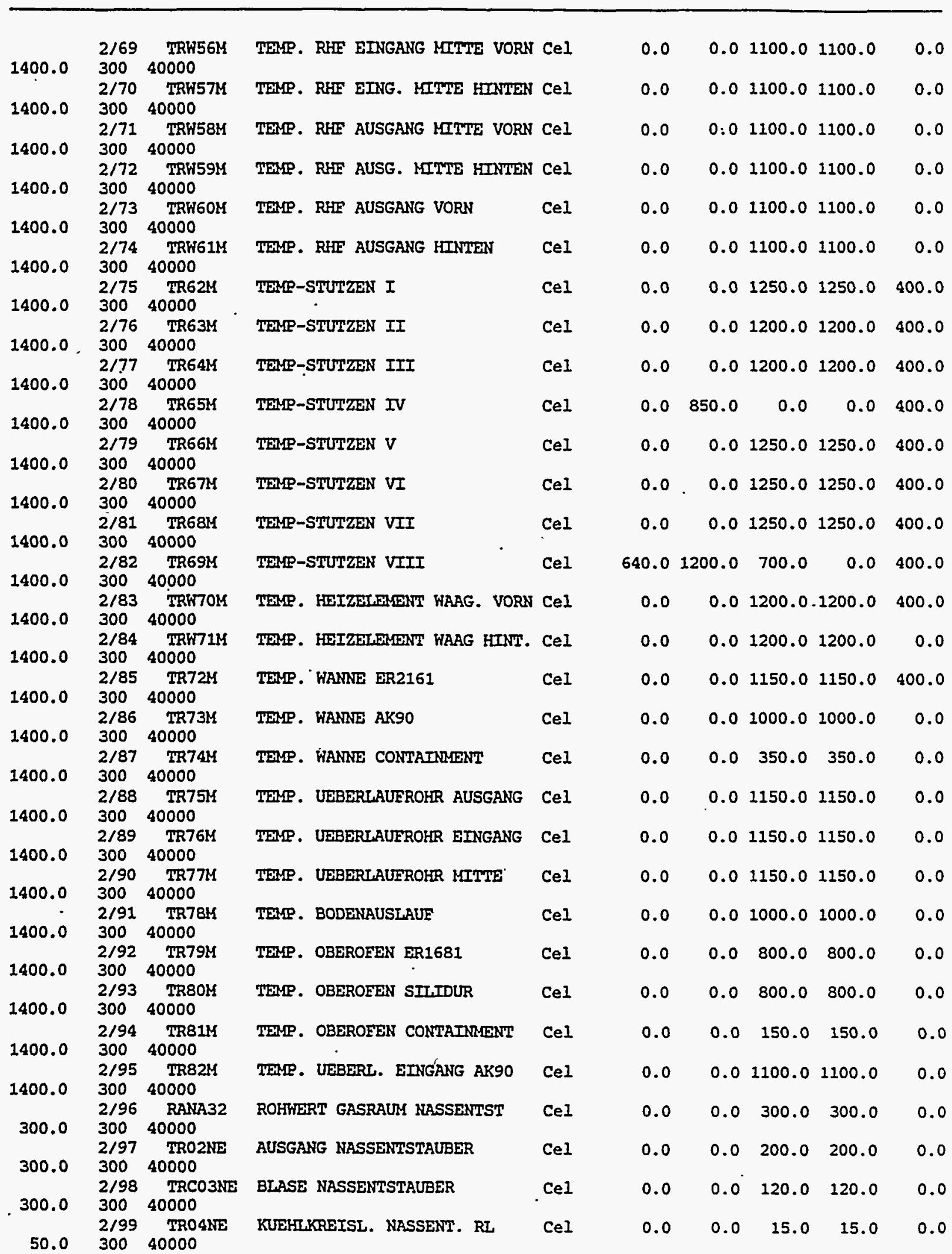


APPENDIX B: Listing of the data base for the PISA-system

KANAL MSR-Nr Signalbeschr.
100₹ Intvl Groesse
EINH T2-Al T1-Al H1-Al H2-Al O\%

\begin{tabular}{|c|c|c|c|c|c|c|c|c|}
\hline 50.0 & $\begin{array}{l}2 / 102 \text { TR01KO } \\
300{ }_{40000}\end{array}$ & BLASE KONDENSATOR & Cel & 0.0 & 0.0 & 50.0 & 50.0 & 0.0 \\
\hline 100.0 & $\begin{array}{l}2 / 103 \text { TR04KO } \\
30040000\end{array}$ & AUSGANG KONDENSATOR & Cel & .0 .0 & 0.0 & 100.0 & 100.0 & 0.0 \\
\hline 50.0 & $\begin{array}{l}2 / 104 \text { TR06KO } \\
30040000\end{array}$ & KUEHLKREISL. KONDENSATOR RL & Cel & 0.0 & 0.0 & 15.0 & 15.0 & 0.0 \\
\hline 100.0 & $\begin{array}{cc}2 / 105 & \text { RANA28 } \\
0 & 0\end{array}$ & & Cel & 0.0 & 0.0 & 0.0 & 0.0 & 0.0 \\
\hline 100.0 & $\begin{array}{cc}2 / 106 & \text { RANA29 } \\
0 & 0\end{array}$ & & Cel & 0.0 & 0.0 & 0.0 & 0.0 & 0.0 \\
\hline 50.0 & $\begin{array}{l}2 / 107 \text { TR02SW } \\
30040000\end{array}$ & WASCHKREISLAUT STRAHLW. RL & Cel & 0.0 & 0.0 & 50.0 & 50.0 & 0.0 \\
\hline 100.0 & $\begin{array}{l}2 / 108 \text { TR05SW } \\
30040000\end{array}$ & AUSGANG STRAHLHAESCHER & Cel & 0.0 & 0.0 & 100.0 & 100.0 & 0.0 \\
\hline 50.0 & $\begin{array}{l}2 / 109 \text { TRO9SW } \\
30040000\end{array}$ & KUEKLKREISL. STRAHLW. RL & Cel & 0.0 & 0.0 & 15.0 & 15.0 & 0.0 \\
\hline 100.0 & $\begin{array}{cc}2 / 110 & \text { RANA30 } \\
0 & 0\end{array}$ & & CeI & 0.0 & 0.0 & 0.0 & 0.0 & 0.0 \\
\hline 100.0 & $\begin{array}{cc}2 / 111 & \text { RANA31 } \\
0 & 0\end{array}$ & & Cel & 0.0 & 0.0 & 0.0 & 0.0 & 0.0 \\
\hline 50.0 & $\begin{array}{l}2 / 112 \text { TR03NO } \\
30040000\end{array}$ & BLASE NOX-ABSORBER & Cel & 0.0 & 0.0 & 50.0 & 50.0 & 0.0 \\
\hline 50.0 & $\begin{array}{l}2 / 113 \text { TR10NO } \\
30040000\end{array}$ & WASCHKREISL. NOZ-ABSORBER RL & $\mathrm{CeI}$ & 0.0 & 0.0 & 50.0 & 50.0 & 0.0 \\
\hline 50.0 & $\begin{array}{l}2 / 114 \text { TR11NO } \\
30040000\end{array}$ & KUEHLKREISL. NOX-ABSOBER RL & Cel & 0.0 & 0.0 & 15.0 & 15.0 & 0.0 \\
\hline 600.0 & $\begin{array}{ll}2 / 115 & \text { TRO1NER } \\
300 & 10\end{array}$ & ROHWERT GASRAUIS NASSENTST. & $\mathrm{Cel}$ & 0.0 & 0.0 & 500.0 & 500.0 & 0.0 \\
\hline 100.0 & $\begin{array}{cc}2 / 116 & \text { RANA33 } \\
0 & 0\end{array}$ & & Cel & 0.0 & 0.0 & 0.0 & 0.0 & 0.0 \\
\hline 50.0 & $\begin{array}{l}2 / 117 \text { TR01A } \\
30040000\end{array}$ & KUEHLKREISL. ABGASKUEHHER RL & Cel & 0.0 & 0.0 & 15.0 & 15.0 & 0.0 \\
\hline 100.0 & $\begin{array}{cc}2 / 118 & \text { RANA34 } \\
0 & 0\end{array}$ & & Cel & 0.0 & 0.0 & 0.0 & 0.0 & 0.0 \\
\hline 100.0 & $\begin{array}{l}2 / 119 \text { TR01GE } \\
30040000\end{array}$ & EINGANG GEBLAESE & Cel & 0.0 & 0.0 & 100.0 & 100.0 & 0.0 \\
\hline 100.0 & $\begin{array}{l}2 / 120 \text { TRO } \\
30040000\end{array}$ & AUSGANG GEBLAESE & Cel & 0.0 & 0.0 & 100.0 & 100.0 & 0.0 \\
\hline 100.0 & $\begin{array}{cc}2 / 121 & \text { RANA35 } \\
0 & 0\end{array}$ & & Cel & 0.0 & 0.0 & 0.0 & 0.0 & 0.0 \\
\hline 50.0 & $\begin{array}{l}2 / 122 \text { TR01V } \\
30040000\end{array}$ & KUEHLWASSER VL & Cel & 0.0 & 0.0 & 20.0 & 20.0 & 0.0 \\
\hline 50.0 & $\begin{array}{l}2 / 123 \quad \text { TR02V } \\
30040000\end{array}$ & KUEHLWASSER RL & Ce] & 0.0 & 0.0 & 35.0 & 35.0 & 0.0 \\
\hline 50.0 & $\begin{array}{l}2 / 124 \text { TR10V } \\
30040000\end{array}$ & KALTHASSER VL & Cel & 0.0 & 0.0 & 10.0 & 10.0 & 0.0 \\
\hline 50.0 & $\begin{array}{l}2 / 125 \text { TR11V } \\
30040000\end{array}$ & KALTWASSER RL & $\mathrm{Ce}$ & 0.0 & 0.0 & 5.0 & 15.0 & 0.0 \\
\hline 50.0 & $\begin{array}{l}2 / 126 \text { TR12V } \\
300.40000\end{array}$ & PLATTENWAERMETAUSCHER VL & Cel & 0.0 & 0.0 & 10.0 & 10.0 & 0.0 \\
\hline 50.0 & $\begin{array}{l}2 / 127 \text { TR13V } \\
30040000\end{array}$ & PLATTENHAERRIETAUSCHER RL & CeI & 0.0 & 0.0 & 20.0 & 20.0 & 0.0 \\
\hline 80.0 & $\begin{array}{l}2 / 128 \text { ERA50KMM } \\
30040000\end{array}$ & LEISTUNG TRAFO NR. 1 EL. $1+2$ & kir & 0.0 & 18.0 & 60.0 & 60.0 & 0.0 \\
\hline 100.0 & $\begin{array}{l}2 / 129 \text { ERA53KWM } \\
30040000\end{array}$ & LEISTUNG TRAFO NR. 2 EL. $3+4$ & $\mathrm{~kW}$ & 0.0 & 0.0 & 60.0 & 60.0 & 0.0 \\
\hline 0.0 & $\begin{array}{cc}2 / 130 & \text { RANAI } \\
0 & 0\end{array}$ & & & 0.0 & 0. & 0.0 & 0.0 & 0.0 \\
\hline 0.0 & $\begin{array}{cc}2 / 131 & \text { RANA2 } \\
0 & 0\end{array}$ & & - & 0.0 & 0.0 & 0.0 & 0.0 & .0 \\
\hline 100.0 & $\begin{array}{cc}2 / 132 & \text { RANA3 } \\
0 & 0\end{array}$ & & & 0.0 & 0.0 & 0.0. & 0.0 & 0.0 \\
\hline
\end{tabular}




\section{APPENDIX B: Listing of the data base for the PISA-system}

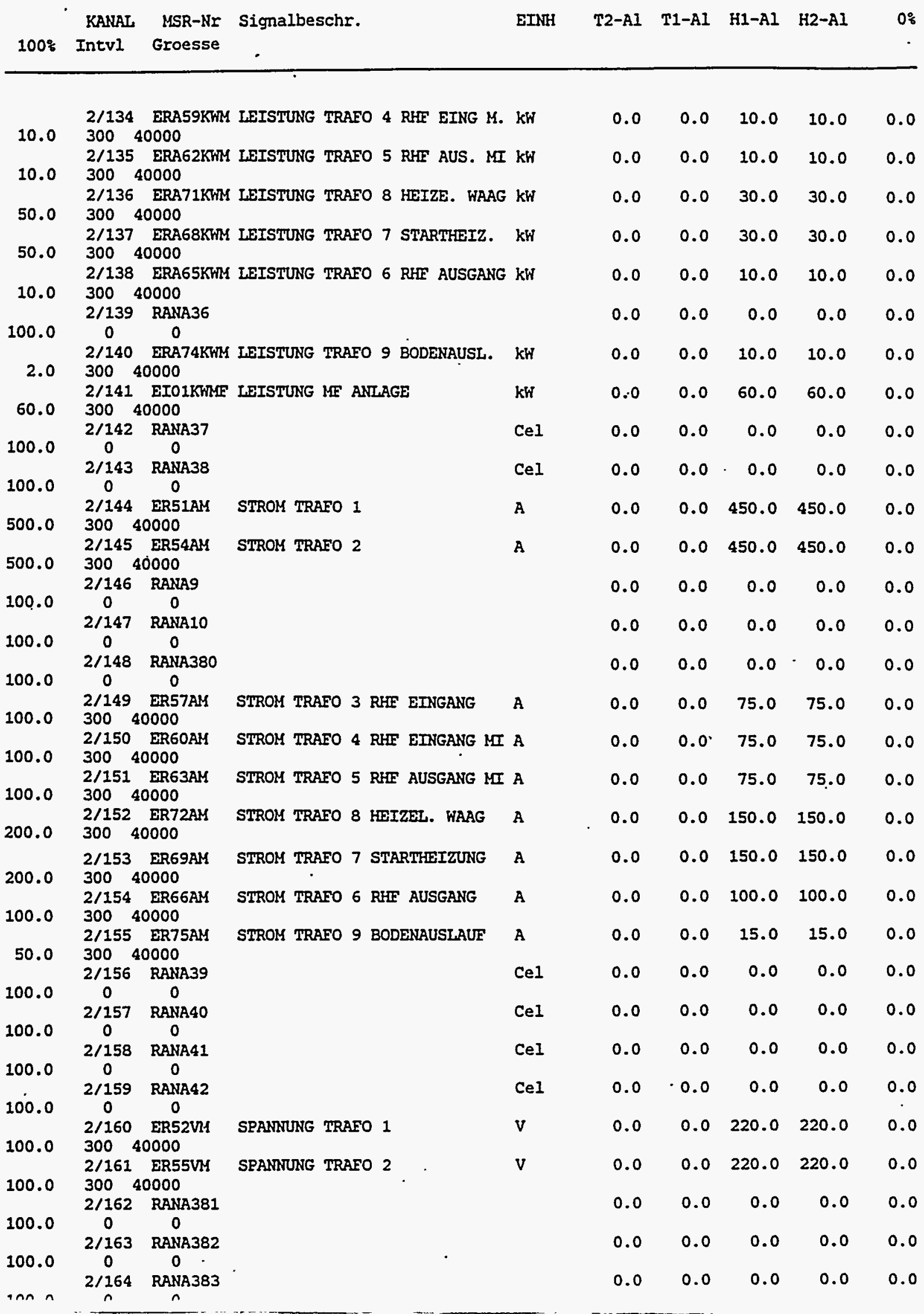


APPENDIX B: Listing of the data base for the PISA-system

KANAL MSR-Nr Signalbeschr.
$100 \%$ Intvl Groesse

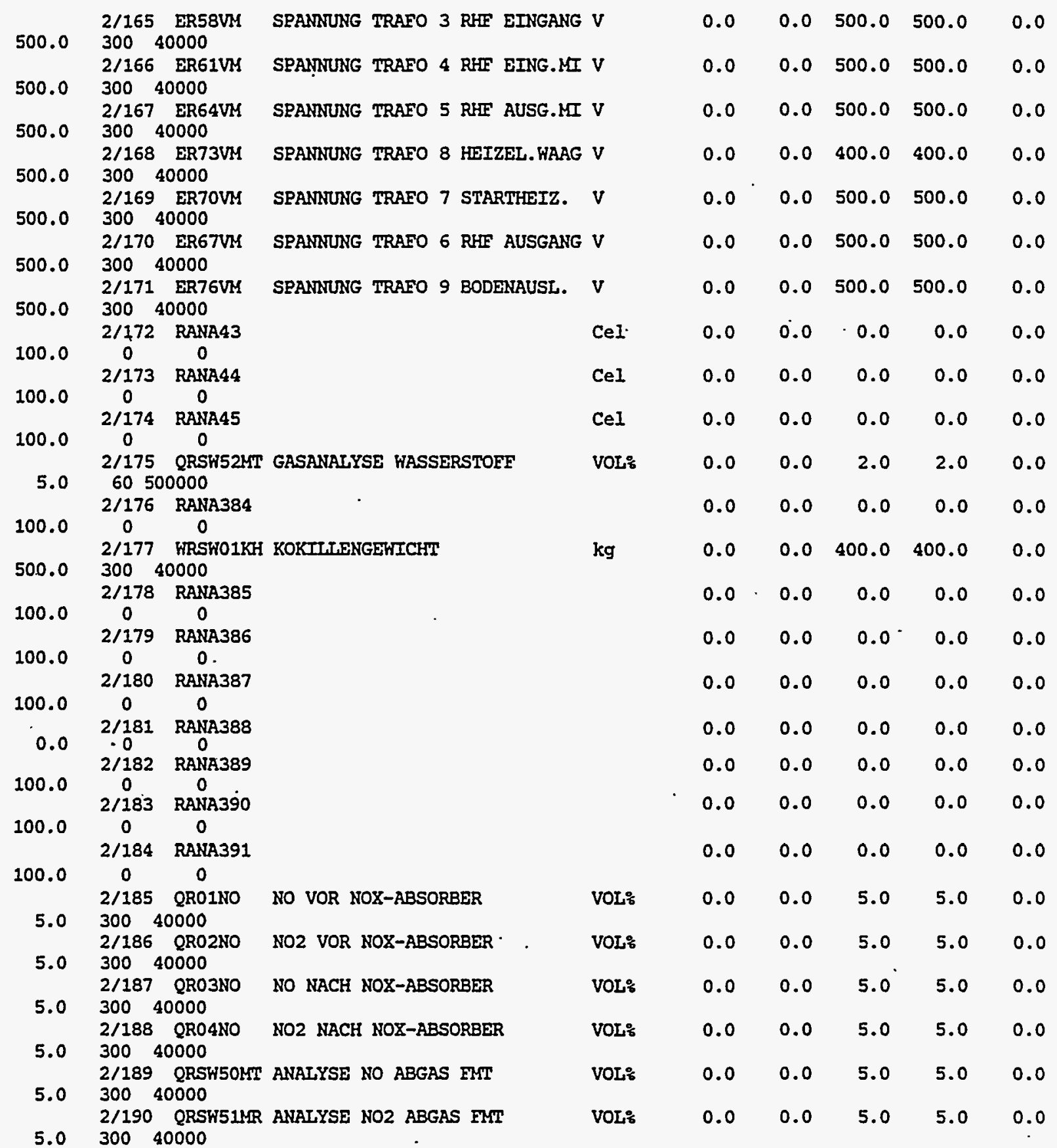


APPENDIX B: Listing of the data base for the PISA-system

\author{
KANAL MSR-NI SIgnalbeschr. EINH T2-RI T1-AI H1-Al H2-Al $0 \%$ \\ 100 Intvl Groesse
}

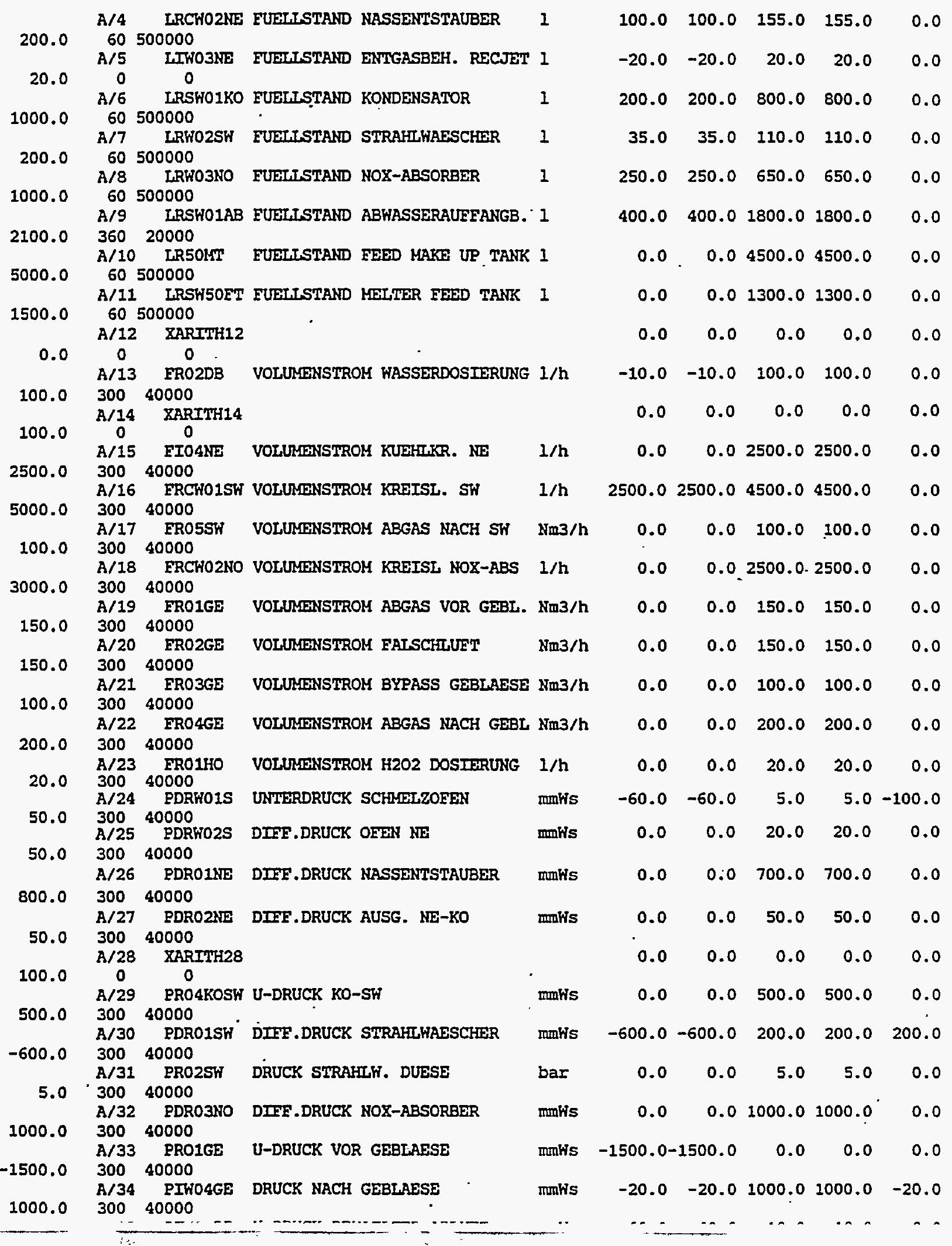


APPENDIX B: Listing of the data base for the PISA-system

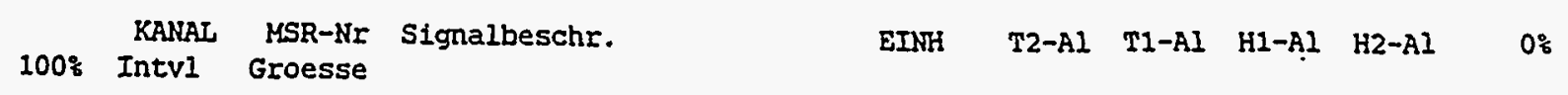

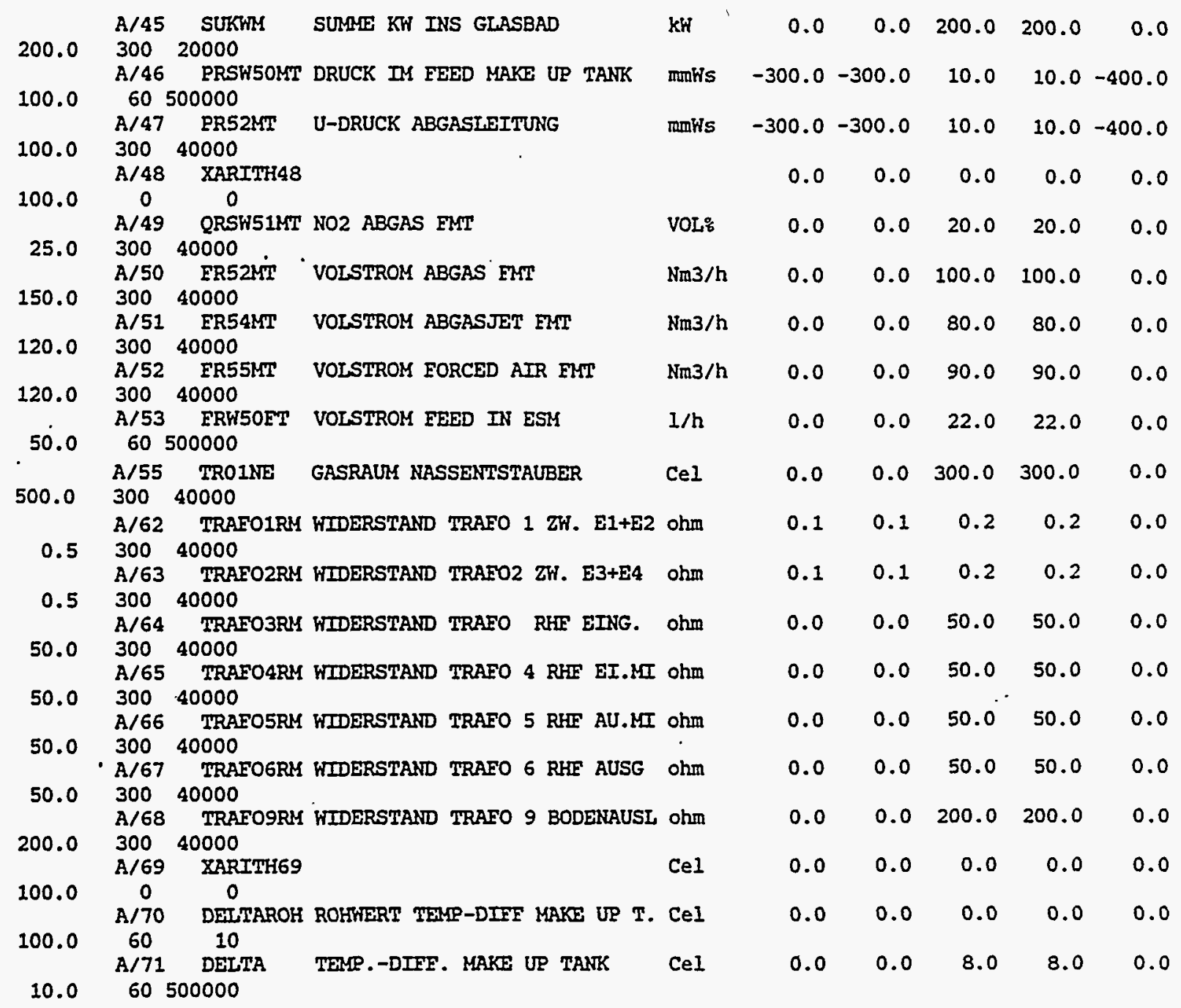


APPENDIX C: Listing of all XRF glass-analysis data performed by INE Analytical Laboratory 


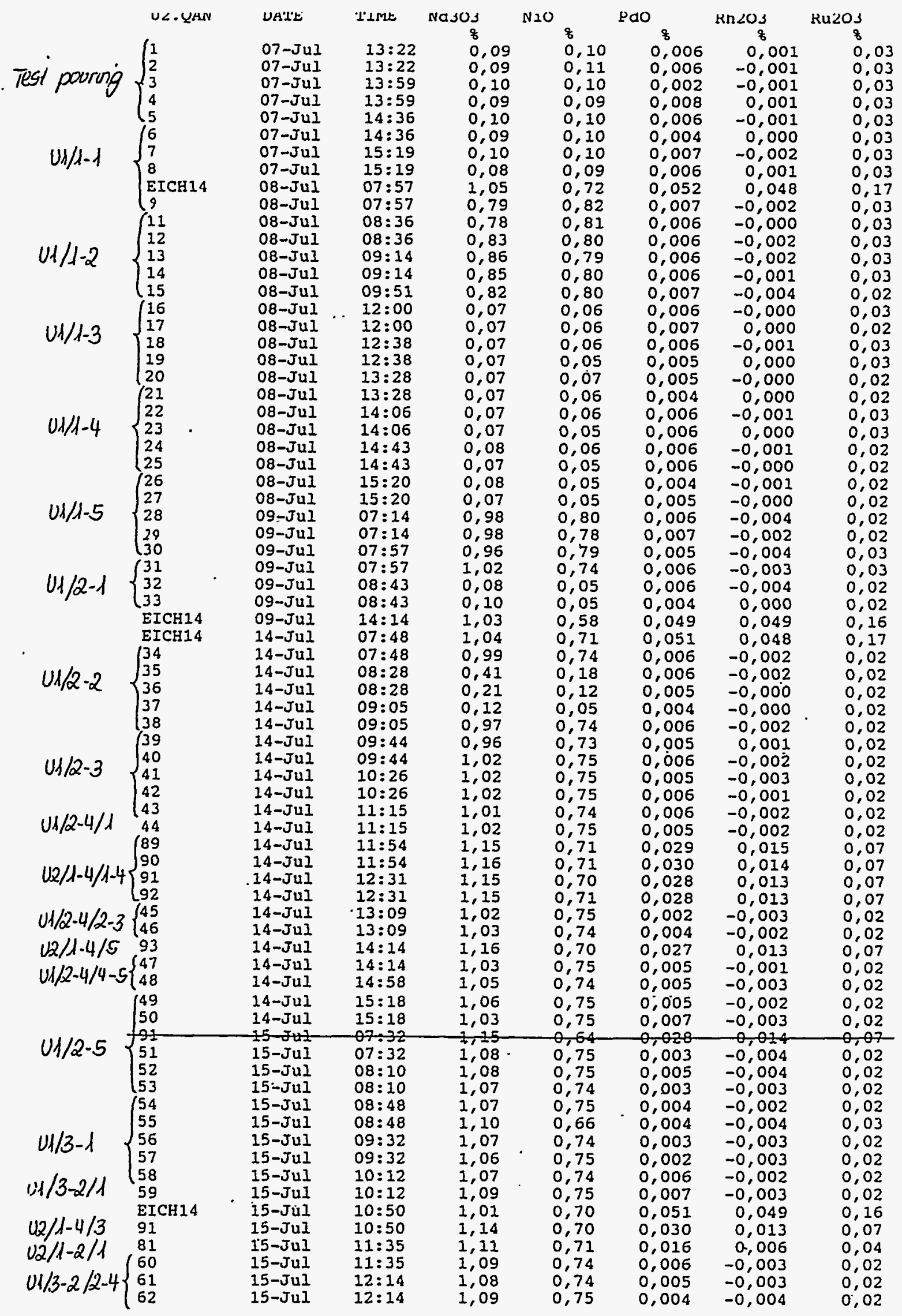




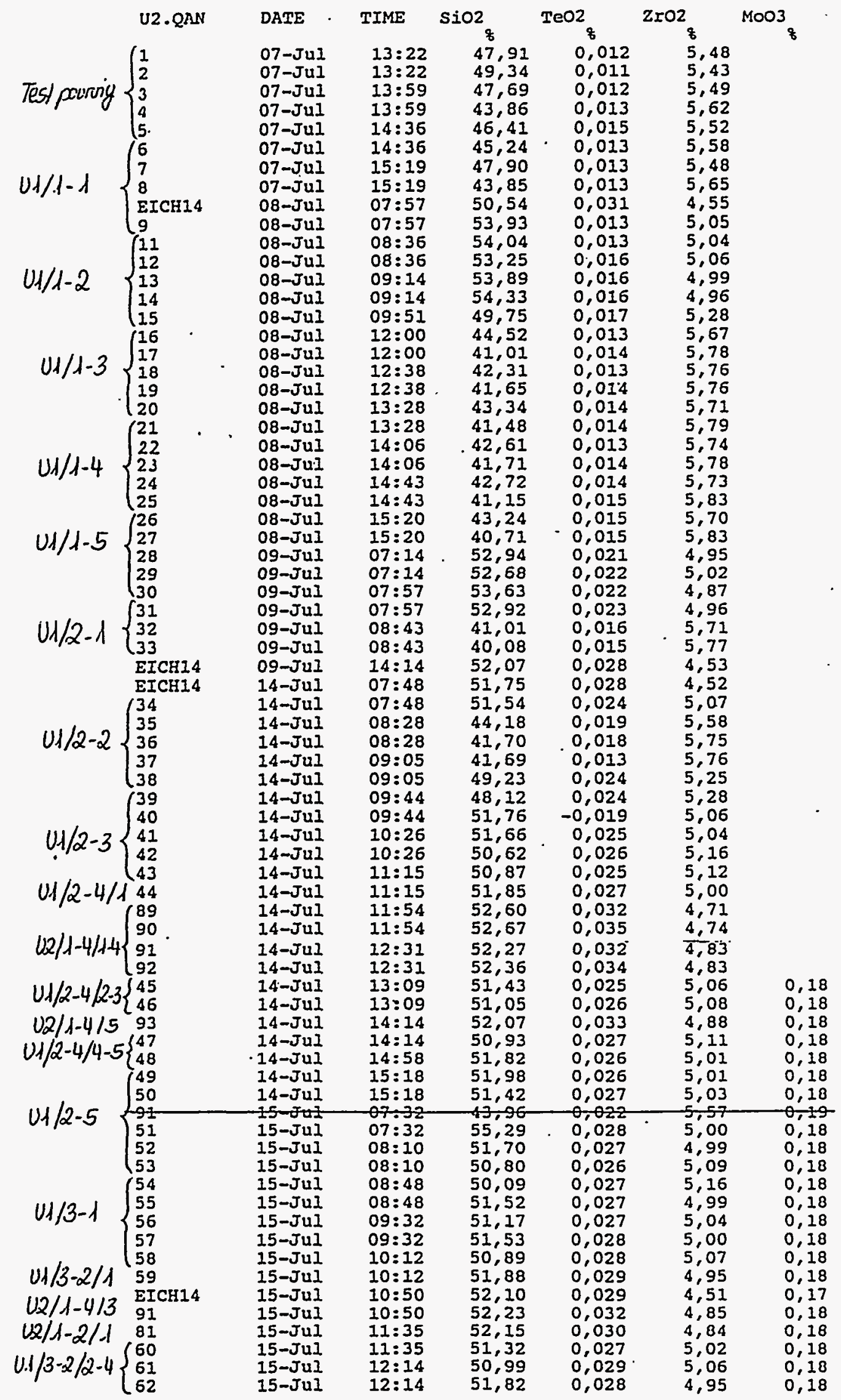




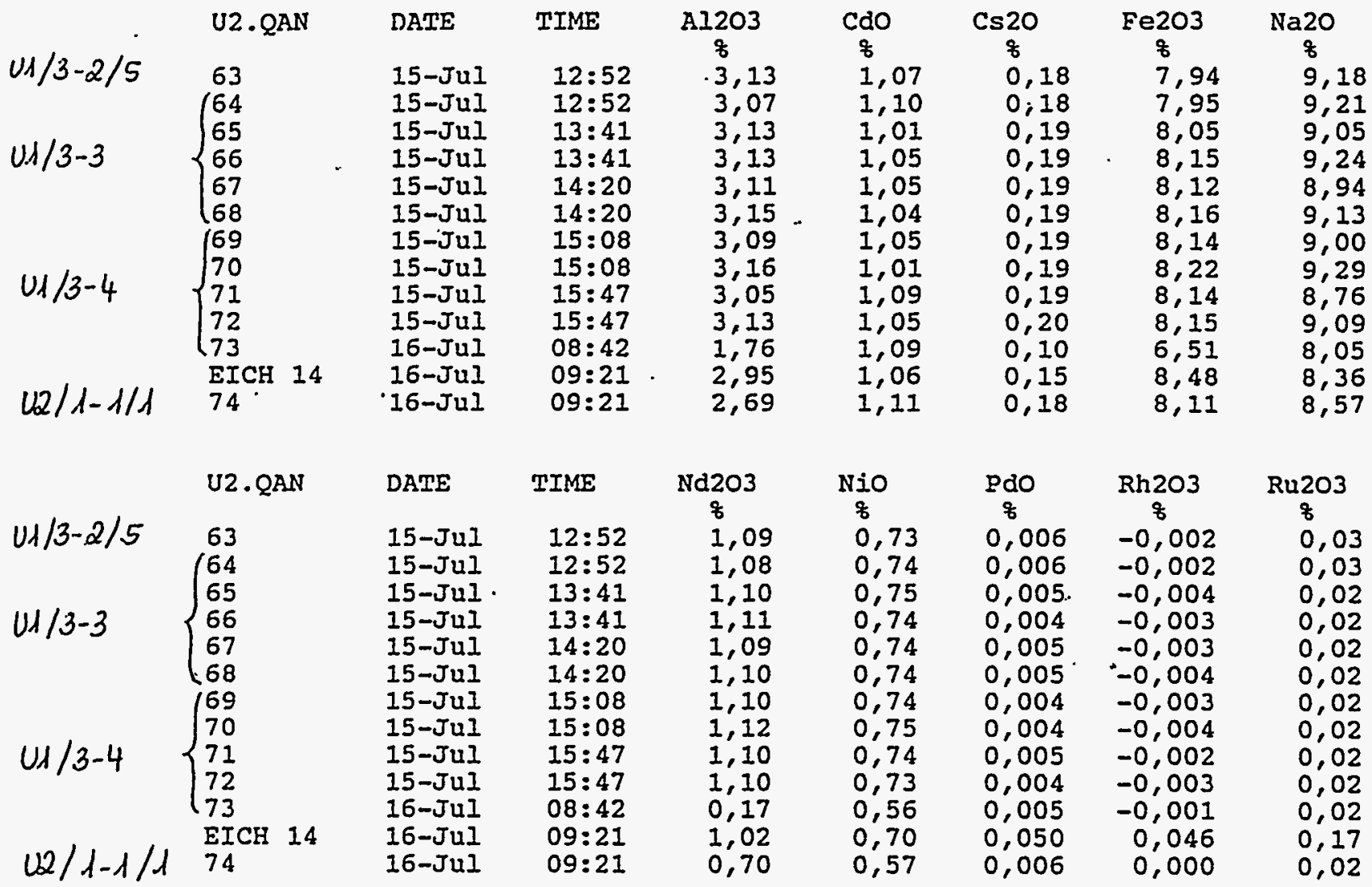

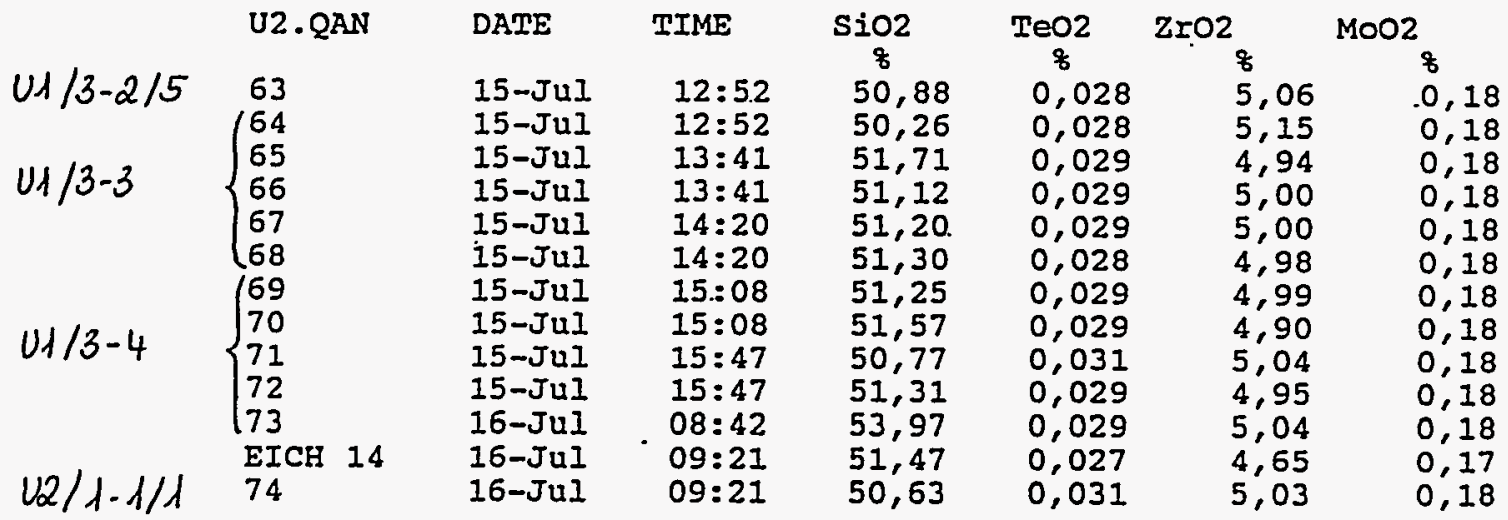




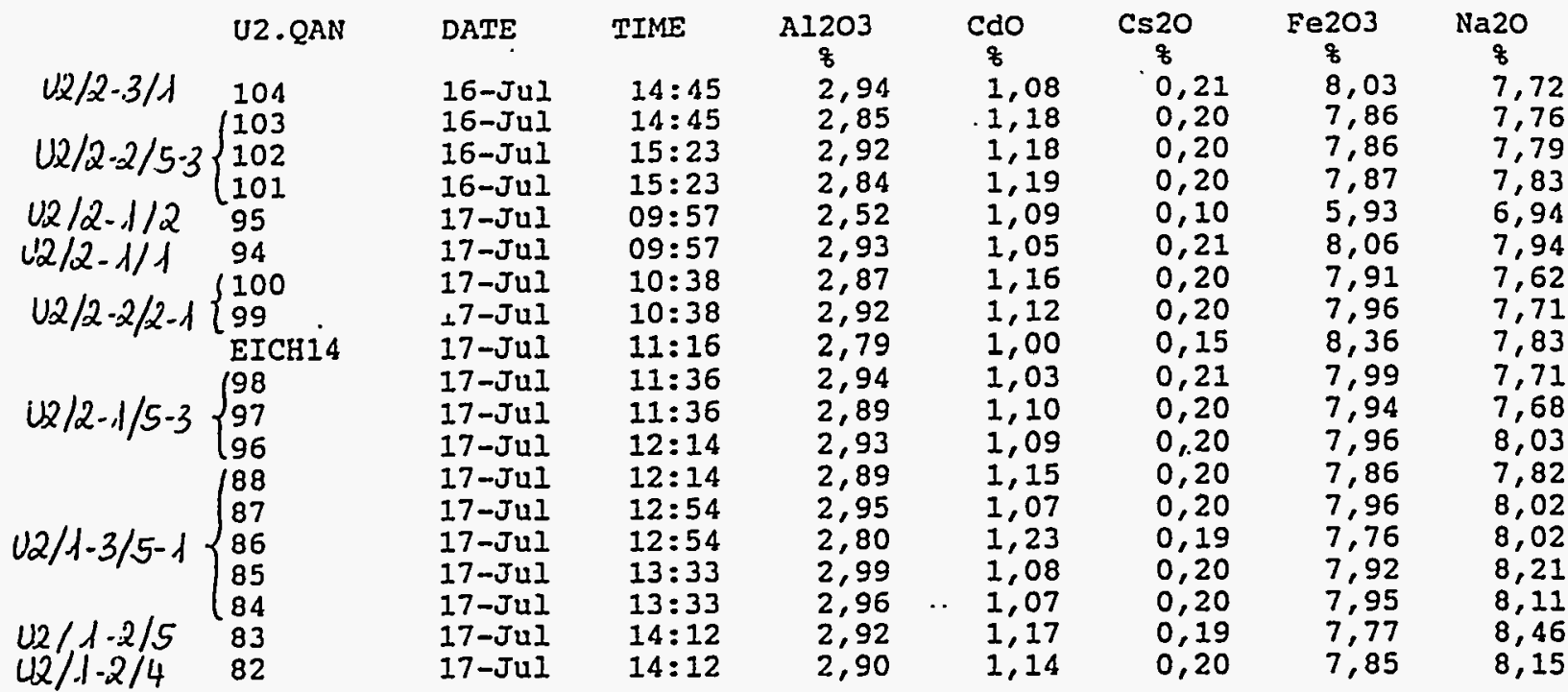

\begin{tabular}{|c|c|c|c|c|c|c|c|c|}
\hline & U2. QAN & DATE & TIME & $\underset{*}{\mathrm{Nd} 2 \mathrm{O} 3}$ & NiO & $\begin{array}{c}\text { Pdo } \\
8\end{array}$ & $\underset{\&}{\mathrm{Rh} 203}$ & $\underset{8}{\mathrm{Ru}_{2} \mathrm{OO} 3}$ \\
\hline$(12 / 2-3 / 1$ & 104 & 16-Jul & $14: 45$ & $1,1.6$ & 0,69 & 0,033 & 0,020 & 0,1 \\
\hline $12 . / 2-2$ & $\left\{\begin{array}{l}103 \\
102\end{array}\right.$ & $\begin{array}{l}\text { 16-JuI } \\
16-J u I\end{array}$ & $\begin{array}{l}14: 45 \\
15: 23\end{array}$ & 1,15 & $\begin{array}{l}0,68 \\
0,69\end{array}$ & $\begin{array}{l}0,032 \\
0,031\end{array}$ & $\begin{array}{l}0,017 \\
0.017\end{array}$ & 0,0 \\
\hline & $\begin{array}{l}102 \\
101\end{array}$ & $16-J u I$ & $15: 23$ & $\begin{array}{l}1,13 \\
1,16\end{array}$ & $\begin{array}{l}0,69 \\
0,68\end{array}$ & 0,030 & 0,017 & 0,0 \\
\hline $12 / 2-1 / 2$ & 95 & 17-JuI & $09: 57$ & 0,15 & 0,02 & 0,024 & 0,014 & \\
\hline $0.2 / 2-1 / 1$ & 94 & 17-JuI & $09: 57$ & 1,17 & 0,70 & 0,030 & 0,014 & 0.8 \\
\hline $12 / 2.2 / 2.1$ & $\begin{array}{l}100 \\
99\end{array}$ & $\begin{array}{l}17-\mathrm{JuI} \\
17-\mathrm{JuI}\end{array}$ & $\begin{array}{l}10: 38 \\
10: 38\end{array}$ & $\begin{array}{l}1,15 \\
1,16\end{array}$ & $\begin{array}{l}0,68 \\
0,69\end{array}$ & $\begin{array}{l}0,031 \\
0,029\end{array}$ & $\begin{array}{l}0,016 \\
0,015\end{array}$ & 0,0 \\
\hline & EICH14 & $17-J u I$ & $11: 16$ & 1,03 & 0 , & 0,046 & 0,046 & \\
\hline $112 / 2 \quad 115.2$ & $\int 98$ & 17-Jul & $11: 36$ & 1,17 & 0,70 & 0,033 & 0,017 & \\
\hline $42 / 2 \cdot 1 / 15 \cdot 3$ & $\left\{\begin{array}{l}97 \\
96\end{array}\right.$ & $\begin{array}{l}\text { 17-Jul } \\
17-J u I\end{array}$ & $\begin{array}{l}11: 36 \\
12: 14\end{array}$ & $\begin{array}{l}1,15 \\
1,15\end{array}$ & $\begin{array}{l}0,69 \\
0,69\end{array}$ & $\begin{array}{l}0,031 \\
0,031\end{array}$ & $\begin{array}{l}0,016 \\
0,016\end{array}$ & \\
\hline & $(88$ & 17-Jul & $12: 14$ & 1,11 & 0,69 & 0,021 & 0,010 & \\
\hline U: & 87 & 17-JuI & $12: 54$ & 1,13 & & 0 & 0,011 & 0 \\
\hline & $\begin{array}{l}86 \\
85\end{array}$ & 17-JuI & $\begin{array}{l}12: 54 \\
13: 33\end{array}$ & 1,09 & $\begin{array}{l}0,69 \\
0.71\end{array}$ & $\begin{array}{l}0,018 \\
0,020\end{array}$ & $\begin{array}{l}0,010 \\
0,008\end{array}$ & \\
\hline & 84 & 17 -JuI & $13: 33$ & 1 , & 0 , & 0,019 & 0,008 & \\
\hline $12 /$ & 83 & $17-J$ & $14: 12$ & 1 , & & & 0,007 & \\
\hline $02 \%$ & 82 & 17-JuI & $14: 12$ & 1,10 & 0 & 0,015 & 0,005 & \\
\hline
\end{tabular}

\begin{tabular}{|c|c|c|c|c|c|c|c|}
\hline & U2.QAN & DATE & TIME ' & $\underset{q}{\mathrm{SiO} 2}$ & $\underset{8}{\mathrm{TeO} 2}$ & $\underset{8}{2 \mathrm{rO} 2}$ & $\underset{8}{\mathrm{MoO} 2}$ \\
\hline $02 / 2-3 / 1$ & 104 & 16-JuI & $14: 45$ & 52,20 & 0,035 & 4,86 & 0,18 \\
\hline $12 / 2-2 / 5-3$ & $\left\{\begin{array}{l}103 \\
102\end{array}\right.$ & $\begin{array}{l}\text { 16-JuI } \\
16-J u I\end{array}$ & $\begin{array}{l}14: 45 \\
15: 23\end{array}$ & $\begin{array}{l}51,11 \\
51 ; 10\end{array}$ & $\begin{array}{l}0,034 \\
0,033\end{array}$ & $\begin{array}{l}5,02 \\
5,02\end{array}$ & $\begin{array}{l}0,18 \\
0,18\end{array}$ \\
\hline & 101 & $16-J u I$ & $15: 23$ & 50,96 & 0,033 & 5,05 & 0,18 \\
\hline & 95 & 17-JuI & $09: 57$ & 56,02 & 0,033 & 4,90 & 0 , \\
\hline $12 / 2-1 / 1$ & $\begin{array}{l}94 \\
100\end{array}$ & $\begin{array}{l}\text { 17-JuI } \\
17-J u I\end{array}$ & $\begin{array}{l}09: 57 \\
10: 38\end{array}$ & $\begin{array}{l}52,25 \\
51,35\end{array}$ & $\begin{array}{l}0,032 \\
0,033\end{array}$ & $\begin{array}{l}4,83 \\
4,98\end{array}$ & $\begin{array}{l}0,18 \\
0,18\end{array}$ \\
\hline U2/2-2/2- & 99 & 17-JuI & $10: 38$ & 51,78 & 0,033 & 4,92 & \\
\hline & $\begin{array}{l}\text { EICH14 } \\
(98\end{array}$ & $\begin{array}{l}\text { 17-Jul } \\
17-J u l\end{array}$ & $\begin{array}{l}11: 16 \\
11: 36\end{array}$ & $\begin{array}{l}52,15 \\
52,62\end{array}$ & $\begin{array}{l}0,028 \\
0,033\end{array}$ & $\begin{array}{l}4,55 \\
4,81\end{array}$ & $\begin{array}{l}0,17 \\
0,18\end{array}$ \\
\hline$U_{2}$ & $\{97$ & 17-JUI & $11: 36$ & 52,04 & 0,034 & 4,89 & 0,18 \\
\hline 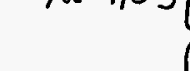 & 196 & 17-Jul & $12: 14$ & 52,12 & 0,032 & 4,87 & $\begin{array}{l}0,18 \\
0,18\end{array}$ \\
\hline & 87 & 17-JUI & $\begin{array}{l}12: 14 \\
12: 54\end{array}$ & $\begin{array}{l}31,13 \\
52,04\end{array}$ & 0,032 & 4,86 & 0, \\
\hline $12 /$ & 86 & 17-JuI & $12: 54$ & 49,78 & 0,031 & 5,11 & 0,18 \\
\hline & $\begin{array}{l}85 \\
84\end{array}$ & $\begin{array}{l}17-J u I \\
17-J u I\end{array}$ & $\begin{array}{l}13: 33 \\
13: 33\end{array}$ & $\begin{array}{l}51,89 \\
51,95\end{array}$ & $\begin{array}{l}0,031 \\
0,032\end{array}$ & $\begin{array}{l}4,88 \\
4,89\end{array}$ & $\begin{array}{l}0,18 \\
0,18\end{array}$ \\
\hline $2 / 1$ & 83 & 17-Jul & $14: 12$ & 50,55 & 0,029 & 5,02 & 0,18 \\
\hline & 82 & 17-JuI & $14: 12$ & 51,06 & 0,031 & 4,98 & \\
\hline
\end{tabular}




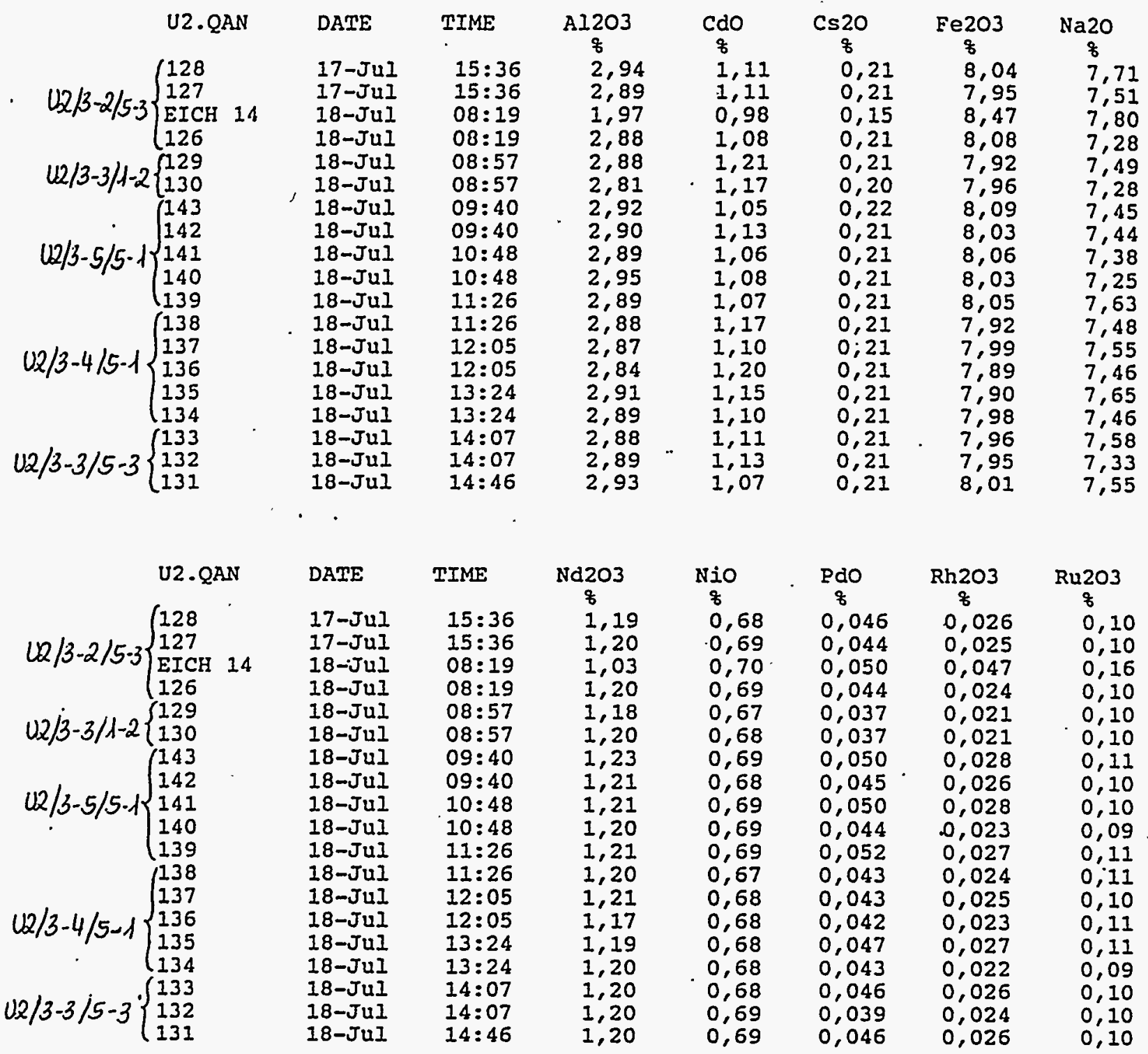

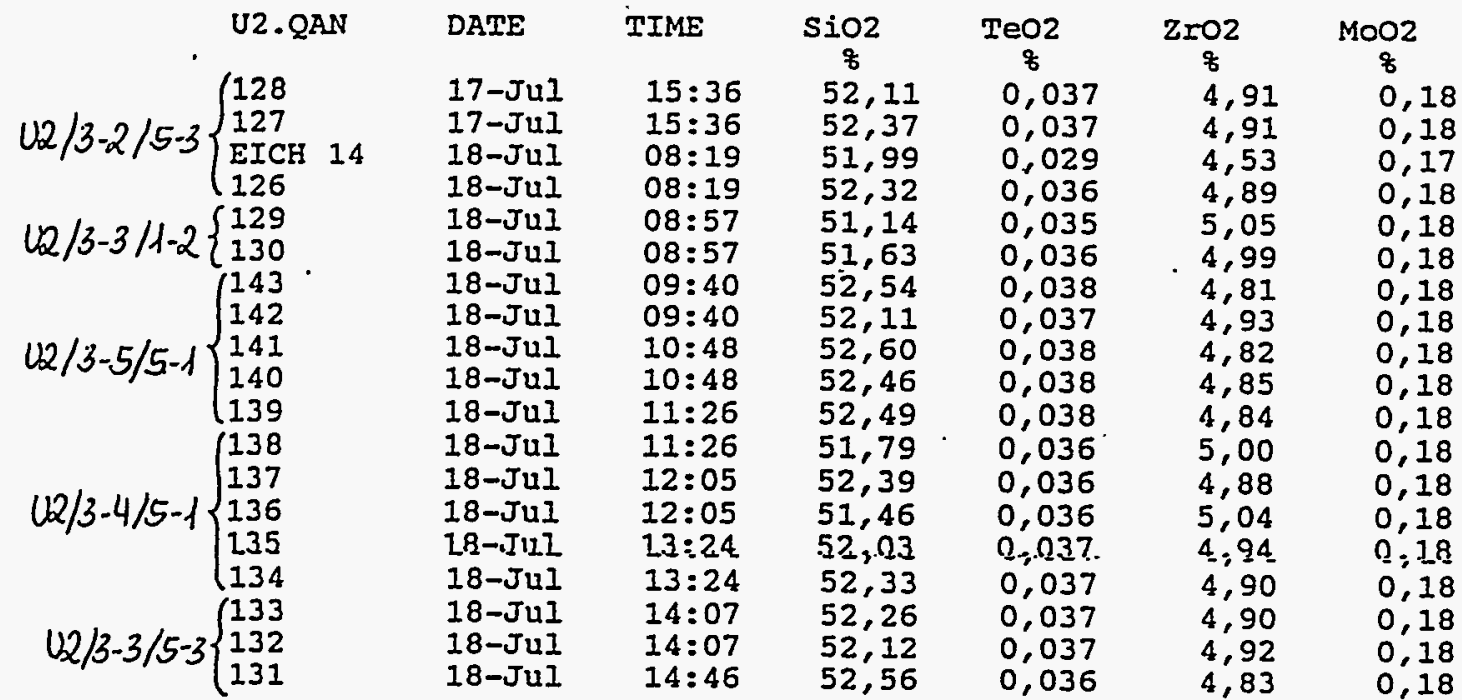




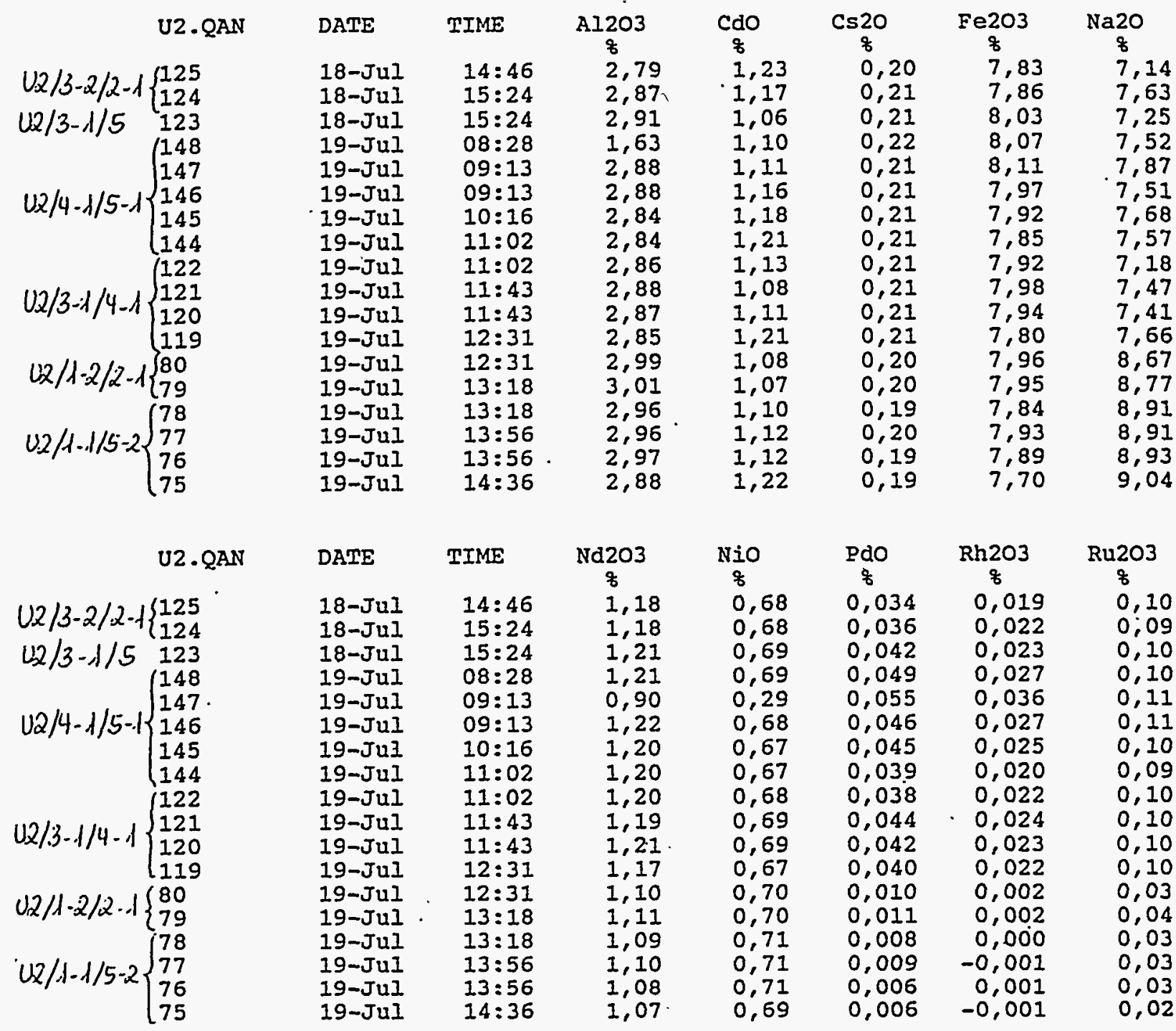

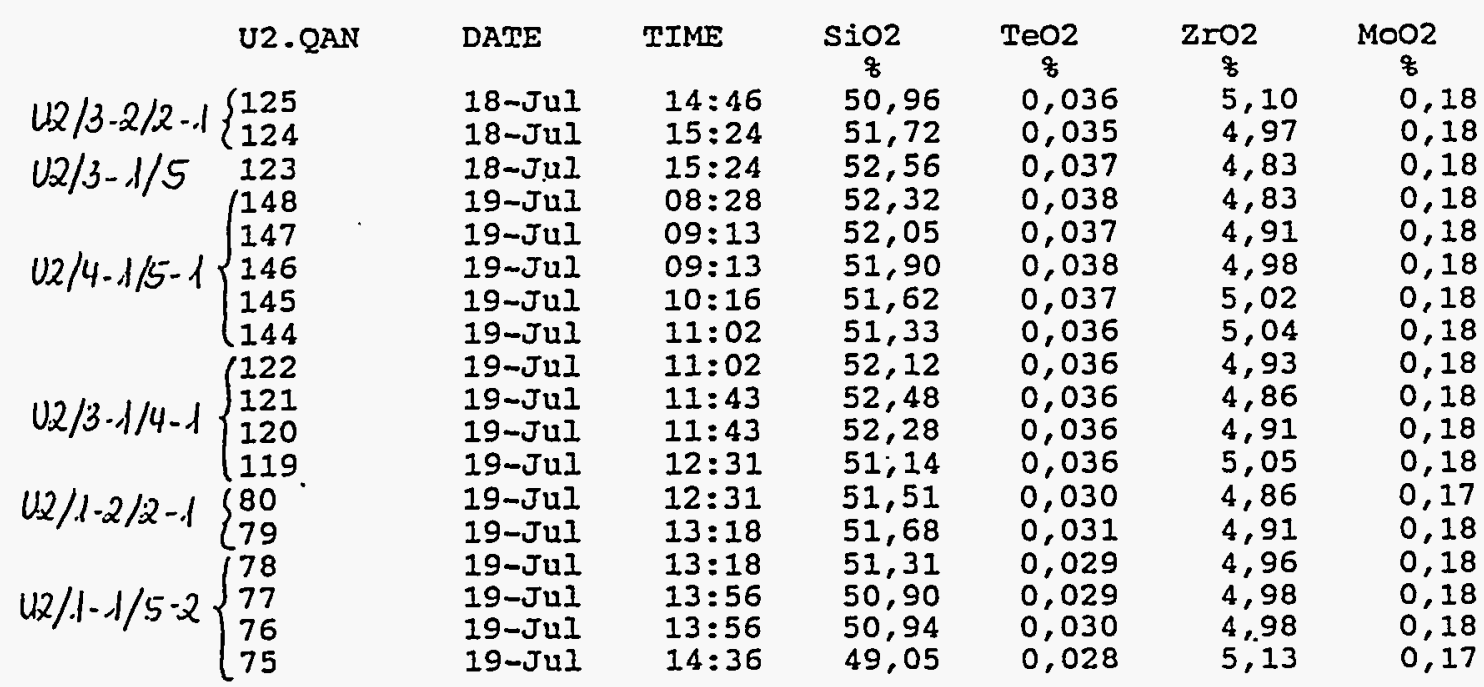




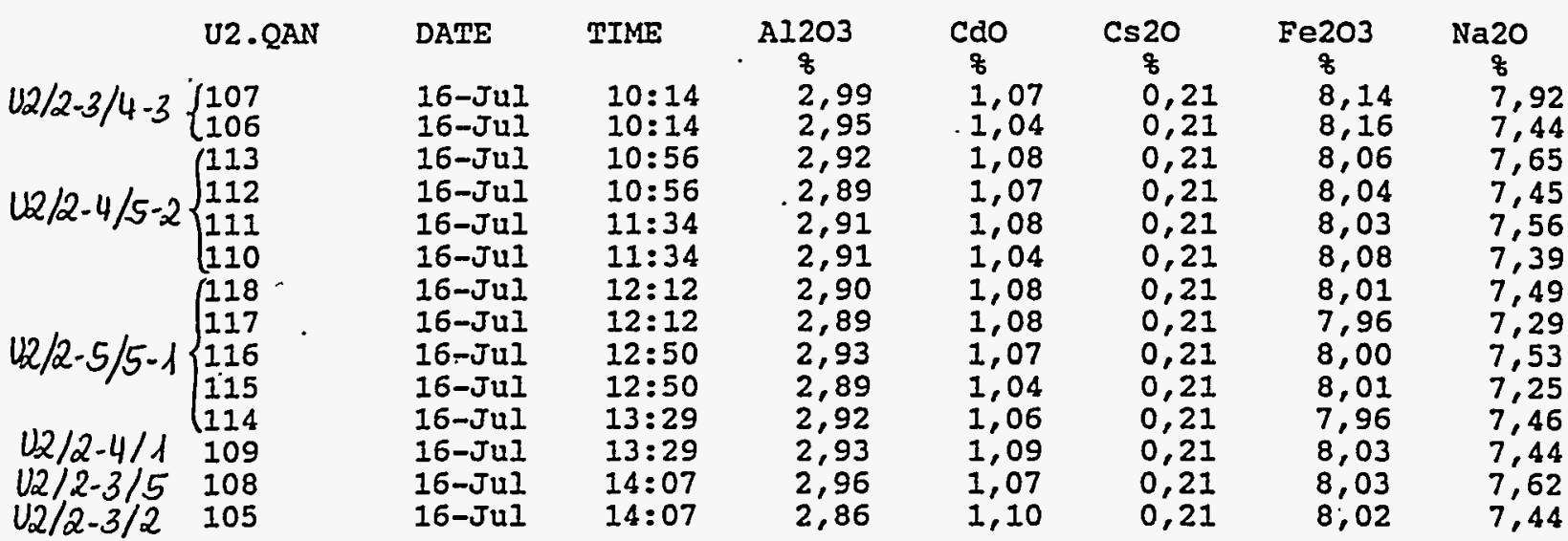

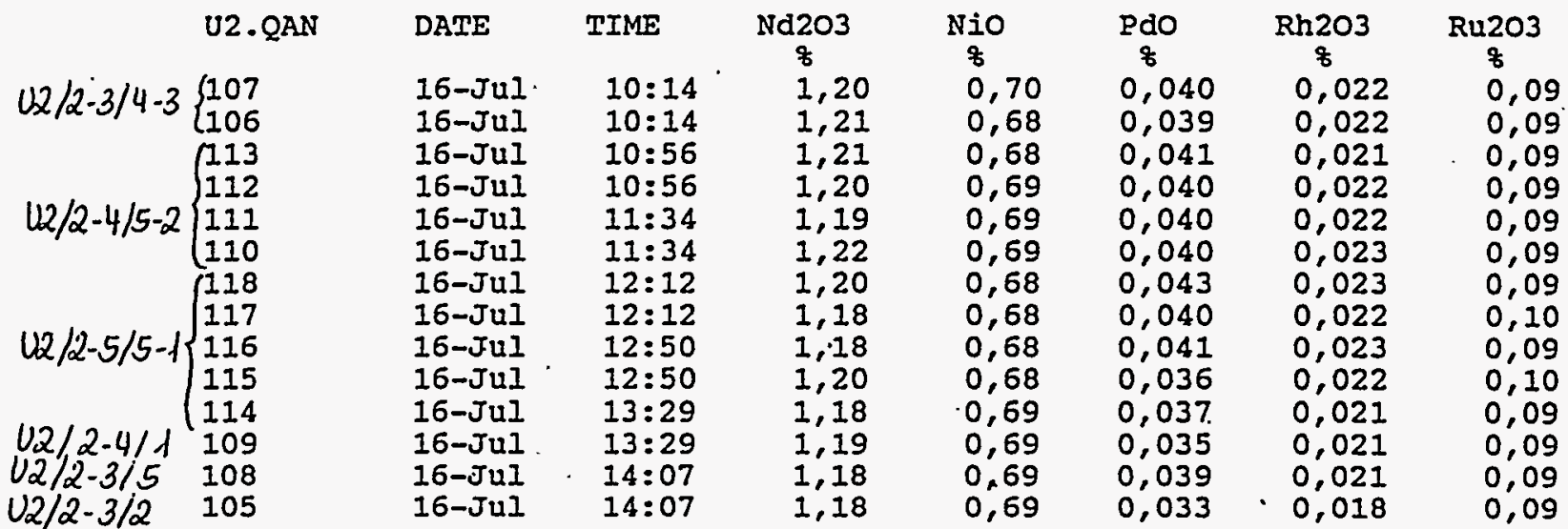

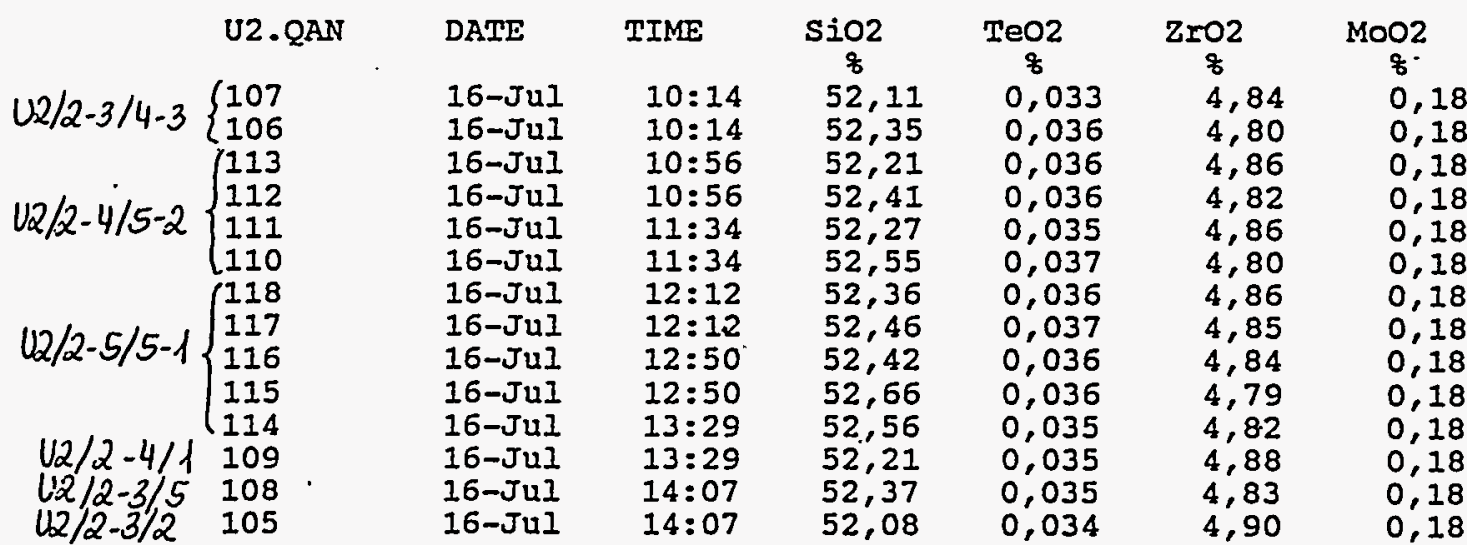




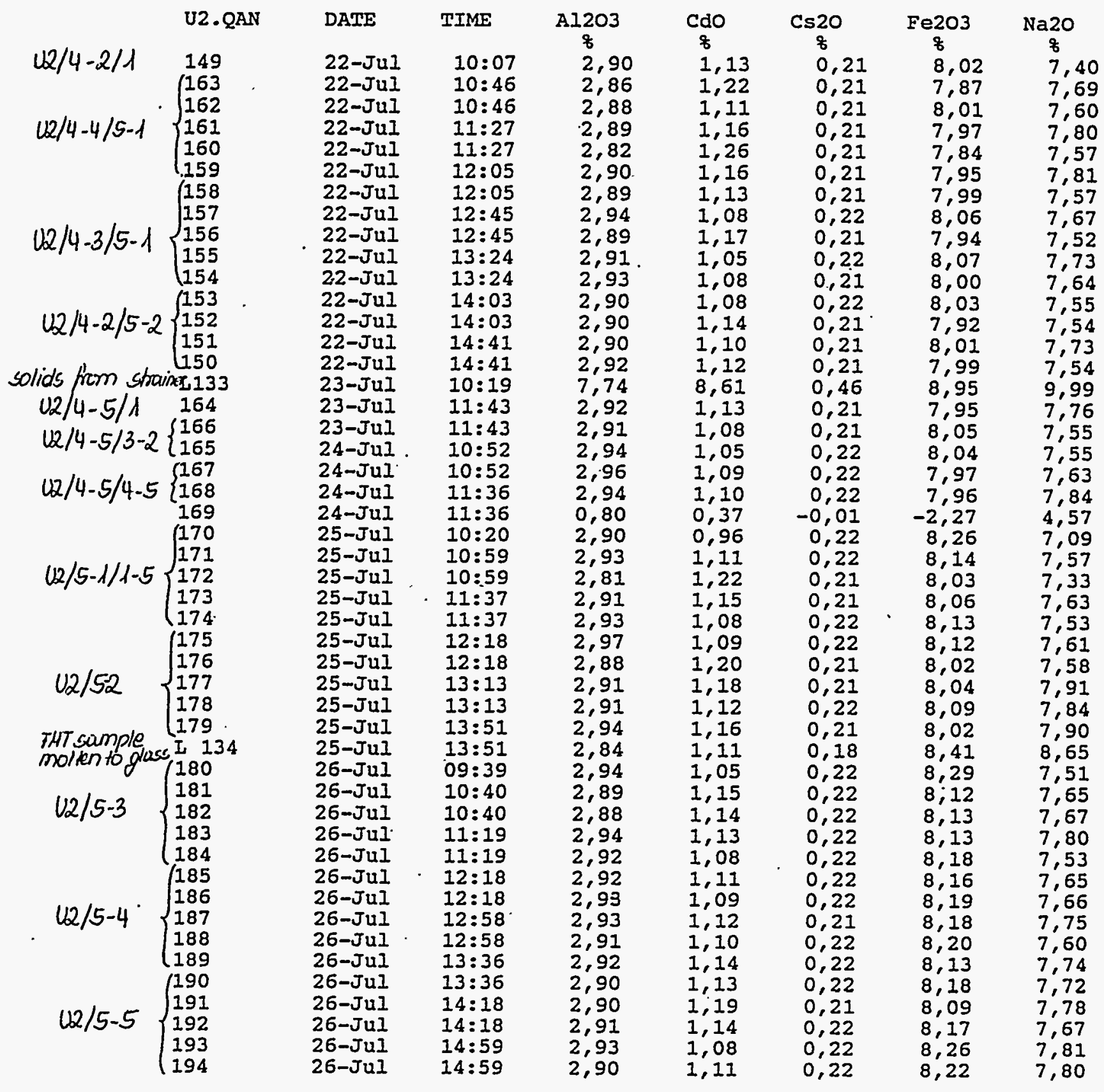




\begin{tabular}{|c|c|c|c|c|c|c|c|c|}
\hline $\begin{array}{l}\text { U2/4-4/5-1 } \\
\text { U2/4-3/5-1 } \\
\text { U2/4-2/5-2 } \\
\text { solids from straune } \\
\text { U2/4-5/1 } \\
\text { U2/4-5/3-2 } \\
\text { U2/4-5/4-.5 } \\
\text { U2/5-1/1-5 }\end{array}$ & 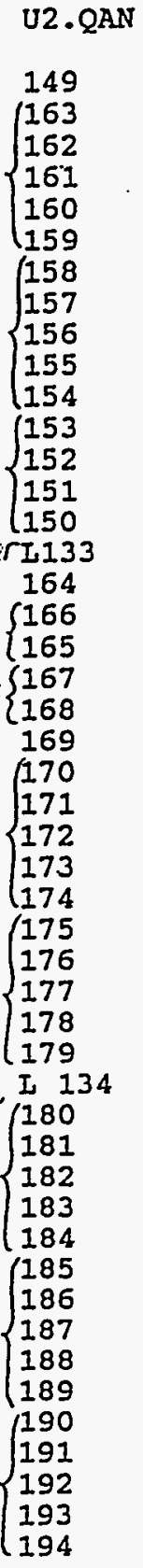 & 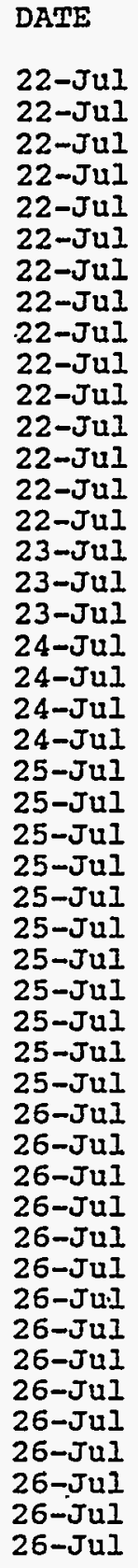 & $\begin{array}{l}10: 07 \\
10: 46 \\
10: 46 \\
11: 27 \\
11: 27 \\
12: 05 \\
12: 05 \\
12: 45 \\
12: 45 \\
13: 24 \\
13: 24 \\
14: 03 \\
14: 03 \\
14: 41 \\
14: 41 \\
10: 19 \\
11: 43 \\
11: 43 \\
10: 52 \\
10: 52 \\
11: 36 \\
11: 36 \\
10: 20 \\
10: 59 \\
10: 59 \\
11: 37 \\
11: 37 \\
12: 18 \\
12: 18 \\
13: 13 \\
13: 13 \\
13: 51 \\
13: 51 \\
09: 39 \\
10: 40 \\
10: 40 \\
11: 19 \\
11: 19 \\
12: 18 \\
12: 18 \\
12: 58 \\
12: 58 \\
13: 36 \\
13: 36 \\
14: 18 \\
14: 18 \\
14: 59 \\
14: 59\end{array}$ & $\begin{array}{c}\text { Nd203 } \\
\text { q } \\
1,22 \\
1,19 \\
1,21 \\
1,23 \\
1,20 \\
1,22 \\
1,22 \\
1,22 \\
1,21 \\
1,22 \\
1,23 \\
1,21 \\
1,20 \\
1,21 \\
1,22 \\
1,53 \\
1,23 \\
1,23 \\
1,23 \\
1,23 \\
1,23 \\
-0,19 \\
1,25 \\
1,24 \\
1,24 \\
1,23 \\
1,24 \\
1,23 \\
1,20 \\
1,22 \\
1,24 \\
1,24 \\
1,30 \\
1,25 \\
1,24 \\
1,22 \\
1,24 \\
1,25 \\
1,23 \\
1,26 \\
1,24 \\
1,27 \\
1,25 \\
1,25 \\
1,23 \\
1,23 \\
1,27 \\
1,26\end{array}$ & 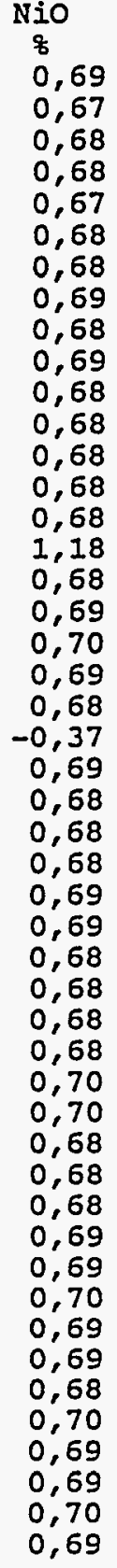 & 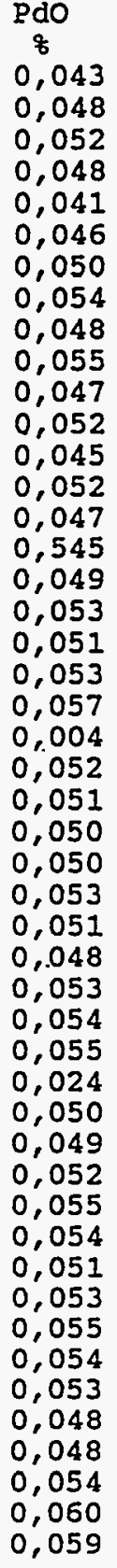 & $\begin{array}{c}\text { Rh203 } \\
\text { \& } \\
0,026 \\
0,027 \\
0,029 \\
0,029 \\
0,023 \\
0,026 \\
0,028 \\
0,030 \\
0,025 \\
0,031 \\
0,029 \\
0,028 \\
0,026 \\
0,028 \\
0,027 \\
0,042 \\
0,025 \\
0,029 \\
0,029 \\
0,029 \\
0,031 \\
0,005 \\
0,027 \\
0,028 \\
0,025 \\
0,028 \\
0,031 \\
0,029 \\
0,027 \\
0,030 \\
0,030 \\
0,029 \\
0,022 \\
0,031 \\
0,028 \\
0,030 \\
0,031 \\
0,031 \\
0,029 \\
0,030 \\
0,030 \\
0,032 \\
0,030 \\
0,026 \\
0,026 \\
0,030 \\
0,034 \\
0,031\end{array}$ & $\begin{array}{c}\text { Ru2, } \\
0 \\
0,10 \\
0,10 \\
0,11 \\
0,11 \\
0,11 \\
0,10 \\
0,10 \\
0,11 \\
0,11 \\
0,10 \\
0,11 \\
0,10 \\
0,11 \\
0,10 \\
0,11 \\
0,11 \\
0,12 \\
0,09 \\
0,11 \\
0,10 \\
0,11 \\
0,11 \\
0,03 \\
0,10 \\
0,11 \\
0,11 \\
0,11 \\
0,11 \\
0,10 \\
0,11 \\
0,11 \\
0,11 \\
0,12 \\
0,06 \\
0,11 \\
0,10 \\
0,12 \\
0,11 \\
0,11 \\
0,10 \\
0,11 \\
0,11 \\
0,12 \\
0,11 \\
0,09 \\
0,09 \\
0,11 \\
0,12 \\
0,11\end{array}$ \\
\hline
\end{tabular}




\begin{tabular}{|c|c|c|c|c|c|c|c|}
\hline & & & & & & & \\
\hline & U2 - QAN & DATE & TIME & SiO2 & $\mathrm{TeO} 2$ & 2r02 & MoO2 \\
\hline$U 2 / 4-2 / 1$ & 149 & 22-JuI & $10: 07$ & 52,06 & 0,037 & 4,94 & 0,18 \\
\hline & $(163$ & 22-JuI & $10: 46$ & 51,25 & 0,038 & 5,05 & 0,18 \\
\hline (12/4-4/5-1 & 162 & 22-Jul & $10: 46$ & 52,37 & 0,038 & 4,89 & 0,18 \\
\hline $12 / 4-4 / 5-1$ & $\left\{\begin{array}{l}161 \\
160\end{array}\right.$ & $\begin{array}{l}\text { 22-JuI } \\
22-J u I\end{array}$ & $11: 27$ & 51,94 & $\begin{array}{l}0,037 \\
0,037\end{array}$ & $\begin{array}{l}4,98 \\
5,1 ?\end{array}$ & 0,18 \\
\hline & $\begin{array}{l}100 \\
159\end{array}$ & 22-JuI & $\begin{array}{l}11: 27 \\
12: 05\end{array}$ & $\begin{array}{l}50,77 \\
51,89\end{array}$ & $\begin{array}{l}0,037 \\
0,038\end{array}$ & $\begin{array}{l}5,12 \\
4,95\end{array}$ & $\begin{array}{l}0,18 \\
0,18\end{array}$ \\
\hline & 158 & $22-J u I$ & $12: 05$ & 52,16 & 0,038 & 4,94 & 0,18 \\
\hline $12 / 4-3 / 5$ & 157 & $22-J u I$ & $12: 45$ & 52,49 & 0,037 & 4,85 & 0,18 \\
\hline $2 / 4=$ & $\{156$ & 22-Jul & $12: 45$ & 51,80 & 0,038 & 4,99 & 0,18 \\
\hline & $\begin{array}{l}155 \\
154\end{array}$ & $\begin{array}{l}22-J U \perp \\
22-J u I\end{array}$ & $\begin{array}{l}13: 24 \\
13: 24\end{array}$ & $\begin{array}{l}52,61 \\
52,53\end{array}$ & $\begin{array}{l}0,037 \\
0,037\end{array}$ & $\begin{array}{l}4,83 \\
4,85\end{array}$ & $\begin{array}{l}0,18 \\
0,18\end{array}$ \\
\hline & 153 & $22-J u I$ & $14: 03$ & 52,50 & 0,038 & 4,84 & 0,18 \\
\hline $15-2$ & $\{152$ & 22-JuI & $14: 03$ & 52,13 & 0,037 & 4,93 & 0,18 \\
\hline & 151 & 22-JuI & $14: 41$ & 52,38 & 0,036 & 4,89 & 0,18 \\
\hline criels of & 1150 & $22-J u 1$ & $14: 41$ & 52,22 & 0,038 & 4,92 & 0,18 \\
\hline $02 / 4$ & $\begin{array}{l}\text { IL133 } \\
164\end{array}$ & $\begin{array}{l}23-J u I \\
23-J u I\end{array}$ & $\begin{array}{l}10: 19 \\
11: 43\end{array}$ & $\begin{array}{l}32,22 \\
52,23\end{array}$ & $\begin{array}{l}0,053 \\
0.037\end{array}$ & $\begin{array}{l}4,36 \\
4,94\end{array}$ & 0,10 \\
\hline & (166 & $23-\mathrm{Jul}$ & $11=43$ & 52,49 & 0,038 & $\begin{array}{l}4,84 \\
4,88\end{array}$ & $\begin{array}{l}0,18 \\
0,18\end{array}$ \\
\hline$U 2 / 4-5 / 3-2$ & $\{165$ & 24-JuI & $10: 52$ & 52,73 & 0,038 & 4,82 & 0,18 \\
\hline & $\{167$ & 24-JuI & $10: 52$ & 52,55 & 0,039 & 4,89 & 0,18 \\
\hline $0,2 / 4$. & $\{168$ & 24-JuI & $11: 36$ & 52,51 & 0,038 & 4,87 & 0,18 \\
\hline & 169 & 24-Jul & $11: 36$ & 78,16 & 0,012 & $-2,56$ & $-0,16$ \\
\hline & $\left(\begin{array}{l}170 \\
171\end{array}\right.$ & 25-JuI & $10: 20$ & 52,59 & 0,039 & 4,69 & $\begin{array}{l}0,19 \\
0,18\end{array}$ \\
\hline$(12 / 5-1 / 1$ & $\left\{\begin{array}{l}172 \\
172\end{array}\right.$ & $\begin{array}{l}25-J u 1 \\
25-J u l\end{array}$ & $\begin{array}{l}10: 59 \\
10: 59\end{array}$ & $\begin{array}{l}52,08 \\
51,21\end{array}$ & $\begin{array}{l}0,039 \\
0,037\end{array}$ & $\begin{array}{l}4,90 \\
5,08\end{array}$ & 0,18 \\
\hline & 173 & 25-JuI & $11: 37$ & 51,86 & 0,039 & 4,95 & 0,18 \\
\hline & $(174$ & 25-JuI & $11: 37$ & 52,35 & 0,039 & 4,86 & 0,18 \\
\hline & $\left(\begin{array}{l}175 \\
176\end{array}\right.$ & 25-Jul & $12: 18$ & 52,31 & 0,038 & 4,86 & $\begin{array}{l}0,18 \\
0,18\end{array}$ \\
\hline $12 / 5-2$ & $\left\{\begin{array}{l}116 \\
177\end{array}\right.$ & $\begin{array}{l}25-\mathrm{JuI} \\
25-\mathrm{JuI}\end{array}$ & $\begin{array}{l}12: 18 \\
13: 13\end{array}$ & $\begin{array}{l}51,38 \\
51,60\end{array}$ & $\begin{array}{l}0,038 \\
0,038\end{array}$ & $\begin{array}{l}5,01 \\
4,97\end{array}$ & 0,18 \\
\hline & 178 & 25-JuI & $13: 13$ & 52,12 & 0,038 & 4,91 & 0,18 \\
\hline & 179 & $25-J u l$ & $13: 51$ & 51,79 & 0,037 & 4,95 & 0,18 \\
\hline ticlos glas, & I 134 & 25-JuI & $13: 51$ & 51,38 & 0,026 & 4,77 & 0,17 \\
\hline & 180 & 26-Jul & $09: 39$ & 52,23 & 0,039 & 4,82 & $\begin{array}{l}0,18 \\
0,18\end{array}$ \\
\hline U2/.5-3 & $\left\{\begin{array}{l}181 \\
182\end{array}\right.$ & $\begin{array}{l}26-J u l \\
26-J u I\end{array}$ & $\begin{array}{l}10: 40 \\
10: 40\end{array}$ & $\begin{array}{l}51,79 \\
51,87\end{array}$ & $\begin{array}{l}0,038 \\
0,038\end{array}$ & $\begin{array}{l}4,92 \\
4,92\end{array}$ & $\begin{array}{l}0,18 \\
0,18\end{array}$ \\
\hline & 183 & 26-JuI & $11: 19$ & 51,97 & 0,038 & 4,89 & 0,18 \\
\hline & 184 & 26-JuI & $11: 19$ & 52,27 & 0,040 & 4,85 & 0,18 \\
\hline & $\int_{186}^{185}$ & 26-Jul & $12: 18$ & 52,12 & 0,037 & 4,86 & $\begin{array}{l}0,18 \\
0,18\end{array}$ \\
\hline$U 2 / 5-4$ & $\left\{\begin{array}{l}180 \\
187\end{array}\right.$ & $\begin{array}{l}26-J u I \\
26-J U I\end{array}$ & $\begin{array}{l}12: 18 \\
12: 58\end{array}$ & 51,96 & $\begin{array}{l}0,038 \\
0,038\end{array}$ & $\begin{array}{l}4,83 \\
4,88\end{array}$ & $\begin{array}{l}0,18 \\
0,18\end{array}$ \\
\hline & 188 & 26-JuI & $12: 58$ & 52,08 & 0,039 & 4,87 & 0,18 \\
\hline & 189 & 26-JUI & $13: 36$ & $.51,86$ & 0,038 & 4,90 & 0,18 \\
\hline & 190 & 26-JuI & $13: 36$ & 51,90 & 0,038 & & 0,18 \\
\hline & 191 & 26-JuI & $\begin{array}{l}14: 18 \\
14: 18\end{array}$ & $\begin{array}{l}1,42 \\
1,80\end{array}$ & 0,037 & & 0,18 \\
\hline $12 / s$ & $\begin{array}{l}192 \\
193\end{array}$ & $\begin{array}{l}26-J u I \\
26-J u I\end{array}$ & $\begin{array}{l}14: 18 \\
14: 59\end{array}$ & $\begin{array}{l}80 \\
12\end{array}$ & $\begin{array}{l}0,039 \\
0,039\end{array}$ & & \\
\hline & 19 & 26-JuI & $14: 59$ & 97 & 0,039 & 4,88 & 0,18 \\
\hline
\end{tabular}




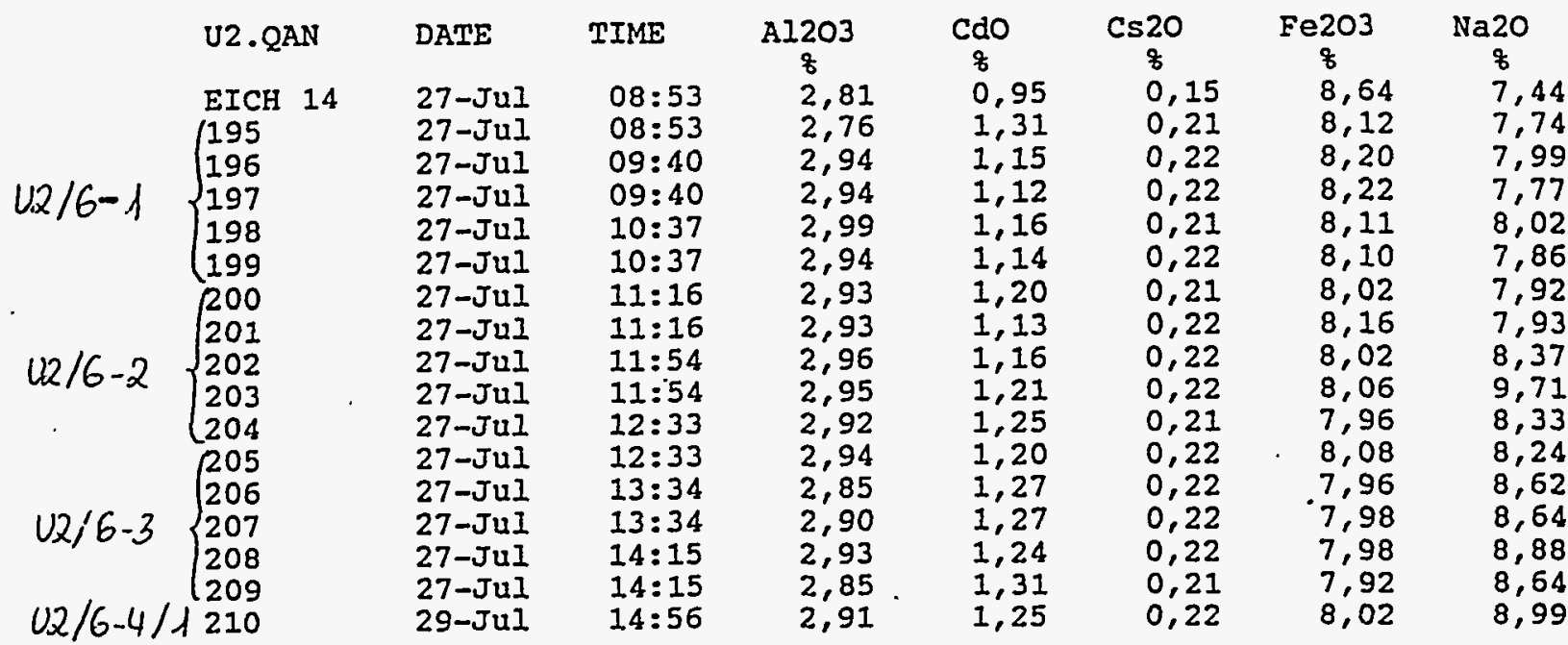

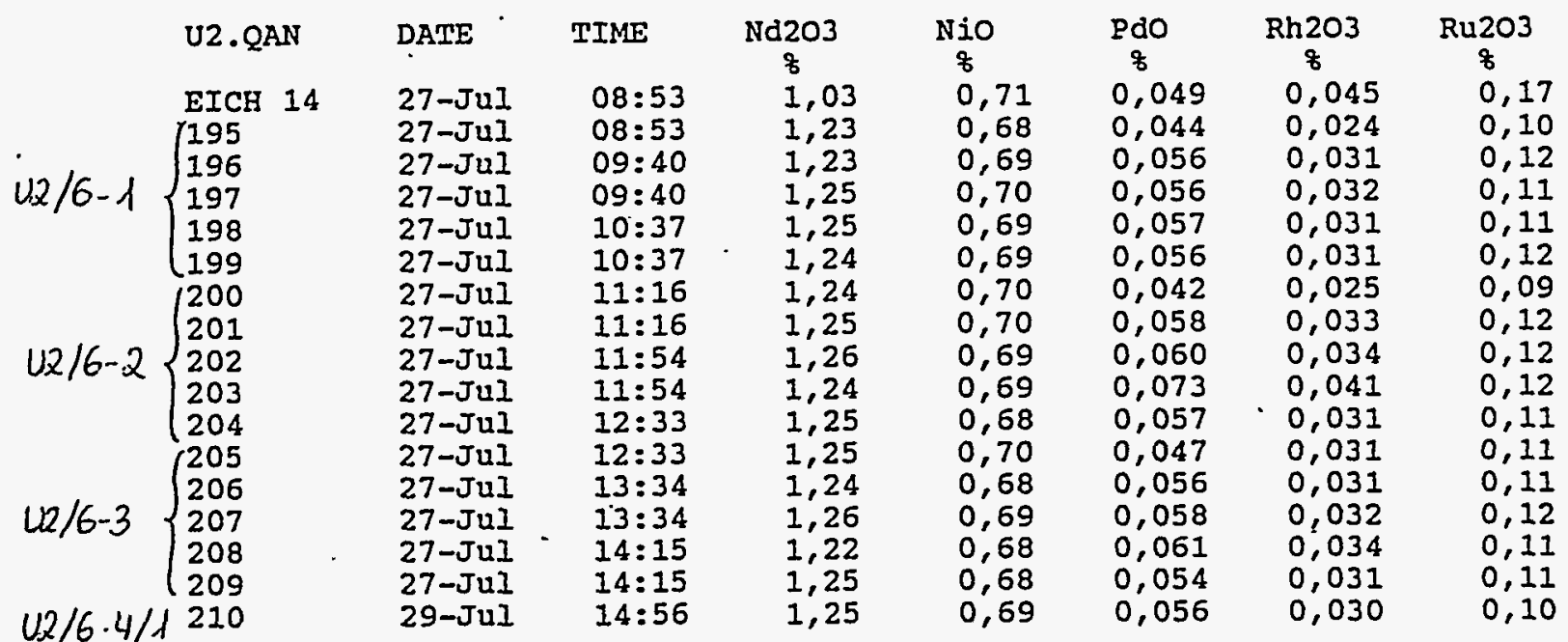

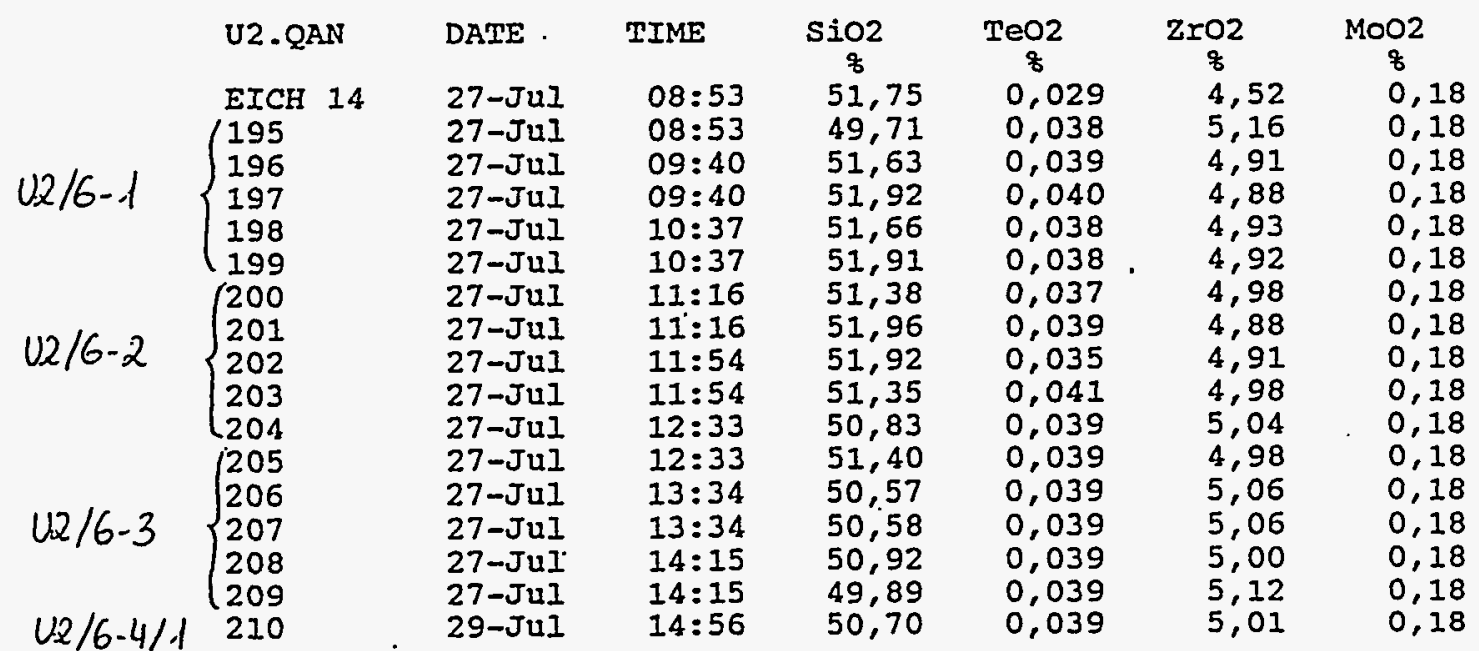




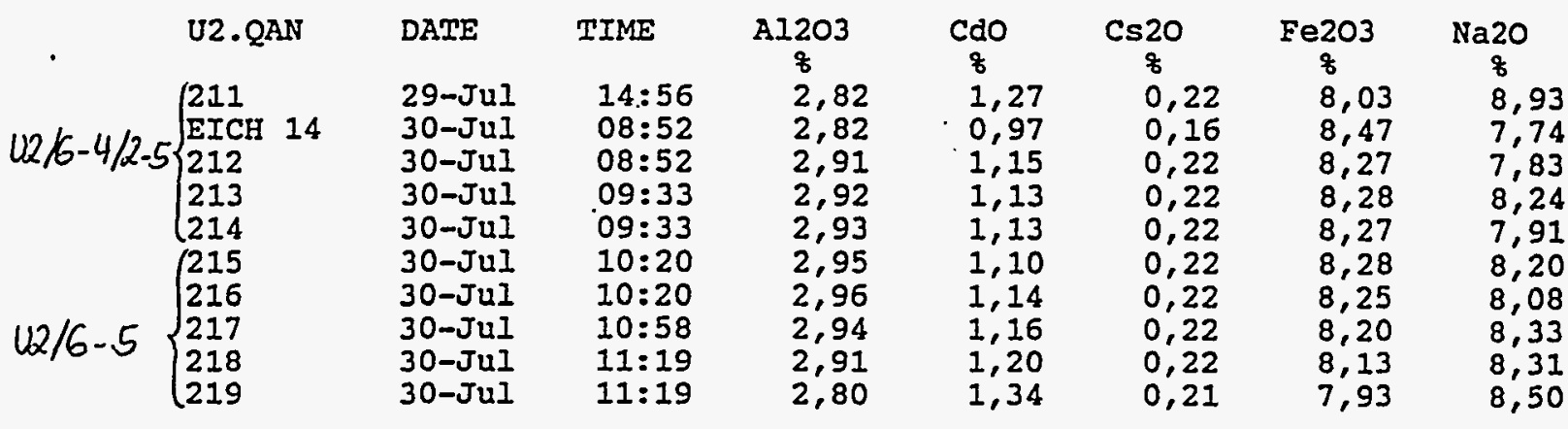

\begin{tabular}{|c|c|c|c|c|c|c|c|c|}
\hline & U2.QAN & DATE & TIME & $\mathrm{Nd2O}$ & NiO & Pdo & Rh203 & 4203 \\
\hline $02 / 6-4 / 2.5$ & $\begin{array}{l}\left\{\begin{array}{l}211 \\
\text { IICH } \\
212 \\
213 \\
214\end{array}\right. \\
\left\{\begin{array}{l}215 \\
216 \\
217 \\
218 \\
219\end{array}\right.\end{array}$ & $\begin{array}{l}29-J u I \\
30-J u I \\
30-J u I \\
30-J u I \\
30-J u I \\
30-J u I \\
30-J u I \\
30-J u I \\
30-J u I \\
30-J u I\end{array}$ & $\begin{array}{l}14: 56 \\
08: 52 \\
08: 52 \\
09: 33 \\
09: 33 \\
10: 20 \\
10: 20 \\
10: 58 \\
11: 19 \\
11: 19\end{array}$ & $\begin{array}{l}1,23 \\
1,04 \\
1,27 \\
1,28 \\
1,28 \\
1,28 \\
1,29 \\
1,26 \\
1,27 \\
1,24\end{array}$ & $\begin{array}{l}0,69 \\
0,71 \\
0,70 \\
0,70 \\
0,70 \\
0,70 \\
0,70 \\
0,69 \\
0,69 \\
0,68\end{array}$ & $\begin{array}{l}0,060 \\
0,050 \\
0,056 \\
0,062 \\
0,059 \\
0,057 \\
0,054 \\
0,060 \\
0,059 \\
0,052\end{array}$ & $\begin{array}{l}0,032 \\
0,048 \\
0,032 \\
0,034 \\
0,032 \\
0,032 \\
0,030 \\
0,034 \\
0,034 \\
0,030\end{array}$ & $\begin{array}{l}0,11 \\
0,17 \\
0,12 \\
0,12 \\
0,12 \\
0,10 \\
0,10 \\
0,12 \\
0,12 \\
0,12\end{array}$ \\
\hline
\end{tabular}

\begin{tabular}{|c|c|c|c|c|c|c|c|}
\hline & U2.QAN & DATE & TIME & Sio2 & $\mathrm{TeO} 2$ & $\mathrm{ZrO}_{q}$ & $\underset{8}{\mathrm{MoO} 2}$ \\
\hline $02 / 6 \cdot 4 / 2$ & $\begin{array}{l}\left\{\begin{array}{l}211 \\
\text { EICH } \\
212 \\
213 \\
214\end{array}\right. \\
\left\{\begin{array}{l}215 \\
216 \\
217 \\
218 \\
219\end{array}\right.\end{array}$ & $\begin{array}{l}29-J u I \\
30-J u I \\
30-J u I \\
30-J u I \\
30-J u I \\
30-J u I \\
30-J u I \\
30-J u I \\
30-J u I \\
30-J u I\end{array}$ & $\begin{array}{l}14: 56 \\
08: 52 \\
08: 52 \\
09: 33 \\
09: 33 \\
10: 20 \\
.10: 20 \\
10: 58 \\
11: 19 \\
11: 19\end{array}$ & $\begin{array}{l}50,41 \\
52,05 \\
51,54 \\
51,58 \\
51,77 \\
51,91 \\
51,73 \\
51,58 \\
51,34 \\
49,34\end{array}$ & $\begin{array}{l}0,040 \\
0,028 \\
0,040 \\
0,039 \\
0,041 \\
0,039 \\
0,040 \\
0,039 \\
0,040 \\
0,038\end{array}$ & $\begin{array}{l}5,06 \\
4,51 \\
4,91 \\
4,84 \\
4,85 \\
4,81 \\
4,87 \\
4,89 \\
4,93 \\
5,13\end{array}$ & $\begin{array}{l}0,18 \\
0,17 \\
0,18 \\
0,18 \\
0,18 \\
0,18 \\
0,18 \\
0,18 \\
0,18 \\
0,17\end{array}$ \\
\hline
\end{tabular}




\begin{tabular}{|c|c|c|c|c|c|c|c|c|}
\hline & U2.QAN & DATE & TIME & $\underset{8}{\mathrm{~A}}{ }_{8} 203$ & $\underset{8}{\text { Cdo }}$ & $\begin{array}{c}\operatorname{Cs} 20 \\
8\end{array}$ & $\underset{8}{\mathrm{Fe} 2 \mathrm{O} 3}$ & $\underset{8}{\mathrm{Na} 2 \mathrm{O}}$ \\
\hline$U 2 / 7-2$ & $\begin{array}{l}\left\{\begin{array}{l}220 \\
221 \\
\text { EICH } 14 \\
222 \\
223 \\
224\end{array}\right. \\
\left\{\begin{array}{l}225 \\
226 \\
227 \\
228 \\
229\end{array}\right.\end{array}$ & $\begin{array}{l}\text { 31-JuI } \\
31-J u I \\
31-J u I \\
31-J u 1 \\
31-J u I \\
31-J u I \\
31-J u I \\
31-J u I \\
31-J u I \\
31-J u I \\
31-J u I\end{array}$ & $\begin{array}{l}11: 26 \\
11: 26 \\
12: 05 \\
12: 05 \\
12: 45 \\
12: 45 \\
13: 25 \\
13: 25 \\
14: 06 \\
14: 06 \\
14: 49\end{array}$ & $\begin{array}{l}2,91 \\
2,89 \\
2,81 \\
2,89 \\
2,96 \\
2,90 \\
2,84 \\
2,87 \\
2,89 \\
2,86 \\
2,76\end{array}$ & $\begin{array}{l}1,22 \\
1,26 \\
1,03 \\
1,21 \\
1,18 \\
1,25 \\
1,29 \\
1,26 \\
1,22 \\
1,26 \\
1,32\end{array}$ & $\begin{array}{l}0,22 \\
0,22 \\
0,15 \\
0,22 \\
0,22 \\
0,22 \\
0,22 \\
0,22 \\
0,22 \\
0,22 \\
0,21\end{array}$ & $\begin{array}{l}8,12 \\
8,08 \\
8,20 \\
8,13 \\
8,18 \\
8,13 \\
8,08 \\
8,14 \\
8,23 \\
8,13 \\
8,06\end{array}$ & $\begin{array}{l}8,22 \\
8,47 \\
7,86 \\
8,63 \\
8,62 \\
9,31 \\
8,37 \\
8,96 \\
8,50 \\
8,74 \\
8,58\end{array}$ \\
\hline
\end{tabular}

\begin{tabular}{|c|c|c|c|c|c|c|c|c|}
\hline & U2. QAN & DATE & TIME & $\underset{8}{\mathrm{Nd} 2 \mathrm{O} 3}$ & $\underset{8}{\mathrm{NiO}}$ & $\underset{8}{P d O}$ & $\underset{8}{\mathrm{Rh} 203}$ & $\underset{8}{\mathrm{Ru} 2 \mathrm{O} 3}$ \\
\hline $12 / 7-2$ & $\begin{array}{l}\left\{\begin{array}{l}220 \\
221 \\
\mathrm{EICH} \quad 14 \\
222 \\
223 \\
224\end{array}\right. \\
\left\{\begin{array}{l}225 \\
226 \\
227 \\
228 \\
229\end{array}\right.\end{array}$ & $\begin{array}{l}31-J u I \\
31-J u I \\
31-J u I \\
31-J u I \\
31-J u I \\
31-J u I \\
31-J u I \\
31-J u I \\
31-J u I \\
31-J u I \\
31-J u I\end{array}$ & $\begin{array}{l}11: 26 \\
11: 26 \\
12: 05 \\
12: 05 \\
12: 45 \\
12: 45 \\
13: 25 \\
13: 25 \\
14: 06 \\
14: 06 . \\
14: 49\end{array}$ & $\begin{array}{l}1,26 \\
1,25 \\
1,02 \\
1,27 \\
1,26 \\
1,25 \\
1,25 \\
1,25 \\
1,27 \\
1,27 \\
1,24\end{array}$ & $\begin{array}{l}0,70 \\
0,69 \\
0,70 \\
0,70 \\
0,70 \\
0,69 \\
0,69 \\
0,70 \\
0,69 \\
0,69 \\
0,68\end{array}$ & $\begin{array}{l}0,049 \\
0,054 \\
0,045 \\
0,060 \\
0,062 \\
0,065 \\
0,048 \\
0,055 \\
0,058 \\
0,058 \\
0,054\end{array}$ & $\begin{array}{l}0,029 \\
0,030 \\
0,043 \\
0,034 \\
0,035 \\
0,037 \\
0,024 \\
0,029 \\
0,034 \\
0,033 \\
0,031\end{array}$ & $\begin{array}{l}0,103 \\
0,110 \\
0,165 \\
0,111 \\
0,120 \\
0,118 \\
0,083 \\
0,093 \\
0,120 \\
0,118 \\
0,122\end{array}$ \\
\hline
\end{tabular}

\begin{tabular}{|c|c|c|c|c|c|c|c|}
\hline & U2 - QAN & DATE & TIME & $\underset{8}{\mathrm{SiO} 2}$ & $\underset{8}{\mathrm{TeO}^{2}}$ & $\underset{8}{\operatorname{zro} 2}$ & $\underset{8}{\mathrm{MOO} 2}$ \\
\hline $02 / 7-1$ & $\begin{array}{l}\left\{\begin{array}{l}220 \\
221 \\
\text { EICH } \\
222 \\
223 \\
224\end{array}\right. \\
\left\{\begin{array}{l}225 \\
226 \\
227 \\
228 \\
229\end{array}\right.\end{array}$ & $\begin{array}{l}31-J u I \\
31-J u I \\
31-J u I \\
31-J u I \\
31-J u I \\
31-J u I \\
31-J u I \\
31-J u I \\
31-J u I \\
31-J u I \\
31-J u I\end{array}$ & $\begin{array}{l}11: 26 \\
11: 26 \\
12: 05 \\
12: 05 \\
12: 45 \\
12: 45 \\
13: 25 \\
13: 25 \\
14: 06 \\
14: 06 \\
14: 49\end{array}$ & $\begin{array}{l}50,99 \\
50,55 \\
52,28 \\
51,09 \\
51,34 \\
50,52 \\
49,98 \\
50,39 \\
50,81 \\
50,31 \\
49,61\end{array}$ & $\begin{array}{l}0,039 \\
0,039 \\
0,028 \\
0,039 \\
0,040 \\
0,039 \\
0,039 \\
0,039 \\
0,041 \\
0,039 \\
0,039\end{array}$ & $\begin{array}{l}4,96 \\
5,01 \\
4,59 \\
4,95 \\
4,92 \\
5,01 \\
5,06 \\
5,02 \\
4,97 \\
5,01 \\
5,11\end{array}$ & $\begin{array}{l}0,18 \\
0,18 \\
0,17 \\
0,18 \\
0,18 \\
0,18 \\
0,18 \\
0,18 \\
0,18 \\
0,18 \\
0,18\end{array}$ \\
\hline
\end{tabular}




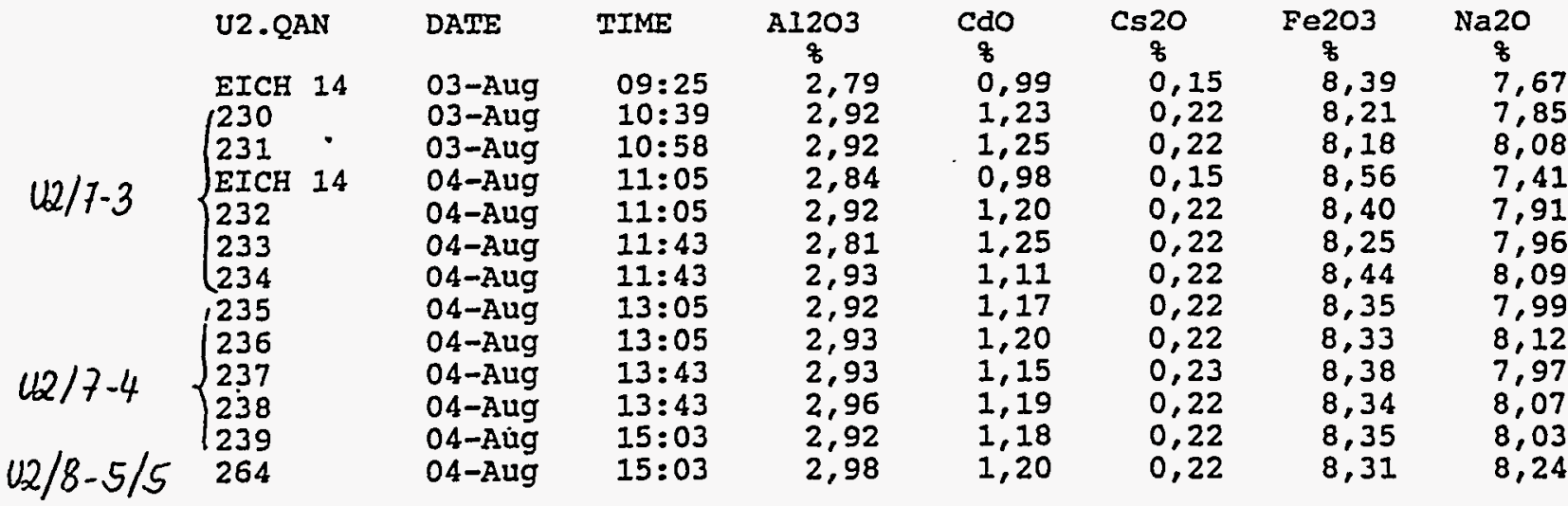

U2.QAN
EICH 14
U2/7-3 $\begin{cases}230 \\ 23 I \\ \text { EICH } & 14 \\ 232 \\ 233 \\ 234\end{cases}$
$02 / 7-4 \quad\left\{\begin{array}{l}235 \\ 236 \\ 237 \\ 238 \\ 239 \\ 264\end{array}\right.$

DATE

03-Âug

03-Aug 03-Aug 04-Aug 04-Aug 04-Aug 04-Aug 04-Aug 04-Aug 04-Aug 04-Aug 04-Aug 04-Aug

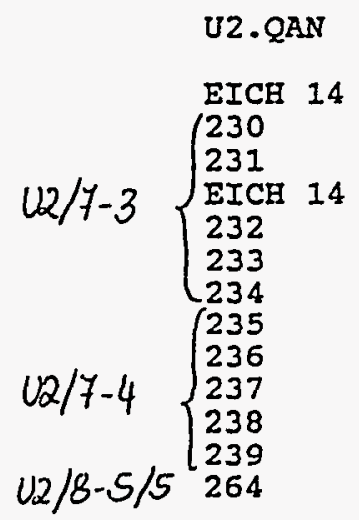

$\begin{array}{ll}\text { DATE } & \text { TIME } \\ \text { 03-Aug } & 09: 25 \\ \text { 03-Aug } & 10: 39 \\ \text { 03-Aug } & 10: 58 \\ \text { 04-Aug } & 11: 05 \\ \text { 04-Aug } & 11: 05 \\ \text { 04-Aug } & 11: 43 \\ \text { 04-Aug } & 11: 43 \\ \text { 04-Aug. } & 13: 05 \\ \text { 04-Aug } & 13: 05 \\ \text { 04-Aug } & 13: 43 \\ \text { 04-Aug } & 13: 43 \\ \text { 04-Aug } & 15: 03 \\ \text { 04-Aug } & 15: 03\end{array}$

TIME

\section{$09: 25$}

$10: 39$

$10: 58$

11:05

$11: 05$

$11: 43$

$11: 43$

$13: 05$

$13: 05$

$13: 43$

$13: 43$

$15: 03$

$15: 03$

$\mathrm{Nd203}$

1,03

1,28

1,25

1,02

1,28

1,26

1,29

1,27

1,32

1,28

1,25

1,27

1,28

$\underset{\mathrm{SiO} 2}{\mathrm{~s}}$

52,14

50,74

50,59

51,85

50,76

50,31

51,56

51,24

50,94

51,43

51,05

51,06

51,01
NiO

0,71

0,70

0,70

0,71

0,70

0,70

0,71

0,71

0,71

0,71

0,71

0,70

0,70

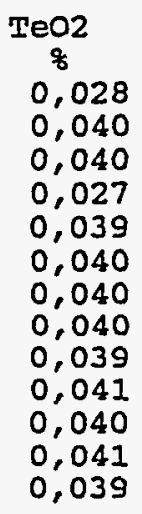

Pdo

0,048

0,051

0,049

0,046

0,054

0,052

0,064

0,050

0,053

0,058

0,058

0,055

0,058

zro

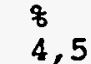

4,54

5,01

5,01

4,58

4,99

5,04

4,84

4,91

4,95

4,82

4,95

4,95

4,93

$\begin{array}{cc}\text { Rh203 } & \text { Ru203 } \\ 8 & 8 \\ 0,045 & 0,169 \\ 0,030 & 0,118 \\ 0,025 & 0,088 \\ 0,045 & 0,176 \\ 0,032 & 0,132 \\ 0,030 & 0,119 \\ 0,035 & 0,119 \\ 0,027 & 0,089 \\ 0,028 & 0,097 \\ 0,032 & 0,118 \\ 0,033 & 0,120 \\ 0,032 & 0,113 \\ 0,035 & 0,120\end{array}$

MoO2

\&

0,17

0,18

0,18

0,18

0,18

0,18

0,18

0,18

0,18

0,18

0,18

0,18 


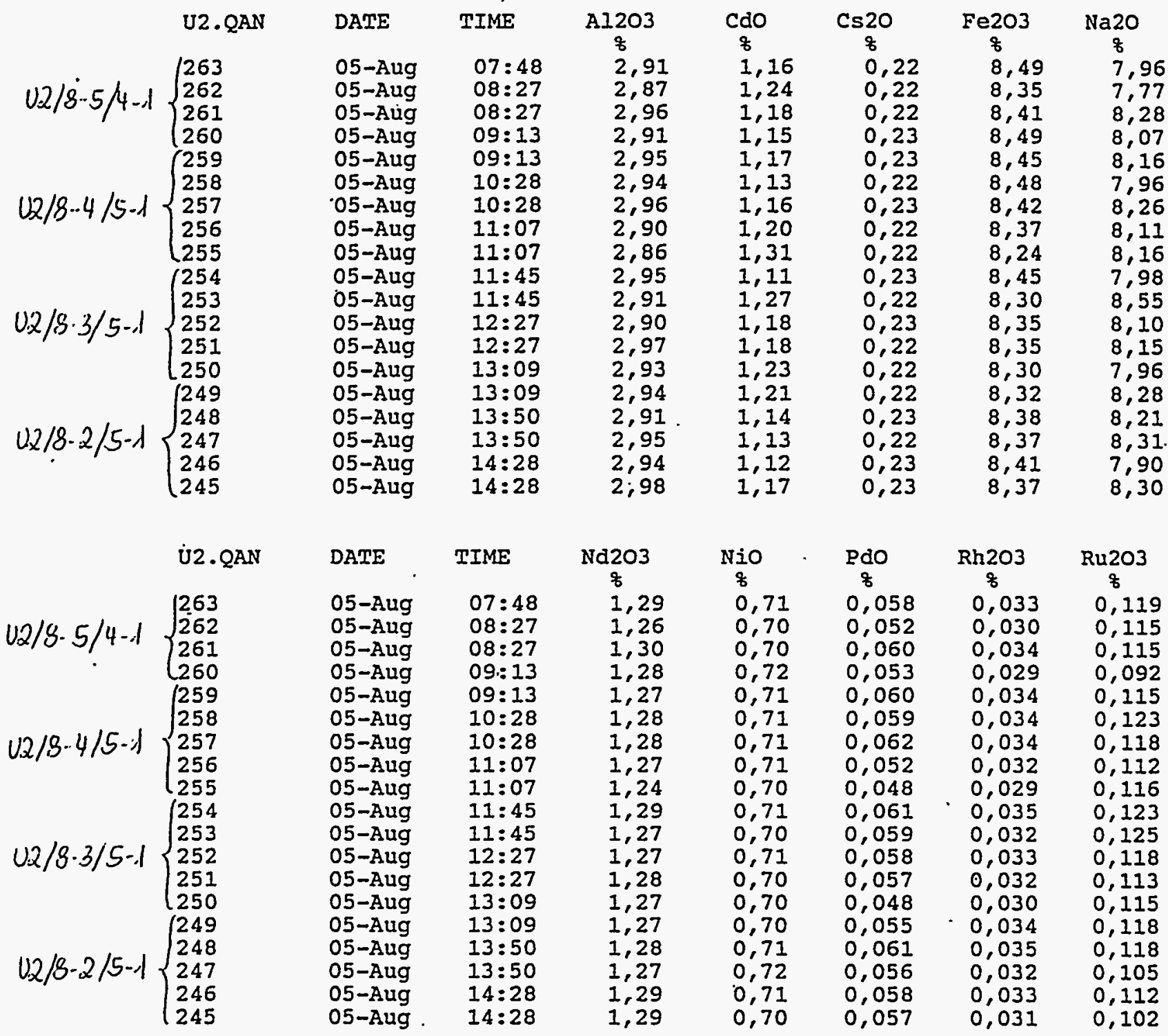

\begin{tabular}{|c|c|c|c|c|c|c|c|}
\hline $\begin{array}{l}02 / 8 \cdot 3 / 5 \\
02 / 5-2 / 5\end{array}$ & $\begin{array}{l}\text { U2.QAN } \\
\left\{\begin{array}{l}263 \\
262 \\
261 \\
260\end{array}\right. \\
\left\{\begin{array}{l}259 \\
258 \\
257 \\
256 \\
255\end{array}\right. \\
\left\{\begin{array}{l}254 \\
253 \\
252 \\
251 \\
250\end{array}\right. \\
\left\{\begin{array}{l}249 \\
248 \\
247 \\
246 . \\
245\end{array}\right.\end{array}$ & $\begin{array}{l}\text { DATE } \\
\text { 05-Aug } \\
\text { 05-Aug } \\
\text { 05-Aug } \\
\text { 05-Aug } \\
\text { 05-Aug } \\
\text { 05-Aug } \\
\text { 05-Aug } \\
\text { 05-Aug } \\
\text { 05-Aug } \\
\text { 05-Aug } \\
\text { 05-Aug } \\
\text { 05-Aug } \\
\text { 05-Aug } \\
\text { 05-Aug } \\
\text { 05-Aug } \\
\text { 05-Aug } \\
\text { 05-Aug } \\
\text { 05-Aug } \\
\text { 05-Aug }\end{array}$ & $\begin{array}{l}\text { TIME } \\
07: 48 \\
08: 27 \\
08: 27 \\
09: 13 \\
09: 13 \\
10: 28 \\
10: 28 \\
11: 07 \\
11: 07 \\
11: 45 \\
11: 45 \\
12: 27 \\
12: 27 \\
13: 09 \\
13: 09 \\
13: 50 \\
13: 50 \\
14: 28 \\
14: 28\end{array}$ & $\begin{array}{c}\text { SiO2 } \\
8 \\
51,05 \\
50,49 \\
51,04 \\
51,17 \\
51,04 \\
51,34 \\
51,15 \\
50,77 \\
49,57 \\
51,55 \\
50,03 \\
51,09 \\
51,05 \\
50,61 \\
50,77 \\
51,46 \\
51,38 \\
51,55 \\
51,14\end{array}$ & $\begin{array}{c}\text { TeO2 } \\
8 \\
0,041 \\
0,039 \\
0,039 \\
0,039 \\
0,039 \\
0,041 \\
0,039 \\
0,040 \\
0,038 \\
0,041 \\
0,039 \\
0,040 \\
0,039 \\
0,039 \\
0,039 \\
0,041 \\
0,038 \\
0,040 \\
0,039\end{array}$ & $\begin{array}{c}\text { ZrO2 } \\
8 \\
4,89 \\
4,99 \\
4,99 \\
4,91 \\
4,88 \\
4,91 \\
4,86 \\
4,89 \\
4,96 \\
5,10 \\
4,82 \\
5,05 \\
4,94 \\
4,93 \\
5,00 \\
4,98 \\
4,88 \\
4,88 \\
4,85 \\
4,92\end{array}$ & $\begin{array}{c}\mathrm{MOO2} \\
8 \\
0,18 \\
0,18 \\
0,18 \\
0,18 \\
0,18 \\
0,18 \\
0,18 \\
0,18 \\
0,18 \\
0,18 \\
0,18 \\
0,18 \\
0,18 \\
0,18 \\
0,18 \\
0,18 \\
0,18 \\
0,18 \\
0,18\end{array}$ \\
\hline
\end{tabular}




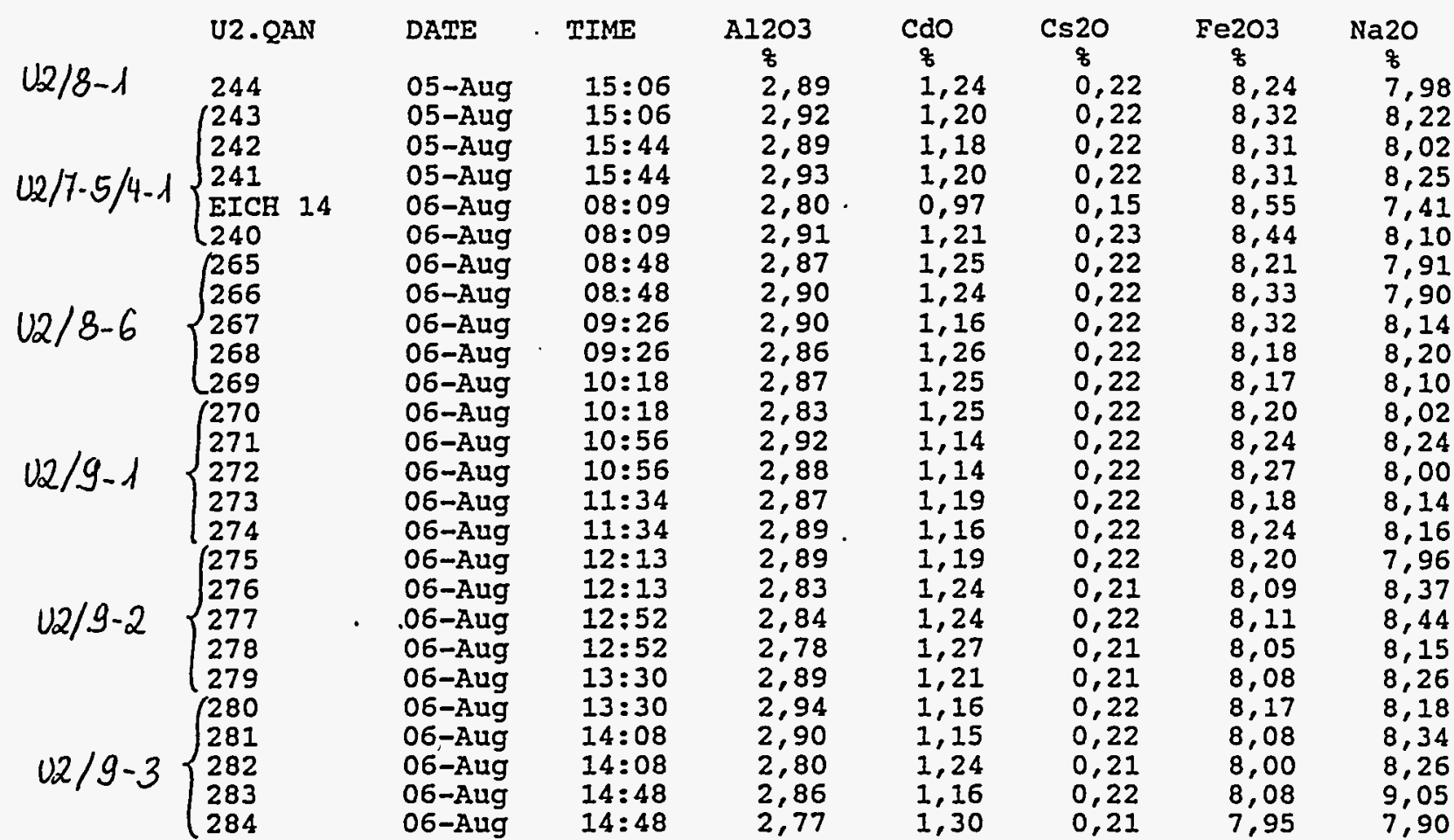

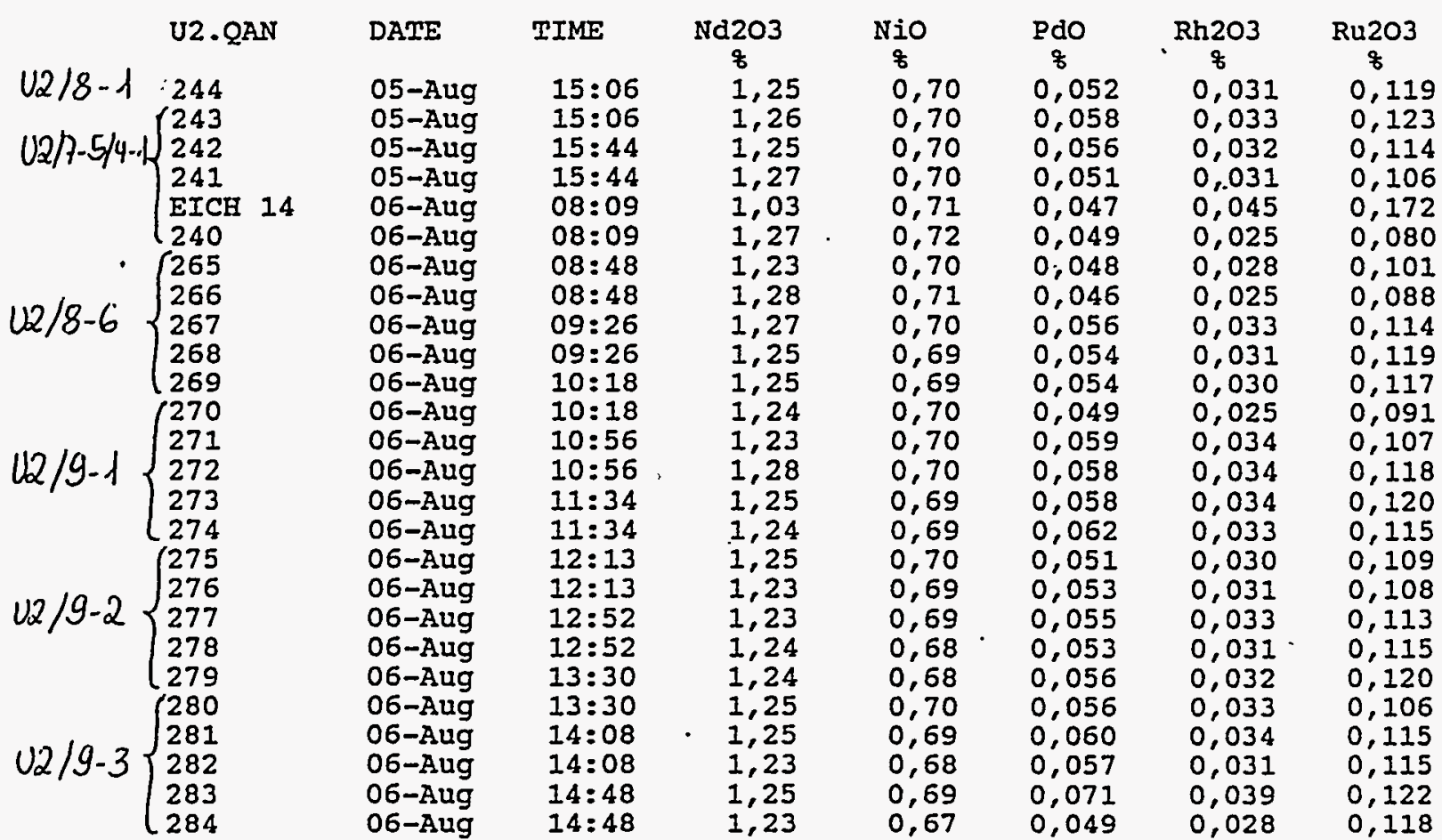




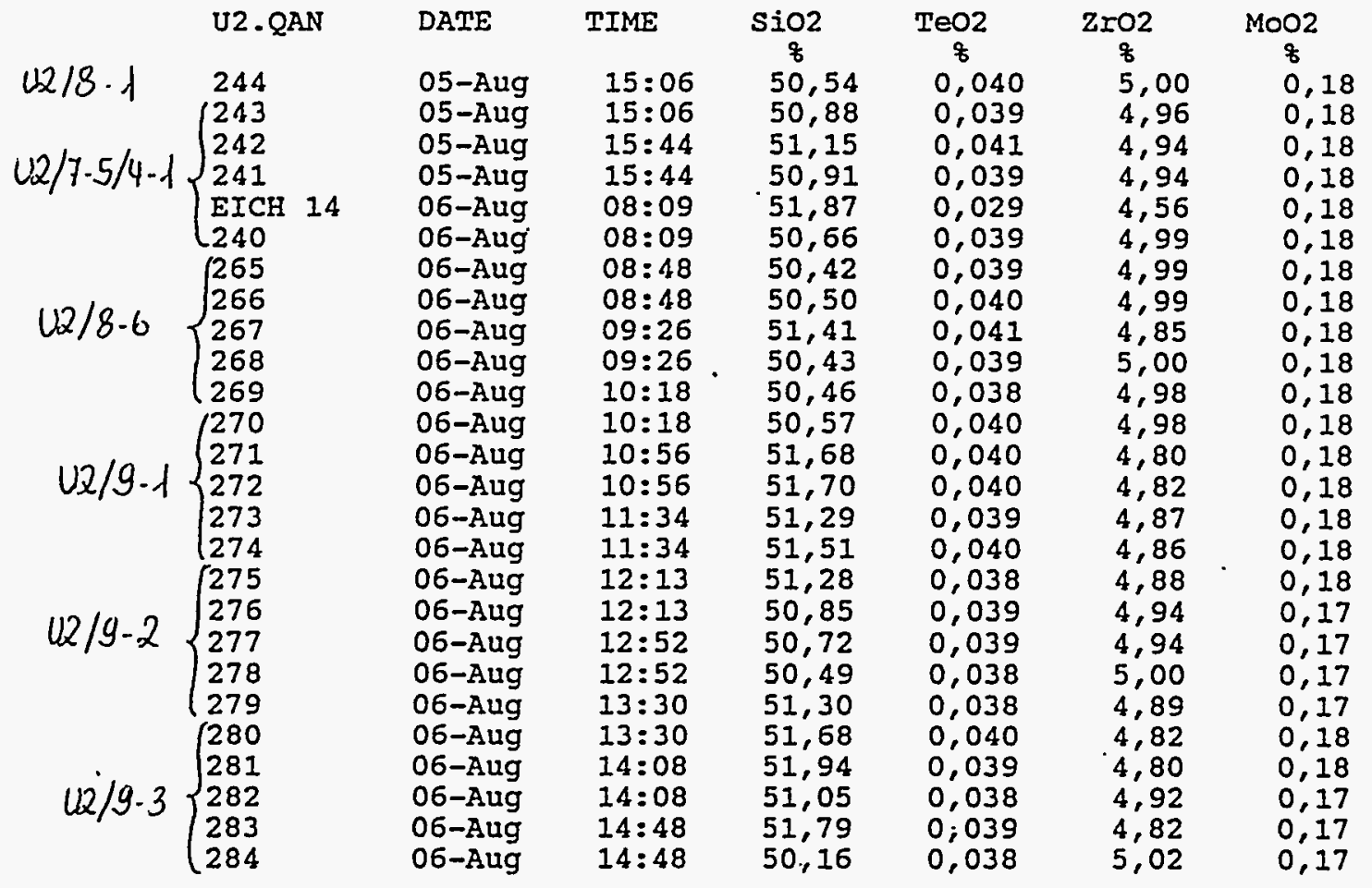




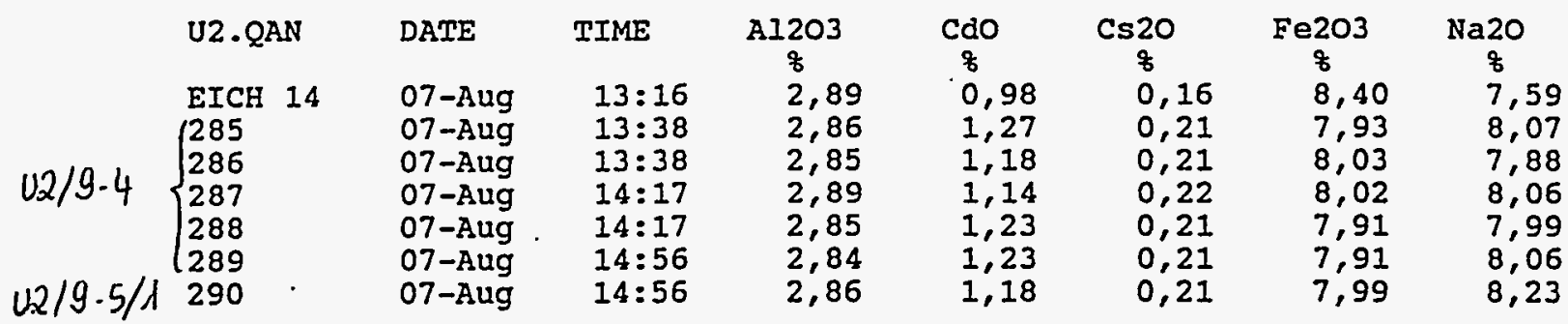

\begin{tabular}{|c|c|c|c|c|c|c|c|c|}
\hline & U2.QAN & DATE & TIME & $\mathrm{Nd2O}$ & & Pdo & $\mathrm{Rh} 203$ & Ru203 \\
\hline $\begin{array}{l}12 / 9-4 \\
(12 / 9.5 /\end{array}$ & $\begin{array}{l}\text { EICH } 14 \\
\left\{\begin{array}{l}285 \\
286 \\
287 \\
288 \\
289 \\
290\end{array}\right.\end{array}$ & $\begin{array}{l}\text { 07-Aug } \\
\text { 07-Aug } \\
07 \text {-Aug } \\
07 \text {-Aug } \\
\text { 07-Aug } \\
\text { 07-Aug } \\
07 \text {-Aug }\end{array}$ & $\begin{array}{l}13: 16 \\
13: 38 \\
13: 38 \\
14: 17 \\
14: 17 \\
14: 56 \\
14: 56\end{array}$ & $\begin{array}{l}1,03 \\
1,21 \\
1,25 \\
1,24 \\
1,22 \\
1,21 \\
1,22\end{array}$ & $\begin{array}{l}0,71 \\
0,68 \\
0,69 \\
0,69 \\
0,67 \\
0,67 \\
0,68\end{array}$ & $\begin{array}{l}0,046 \\
0,047 \\
0,052 \\
0,058 \\
0,054 \\
0,055 \\
0,054\end{array}$ & $\begin{array}{l}0,045 \\
0,027 \\
0,029 \\
0,033 \\
0,031 \\
0,030 \\
0,030\end{array}$ & $\begin{array}{l}0,164 \\
0,102 \\
0,106 \\
0,119 \\
0,117 \\
0,118 \\
0,101\end{array}$ \\
\hline
\end{tabular}

$\begin{array}{lllcccc}\text { U2.QAN } & \text { DATE } & \text { TIME } & \text { SiO2 } & \text { TeO2 } & \text { ZrO2 } & \text { MOO2 } \\ \text { U2/9-4 } & & & 8 & 8 & 8 & 8 \\ \text { EICH } 14 & \text { 07-Aug } & 13: 16 & 52,15 & 0,043 & 4,56 & 0,18 \\ 285 & \text { O7-Aug } & 13: 38 & 50,56 & 0,038 & 4,95 & 0,17 \\ 286 & \text { O7-Aug } & 13: 38 & 51,75 & 0,040 & 4,84 & 0,18 \\ 287 & \text { O7-Aug } & 14: 17 & 52,17 & 0,038 & 4,75 & 0,17 \\ 288 & \text { O7-Aug } & 14: 17 & 51,22 & 0,040 & 4,90 & 0,17 \\ 289 & \text { O7-Aug } & 14: 56 & 51,21 & 0,038 & 4,90 & 0,17 \\ \text { U2/9.5/.1 } 290 & \text { 07-Aug } & 14: 56 & 51,74 & 0,040 & 4,83 & 0,17\end{array}$




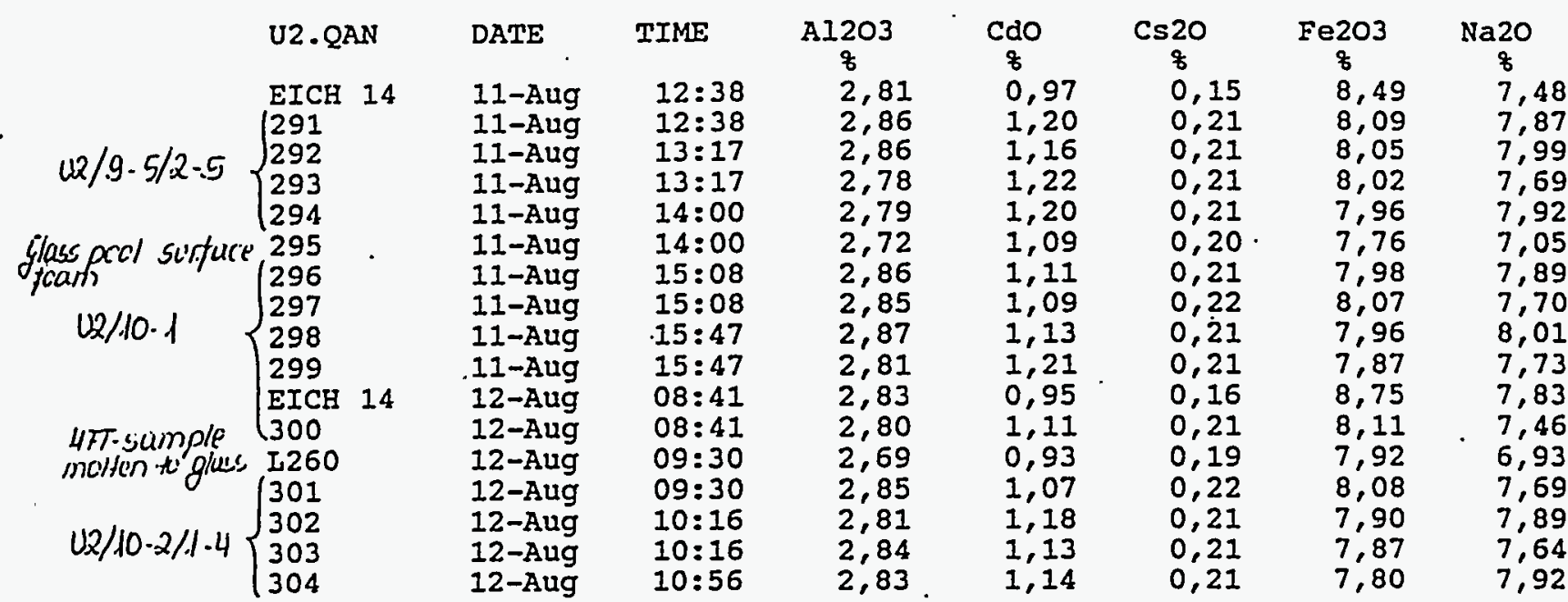

\begin{tabular}{|c|c|c|c|c|c|c|c|c|}
\hline $\begin{array}{l}02 / 9-5 / 2-5 \\
\text { qlasc pcol } \\
\text { quiface foum } \\
u_{2} / 10-1 \\
41 F T \text {-sumple } \\
\text { melten /a glass } \\
\text { U2/10-2/1-4 }\end{array}$ & 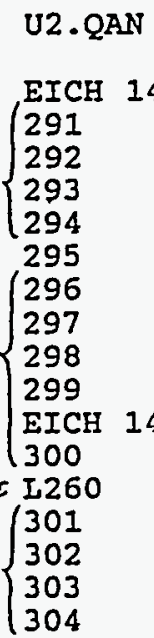 & $\begin{array}{l}\text { DATE } \\
\text { 11-Aug } \\
\text { 11-Aug } \\
11-\text { Aug } \\
11-\text { Aug } \\
11-\text { Aug } \\
11-\text { Aug } \\
11-\text { Aug } \\
11-\text { Aug } \\
11-\text { Aug } \\
11-\text { Aug } \\
12-\text { Aug } \\
12-\text { Aug } \\
12-\text { Aug } \\
12-\text { Aug } \\
12-\text { Aug } \\
12-\text { Aug } \\
12-\text { Aug }\end{array}$ & $\begin{array}{l}\text { TIME } \\
12: 38 \\
12: 38 \\
13: 17 \\
13: 17 \\
14: 00 \\
14: 00 \\
15: 08 \\
15: 08 \\
15: 47 \\
15: 47 \\
08: 41 \\
08: 41 \\
09: 30 \\
09: 30 \\
10: 16 \\
10: 16 \\
10: 56\end{array}$ & $\begin{array}{c}\mathrm{Nd20} \\
\mathrm{q} \\
1,03 \\
1,24 \\
1,24 \\
1,21 \\
1,21 \\
1,19 \\
1,21 \\
1,23 \\
1,21 \\
1,19 \\
1,07 \\
1,23 \\
1,20 \\
1,24 \\
1,22 \\
1,23 \\
1,22\end{array}$ & $\begin{array}{l}\text { Nio } \\
8 \\
0,71 \\
0,69 \\
0,68 \\
0,68 \\
0,68 \\
0,65 \\
0,68 \\
0,69 \\
0,68 \\
0,67 \\
0,67 \\
0,68 \\
0,66 \\
0,70 \\
0,67 \\
0,67 \\
0,67\end{array}$ & $\begin{array}{l}\text { Pdo } \\
8 \\
0,047 \\
0,053 \\
0,056 \\
0,050 \\
0,054 \\
0,053 \\
0,056 \\
0,054 \\
0,058 \\
0,051 \\
0,055 \\
0,055 \\
0,024 \\
0,053 \\
0,053 \\
0,054 \\
0,057\end{array}$ & $\begin{array}{c}\text { Rh203 } \\
8 \\
0,045 \\
0,029 \\
0,033 \\
0,029 \\
0,032 \\
0,030 \\
0,031 \\
0,030 \\
0,034 \\
0,030 \\
0,052 \\
0,033 \\
0,026 \\
0,032 \\
0,031 \\
0,032 \\
0,032\end{array}$ & $\begin{array}{c}\text { Ru203 } \\
8 \\
0,171 \\
0,112 \\
0,118 \\
0,121 \\
0,118 \\
0,129 \\
0,102 \\
0,098 \\
0,117 \\
0,121 \\
0,174 \\
0,117 \\
0,102 \\
0,108 \\
0,101 \\
0,120 \\
0,120\end{array}$ \\
\hline
\end{tabular}

\begin{tabular}{|c|c|c|c|c|c|c|c|}
\hline 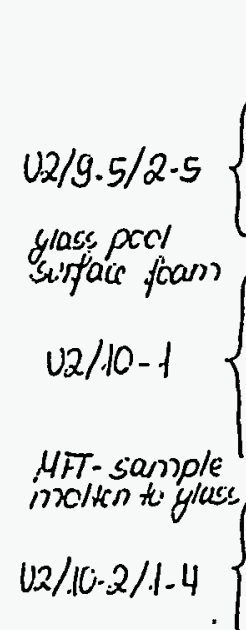 & $\begin{array}{l}\text { U2.QAN } \\
\begin{array}{l}\text { EICH } 14 \\
291 \\
292 \\
293 \\
294 \\
295 \\
296 \\
297 \\
298 \\
299 \\
\text { EICH } \\
300 \\
1260\end{array} \\
\left\{\begin{array}{l}1261 \\
302 \\
303 \\
304\end{array}\right.\end{array}$ & $\begin{array}{l}\text { DATE } \\
\text { 11-Aug } \\
11 \text {-Aug } \\
\text { 11-Aug } \\
\text { 11-Aug } \\
11-\text { Aug } \\
11-\text { Aug } \\
11 \text {-Aug } \\
11 \text {-Aug } \\
11 \text {-Aug } \\
11 \text {-Aug } \\
12 \text {-Aug } \\
12-\text { Aug } \\
12-\text { Aug } \\
12-\text { Aug } \\
12 \text {-Aug } \\
12 \text {-Aug } \\
12 \text {-Aug }\end{array}$ & $\begin{array}{l}\text { TIME } \\
12: 38 \\
12: 38 \\
13: 17 \\
13: 17 \\
14: 00 \\
14: 00 \\
15: 08 \\
15: 08 \\
15: 47 \\
15: 47 \\
08: 41 \\
08: 41 \\
09: 30 \\
09: 30 \\
10: 16 \\
10: 16 \\
10: 56\end{array}$ & $\begin{array}{c}\text { SiO2 } \\
8 \\
51,99 \\
51,38 \\
51,90 \\
51,33 \\
51,54 \\
53,14 \\
52,43 \\
52,43 \\
52,32 \\
51,63 \\
51,50 \\
52,28 \\
53,38 . \\
52,60 \\
51,92 \\
52,52 \\
52,55\end{array}$ & $\begin{array}{c}\text { TeO2 } \\
8 \\
0,028 \\
0,039 \\
0,038 \\
0,041 \\
0,038 \\
0,039 \\
0,039 \\
0,040 \\
0,039 \\
0,039 \\
0,028 \\
0,039 \\
0,032 \\
0,039 \\
0,038 \\
0,039 \\
0,038\end{array}$ & $\begin{array}{c}\text { ZrO2 } \\
8 \\
4,56 \\
4,88 \\
4,79 \\
4,90 \\
4,86 \\
4,58 \\
4,70 \\
4,70 \\
4,73 \\
4,85 \\
4,56 \\
4,74 \\
4,38 \\
4,67 \\
4,83 \\
4,72 \\
4,75\end{array}$ & $\begin{array}{c}\mathrm{MOO2} \\
8 \\
0,18 \\
0,18 \\
0,17 \\
0,18 \\
0,17 \\
0,17 \\
0,17 \\
0,17 \\
0,17 \\
0,17 \\
0,18 \\
0,18 \\
0,17 \\
0,18 \\
0,17 \\
0,17 \\
0,17\end{array}$ \\
\hline
\end{tabular}




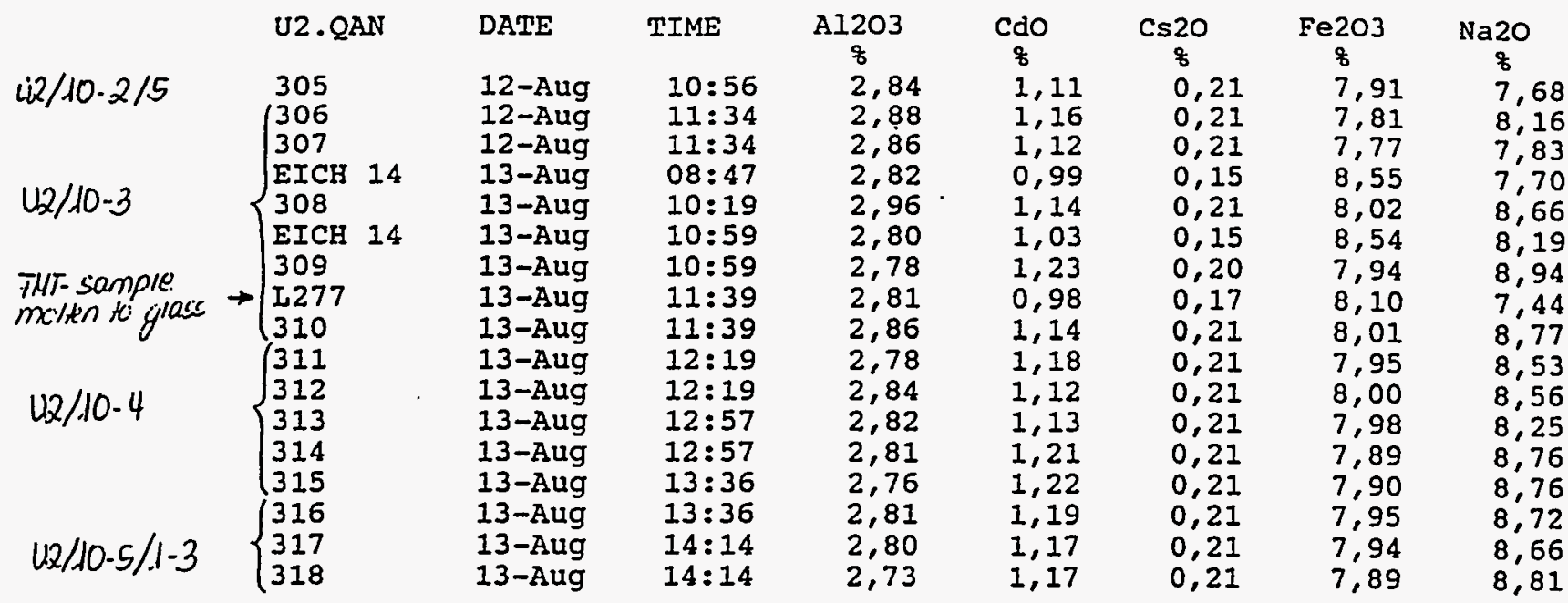

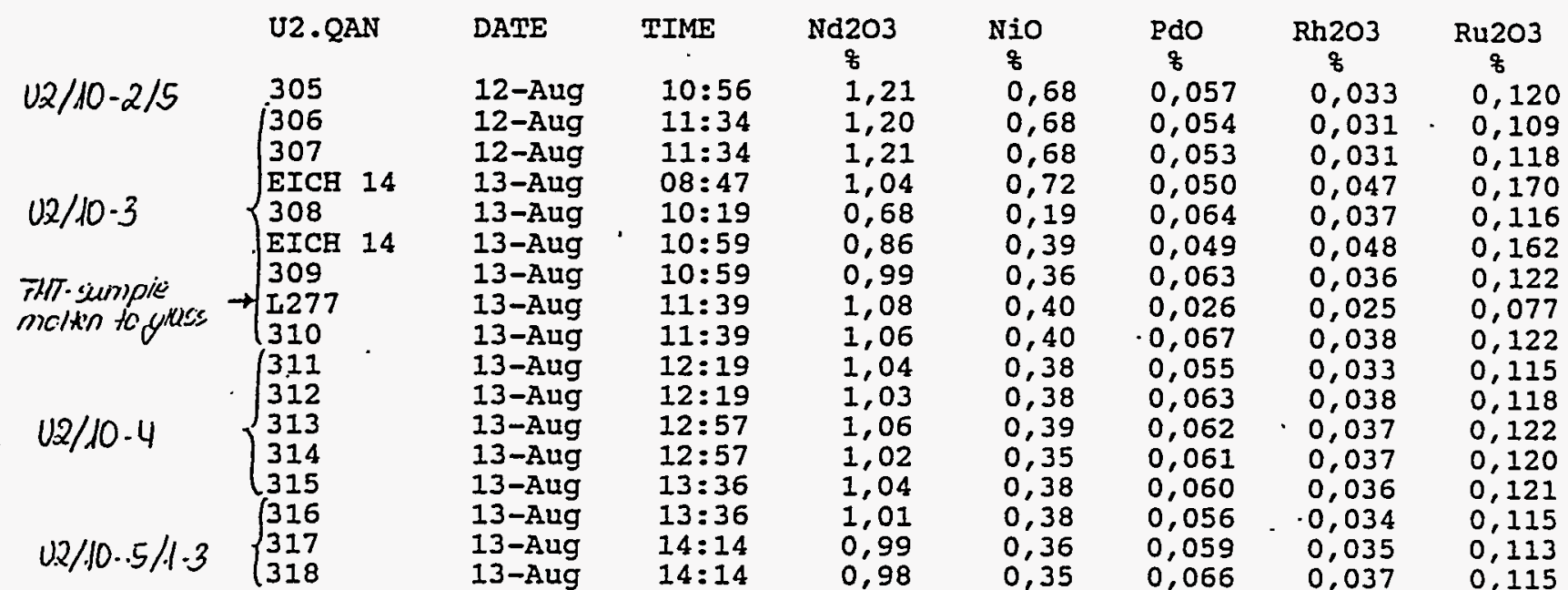

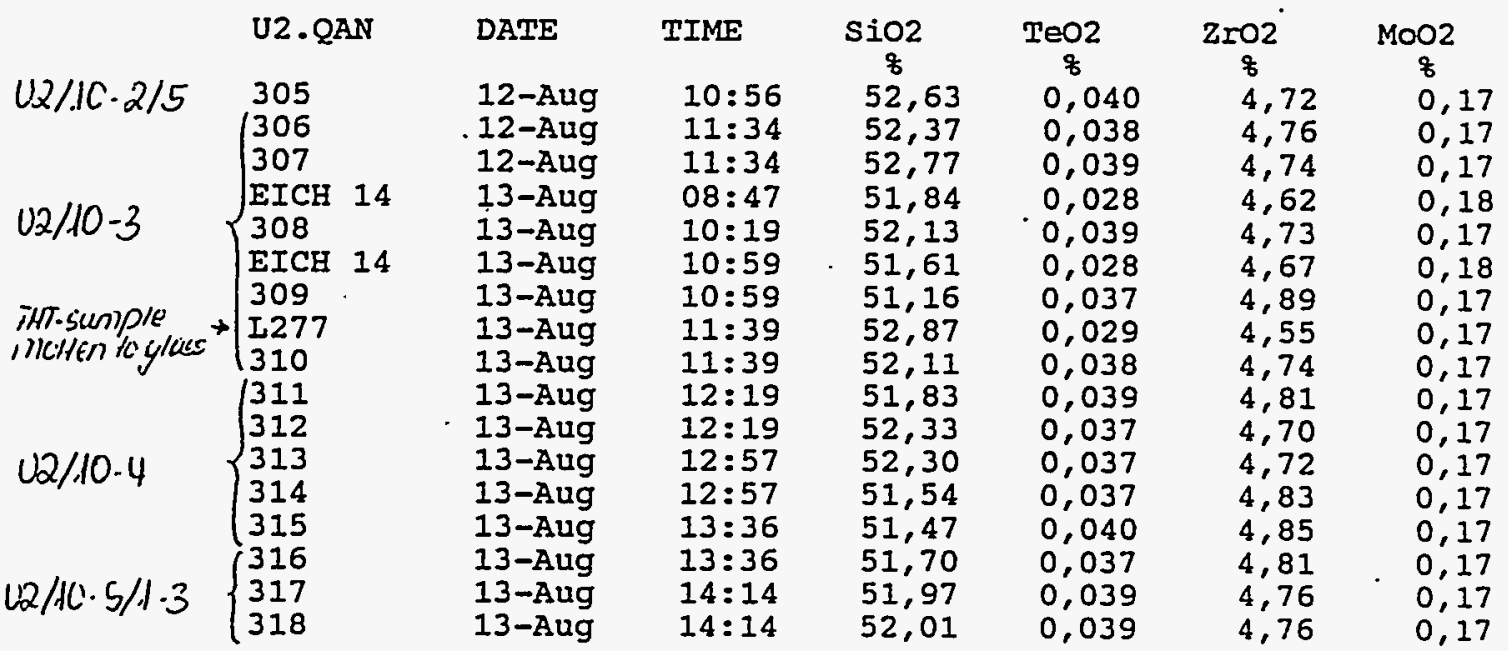




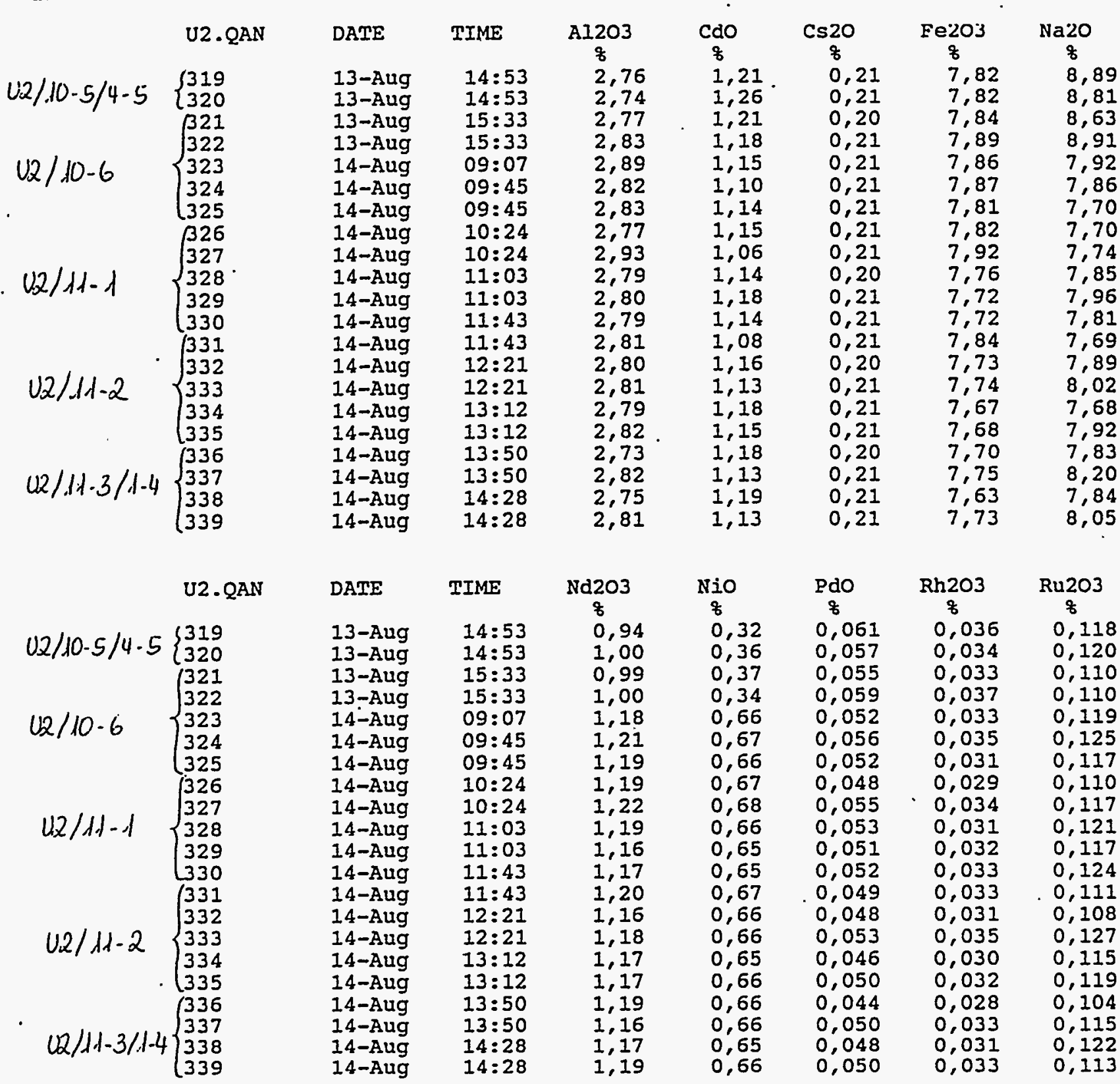

\begin{tabular}{|c|c|c|c|c|c|c|c|}
\hline & U2. QAN & DATE & TIME & $\underset{z}{\operatorname{SiO} 2}$ & $\underset{8}{\mathrm{TeO} 2}$ & $\underset{8}{\operatorname{ZrO}_{6}}$ & $\underset{8}{\mathrm{MOO} 2}$ \\
\hline $02 / 10.5 / 4.5$ & $\left\{\begin{array}{l}319 \\
320\end{array}\right.$ & $\begin{array}{l}\text { 13-Aug } \\
13 \text {-Aug }\end{array}$ & $\begin{array}{l}14: 53 \\
14: 53\end{array}$ & $\begin{array}{l}51,68 \\
51,05\end{array}$ & $\begin{array}{l}0,038 \\
0,037\end{array}$ & $\begin{array}{l}4,82 \\
4,89\end{array}$ & $\begin{array}{l}0,17 \\
0,17\end{array}$ \\
\hline & 1321 & 13-Aug & $15: 33$ & 51,67 & 0,036 & 4,81 & 0,17 \\
\hline 0. & 322 & 13-Aug & $15: 33$ & 51,93 & 0,037 & 4,77 & 0,17 \\
\hline D. & 323 & 14-Aug & $\begin{array}{l}09: 07 \\
09: 45\end{array}$ & 52,34 & $\begin{array}{l}0,037 \\
0,040\end{array}$ & $\begin{array}{l}4,74 \\
4.64\end{array}$ & $\begin{array}{l}0,17 \\
0,17\end{array}$ \\
\hline & $\left\lfloor\begin{array}{l}224 \\
325\end{array}\right.$ & $\begin{array}{l}\text { 14-Aug } \\
\text { I4-Aug }\end{array}$ & $09: 45$ & 52,53 & 0,037 & 4,71 & 0,17 \\
\hline & 326 & $14-\mathrm{Aug}$ & $10: 24$ & & 0,038 & 4,73 & 0,17 \\
\hline & 327 & 14-Aug & $10: 24$ & 52,96 & 0,038 & 4,59 & 0,17 \\
\hline U2/H-A & 328 & $14-A u g$ & $11: 03$ & 52,65 & 0,038 & 4,70 & 0,17 \\
\hline & 329 & 14-Aug & $11: 03$ & 52,27 & 0,037 & 4,75 & 0,17 \\
\hline & $\begin{array}{l}1330 \\
1331\end{array}$ & $\begin{array}{l}14-\text { Aug } \\
14-\text { Aug }\end{array}$ & $\begin{array}{l}11: 43 \\
11: 43\end{array}$ & $\begin{array}{l}52,65 \\
53,01\end{array}$ & $\begin{array}{r}0,039 \\
0,038\end{array}$ & $\begin{array}{r}4,70 \\
4,62\end{array}$ & 0,17 \\
\hline & 332 & 14-Aug & $12: 21$ & 52,52 & 0,038 & 4,71 & 0,17 \\
\hline$U_{0}^{\circ}$ & 333 & 14-Aug & $12: 21$ & 78 & 0,038 & 4,68 & 0,17 \\
\hline & 334 & 14-Aug & & & & & 0,17 \\
\hline & 335 & 14-Aug & $13=12$ & 65 & 0,038 & 4,71 & 0,17 \\
\hline 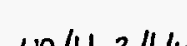 & 336 & 14-Aug & $\begin{array}{l}13: 50 \\
13: 50\end{array}$ & $\begin{array}{l}52,33 \\
52,65\end{array}$ & $\begin{array}{l}0,037 \\
0,038\end{array}$ & $\begin{array}{l}4,75 \\
4,68\end{array}$ & 0,17 \\
\hline 02/1 & 338 & $14-A u g$ & $14: 28$ & & 0,038 & & 0,17 \\
\hline & 339 & $14-A u g$ & $14: 28$. & 52,76 & 0,038 & 4, & 0,3 \\
\hline
\end{tabular}




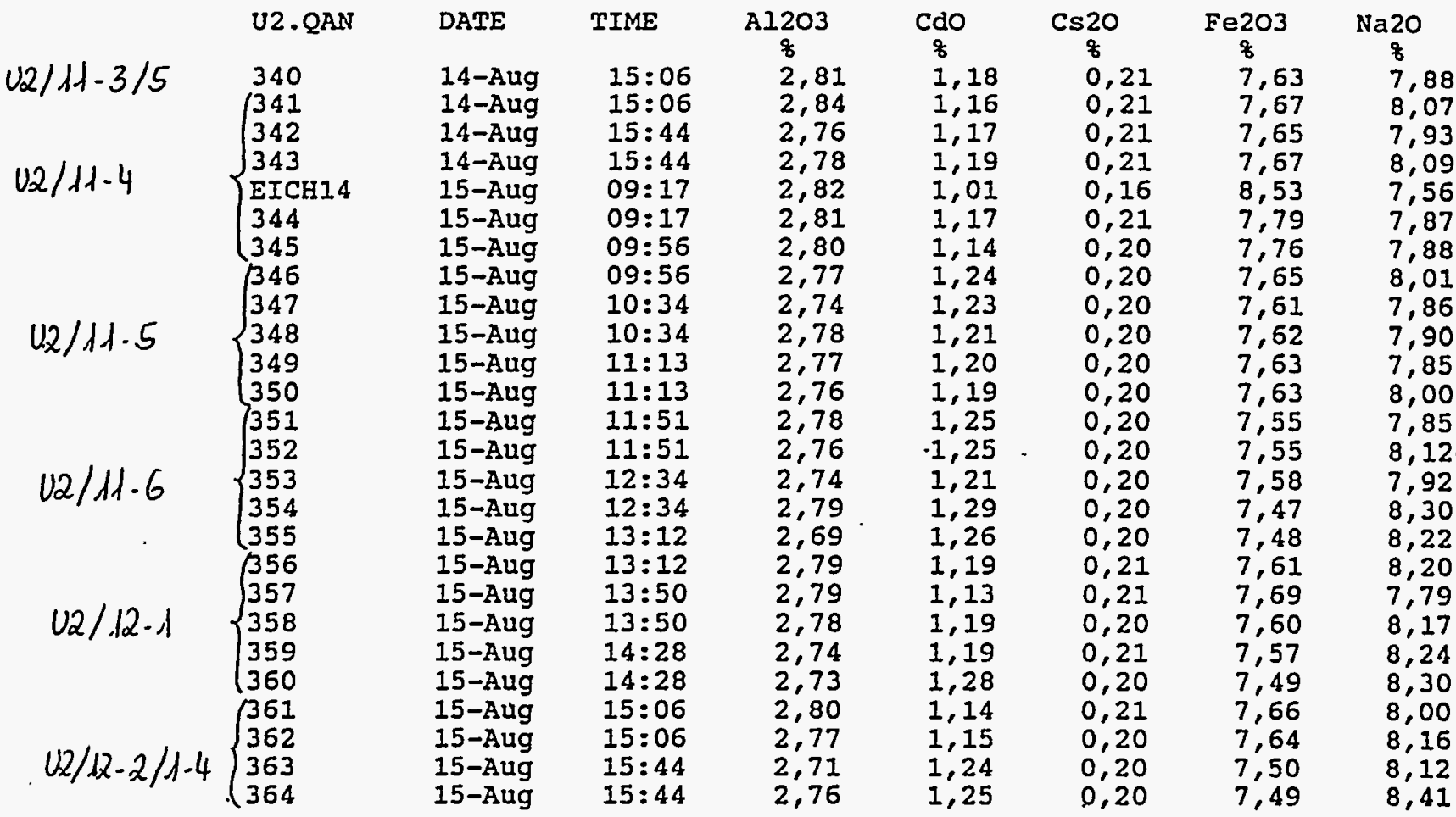

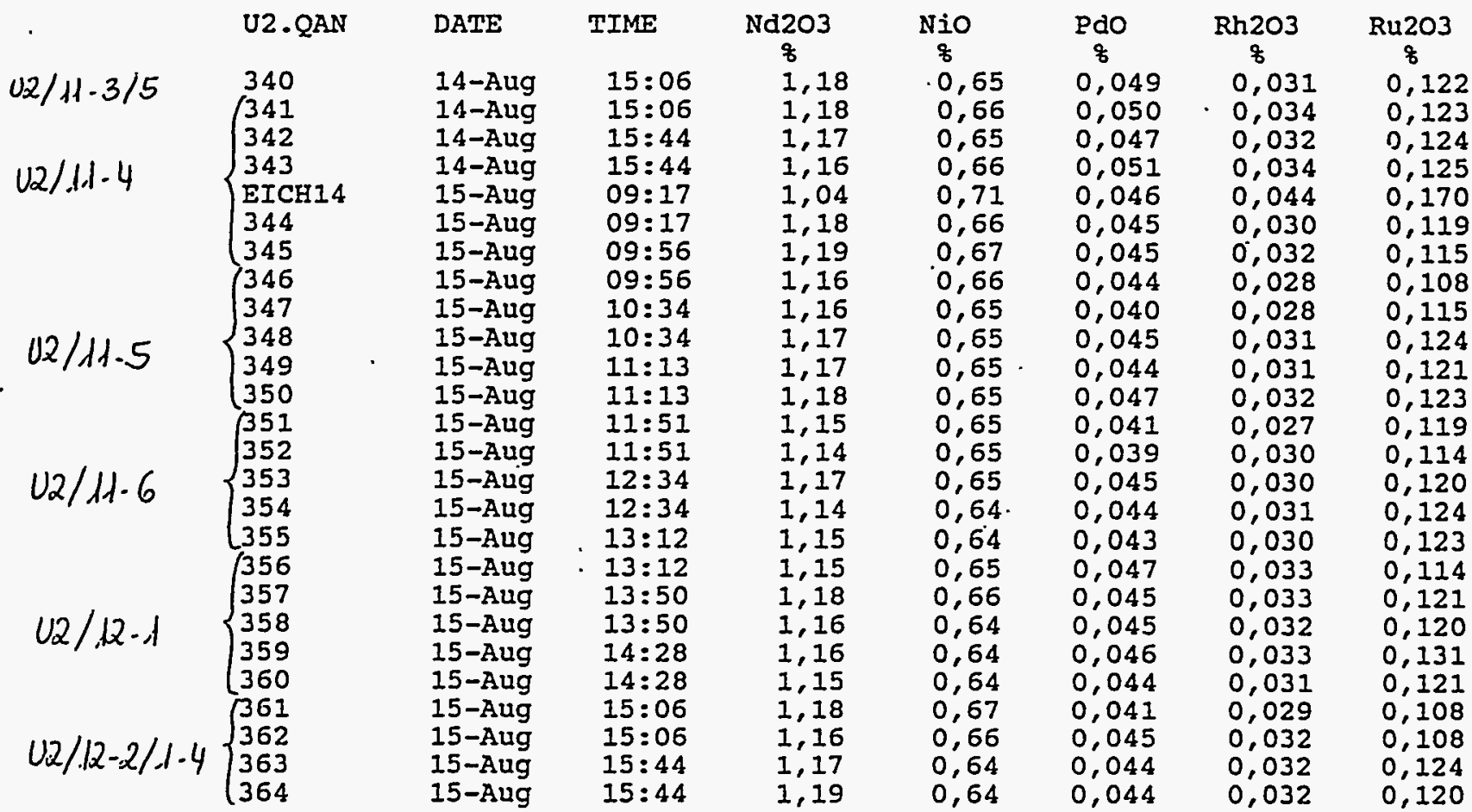




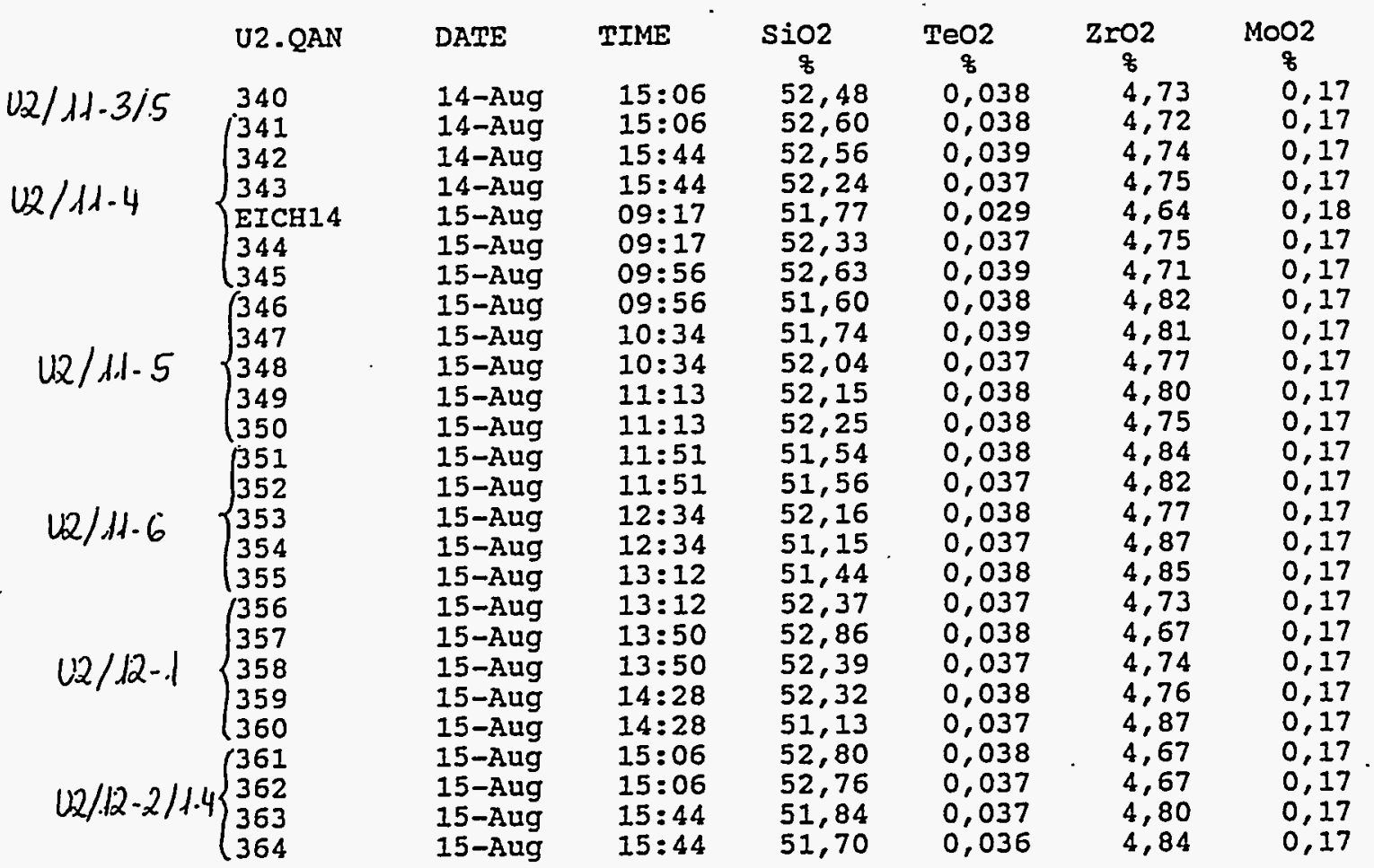




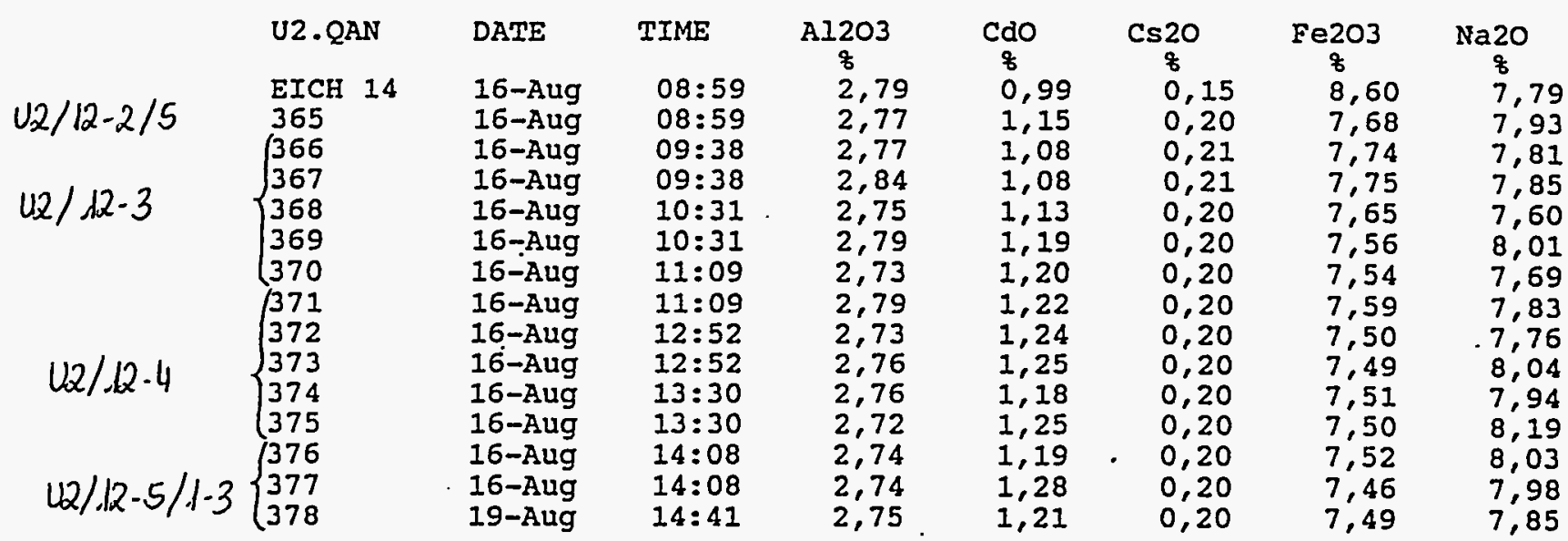

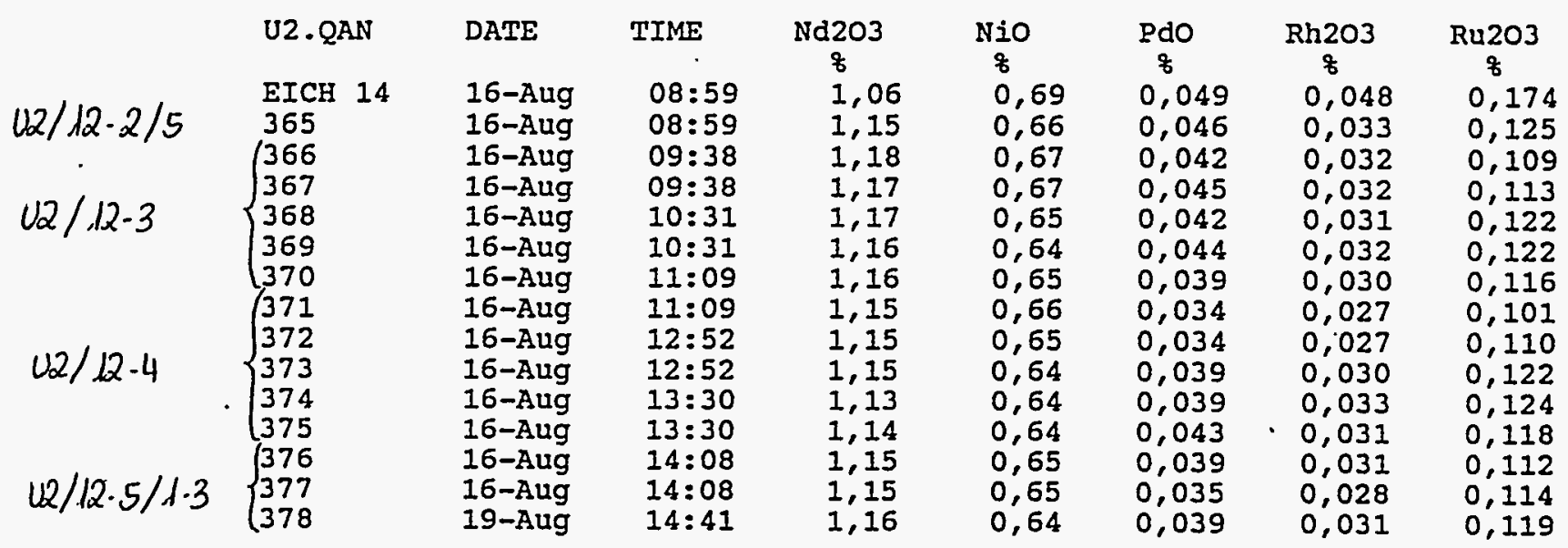

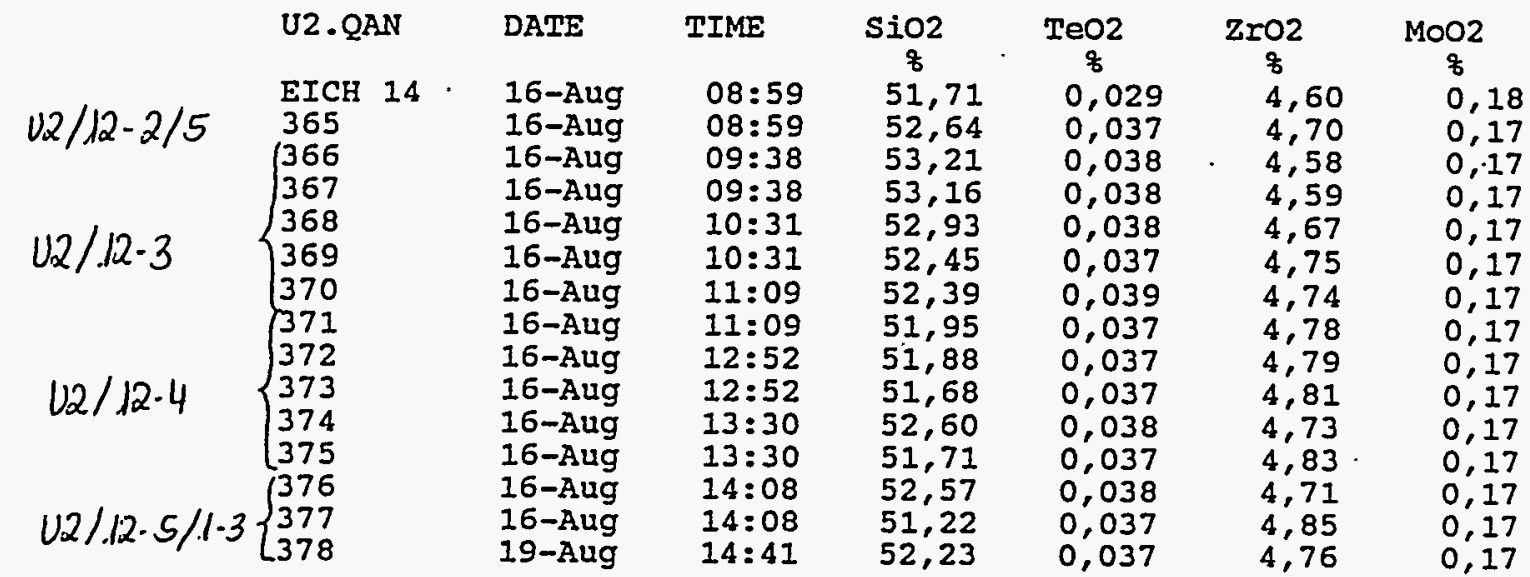




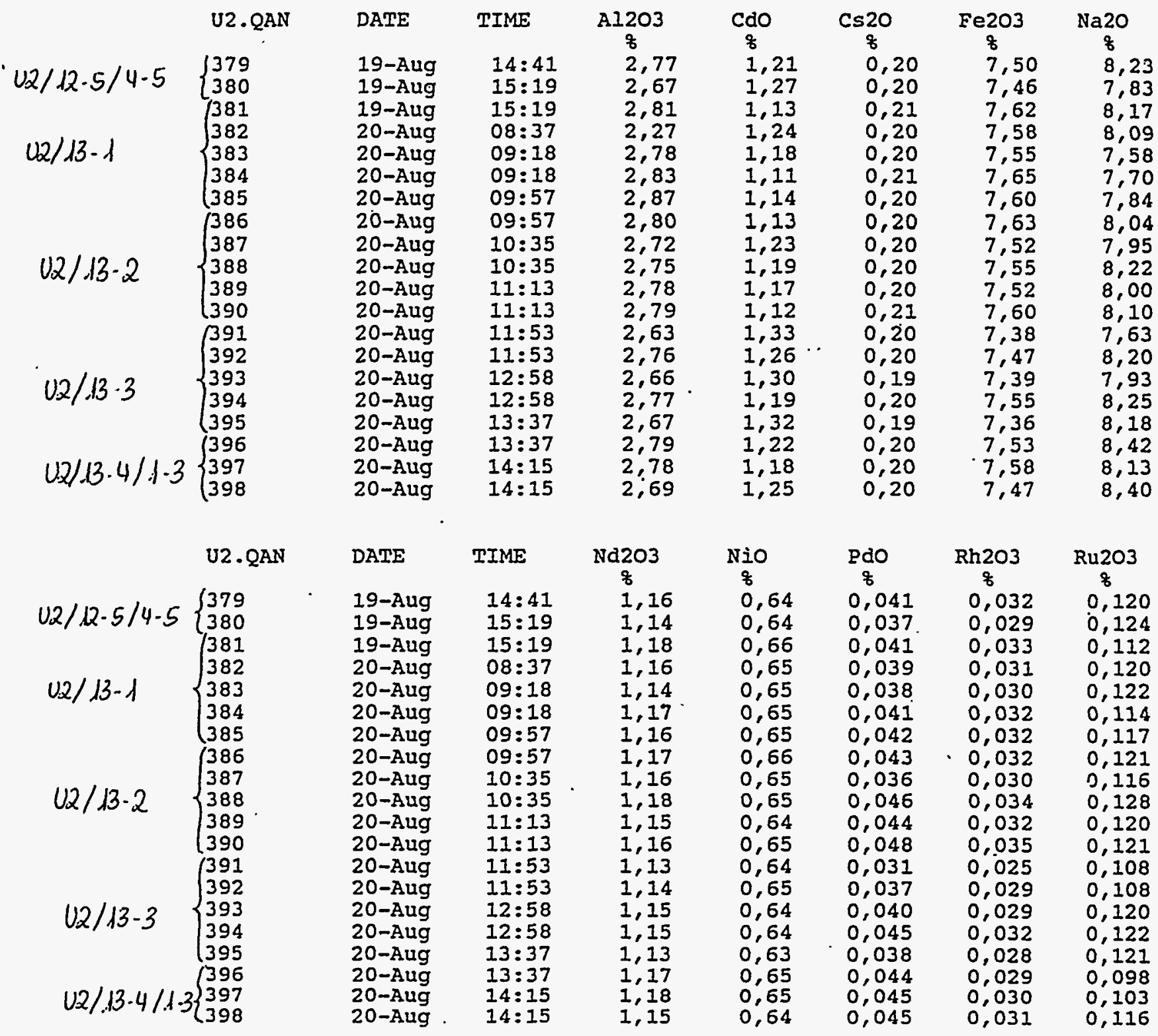




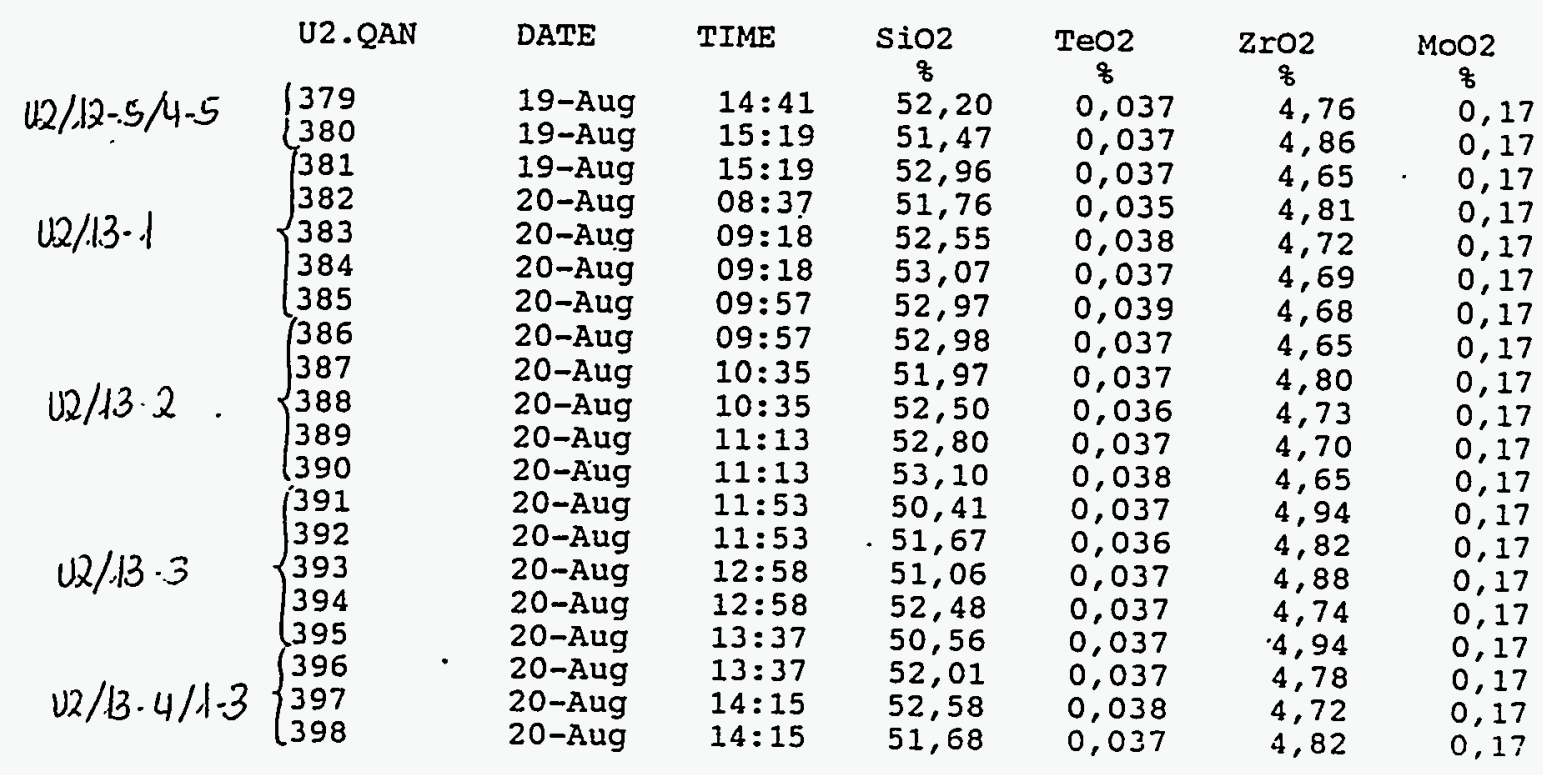




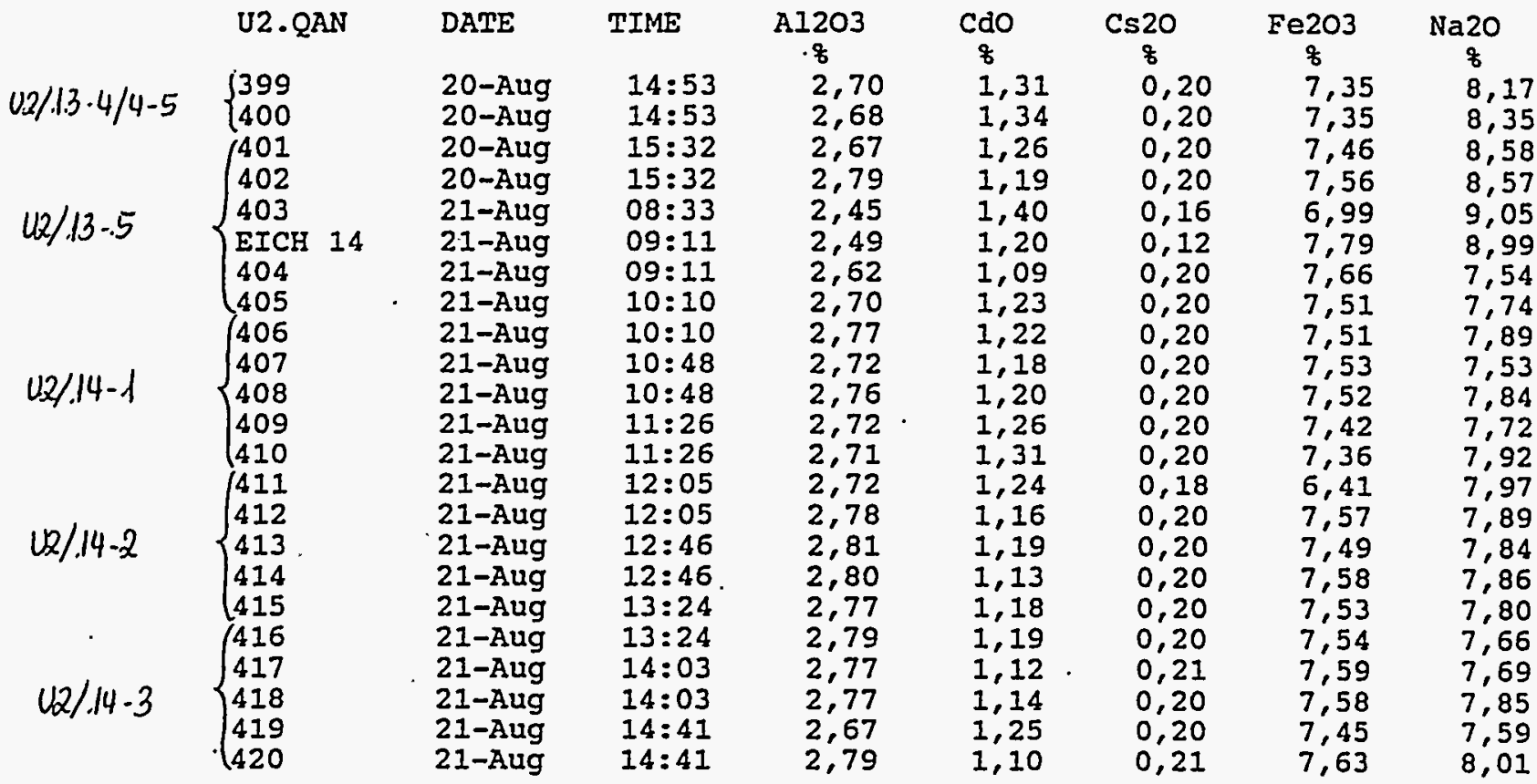

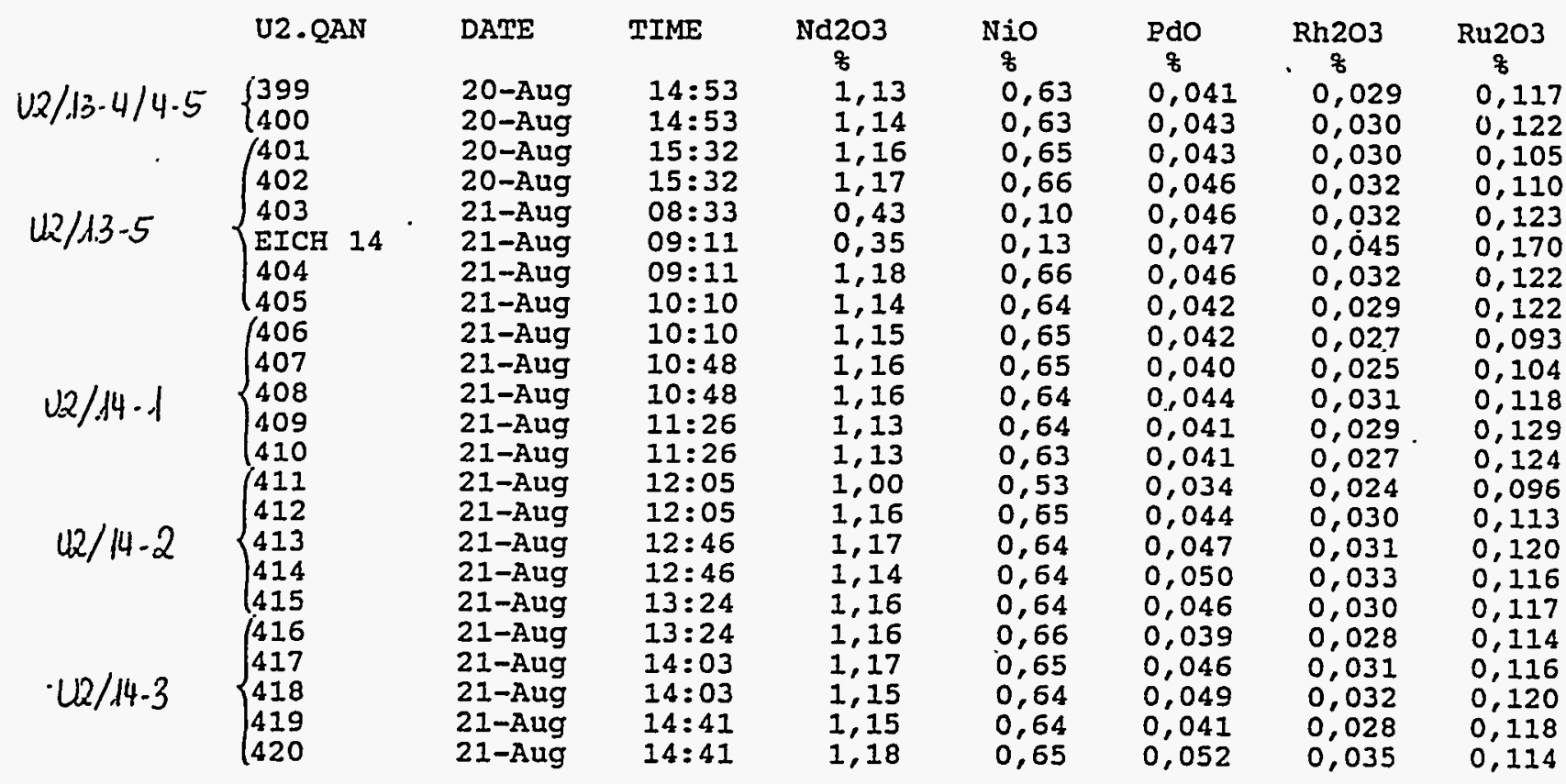




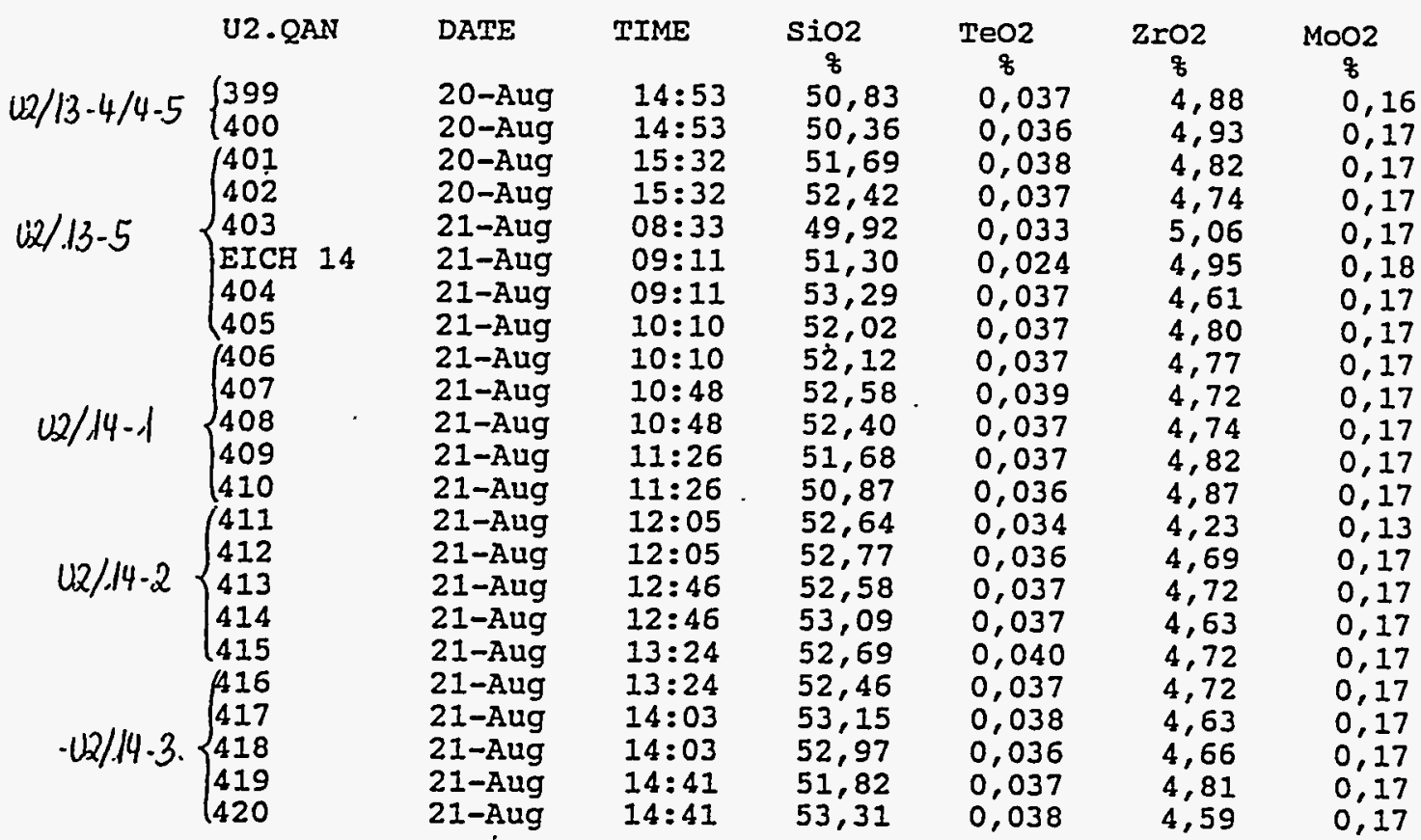




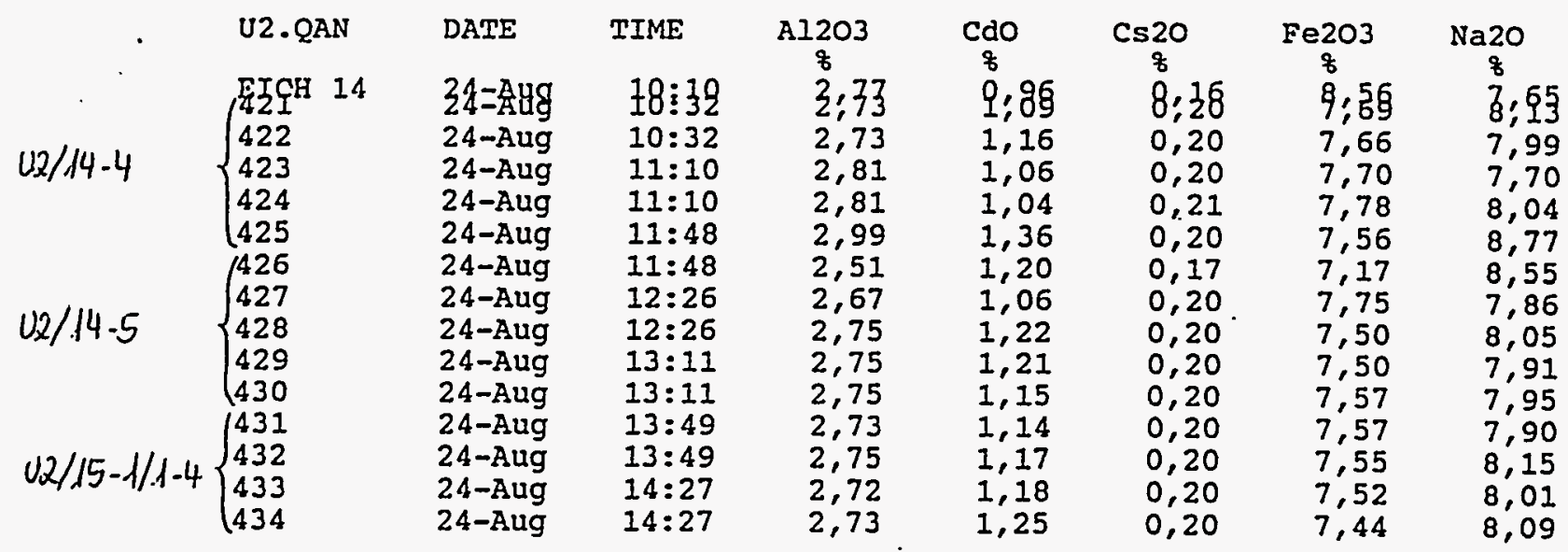

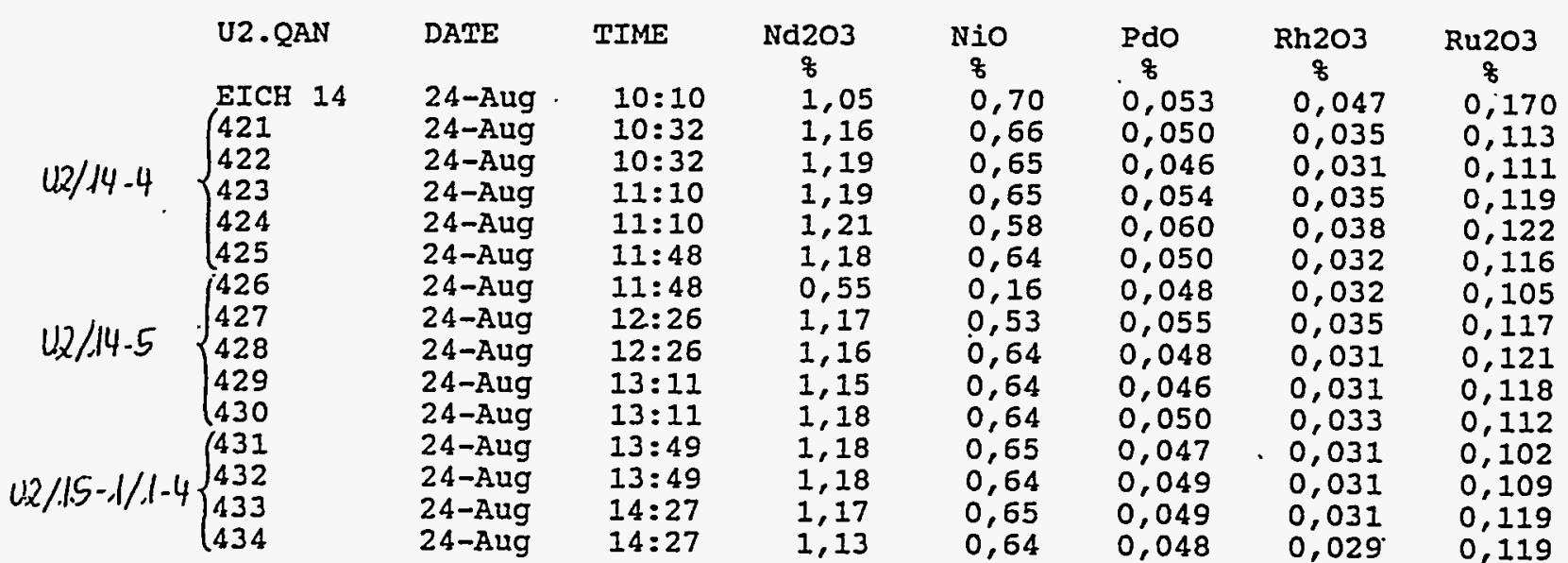

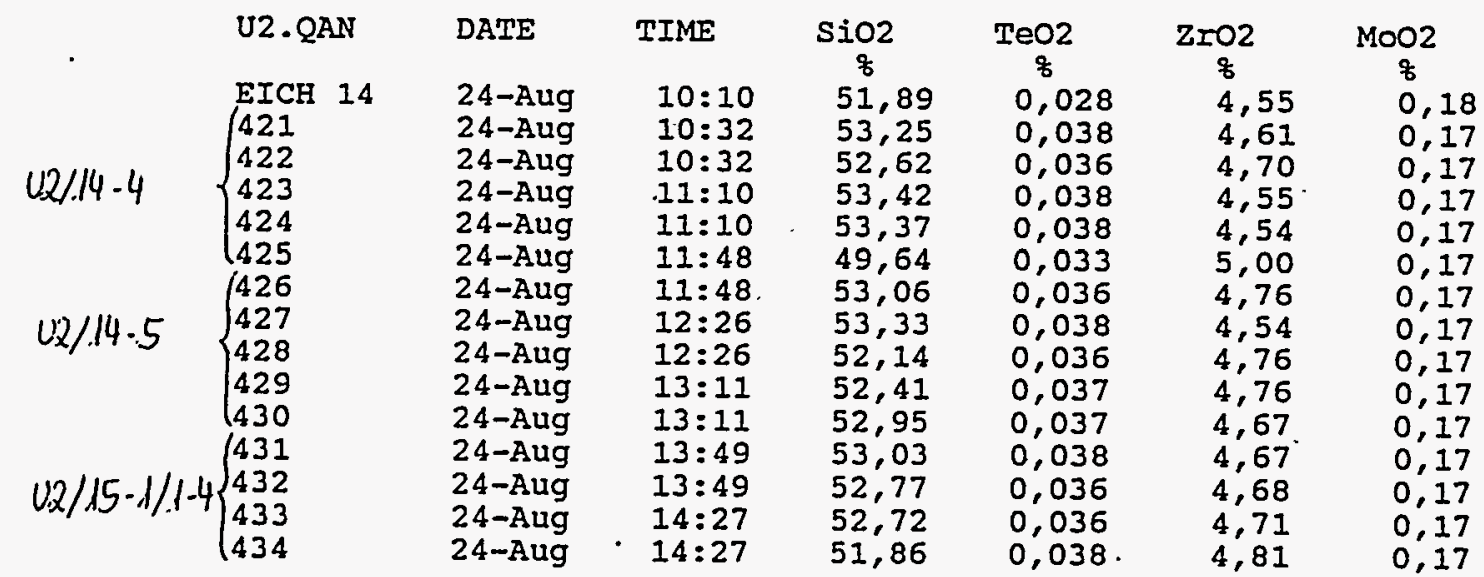




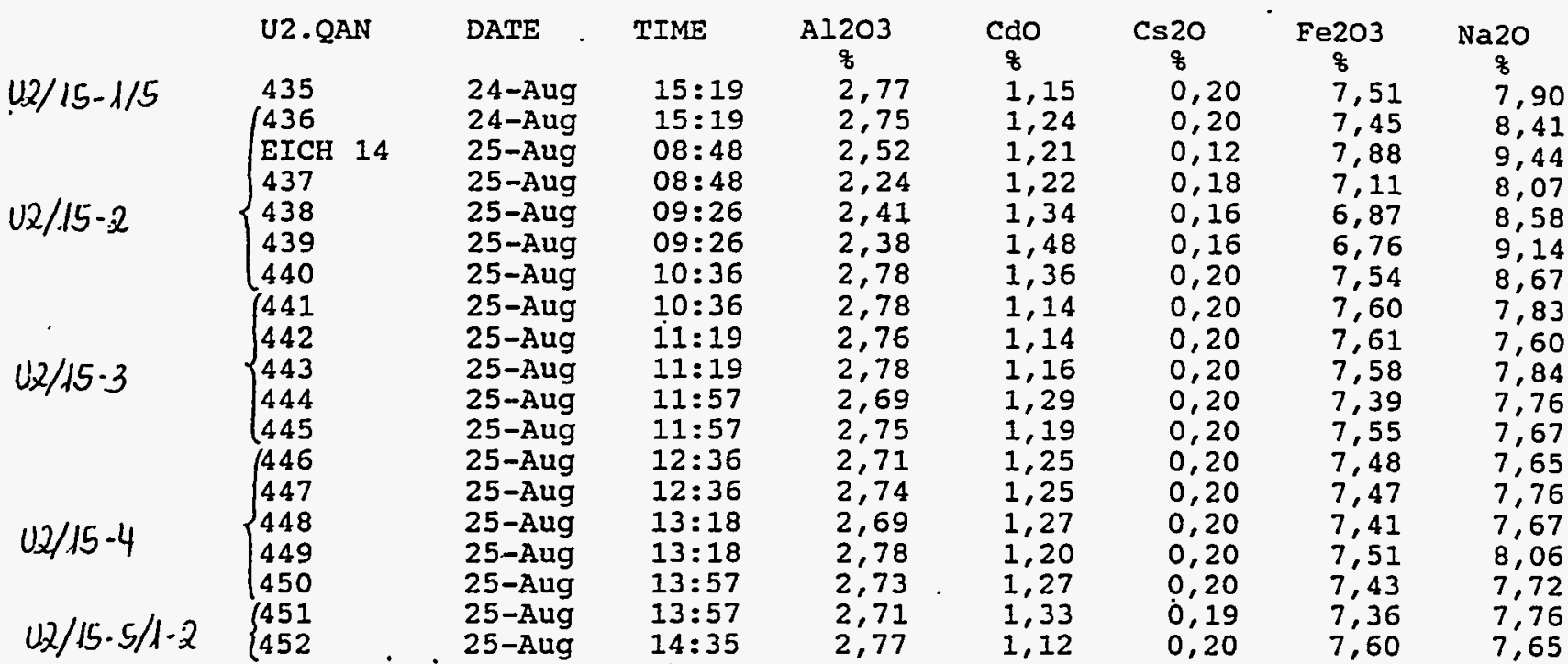

\begin{tabular}{|c|c|c|c|c|c|c|c|c|}
\hline & U2 - QAN & DATE & TIME & $\underset{8}{\mathrm{Nd} 2 \mathrm{O} 3}$ & $\underset{z}{\mathrm{NiO}}$ & $\begin{array}{l}\text { Pdo } \\
\frac{8}{8}\end{array}$ & $\underset{8}{\mathrm{Rh} 2 \mathrm{O} 3}$ & $\underset{8}{\mathrm{Ru} 203}$ \\
\hline $02 / 15-1 / 15$ & $\begin{array}{r}435 \\
1436\end{array}$ & $\begin{array}{l}\text { 24-Aug } \\
24-\text { Aug }\end{array}$ & $\begin{array}{l}15: 19 \\
15: 19\end{array}$ & $\begin{array}{l}1,17 \\
1,16\end{array}$ & $\begin{array}{l}0,64 \\
0,65\end{array}$ & $\begin{array}{l}0,050 \\
0,046\end{array}$ & $\begin{array}{l}0,033 \\
0,030\end{array}$ & $\begin{array}{l}0,124 \\
0,116\end{array}$ \\
\hline & EICH 14 & 25 -Aug & $08: 48$ & 0,38 & 0,13 & 0,053 & 0,048 & 0,169 \\
\hline $5-2$ & 437 & 25-Aug & $08: 48$ & 0,45 & 0,10 & 0,045 & 0,028 & 0,114 \\
\hline & 438 & $25-\bar{A}$ & $09=26$ & 0,41 & 0,09 & 0,048 & 0,030 & 0,118 \\
\hline & $\begin{array}{l}439 \\
440\end{array}$ & 25-Aug & $09: 26$ & 0,42 & 0,08 & 0,048 & 0,031 & 0,123 \\
\hline & $(441$ & $\begin{array}{l}25 \text {-Aug } \\
25-\text { Aug }\end{array}$ & $10: 36$ & $\begin{array}{l}0,91 \\
1,16\end{array}$ & $\begin{array}{l}0,29 \\
0,66\end{array}$ & $\begin{array}{l}0,048 \\
0,047\end{array}$ & $\begin{array}{l}0,031 \\
0,030\end{array}$ & 0,107 \\
\hline & 442 & $25-\mathrm{Au}$ & $11: 19$ & 1,17 & 0,65 & 0,046 & & 0,119 \\
\hline $02 / 15-3$ & $\{443$ & 25-Aug & $11: 19$ & 1,14 & 0,65 & 0,051 & 0,032 & 0,120 \\
\hline & 444 & 25-Aug & $11: 57$ & 1,14 & 0,62 & 0,041 & 0,027 & 0,118 \\
\hline & 445 & 25-Aug & $11: 57$ & 1,15 & 0,64 & 0,046 & 0 , & 0,123 \\
\hline & 446 & 25-Aug & $12: 36$ & 1,15 & 0,64 & 0,041 & 0,026 & 0,115 \\
\hline & 447 & $25-A \mathrm{u}$ & $12: 36$ & 1,13 & 0 ， & 0,041 & 0,028 & 0,118 \\
\hline$U: 2 / 15-4$ & $\{448$ & 25-Aug & $13=18$ & 1,16 & 0 , & 0,042 & 0,027 & 0,123 \\
\hline & 449 & 25-Aug & & 1,15 & 0 , & 0,047 & 0 , & 0,122 \\
\hline & 1450 & 25-Aug & $13=57$ & 1,14 & 0 , & 0,043 & 0,0 & 0,117 \\
\hline $02 / 15-5$ & $\left\{\begin{array}{l}451 \\
452\end{array}\right.$ & $\begin{array}{l}25 \text {-Aug } \\
25 \text {-Aug }\end{array}$ & $\begin{array}{l}13: 57 \\
14: 35\end{array}$ & $\begin{array}{l}1,11 \\
1,17\end{array}$ & $\begin{array}{l}0,63 \\
0,66\end{array}$ & $\begin{array}{l}0,037 \\
0,044\end{array}$ & $\begin{array}{l}0,025 \\
0,031\end{array}$ & $\begin{array}{l}0,110 \\
0,109\end{array}$ \\
\hline & & & & & & & & \\
\hline
\end{tabular}

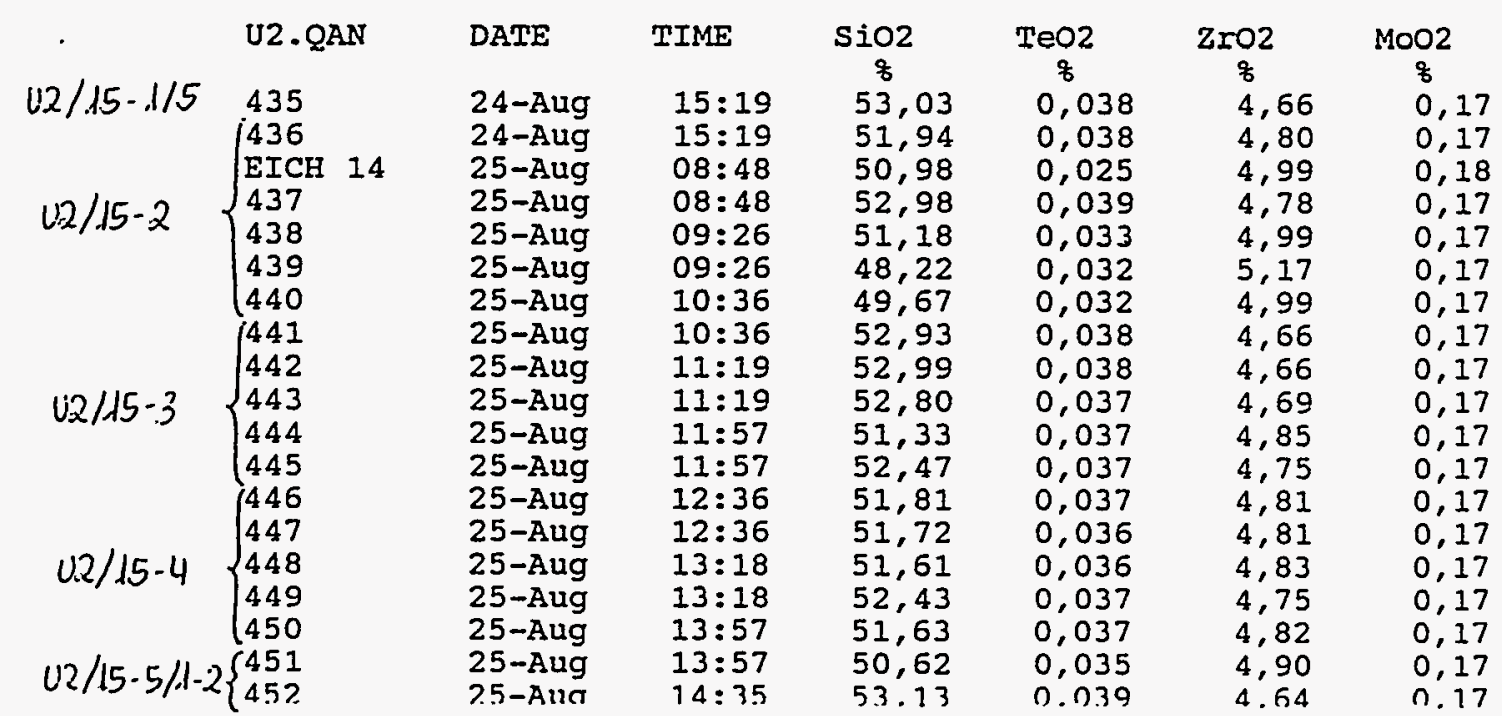




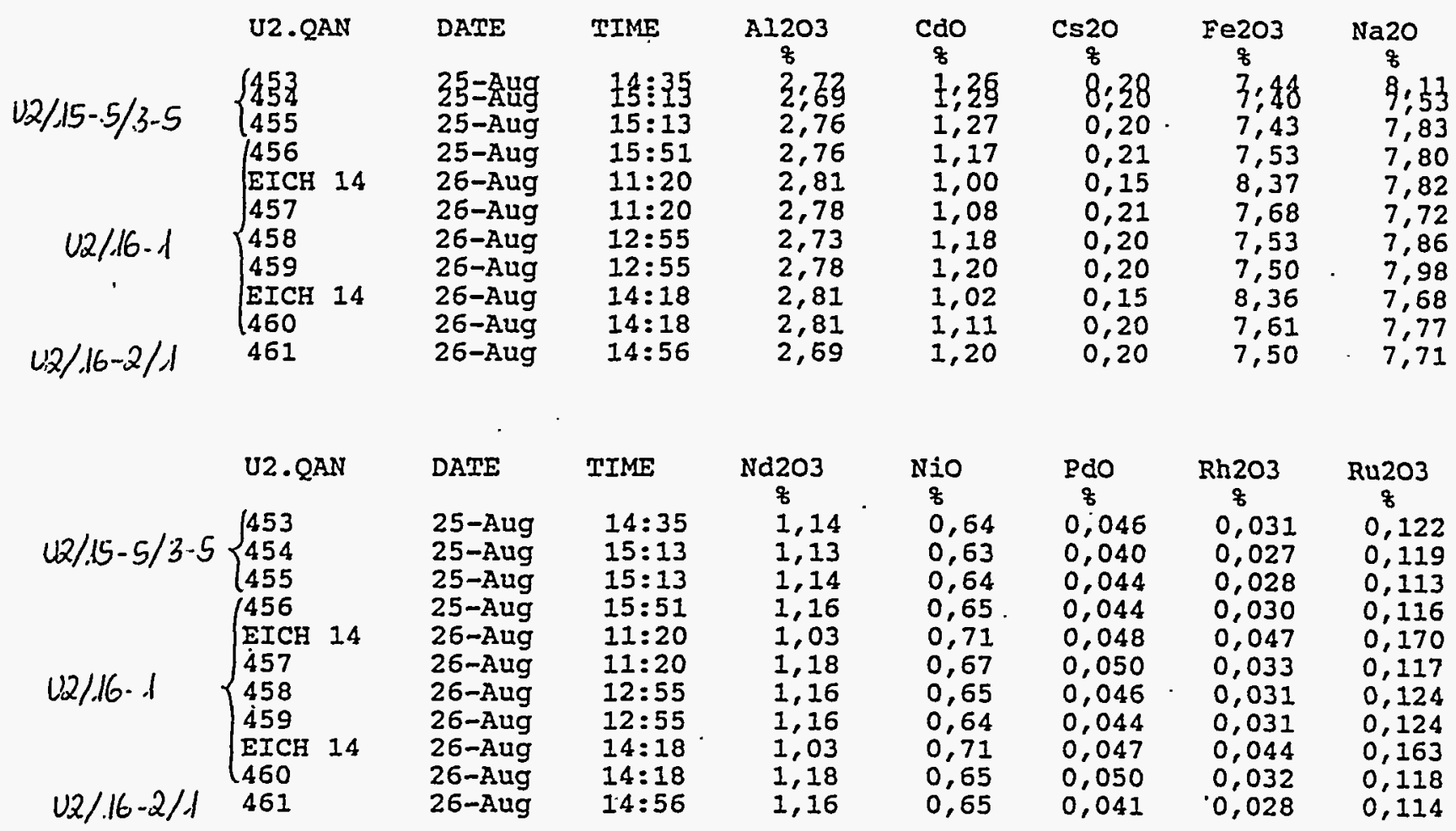

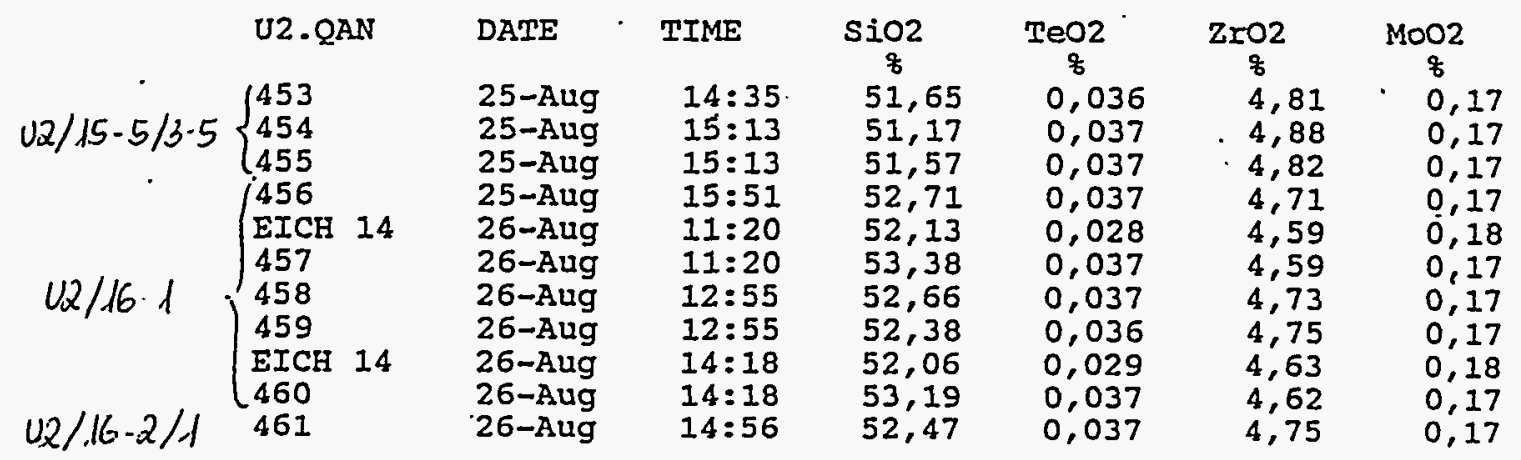




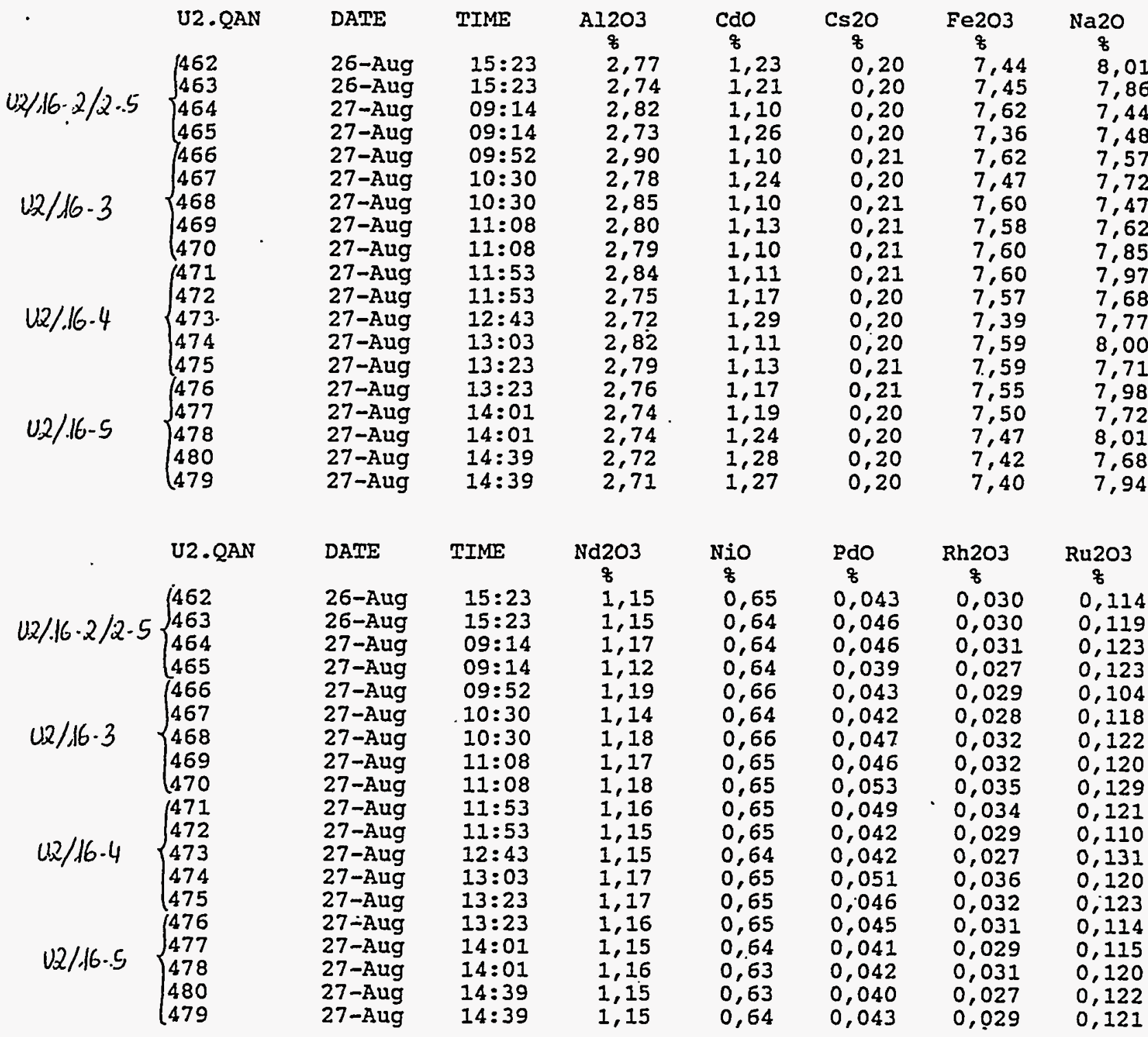

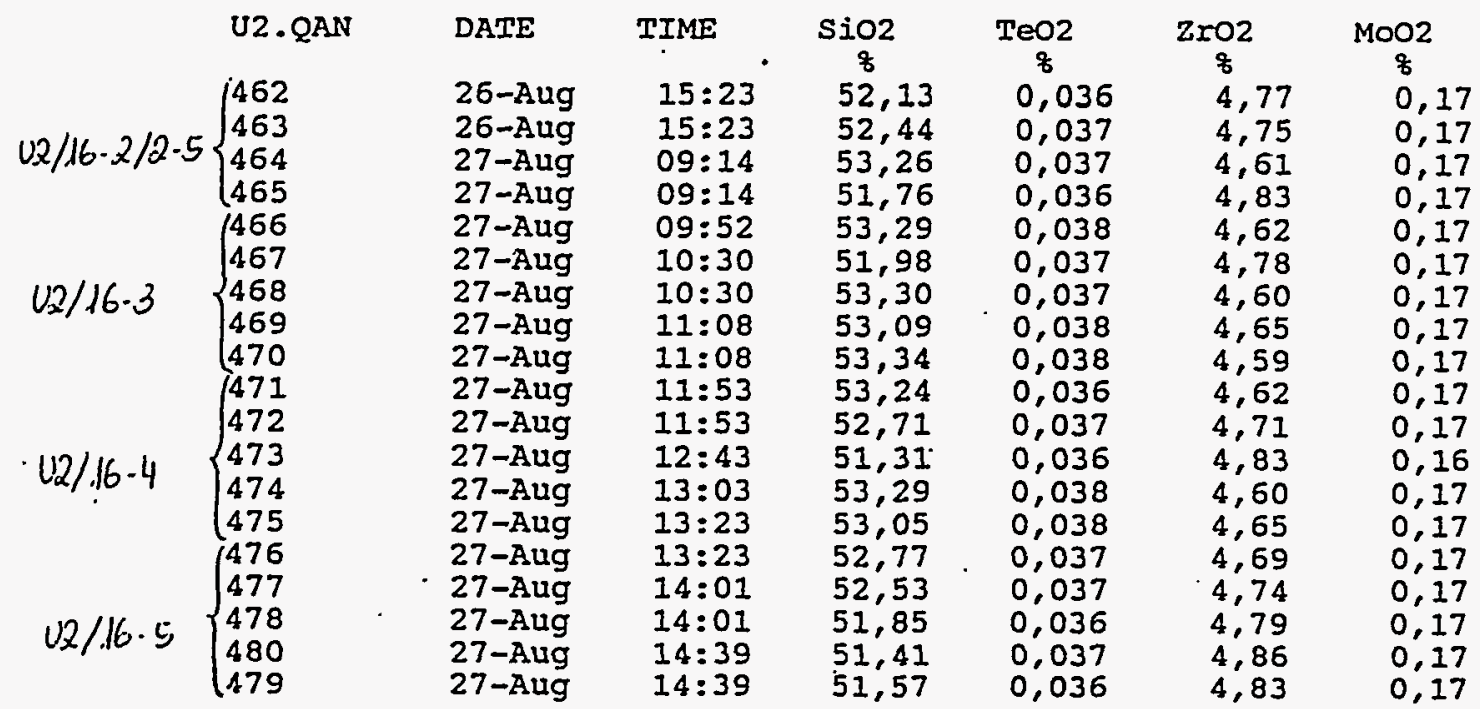




\begin{tabular}{|c|c|c|c|c|c|c|c|c|}
\hline 021.16 .6 & $\begin{array}{l}\text { U2.QAN } \\
\text { EICH } 14 \\
\left\{\begin{array}{l}481 \\
482 \\
483 \\
484 \\
485\end{array}\right.\end{array}$ & $\begin{array}{l}\text { DATE } \\
\text { 31-Aug } \\
31-\text { Aug } \\
31 \text {-Aug } \\
31 \text {-Aug } \\
31-\text { Aug } \\
31 \text {-Aug }\end{array}$ & $\begin{array}{l}\text { TIME } \\
13: 54 \\
14: 28 \\
14: 28 \\
15: 07 \\
15: 07 \\
15: 47\end{array}$ & $\begin{array}{c}\mathrm{A} 1203 \\
8 \\
2,82 \\
2,87 \\
2,80 \\
2,74 \\
2,92 \\
2,77\end{array}$ & $\begin{array}{l}\text { Cdo } \\
8 \\
0,98 \\
1,14 \\
1,07 \\
1,15 \\
1,10 \\
1,17\end{array}$ & $\begin{array}{l}\operatorname{cs} 20 \\
8 \\
0,15 \\
0,20 \\
0,21 \\
0,21 \\
0,21 \\
0,20\end{array}$ & $\begin{array}{c}\mathrm{Fe} 203 \\
8 \\
8,45 \\
7,59 \\
7,60 \\
7,53 \\
7,60 \\
7,51\end{array}$ & $\begin{array}{c}\mathrm{Na} 20 \\
8 \\
7,28 \\
7,45 \\
7,7 \\
7,4 \\
7,5\end{array}$ \\
\hline
\end{tabular}

\begin{tabular}{|c|c|c|c|c|c|c|c|c|}
\hline $0.2 / .16 \cdot 6$ & $\begin{array}{l}\text { U2. QAN } \\
\text { EICH } 14 \\
\left\{\begin{array}{l}481 \\
482 \\
483 \\
484 \\
485\end{array}\right.\end{array}$ & $\begin{array}{l}\text { DATE } \\
\text { 31-Aug } \\
\text { 31-Aug } \\
31-\text { Aug } \\
\text { 31-Aug } \\
31-\text { Aug } \\
\text { 31-Aug }\end{array}$ & $\begin{array}{l}\text { TIME } \\
13: 54 \\
14: 28 \\
14: 28 \\
15: 07 \\
15: 07 \\
15: 4.7\end{array}$ & $\begin{array}{l}\mathrm{Nd} 203 \\
8 \\
1,01 \\
1,15 \\
1,19 \\
1,17 \\
1,17 \\
1,16\end{array}$ & $\begin{array}{l}\text { NiO } \\
8 \\
0,70 \\
0,65 \\
0,66 \\
0,65 \\
0,65 \\
0,65\end{array}$ & $\begin{array}{l}\text { Pdo } \\
8 \\
0,043 \\
0,038 \\
0,047 \\
0,042 \\
0,045 \\
0,042\end{array}$ & $\begin{array}{c}\text { Rh203 } \\
q \\
0,042 \\
0,028 \\
0,032 \\
0,030 \\
0,031 \\
0,030\end{array}$ & $\begin{array}{c}\text { Ru203 } \\
8 \\
0,173 \\
0,114 \\
0,112 \\
0,123 \\
0,116 \\
0,127\end{array}$ \\
\hline
\end{tabular}

$\begin{array}{llccccc}\text { U2.QAN } & \text { DATE } & \text { TIME } & \text { SiO2 } & \text { TeO2 } & \text { ZrO2 } & \text { MOO2 } \\ \text { U2/16-6 } & & & 8 & 8 & 8 & 8 \\ \text { EICH 14 } & \text { 31-Aug } & 13: 54 & 52,04 & 0,027 & 4,57 & 0,18 \\ 481 & \text { 31-Aug } & 14: 28 & 52,98 & 0,038 & 4,67 & 0,17 \\ 482 & \text { 31-Aug } & 14: 28 & 53,59 & 0,039 & 4,56 & 0,17 \\ 483 & 31 \text {-Aug } & 15: 07 & 53,01 & 0,039 & 4,66 & 0,17 \\ 484 & 31 \text {-Aug } & 15: 07 & 53,31 & 0,037 & 4,60 & 0,17 \\ 485 & \text { 31-Aug } & 15: 47 & 52,77 & 0,036 & 4,69 & 0,17\end{array}$




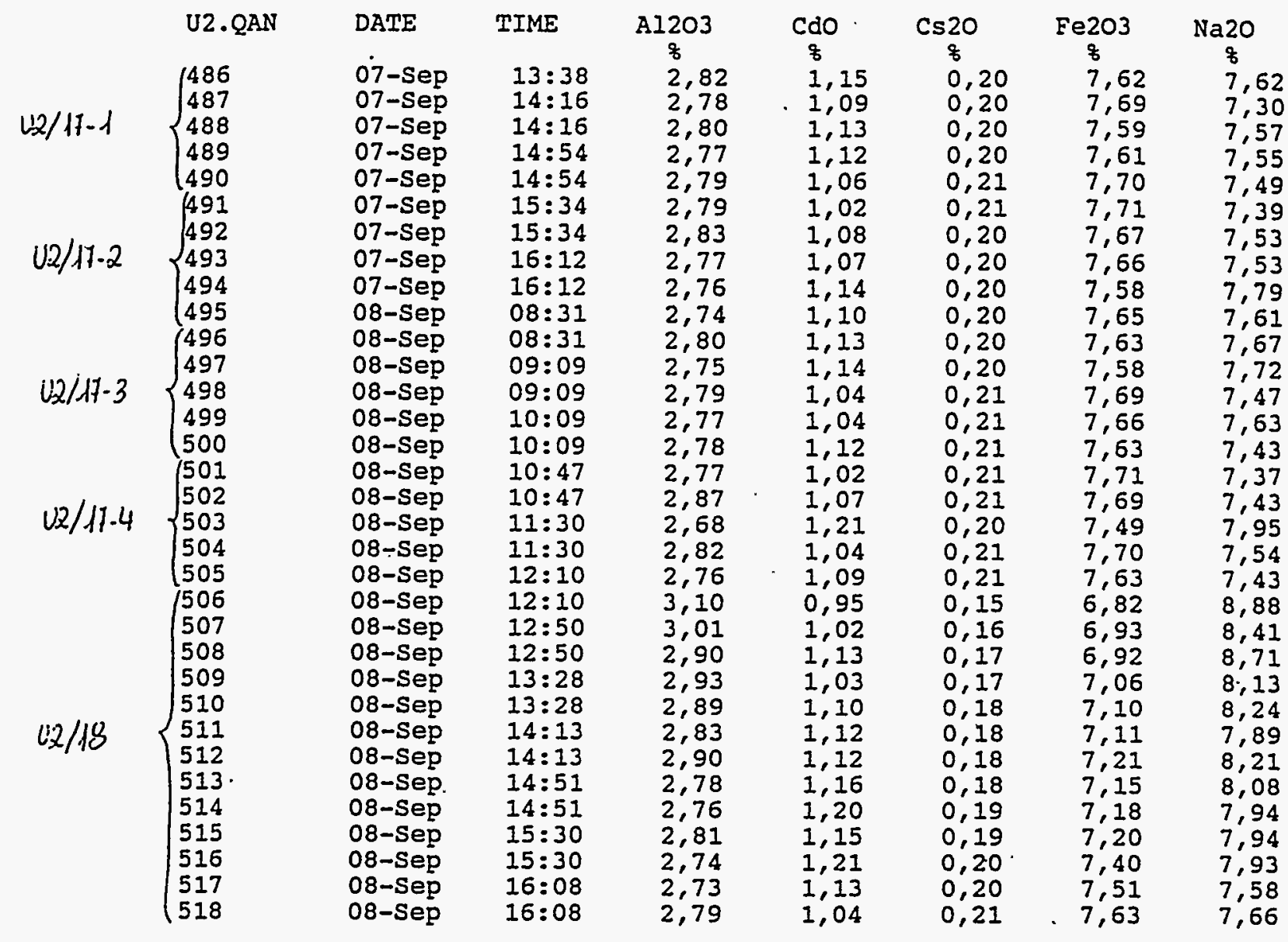

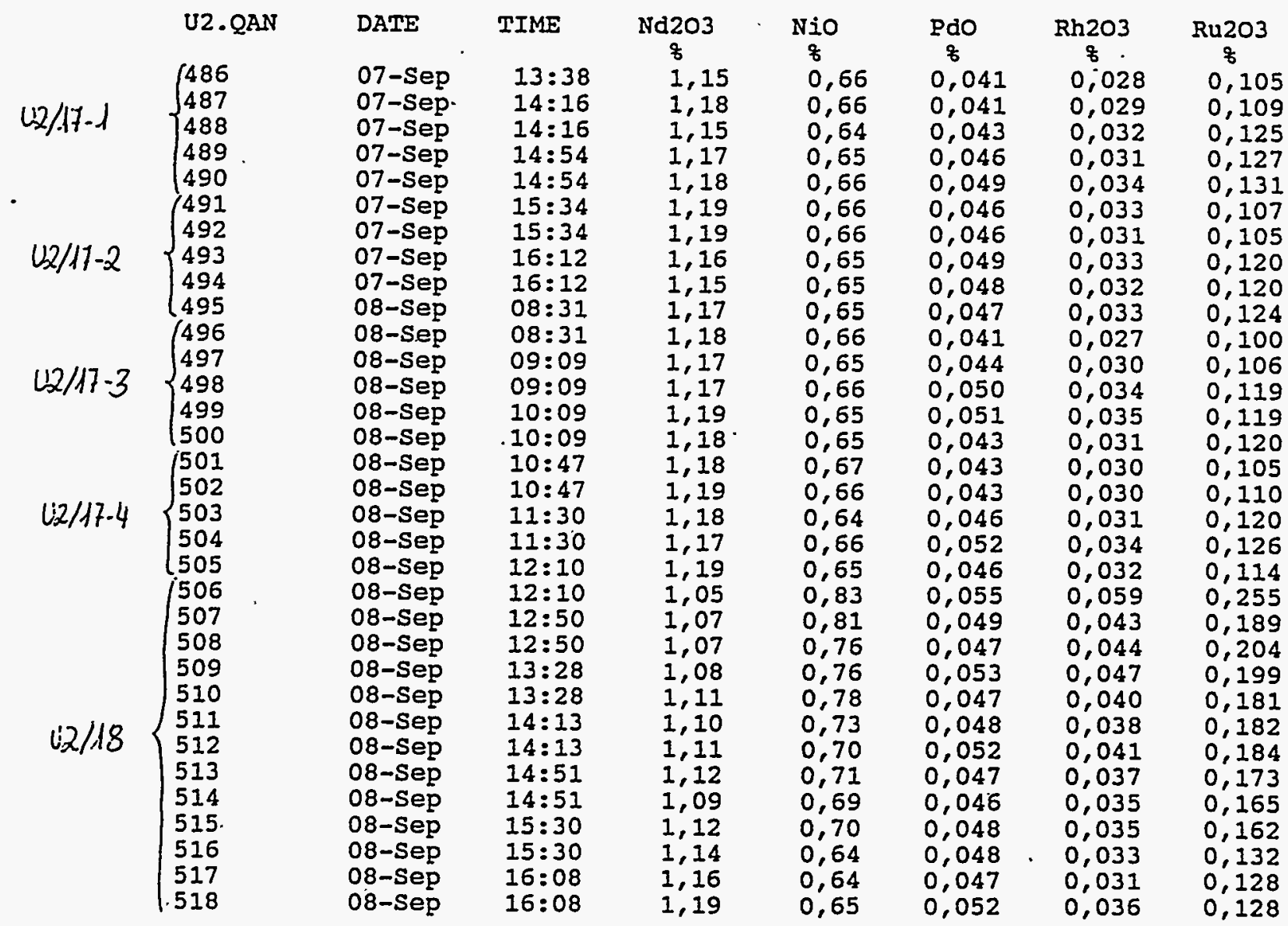




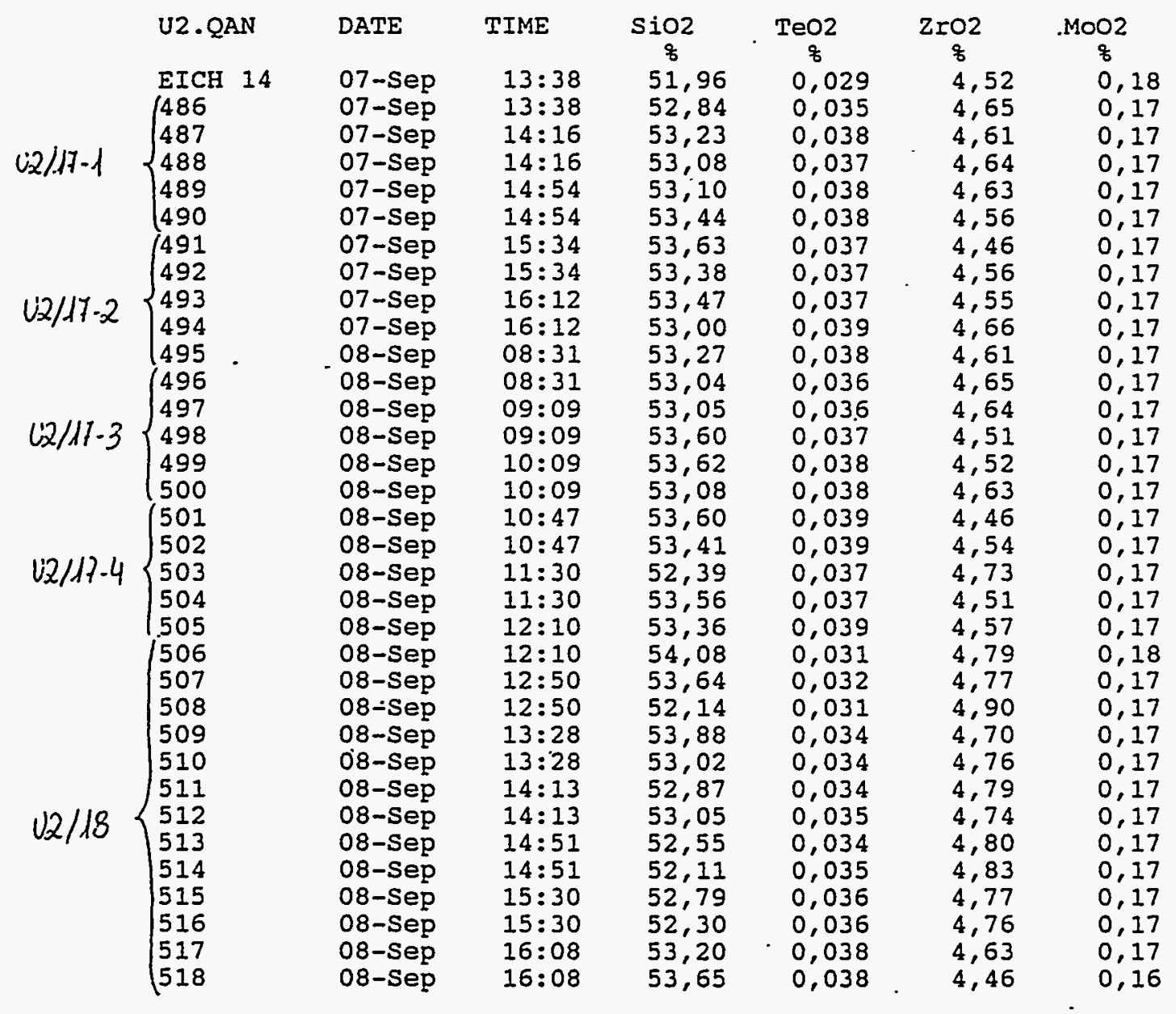




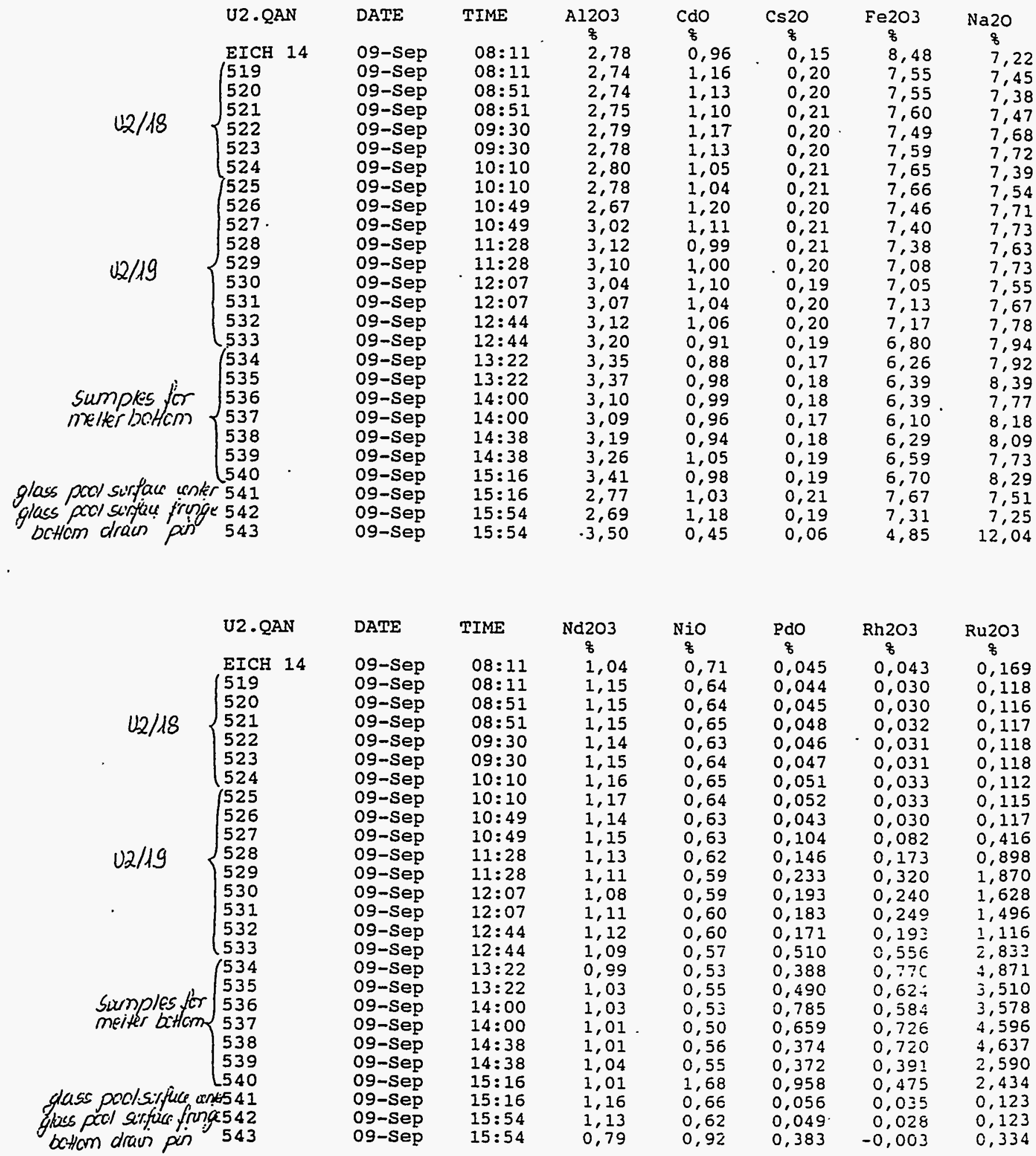




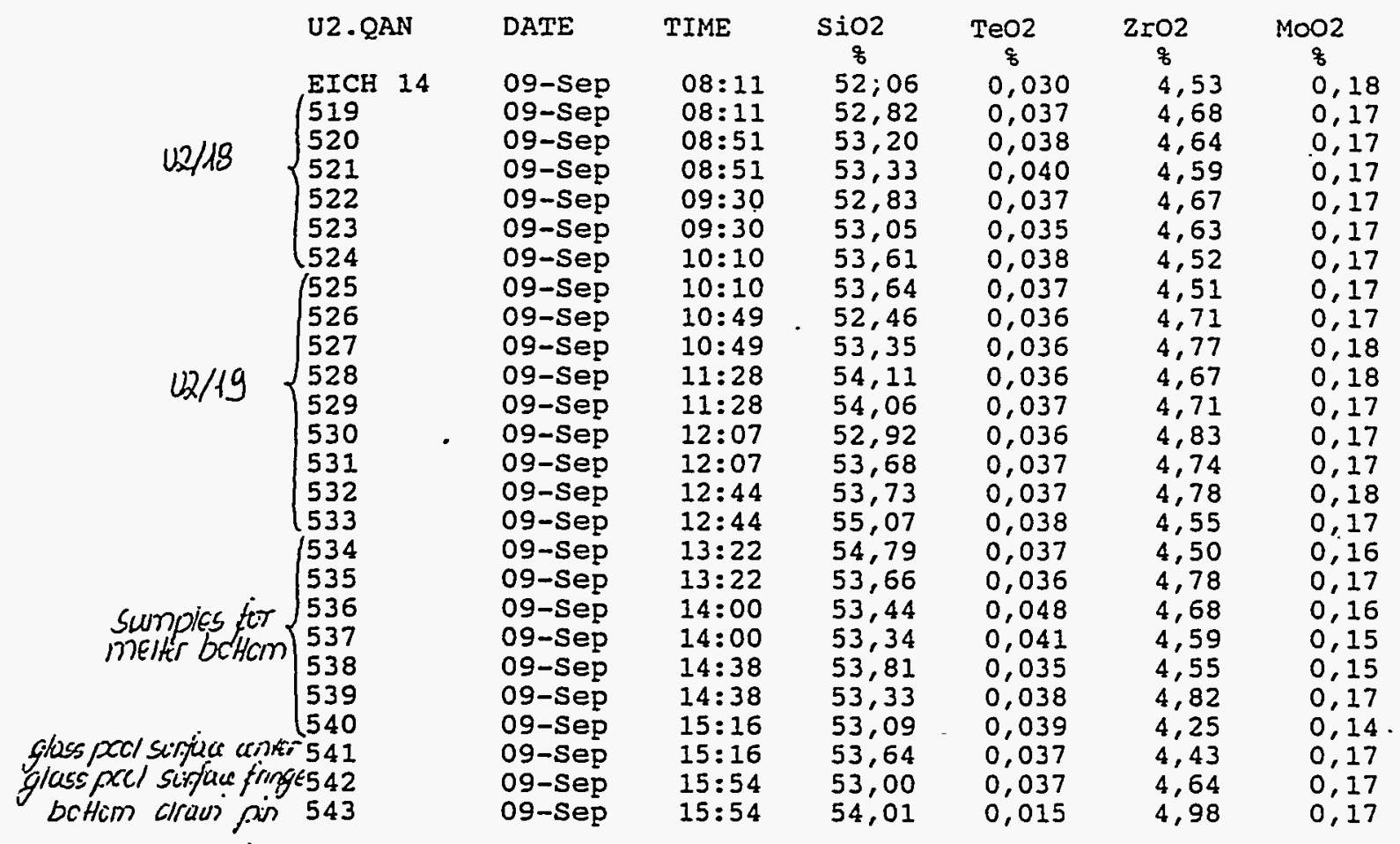




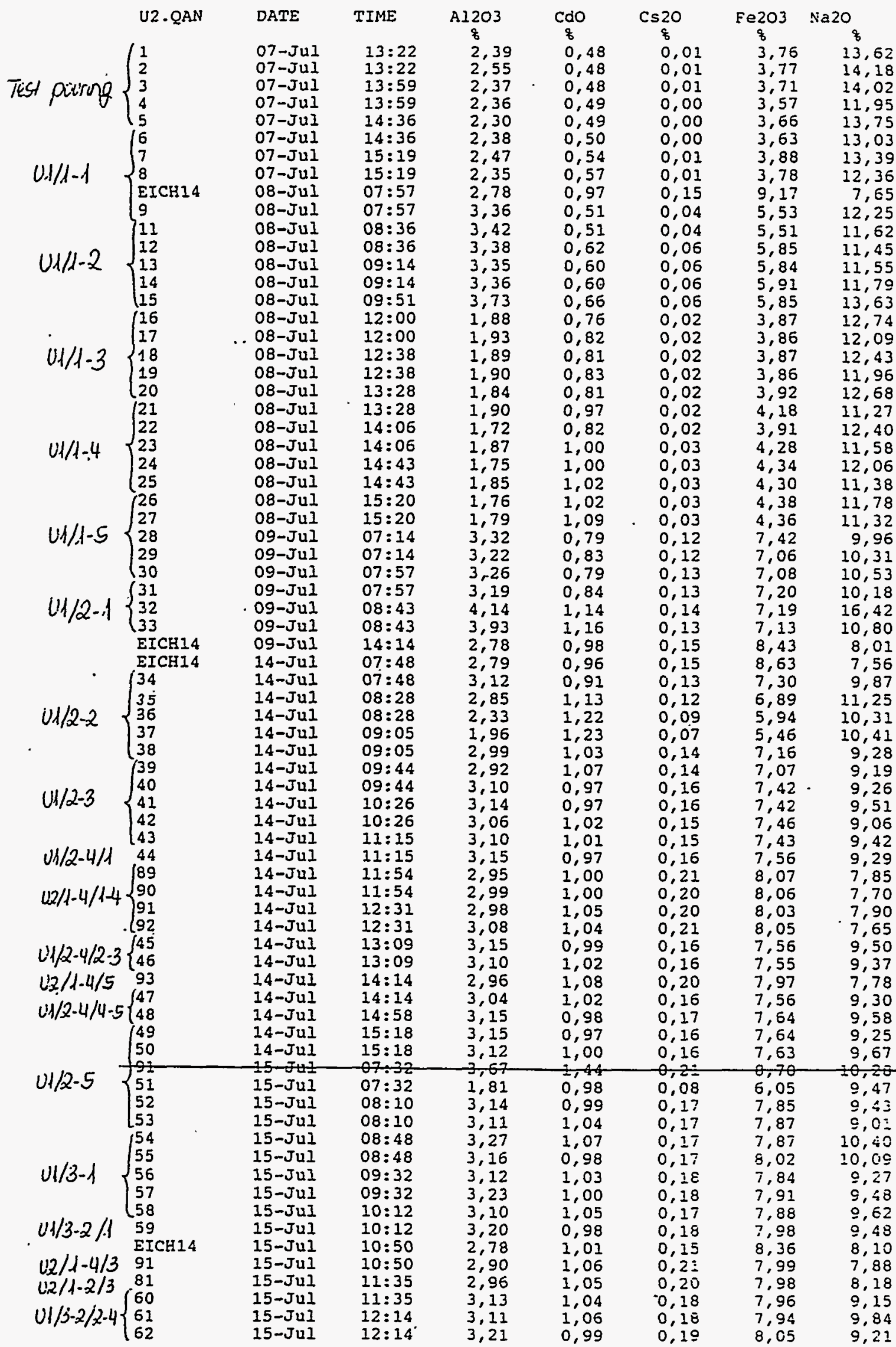




\section{Appendix D. Computer Modeling}

Appendix D. Computer Modeling

D.1 Tempest Computer Program Description

D.1.1 Species Transport - Continuum Approach

D.1.2 Species Transport - Particle Tracker Approach

D.1.3 Electric Field Equations - AC Model

D.2 Computer Submodel Connections

D.2.1 Enhanced Electrical and Thermal Conductivities

D.2.2 Glass Viscosity

D.2.3 Particle Settling

D.2.3.1 Nonsphericity

D.2.3.2 Porosity

D.2.3.3 Hindered Settling

D.2.4 Power Controller

D.2.5 Deposition Model

D.3 ESM Computer Model Description

D.3.1 Melter Description

D.3.2 Modeling Approach

D.3.3 Pre-test and Post-test Data Sources

D.3.4 Discretised Model Description

D.3.5 Boundary Conditions

D.4 Properties Used in Simulations

D.4.1 Electric Conductivity

D.4.2 Thermal Conductivity

D.4.3 Density

D.4.4 Viscosity

D.4.5 Particle Settling

D.4.5.1 Nonsphericity

D.4.5.2. Porosity

D.4.5.3 Isolated-particle settling velocities

D.4.5.4 Hindered settling

D.5 ESM Spout Model

D.6 Lumped-Parameter Melter Model

D.7 Retention

References 
The equations solved by TEMPEST are

Continuity:

$$
\frac{\partial \mathrm{u}_{\mathrm{i}}}{\partial \mathrm{x}_{\mathrm{i}}}=0
$$

Momentum:

$$
\rho_{0}\left[\frac{\partial \mathrm{u}_{\mathrm{i}}}{\partial \mathrm{t}}+\frac{\partial\left(\mathrm{u}_{\mathrm{i}} \mathrm{u}_{\mathrm{j}}\right)}{\partial \mathrm{x}_{\mathrm{j}}}\right]=-\frac{\partial}{\partial \mathrm{x}_{\mathrm{i}}}+\frac{\partial}{\partial \mathrm{x}_{\mathrm{j}}}\left(\mu \frac{\partial \mathrm{u}_{\mathrm{i}}}{\partial \mathrm{x}_{\mathrm{j}}}\right)+\frac{\partial \mu}{\partial \mathrm{x}_{\mathrm{j}}} \frac{\partial \mathrm{u}_{\mathrm{j}}}{\partial \mathrm{x}_{\mathrm{i}}}+\rho \mathrm{g}_{\mathrm{i}}
$$

Energy:

$$
\rho_{0} c\left[\frac{\partial \mathrm{T}}{\partial}+\frac{\left.\partial \mathrm{u}_{\mathrm{j}} \mathrm{T}\right)}{\partial \mathrm{x}_{\mathrm{j}}}\right]=\frac{\partial}{\partial \mathrm{x}_{\mathrm{j}}}\left(\mathrm{k} \frac{\partial \mathrm{T}}{\partial \mathrm{x}_{\mathrm{j}}}\right)+\dot{\mathrm{Q}}
$$

A combination of numerical solution algorithms are used in TEMPEST, depending upon the problem under consideration. These include explicit, semi-implicit, and implicit algorithms. The choice of solution algorithm is dependent upon numerical stability and accuracy considerations and upon the need for computational efficiency [minimizing Central Processing Unit (CPU) time].

The transport equations presented above are coupled through material properties. The primary couplings are through temperature-dependent density, thermal conductivity, and viscosity relationships. Coupling also occurs through a resistance heating thermal energy source term arising from the electric field solution in an electrically conducting material. During species transport, additional coupling can occur through concentration-dependent density, viscosity, and thermal and electric conductivity. In the case of melter operation with a noble metals buildup on the melter floor, all these couplings are present and must be considered in the modeling analysis. This is referred to as fully coupled analysis.

\section{D.1.1 Species Transport - Continuum Approach}

The continuum approach to modeling species transport involves solving the transport equation for the concentration of a species,

$$
\frac{\partial C_{k}}{\partial}+\frac{\partial\left(u_{j} C_{k}\right)}{\partial x_{j}}=\frac{\partial}{\partial x_{j}}\left(D_{k} \frac{\partial C_{k}}{\partial x_{j}}\right)+\dot{C}_{k} \quad(\dot{k}=1,2,3 \ldots)
$$


In the continuum approximation, the species concentration may represent a single discrete phase with characteristic particle size. Multiple particle size distributions may be approximated by solving Eq. (D.4) for each of several discrete particle sizes representative of a range within a distribution. Eq. (D.4) may also be solved for discrete species materials, such as $\mathrm{Rh}, \mathrm{Ru}, \mathrm{Pd}, \mathrm{Te}$, or Au or an alloy or compound of these. It can also be used to represent dissolved species if precipitation kinetics were identified as of significance. Thus, the continuum approximation approach offers the advantage of being applicable to a wide variety of cases, assuming appropriate boundary and source/sink information is available from either data or physical models. Also, the entire model is contained in TEMPEST, unlike the particle tracker approach.

\section{D.1.2 Species Transport - Particle Tracker Approach}

The particle tracker approach involves solving a Lagrangian equation for the path of individual particles within a convecting melt pool. The general equation is based on a force balance on a single particle,

$$
\Sigma \underline{F}=m d \underline{u} / d t=\underline{B}+\underline{W}+\underline{F}_{D}
$$

where $m$ is the particle mass, $\underline{u}$ is the particle velocity, $t$ is time, $\underline{B}$ is buoyancy force, $\underline{W}$ is weight, and $\underline{F}_{D}$ is drag force. Each of the terms on the right-hand side are relatable to the particle density, a drag coefficient which is in turn a function of particle shape and size, and the flow field the particle experiences. The position of the particle with time is obtained by integrating Eq. (D.5) and noting that the position of the particle is obtainable from

$$
\mathrm{d} \underline{\mathrm{x}} / \mathrm{dt}=\underline{\mathrm{u}}
$$

In this approach, the fluid velocity moves the particles subject to gravitational and drag forces acting on the particle. The flow field upon which the particles are transported has to be precomputed. If the flow field is steady, this is a rather straight-forward process, except that correct treatment of particles within the very near wall region requires special treatment. If the flow field is unsteady, a rather complicated procedure has to be implemented which involves the use of "recycling" a sequence of flow fields that represent a quasi-periodic flow field, or it requires direct solution of particle tracking within the flow field solution procedures. Submodels for forces on particles are based on data for particle characteristics such as size and shape. Data for these submodels come from GFT, RSM, and ESM glass sample analysis.

The particle tracker approach offers advantages in treating specifics of larger particles where inertia or particle-to-particle interactions, such as agglomeration, may be important. The approach suffers from a disadvantage of being computational intensive when sufficient numbers of discrete particles are included so as to be statistically representative. The approach also has the 
disadvantage of being decoupled from the hydrodynamics of the melt pool. Thus, a procedure must be developed for coupling the predicted effects of particle settling and sludge buildup back into calculation of operation characteristics of the melt pool.

The particle tracker approach was extensively investigated for its application to transport of simulated noble metals particles. The conclusion of these investigations was that the method could not be used in the present work. The computer time required to compute a sufficient number of particles to be significantly representative was excessive. Also, the integration of the circulation path of a single particle in a recirculating flow field could not be calculated accurately enough to distinguish the path position numerical error from path position variation that occurs because of particle settling under the influence of gravity. The particle tracker approach has been abandoned in favor of the continuum species transport approach.

\section{D.1.3 Electric Field Equations - AC Model}

Joule heat $Q_{J}$ as a source in the energy equation is generated by electric currents resulting from potentials applied to a system of electrodes. To compute joule heat efficiently, the potential field $\phi$ $(\mathrm{r}, \mathrm{t})$ and the associated electric current flux $\mathrm{J}(\mathrm{r}, \mathrm{t})$ are factored into a sum of space and time factors as

$$
\begin{aligned}
& \phi(\underline{r}, t)=\Sigma^{N}{ }_{n=1} f_{n}(t) \phi_{n}(\underline{r}) \\
& \underline{J}(\underline{r}, t)=\Sigma^{N}{ }_{n=1}^{N} f_{n}(t) \underline{J}_{n}(\underline{r})
\end{aligned}
$$

- where the spatial current flux is determined from a spatial potential field as

$$
\underline{\mathrm{J}}_{-n}(\underline{\mathrm{r}})=-\sigma \nabla \phi_{\mathrm{n}}(\underline{\mathrm{r}})
$$

The spatial potential field is determined from solution of a Poisson equation of the form

$$
\nabla \cdot\left[-\sigma \phi_{n}(\underline{r})\right]=I_{v, n}^{\circ}(\underline{r})
$$

where $I_{v, n}^{\circ}(\underline{I})$ is a reference current source (or sink where negative) per unit volume, chosen to be nonzero only within the $n$-th electrode pair. The cycle-averaged joule heat-per-unit volume is calculated as

$$
\begin{aligned}
Q_{J}(\underline{r}) & =\langle\underline{J}(\underline{r}, \underline{t}) \cdot \underline{J}(\underline{r}, t) / \sigma> \\
& =\sum_{n=1}^{N} \cdot \Sigma^{N}{ }_{m=1}^{N} F_{m n} I_{m}(\underline{r}) \cdot J_{n}(\underline{r}) / \sigma
\end{aligned}
$$


where

$$
F_{m n}=\left\langle f_{m}(t) f_{n}(t)>\right.\text {. }
$$

The symbol $>$ indicates a time average of the enclosed quantity. In a glass melter, the electric conductivity, $\sigma$, will be spatially varying with temperature and may be spatially varying with noble metals concentration. As a sludge layer develops, the electric conductivity may also be temporally varying.

Use of this model requires specification of a set of $F_{m a}$ values or a combination of timeaveraged voltage products, partial powers, and $F_{m s}$. This formulation allows for phase differences and for non-sinusoidal waveforms in driving a multi-electrode, multi-phase electric system. The number $\mathrm{N}$ of spatial potential field solutions required in this representation depends on the number of electrode pairs, the number of electromotive force sources, and their connections.

A more detailed explanation of the electric field solution and analytical basis can be found in Lessor et al. (1991).

\section{D.2 Computer Submodel Connections}

Computation of noble metals transport through, and holdup within, the melt pool requires boundary source information at the cold cap/melt pool interface. Particle data from the GFT experiments and slurry feed makeup can be used as the bases for characteristic particle size, shape, and content and material quantity at the cold cap. These data have been reported by Anderson et al. (1992). Once in the melt pool, the noble metals material is transported around the melt pool by the buoyancy-induced convection currents. Glass sample data from the RSM and ESM during pouring and from melter post-mortem examinations provide data for particle characteristics needed for computational analysis. The noble metals particles may undergo physical and/or chemical changes while in the glass melt which may lead to improvements to the modeling at some future date as information on these changes becomes available to the computer modeling task. One such improvement may be the need to model the reduction process of $\mathrm{RuO}_{2}$ particles to $\mathrm{Ru}$ metal, an effect concluded to have occurred in the RSM tests. Another may be the need to model the time-rate of growth of particles (agglomeration).

As a noble metals enriched sludge layer develops on the floor of the melter, several effects can occur that affect melter operations. The primary one is the potential to cause shorting of the electric current between the lower electrode pair. During development of the sludge layer, properties of the sludge layer may vary with time. These properties include viscosity thermal conductivity, and electrical conductivity. Computer submodels are required to represent the concentration-dependent properties. Additionally, because the simulated noble metals particles are heavier than the glass melt, they are subject to gravitational settling. Thus, a particle settling model must be used to describe this effect in the computational analysis. 
In the following sections, the mathematical and physical bases for submodels of concentrationdependant properties and particle settling are described.

\section{D.2.1 Enhanced Electrical and Thermal Conductivities}

In a melter, noble metals occur as a discrete particle phase in a continuum (glass). The presence of the dispersed noble metals particles can enhance the effective electric and thermal conductivities. Goring and Churchill (1961) provide an excellent review of empirical modeling approaches in a review of literature back to work done in 1891. In the absence of polarization effects, the electro-static and thermo-static problems are identical.

Both the thermal and electric conductivity of an assumed cubic packed, noncontacting, monodispersed discrete spherical particle phase in a continuous fluid field can be related analytically to the conductivity of the continuous phase; subject to assumptions. Mathematically, Rayleigh's model can be expressed as

$$
\frac{\sigma}{\sigma_{\mathrm{f}}}=1-\frac{3 v_{\mathrm{p}}}{\frac{2+\Sigma}{1-\Sigma}+v_{\mathrm{p}}-\frac{1-\Sigma}{(4 / 3)+\Sigma} \mathrm{a} v_{\mathrm{p}}^{20 / 3}+\ldots}
$$

where $v_{\mathrm{p}}$ is the volume fraction, $\mathrm{a}$ is a constant dependent on assumed packing arrangement, and $\Sigma=\sigma_{\mathrm{p}} / \sigma_{\mathrm{r}}$ is the ratio of the electric (or thermal) conductivity of the discrete particle phase to the electric (or thermal) conductivity of the continuous fluid phase. The constant a in Eq. (D.13) takes on different values depending upon the packing arrangement: simple cubic $(a=1.131)$, body centered cubic $(a=0.129)$, or face centered cubic $(a=0.0752)$. The basis for this model is applicable to largely round, solid particles such as Pd particles observed in some glass samples.

Figure D-1 presents the theoretical ratio of the enhanced conductivity for infinite $\Sigma$ for the simple cubic assumption that is the most conservative. Note the large increase in the relative conductivities that results, but that the largest effect according to Eq. (D.13) is at concentrations approaching maximum packing factors. Eq. (D.13) has been implemented into TEMPEST for use with determining the electric conductivity of a developing sludge that consists primarily of round, solid particles. This provides one basis for investigating temporal changes in sludge layer conductivities as particles settle and an enhanced conductivity layer develops.

Data from German melter operation experience indicate a factor of 10 to 100 increase in electrical conductivities of a settled sludge layer of noble metals. ${ }^{1} \mathrm{~A}$ ten-fold increase is at least in

1 Personal correspondence from W. Grünewald of KfK, February 15, 1993 [also see Choi (1992)]. 
qualitative agreement the upper limit of the curves in Figure D-1. The concentration at which the ten-fold increase occurs, however, is only about 5 to $6 \%$ by volume. Thus, a more empirically based model has also been implemented in TEMPEST. This model is referred to as a shape function that provides similar variational dependency with concentration as that depicted in Figure $\mathrm{D}-1$, but offers the computer modeler more flexibility in curve-fitting data as a function of volumetric concentration. The mathematical approach is to separate the temperature dependence from the concentration dependence as

$$
\sigma\left(T, C_{r}\right)=\sigma(T) * f\left(C_{r}\right)
$$

where $\sigma(\mathrm{T})=$. temperature-dependent glass conductivity

$\mathrm{f}\left(\mathrm{C}_{\mathrm{r}}\right)=$ functional concentration dependence

$\mathrm{C}_{r}=$ ratio of volumetric concentration to maximum volumetric concentration, $\left(\mathrm{C}_{\mathrm{v}} / \mathrm{C}_{\mathrm{v}, \mathrm{max}}\right)$

The functional from of Eq. (D.14) allows for expressing the ratio of the maximum conductivity to the reference conductivity as the settled volumetric concentration approaches the maximum settled packing fraction. Note that both the temperature and concentration dependence of the conductivity are modeled in this approach. Concentration-dependent conductivity data for ESM glass has been measured (Figure 5-19 and 5-23). Independent measurements with ESM glass samples have also been done at PNL.

\section{D.2.2 Glass Viscosity}

Molten glass in melters is known to be strongly temperature dependent. The presence of noble metals particles may also lead to a particle concentration dependence. Indications of German melter operation experience, ${ }^{2}$ published data (Krause and Luckscheiter 1991), and HWVP data (Cobb and Hrma 1991) are that the glass with noble metals particles may behave more like a nonNewtonian fluid than a Newtonian fluid as the volumetric concentration of noble metal particles increases. Plodinec (1986) also presents a summarization of Defense Waste Processing Facility (DWPF) data on crystalline containing glass which exhibit both Newtonian and non-Newtonian character. For the present work, and for several other waste processing problems, several concentration-dependent Newtonian and non-Newtonian fluid properties models have been implemented into TEMPEST. These offer a wide range of options for treatment of concentrationdependent viscosity properties.

2 Weisenburger, S. "KfK Melter Modeling Experience." Presentation to the Noble Metals Workshop, March 16-20, 1992, Richland, Washington. T. Weber, Westinghouse Hanford Company/HWVP, organizer. 


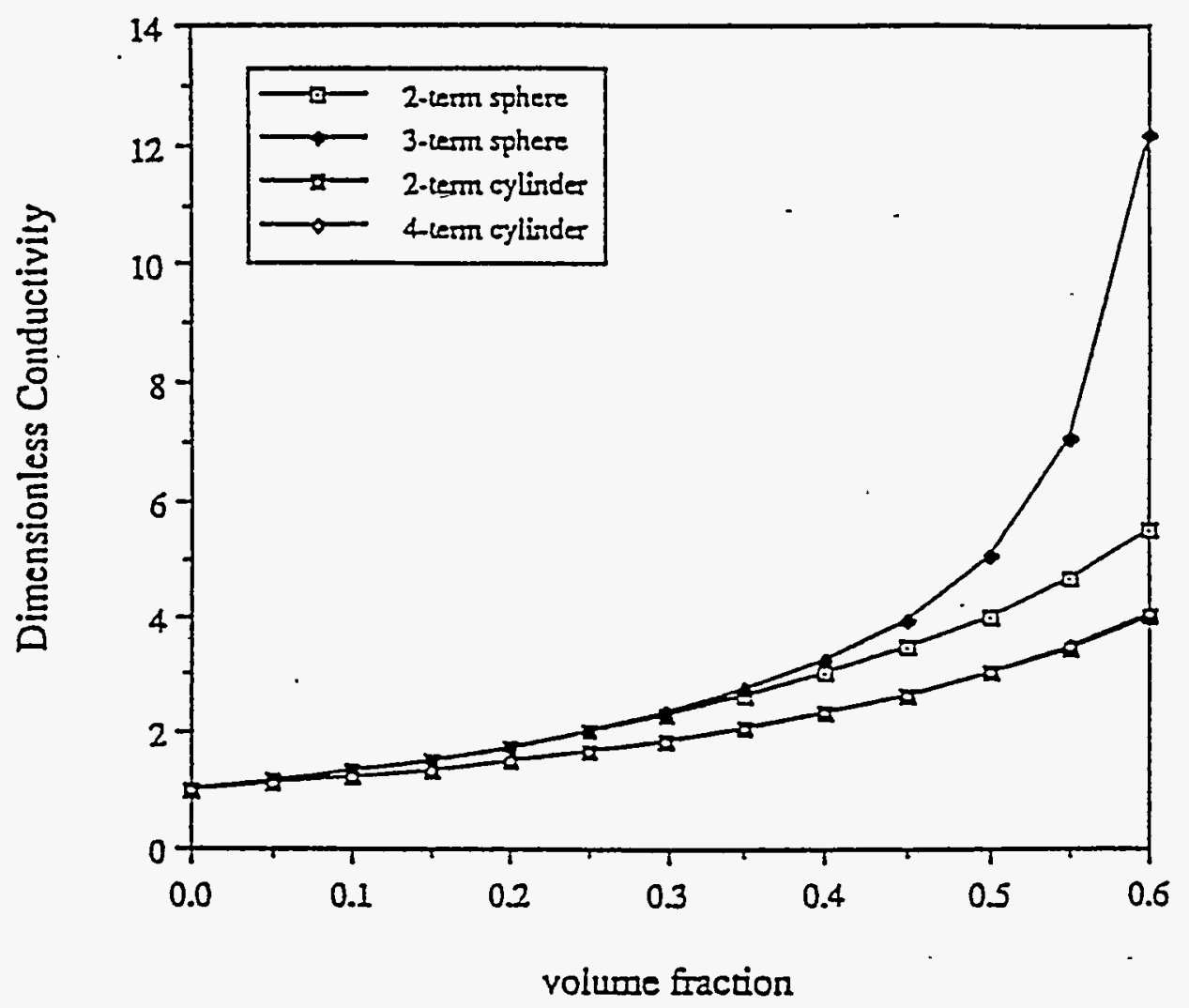

Figure D-1. Theoretical Ratio of Electrical Conductivity for a High Conductivity Discrete Particles Distributed in a Continuous Medium 
In general, effective viscosity in TEMPEST is

$$
\mu_{\mathrm{eff}}=\mathrm{f}(\mu, \beta) \dot{\gamma}^{\mathrm{g}(\beta)}
$$

where $\mu=\mu(\mathrm{t})$, temperature-dependent dynamic viscosity,

$\dot{\gamma}=$ strain rate,

$\beta=$ ratio of volumetric concentration to maximum concentration $\left(C_{v} / C_{v, \text { max }}\right)$,

$f(\mu, \beta)$ and $g(\beta)$. = functional forms.

For concentration-dependent Newtonian models, the following functional forms are available in TEMPEST:

$\begin{array}{lc}\frac{f(\mu, \beta)}{\mu\left(1+a_{3} \beta^{24}\right)} \cdot \frac{g(\beta)}{\cdot} \cdot \frac{0}{a_{5} \beta} & 0 \\ \mu\left(1+a_{1} \beta+a_{2} \beta^{2}+a_{3} \beta^{3}\right) & 0\end{array}$

\begin{tabular}{l} 
Description \\
\hline Power shape \\
Exponential shape \\
Cubic power shape
\end{tabular}

In each of these, $\mu$ is treated as temperature dependent.

For non-Newtonian fluids, the following functional forms are available:

\begin{tabular}{lcll}
\multicolumn{1}{c}{$\mathrm{f}(\mu, \beta)$} & $\mathrm{g}(\beta)$ & & \multicolumn{1}{c}{ Description } \\
$\mathrm{K}$ & $\mathrm{m}$ & & $\begin{array}{l}\text { Power law: Ostwald-DeWaele } \\
\text { Power law: Ostwaid-DeWaele, power } \\
\text { shape consistency }\end{array}$ \\
$\mathrm{Ka}\left(1+\mathrm{a}_{3} \beta^{24}\right)$ & $\mathrm{m}$ & & $\begin{array}{l}\text { Power law: Ostwald-DeWaele, } \\
\text { exponential shape consistency }\end{array}$ \\
1 & $\mathrm{~m}\left(1+\mathrm{a}_{5}-\beta-\mathrm{a}_{6}-\beta\right)$ & $\begin{array}{l}\text { Power law: Concentration-dependent } \\
\text { behavior index-double exponential } \\
\text { form }\end{array}$
\end{tabular}

In these expressions, $K$ is consistency index, $m$ is behavior index, and $a_{1}$ to $a_{5}$ are constants supplied by the user. To use any of these models effectively, data for the fluid is needed.

\section{D.2.3 Particle Settling}

Particles in the melter settle in the Stokes flow (or viscous creeping flow) regime with a particle Reynolds number far less than unity. Although Stokes flow for simple solid particles is well characterized in the literature, calculations of the melter particle settling velocity are 
complicated by the porosity and nonsphericity of the noble metals particles. Furthermore, it is necessary to choose a model for "hindered settling." This is the decreased particle settling velocity observed at higher solid volume fractions (such as those expected in the sludge at the bottom of the melter). Settling velocity must go to zero when the particles become packed so that no further settling can occur.

The particle settling submodels in the TEMPEST computer code accept reference settling velocities as input. The modeler calculates the reference velocities, accounting for nonsphericity and porosity of the particles. These reference velocities are then scaled by TEMPEST to account for the variation of local particle concentration, fluid viscosity, and density in the melter.

The basic equation for the Stokes regime particle settling velocity is

$$
V_{s}=d^{2} g\left(\rho_{p}-\rho_{f}\right) /(18 \mu)
$$

Here the diameter $d$ is that of an equivalent spherical particle; the densities, $\rho_{p}$ and $\rho_{f}$, are those of the solid particle and the fluid, respectively. The local dynamic viscosity is $\mu$. Strictly speaking, Eq. (D.15) holds only for a solid spherical particle which is isolated from other particles. The effects of nonsphericity, porosity, and hindered settling, which are all relevant to the ESM particle behavior, are discussed in following sections.

\section{D.2.3.1 Nonsphericity}

Many of the particles observed in the GFT, RSM, and ESM tests were not spherical. The GFT data showed a number of particles whose length was two or three times the width (as viewed in two dimensions). A very small percentage of the GFT particles were longer, with length over six times the width. Supporting data can be found in Appendix B of Anderson et al. (1992). In the RSM and ESM tests, the particles consisted of clusters of small needles. While the needles had large length to diameter (L/D) ratios, the pertinent shape for purposes of settling velocity calculation is the overall shape of the cluster. Observations from the GFT, RSM, and ESM clusters generally indicate an L/D ratio of 3 or less. A settling velocity correction for nonspherical particles can be made. The important variables can be determined by reviewing the derivation of Eq. (D.15). Settling occurs when gravity acts on a particle. A terminal settling velocity is reached when gravitational and drag force on a particle are equal.

$$
\begin{gathered}
\text { Drag force }=C_{D} A_{p} \rho_{f} V_{s}^{2} / 2 \\
\text { Gravitational force }=g\left(\rho_{p}-\rho_{f}\right) v_{p}
\end{gathered}
$$


Here $C_{D}$ is the drag coefficient, $A_{p}$ the projected (cross-sectional) area of the particle, and $v_{p}$ the particle volume. In Stokes flow, the drag coefficient is an inverse function of Reynolds number:

$$
C_{D}=24 \mu /\left(V_{s} d \rho_{f}\right)
$$

To determine the equivalent spherical diameter $d$ of a nonspherical particle, the important variables are the volume $v_{p}$ and the surface area $s_{p}$ of the particle (McCabe and Smith 1976, p. 149). First, the equivalent diameter of the particle is defined as that of a sphere with equal volume. Second, a dimensionless parameter $\Phi_{3}$ (the sphericity) is defined as the ratio of the surface area of the sphere of equal volume to the surface area of the actual particle. With these corrections in place, the equivalent spherical diameter $d$ is defined as

$$
d=6 v_{p} /\left(\Phi_{s}\right)
$$

The drag coefficient is

$$
C_{D}=\left(4 \mu / V_{s} \rho_{f}\right)\left(\Phi_{s} / v_{p}\right)
$$

and the settling velocity is derived as

$$
V_{s}=\left(g\left(\rho_{p}-\rho_{f}\right) /(2 \mu)\right)\left(1 / \Phi_{s}\right)\left(V_{p} / s_{p}\right)\left(V_{p} / A_{p}\right)
$$

\section{D.2.3.2 Porosity}

The noble metal clusters observed in the RSM and ESM samples were not simple solid shapes, as tacitly assumed in Eq. (D.21), but highly porous agglomerates of randomly oriented needles. Flow through the pores of these particles must be accounted for in calculating the settling velocity. The literature contains closed-form methods to estimate the settling velocity of highporosity particles in the Stokes flow regime. Because these methods do not require any adjustable parameters, they are immediately usable in the current study.

The important variables are the cluster's solid volume fraction and the thickness of the needles or rods comprising the particle. From these, the particle permeability (analogous to the permeability of a packed bed) can be estimated. Flow through the cluster can be treated as a case of flow normal to a fiber mat or an array of cylinders, as noted by Masliyah et al. (1987, p. 252). The equation for permeability $k$ is Eq. (41) (op. cit.):

$$
k=-\left[\left(a^{2}\right) / 8 c\right] *\left[\ln c+\left(1-c^{2}\right) /\left(1+c^{2}\right)\right]
$$


where $\mathrm{a}$ is the thickness of the needles making up the agglomerate and $\mathrm{c}$ is the volume fraction of the cluster that is solid, equal to ( 1 - the void fraction).

Given the particle permeability, the drag force for a permeable sphere (relative to that for a solid sphere) can be calculated. A nonspherical particle is treated by using the equivalent diameter $d$. The parameter $\beta$, a dimensionless particle radius, is defined in Eq. (4) of Matsumoto and Suganuma (1977) as

$$
\beta=\{d /[2 * \text { sqrt }(k)]\}
$$

The ratio $\mathrm{F}$ of the drag force for the impermeable sphere to that for the permeable sphere can be calculated from Eq. (6) of Matsumoto and Suganuma (1977):

$$
F=\left\{\beta /[\beta-\tanh (\beta)]+1.5 /\left(\beta^{2}\right)\right\}
$$

where $F=$ (drag force on solid particle) / (drag on porous particle of same equivalent diameter $\mathrm{d}$ and bulk density $\rho_{\mathrm{p}}$ )

and $\mathrm{F}=$ (settling velocity of porous particle) / (settling velocity of solid particle of same $d$ and $\rho_{p}$ )

The bulk density $\rho_{s}$ is the linear average of the density $\rho_{f}$ of the fluid in the particle pores and the intrinsic density of the solid $\rho_{s}$, or

$$
\rho_{\mathrm{p}}=c \rho_{\mathrm{s}}+(1-c) \rho_{\mathrm{f}}
$$

Use of this formula gives the correct result that when the particle porosity (1-c) is zero, the particle density is that of the solid, and when the porosity is unity, the particle density is that of the fluid.

It follows that the particle settling velocity, including the effect of porosity, can be expressed as

$$
V_{s}=\left[g F\left(\rho_{p}-\rho_{g}\right) /(2 \mu)\right]\left(1 / \Phi_{s}\right)\left(v_{p} / s_{p}\right)\left(v_{p} / A_{p}\right)
$$

Eq. (D.26) is the Stokes settling velocity expression [Eq. (D.15)], modified to account for sphericity and porosity. There is no quantified data for the porosity of GFT particles, but some "sponginess," interpreted as a porosity of perhaps 20 to $30 \%$, was noted. This porosity is not high enough to allow significant flow through the particle. However, the porosity of the clusters in the RSM samples was much greater. Viewing the RSM clusters under reflected light, the occluded area fraction of the RSM clusters was between 5 and $17 \%$. Large clusters typically had 
lower occluded area fractions than small ones, but the correlation between cluster size and occluded area fraction was not very strong. Because the area fraction was determined by reflected light-giving the fraction of cross-sectional area that was solid-the solid volume fraction of a cluster can be taken as about equal to the occluded area fraction.

\section{D.2.3.3 Hindered Settling}

Should particles settle to the bottom of the meiter in significant quantities, their concentration will be great enough to cause their settling velocity to decrease. At some maximum packing factor, the settling velocity becomes zero because no further movement is possible.

The TEMPEST computer code uses three different options to calculate hindered settling and packing effects. In the first option, a constant settling velocity unaltered by particle concentration is used. This option is primarily designed for nonaccumulating, low-concentration species. It could lead to overpacking the cells at the bottom of the melter, raising their solid volume fraction to physically impossible values higher than unity. This option has not been used in the present work. In the second option, a "table" of settling velocities is specified by the user. The input may specify up to five values of particle concentration and the corresponding settling velocity to describe the variation of velocity with concentration. This permits specifying a maximum packing fraction, thus preventing overpacking. Finally, the third option uses a formula relating settling velocity to concentration, providing a continuum of velocities.

The formula used in the third option is taken from Perry and Chilton (1973, pp. 5-64). The hindered settling velocity for particles in the Stokes regime is

$$
V_{3}=V_{3}\left(1-C_{\sqrt{ }} / C_{V, m a x}\right)^{n}
$$

Here $V_{3}$ is the terminal settling velocity at negligible concentration, $C_{v}$ is the solid (volume) fraction in the suspension, and $\mathrm{n}$ is an exponent that depends on the particle flow regime. For Stokes flow, $\mathrm{n}=4.65$, according to Perry and Chilton (1973). TEMPEST allows an exponent $\mathrm{n}$ to be chosen by the user. TEMPEST also takes input of $V_{s}$ and of the maximum packing fraction $\mathrm{C}_{\mathrm{v}, \max }$ at which settling velocity becomes zero.

A plausible maximum packing fraction would be about $60 \%$ for mono-disposed spherical particles. The atomic packing factors for pure metals range from 0.68 (body-centered cubic) to 0.74 (face-centered cubic). However, a much lower value can be expected for space-filling spiny particles such as found in the RSM and ESM glass samples. Noble metals concentrations on the order of 5 to $6 \%$ (by volume) are reported from the German melter program for sludge samples of noble metals enriched glass. Glass samples from the bottom of the ESM (see Figure 5.18) are of the order of $1-2 \%$ vol. 


\section{D.2.4 Power Controller}

The power controller used in TEMPEST to control melter glass temperature is based on the PID concept used in the operation of the RSM. The basis for this method is presented by Westsik (1986). The mathematical expression implemented in TEMPEST is

where

$$
\dot{P}_{\text {tod }}=P_{\text {totold }}\left(1+\alpha\left(T_{\text {op }}-T_{\text {ave }}\right) /\left(T_{\text {ave }}-T_{\text {ref }}\right)\right)
$$

$\begin{array}{lll}\mathrm{P}_{\text {tor }}= & \text { the estimated total power } \\ \mathrm{P}_{\text {totold }}= & \text { the old time power estimate } \\ \alpha & = & \text { a relaxation factor } \\ \mathrm{T}_{\text {op }}= & \text { the desired operation temperature } \\ \mathrm{T}_{\text {ave }}= & \text { the average temperature desired } \\ \mathrm{T}_{\text {ref }}= & \text { a reference temperature }\end{array}$

The assumption is made that the steady-state bulk average temperature of the melt scales linearly with the joule heat power generation. In practice, a representation of this bulk melt temperature is obtained by either an arithmetic average of point-wise temperatures (replicating point-wise control thermocouples) or as a volume integrated average temperature; both have been programmed into TEMPEST. Both methods have been used successfully in modeling the RSM.

The ESM was controlled throughout the experiment by setting the current to the lower pair of electrodes and manually varying the current to the upper electrodes to obtain the desired glass temperature. In the ESM analysis, the power controller of Eq. (D.28) is used as means of controlling the melt temperature at locations in the melt approximating the thermocouple stalk temperature measurement positions.

\section{D.2.5 Deposition Model}

A model has been developed to predict deposition on the floor of a simulation model. For application to the ESM, this is a subset of the more general turbulent deposition and erosion model in TEMPEST. The model was modified for application to laminar flow in melters. The two primary assumptions of the model are that particle sizes are small enough for Stokes settling to apply and that the accumulated layer on the floor is thin. This is referred to as the floor model. A second deposition model, referred to as the floor-layer model, is available and described subsequently.

The floor model assumes small particle sizes and thin stationary particle sizes and thin stationary particle bed forms. A stationary bed implies that particle rolling, sliding and saltation are not considered as a means of particle transport. This implies that the deposition problem is 
always quasi-static, depending only on the local flow field parameters and the availability of particles for deposition.

The species transport equation, at the floor boundary, takes the form

$$
\mathrm{V}_{\mathrm{s}} \mathrm{C}=\ddot{\mathrm{m}}
$$

where $V_{s}$ is the settling velocity, $C$ is the mass concentration, and $m$ is the mass flux at the fluid interface.

The floor model links this boundary condition by modeling the net mass flux at the floor as a function of local flow conditions and local solid phase mass fraction. This is a commonly used model for calculating the settling of fine particles (Onishi 1989, 1985, 1982). It is generally accepted that for meaningful particle erosion to occur, the boundary layer at the sediment bed must be turbulent since turbulent bursting is the primary mechanism for small particle resuspension (Fromentin 1989). For melter application, erosion from a settled sludge layer is not considered. Accumulation of the floor in terms of a surface mass density follows by integrating the mass flux at each position on the floor,

$$
m(x, t)=m_{0}(x)+\int_{0}^{t} \ddot{m}(x, t) d t
$$

where $\mathrm{x}$ is a position vector on the floor. The total mass on the floor is the surface mass density summed over the floor area. This model was used in predicting deposition and retention mass balances presented in Section 6.2.

One of the disadvantages of the floor model is that material which settles to the floor, while maintained in the total system mass balance, is external to the fluid domain. As such, it is decoupled from the fluid dynamics.

A second, related model has also bee implemented for use in ESM application. This is referred to as the floor-layer model. This model overcomes the primary disadvantage of the floor model and couples the stationary presence of the sludge layer. The floor-layer model uses the floor deposition model as a basis for determining the amount of material which settles to the floor. The total amount of material is then installed back into floor adjacent fluid cells for use in determining all concentration dependent properties in flow, heat transfer, and electric field solutions. In this way, density, viscosity, and electric conductivity are affected by the mass concentration of material that has settled to a stationary sludge layer. Then prior to solution of the species transport equation, the material is removed from the floor adjacent fluid cells. The advantage of this method is that the thin layer approximation is the floor deposition model can be circumvented. 
To improve upon the floor-layer model, it would be necessary to implement and test a fully coupled yield stress model. A preliminary version of such a model exists in TEMPEST. Data other than that presented by Krause and Luckscheiter (1991) are not available upon which to base the nonNewtonian rheology and yield character of the noble metals enriched sludge layer.

\section{D.3 ESM Computer Model Description}

The TEMPEST computer program solves the governing conservation equations using finite volume approximations. The mathematical basis is described in Section D.1. Included in ESM melter analyses are submodels for property dependencies and noble metals particles transport. Models available are described in Section D.2. The ESM geometry, analysis procedures, and boundary conditions used in computing pre- and post-test results are presented in this section.

\section{D.3.1 Melter Description}

The ESM melter was designed and built for testing at Kernforschungzentrum Karlsruhe-Institut für Nukleare Entsorgungstechnik (KfK-INE). Detailed drawings and description of this melter are presented in Section 3 of this report. In summary, the ESM melter has an octagonal melt pool cross-section with a flat-to-flat dimension of $60 \mathrm{~cm}$ and a maximum melt depth of $78 \mathrm{~cm}$. The melt pool is contained with refractory ceramic which is contained within a cylindrical tank. There are two pairs of Inconel electrodes that are to be fired in-phase from a single electrical source. Operation was a batch pour mode wherein a slurry/frit mixture was continuously fed to the melt surface. When the glass reached a certain level, it was poured from the overflow section of the melter for a period of time.

\section{D.3.2 Modeling Approach}

The computer modeling approach utilizes the TEMPEST computer program. TEMPEST is a computational fluid dynamics computer program which solves discretized conservation equations for flow, thermal energy, species, and electric fields. These equations are coupled through temperature dependent properties and source terms. The equations are solved using explicit, semiimplicit, and implicit numerical procedures, depending upon the problem under consideration.

The computer program is used in several ways in the analysis. A model of a melter is setup and described by data known as input. The model setup process involves defining boundary conditions, defining material properties, initializing variables, and setting computational control parameters. Once a model is setup, it is debugged. Debugging a model involves confirming that the model represents what is being modeled, checking dimensions, and generally comparing what 
the computer spits out with what is known about the problem. Debugging a model also involves performing reality checks. These include checking net heat transfer rates, glass pour rates, and material volumes.

Once checked out, a computer model can be modified to particular needs. For example, a computer model of a melter can be used to investigate thermal characteristics of the refractory by turning off the fluid flow solution. Another example would be to use the model to investigate parameter dependencies, such as sensitivity of results to variations in assumed material properties. This also makes the model useful in the design of new melters.

In the present work, the goal of the computer modeling is to compute the convection flow pattern in the melt pool, use this flow field as a species (noble metals) transport medium, and predict the noble metals accumulation on the floor of the melter. The prediction of the transport of species (noble metals particulates) is to be either by continuum modeling or by particle transport. In continuum modeling, a governing differential (conservation) equation for the advection and diffusion of the species is solved. In particle transport, an ordinary differential equation is integrated in a Lagrangian sense to predict the path of individual particles. Obtaining statistical significance with the particle tracker method requires large numbers of particles and extremely accurate particle path integration techniques. With either approach, the goal is to predict the development of an enhanced conducting sludge layer on the melter floor.

The effect on melter operation of such a sludge layer is then analyzed using the set of flow, thermal energy, and electric fields in TEMPEST. This is done with a combination of fully coupled and decoupled analysis techniques. Fully coupled means that all of the equations interact through the properties and source terms. Fully coupled calculations in melters are very computer time intensive and are normally limited to typically hours of simulations time. The decoupled analysis approach assumes that the time variation of a process within the glass melt is very slow, such as the build up of a noble metals sludge layer. The decoupled approach assumes that the flow field is "frozen" in time as the simulated noble metals particles are transported around the glass melt. These calculations typically are of the order of days and weeks. Periodically, the noble metals are re-coupled to the calculation to account for any coupling effects that may have occurred as a result of the transport.

\section{D.3.3 Pre-test and Post-test Data Sources}

Pre-test calculations were conducted using several sources of information. These included:

1. Test Plan - PHTD-KfK 1, Rev: 0 - for the vitrification of noble metal containing NCAW-simulant with the ESM-melter in the mock up facility VA-WAK, November 1991 (PHTD-91-04.01-K903). This test plan provided "target" parameters for pre-test numerical computations. 
2. Physical properties of the ESM ceramic. W. Grünewald, 6.12.91, modata.txt. A transmittal received from KfK containing (primarily) thermal conductivities, densities, and electrical properties of the ESM refractory ceramics. These data were used to define the thermal and electric properties of the melter model.

3. Blueprint-type drawings of the melter design showing configuration, material placements, and dimensions of the melter.

4. Memo from ML Elliott/PNL to W. Grünewald/KfK-INE dated October 23, 1991 containing glass properties information. This memo contained glass viscosity, electric conductivity, and density correlations.

Post-test calculations are conducted using data and information contained in the main body of this report. The computer model property data and functional dependencies are presented subsequently in Section D.4.

\section{D.3.4 Discretised Model Description}

In developing a computer model of the ESM melter, it is first necessary to determine a computational grid system. Options considered included Cartesian, cylindrical, and a generalized curvilinear grid which conformed to both the octagonal internal as well as the cylindrical exterior boundary. While the latter of these is most ideal, its use requires computer model developments beyond the scope of the present work. The cylindrical coordinate system has the advantage of more closely matching both the octagonal interior and cylindrical outer boundary, but it suffers from being difficult to match the electrode/melt interface boundary which is quite important to the electric field solution. Thus, the Cartesian grid system was chosen based on previous experience and shortcomings and difficulties associated with each of the other grid systems in application to the present problem. The primary deficiency in using the Cartesian grid system for this problem, is that certain curved boundaries have to be approximated within the rectangular computational system. Figure D-2 presents a schematic of the material boundaries in a cutaway cross-sectional view of the three dimensional model.

A total of over 42,000 computational cells (discretised finite volumes) are used in the model. Thirteen separate material types are used to account for the glass, inconel, and various refractory ceramics surrounding the melt pool. The full melter is modeled because no symmetry assumptions can be made when the pour spout and batch pouring operations is considered. The nominal melt pool volume is $0.237 \mathrm{~m}^{3}$ in the model compared to $0.229 \mathrm{~m}^{3}$ in the experiment. 


\section{D.3.5 Boundary Conditions}

The computer model of the ESM requires boundary conditions to the transport equations being solved. Boundary conditions to the flow equations are straight forward. No flow boundary conditions are used at the melt pool/refractory interface and the cold cap surface is assumed to be rigid. Boundary conditions to the thermal energy equation are required at both internal and external surfaces. A fixed temperature of $40^{\circ} \mathrm{C}$ is specified on all exterior surfaces. Interior to the melter cavity, a temperature boundary condition is required to mimic the cooling effect at the cold cap surface. This is done based on previous melter modeling experience and melter experimental observations which indicate that the top surface of the melt consists of three principal zones: An inner zone over which liquid feed is being boiled, a surrounding annular zone consisting primarily of dried out feed, and an outermost annular zone consisting of molten glass exposed to the upper plenum. This outer zone is referred to as shining. In the computer model, a fixed temperature condition is specified for each of these zones. The boiling zone is assigned a temperature of $100^{\circ}$ $\mathrm{C}$ to mimic the boiling process at constant temperature over approximately the central 70 percent of the melt surface. The dryout zone is assigned a temperature of $400^{\circ} \mathrm{C}$ over an annular region comprising approximately 15 percent of the melt surface. The shining is assigned a temperature of $900^{\circ} \mathrm{C}$ over the remaining outer annular surface region.

Boundary conditions to the electric field solution include specification of surrounding refractory as being electrically non-conducting. At the electrodes, a current source term is initialized in one side of each electrode pair, and an equal and opposite current sink term is initialized on the other side of the corresponding pair. Once the calculation commences, the temperature controller (if enabled) adjusts the current source/sink terms appropriately to attain the power level requisite with the targeted average melt temperature of $1150^{\circ} \mathrm{C}$.

D.4 Properties Used in Simulations

Density, viscosity, thermal conductivity, and electric conductivity conductivities are required for computational modeling. This section presents the temperature- and concentration-dependent variations and the property model forms used in the computer analyses.

\section{D.4.1 Electric Conductivity}

Computer simulations of the ESM melter have been conducted using two representations of electric conductivity. One set was used in pre-test simulations and one set was used in post-test simulations. 


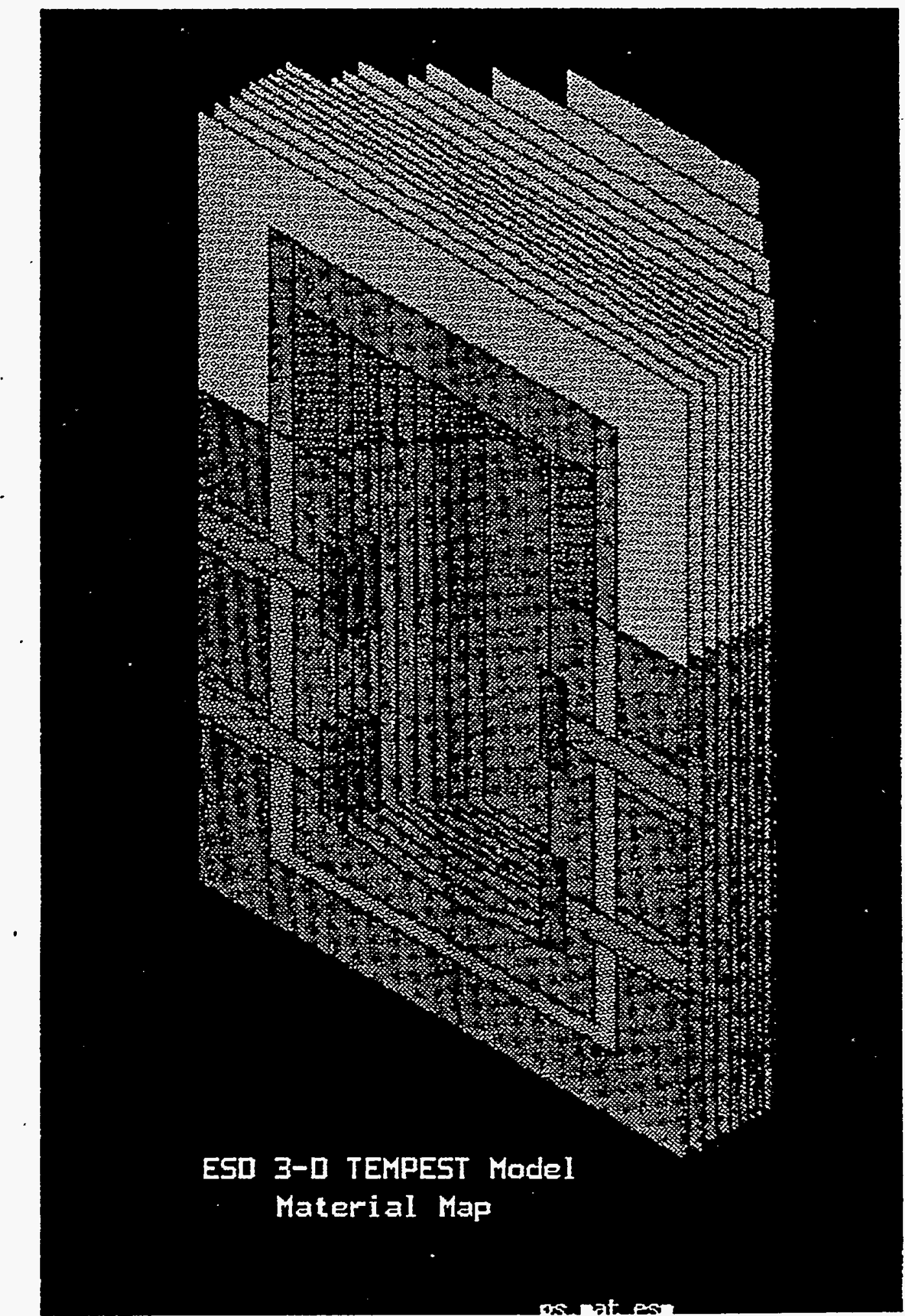

Figure D-2. Three Dimensional ESM Model - Material Boundary Schematic 
The electric conductivity used in pre-test simulations was determined from a correlation ${ }^{3}$ based on the target glass. The correlation, identified in the present work as ESM/pre, is the same correlation used in RSM pre-test simulations (Cooper, et al. 1993). The correlation is given as:

where

$$
\ln (\sigma(T))=A+B / T
$$

$$
\begin{array}{ll}
\mathrm{A} & =9.31 \\
\mathrm{~B} & =-8469 \mathrm{~K} \\
\mathrm{~T} & =\text { Temperature }(\mathrm{K}) \\
\sigma(\mathrm{T}) \cdot & =\text { Electric conductivity }(\mathrm{S} / \mathrm{m})
\end{array}
$$

\begin{tabular}{|c|c|}
\hline & Electrical \\
\hline Temperature & Conductivity \\
\hline $\mathrm{T}\left({ }^{\circ} \mathrm{C}\right)$ & $\underline{\sigma}(\mathrm{S} / \mathrm{m})$ \\
\hline 950 & 6.0 \\
\hline 1,000 & 7.9 \\
\hline 1,015 & 8.6 \\
\hline 1,055 & 10.3 \\
\hline 1,100 & 12.4 \\
\hline 1,150 & 15.2 \\
\hline 1,200 & 18.0 \\
\hline 1,210 & 18.5 \\
\hline
\end{tabular}

The electric conductivity used in post-test calculations is that obtained experimentally in the ESM experiment. These data are given in Figures 3-12, 5-19, and 5-23. For use in the computer modeling, the data in the figures were digitized and then curve fit. The digitized data are:

These data were curve fit with Eq. (D.29) to give the following:

$$
\begin{array}{lll}
\mathrm{A} & = & 8.092 \\
\mathrm{~B} & = & -7660 \mathrm{~K} \\
\mathrm{~T} & = & \text { Temperature }(\mathrm{K}) \\
\sigma(\mathrm{T}) & = & \text { Electric conductivity }(\mathrm{S} / \mathrm{m})
\end{array}
$$

Comparison of the temperature dependence correlations and data are made in Figure D-3. The tabulated values that were used by the TEMPEST computer code in simulating the ESM experiments were as follows:

${ }^{3}$ Personal correspondence: M. L. Elliott/PNL to W. Grünewald/KfK-INE, October 23, 1991. 


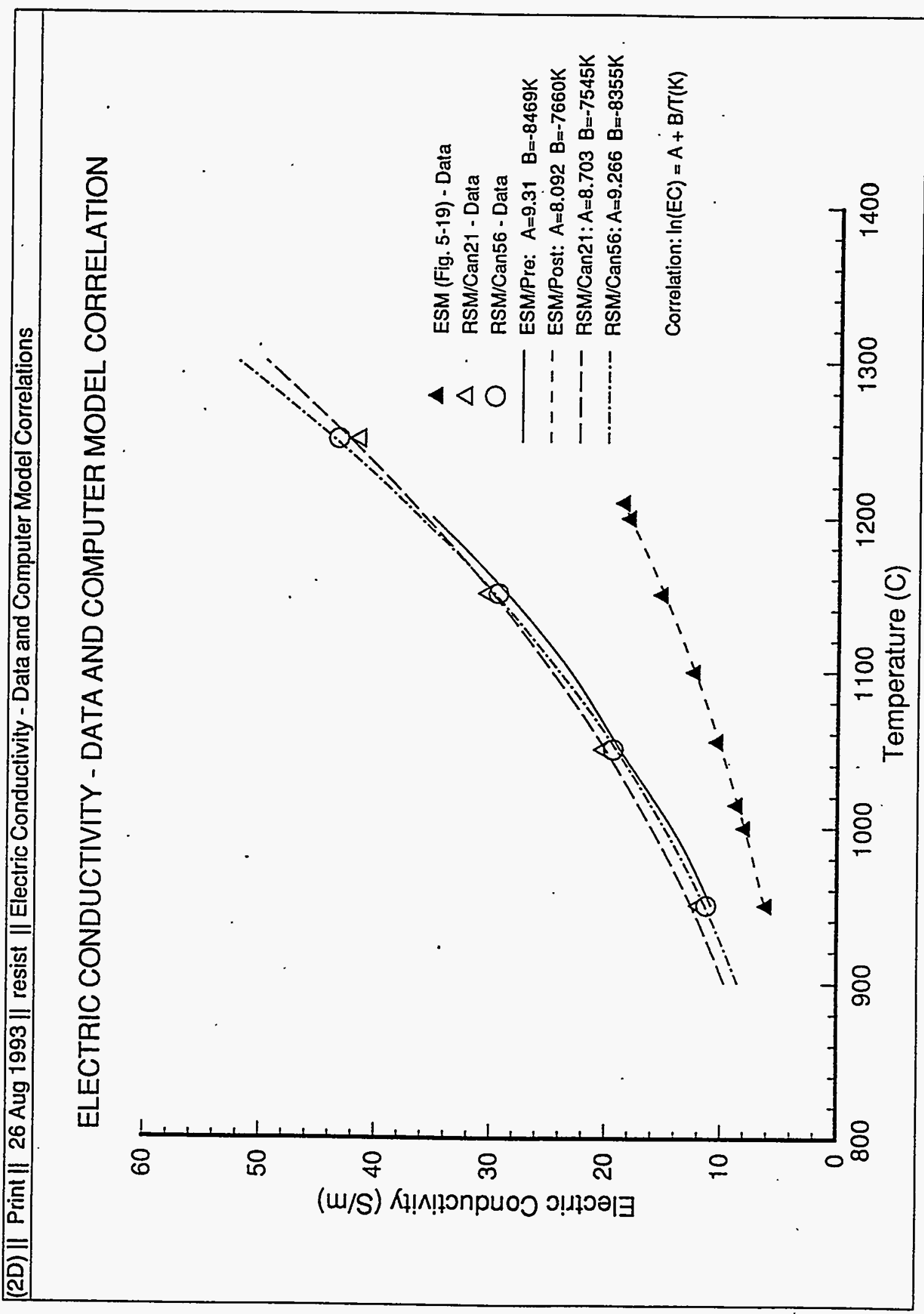

告 


\begin{tabular}{|c|c|c|}
\hline $\begin{array}{l}\text { Temperature } \\
\left({ }^{\circ} \mathrm{C}\right)\end{array}$ & $\begin{array}{l}\text { Electrical } \\
\text { Resistance } \\
\text { (ohm cm) }\end{array}$ & $\begin{array}{l}\text { Electrical } \\
\text { Conductivity } \\
(\mathrm{S} / \mathrm{m})\end{array}$ \\
\hline 700 & & $(2.07)$ \\
\hline 950 & 16.6 & 6.02 \\
\hline 1000 & 12.6 & 7.91 \\
\hline 1100 & 8.11 & 2.35 \\
\hline 1150 & 6.61 & 5.20 \\
\hline 1200 & 5.55 & 18.00 \\
\hline 1300 & & $(24.85)$ \\
\hline 1401 & & $(32.90)$ \\
\hline
\end{tabular}

Numbers in parentheses are extrapolated as follows. The specific electrical resistances were measured for NCAW glasss product during the ESM campaign (Figure 5-19, Grünewald et al., 1993). The conductivities were derived from these measurements. Between $950^{\circ} \mathrm{C}$ and $1200^{\circ} \mathrm{C}$ inclusive the conductivities were found from

Conductivity $(\mathrm{S} / \mathrm{m})=(100 \mathrm{~cm} / \mathrm{m}) /($ specific resistance, $\mathrm{ohm} \mathrm{cm})$

Extrapolation was used to estimate the conductivities outside the measured temperature range.

Slopes of conductivity with temperature:

$$
\begin{aligned}
& 950-1000^{\circ} \mathrm{C}:(7.91-6.02) /(1000-950)=0.0378 \mathrm{~S} / \mathrm{m}^{\circ}{ }^{\circ} \mathrm{C} \\
& 1000-1100^{\circ} \mathrm{C}:(12.35-7.91) /(1100-1000)=0.0444 \mathrm{~S} / \mathrm{m}^{\circ}{ }^{\circ} \mathrm{C} \\
& 1100-1200^{\circ} \mathrm{C}:(18.00-12.35) /(1200-1100)=0.0565 \mathrm{~S} / \mathrm{m}^{\circ} \mathrm{C}
\end{aligned}
$$

Second derivatives of conductivity:

$$
\begin{aligned}
& 950-1100^{\circ} \mathrm{C}:(0.0444-0.0378) /(1050-975)=8.8 \times 10^{-5} \\
& 1000-1200^{\circ} \mathrm{C}:(0.0565-0.0444) /(1150-1050)=1.2 \times 10^{-4}
\end{aligned}
$$

Conductivity at $700^{\circ} \mathrm{C}$ :

$$
=6.02+(700-950)\left(0.0378-(700-950)\left(8.8 \times 10^{-5}\right)\right)=2.07
$$

Conductivity at $1300^{\circ} \mathrm{C}$ :

$$
=18.00+(1300-1200)\left(0.0565+(1300-1200)\left(1.2 \times 10^{-4}\right)\right)=24.85
$$


Conductivity at $1401^{\circ} \mathrm{C}$ :

$$
\begin{aligned}
= & 24.85+(1401-1300)\left(\left(0.0565+(100)\left(1.2 \times 10^{-4}\right)\right)+\right. \\
& \left.(1401-1301)\left(1.2 \times 10^{-4}\right)\right)=32.9
\end{aligned}
$$

In addition to the temperature dependence of electric conductivity, it is necessary to include concentration dependence also. Section D.2.1 presents model approaches. ESM data presented in Figure 5-19 and the data of Krause and Luckscheiter (1991) were used. It was first assumed that separation of the temperature and concentration dependericies could be done to determine constants in the expression

$$
\sigma\left(\mathrm{T}, \mathrm{C}_{\mathrm{v}}\right)=\sigma(\mathrm{T}) *\left(1+(\mathrm{a}-1) \mathrm{C}_{\mathrm{r}}\right)
$$

where $\sigma(T)=\quad$ temperature-dependent electric conductivity at $\mathrm{C}_{\mathrm{v}}=0$

$\mathrm{C}_{\mathrm{r}}=$ ratio of volumetric concentration to maximum concentration $\left(\mathrm{C}_{\checkmark} / \mathrm{C}_{\mathrm{v}, \max }\right)$

$\mathrm{a}=$ maximum conductivity ratio at $\mathrm{C}_{\mathrm{r}}=1$

b $=$ curvature shape constant

First, the shape of the concentration dependence curve was determined. Krause and Lucksheiter (1991) collected data for glass electrical conductivity at two different temperatures, $950 \mathrm{C}$ and

\begin{tabular}{|c|c|c|c|c|c|}
\hline \multirow[b]{2}{*}{$\begin{array}{l}\text { PM Content } \\
\text { (wt } \%)\end{array}$} & \multicolumn{2}{|c|}{$\begin{array}{l}\text { Electrical } \\
\text { resistance }\end{array}$} & \multirow[b]{2}{*}{$\begin{array}{c}\text { PM Content } \\
(\mathrm{vol} \%)\end{array}$} & \multicolumn{2}{|c|}{$\begin{array}{l}\text { Conductivity ratio } \\
\text { to pure glass }\end{array}$} \\
\hline & $\begin{array}{c}1150^{\circ} \mathrm{C} \\
(\mathrm{ohm} \mathrm{cm})\end{array}$ & $\begin{array}{c}950^{\circ} \mathrm{C} \\
(\mathrm{ohm} \mathrm{cm})\end{array}$ & & $1150^{\circ} \mathrm{C}$ & $950^{\circ} \mathrm{C}$ \\
\hline 0 & 7.4 & 22.5 & 0 & 1 & 1 \\
\hline$<0.5$ & 7.2 & 20.5 & 0.16 & 1.03 & 1.10 \\
\hline$<0.5$ & 7.8 & 24.0 & 0.16 & 0.95 & 0.94 \\
\hline 0.7 & 7.8 & 22.0 & 0.23 & 0.95 & 1.02 \\
\hline 0.7 & 7.8 & 24.0 & 0.23 & 0.95 & 0.94 \\
\hline .0 .9 & 7.5 & 23.5 & 0.29 & 0.99 & 0.96 \\
\hline 1.0 & 7.3 & 20.0 & 0.32 & 1.01 & 1.13 \\
\hline 1.3 & 7.2 & 21.0 & 0.42 & 1.03 & 1.07 \\
\hline 2.0 & 5.8 & 13.5 & 0.65 & 1.27 & 1.67 \\
\hline 2.7 & 3.1 & .5 .7 & 0.89 & 2.38 & 3.94 \\
\hline 3.1 & 2.8 & 5.5 & 1.0 & 2.64 & 4.10 \\
\hline 3.7 & 2.5 & 4.6 & 1.2 & 2.96 & 4.89 \\
\hline 5.5 & 1.5 & 2.7 & 1.8 & 4.94 & 8.33 \\
\hline 9.6 & 0.5 & 1.2 & 3.3 & 15 & 19 \\
\hline 16.5 & 0.1 & 0.3 & 6.0 & 74 & 75 \\
\hline
\end{tabular}
$1150 \mathrm{C}$, over a range of concentrations of noble metal particulate material (PM). Their data are given below. 
A standard linear regression was used to fit the higher-concentration data (those in boldface above) to an equation of the form $y=m x+b$.

$$
\ln \left[\left(\sigma / \sigma_{0}-1\right) /(\mathrm{a}-1)\right]=\mathrm{n} * \ln \left(\mathrm{C} / \mathrm{C}_{\mathrm{m}}\right)
$$

In performing the regression, $C_{m}$ was set equal to the maximum measured concentration (6.0 volume \% PM) and a was set equal to the value of $\left(\sigma / \sigma_{0}\right)$ at that concentration. This approach ensured that the regression curve would pass directly through the data at the high-concentration end, the region of most technical interest. The regression determined only the value of the exponent $\mathrm{n}$. It was found to be about 2.6 for a temperature of $1150^{\circ} \mathrm{C}$ and 2.1 for $950^{\circ} \mathrm{C}$. A value of 2.5 was found to reasonably represent both data temperature sets.

With the shape of the curve determined by a known power-law exponent, it was possible to use ESM data (Figure 5-19) to find the scaling coefficient a that was appropriate. The ESM data contained electrical conductivities for two different concentrations, $0 \%$ and approximately $2.2 \%$ by volume noble metals, over a range of temperatures. These data as digitized from the figure are given below.

\begin{tabular}{|c|c|c|c|}
\hline \multirow{3}{*}{$\begin{array}{l}\text { Temperature } \\
\left({ }^{\circ} \mathrm{C}\right)\end{array}$} & \multicolumn{2}{|c|}{ Electrical conductivity } & \multirow{3}{*}{$\begin{array}{r}\text { Conductivity } \\
\text { Ratio }\end{array}$} \\
\hline & (a) $0 \% \mathrm{PM}$ & (a) $2.2 \% \mathrm{PM}$ & \\
\hline & $(\mathrm{S} / \mathrm{cm})$ & (S/ohm) & \\
\hline 950 & 6.02 & 117.1 & 19.5 \\
\hline 1000 & 7.91 & 133.5 & 16.9 \\
\hline 1015 & 8.62 & 141.8 & 16.4 \\
\hline 1055 & 10.31 & 165.1 & 16.0 \\
\hline 1100 & 12.35 & 175.6 & 14.2 \\
\hline 1150 & 15.2 & 189.5 & 12.5 \\
\hline 1200 & 18 & 171.4 & 9.52 \\
\hline 1210 & 18.5 & 166.1 & 8.98 \\
\hline
\end{tabular}

A scaling coefficient of $a=140$ is needed to match the ESM value of $\sigma / \sigma_{0}$ at $1150^{\circ} \mathrm{C}$, the temperature that is most relevant to melter modeling. Using this coefficient throughout the temperature will produce errors in the conductivity of less than $40 \%$ over the temperature range from 950 to $1210^{\circ} \mathrm{C}$. A better fit to both data temperature sets can be obtained if the "constant" a is allowed to be a linear function of temperature.

Using the data at $1150^{\circ} \mathrm{C}$ as a reference, it was determined that a best fit was achieved with

$$
a=140 \text { and } b=2.5 \text { at } C_{v}=0.06 \% \text { vol. }
$$


However, the ratio of the glass product and the floor sample electric conductivity varies from about 9 to 19 over the temperature range from $1200^{\circ} \mathrm{C}$ to $950^{\circ} \mathrm{D}$. Including this leads to

$$
\mathrm{a}=670-0.467 * \mathrm{~T}\left({ }^{\circ} \mathrm{C}\right)
$$

in Eq. (C-30). In developing the above correlation, a noble metals density of $6970 \mathrm{~kg} / \mathrm{m}^{3}$ and a glass density of $2170 \mathrm{~kg} / \mathrm{m}^{3}$ were used to convert from wt\% to vol\% and back. Figure D-4 presents the results of the correlation with the ESM data from Figure 5-19 and the data of Krause and Luckscheiter (1991).The correlation is only presented for temperatures of $950^{\circ} \mathrm{C}$ and $1150^{\circ} \mathrm{C}$. While the correlation is design to specifically fit the limited ESM data at two concentrations, it replicates the distribution of Krause and Luckscheiter's data quite well.

\section{D.4.2 Thermal Conductivity}

Thermal conductivity used in ESM computer modeling is presented in Figure D-5. These data, identified as HW 39, were obtained from an earlier analysis and are extrapolated from data presented by Larson (1989). No concentration dependency of the thermal conductivity was included in the present analysis, although the same modeling approach used for electrical conductivity could be used if there were data to justify it (see Section D.2.1).

\section{D.4.3 Density}

Density as a function of temperature is presented in Figure D-6. These data, identified as HW 39 , were used in ESM computer modeling herein and were obtained from an earlier analysis. The data are from Larson (1989). For calculations in which noble metal particle transport is done, the density of the mixture of glass and noble metals particles is calculated as a volume-weighted sum of the glass fraction and the solid fraction. The mixture density is

$$
\rho_{m}=\left(1-C_{v}\right) \rho_{g}(T)+C_{v} \rho_{s}
$$

where

$$
\begin{array}{lll}
\rho_{m} & = & \text { mixture density } \\
C_{v} & = & \text { volumetric concentration of solid particle phase } \\
\rho_{g}(T)= & \text { temperature-dependent glass density } \\
\rho_{s}= & \text { solid particle density }
\end{array}
$$

The temperature dependence of the intrinsic density of the noble metals particles, $\rho_{3}$, is not presently considered. 


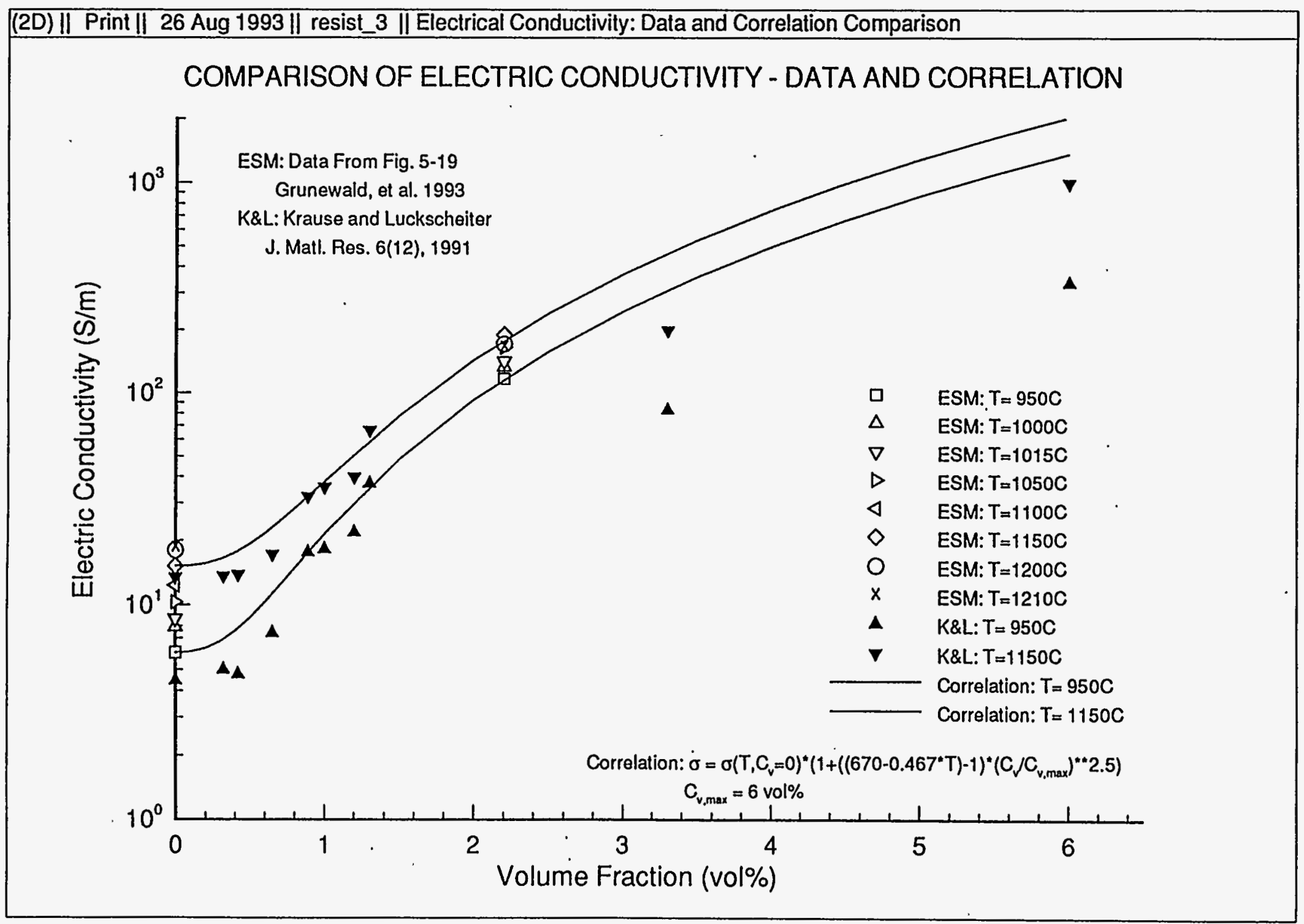

Figure D-4. Comparison of Electric Conductivity Correlation as a Function of Concentration 


\section{(20) II Print II prop_ghass II HWVP Glass Properies}

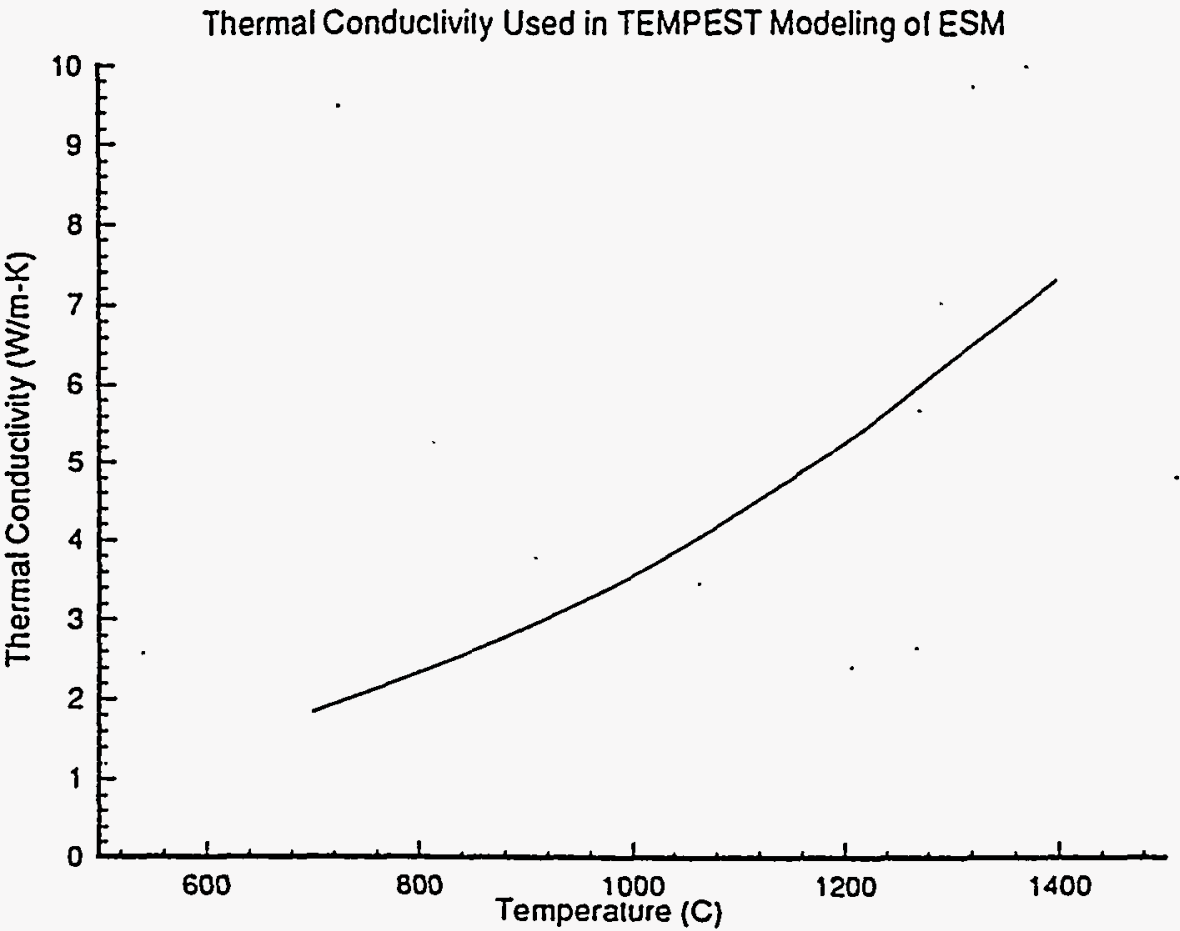

Figure D-5. Temperature Dependence of Thermal Conductivity Used in ESM Computer Modeling 
(2D) II Prinl II prop_glass |I HWVP GIass Propentios

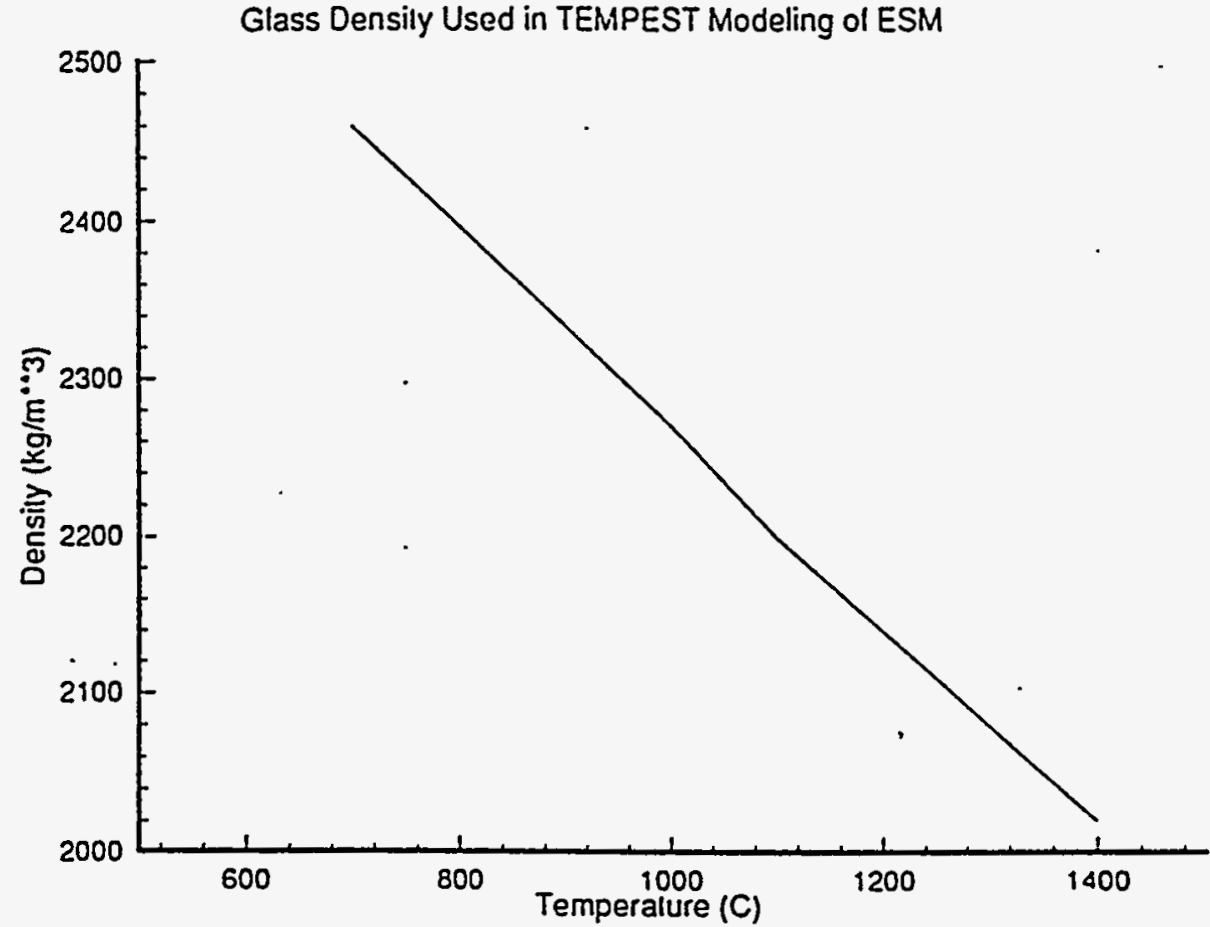

Figure D-6. Temperature Dependence of Density Used in ESM Computer Modeling 


\section{D.4.4 Viscosity}

Pre-test computer simulations were conducted with data supplied as a correlation ${ }^{4}$ given as

$$
\ln (\mu(T))=A+B /\left(T-T_{0}\right)
$$

where

$$
\begin{array}{ll}
\mu(\mathrm{T}) & =\text { dynamic viscosity }(\mathrm{Pa}-\mathrm{s}) \\
\mathrm{T} & =\text { temperature }(\mathrm{K}) \\
\mathrm{A} & =-7.60 \\
\mathrm{~B} & =9,615 \mathrm{~K} \\
\mathrm{~T}_{0} & =397 \mathrm{~K}
\end{array}
$$

A comparison of the ESM viscosity data (from Figure 3-11) with this correlation is made in Figure D-7.

For fully coupled calculations in which viscosity of the glass is assumed to be a function of concentration, the functional form used is a power shape function

$$
\mu\left(T, C_{v}\right)=\mu(T) *\left(1+(a-1) * C_{v}\right)
$$

$$
\begin{aligned}
& \text { where } \mu(T)=\text { temperature-dependent viscosity } \\
& \mathrm{C}_{\mathrm{r}}=\text { ratio of volumetric concentration to maximum volume concentration } \\
& \left(C_{\sqrt{ }} / \mathrm{C}_{\mathrm{v}, \max }\right) \\
& \text { a }=\text { maximum viscosity ratio at } \mathrm{C}_{\mathrm{r}}=1 \text {. } \\
& \mathrm{b}=\text { curvature shape constant. }
\end{aligned}
$$

For pre-test calculations, the maximum viscosity ratio, a, was selected to be 10 . The choice of a maximum viscosity ratio of 10 is based on data for noble metals given by Krause and Luckscheiter (1991). They indicate, however, that noble metals laden glass exhibits a non-Newtonian character in a stress versus strain diagram. In the present work, the glass was assumed to be concentration dependent, but Newtonian. This implies that while the viscosity may become-large as concentration increases, the glass is continuously shearable. Data on ESM glass samples (both KfK's in Figures 5-24 and PNL's independent determination using ESM glass samples) are insufficient to isolate any non-Newtonian character. The KfK data (Figure 5-24) does not span a sufficiently wide concentration range to allow for determining the viscosity dependency near the concentrations of floor samples and the viscosity data near the $1150^{\circ} \mathrm{C}$ temperature does not indicate any discernible concentration dependency for the maximum

\footnotetext{
4 Personal correspondence M.L. Elliott/PNL to W. Grünewald/KfK-INE, October 23, 1991.
} 


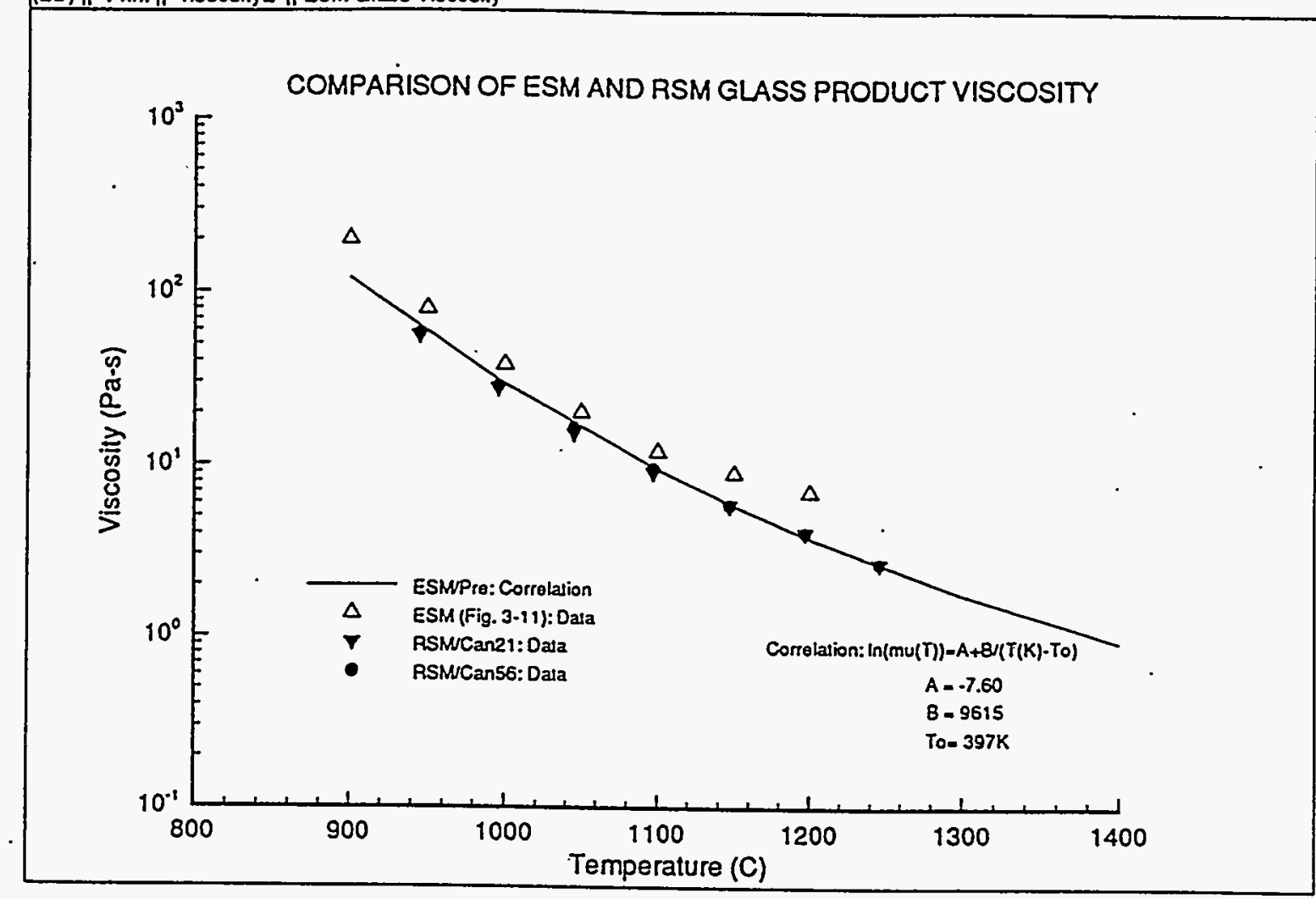

Figure D-7. Temperature Dependence of Viscosity Used in ESM Computer Modeling 
concentration measured at $0.208 \mathrm{wt} \%$ It is noted by the experimenters (Section 5.4.2) that samples obtained from the floor layer were of insufficient quantity to determine viscosity.

PNL utilized the ESM glass samples to measure a concentration-dependent viscosity effect. Figure D-8 presents the results of PNL's concentration dependent viscosity as a function of concentration and temperature. Curve fits of each concentration as a function of temperature were performed for the expression

$$
\mu(T)=\exp (A+B / T(K))
$$

The constants in this curve fit are:

\begin{tabular}{|c|c|c|}
\hline $\begin{array}{c}\text { Concentration } \\
\mathrm{wt} \%\end{array}$ & $\begin{array}{c}\text { Constant } \\
\mathrm{A}\end{array}$ & $\begin{array}{c}\text { Constant } \\
\mathrm{B}\end{array}$ \\
\hline 0. & $\overline{-12.83}$ & $\overline{20776 \mathrm{~K}}$ \\
\hline 1. & -11.79 & 19552 \\
\hline 2. & -11.44 & 19361 \\
\hline 3. & -11.96 & 20436 \\
\hline & -10.74 & 19148 \\
\hline 5.5 & -10.42 & 19074 \\
\hline
\end{tabular}

These curve fits are also presented in Figure D-8. Attempts to subsequently curve fit each of the constants $\mathrm{A}$ and $\mathrm{B}$ were fruitless. Using the data in the 1000 to $1200^{\circ} \mathrm{C}$ range, the ratio of the viscosity at $5.5 \mathrm{wt} \%$ to that of $0 \mathrm{wt} \%$ is found to be approximately 3.2 , or

\begin{tabular}{cc} 
Temperature & $\mu\left(\mathrm{C}_{\mathrm{w}}=5.5 \mathrm{wt} \%\right)$ \\
$\mathrm{T}\left({ }^{\circ} \mathrm{C}\right)$ & $\frac{\mu\left(\mathrm{C}_{\mathrm{w}}=0 . \mathrm{wt} \%\right)}{3.2}$ \\
\hline 1000 & 3.5 \\
1100 & 3.0 \\
1200 &
\end{tabular}

This is encouraging because it supports the contention that the temperature and concentration dependence can be separated as

$$
\mu(T, C)=\mu(T) * f(C)
$$

\footnotetext{
${ }^{5}$ Personal communication. M. L. Elliott to L. L. Eyler, August 20, 1993. It was noted that there is a possibility that the sample preparation process used in making the viscosity measurements caused the $\mathrm{RuO}_{2}$ hairball particles to be destroyed. This is suspected because the process ground the glass sample to a fine power before melting it and making the viscosity measurements.
} 
Viscosity vs Temperature for Various Noble Metal Concentrations with Curve Fit A
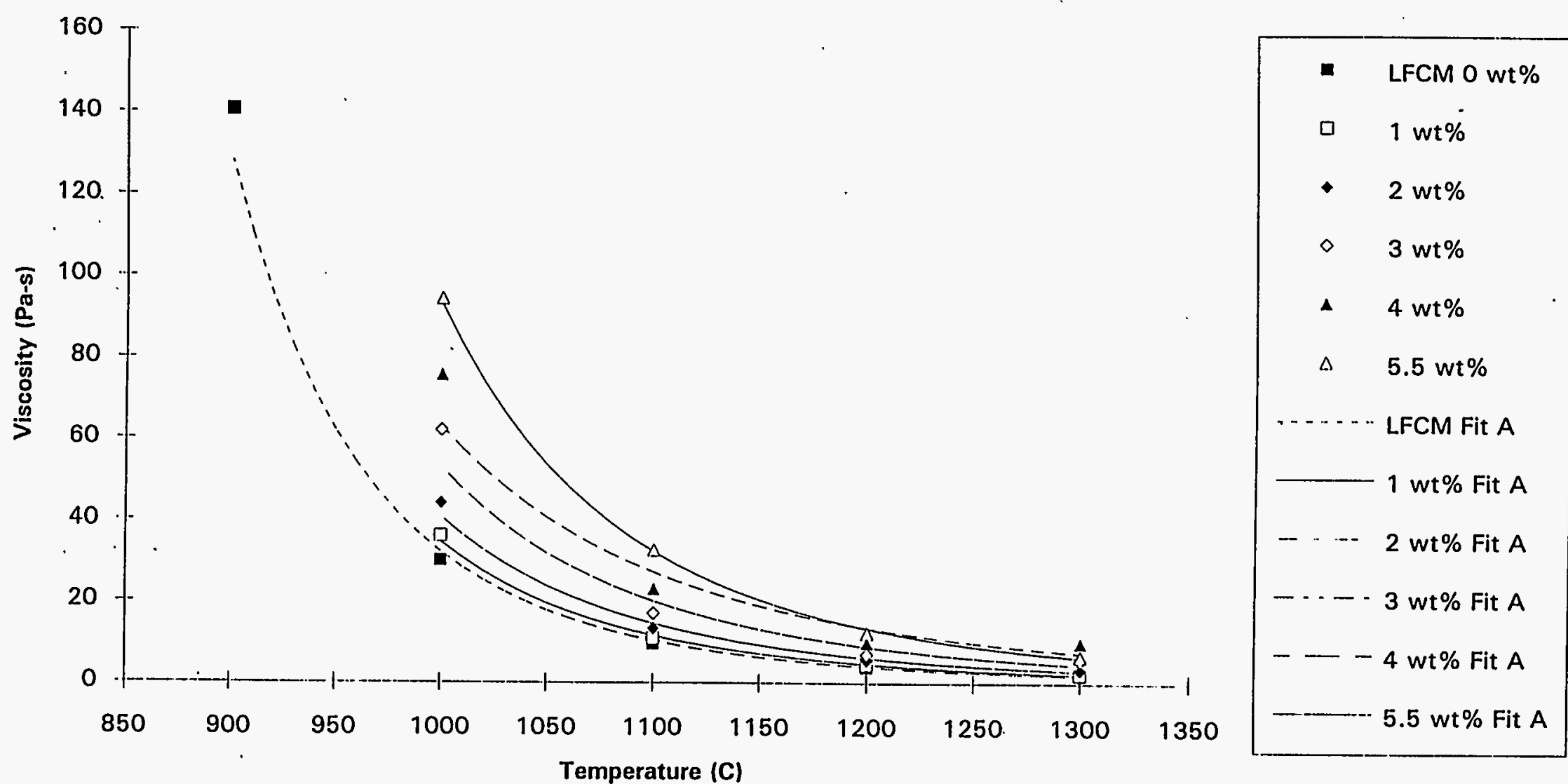

Figure D-8. Temperature and Concentration Dependent ESM Glass Viscosity (PNL Test Results) 
Because the data at $1000^{\circ} \mathrm{C}$ has a wider spread, they were fit with the functional form given by Eq. (D-32). Results of this fit are presented in. Figure D-9. Included in the figure are the concentration dependent data at $\mathrm{T}=1000^{\circ} \mathrm{C}$ and three curve fits. The data are the black circles. The solid black line is an exponential curve fit. The other two curve fits are of the form of Eq. (D.32). Note that the expression which was used in pre-test simulations with

$$
a=10 \text { and } b=10
$$

is not a good representation of this data. A better representation is given with

$$
a=15 \text { and } b=1.5
$$

in Eq. (D.32). These data are for an assumed maximum packing factor, $\mathrm{C}_{\mathrm{v}, \max }=6 \mathrm{vol} \%\left(\mathrm{C}_{\mathrm{w}, \max }=\right.$ $19.3 \mathrm{wt} \%)$. Figure D-10 presents the same data and curve fits assuming $\mathrm{C}_{\mathrm{v}, \max }=2 \mathrm{vol} \%\left(\mathrm{C}_{\mathrm{w}, \max }=\right.$ $5.5 \mathrm{wt} \%)$. In this case, the best exponent in the curve fit is still $b=1.5$, but the ratio of the maximum concentration at maximum packing is a $=3.2$. The composite of available data from the ESM and RSM experiments is presented in Figure D-11 along with pre- and post-experiment correlations. 


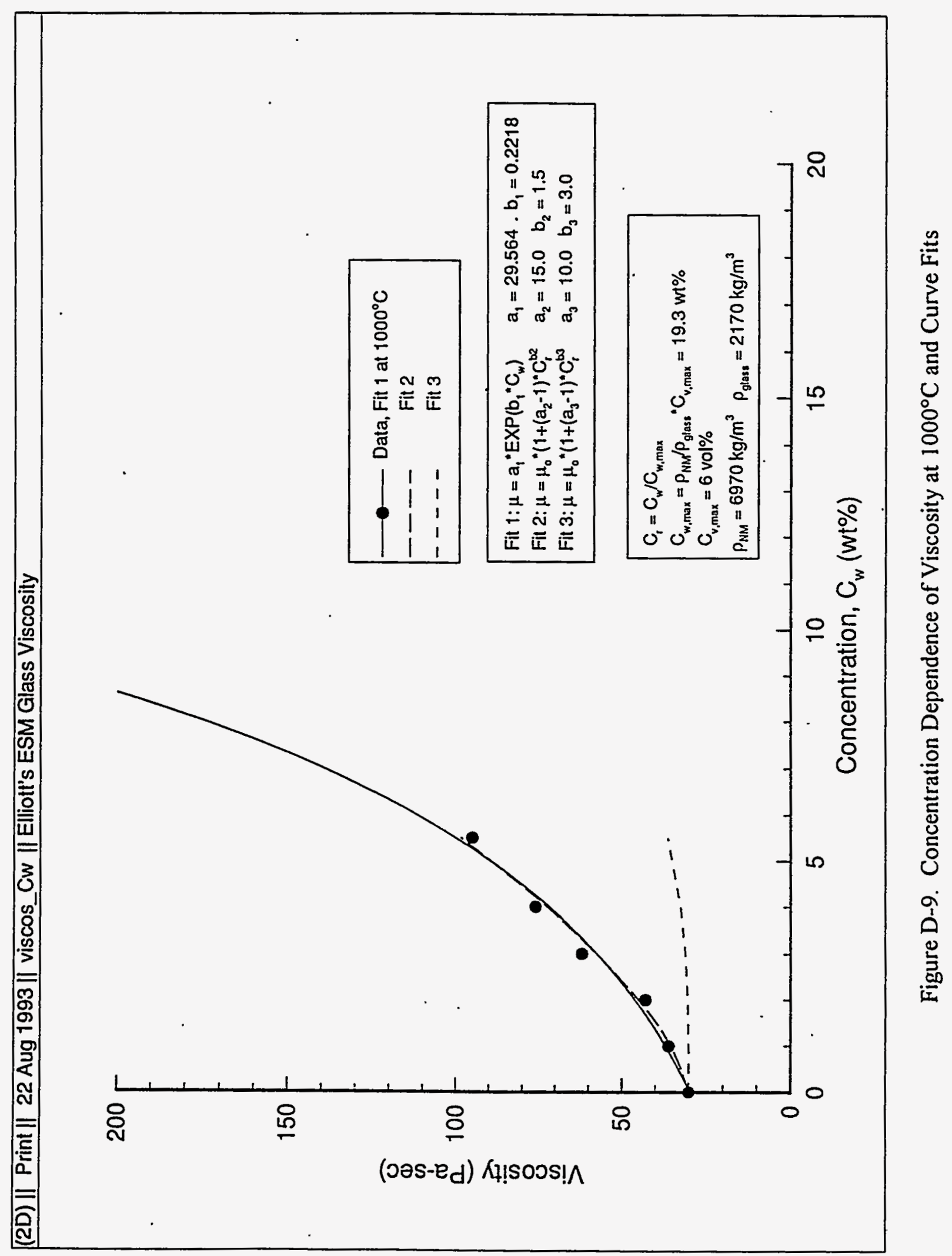




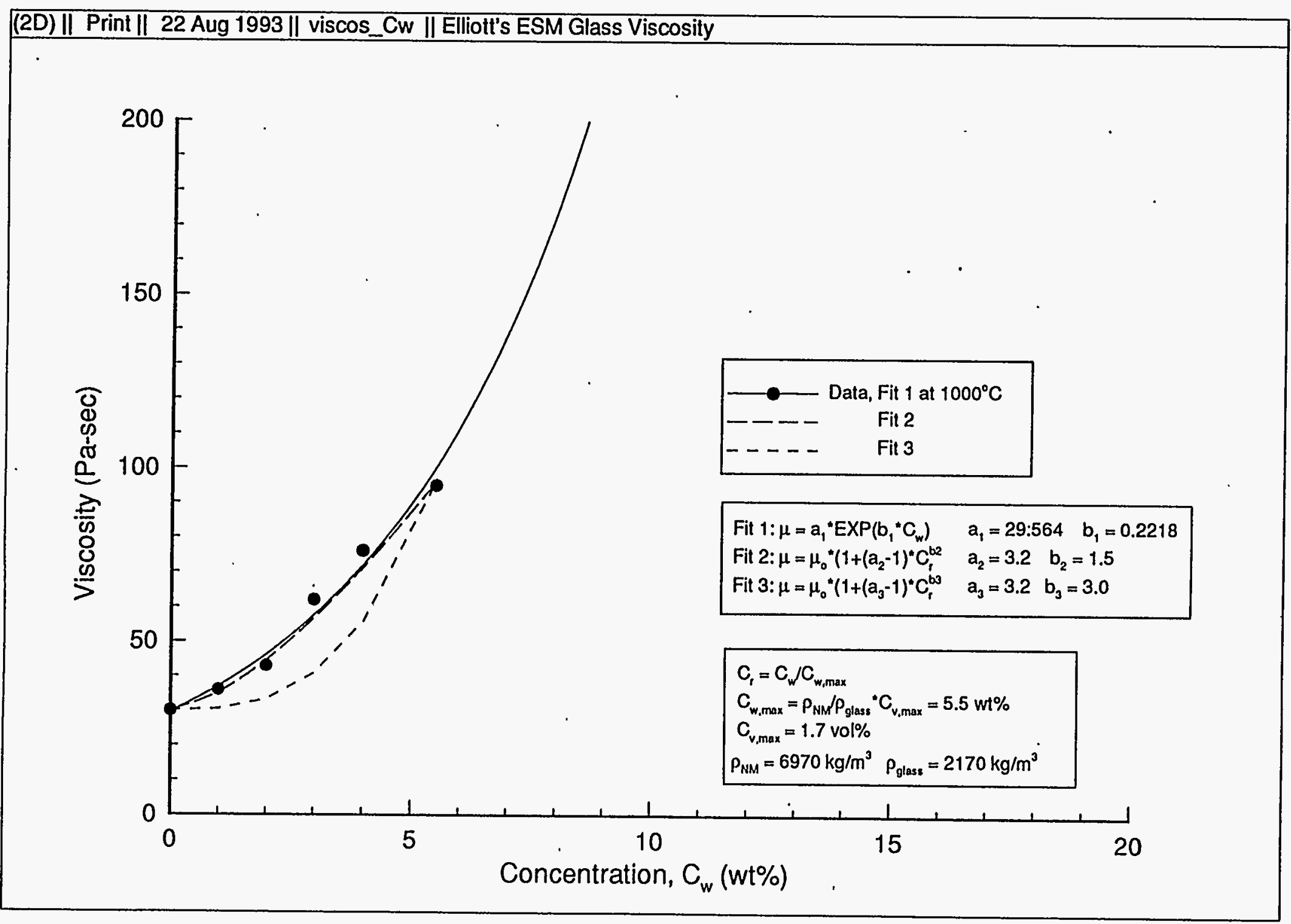

Figure D-10. Concentration Dependence of Viscosity at $1000^{\circ} \mathrm{C}$ and Curve Fits 


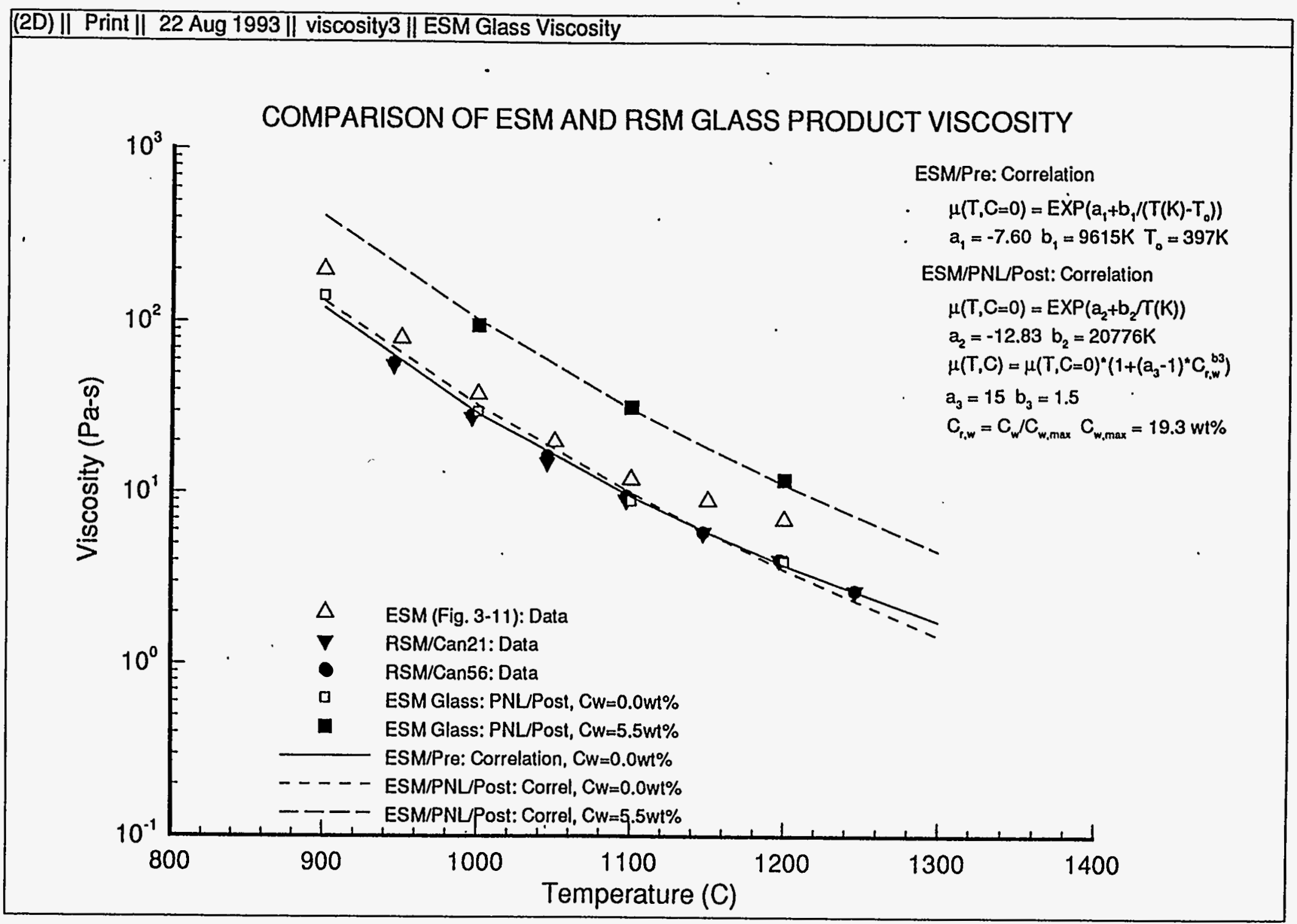

Figure D-11. Concentration Dependence of Viscosity at $1000^{\circ} \mathrm{C}$ - Composite of ESM and RSM Data and Curve Fits 


\section{D.4.5 Particle Settling}

Particles in the melter settle in the Stokes flow (or viscous creeping flow) regime with a particle Reynolds number far less than unity. Although Stokes flow for simple solid particles is well characterized in the literature, calculations of the melter particle settling velocity are complicated by the.porosity and nonsphericity of the noble metals particles. Furthermore, it is necessary to choose a model for "hindered settling". This is the decreased particle settling velocity observed at higher solid volume fractions (such as those expected in the packed sludge at the bottom of the melter). Settling velocity must go to zero when the particles become densely enough packed that no further settling can reasonably be expected.

The particle settling submodels in the TEMPEST computer code accept reference velocities as input. The modeler calculates the reference velocities, accounting for nonsphericity and porosity of the particles. These reference velocities are then scaled by TEMPEST to account for the variation of local particle concentration, fluid viscosity, and density in the melter.

The basic equation for the Stokes regime settling velocity is

$$
V_{s}=d^{2} g\left(\rho_{p}-\rho_{f}\right) /(18 \mu)
$$

Here the diameter $d$ is that of an equivalent spherical particle; the densities, $\rho_{p}$ and $\rho_{f}$, are those of the bulk solid particle and the fluid, respectively. The local dynamic viscosity is $\mu$.

Strictly speaking, Equation (D.34) holds only for a solid spherical particle which is isolated from other particles. The effects of nonsphericity, porosity, and hindered settling, which are all relevant to the RSM particle behavior, are discussed in following sections. As a reference basis for the discussion, certain observed particle size distributions from the GFT and RSM experiments are presented in Table D-1. Detailed particle size distribution data were not available for the ESM run.

Table D-1. Measured particle size distributions.

\begin{tabular}{cccc}
$\begin{array}{c}\text { Diameter range } \\
(\mu \mathrm{m})\end{array}$ & GFT data & $\begin{array}{r}\text { Segments 4, 5, 6 } \\
\text { Cans 26, 30, 35 }\end{array}$ & $\begin{array}{c}\text { Segments 9, } 10 \\
\text { Cans 57, 63 }\end{array}$ \\
\hline $0-1$ & 0.1 & & \\
$1-3$ & 13.5 & & \\
$3-5$ & 32.2 & 11.7 & 0.1 \\
$5-7$ & 20.9 & 19.8 & 0.6 \\
$7-9$ & 0 & 24.3 & 1.6 \\
$9-11$ & 0 & 4.9 & 2.9 \\
$11-13$ & 33.4 & &
\end{tabular}


13-15

15-17

17-19

19-21

21-23

23-25

25-30

$30-40$

40-50

$50-60$

60-80
27.5

11.7

2.8

2.6

5.2

5.7

1.4

2.7

2.7

16.5

11.7

21.4

22.1

The size distribution is expressed in terms of volume fraction, this being the most appropriate distribution for considering sludge accumulation problems. The volumes are approximate, being based on the volume of spheres having a cross-sectional area equal to the projected area of the observed particles. The GFT data show the smallest particle size and narrowest distribution. The samples from RSM Test Segments 9 and 10 (cans 57 and 63) show a much higher volume fraction of large particles than the earlier samples from Segments 4, 5, and 6 (Cans 26, 30 and 35). The ESM data, though incomplete, suggest about the same breadth of distribution as for the later RSM runs and a larger mean particle size ${ }^{6}$. The maximum particle sizes in ESM product probably equalled or slightly exceeded $100 \mu \mathrm{m}$. The larger particle size may have resulted from the longer average residence time for the ESM, about 90 hours, compared to the 5-hour residence time for the RSM.

\section{D.4.5.1 Nonsphericity}

Many of the particles observed in the melter tests to date were not spherical. But in general the GFT particles and the clusters in the RSM were not very elongated. The length to diameter ratios (L/Ds) were less than 3 for almost all of the GFT particles that were observed. The same can be said for the clusters of small needles that were found in the RSM glass samples (Anderson et al., 1992; Cooper et al., 1993). (While the needles had large L/D ratios, the pertinent shape for purposes of settling velocity calculation is the overall shape of the cluster.)

\footnotetext{
${ }^{6} \mathrm{Kim}, \mathrm{D}-\mathrm{S} .1993$. "Microscopic observation of glasses from Germany." Internal memorandum from DongSang Kim to Mike Elliott, Pacific Northwest Laboratories, Richland, Washington. 12 April 1993.

${ }^{6}$ Grünewald, W., et al. "Vitrification of Noble Metals Containing NCAW-Simulant with an Engineering Scale Melter (ESM)". Draft Campaign Report. February 15, 1993. Figures upon which many of the following observations were made have been omitted from the present campaign report.
} 
Appendix A of the first ESM Draft Campaign report ${ }^{7}$ shows the particles found in samples from the ESM bottom. A variety of particles were present. Some of the particle mass was found in small solid blobs and needles, with $L / D$ ranging from 1 to about 6 and with $L$ between 2 and 10 $\mu \mathrm{m}$. There also were some large porous clusters with L/D typically less than 3 and $\mathrm{L}$ between 20 and $80 \mu \mathrm{m}$; examples can be seen at the center of Figures 4 and 14 of the reference. Another fairly common type of particle was a solid or slightly porous near-sphere with diameter of 5 to 50 $\mu \mathrm{m}$ (Figures A-5 and A-6). In some cases (Fig. A-10) two or three of the spheres joined into a single large conglomerate particle. There were also large oblongs, slightly porous, with L/D of about 4 and L from 50 to $100 \mu \mathrm{m}$, or with L/D greater than 10 and L of 200 to $800 \mu \mathrm{m}$ (Figures A-11, 24, 30, 34, 35).

The ESM particles that were poured out in product glass were not as large and varied in shape as those in the ESM sludge. Perhaps the largest particles never reached the product glass. The ESM product particles were clusters that strongly resembled the RSM clusters in shape and structure but appeared to be larger ${ }^{8}$. The size and shape distribution of the ESM product clusters have not been quantified but it is reasonable to consider them to have an L/D of less than 3 , as for the similar RSM and GFT clusters.

A settling velocity correction for nonspherical particles can be made. The important variables can be determined by reviewing the derivation of Eq (D.34). Settling occurs when gravity acts on a particle. The terminal settling velocity is reached when the drag and gravitational forces on a particle are equal.

$$
\begin{aligned}
& \text { Drag force }=C_{D} A_{p} \rho_{f} V_{s^{2}} / 2 \\
& \text { Gravitational force }=g\left(\rho_{p}-\rho_{f}\right) v_{p}
\end{aligned}
$$

Here $C_{D}$ is the drag coefficient, $A_{p}$ the projected (cross-sectional) area of the particle, and $v_{p}$ the particle volume. In Stokes flow, the drag coefficient is an inverse function of Reynolds number:

$$
C_{D}=24 \mu /\left(V_{s} d \rho_{f}\right)
$$

To determine the equivalent spherical diameter $\mathrm{d}$ of a non-spherical particle, the important variables are the volume $v_{p}$ and the surface area $s_{p}$ of the particle (McCabe and Smith, 1976, p. 149). First, the equivalent diameter of the particle is defined as that of a sphere with equal

- ${ }^{8} \mathrm{Kim}, \mathrm{D}-\mathrm{S} .1993$. "Microscopic observation of glasses from Germany." Internal memorandum from DongSang Kim to Mike Elliott, Pacific Northwest Laboratories, Richland, Washington. 12 April 1993. 
volume. Second, a dimensionless parameter $\Phi_{s}$ (the sphericity) is defined as the ratio of the surface area of the sphere of equal volume to the surface area of the actual particle. With these corrections in place, the equivalent spherical diameter $d$ is defined as

$$
\mathrm{d}=6 \mathrm{v}_{\mathrm{p}} /\left(\Phi_{\mathrm{s}} \mathrm{s}_{\mathrm{p}}\right)
$$

The drag coefficient is

$$
C_{D}=\left(4 \mu / V_{s} \rho_{f}\right)\left(\Phi_{s} s_{p} / V_{p}\right)
$$

And the settling velocity is derived as

$$
V_{s}=\left(g\left(\rho_{p}-\rho_{f}\right) /(2 \mu)\right)\left(1 / \Phi_{s}\right)\left[\left(v_{p} / s_{p}\right)\left(v_{p} / A_{p}\right)\right]
$$

Treating the particles as cylinders characterized by the parameter $\mathrm{L} / \mathrm{D}$, it is possible to derive the volume to area ratio (the term in square brackets above) and the sphericity. The equations are given below. Table D-2 presents particle shape factors for cylindrical particles with various degrees of elongation.

$$
\begin{aligned}
& \left(v_{p} / s_{p}\right)\left(v_{p} / A_{p}\right)=[\pi L / D /(2 L / D+1)(4 L / D+\pi)] * A_{p}(D .41) \\
& \Phi_{s}=2(1.5 L / D)^{2 / 3} /(2 L / D+1)
\end{aligned}
$$

Table D-2. Particle shape factors for elongated cylinders.

$\begin{array}{lll}\mathrm{L} / \mathrm{D} & \left(\mathrm{v}_{2} / \mathrm{S}_{2}\right)\left(\mathrm{v}_{2} / \mathrm{A}_{2}\right) / \mathrm{A}_{2}- & \text { Sphericity } \\ 1 & 0.147 & 0.87 \\ 2 & 0.113 & 0.83 \\ 3 & 0.0889 & 0.78 \\ 5 & 0.0617 & 0.70 \\ 10 & 0.0347 & 0.58 \\ 20 & 0.0184 & 0.47\end{array}$

These values were used as shown in Section D.4.5.3 to estimate settling velocities for ESM particles. 


\section{D.4.5.2. Porosity}

The noble metal clusters observed in the ESM and RSM product samples were not simple solid shapes, as tacitly assumed in Eq. (D.39), but highly porous agglomerates of randomly oriented needles. Flow through the pores of these particles must be accounted for in calculating the settling velocity. The literature contains closed-form methods to estimate the settling velocity of high-porosity particles in the Stokes flow regime. Because these methods do not require any adjustable parameters, they are immediately usable in the current study.

The important variables are the cluster's solid volume fraction and the thickness of the needles or rods comprising the cluster. From these the particle permeability (analogous to the permeability of a packed bed) can be estimated. Flow through the cluster can be treated as a case of flow normal to a fiber mat or an array of cylinders, as noted by Masliyah et al. (1987, p. 252). The equation for permeability $k$ is Equation (41) (op. cit.):

$$
\mathrm{k}=-\left[\left(\mathrm{a}^{2}\right) / 8 \mathrm{c}\right] *\left[\ln \mathrm{c}+\left(1-\mathrm{c}^{2}\right) /\left(1+\mathrm{c}^{2}\right)\right]
$$

where $\mathrm{a}$ is the thickness of the needles making up the agglomerate and $\mathrm{c}$ is the volume fraction of the particle that is solid, equal to ( 1 - the void fraction).

Given the particle permeability, the drag force for a permeable sphere (relative to that for a solid sphere) can be calculated. (A non-spherical particle is treated by using the equivalent diameter d.) The parameter $\beta$, a dimensionless particle radius, is defined in Equation (4) of Matsumoto and Suganuma (1977) as

$$
\beta=(d /(2 * \operatorname{sqrt}(k)))
$$

The ratio $\mathrm{F}$ of the drag force for the impermeable sphere to that for the permeable sphere can be calculated from Equation (6) of Matsumoto and Suganuma (1977):

$$
F=\left(\beta /(\beta-\tanh (\beta))+1.5 /\left(\beta^{\wedge} 2\right)\right.
$$

where

$F=\quad$ (drag force on solid particle)/ (drag on porous particle of same equivalent diameter $d$ and bulk density $\rho_{p}$ )

and

$\mathrm{F}=$ (settling velocity of porous particle) $/$ (settling velocity of solid particle of same $d$ and $\rho_{p}$ ) 
The bulk density of the particle $\rho_{s}$ is the linear average of the density of the fluid $\rho_{\mathrm{f}}$ in the particle pores and the intrinsic density of the solid $\rho_{s}$, or

$$
\rho_{\mathrm{p}}=\mathrm{c} \rho_{\mathrm{s}}+(1-\mathrm{c}) \rho_{\mathrm{f}}
$$

Use of this formula gives the intuitively reasonable result that when the particle porosity (1-c) is zero, the particle density is that of the solid, and when the porosity is unity, the particle density is that of the fluid.

It follows that the particle settling velocity, including the effect of porosity, can be expressed as

$$
V_{s}=\left(g F\left(\rho_{p}-\rho_{f}\right) /(2 \mu)\right)\left(1 / \Phi_{s}\right)\left(v_{p} / s_{p}\right)\left(v_{p} / A_{p}\right)
$$

Eq. (D.46) is the Stokes settling velocity expression (Eq. [D.35]), modified to account for nonsphericity and porosity. There were no quantified data for the porosity of GFT particles, but some "sponginess", interpreted as a porosity of perhaps $20-30 \%$, was noted for the particles in Group 2 and Group 3 (Anderson et al., 1992). This porosity is not high enough to allow significant flow through the particle. However, the porosity of the ESM and RSM product clusters was much greater. Viewing the RSM clusters under reflected light, the occluded area fraction of the RSM clusters was between 5 and 17 percent (Cooper et al., 1993). Large particles typically had lower occluded area fractions than small ones, but the correlation between particle size and occluded area fraction was not very strong. Because the area fraction was determined by reflected light -- giving the fraction of cross-sectional area that was solid -- the solid volume fraction of a cluster can be taken as about equal to the occluded area fraction.

The needle thickness a can be ascertained from the data. One GFT particle photo -- Figure 3.6 of Anderson et al. (1992) -- shows a spiny aggregate, about 16 by $4 \mu \mathrm{m}$ in size, of $\mathrm{RuO}_{2}$ needles that are 0.3 to $0.5 \mu \mathrm{m}$ thick. Other photos (Figures 3.9 and 3.19, op. cit.) show $\mathrm{RuO}_{2}$ needles that are 0.5 to $1 \mu \mathrm{m}$ thick. RSM observations (Appendix A, Cooper et al., 1993) confirm a needle thickness of about 0.5 to $1 \mu \mathrm{m}$. These needle sizes are used to calculate the factor $\mathrm{F}$ for ESM product clusters, which strongly resemble RSM clusters. The porosity estimates for ESM clusters are drawn from the RSM data.

The extent of the effect of flow through a porous particle can be seen in the value of the factor $F$. Values of $F$ were calculated for the porosity and needle-size ranges characteristic of ESM clusters. Most values were between 1.0 and 1.2. The highest values of $F$ were at the extreme end of the parameter range. For a particle with the highest porosity $(95 \%)$, the greatest needle diameter $(1 \mu \mathrm{m})$, and the smallest diameter $(10 \mu \mathrm{m})$, the value of $\mathrm{F}$ was the maximum value (in this range) of 2.1. A value of $F$ of 1.2 was used for settling velocity calculations for ESM clusters. 


\section{D.4.5.3 Isolated-particle settling velocities}

The information given in the preceding sections was used with Eq. (D.46) to estimate the range of reference settling velocities to be found in the ESM. For comparison, none of the particles in the RSM product had a settling velocity greater than $3 \times 10^{-7} \mathrm{~m} / \mathrm{s}$, and only about $50 \%$ had settling velocities greater than $1 \times 10^{-7} \mathrm{~m} / \mathrm{s}$.

Small solid blobs and needles (ESM sludge):

L/D: 1 to $6 \quad$ L: 2 to $10 \mu \mathrm{m} \quad$ Porosity: 0

Volume/area ratio: 0.06 to 0.15 Sphericity: 0.7 to 0.87

Bulk density of particle: $6970 \mathrm{~kg} / \mathrm{m}^{3}$ (as for $\mathrm{RuO}_{2}$ )

$$
\begin{array}{ll}
\text { For } L / D=1, L=2 \mu \mathrm{m}, & V_{s}=2 \times 10^{-9} \mathrm{~m} / \mathrm{s} \\
\text { For } L / D=6, L=2 \mu \mathrm{m}, & V_{s}=2 \times 10^{-10} \mathrm{~m} / \mathrm{s} . \\
\text { For } L / D=1, L=10 \mu \mathrm{m}, & V_{s}=5 \times 10^{-8} \mathrm{~m} / \mathrm{s} . \\
\text { For } L / D=6, L=10 \mu \mathrm{m}, & V_{s}=4 \times 10^{-9} \mathrm{~m} / \mathrm{s} .
\end{array}
$$

Large porous clusters (ESM sludge and product):
L/D: 1 to 3 L: 20 to $100 \mu \mathrm{m}$
Volume/area ratio: 0.09 to 0.15
Bulk density of particle: $2650 \mathrm{~kg} / \mathrm{m}^{3}$

$\begin{array}{ll}\text { For } L / D=1, L=20 \mu \mathrm{m}, & V_{s}=2 \times 10^{-8} \mathrm{~m} / \mathrm{s} . \\ \text { For } L / D=3, L=20 \mu \mathrm{m}, & V_{s}=4 \times 10^{-9} \mathrm{~m} / \mathrm{s} . \\ \text { For } L / D=1, L=100 \mu \mathrm{m}, & V_{s}=5 \times 10^{-7} \mathrm{~m} / \mathrm{s} . \\ \text { For } L / D=3, L=100 \mu \mathrm{m}, & V_{s}=1 \times 10^{-7} \mathrm{~m} / \mathrm{s} .\end{array}$

Porosity: $90 \%(\mathrm{~F}=1.2)$

Spherical particles (ESM sludge):

Spherical D: $5-50 \mu \mathrm{m}$

Porosity: $20 \%$

Volume/area ratio: 0.14

Bulk density of particle: $6010 \mathrm{~kg} / \mathrm{m}^{3}$

$$
\begin{array}{ll}
\text { For } D=5 \mu \mathrm{m}, . & V_{s}=6 \times 10^{-9} \mathrm{~m} / \mathrm{s} . \\
\text { For } D=50 \mu \mathrm{m}, & V_{s}=6 \times 10^{-7} \mathrm{~m} / \mathrm{s} .
\end{array}
$$

Short oblongs (ESM sludge):
L/D: 4
L: $50-100 \mu \mathrm{m}$
Porosity: $20 \%$ 
Volume/area ratio: 0.073

Bulk density of particle: $6010 \mathrm{~kg} / \mathrm{m}^{3}$

Sphericity: 0.73

$\begin{array}{ll}\text { For } L / D=4, L=50 \mu \mathrm{m}, & V_{s}=1 \times 10^{-7} \mathrm{~m} / \mathrm{s} . \\ \text { For } L / D=4, L=100 \mu \mathrm{m}, . & V_{s}=6 \times 10^{-7} \mathrm{~m} / \mathrm{s} .\end{array}$

Large needles (sludge):
L/D: $10-20$
L: $200-800 \mu \mathrm{m}$
Volume/area ratio: $-0.018-0.035$
Bulk density of particle: $6010 \mathrm{~kg} / \mathrm{m}^{3}$
$\begin{array}{ll}\text { For } L / D=10, L=200 \mu \mathrm{m}, & V_{s}=6 \times 10^{-7} \mathrm{~m} / \mathrm{s} . \\ \text { For } L / D=20, L=200 \mu \mathrm{m}, & V_{s}=2 \times 10^{-7} \mathrm{~m} / \mathrm{s} . \\ \text { For } L / D=20, L=800 \mu \mathrm{m}, & V_{s}=3 \times 10^{-6} \mathrm{~m} / \mathrm{s} .\end{array}$

Porosity: $20 \%$

Sphericity: $0.47-0.58$

In the case of the ESM product clusters, a distribution of cluster settling velocities was estimated in the same manner.as for the RSM product, but increasing the diameter by $20 \mu \mathrm{m}$. (The maximum diameter observed in the RSM was about $70 \mu \mathrm{m}$, while $90-100 \mu \mathrm{m}$ clusters were found in the ESM.) The increased size causes an increase in settling velocity. Where only about $50 \%$ of the particle mass had a settling velocity of $1 \times 10^{-7} \mathrm{~m} / \mathrm{s}$ in the RSM product, $70 \%$ to $80 \%$ were estimated to be in that velocity range in the ESM. The maximum settling velocity increased only slightly, from about $3 \times 10^{-7} \mathrm{~m} / \mathrm{s}$ (RSM) to $5 \times 10^{-7} \mathrm{~m} / \mathrm{s}$ (ESM).

Some ESM clusters may have higher settling velocities. According to Kim (1993), the photos on which the above calculations were based did not necessarily show the largest clusters, and indicated an average cluster size two or three times as large as that in the RSM. Even considering this datum, it seems unlikely that a maximum settling velocity of $1 \times 10^{-6} \mathrm{~m} / \mathrm{s}$ is exceeded. For lack of a more detailed analysis of the cluster size, shape, and porosity, an upper-limit settling velocity of $1 \times 10^{-6} \mathrm{~m} / \mathrm{s}$ (or $3.6 \mathrm{~mm} / \mathrm{hr}$ ) was used as a TEMPEST input.

\section{D.4.5.4 Hindered settling}

When particles settle to the bottom of the melter in significant quantities, their concentration is great enough to cause their settling velocity to decrease. At some maximum packing factor, the settling velocity becomes zero because no further movement is possible.

The TEMPEST computer code uses three different options to calculate hindered settling and packing effects. In the first option, a constant settling velocity unaltered by particle concentration is used. This option is primarily designed for non-accumulating, low-concentration species. It 
could lead to overpacking the cells at the bottom of the melter, raising their solid volume fraction to physically impossible values higher than unity. This option has not been used in the present work. In the second option, a "table" of settling velocities is specified by the user. The input may specify up to five values of particle concentration and the corresponding settling velocity to describe the variation of velocity with concentration. This permits specifying a maximum packing fraction, so preventing overpacking. Finally, the third option uses a formula relating settling velocity to concentration, providing a continuum of velocities. This third option is used in the present work.

The formula used in the third option is taken from Perry and Chilton (1973, p. 5-64). The hindered settling velocity $V_{\text {sh }}$ for particles in the Stokes regime is

$$
V_{s h}=V_{s}\left(1-s / s_{\max }\right)^{n}
$$

Here $\mathrm{V}_{3}$ is the settling velocity at negligible concentration, $\mathrm{s}$ is the solid fraction in the suspension, and $n$ is an exponent that depends on the particle flow regime. For Stokes flow, $n=4.65$, according to Perry and Chilton (1973). TEMPEST allows an exponent $\mathrm{n}$ to be chosen by the user. TEMPEST also takes input of $V_{3}$ and of the maximum packing fraction $s_{\max }$ at which velocity becomes zero.

The layer of particles on the melter bottom is expected to be a loosely packed, highly porous bed of randomly oriented particles, much like the RSM clusters. The maximum packing fraction of this bed is unlikely to be more than $20 \%$ solid by volume. The RSM clusters themselves were no more than $17 \%$ solid by volume, and the particles were probably not crushed to a higher density after settling. It might be thought that a maximum packing fraction of $60 \%$ or more would be seen, based on the atomic packing factors for metal crystals - from $68 \%$ (body-centered cubic) to $74 \%$ (face-centered cubic). However, these high atomic packing factors depend on the atoms' propensity for moving into minimum-energy locations relative to each other. Noble metal particles probably do not move about once in contact with each other, but weld together at once, leading to a much more inefficiently packed matrix.

According to Eq. (D.47), the settling velocity would be a factor of 10 lower than the unhindered value at a concentration of about $40 \%$ of the maximum packing. The maximum noble metals concentration measured in the ESM bottom sludge was about $6.5 \%$ by mass, or $2.2 \%$ by volume (Grünewald et al., 1993). If this were the concentration at which $\mathrm{V}_{\mathrm{sh}}$ was only 10 to 20 percent of $V_{s}$, effectively stopping further deposition, it would imply that the maximum packing fraction was $5.5 \%$ to $7.5 \%$ solids by volume. This range of solid fractions is consistent with the inefficient packing to be expected from the observed ESM noble metal clusters: A maximum packing factor of $s_{\max }=0.06$ was used for ESM settling calculations. 


\section{D.5 ESM Spout Model}

The product glass concentration profiles -- Figures 5-9 through 5-14 -- showed lower concentrations in the first glass sample of each pour than for later samples. In many (but not all) cases, the concentration was highest in the second sample and decreased slightly to a level that was constant in the third through fifth samples.

The explanation offered was that the noble metals that remained in the spout after each pour might have settled to the bottom of the spout and melter during the 7 to 9 hours of quiescence between pours. The settled material could then be available for resuspension and removal when pouring resumed, leading to temporarily increased concentrations. This hypothesis was examined using the TEMPEST model, and appears to be correct.

For purposes of TEMPEST simulation, the spout was represented in a 2-D simulation as a plane $1.1 \mathrm{~m}$ long by $4 \mathrm{~cm}$ wide. The glass (containing noble metals at $4.04 \mathrm{~kg} / \mathrm{m}^{3}$ ) flowed along the long axis of the plane, which was sloped at 30 degrees up from the horizontal. A horizontal free surface was placed at the outflow end in order to model the flow immediately after a pour is started, when the glass just begins to trickle over the end of the spout and the whole spout volume is not yet filled with glass. Settling was modeled in a non-coupled mode -- with glass properties independent of noble metals concentration -- and pouring was modeled in a coupled mode. The noble metal particles were assumed to settle for 7 to $10 \mathrm{hr}$, a typical feed period, before a pour began. The average glass pour velocity was set at $0.93 \mathrm{~cm} / \mathrm{s}$ and the temperature at $1088^{\circ} \mathrm{C}$, the same values predicted for the outflow in the complete melter TEMPEST runs. The glass and noble metal particle properties were the same as in the melter simulations, and a settling velocity of $1 \times 10^{-6} \mathrm{~m} / \mathrm{s}$, or $3.6 \mathrm{~mm} / \mathrm{hr}$, was used.

The throughflow time constant for the TEMPEST spout was $(1.1 \mathrm{~m} / 0.0093 \mathrm{~m} / \mathrm{s})$, or $118 \mathrm{~s}$. In the actual melter, the pour rate of $50 \mathrm{~kg} / \mathrm{hr}$ corresponds to a volumetric flow of about $0.02 \mathrm{~m} / \mathrm{hr}$. Because the spout has a length of $1.1 \mathrm{~m}$ and a diameter of $4 \mathrm{~cm}$, its volume is about $0.0014 \mathrm{~m}^{3}$ and the throughflow time constant is about $0.07 \mathrm{hr}$ or $252 \mathrm{~s}$. In order to make the TEMPEST results comparable to the ESM observations -- on the basis of having equal amounts of glass flow-through, expressed as fraction of spout volume -- the TEMPEST time scale must be multiplied by a factor of $(252 / 118)$. The time-scaled TEMPEST results can be compared to the first three samples of each pour. These samples were taken in the first $1 \mathrm{~kg}$ of glass (within the first $0.02 \mathrm{hr}$ or $72 \mathrm{~s}$ ), after $3 \mathrm{~kg}$ of glass (at $0.06 \mathrm{hr}$ or $216 \mathrm{~s}$ ), and at $10 \mathrm{~kg}(720 \mathrm{~s})$. The amounts of sample were respectively $120 \mathrm{~g}, 120 \mathrm{~g}$, and $400 \mathrm{~g}$, for sampling durations of $9 \mathrm{~s}, 9 \mathrm{~s}$, and $29 \mathrm{~s}$.

The concentration profiles predicted by TEMPEST qualitatively matched those shown in many of the ESM observations, with the limitation that the observations were discrete and could not show a continuous time profile of concentration. Figure D-12 shows the TEMPEST predicted concentration profile together with representative ranges of observed values. A very low initial 


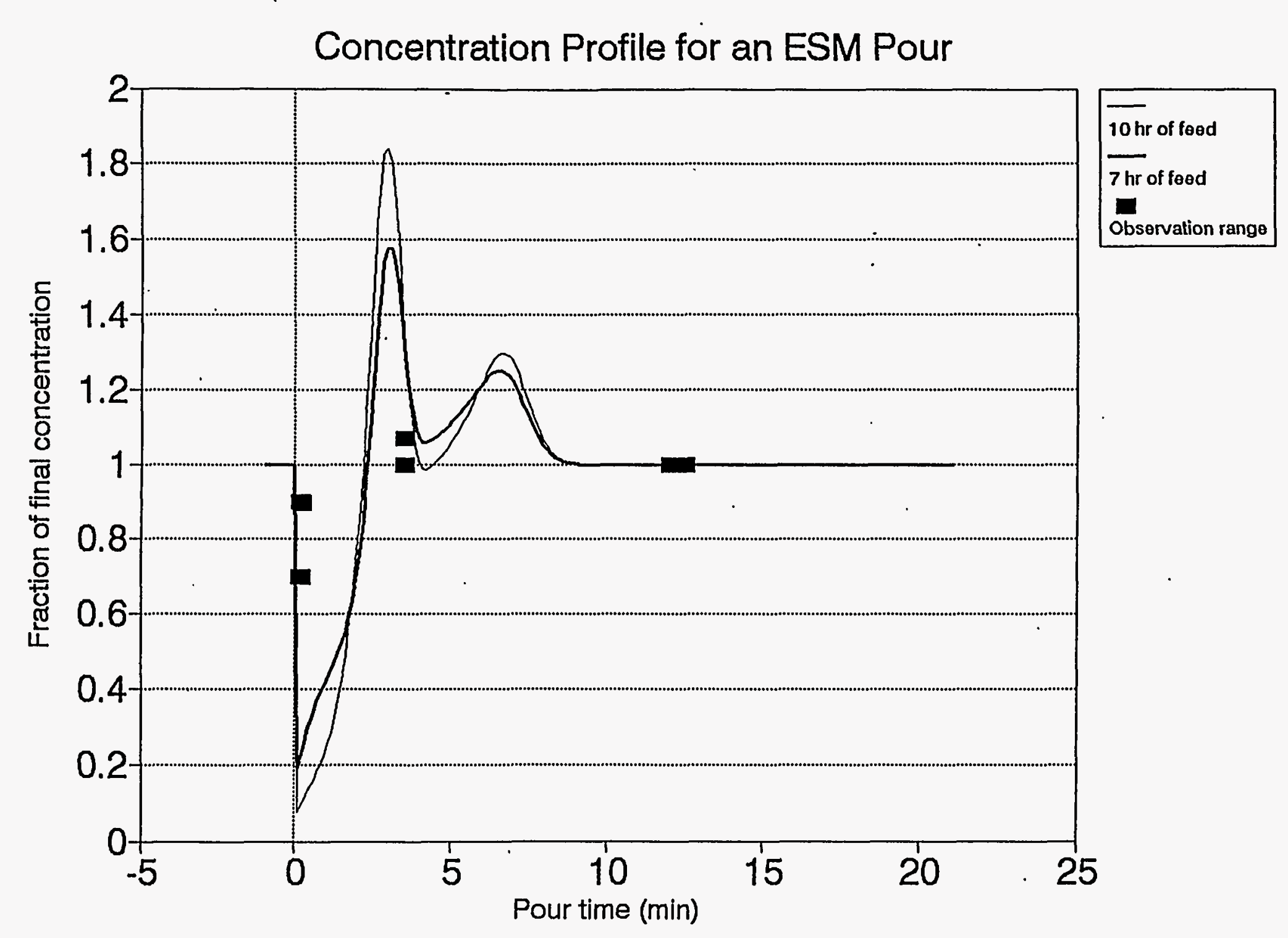

Figure D-12. Concentration profile for an ESM pour spout. 
concentration increased over a period of a few minutes to a maximum, which then decreased to the steady-state concentration in the melter. As flow began, the relatively "clean" glass initially present in the spout was replaced by melter glass, which carried along with it a high-concentration "pulse" of accumulated settled material. Quantitatively, the TEMPEST results exaggerate the concentration changes seen during actual operation. The minimum concentrations given by TEMPEST are $10 \%$ to $25 \%$ of the final steady-state value, and the maxima are nearly twice the final value. By comparison, the minimum observed concentrations are no lower than $70 \%$ of the final concentrations and the maxima (when visible) are only a few percent above.

While these results qualitatively match the measured data, the absolute magnitude differences may be the result of several things. The assumed initial concentration is $4.04 \mathrm{~kg} / \mathrm{m}^{3}$ of noble metals. This value corresponds to $(4.04 / 2170)=0.186 \mathrm{wt} \%$ which is the target concentration, not the actual equilibrium discharge value of about $0.13 \mathrm{wt} \%$ total noble metals. The temperature gradient along the spout -- with cooler temperatures at the higher end -- was not modeled. Consequently the temperature-driven convection currents that are expected to be present in the spout during feed were not accounted for. Thus, the glass in the spout would be better mixed in the actual melter than in the model, which would lead to smaller concentration variations during the actual pour (as observed). It is also possible that the actual settling velocity was lower than the modeled one. The effect of a settling velocity that was lower than modeled would be the same as that of additional convective mixing.

In addition, the model did not allow the noble metals that settled during feed to leave the spout by dropping back into the melter. This would lead to an overestimation of the concentration peak that occurs early in the pour; in the actual melter much of that settled material would no longer be available in the spout. This effect by itself would not account for the exaggeratedly low concentrations predicted by the model at the beginning of the pour, though. Those low concentrations are likely to be the result of underpredicted convection or overpredicted settling. Further modeling that included convection would be needed to distinguish between the possible causes.

\section{D.6 Lumped-Parameter Melter Model}

A "lumped-parameter" analytical model of melter operation was developed and tested against the ESM noble metals discharge data. The lumped-parameter model assumed that the melter was a well-mixed tank whose volume fluctuated predictably during each feed/pour cycle. It also assumed that the noble metals settled at a constant rate; the unhindered settling velocity of $1 \times 10^{\circ}$ ${ }^{6} \mathrm{~m} / \mathrm{s}$ was used, as was for the TEMPEST runs. These assumptions permitted separable differential equations to be solved for the feed and pour segments of the cycle. 
During the feed segment of the cycle, glass and noble metals are being fed but not poured, and the glass volume in the melter is increasing. The governing equations are

Glass mass balance: $V=V_{L}+Q_{f} t$

Noble metals balance: $d M / d t=m_{f}-V_{s} A C$

Here $t$ is time, $V$ is the glass volume in the melter, $V_{L}$ the minimum glass volume (the volume at the beginning of the feed segment), $Q_{r}$ the volumetric glass feed rate, $M$ the mass of noble metals in the melter, $m_{f}$ the noble metal mass feed rate, $V$ the particle settling velocity, $A$ the melter floor area, and $\mathrm{C}$ the mass concentration of noble metals in the melter. The noble metals balance can be expressed entirely in terms of $\mathrm{C}$ :

$$
\left(V_{L}+Q_{f} t\right) d C / d t=m_{f}-\left(V_{s} A+Q_{f}\right) C
$$

At the end of the feed segment, the solution to this separable differential equation is

$$
C_{f}=\left(C_{0}-m_{f} /\left(V_{s} A+Q_{f}\right)\right)\left[\left(Q_{f} t_{f}+V_{L}\right) / V_{L}\right]^{\left(-V_{s} A+O f\right) / Q f}+m_{f} /\left(V_{s} A+Q_{f}\right)
$$

The concentration at the end of the feed segment (and beginning of the pour segment) is $\mathrm{C}_{\mathrm{f}}$. The variable $t_{q}$ is the duration of the feed segment, and $\mathrm{C}_{0}$ is the concentration at the beginning of the feed segment.

The next step is to solve the governing equations for the pour segment, during which glass and noble metals are removed from the melter and its glass volume decreases. The equations are

$$
\begin{aligned}
& \text { Glass mass balance: } V=V_{H}+\left(Q_{f}-Q_{x}\right) t \\
& \text { Noble metals balance: } V d C / d t=m_{f}-\left(Q_{f}+V_{s} A\right) C
\end{aligned}
$$

The new variables are $Q_{x}$, the volumetric glass pour rate, and $V_{H}$, the maximum melter glass volume, defined as

$$
V_{H}=V_{L}+Q_{r} t_{r}
$$

At the end of the pour segment (which is the end of the cycle), the concentration $C_{s}$ is

$$
C_{s}=C_{i}+\left(C_{f}-C_{i}\right)\left[\left(\left(Q_{f}-Q_{x}\right) t_{p}+V_{H}\right) / V_{H}\right]^{-\left(Q f+V_{s} A y(Q f-Q x)\right.}
$$

The variable $\mathrm{C}_{\mathrm{f}}$ has already been defined in Equation (D.51); $\mathrm{C}_{\mathrm{i}}$ is the mass concentration of noble metals in the feed. It is equal to 


$$
\mathrm{C}_{\mathrm{i}}=\mathrm{m}_{\mathrm{f}} / \mathrm{Q}_{\mathrm{r}}
$$

Since the melter can be assumed to start each cycle with the same glass volume, a relationship between the feed and pour times can be established:

$$
\left(Q_{x}-Q_{f}\right) t_{p}=Q_{f} t_{f}
$$

This relationship allows the equations for concentration to be simplified.

$$
\begin{aligned}
& C_{s}=C_{i}+\left(C_{f}-C_{i}\right)\left(V_{L} / V_{H}\right)^{-\left(Q f+V_{s} A\right)(Q f-Q x)} \\
& C_{f}=\left(C_{0}-m_{f} /\left(V_{s} A+Q_{f}\right)\right)\left[V_{H} / V_{L}\right]^{-\left(Q f+V_{s} A\right) / Q f}+m_{f} /\left(V_{s} A+Q_{f}\right)
\end{aligned}
$$

The total noble metals discharge over many cycles can be calculated with this model if the final concentration $C_{s}$ for each cycle is taken as the initial concentration $C_{0}$ for the next cycle. Such calculations can readily be carried out with spreadsheet software.

The discharged mass of noble metals for each cycle can be calculated from mass balance considerations. The calculation is simplified by recognizing that during the feed segment no noble metals are discharged, and during the pour segment the noble metals are removed by both settling and discharge. Because both of these processes are proportional to concentration, the ratio of the discharged mass to the total removed mass is the ratio of the respective volumetric removal rates:

$$
\left(\mathrm{m}_{\text {poured }} / \mathrm{m}_{\text {removed }}\right)=\left(\mathrm{Q}_{\mathrm{f}} /\left(\mathrm{V}_{\mathrm{s}} \mathrm{A}+\mathrm{Q}_{\mathrm{f}}\right)\right)
$$

Then the mass discharged during each cycle is

$$
m_{\text {pouree }}=\left(Q_{f} /\left(V_{s} A+Q_{f}\right)\right)\left(m_{f} t_{p}+C_{f} V_{H}-C_{s} V_{L}\right)
$$

The total mass discharged is obtained by summing up the $m_{\text {poured }}$ increments over all the cycles of operation.

The noble metals discharge predicted by this lumped-parameter model can be compared with the observed value and with TEMPEST predictions. The inputs to the lumped-parameter model are

$\begin{array}{lllll}\mathrm{m}_{\mathrm{f}}= & 0.0178 \mathrm{~kg} / \mathrm{hr} & \mathrm{t}_{\mathrm{p}} & =1 \mathrm{hr} \text { pour } \\ \mathrm{t}_{\mathrm{f}} & =9 \mathrm{hr} \text { feed } & \mathrm{V}_{\mathrm{H}} & =0.248 \mathrm{~m}^{3} \\ \mathrm{Q}_{\mathrm{f}} & =0.00209 \mathrm{~m}^{3} / \mathrm{hr} & & \mathrm{Q}_{\mathrm{x}}=0.0209 \mathrm{~m}^{3} / \mathrm{hr} \\ \mathrm{V}_{\mathrm{s}}=0.0036 \mathrm{~m} / \mathrm{hr} & \mathrm{V}_{\mathrm{L}}=0.227 \mathrm{~m} \\ \rho_{\text {glass }}= & =2170 \mathrm{~kg} / \mathrm{m}^{3} & \mathrm{~A} & = & 0.2973 \mathrm{~m}^{2}\end{array}$


These values are consistent with the inputs to the TEMPEST computer code for the single NM species simulations and with the noble metals feed rate, pour and feed times, and residence times used in the ESM experiments. Figure D-14 presents a comparison between the noble metal fed to the ESM and the discharges that were observed, predicted by TEMPEST, and predicted by the lumped-parameter model.

Both of the computer models predict the discharge quite accurately. Three conclusions can be drawn. First, the settling velocity of $1 \times 10^{-6} \mathrm{~m} / \mathrm{s}$ is not far from the mean settling velocity of noble metals particles in the melter. Second, that the flow field predicted by TEMPEST produces a well-mixed glass volume. And third, that the lumped-parameter model can be relied on to supplement TEMPEST to simulate longer melter operational periods. This allows a significant savings in computational time in performing parametric analysis.

\section{D.7 Retention}

During TEMPEST calculations, the concentration of noble metals is monitored at the exit of the simulated pour spout. This data is combined with monitored pouring velocity and spout cross sectional area. Knowing these, the amount of material discharged from the melter can be calculated as:

$$
\mathrm{M}_{\text {pour, } \mathrm{i}}=\int_{\text {time }} \mathrm{C}_{\mathrm{v}, \mathrm{i}} * \mathrm{~V}_{\text {pour }} * \mathrm{Adt}
$$

where

$$
\begin{array}{ll}
\mathrm{M}_{\text {pour, }}= & \text { Total mass of species i discharged over time interval } \mathrm{t}, \mathrm{kg} \\
\mathrm{C}_{\mathrm{v}, \mathrm{i}}= & \text { Concentration of species } \mathrm{i}, \mathrm{kg} / \mathrm{m}^{3} \\
\mathrm{~V}_{\text {pour }}= & \text { Velocity of glass in pour spout, } \mathrm{m} / \mathrm{s} \\
\mathrm{A}_{\mathrm{p}}= & \text { Area of pour spout, } \mathrm{m}^{2} .
\end{array}
$$

Mass of species material entering the melter under the cold cap is determined from the source rates as:

$$
M_{i n, i}=\int_{\text {lime }} M_{i n, i}(t) d t
$$

where

$$
\begin{array}{ll}
\mathrm{M}_{\mathrm{ini}}= & \text { Total mass source of species } \mathrm{i} \text { entering the melt, } \mathrm{kg} \\
\mathrm{M}_{\mathrm{in}, \mathrm{i}}(\mathrm{t})= & \text { Mass source rate of species } \mathrm{i}, \mathrm{kg} / \mathrm{s}
\end{array}
$$


With these two quantities, mass of the species retained in the melter up to time $t$ can be determined as:

$$
\mathrm{R}=\mathrm{M}_{\mathrm{in}, \mathrm{i}}-\mathrm{M}_{\text {pour,i }}
$$

This value of retention can be normalized by the mass-in to obtain a percentage retention. This was the method used to determine retention in the computer model results presented in Figures 6$4,6-5,6-7$, and 6-9.

An alternate method of determining retention which is sometime used in experiments is to determine retention as the ratio of the weight percent of noble metals in the discharge glass (from pour sample measurements) to the target weight percent of noble metals determined from the mass content of the feed stream. The first method is cumbersome in experiments because it requires a large number of samples be taken and analyzed. The second method suffers from the disadvantage of being inaccurate in scenarios where significant numbers of feed stream interruptions occur, thus not allowing the concentration in the glass to reach an equilibrium concentration. Experimental retention rates presented in Figures 6-4, 6-5, 6-7, and 6-9 were determined with this second method. In the long term, once equilibrium is established, the two methods asymptotically approach each other. However, in operational scenarios where intermittent feed stoppages occur (extended idle), the two methods of determining retention will not necessarily yield the same result. A byproduct of this effect is that during melter operation, determining retention based on a very limited number of widely spaced samples could lead to erroneous results. 


\section{$\underline{\text { References }}$}

Anderson, L.D., T. Dennis, M.L. Elliott, L.L. Eyler, and P.R. Hrma. 1992. "Laboratory Testing and Computer Modeling of HWVP Melter Feed. Draft." PHTD-C91-04.01B, Pacific Northwest Laboratory, Richland, Washington.

Cobb, W. T., and P. R. Hrma. 1990. "Behavior of $\mathrm{RuO}_{2}$ in a Glass Melt", Ceramic Transactions, 23:233-237.

Cooper, M.F., M.L. Elliott, L.L. Eyler, C.J. Freeman, J.J. Higginson, L.A. Mahoney, and M.R. Powell. 1993. "Research-Scale Melter Test Report." PHTD-K902, Pacific Northwest Laboratory, Richland, Washington.

Fromentin, A. 1989. Particle Resuspension from a Multi-Layer Deposit by Turbulent Flow, PhD. Dissertation, Paul Scherrer Institut, Switzerland.

Masliyah, J.H., Neale, G., Malysa, K., and T.G.M. Van de Ven. 1987. "Creeping Flow Over a Composite Sphere: Solid Core With Porous Shell." Chem. Eng. Sci. 42, p. 245-253.

Matsumoto, K., and A. Suganuma. 1977. "Settling Velocity of a Permeable Model Floc." Chem. Eng. Sci. 32, p. 445-447.

McCabe, W.L., and J.C. Smith. 1976. Unit Operations of Chemical Engineering, 3rd Ed. McGraw-Hill, Inc., New York, New York.

Onishi, Y., D. Dummuller, and D. S. Trent. 1989. Preliminary Testing of Turbulence and Radiomuclide Transport Modeling in the Deep-Ocean Environment, EPA520/1-89-018.

Onishi, Y., and D. S. Trent. 1982. Mathematical Simulation of Sediment and Radiomuclide Transport in Estwaries, NUREG/CR-2423, PNL-4109.

Onishi, Y., and D. S. Trent. 1985. "Three-Dimensional Simulation of Flow, Salinity, and Radionuclide Movements in the Hudson River Estuary," Proceedings of the Specialty Conference: Hydraulics and Hydrology in the Small Computer Age, August 12-17, 1985. HY Div. ASCE, Lake Buena Vista, Florida.

Perry, R.H., and C.H. Chilton. 1973. Chemical Engineers' Handbook, 5th Ed. McGraw-Hill Book Company, New York, New York.

Westik, J. H., Jr. 1986. "Temperature Control System for Liquid-Fed Ceramic Melters". PNL6009, Pacific Northwest Laboratory.

DE Larson - HWVP Tech manual - 1989 